Stilfragen 


\section{Institut für deutsche Sprache Jahrbuch 1994}




\section{Stilfragen}

Herausgegeben von

Gerhard Stickel

$W$
$\mathrm{DE}$
$\mathrm{G}$

Walter de Gruyter - Berlin - New York 1995 
Redaktion: Franz Josef Berens

(6) Gedruckt auf säurefreiem Papier, das die US-ANSI-Norm über Haltbarkeit erfüllt.

Die Deutsche Bibliothek - CIP-Einheitsaufnahme

\section{Institut für Deutsche Sprache〈Mannheim〉:}

Jahrbuch ... / Institut für Deutsche Sprache. - Berlin ; New York : de Gruyter.

Früher Schriftenreihe

ISSN 0537-7900

1994. Stilfragen. - 1995

Stilfragen / hrsg. von Gerhard Stickel. - Berlin ; New York : de Gruyter, 1995

(Jahrbuch ...; 1994)

ISBN 3-11-014748-3

NE: Stickel, Gerhard [Hrsg.]

(C) Copyright 1995 by Walter de Gruyter \& Co., D-10785 Berlin

Dieses Werk einschließlich aller seiner Teile ist urheberrechtlich geschützt. Jede Verwertung außerhalb der engen Grenzen des Urheberrechtsgesetzes ist ohne Zustimmung des Verlages unzulässig und strafbar. Das gilt insbesondere für Vervielfältigungen, Übersetzungen, Mikroverfilmungen und die Einspeicherung und Verarbeitung in elektronischen Systemen.

Printed in Germany

Druck: Arthur Collignon GmbH, Berlin

Buchbinderische Verarbeitung: Lüderitz \& Bauer, Berlin 


\section{INHALT}

Gerhard Stickel: Vorwort 1

Horst Sitta: Eröffnung 3

Hans-Martin Gauger: Was ist eigentlich Stil? 7

Barbara Sandig: Tendenzen der linguistischen Stilforschung 27

Bernd Spillner: Stilsemiotik $\quad 62$

Gotthard Lerchner: Stilwandel 94

Johannes Anderegg: Stil und Stilbegriff in der neueren 115

Literaturwissenschaft

Jean-Marie Zemb: Ist [der] Stil meBbar? 128

Hartmut Schröder: Der Stil wissenschaftlichen Schreibens $\quad 150$ zwischen Disziplin, Kultur und Paradigma - Methodologische Anmerkungen zur interkulturellen Stilforschung

Monika Doherty: Prinzipien und Parameter als Grundlagen einer allgemeinen Theorie der vergleichenden Stilistik

Liisa Tiittula: Stile in interkulturellen Begegnungen 198

Margret Selting: Sprechstile als Kontextualisierungshinweise 225

Anne Betten: Stilphänomene der Mündlichkeit und 257

Schriftlichkeit im Wandel

Klaus-Dieter Ludwig: Stilkennzeichnungen und

Stilbewertungen in deutschen Wörterbüchern der Gegenwart

Ulrich Püschel: Stilpragmatik - Vom praktischen

Umgang mit Stil

Ingrid Kühn: Alltagssprachliche Textsortenstile 329

Gerd Antos: Warum gibt es normative Stilistiken? 355

Statements und Plenardiskussion: 378

Aufgaben einer modernen Stilistik

Das Institut für deutsche Sprache im Jahre 1994 



\section{Vorwort des Herausgebers}

Stil gehört zu den geläufigsten bildungssprachlichen Wörtern. Wir gehen mit Stil ungezwungen um, wenn wir über so Verschiedenes sprechen wie Literatur (Personalstil, Gattungssti), Architektur (Gründerstil, postmoderner Sti), Geschäftswelt (Verhandlungsstil), Sport (Laufstil), Kleidung (lässiger Stil) bis hin zur amerikanisierenden Lebensweise (lifestyle). Sprachwissenschaftler tun sich dagegen - besonders, wenn sie sich einer der vielen Richtungen der Systemlinguistik verpflichtet fühlen - mit dem denotationsreichen Vielzweckausdruck Stil etwas schwer, sofern sie ihn nicht als Fachwort sogar ganz meiden. Diese bis zur terminologischen Abstinenz reichende Scheu vor Sprachstil und -stilen wurde in anderen linguistischen Forschungsrichtungen und -gebieten schon seit den siebziger Jahren nach und nach überwunden, unter anderem in der Soziolinguistik, der Gesprächsanalyse und der Textlinguistik.

Zweck der 30. Jahrestagung des Instituts für deutsche Sprache vom 15. bis 17. März 1994 war es, den komplexen Phänomenbereich von 'Stilistischem' in der Sprache unter mehreren Aspekten zu beleuchten und Anregungen für einen modernen, linguistisch fundierten Stilbegriff, vielleicht sogar für eine nutzbare Stilistik zu gewinnen. Die Referenten waren eingeladen, Stil unter anderem nach folgenden Dimensionen und Aspekten zu erörtern:

- Stil: deskriptiv und normativ

- Stilphänomene nach sprachlichen Strukturebenen

- Stilistica der gesprochenen und geschriebenen Sprache

- Stilwandel

- Stilsemiotik

- Gesprächsstile

- Sprachstil als soziales Merkmal

- Stile in interkulturellen Begegnungen

- Stil in der Übersetzung

- Stile in der Gegenwartsliteratur

- Stile in Wissenschaftstexten

- Stil als Lehr- und Lerngegenstand

Das vorliegende Jahrbuch vereint die Texte der 16 Vorträge und die Beiträge zu der abschließenden Podiumsdiskussion. DaB nicht alle 'Stilfragen' beantwortet wurden und zum Tagungsende keine endgültige Stildefinition oder ein umfassender neuer Stilbegriff beschlossen und mitgenommen werden konnte, wird nur den irritieren, der einen geisteswissenschaftlichen Kongreß mit einer Geschäftsverhandlung verwechselt, die mit einem Vertragsabschluß endet. 
Der VorbereitungsausschuB (Siegfried Grosse, Werner Kallmeyer, Barbara Sandig, Gerhard Stickel) glaubte, mit dem mehrdeutigen Ausdruck Stilfragen ein originelles und passendes Generalthema für die Tagung gefunden zu haben. Bei der weiteren Vorbereitung steilte sich die angenommene Originalität der Themenwahl als Irrtum heraus, da schon ein Sammelband mit eben diesem Titel erschienen war: Willi Erzgräber und Hans-Martin Gauger (Hg.), Stilfragen (Tübingen: Narr, 1992). Herrn Kollegen Gauger, der an unserer Tagung als Referent beteiligt war, und seinem Mitherausgeber Erzgräber sei herzlich dafür gedankt, daB sie uns Stilfragen weder als besonders passendes Tagungsthema noch als Titel dieses Buches streitig gemacht haben.

Das Jahrbuch schließt wie stets mit dem Bericht über die Arbeiten des Instituts ab. Auf die Arbeit des IDS und einige wichtige Institutsereignisse geht auch Horst Sitta in seinem Eröftnungsbeitrag zur Tagung und zu diesem Band ein.

Gerhard Stickel 


\title{
Eröffnung der Jahrestagung am 15.3.1994
}

\author{
Meine sehr verehrten Damen und Herren,
}

im Namen des Kuratoriums und des Vorstands des Instituts für deutsche Sprache heiße ich Sie zur Jahrestagung 1994 herzlich willkommen.

Im besonderen begrüße ich Herrn Ministerialrat Dr. Eschelbacher vom Bundesministerium für Forschung und Technologie sowie Herrn Staatssekretär Dreier vom Ministerium für Wissenschaft und Forschung in Stuttgart. Beide werden anschließend noch $\mathrm{zu}$ uns sprechen.

Ich begrüße Herrn Bürgermeister Mark und Herrn Prorektor Frankenberg, ich freue mich darüber, daß zahlreiche Repräsentanten aus Politik und Kultur in Mannheim zu uns gekommen sind, und ich begrüße besonders die Vertreter des Vereins der Freunde des IDS, Herrn Roschy und Herrn Beyer.

Das Rahmenthema, unter dem unsere Tagung in diesem Jahr steht, lautet "Stilfragen". Sieht man einmal davon ab, daß es nicht wenige Linguisten gibt, die - fast lemmingartig oder jedenfalls wie unter einem bedingten Reflex - in jedem März nach Mannheim aufbrechen, völlig unabhängig von der Thematik, dürfte wohl vor allem die Attraktivität dieses Themas verantwortlich dafür sein, daß sich an die 600 Teilnehmer zur Jahrestagung angemeldet haben. Auch ich selbst freue mich sehr, da $B$ es gelungen ist, eine Tagung mit dieser Thematik zu veranstalten. Selbstverständlich ist es ja nicht. Fast unabweisbar muß der Eindruck sein, das Institut (und die Linguistik insgesamt) tue sich mit dem Phänomen Stil eher schwer. Als Indiz dafür kann genommen werden, daß in den 30 Themen der zurückliegenden Jahrestagungen, wie sie dankenswerterweise im jüngsten 'Sprachreport' zusammengestellt sind, das Wort „Stil” nie auftritt. Und der Umstand, daß es im Thema dieses Jahres lediglich als Bestimmungswort auftaucht und dabei einem Grundwort „Fragen” zugeordnet ist, kann von manchen auch eher als eingeschränktes Bekenntnis und als Symptom für gebremste Begeisterung gegenüber dieser Thematik angesehen werden. Stilfragen haben es grundsätzlich in sich, und das gilt noch ganz speziell für eine Linguistik, die sich vorrangig dem Beschreiben, viel weniger dem Bewerten und dem Vorschreiben verpflichtet sieht. Im Kuratorium ist das Thema nun beschlossen worden. Ich verrate kein Geheimnis, wenn ich berichte, daß sich das nicht zuletzt der entschiedenen Absicht verdankt, den Kollegen aus der Auslandsgermanistik etwas 
zu bieten, wonach sie schon immer verlangt haben. Ich hoffe, daB die Tagung so verläuft, wie es sich die wünschen, denen das Thema besonders am Herzen liegt.

Meine Damen und Herren, lassen Sie mich, bevor wir in die eigentliche Arbeit einsteigen, noch ein paar Punkte ansprechen, die mir wichtig sind. Vor allem liegt mir daran, von dieser Stelle aus zu danken - dreifach:

1. Ich danke herzlich den Mitgliedern des Ausschusses, der diese Jahrestagung wissenschaftlich vorbereitet hat. Es sind dies Frau Kollegin Sandig und die Herren Kollegen Grosse, Kallmeyer und Stickel. Ich danke Ihnen für die immense Arbeit, die es gebraucht hat, das ungemein appetitliche Menü zusammenzustellen, das uns offeriert wird, für Kreativität im Dienste der Sache, für beharrliches Werben um die richtigen Referenten. Und ich danke schon jetzt denen, die sich bereitgefunden haben, das Programm zu exekutieren, den Referentinnen und Referenten der nächsten Stunden und Tage. Sie verleihen unserer Tagung ihr Gesicht.

2. Im Herbst des vergangenen Jahres endete die Amtszeit von Siegfried Grosse als Präsident des Instituts für deutsche Sprache. 6 Jahre lang hat er sein Amt mit Hingabe ausgefüllt. In diesen 6 Jahren hat sich die Welt verändert und mit ihr das Institut. Ich erinnere mich: Als er das Amt antrat, überlegte man, ob es an der Zeit sei, einmal mit der Führung des Zentralinstituts für Sprachwissenschaft an der Akademie der Wissenschaften der DDR zusammenzutreffen, um - behutsam, wie das damals nur sein konnte - über gemeinsame Aktivitäten nachzudenken. Präsident und Vorstand sind damals nach Berlin gefahren. Als Herr Grosse aus dem Amt schied, war Deutschland wiedervereinigt, das Zentralinstitut war aufgelöst, 22 Mitarbeiterinnen und Mitarbeiter dieses Instituts haben ihren Platz in Mannheim gefunden. Als Herr Grosse sein Amt übernahm, arbeitete das Institut in der drangvoll-stickigen Enge und Unübersichtlichkeit der Friedrich-Karl-Straße. Als wir ihn im Oktober vergangenen Jahres als Präsident verabschiedet haben, geschah das im wohlstrukturierten Ambiente des neuen, lichtdurchfluteten Hauses. Herr Grosse war immer präsent, wenn er gebraucht wurde, er hat dem Institut viel gegeben. Das Institut ist ihm zu großem Dank verpflichtet.

Nun ist es natürlich nicht der Präsident, der in diesem Hause die entscheidende Arbeit leistet, es sind die Mitarbeiter und es ist der Vorstand. Damit komme ich zu meinem dritten Punkt.

3. Wer - wie ich in den letzten Monaten - die Möglichkeit hat, dieses Institut in seinem Alltagsgewand zu erleben, außerhalb also der ex- 
zeptionellen Situation von Hauseinweihungen, Amtsübergaben oder Jahrestagungen, Mitarbeiter und Vorstand einfach arbeitend, nachdenkend, anleitend, der ist - auch noch nach zehn Jahren im Kuratorium - tief beeindruckt von dem, was hier läuft. Das betrifft einmal die Arbeit. Wer das Institut von außen sieht, kann nur die Produkte sehen - das ist zwangsläufig so. Nun wissen wir alle, die wir wissenschaftlich arbeiten, daB nicht alles, was wir bedacht haben, auch sichtbar in den Produkten Ausdruck findet. Gerecht beurteilen kann man daher nur, wenn man auch die Prozesse verfolgen kann. Und was das angeht, habe ich dieses Institut, wo ich Einblick nehmen konnte, als eine Denkfabrik mit intensiver Atmosphäre erlebt. Hier wird ernsthaft gearbeitet, hier wird an wichtigen Fragen gearbeitet, die Mitarbeiter in diesem Institut verdienen unsere Anerkennung. - Und: Ein solches Institut zu leiten ist eine Aufgabe von hoher Komplexität. Der normale Lehrstuhlinhaber von der Straße neigt wahrscheinlich sehr schnell dazu, ein Institut wie das IDS anzusehen wie eine quantitativ etwas anspruchsvollere Variante seines Lehrstuhls. Ich kann bezeugen, daß solche Vorstellungen weitab von der Realität liegen. Und ich bekenne meinen Respekt vor denen, die hier leiten. Das betrifft den Vorstand, die Herren Kollegen Stickel und Wimmer, und das betrifft die Abteilungsleiter. Und ein Letztes, was mich ganz besonders beeindruckt hat - es gehört nicht so sehr zur Arbeit als vielmehr zum Leben, und das ist $\mathrm{ja}$ auch etwas Wichtiges. Ich habe es schon gesagt: Vor zwei Jahren sind 22 Kolleginnen und Kollegen aus Berlin zu uns gekommen. Ich hatte dem Gremium angehört, das ihre Bewerbungen geprüft hat, und ich war, als die 22 da waren, ängstlich gespannt, wie es mit ihrer Integration gehen würde, habe sie immer wieder nach ihrem Ergehen gefragt, danach, ob sie sich in Mannheim wohlfühlen. Meine Sorge war unbegründet. Obwohl - natürlich - mit der Erweiterung Probleme zu lösen waren - so war zum Beispiel das neue Haus durchaus nicht für 22 Mitarbeiter zusätzlich geplant gewesen - habe ich nur Positives gehört. Selbstverständlich ist das nach allem, was wir über die menschlichen Probleme der Wiedervereinigung wissen, nicht. Das IDS hat hier Vorzügliches geleistet. Für all das möchte ich - ich bin wohl so weit drauBen, daß ich das darf - an dieser Stelle sehr herzlich danken.

Bleibt ein Letztes. Unser Institut wird 199430 Jahre alt. Das ist ein runder Geburtstag. Vielleicht nicht gerade einer, der - wie der 25. oder der 50. - zwingend nach Feiern verlangt, zumal so manchem aus meiner Generation ja noch das „Trau keinem über 30!” im Hinterkopf steckt. So mögen viele die Frage, ob man das Datum zum Anlaß für Nachdenklichkeit oder gar feierliche Rückbesinnung nehmen will; schon den Stilfragen zuordnen, die die Tagung zu beantworten verspricht. Was mich an diesem Punkt anlangt: Ich würde es gern mit Bernd Ulrich Biere halten, 
der im letzten 'Sprachreport' den Gedanken zu propagieren versucht hat, wir könnten überhaupt nicht anders feiern als im tätigen Zusammensein mit denen, die sich den Aufgaben und Zielen des Instituts verpflichtet und den hier Arbeitenden freundschaflich verbunden fühlen. Ich nehme das auf, heiße Sie in diesem Sinne alle noch einmal sehr herzlich willkommmen - als Festgemeinschaft -, lade Sie ein zu feierndem Arbeiten und wünsche allen eine schöne Jahrestagung. 


\section{HANS-MARTIN GAUGER}

\section{Was ist eigentlich Stil?}

Was ist eigentlich Stil? - lautet also die kecke Frage, irritierend verschärft durch die ominöse Abtönungspartikel eigentlich, von der schwer zu sagen ist, was sie semantisch-pragmatisch impliziert. Aber: eine Frage stellen, heibt ja nicht, sie beantworten; es heift nicht beanspruchen, sie beantworten zu können. Wirklich will ich die Frage nach dem Stil nur sozusagen präsentieren; ich will versuchen, sie expliziter und konkreter zu stellen.

Bekanntlich stehen wir ja bei der Kategorie des Stils vor vielen Schwierigkeiten. Ich will sie erst gar nicht darlegen. Es beginnt mit der Schwierigkeit, diese Kategorie so zu fassen, daB man wissenschaftlich oder auch nur rational mit ihr arbeiten kann, und mit der damit verbundenen Schwierigkeit, daB es einerseits mit diesem Begriff bei der Betrachtung von Texten kaum geht, ohne ihn andererseits aber auch nicht. Klar und unbestreitbar ist bei all diesen Schwierigkeiten aber doch eines: es gibt das Wort Stil. Halten wir uns also zunächst an das Wort! Mephistos Rat (in der Rolle Fausts) an den Studienanfänger, den "mulus", ist ja nicht in jeder Hinsicht ungeschickt: „Im Ganzen haltet Euch an Worte!”. Das Wort Stil hat erstens eine komplexe und interessante Geschichte, und es kann zweitens, wie jedes andere Wort, untersucht werden in synchronischer und dann zweckmäßigerweise auf die Gegenwart gerichteter Perspektive.

Ich will, was das Historische angeht, auf das mir als wichtig Erscheinende nur kurz hinweisen und dabei gleich einiges Systematische aufgreifen. ${ }^{1}$

Das lateinische stilus, unser Etymon, meinte zunächst etwas Pflanzliches: einen Stengel. Daraus wurde der Griffel zum Schreiben. Und aus dem Griffel wurde - jeder weiß es - die Schreibart. Es ist eine naheliegende Übertragung, eine Metonymie. Schon bei Terenz und besonders (hundert Jahre später) bei Cicero ist sie belegt. So hat auch stilus, wie wir es häufig gerade im Lateinischen finden, ursprünglich landwirtschaftliche Bedeutung; es gilt zum Beispiel auch für cultura, das ja zunächst "Anbau" bedeutete ... Also der Griffel: entscheidend ist hier aber der spezifische Charakter dieses Instruments; es war dies nämlich ein besonderer Griffel: in ihm wird - darum insistiere ich, und ich insistiere auch, weil dieser Hinweis zumeist fehlt - auf historisch kontingente Weise etwas deutlich

1 Vgl. hierzu Gauger, Hans-Martin (1990): Zur Frage des Stils - etymologisch gesehen. In: Comparatio. Revue Internationale de Littérature Comparée 2, S. 3-18. 
von dem konkreten systematischen Zusammenhang $z$ wischen Stil einerseits, Schriftlichkeit andererseits. Also: historisch kontingent zeigt sich hier ein Bedingungszusammenhang; Stil ist bedingt durch Schriftlichkeit, und zwar wegen eines (nicht immer gesehenen) technischen Vorteils der Schriftlichkeit. Jener Griffel (aus Holz oder aus Metall oder aus Bein) hatte zwei Enden: ein spitzes, mit dem man schrieb - es wurde meist auf Wachstafeln geschrieben -, und ein breites, abgeplattetes, das dazu diente, das Geschriebene wieder glattzustreichen und also auszulöschen. Dies ist nun auch geistig bedeutsam. "Den Griffel umdrehen”, stilum vertere sagt man lateinisch für "verbessern". So war in diesem Instrument beides vereint: das Schreiben und das Löschen. Was aber bereits für den Griffel gilt, gilt noch immer und, möchte man sagen, erst recht für den Computer: das - jedenfalls durch "Überschreiben" - Gelöschte ist auch hier in jeder Hinsicht gelöscht; mehr jedenfalls als das Abgewaschene beim Papyrus und das Abgeschabte beim Pergament: hier, beim Wachs und beim Computer, gibt es keinen Palimpsest.

Warum ist die Möglichkeit des Ausstreichens, des Löschens, so wichtig? Was hat sie zu tun mit Stil? Verbessern kann man sich auch im Sprechen: man kann in mehreren Anläufen, nach und nach, was man sagt, mit dem zur Deckung bringen, was man sagen will. Aber eines kann man beim Sprechen nicht: man kann nicht so tun, als hätte man sich nicht verbessert. Man kann die Korrektur, die man vorgenommen hat, nicht verwischen. Im Unterschied zum Sprechen hat man (und mit größter Leichtigkeit und bereits von diesem römischen Griffel an) beim Schreiben die Möglichkeit, die Korrektur, die Tatsache also, daß korrigiert wurde, ganz unsichtbar zu machen: Korrekturverwischungsmöglichkeit. $\mathrm{Da} \beta$ diese technische Möglichkeit auch geistig, im geistigen Resultat des Schreibens Konsequenzen mit sich bringt, ist evident. Das Technische beeinflußt hier - es tut dies ja durchaus nicht immer - das Geistige unmittelbar. Das im Geschriebenen erscheinende Sprachliche erreicht durch verwischte, unsichtbar gemachte Korrektur eine Intensität (oder kann sie erreichen), die im Sprechen, das sich nicht auf zuvor Geschriebenes stützen kann, unerreichbar ist. Eine Intensität, die sich dadurch noch steigert, daß sich das Schreiben - dies freilich ist eine kleine Kunst bereits während des Schreibaktes an der Realisierung - und dies heißt vor allem an den Adressaten - orientieren kann, die zu einem späteren Zeitpunkt in der geplanten oder vorausgesehenen, im Erleben gleichsam vorweggenommenen Situation akustisch geschieht. So kann das Schreiben dann auch noch zusätzlich die Vorteile des Sprechens, des Gesprochenen nutzen. Vorteile des Gesprochenen? Nun, sie liegen vor allem im Fehlen der nicht wenigen Defizienzen des Geschriebenen. Der positive Vorteil aber des Gesprochenen liegt vor allem in der Unmittelbarkeit, 
der spontanen Direktheit des Ansprechens. Und nun ergibt sich durch Schriftlichkeit die enorme Möglichkeit, den Eindruck von Unmittelbarkeit, der etwas Bestrickendes haben kann, zu schaffen, den Eindruck, daB hier etwas von sich aus flieBt, während man es doch in Wirklichkeit genauestens vorbereitet hat.

Dies ist nun bereits einigermaßen komplex. Korrekturverwischungsmöglichkeit als wichtiges technisches Element von Schriftlichkeit, symbolisiert in diesem besonderen Griffel - stilum vertere -, dadurch eine Verdichtung des Sprachlichen und übrigens auch natürlich des Gedanklichen, die man Stilisierung nennen kann, die jedenfalls etwas wie "Stil" eigentlich hervorrufen $m u \beta$, dann die Mündlichkeitsvorwegnahmemöglichkeit, die mit der Schriftlichkeit einhergeht, mögliche Schaffung also von Mündlichkeit in und mit den Mitteln der Schriftlichkeit selbst, geballte Verbindung gleichsam der Vorzüge des Schriftlichen mit denen des Mündlichen; künstliche, produzierte, vorbereitete Spontaneität. Auch dies hat mit Stil viel zu tun, denn der Stil lebt stark von der Spannung zwischen Gesprochenem und Geschriebenem. Wobei es - dies brauche ich hier kaum zu betonen - bei "gesprochen" und "geschrieben" nicht nur (und nicht einmal primär) um die Differenz des Medialen - akustisch und optisch - geht, sondern um den verschiedenen Duktus, die jeweils verschiedene Anlage des Sprachlichen selbst. Was Peter Koch und Wulf Oesterreicher „konzeptionelle Mündlichkeit” und „konzeptionelle Schriftlichkeit" nennen, ist eigentlich das sprachliche Korrelat des typischerweise Mündlichen und des typischerweise Schriftlichen. Die Differenz zwischen "gesprochen" und "geschrieben" liegt hier somit im Sprachlichen, nicht nur (oder eigentlich nur mittelbar) im Medium der Realisierung.

Im übrigen ist stilus „Schreibart” eine rein lateinische Prägung; keine Anlehnung, wie sonst so oft, an das Griechische; stilus "Schreibart" ist keine Lehnübersetzung; graphis und grapheion hießen nur eben "Griffel” oder auch "Pinsel”.

Sodann ist bedeutsam: in der Antike und im ganzen Mittelalter und darüber hinaus bezogen sich stilus und auch die entsprechenden Wörter der Volkssprachen stets nur auf Sprachliches, wobei im Mittelalter, jedenfalls im Lateinischen, stilus nicht im Sinne von "Schreibart" verwendet wurde. Diese Verwendung gehört also nicht zur mittelalterlichen Latinität. Übrigens hieß im klassischen Latein stilus im übertragenen Sinn durchaus nicht nur "Schreibart", es meinte auch "Literatur" und vor allem schlicht "Sprache”. Graeco stilo hieB einfach "griechisch" und war insofern ein Synonym des normalen adverbialen graece. Man sieht: dies ist eine durchaus skriptistische, eine geradezu skriptozentrische Auffassung von Sprache, wie sie uns ja auch in den Bildungen grammatica 
und litteratura entgegentritt; beide Ausdrücke meinen etymologisch ja dasselbe, denn beide enthalten in sich den "Buchstaben”, und litteratura ist eine bloße Lehnübersetzung von grammatica. Derrida, wenn er es wüßte, müßte sich darüber freuen. Denn dies ist jedenfalls nicht "phonozentrisch", wobei hier Derrida überhaupt einen Popanz aufbaut, gegen den er dann anrennt. Es gibt in der „abendländischen” Tradition sowohl graphozentrische als auch phonozentrische Elemente; sie ist hier durchaus nicht einheitlich und insgesamt wohl eher graphozentrisch; auch die moderne fachsprachliche Gleichsetzung von Text mit jeglicher, also auch mündlicher Sprachäußerung ist graphozentrisch: etwas Gesprochenes wird vom Schriftlichen her gefaßt.

Die Ausweitung des Stilbegriffs auf anderes als auf Geschriebenes - auf die bildenden Künste, dann auf die Musik - findet sich erst im 17. Jahrhundert, also sechzehnhundert Jahre nach Cicero! Vorher finden sich nur einige versprengte Belege, und weiter als das 16 . Jahrhundert gehen sie kaum zurück. Somit eine sehr späte Ausweitung von der "Schreibart" auf die "Machart". Und hier, übrigens, ist wieder Graphozentrik!

Die Ausweitung über das handwerklich Künstlerische hinaus auf Erscheinungen der "Lebenswelt" gehört dann bereits zur Gegenwart: es gibt heute den Arbeitsstil, den Verhandlungsstil, den Führungsstil, dann den Umgangsstil, auch den Fahrstil, den Laufstileines Joggers, schließlich gibt es den Lebensstil, dem sich neuerdings der lifestyle hinzugesellt hat. Auch das styling wollen wir nicht vergessen. Auffallend ist an dem allen, daß wir Stil offensichtlich nur Dingen zuerkennen, die entweder Erzeugnisse oder Tätigkeiten des Menschen sind. Es ist also so, daß unsere Sprachen in dem Wort Stil auf nicht ausdrückliche Weise einen Unterschied setzen zwischen Mensch und Tier. Allenfalls dem Menschen sehr nahestehende und in gewissem Sinn vermenschlichte Tiere, etwa dem Pferd oder dem Hund, würden wir diese Kategorie - aber auch nur zögernd - zugestehen.

Ein anderer bedeutsamer Punkt ist der: wir verwenden das Wort Stil in zwei sehr verschiedenen Weisen, die aber zusammenhängen. Erstens im Sinne eines Sich-Einfügens: der Einzelne fügt sich ein in ein Vorgegebenes; Stil ist in diesem Fall Erwartungserfüllung. Zweitens reden wir von Stil - und daran vor allem denken wir heute bei dem Begriff - im Sinne eines Sich-Ausfügens. Stil ist hier - umgekehrt - gerade das SichAbheben von einem Vorgegebenen; er erscheint hier gerade nicht als Erwartungserfüllung, sondern als "Erwartungsbesiegung"; Stil, so hat bekanntlich Roman Jakobson definiert (es ist aber nur eine Seite und auch diese keineswegs ganz), ist "besiegte Erwartung”, „defeated expectancy". In diesem Sinne entspricht Stil so etwas wie der persönlichen Eigenprägung einer Äußerung und speziell einer sprachlichen. Einfügung 
also und Ausfügung, englisch mit den handlichen Ausdrücken: "opting in" und „opting out".

Gerade hier aber - Einfügung und Ausfügung - haben wir nun historisch einen bemerkenswerten Wandel. Von der Antike bis weit in die Neuzeit, bis ins 18. Jahrhundert hinein und darüber hinaus, ist Stil durchweg im Sinne eines Sich-Einfügens verstanden worden: Stil als etwas einem Konventionellen, Typischen Entsprechendes. Das Individuelle, das sich hier natürlich auch zeigte, ist innerhalb dieser Sicht eher als Schlacke, als etwas Negatives empfunden worden (so sagt man uns - aber war es so wirklich, in jeder Hinsicht?). Der Wandel vollzog sich im 18. Jahrhundert, in dessen zweiter Hälfte, in der so vieles begann. Stil wird von nun an mehr und mehr - und in der Romantik erst recht - zum Individualstil oder Personalstil, was sich bis heute und sich verstärkend fortgesetzt hat. Von nun an dominiert das Element Ausfügung eindeutig und verdrängt das andere, das Jahrhunderte und die weitaus längste Zeit hindurch dominiert hatte: die Einfügung. Aber eben: die Einfügung ist nur in den Hintergrund gedrängt worden, sie ist immer noch da.

Gegen Ende des 18. Jahrhunderts haben wir nun aber eine zusätzliche Wandlung. Sie hängt zusammen mit dem Aufkommen einer historischen Sicht, dem Durchbruch des historischen BewuBtseins. Die historische Sicht oder "der historische Sinn", wie Nietzsche sagen wird, ist uns so natürlich, daß uns die Bedeutung dieses Wandels, wie auch er selbst, kaum mehr zu Bewußtsein kommen. Der ganze Bildungsbegriff, die Auffassung des Menschen überhaupt, werden in jener Zeit (und sich fortsetzend im 19. Jahrhundert) historisiert: umfassende Vergeschichtlichung. Es ist alles andere als überraschend, daß ein Begriff wie der des Stils an dieser geistesgeschichtlichen Veränderung partizipieren mußte. Stil hat seither unumkehrbar, wie es scheint, dies historisch relativierende, zeitbezogene Element. Das heißt: wir urteilen auch hier nicht mehr nach absoluten Kriterien, sondern gestehen jedem Zeit-Stil sein eigenes, jeweils historisch bedingtes Recht zu. Wir sind in der Lage, was frühere Zeiten nicht konnten, uns einzuleben in die verschiedensten Stile und dabei jeweils ästhetische Befriedigung zu erfahren. Wir tun sogar etwas, im Sinne jener Historisierung, das frühere Zeiten nicht nur nicht taten, sondern nicht einmal verstanden hätten: wir stellen, etwa in Bauwerken, die ursprüngliche Stilreinheit wieder her, und "Stilreinheit" ist ja ein durch und durch historischer, historisches Bewußtsein voraussetzender Begriff. Aristoteles, Thomas, aber auch noch Kant hätten nichts mit ihm anfangen können ...

Also zusammenfassend: eine Übertragung am Ausgangspunkt, eine Metonymie. Die Übertragung vom Instrument auf das Produkt; das mit dem 
Instrument Geschaffene wird mit dem Namen des Instruments selbst bezeichnet: vom "Griffel” zur "Schreibart”. Dann, viel später, eine erste Ausweitung: von der "Schreibart" eines Texts zur "Machart" in den bildenden Künsten und der Musik. Die zweite, bereits moderne Ausweitung ist die von der "Schreibart" und der „Machart” zu anderen Tätigkeiten des Menschen, die ganz kunstfern sein können. Es bleibt aber doch eine unbestimmte Referenz auf das Künstlerische oder doch Kulturelle, selbst bei Fahrstiloder Organisationsstil fehlt sie nicht ganz. Schließlich die beiden entscheidenden und spezifisch modernen, auf die zweite Hälfte des 18. Jahrhunderts zurückgehenden Wandlungen des Stilbegriffs: erstens die Individualisierung, die Dominanz des „opting out” gegenüber dem "opting in", die Umkehrung also des Verhältnisses, das vorher war; zweitens die Historisierung.

Was die historische Relativierung des Stilbegriffs angeht, so war es Nietzsche, der wohl als erster das latent Nihilistische in ihr erkannte. In "Jenseits von Gut und Böse" lautet ein Abschnitt (Nummer 223):

„Der europäische Mischmensch - ein leidlich häßlicher Plebejer, Alles in
Allem - braucht schlechterdings ein Kostüm: er hat die Historie nöthig
als die Vorrathskammer der Kostūme. Freilich bemerkt er dabei, daß
ihm keines recht auf den Laib paßt, - er wechselt und wechselt. Man
sehe sich das neunzehnte Jahrhundert auf diese schnellen Vorlieben und
Wechsel der Stil-Maskeraden an; auch auf die Augenblicke der Ver-
zweiflung darüber, daß uns 'nichts steht'; unnütz, sich romantisch oder
klassisch oder christlich oder florentinisch oder barokko oder 'national'
vorzuführen, in moribus et artibus: es 'kleidet nicht'! Aber der 'Geist',
insbesondere der 'historische' Geist ersieht sich auch noch an dieser Ver-
zweiflung seinen Vortheil: immer wieder ein Stück Vorzeit und Ausland
versucht, umgelegt, abgelegt, eingepackt, vor allem studirt: - wir sind
das erste studirte Zeitalter in puncto der 'Kostüme', ich meine der Mo-
ralen, Glaubensartikel, Kunstgeschmäcker und Religionen, vorbereitet
wie noch keine Zeit es war, zum Karneval großen Stils, zum geistigsten
Faschings-Gelächter und Übermuth, zur transscendentalen Höhe des
höchsten Blödsinns und der aristophanischen Welt-Verspottung. Viel-
leicht, daß wir hier gerade das Reich unserer Erfindung noch entdecken,
jenes Reich, wo auch wir noch original sein kōnnen, etwa als Parodisten
der Weltgeschichte und Hanswürste Gottes, - vielleicht daß, wenn auch
Nichts von heute sonst Zukunft hat, doch gerade unser Lachen noch
Zukunft hat!".

Die vorausahnende Modernität Nietzsches machen Stellen wie diese gerade auch indirekt "stilistisch", in ihrer grellen und, wie ich finde, etwas unguten Brillanz - deutlich. Der Nihilismus im Stilistischen - man hat alle Stile und daher selbst eigentlich keinen - geht mit einer Stilisierung, einer Verstilung alles Inhaltlichen einher: da ist, in einem bestimmten, das Inhaltliche vergleichgültigenden Sinne Ästhetisierung. Mit 
Paul Feyerabends "anything goes" zieht dies auch in die Wissenschaft ein. Wobei er eine Kleinigkeit übersah: wenn alles geht, geht eigentlich nichts.

Nunmehr zum Systematischen. Beginnen wir mit einer kurzen Analyse des heutigen Gebrauchs von Stil. Eine umfangreiche und detaillierte Untersuchung wäre hier sehr vonnöten. Wann reden wir von Stil? In welchen Zusammenhängen gebrauchen wir dieses Wort? Konzentrieren wir uns auf das Sprachliche, auf den Stil, wie er sich im Sprachlichen zeigt. Wir reden hier vom Stil im Sinne des Individualstils: jemand schreibt einen bestimmten, für ihn charakteristischen Stil. Wir beziehen uns aber auch, mit diesem Begriff, auf eine Qualität, die bestimmten Textarten entspricht, also: Gattungsstil, wenn wir „Gattung” in einem weiteren als dem literarischen Sinne nehmen, also im linguistischen. Es geht da um Traditionen des Sprechens und - vor allem - des Schreibens insgesamt, um „Diskurstraditionen”. Stil somit als Individualstil und als Textartenstil. Es sind zwei sehr verschiedene Verwendungen: im zweiten Fall fügt sich der einzelne in ein Vorgegebenes ein, eben in eine Textart; im ersteren Fall hingegen meinen wir, daB sich der einzelne gleichsam ausfügt; hier ist Stil wirklich etwas wie Jakobsons ,besiegte Erwartung”. Dies ist vom Rezipienten her gesehen und gilt im strengen Sinn freilich nur bei erster Bekanntschaft, denn wir erwarten bald, einmal darauf eingestellt, die charakteristische Abweichung, die Eigenprägung, die wir dann schon kennen und in die wir uns "eingelesen" haben; dann wird auch hier, aber in anderer Weise, Erwartung erfüllt und also gerade nicht "besiegt". Sie kann aber auch, wenn der Autor einmal anders schreibt, erneut „besiegt” werden ... Übrigens muß man sich in einen bestimmten Stil in solch individuellem Sinn, wenn es um dessen Aufnahme geht, oft wirklich erst mit einer gewissen Anstrengung einlesen oder gar einarbeiten, und wie im Inhaltlichen ist es ratsam, einem Autor eine bestimmte, also keineswegs unbefristete Vorgabe an Bereitschaft, ja, wirklichem Wohlwollen zu gewähren. Man sollte nicht zu schnell abweisend reagieren, denn eben dies ist eine Gefahr der "Erwartungsbesiegung”: der Sieg kann so sein, daß man nicht weiterliest ... Zwar gibt es auch beim Stil eines Autors das Analogon zur "Liebe auf den ersten Blick", zum "coup de foudre”, aber dieses Phänomen ist da doch eher Ausnahme: das Interesse, die Geneigtheit des Lesers, die Anmutung durch Anmut - nicht ohne Grund stellen sich hier Wörter mit erotischer Aura ein - zeigen sich oft erst nach einigem „Umgang”.

Zurück jedoch zu Einfügung und Ausfügung, oder „opting in" und "opting out". Bemerkenswert ist nun, daß beide Formen von Stil sich verschränken können, daB - genauer gesagt - das „opting out” sich in- 
nerhalb eines „opting in" vollziehen kann und eigentlich vollziehen muß. Hierfür ein musikalisches Beispiel. Das berühmte "Italienische Konzert" für Cembalo oder Klavier von Bach findet sich unter einem längeren Titel, der anderes einbezieht und so lautet: „Zweyter Theil der ClavierÜbung, bestehend in einem Concerto nach italiaenischem Gusto und einer Ouverture nach französischer Art vor ein Clavizymbel mit zweyen Manualen". Dies meint offensichtlich: da ist ein Konzert, wie Italiener es erwarten, wie es ihnen gefällt, sodann eine Ouverture nach der Art, wie französische Komponisten sie zu machen pflegen. Man erkennt an diesen beiden Ausdrücken - Gusto und Art-deutlich das Element "Machart", aber auch und vor allem das Element "Einfügung”: Bach fügt sich ein in ein italienisches und in ein französisches Muster, was ja keineswegs ausschlieBt, daB sich hierin auch das individuelle Sich-Ausfügen zeigt. Bach will nämlich dartun - es ist seine Voraussetzung -, indem er dem jeweils gegebenen "Gusto" entspricht, wie er - ganz persönlich er - diese Entsprechung zuwegebringt. Übrigens ist der Begriff "Gusto” offensichtlich rezeptionsästhetisch konzipiert, während der Begriff "Art" in dieser Hinsicht offener ist; er dürfte sich aber doch eher - „Machart" - auf die Produktion beziehen.

Sodann (und wichtiger) ist zu sehen, daB Stil in jedem Fall stets innerhalb von etwas ist. Er ist zunächst einmal - noch vor jeder Diskurstradition - unvermeidlich innerhalb einer ihm vorgegebenen Sprache: er realisiert sich innerhalb der Realisierung von Sprache als Besitz einer Gemeinschaft. Er unterliegt insofern, da zur Sprache Norm gehört oder Sprache eigentlich Norm ist, einem Korrektheitsrahmen. Daher gebrauchen wir Stil oft überhaupt im schlichten Sinn von Korrektheit. Stil ist Freiheit innerhalb von Bindung. Dieser durch die Sprache selbst gesetzte Rahmen ist so selbstverständlich, daB er eigentlich, wenn von Stil die Rede ist, verborgen bleibt. Gleichwohl ist er da, und so haben wir, noch vor dem Rahmen der jeweiligen Diskurstradition (oder Textart), den einer Sprache, eines Sprachbesitzes. Hierfür ein Beispiel.

Der siebzehnjährige Sigmund Freud schreibt am 16. Juni 1873 an den Freund Emil Fluss, dem er von seinem Abituraufsatz berichtet: "Mein Professor sagte mir zugleich - und er ist der erste Mensch, der sich untersteht, mir das zu sagen -, daß ich hätte, was Herder so schön einen idiotischen Stil nennt, das ist ein Stil, der zugleich korrekt und charakteristisch ist." Hier ist nun in der Erläuterung „korrekt und charakteristisch" beides beieinander: die Einfügung im Blick auf Korrektheit (es ist der Korrektheitsrahmen des Sprachbesitzes selbst, aber auch - möglicherweise - der einer bestimmten Diskurstradition) und die Ausfügung, dergestalt, daß gerade innerhalb von Korrektheitserfüllung das Eigene her- 
vortritt. Also: charakteristische Korrektheit, sich ausfügende Einfügung; man fügt sich in ein Vorgegebenes ein (den Sprachbesitz, die jeweilige Diskurstradition), tut dies aber in sich ausfügender, individualisierender oder, in Herders etymologisierender Wortverwendung, "idiotischer" Weise. Die Stelle zeigt auch, daß Freud hier einen hervorragenden Lehrer hatte - nicht nur wegen der Richtigkeit seines Urteils, sondern auch und vor allem wegen dessen Differenziertheit. Der tüchtige Mann sah genau, worauf es hier ankommt: auf Eigenheit innerhalb von etwas, nämlich des Korrekten.

Stil, also, notwendig innerhalb eines Rahmens: erstens innerhalb der Sprache, zweitens innerhalb einer Diskurstradition, Sprachrahmen und Textartrahmen. Zum Stil gehört essentiell diese Rahmenbedingung; Rahmen, Rahmenbegrenztheit der Bewegung ist die Bedingung der Möglichkeit von Stil.

Die andere Bedingung dieser Möglichkeit ist dann natürlich die Möglichkeit von Bewegung überhaupt: die Möglichkeit somit eines so oder so oder so. Wo es nur eine Möglichkeit gibt, ist Stil unmöglich. Gerade im Sprachlichen läBt sich dies exemplarisch zeigen: Stilistisches kann es im Sprachlichen nur geben, wo sprachlich gewählt werden kann. Dort, wo der grammatische Rahmen des Sprachbesitzes nur eines vorschreibt („servitude grammaticale"), ist Stilistisches ausgeschlossen.

Ausfügung also und Einfügung. Gibt es zwischen diesen beiden Verwendungsweisen, die gegensätzlich sind, Gemeinsamkeit? Nun, die Gemeinsamkeit besteht offensichtlich darin, daB sich beide mehr auf das Formale als auf das Inhaltliche beziehen: mehr, um es schlichter und „phänomenologischer" zu sagen, auf das Wie als auf das Was. Der implizite Gedanke ist dabei der: etwas ist schon da, das Was des Gesagten; nun kommt das Wie hinzu, denn die Unterscheidung von Was und Wie setzt die Vorgängigkeit des ersteren voraus; ein Wie kann ohne ein Was nicht gedacht werden; eher schon ein Was ohne Wie. „What do you read, my Lord?", fragt Polonius den Hamlet, und wie dieser ausweichend und zweideutig antwortet: „Words, words, words”, insistiert Polonius, und wir fühlen: zu Recht, denn Hamlets Antwort ist keine Antwort, da sie ja für jegliche Lektüre gilt: „What is the matter, my Lord?”. Das heißt: Polonius fragt nicht nach dem Stil, nicht nach dem Wie, er fragt nach dem Inhalt, er möchte wissen, worum es in dem Buch geht, und dies ist ja vernünftigerweise die erste Frage, die im Blick auf ein Buch zu stellen ist. Später sagt Hamlets Mutter Gertrude im Blick auf eine recht blumige Darlegung des Polonius (und da haben wir nun wieder wie selbstverständlich die Trennung): „More matter with less art”. Hier wird also mehr Inhalt gewünscht, mehr Mitteilung; und „art” ist hier doch wohl 
(und wohl eher im Sinn der Einfügung) ein anderes Wort für Stil; Gertrude will, in unseren Worten, mehr Was hören und weniger Wie.

Natürlich berufe ich mich hier nicht auf Shakespeare; ich berufe mich darauf, dab uns, was hier intelligent und anmutig gesagt ist, spontan einleuchtet: diese Sätze formulieren die Voraussetzung, die auch die des vorwissenschaftlichen SprachbewuBtseins ist, wenn es um SprachäuBerungen und um ihren Stil geht. Dies ist nun ein systematisch wichtiger, oft mißachteter Punkt: die wissenschaftliche Betrachtung darf, ja, sie $m u ß$ hier auf dieses Sprachbewußtsein rekurrieren, denn Stil, was immer er ist, ist etwas, das sich nicht erst der wissenschaftlichen Untersuchung zeigt; er ist schon vor ihr im Sprachgebrauch als etwas Erlebtes da und ist ein Bestandteil der Impression des nicht-sprachwissenschaftlich oder literarkritisch gebildeten Lesers. Eine Stiluntersuchung ist absurd, wenn sie sich vom Erleben des Lesers trennt oder sich gar zu diesem Erleben nicht mehr in Beziehung setzen läßt. Die Unterscheidung von Was und Wie gehört nun aber gerade zu diesem Erleben. Sie gehört zum vorwissenschaftlichen SprachbewuBtsein. An ihr ist nicht zu rütteln. Da gibt es nur noch Differenzierung; diese allerdings ist nötig. Ich nenne zwei Beispiele.

Der Kritiker Johannes Willms schrieb vor kurzem in der „Süddeutschen” sehr kritisch über "Das Echolot” (1993) von Kempowski: der Autor habe unter dem auch von ihm selbst gefühlten Druck der Banalität der vielen von ihm zusammengestellten Texte "Auszüge aus Briefen und Tagebüchern von André Gide, Julien Green, Paul Léautaud, Anaïs Nin oder Paul Valéry ... in seine Sammlung aufgenommen". Und nun fährt er fort:

„So willkürlich diese Auswahl 'edler Federn' (nota bene!) anmutet, so deutlich kommt die mit ihr verfolgte Absicht zum Vorschein: Von diesen Texten, die allesamt ein wesentlich höheres stilistisches als reflexives Niveau haben (note bene!), sollte einiger Glanz auf die ansonsten überall vorwaltende Spracharmut und Banalität fallen." (Süddeutsche Zeitung, 2. Januar 1994, S. 17)

Eine Unterscheidung also $\mathrm{zwischen} \mathrm{"reflexivem",} \mathrm{somit} \mathrm{auf} \mathrm{das} \mathrm{Inhalt-}$ liche zielendem, und dem "stilistischen Niveau", das allein das formale Wie und hier speziell wohl das Sprachliche meint. Man kann also - und so ist es in der Tat - im Wie Niveau haben (nur im Wie) und im Was (nur im Was) und gewiß auch in beiden zugleich. Oder der alte Fontane an seinen Verleger über den „Stechlin” (es ist ein „abstract”): „Zum Schluß stirbt ein Alter, und zwei Junge heiraten sich; und das ist so ziemlich alles, was auf den 500 Seiten geschieht". Dies also, nach Fontane, der Inhalt, das Was; nun aber fährt er fort: alles habe ihm gelegen an der 
„Mache", und er versieht dies vielleicht etwas überraschende, auch so schmissig modern klingende Wort, das ein interessantes, ins Handwerkliche gewendetes Synonym für "Stil" ist, mit einem Ausrufungszeichen. ${ }^{2}$ Also wieder: das Wie ist ihm entscheidend; man könnte wohl auch sagen: es wird ihm zum Was. Dies ist nämlich das Kennzeichnende literarischen Schreibens: das Was tritt vielfach zurück hinter dem Wie; auf dem Wie liegt der Nachdruck dessen, der sich literarisch zu schreiben müht.

Stil ist also bei einem Text (auch bei einem Text) das Wie: wie ist er gemacht? Oder einfach: wie ist er? Nicht also: „What do you read, my Lord?" - sondern: How is what you are reading, my Lord? How is it written?

Wenn wir aber $z$ wischen Was und Wie unterscheiden, stoßen wir auf eine klassische Schwierigkeit: das Wie kann nicht immer eindeutig vom Was getrennt werden. Und hier zeigt sich gerade ein Spezifisches des literarischen Texts: die Trennbarkeit von Was und Wie ist bei ihm entschieden geringer als beim nicht-literarischen. Das Was gehört beim literarischen Text in gewissem Sinn selbst schon zum Wie, wobei der literarisch-poetische Diskurs, auch in dieser Hinsicht, nicht völlig verschieden ist von der nicht-literarischen Äußerung: es gibt da eine Skala, einen Übergang, keinen eigentlichen Bruch. Das Spezifische des literarischen Texts liegt darin, daB in ihm die Verschränkung von Was und Wie bis zur völligen Untrennbarkeit gehen kann, was sich dramatisch in der Übersetzung zeigt: sie kann nahezu unmöglich sein, eben weil das Materielle eines Texts so $z$ ihm gehören kann, daß es von ihm nicht abziehbar ist. Wieder zeigt sich hierin die querliegende Unabhängigkeit dieser Kategorie: Stil ist ein Wie besonderer Art, eben weil er, beim literarischen Text, so stark auch - und gerade - durch das Inhaltliche bedingt ist, durch die "Gegenstände und Sachverhalte”, um mit Karl Bühler zu sprechen, auf die er zielt (wobei - wohlverstanden - diese "Gegenstände und Sachverhalte" auch fiktiv sein können, ja, in der Regel sind). Anders im wissenschaftlichen Diskurs, der dem literarischen konträr entgegensteht: in ihm lassen sich die Elemente der "Appellfunktion" und der "Ausdrucksfunktion” leichter und - im Idealfall - vollständig trennen von der "Darstellungsfunktion". Radikal, aber eigentlich zutreffend, erklärt Roman Ingarden:

„In einem wissenschaftlichen Werk können ... in den verschiedenen Schichten ästhetisch relevante Qualitäten auftreten ... Sie brauchen aber in diesem Werk gar nicht vorhanden zu sein und stellen - falls

2 Zit. bei Heller, E. (1979): Fontane und die Kunst des Romanciers. In: Jahrbuch der Deutschen Akademie für Sprache und Dichtung, S. 69. 
sie doch da sind - einen im Grund entbehrlichen Luxus dar. Manchmal können sie sogar das betreffende Werk in der Ausübung der ihm eigenen Funktion stōren, indem sie dem Leser die Annäherung an die im Werk zur erkenntnismäfigen Erfassung gebrachte transzendente Wirklichkeit erschweren. In einem literarischen Kunstwerk dagegen bilden diese Qualitäten ... das bedeutendste Moment in dem zur ästhetischen Konkretisierung gebrachten Kunstwerk." 3

Ingarden erfüllt hier selbst die von ihm erhobene Forderung luxusfreien Diskurses. Oder ist dies - rien n'est simple - ein Luxus besonderer Art? Von hier aus ließe sich argumentieren, daB gerade dem wissenschaftlichen Diskurs entschieden mehr Stil zugestanden werden könnte (und müßte), als dies der Fall ist: da hier das Was klar abtrennbar ist, da das Wissenschaftliche gerade nicht Stil ist und sein darf, da der Stil hier wirklich nur hinzukommt als etwas Persönliches, sollte man ihn auch hinzukommen lassen und sein Hinzukommen (im Sinne individueller Ausfügung) tolerieren, ja, begrüßen. Gerade hierin pflegen wir jedoch, streng zu sein ("das ist nicht der Stil einer Doktorarbeit!"). Übrigens denkt Buffon bei seinem berühmten dictum in dem nicht ganz so berühmten „Discours sur le style" gerade an die wissenschaftliche (er sagt "philosophische") Darlegung: "Le style, c'est l'homme même”. Er ist für ihn das vom Persönlichen her (durch bewußte Arbeit) Hinzugefügte, zusätzlich ins Werk, in den Text Gesetzte. ${ }^{4}$

Für die Trennung von Was und Wie eine charakteristische Äußerung von Sigmund Freud. Er beginnt seine eigentümlich spröde Abhandlung „Der Moses des Michelangelo" aus dem Jahr 1914 (wir wissen, wie sehr ihn diese Statue faszinierte) mit diesem Satz:

"Ich schicke voraus, daß ich kein Kunstkenner bin, sondern Laie. Ich habe oft bemerkt, daß mich der Inhalt eines Kunstwerkes stärker anzieht als dessen formale und technische Eigenschaften, auf welche doch der Kūnstler in erster Linie Wert legt. Für viele Mittel und manche Wirkungen fehlt mir eigentlich das richtige Verständnis." (Gesammelte Werke, X, S. 172)

Eine, man möchte sagen, souverän biedere Äußerung, die sicher Freuds redlichem Empfinden entspricht; Koketterie war ihm einigermaßen fremd. Freud meint also, das heißt: er gibt $\mathbf{z u}$ - und weiß, daß dies vom Standpunkt des „Kunstkenners” aus ein gravierender Fehler ist -,

3 Ingarden, Roman (1968): Vom Erkennen des literarischen Kunstwerks. Tübingen. S. 156.

4 Hierzu zwei Arbeiten von mir: „Stil in der Wissenschaft” und „Graf Buffon über den Stil oder >Stil ist der Mensch selbst<" in einem 1995 bei C.H. Beck, München, erscheinenden Buch. 
daB ihn (in unseren Worten) das Wie eines Kunstwerks, für den Kenner das Eigentliche, weniger interessiere als dessen Was, in diesem Fall somit die Auffassung des Mose durch Michelangelo, wie sie sich ausdrückt in diesem gewaltigen Werk, das wie wenig andere einlädt zu solcher "Stoffentgleisung", der Entgleisung, wenn es denn eine ist, in das Was.

Somit: Stil ist in einer noch näher zu bestimmenden Weise das Formale, das Wie: etwas, das schon da ist, ein Inhaltliches, ein Was tritt in spezifischer Weise hervor; es könnte so oder so oder so hervortreten, tritt aber so hervor. Das Was wird mit einem Wie versehen. Und an dieser Stelle sind mir nun zwei Dinge in gleicher Weise wichtig. Erstens und einerseits, daB es bei diesem Wie bleibt: man kommt nicht weiter, denn wenn man einzuengen sucht, wird der Begriff in der Tat zu eng. Zweitens und andererseits, daB dieses Wie als etwas rein Formales und nur Hinzukommendes und also analytisch von den übrigen Elementen des Textes rein Ablösbares nicht vorauszusetzen ist, daB somit, in anderen Worten, in diesem Wie, das als solches bleibt, auch Inhaltliches ist und daB dies insbesondere für das Literarische, den Stil im Literarischen gilt. Die Metapher vom stilistischen "Kleid”, von der stilistischen „Einkleidung”, zu der ja auch der zentrale Begriff des "ornatus" der Rhetorik gehört, ist unangemessen. Es ist alles andere als neu, dies festzustellen. Wichtiger wäre jedoch, sich darüber klar zu werden, daß es gleichwohl - es war mein "einerseits" - beim Stil als einem Wie bleiben muB. Stil ist ein Wie, anders ist der Begriff nicht zu fassen. Zu diesem Wie gehören aber auch und im Literarischen auf jeden Fall - Elemente, die dem Was zuzurechnen sind. Demzufolge gibt es im Literarischen auch kein reines Was. Und dies markiert - ich sage es bewußt gegen bestimmte modische Sperenzien - den abgrundartigen Unterschied zum wissenschaftlichen Reden, wie es sein sollte. Hier, im Wissenschaftlichen, gibt es das reine Was. Stil ist also im Medium des Sprachlichen jenes komplexe Wie: einerseits muB man festhalten, beim sich einfügenden wie bei dem sich ausfügenden Stil, an dieser Bestimmung; Stil ist ein Wie, dem also ein Was entgegensteht, andererseits gilt es, dieses Wie in seiner Komplexheit zu sehen, es nicht, wie es neuerdings anschaulich heiBt, „unterkomplex" zu fassen.

Hieraus folgt nun unmittelbar, daB es ein unterkomplexes Mißverständnis von Stil im Sprachlichen ist, diesen in erster Eingrenzung als etwas bloß Sprachliches zu betrachten. Und mir scheint, daß dies die gängige Auffassung gerade und vor allem unter Sprachwissenschaftlern ist. Ich will die Zitate nicht häufen. Vielleicht zitiere ich eher einen Philosophen. Manfred Frank erklärt in seinem 1992 erschienenen bemerkenswerten Buch „Stil in der Philosophie”: „Über eines jedenfalls besteht Einigkeit” - man sieht: dies ist für ihn der Fels in der Brandung - „darüber, daß 
der Stil ... ein Zug des Sprachlichen ist." Ich setze meine These dagegen: Stil ist, auch im Sprachlichen, auch als Eigenschaft eines Texts, nichts rein Sprachliches, er ist kein „Zug des Sprachlichen”; aber wir müssen noch weiter gehen und sagen: er ist nicht einmal etwas primär Sprachliches. Und hier darf darauf aufmerksam gemacht werden, daß schon die Sprachäußerung selbst, von welcher der "Text" eine spezifische Erscheinung ist, nichts rein Sprachliches ist, obschon überall in ihr, da sie ja Sprachäußerung ist, Sprachliches ist. Rein sprachlich ist in ihr nur, was Sprachbesitz realisiert. Die Sprachäußerung ist etwas Nicht-Sprachliches im Medium des Sprachlichen; nicht-sprachlich in ihr ist zumindest das Was des durch sie Gesagten, ihr Inhalt. Eine Äußerung - das sind eben nicht "words, words, words", sondern etwas, ein Was im Medium von Wörtern (und anderem Sprachlichem). Weder also ist der Text selbst (im weiteren, fachsprachlichen oder im engeren Sinn) etwas bloß Sprachliches noch ist dies der Stil, der sich an ihm - möglicherweise - zeigt.

Wir müssen also sagen, daß zum stilistischen Wie, also einfach zum Stil eines Texts, drei Arten von Elementen gehören. Erstens inhaltliche Elemente, die - im Sinne der Vermeidung des Unterkomplexen - jenem Wie zuzurechnen sind, sie sind schon Elemente von Stil, tragen konstitutiv zu ihm bei. Zweitens sodann gibt es als Bestandteile des Stils formale Elemente, die nicht-sprachlich sind (das heiBt: sie erscheinen zwar sprachlich, da sie ja in einem Text erscheinen; sie erscheinen im Medium der Sprache, an Sprache gebunden, sie sind aber nicht eigentlich sprachlicher Natur). Nicht-sprachlich formale Elemente von Stil, die stark zu ihm beitragen, wären zum Beispiel: Pathos, Feierlichkeit, Leichtigkeit, Tempo, Umständlichkeit und so fort. Solche Elemente sind nicht Exteriorisierungen eines Sprachbesitzes. Darum sind sie auch - es ist ein gutes operationales Kriterium - ohne Schwierigkeit übersetzbar. Drittens gibt es formale und nun wirklich sprachliche Elemente, die zu jenem Wie, das der Stil ist, mit beitragen, Elemente, die also wirklich Exteriorisierungen von Sprachbesitz, also eigentlich sprachlich sind. Als sprachlich darf somit mit Recht nur dasjenige im Stil eines Texts betrachtet werden, das Sprache, Sprachbesitz, „langue”, realisiert. Und bei diesen letzteren Elementen trifft nun beides zu: diese Elemente von Stil realisieren die als Rahmen vorgegebene Sprache, und sie werden durch die dem Text vorgegebene Sprache realisiert.

Natürlich kann ich mich als Linguist oder Literaturwissenschaftler konzentrieren oder beschränken auf die sprachlichen Elemente von Stil. Nur muß ich dann wissen (und die anderen wissen lassen), daß ich mich unterkomplex verhalte und nur einen Teil des Stils - und nicht einmal den bedeutsamsten - zum Gegenstand mache. Andererseits liegt es auf der 
Hand, daß gerade die Sprachwissenschaft zu diesem - wichtigen - Teil des Stils Bündiges zu sagen hat.

Zusammengefaßt also: Stil im Sprachlichen ist das in gewissem Sinn vom Was des Gesagten trennbare Wie. Dieses Wie enthält drei sehr verschiedene Arten von Elementen: inhaltliche Elemente (dies gilt für literarische Texte im weitesten Sinn dieses Begriffs), dann formale Elemente, die nicht-sprachlich sind, die sich zwar, wie die inhaltlichen, sprachlich, das heift im Medium einer Sprache realisieren, aber nicht Realisierungen von Sprache sind. Schlieblich sprachliche Elemente, die zum Stil insgesamt dadurch beitragen, daß sie die vorgegebenen Möglichkeiten der jeweiligen Sprache spezifisch ins Werk setzen.

Und festzuhalten, noch einmal, ist die nicht bloB kontingent etymologische Bindung von Stil an Schriftlichkeit. An den Griffel, den stilus mit den beiden Enden: dem spitzen und dem abgeplatteten. Die Schrift ermöglicht und fordert ein intensiveres, ein stilisiertes Sprechen, ein Sprechen mit Korrekturverwischung und auf der Grundlage von deren erst durch sie gegebenen technischer Möglichkeit. Stil ist also - so gesehen - der Griffel, oder da französisch style noch immer „Griffel” heißt: „le style, c'est le style même".

Ich will nun versuchen, meine These, daB Stil, auch wenn er sich im Medium des Sprachlichen zeigt, nichts rein Sprachliches, ja, nicht einmal primär etwas Sprachliches sei, an einem kurzen Textstück, natürlich nur ansatzweise, zu illustrieren.

Coda: Ernst Jünger, Auf den Marmorklippen

Nehmen wir den Beginn von Ernst Jüngers „Auf den Marmorklippen”, eines schmalen Buchs, das 1939 erschien (und auch in diesem Jahr geschrieben wurde) und damals weithin als "kritisch" gegenüber dem Regime aufgefaßt wurde (von einer Auffassung des Buchs als einem Beitrag zum „Widerstand" zu reden, wäre aber anachronistisch; dieser Begriff trat erst später hervor und wird heute leider für alles Mögliche, meist ganz und gar Gefahrloses „stillos” und mehr als dies verwendet). Es ist zweckmäßig, für eine solche Illustrierung den Beginn eines Werks zu nehmen, weil dann ja zuvor noch nichts ist; da wird erst etwas „aufgebaut”.

"Ihr alle kennt die wilde Schwermut, die uns bei der Erinnerung an Zeiten des Glückes ergreift. Wie unwiderrufich sind sie doch dahin, und unbarmherziger sind wir von ihnen getrennt als durch alle Entfernungen. Auch treten im Nachglanz die Bilder lockender hervor; wir denken an sie wie an den Körper einer toten Geliebten zurück, der tief in der Erde ruht und der uns nun gleich einer Wüsten-Spiegelung in einer höheren und geistigeren Pracht erschauern läßt. Und immer wieder tasten wir in unseren durstigen Träumen dem Vergangenen in jeder 
Einzelheit, in jeder Falte nach. Dann will es uns scheinen, als hätten wir das MaB des Lebens und der Liebe nicht bis zum Rande gefüllt gehabt, doch keine Reue bringt das Versāumte zurück. Oh, möchte dieses Gefühl uns doch für jeden Augenblick des Glückes eine Lehre sein!

Und süßer noch wird die Erinnerung an unsere Mond- und Sonnenjahre, wenn jäher Schrecken sie beendete. Dann erst begreifen wir, wie sehr es schon ein Glūcksfall für uns Menschen ist, wenn wir in unseren kleinen Gemeinschaften dahinleben, unter friedlichem Dach, bei guten Gesprächen und mit liebevollem Gruß am Morgen und zur Nacht. Ach, stets zu spät erkennen wir, daß damit schon das Füllhorn reich für uns geöffnet war.

So denke ich auch an die Zeiten, in denen wir an der großen Marina lebten, zurück - erst die Erinnerung treibt ihren Zauber hervor. Damals freilich schien es mir, als ob manche Sorge, mancher Kummer uns die Tage verdunkelten, und vor allem waren wir vor dem Oberförster auf der Hut. Wir lebten daher mit einer gewissen Strenge und in schlichten Gewändern, obwohl kein Gelübde uns band. Zweimal im Jahre ließen wir indessen das rote Futter durchleuchten - einmal im Frühling und einmal im Herbst.

Im Herbste zechten wir als Weise und taten den kōstlichen Weinen, die an den Südhāngen der großen Marina gedeihen, Ehre an.”

Zunächst sind da, blicken wir auf das Was, Gedanken, Gefühle, Beobachtungen, auch eine Mahnung; sie alle sind - als solche - gewiB nicht sprachlich, sie sind nur sprachlich ausgedrückt, andererseits haben sie aber zu tun mit dem Stil, dem Wie, dieses Passus; sie schaffen ihn mit: die mehr oder weniger heftige Trauer bei der Erinnerung an eine Zeit des Glücks; die Beobachtung, daß Zeit definitiver trennt als Raum, worin auch impliziert ist, daß wir Zeit nur als Raum erleben können, obwohl sie etwas völlig anderes ist als er; die Beobachtung, daß die Erinnerung etwas von sich selbst aus hinzufügt zu dem Glück, an das wir uns erinnern; das Bedauern, das uns ergreift im Blick darauf, daB wir uns gebotene Möglichkeiten nicht genutzt haben; der Appell, das gerade gegenwärtige Glück voll und bewuBt auszuleben; und so fort. Es sind keine profunden, sondern normale Gedanken, denen man sogleich zustimmen wird. Übrigens ist der allererste Satz kaum mehr als eine Übersetzung eines Dante-Satzes: Francesca da Rimini sagt in dem berühmtesten Gesang des "Inferno” und wohl der ganzen "Commedia” : „Es gibt keinen größeren Schmerz, als sich im Elend an die Zeit des Glücks zu erinnern”, „Nessun maggior dolore / che ricordarsi del tempo felice / nella miseria” (5. Gesang, 121-123). Das „Elend” fehlt bei Jünger (aber nicht ganz), und wichtig ist natürlich der Unterschied zwischen "groBem Schmerz" und „wilder Schwermut": da steht (romanische) > Klassik< gegen $>$ Romantik<! Oder nehmen wir den Vergleich, der ja auch ein Gedanke ist, der Erinnerung an das Glück mit einer verstorbenen Ge- 
liebten. Gerade dieser überraschende Gedanke, besonders in seiner eigentümlichen Konkretheit (nicht einfach die Geliebte, die in der Erde ruht, sondern, auf der Materialität insistierend, der „Körper einer toten Geliebten ..., der tief in der Erde ruht"). Der Vergleich ist umso überraschender, ja, befremdlicher, als dies ja - im Text selbst, nicht im Leben des Autors - die Erinnerung nicht eines alten Mannes, sondern die eines Vierzig- oder Fünfzigjährigen ist. Natürlich wäre dieser Vergleich eine gute Stelle für Elisabeth Bronfen: die definitiv ruhiggestellte Frau, die aber dann gerade - angenehm - wiederkehrt als eine Fata Morgana. ${ }^{5}$ Und dann die Merkwürdigkeit (man kommt nicht sogleich darauf), daß, so wie die Formulierung ist, eigentlich unklar bleibt, wo denn die "höhere und geistigere Pracht" zu suchen (und zu finden) sei: bei dem in der Erinnerung wiedererstehenden Körper der Frau oder - so steht es eigentlich da - bei dem Erschauernden selbst, dem sich erinnernden Mann. Zum Stil tragen gewiß auch die erotischen Anklänge des Passus bei. Es ist da eine eigentümliche Präsenz des Erotischen, die wir schwerlich als sprachlich bezeichnen können, obwohl sie sich mit und durch Sprache ergibt, aber sie ergibt sich nicht aus spezifischer Sprachverwendung: die "lockenden Bilder”, dann eben der „Körper” einer toten Geliebten, das "Erschauern", die "Pracht”, die eigentümliche „Falte”, die explizite Fast-Gleichsetzung von Leben und Liebe, das "rote Futter". Ein stilistisches Element ist auch die Unbestimmtheit des Orts, ebenfalls sicher nicht sprachlich: „die groBe Marina”, die auf eher unbestimmte Weise angrenzt an Burgund. Hierher gehört auch das Bedrohliche, das suggeriert wird durch die gleichsam vorlaufende, hier zunächst unverständliche Nennung des „Oberförsters” (diese Figur wurde auf Hermann Goering bezogen). All dies - und einiges andere könnte noch genannt werden sind inhaltliche Elemente, die den Stil des Passus mitkonstituieren und doch ihrer Natur nach nicht sprachlich sind.

Dann die Erzählhaltung, der Ton: die direkte Anrede an den Leser, und zwar in der Form, als werde hier, mit ihm zusammen, gleichsam eine Gruppe von Vertrauten des Redenden, zu denen er selber zählt, angeredet. Der Appell sodann in dem Text - dies geschieht gerade durch die Normalität der Gedanken und Beobachtungen - an Vertrautes, an geteilte Erfahrung. Das "wir" und "uns", die hier erscheinen, sind "einschließend"; der Angeredete wird eingeschlossen. Dies ändert sich dann im dritten Abschnitt, in dem ein die Angeredeten ausschliefendes "wir" erscheint. Dieser Ton wäre ungefähr so zu kennzeichnen: eine gemäBigte, ruhige, nachdenkliche Feierlichkeit, ein ernstes und gewähl-

5 Bronfen, Elisabeth (1994): Nur über ihre Leiche. Tod, Weiblichkeit und Ästhetik, München. Antje Kunstmann-Verlag. 
tes parlando, durchaus also Sprechnähe, Einbeziehung des Angeredeten, Abwesenheit von ironischer oder humoriger Distanzierung, das Affirmative in der Haltung überhaupt. Dies wären nun also formale Elemente, die ohne Zweifel nicht-sprachlich sind, die sich nur eben im Medium des Sprachlichen realisieren, aber doch nicht - darauf käme es an - Realisierungen von Sprache sind.

Im eigentlichen Sinn sprachliche Elemente wären etwa die folgenden: Gleich das erste Wort, das "Ihr"; hier hätte der Erzähler auch sagen können: „Sie alle kennen die wilde Schwermut ...”; das heiBt: hier wurde nun wirklich sprachlich gewählt, hier wurde eine Möglichkeit des Deutschen genutzt (im Französischen oder Englischen ist da gleich eine Schwierigkeit für den Übersetzer). Dann natürlich die gewählten Wörter: der „Nachglanz”, eine Art Synonym für „Erinnerung”; dieses Wort erscheint ja dann im dritten Abschnitt: „erst die Erinnerung treibt ihren Zauber hervor” (gegenüber vorher: „Auch treten im Nachglanz die Bilder lockender hervor ..."). Dann zum Beispiel die Weine, die an den südlichen Hängen "gedeihen" und nicht etwa „wachsen". Ein schönes Beispiel für ein genuin sprachliches Stilement ist natürlich "Wüsten-Spiegelung" für das übliche „Fata Morgana” (oft sind Verdeutschungen gewählter als die Fremdwörter, die sie verdeutschen). Gewählt ist übrigens auch die Syntax: das einleitende „Auch” mit Inversion, das im ganzen Buch und bei Jünger überhaupt immer wieder vorkommt und ihn sprachlich charakterisiert. Dann die Zusammenstellungen „wilde Schwermut” und "durstige Träume": auch hier geht es um Inhaltliches, aber dieser Zug ist doch auch sprachlich, weil es sich um gewählte oder doch seltene sprachliche Zusammenstellungen handelt (im Unterschied etwa zum sprachlich normalen - ,jähen Schrecken"). Bemerkenswert in semantischer Hinsicht ist die hier vollkommen entchristlichte "Reue" : sie bezieht sich ja ausschließlich auf nicht ausgekostetes Leben, auf nicht ergriffene GenuBmöglichkeiten (etwas platt ausgedrückt, aber kaum neben der Sache). Sprachlich ist auch die geschickte Benutzung der beiden Interjektionen "oh" und "ach", ihre Verteilung: das erstere als Wunsch, das letztere als Klage. Zum Sprachlichen gehören dann ebenfalls solche Kleinigkeiten wie das „e" bei „Glückes" (zweimal in unserem Passus) oder der Wechsel unmittelbar hintereinander von „im Herbst" und "Im Herbste” (vierter Abschnitt). Als eigentlich sprachlichen Beitrag zum Stil würde ich dann auch nennen die Bögen, die hier sprachlich realisiert werden, etwa durch die Endstellung des Verbs oder die des Verbzusatzes. Also nicht etwa: wir denken an sie zurück wie an den Körper einer toten Geliebten, sondern: „wir denken an sie wie an den Körper einer toten Geliebten zurück”; auch nicht: und immer wieder tasten wir in unseren durstigen Träumen dem Vergangenen nach: in jeder Einzelheit, in jeder Falte, sondern das "nach" 
steht erst am Ende des Satzes: „dem Vergangenen in jeder Einzelheit, in jeder Falte nach". Auch nicht etwa: daß damit schon das Füllhorn reich geöffnet war für uns, sondern: „daB damit schon das Füllhorn reich für uns geöffnet war ...". Dasselbe im darauffolgenden Satz: auch hier steht das "zurück" am Ende; es könnte ja auch heißen: So denke ich auch an die Zeiten zurück, in denen wir an der großen Marina lebten, heißt aber: "So denke ich auch an die Zeiten, in denen wir an der großen Marina lebten, zurück ...". Diese Bögen geben dem Text Ruhe und etwas Strömendes. Man müßte dem genauer nachgehen, und natürlich mehr Text hinzunehmen. Jedenfalls handelt es sich hier nun klar um ein wirklich sprachliches Element, wie ich denn hier überall solche sprachlichen Elemente genannt habe - nur solche -, die mit dem Stil dieses Texts etwas zu schaffen haben, denn es gibt viele andere, die stilistisch neutral sind. Natürlich gehen das Inhaltliche und das Sprachliche zuweilen ineinander über: dies gilt etwa für die eigentümlichen „Mond- und Sonnenjahre", denn diese Zusammenstellung ist inhaltlich und sprachlich in gleicher Weise stilbildend für diesen Text. Unmittelbar einleuchtend ist diese schöne Prägung im übrigen nicht, denn wie sollten die Jahre, die auf sie folgen, falls sie folgen, dann genannt werden: Sternenjahre? Natürlich wird aus dem Zusammenhang klar, was gemeint ist: „unsere schönsten Jahre", aber dies wäre nun gewiß etwas platt ... Die Wendung trägt bei zum Geheimnisvollen oder doch nicht voll Auflösbaren dieses Texts: was sind das für Gemeinschaften, in denen "mit einer gewissen Strenge” gelebt wird, „in schlichten Gewändern”, aber ohne Bindung durch ein "Gelübde"? Was sind dies für rot unterfütterte Mönche?

Aber hier sollte nur dies dargetan werden: das Sprachliche ist nur ein Teil dessen, was den Stil dieses Textpassus ausmacht. Ich will auch nicht verschweigen, daß ich diesen Eingang (wie das Buch überhaupt, besonders aber diesen Eingang) berückend finde. Er scheint mir im vollen Sinne schön (einen leichten Einbruch habe ich freilich beim „Körper einer toten Geliebten, der tief in der Erde ruht": da ist etwas mir Unangenehmes, Fremdes - stilistische Analysen zwingen oft zu Selbstbekenntnissen ...); auch sind da - für mich - einige gedankliche Inkonsistenzen: wir denken zum Beispiel ja doch nicht an "Bilder” zurück, sondern an die Wirklichkeiten, die waren, und tun dies mit Hilfe von Bildern; die Wirklichkeiten treten dann als Bilder, die sie erst in der Erinnerung sind, lockender hervor; es gibt die Wirklichkeiten, an die wir uns erinnern, und die Bilder dieser Wirklichkeiten, die in der Erinnerung sind, und diese Bilder sind es, die "lockender hervortreten" als die Wirklichkeiten, die sie spiegeln. Trotzdem (und vielleicht zum Teil auch gerade deshalb): dieser Eingang ist stilistisch - Stil als Inhalt, als Gebärde und als Sprache - sehr schön. Ich kann nur zustimmend - lebhaft zustimmend - zur Kenntnis neh- 
men, daß ihn Peter Wapnewski in einem gewichtigen Aufsatz unter den „Stellen" nennt, die es ihm besonders angetan haben: „Wortfügungen, deren magische Gewalt höher ist denn alle Vernunft." ${ }^{6}$

6 Wapnewski, Peter (1991): Sprache - der wahre Verräter: Stilistische Beobachtungen zum Sprachgebrauch der Gegenwart. In: Jahrbuch 5, Bayerische Akademie der Schönen Künste. S. 141-167. 


\section{Tendenzen der linguistischen Stilforschung}

\section{Einleitung}

Innerhalb der letzten beiden Jahrzehnte hat sich die Stilistik zwar unspektakulär, aber doch kontinuieriich entwickelt. ${ }^{1}$ Generelles Ziel linguistischer Stilistik ist die Beschreibung, Deskription stilistischer Gegebenheiten. Die Ergebnisse einer deskriptiven Stilistik können dann normativ umgesetzt werden für $Z$ wecke, die Normierung sinnvoll erscheinen lassen; auBerdem können sie dazu dienen, traditionsbedingte Normierungen daraufhin zu befragen, ob und wenn wo sie in der heutigen Sprachgemeinschaft angemessen sind. ${ }^{2}$

Das Interesse gilt heute besonders der Vielfalt und Verschiedenheit von Stilen, den gesellschaftlichen Zwecken von Stilvielfalt und den linguistischen Möglichkeiten ihrer Beschreibung.

Neben Textlinguistik, Textsortenlinguistik und Pragmatik haben besonders die Gesprächslinguistik und die sich differenzierende Soziolinguistik zur Entwicklung beigetragen; deren vielfältige stilistisch relevante Ergebnisse sind allerdings oft erst noch in die Stilistik zu integrieren. Außerdem sind Ergebnisse weiterer linguistischer Teilbereiche und Themen für Stilbeschreibung relevant, z.B.:

- Sprachvarietätenforschung, denn Sprachvarietäten können auch stilistisch wirksam eingesetzt werden (z.B. Selting 1989; Schwitalla 1989);

- Stadtsprachenforschung als Vielstimmigkeit und Vielfalt sprachlichen Handelns (Keim/Schwitalla 1989; Dittmar 1989);

- feministische Linguistik unter dem Gesichtspunkt von Sprachverwendungen von Frauen und Männern (s.u. 3., Punkt 6);

- Jugendsprachforschung (Neuland 1987; Schwitalla 1988; Schwitalla/ Streeck 1989);

- Fachsprachenforschung (Gläser 1990; Schröder (Hg.) 1993);

- mündliche Kommunikation in Institutionen (z.B. Selting 1986, 1989; Löning 1985; Günthner/Kotthoff (Hg.) 1992);

- Emotion im Gespräch (Fiehler 1990);

- Sprachverwendung in den Medien (Holly/Kühn/Püschel 1986; Burger 1990, 1991);

- Sprache in der Politik (Holly 1990);

1 Vgl. Pũschel (1991).

2 Vgl. Sandig (1986, Kap. 2.2.4). 
- Stilprobleme beim Übersetzen (z.B. Stolt 1978; Koller 1994);

- interkulturelle Linguistik (Günthner 1992; Kotthoff 1989).

\section{Was verstehe ich unter Stil?}

Stil ist immer ein "Wie", „die Art und Weise, wie ..." ${ }^{3}$ Wichtig ist allerdings, "was" wie stilistisch gestaltet wird und weiter, wie dieses "WasWie" zu interpretieren ist: das "Wozu" . "Welcher soziale Sinn wird durch dieses Was-Wie hergestellt?

Ein Grundsatz, der heute anerkannt zu sein scheint, liegt meinen Ausführungen zugrunde: Jede ÄuBerung und jeder Text hat Stil (vgl. Riesel/Schendels 1975), gleichgültig ob auffällig stilisiert oder stilistisch 'neutral'. Das heißt, es kann jede Sprachverwendung zum Gegenstand stilistischer Untersuchung gemacht werden - je nach der Zielsetzung.

Als Grundlage der Erläuterung möglichen stilistischen Sinns, des Wozu also, verwende ich eine Modellierung der bekannten Komponenten sprachlicher Interaktion, die stilistisch relevant sind. ${ }^{5}$

(siehe Abbildung 1 auf der folgenden Seite)

Nun meine Definition von Stil: Sprachlicher Stil ist die sozial relevante Art der Durchführung einer Handlung mittels Text oder interaktiv als Gespräch. Diese Art der Handlungsdurchführung wird durch Eigenschaften des Textes oder des Gesprächs im Kontext ausgedrückt und ist bezogen auf Komponenten der Interaktion; in Bezug auf diese wird die Handlung mit stilistischem Sinn angereichert.

(siehe Abbildung 2 auf S. 30)

3 Z.B. Riesel/Schendels (1975, S. 6 und 15).

4 Vgl. Sandig (1986, Kap. 1.2).

5 Vgl. dazu auch Stolt (1984) und Spillner (in diesem Band). 
Abb.1: Voraussetzungen

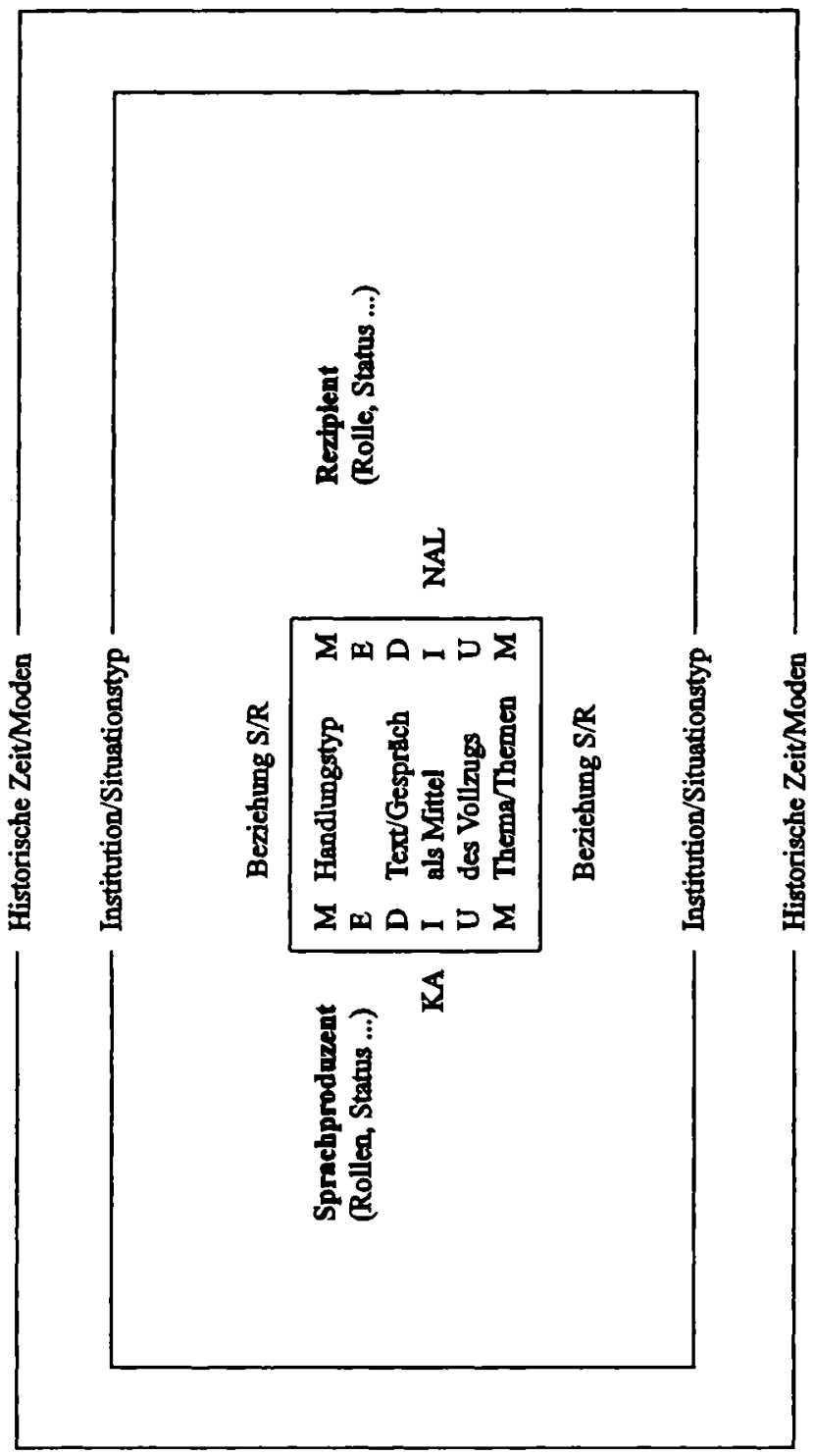


Abb.2: Stilistische Relevanz

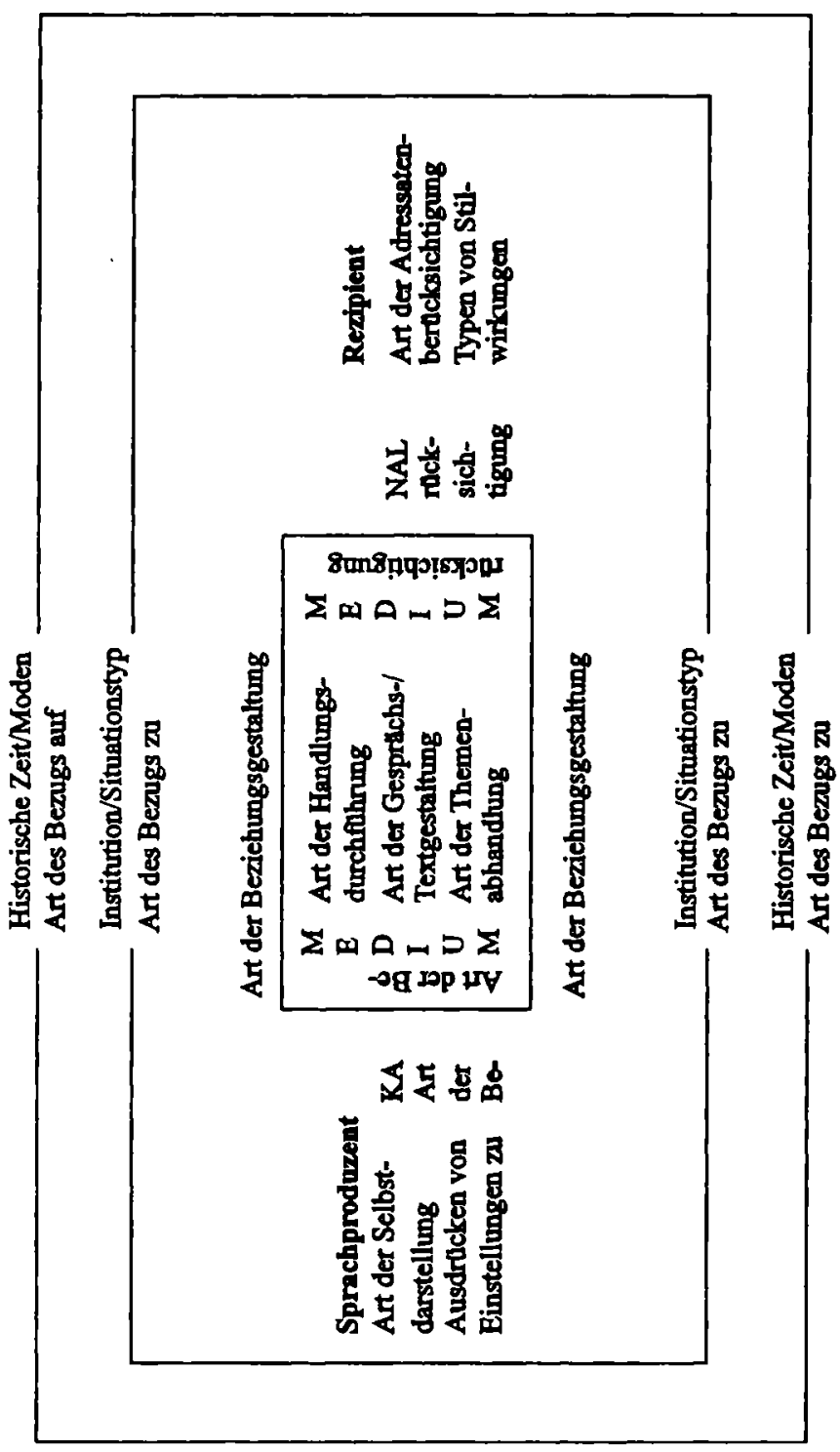


Das bedeutet:

- Stile sind eingebunden in historische Zeiten; sie reflektieren Moden ${ }^{6}$ und verändern sich mit der Zeit ${ }^{7}$;

- Stile sind geprägt durch Institutionen und Situationstypen; sie zeigen institutionelle Gültigkeit an (z.B. bei Rechtstexten), und sie zeigen Situationstypen als solche an;

- Stil ist ein wesentliches Mittel sprachlicher Selbstdarstellung; mit ihm wird soziale Zugehörigkeit ebenso angezeigt wie Individualität; auch ist er ein Mittel der aktiven Gestaltung sozialer Rollen und von Gesprächsrollen.

- Mit Stil werden soziale Beziehungen gestaltet, z.B. bestätigt oder verändert. ${ }^{8}$

- Mit Stil werden sozial relevante Handlungstypen als solche differenziert (eine Medikamenten-Gebrauchsinformation ist stilistisch deutlich verschieden von einem Kochrezept, obwohl beide anweisende Textmuster sind); ebenso wird aber auch individuelles Handeln dadurch angezeigt.

- Dasselbe Thema kann zu verschiedenen $Z$ wecken in verschiedenen Stilen entfaltet werden.

- Eigenschaften des Kanals wie Schriftlichkeit oder Mündlichkeit der Übermittlung prägen Stile entscheidend, auch die Gleichzeitigkeit mehrerer Kanäle oder die Nutzung mehrerer Kanäle z.B. bei der sog. „sekundären Oralität”, wo schriftlich Vorbereitetes als mündlichspontan 'inszeniert' wird (Holly in Vorb.).

- Verschiedene Medien und ihre sozialen Funktionen führen zu verschiedenen Stilerwartungen, z.B. einzelne Schriftmedien, Rundfunkprogramme, Fernsehkanäle.

- Stil kann weiter geprägt sein durch die Art, wie die Adressaten berücksichtigt werden (z.B. durch Verständlichkeit oder Attraktivität eines Stils).

- Schließlich ist Stil ein ausgezeichnetes Mittel, nebenher Einstellungen auszudrücken, z.B. Wertungen oder Emotionen, auch Einstellungen zur Sprache.

Alle derartigen Gesichtspunkte werden durch die Art, wie ein Text schriftlich oder als Gespräch gestaltet ist und wie er verwendet wird,

6 Vgl. Assmann (1986): „opting in" vs. „opting out”.

7 Riesel/Schendels (1975): historische Verānderbarkeit.

$8 \mathrm{Zu}$ diesem und dem vorherigen Punkt: Franck (1984), Kotthoff (1989, S. 187); Adamzik (in Vorb.). 
ausgedrückt - oft überlagern sich auch mehrere Gesichtspunkte ${ }^{9}-$, und sie können bei Adressaten zu vielfältigen Stilwirkungen (Sandig 1986, Kap. 1.4) führen.

Damit ist Stil d a $s$ Mittel der Individuierung und Situationsanpassung von Handlungen. ${ }^{10}$ Dabei kann der Stil geprägt sein durch das, was einzelne Komponenten der Interaktion konventionell vorgeben, aber Sprecher können auch Handlungen, Situationstypen, Sprecherrollen, Einstellungen, Beziehungen usw. erst als solche mittels Stil aktiv ${ }^{11}$ herstellen und anzeigen. So dient Stil wesentlich dazu, daB Sprecher möglichst erfolgreich interagieren können.

Voraussetzung sind intersubjektiv geltende Typen stilistischen Sinns (wie die oben aufgeführten: Sandig 1986), die jeweils weiter in sich zu differenzieren sind. Mit der Beschreibung dieser Typen ist aber auch der Bereich des stilistisch Relevanten eingegrenzt: Nur sprachliche Möglichkeiten, die funktional in dieser Weise einsetzbar sind, sind stilistisch relevant.

E i n e Schwierigkeit der Stilistik liegt also bereits in der Komplexität dessen, was Stil 'bedeuten' kann, im stilistischen Sinn also; hinzu kommen vielfältige ${ }^{12}$ mögliche Stilwirkungen (Sandig 1986, Kap. 1.4). Eine a n d e re Schwierigkeit bieten Stilstrukturen: Stilstrukturen sind in die Strukturen der sie tragenden Handlung und ihres Textes eingelassen, an sie angepaBt; sie entstehen durch das Zusammenwirken von sehr verschiedenen Einheiten, die auf mehreren unterschiedlichen linguistischen Ebenen zu beschreiben sind ${ }^{13}$ Eine $\mathrm{d} r$ i $t \mathrm{t}$ e Schwierigkeit liegt darin, daB eine Stilstruktur nicht per se einen bestimmten stilistischen Sinn hervorruft, sondern ihre Verwendung ${ }^{14}$ im konkreten Fall ist entschei-

9 Vgl. Günthner (1992), auch die Analyse von Text 2 in 4.

$10 \mathrm{Vgl}$. Fix (1991b). Zu Indexikalität durch Stil in der ethnomethodologischen Gesprächsforschung: Hinnenkamp/Selting (Hg.) (1989).

11 Vgl. Hinnenkamp/Selting (Hg.) (1989, Einleitung); Selting (1990).

12 Ebenfalls auf Typen zu beziehende.

13 Mit Stil können aufgrund seiner strukturellen Eigenschaften gleichzeigtig mehrere verschiedene Handlungen vollzogen werden (z.B. Holly/Kühn/ Püschel 1986, Holly 1990). Es können Abstufungen bei der Deutlichkeit und Wichtigkeit der Handlungen vorgenommen werden.

14 Es ist zu unterscheiden $z$ wischen Stil und Stilverwendung wie auch $z w i-$ schen Text und Textverwendung (Bucher 1986, S. 62ff.), Bild und Bildverwendung (Muckenhaupt 1986) und natürlich Lexem und Satz und ihrer jeweiligen Verwendung. 
dend. Abweichungen vom Erwartbaren sind möglich. Stil ist relational: ${ }^{15}$ Der realisierte Stil wird interpretiert in Relation zu den Kenntnissen und Erwartungen bezüglich der Komponenten der Interaktion.

\section{Tendenzen der Stilistik - aus meiner Sicht}

Ich beschreibe Tendenzen so, wie sie sich $\mathrm{m}$ i r darstellen, andere Sichten sind, angesichts dieses komplexen Gegenstandes und Forschungsfeldes, durchaus möglich.

(1) Stil ist nicht mehr nur Stil von Texten (so noch Sandig 1986, S. 157), sondern auch Eigenschaft von Gesprächen, Gesprächsphasen (Selting 1989), Gesprächsbeiträgen oder Teilen davon ${ }^{16}$, auch Eigenschaft der Beiträge bestimmter Sprecher. ${ }^{17}$

(2) Stil ist eingebunden in Verwendungszusammenhänge der Texte oder Gespräche und Gesprächspassagen. Er ist ein relationales Phänomen: Verschiedenheit der Stile macht diese erst untereinander unterscheidbar. Stilstrukturen und stilistischer Sinn sind zu beziehen auf den Situationstyp und seine Eigenschaften, auf den Handlungstyp und die Konventionen für seine Durchführung, ebenso auf soziale Rollen der Stilbenutzer. Deshalb muß stilistischer Sinn nicht notwendig mit bestimmten Stilstrukturen angezeigt werden: Es kann die Relation zu den konventionsbedingten Erwartungen genügen, um stilistischen Sinn hervorzurufen. Ein Text kann in einem ganz anderen Handlungskontext verwendet werden und dort völlig anderen stilistischen Sinn entfalten. ${ }^{18}$ Eine andere Art der Relation ist der Vergleich eines Stils mit der Norm ${ }^{19}$ einer

Vgl. Franck (1984), Kotthoff (1989).

$16 \mathrm{Vgl}$. Selting (in diesem Band).

17 Tannen (1984); Schwitalla/Streeck (1989): Jugendliche und Interviewer als verschiedene Sprecherrollen; das institutionell bedingte Sprechen des Beamten bei Selting (1989). Vgl. auch die Beiträge zu „Sprech- und Gesprächsstilen" auf den GAL-Jahrestagungen 1993 und 1994, die von M. Selting und mir herausgegeben werden.

18 Ein Beispiel ist das Gedicht "Tiermarkt/Ankauf" von Erich Fried, das als Zeitungsannonce erschienen war (vgl. Kloepfer, R. (1975): Poetik und Linguistik. Semiotische Instrumente. München. S. 88) oder auch Gedichte von Peter Handke.

19 Z.B. mit der statistischen Norm, die in einem großen Corpus einer Sprache repräsentiert ist, z.B. Gerbig (1994) für das Englische bezogen auf spezielle perspektivegeprägte Stile. 
Sprache. Auch "Individualstil” ist ein relationales Konzept: 'individuell in Relation zu ...', ebenso „Epochenstil”: 'repräsentativ für eine Epoche im Vergleich zu anderen Epochenstilen'; insgesamt sind auch literarische Stile untereinander in Relation zu sehen und zu nicht-literarischen Stilen, zu Gebrauchsstilen. Was ein Stil ist, ist abhängig vom Wissen der Beteiligten (vgl. Tannen 1981; 1984).

(3) Stil und Kontext. Hier gibt es mehrere einander ergänzende Auffassungen:

a) Stilistische Textqualitäten sind determiniert durch Eigenschaften des situativen Kontexts, sie reflektieren ihn (M. Hoffmann 1990/91, Baumann 1992). Der Kontext schafft Erwartungen bezüglich des Stils der in ihm realisierten Handlungen.

b) Stil stellt Kontext her. ${ }^{20}$ In diesem Zusammenhang nun geht es darum, dab mit einem Stil(wechsel) eine soziale Situation aktiv hergestellt, als solche "definiert" werden kann, daB durch den gewählten Stil ein Kontext erst geschaffen wird, in dem die sprachlichen Aktivitäten der Beteiligten zu interpretieren sind. So werden bei Lesern Fortsetzungserwartungen erzeugt und bei Hörern Ratifizierungen erforderlich. Selting (1989) zeigt am Beispiel Sozialamtsgespräch die verschiedenen Stile in stitutionsrelevanter und informeller Rede. ${ }^{21}$

c) SchlieBlich sind hier "praktisch dominierte Tätigkeitszusammenhänge” zu erwähnen, wie sie Fiehler (z.B. 1993) analysiert hat: Die Einlagerung sprachlicher Äußerungen in übergreifende praktische Kooperationen führt $z u$ besonderen Stileigenschaften der sprachlichen Teil- oder Nebenhandlungen.

d) Interessant ist in diesem Zusammenhang auch die umfassende Beschreibung der Alternativen in einem Situationstyp (Ingendahl 1988).

(4) Stil ist im Gespräch interaktiv produzierter Sinn (Selting 1990). Einerseits produzieren die Beteiligten gemeinsam einen Stil, z.B. den eines Interviews (Uhmann 1989) oder eines Bürger-Verwaltungsdialogs (z.B. Selting 1989), andererseits produzieren einzelne Beteiligte einen Stil oder mehrere Stile, und sie verdeutlichen den intendierten Sinn mit Hilfe sogenannter Kontextualisierungshinweise ${ }^{22}$ diese sind Hinweise darauf, wie

20 Z.B. Günthner (1992); Hinnenkamp/Selting (Hg.) (1989).

${ }^{21}$ Vgl. Uhmann (1989): Eine "Interviewsituation” wird hergestellt durch die Realisierung von Äußerungen des „Kommmunikationsstils Interview”.

Selting (1991) und (in diesem Band). 
das Gesagte zu verstehen ist. Einzelne Beteiligte können auch unfreiwillig als Symptom Hinweise darauf geben, welchem sozialen Status sie angehören, aus welcher Region sie stammen usw. ${ }^{23} 24$ In der Formulierung von Garfinkel/Sacks (1976, S. 147) ist es „ein Mit-vielen-Worten-sagenwas-wir-tun (...) (oder worüber wir sprechen, oder wer spricht, oder wer wir sind, oder wo wir sind)".

(5) Ethnomethodologische Gesprächsanalyse enthält bereits als Programm die Relevanz von Stilistischem, insofern die Situationsanpassung ( Indexikalität”) von Sprachverwendungen betont wird (vgl. Franck 1984, Tannen 1984). Die neueren Analysen in dieser Methodik z.B. von Alltagskommunikation (z.B. Selting 1991) oder von interkultureller Kommunikation (etwa von Günthner und Kotthoff), von Kommunikation in Institutionen (z.B. Selting) oder von Stadtsprachenforschung (z.B. Kallmeyer (Hg.) 1994) zielen auf das Herausarbeiten von sozialen Mustern oder auch von Aspekten der Nutzung des in einer Sprachgemeinschaft Verfügbaren zum konkreten Zweck („Ressourcen”, z.B. Hinnenkamp/Selting (Hg.) 1989, Kap. 1,3). Auch geht es um Beschreibungen harmonierender oder konfliktärer Interaktion. ${ }^{25}$

(6) Soziostilistik: Bereits Labov (1976) hat auf die interne stilistische Differenzierung der soziolinguistischen Varietäten hingewiesen. In konversationsanalytisch geprägten soziolinguistischen Forschungen geht es um Stil als Mittel sozialer Kategorisierung ${ }^{26}$, als Mittel der Kennzeichnung von Gruppen durch ihren jeweiligen Stil nach außen (Soeffner 1986) und um Stile bei der Durchführung von Handlungstypen als gruppeninterne Signalisierung der Mitgliedschaft in einer Gruppe ${ }^{27}$, ja der Gruppenidentität (Schwitalla/Streeck 1989), auch des Grades der Zugehörigkeit zur Gruppe (Keim in Vorb.) oder unterschiedlicher Funktionen in einer Gruppe (Dittmar 1989). Hinzuweisen ist hier auch auf die Erforschung der Stile von Frauen und Männern: Es gibt allerdings nicht nur einen weiblichen und einen männlichen Stil (Schmidt 1988), sondern die stilistische Vielfalt in diesem Bereich steht erst noch am Beginn der Erar-

$23 \mathrm{Zu}$ erwähnen sind hier auch Ergebnisse der Sprechwissenschaft, die stilistisch relevant sind: Gutenberg (1983), Slembek (1983), Herbig (1992).

$24 \mathrm{Zu}$ „Sprechstilen” Schlobinski/Kohl/Ludewigt (1993).

25 Tannen (1984), Kotthoff (1989), Keim/Schwitalla (1989), Schwitalla/ Streeck (1989).

26 Vgl. Hinnenkamp/Selting (Hg.) (1989, Kap. III).

27 Kallmeyer/Keim (1986), Keim/Schwitalla (1989), Schwitalla (1990), (in Vorb.), Keim (1993). 
beitung. ${ }^{28} \mathrm{Vgl}$. auch den Überblick zu soziostilistischen Fragestellungen bei Spillner (1987).

(7) $\mathrm{Zu}$ erwähnen sind weiter Arbeiten über Stile, die auf bestimmten ideologischen (Kress 1985, Kalivoda 1988, Good 1983) oder anderen Grundeinstellungen beruhen: Z.B. bringt vorurteilshafte Rede charakteristische Stileigenschaften hervor (van Dijk 1984, Moosmüller 1993); ebenso rassistischer (OBST 1992) und antisemitischer Diskurs (z.B. Gruber 1991), auch Sprachverwendung im Nationalsozialismus (Maas 1984). ${ }^{29}$ In diesen Zusammenhang gehören auch Analysen von Ritualen mit ihren Stilen (z.B. Rauch 1992) und zur Sprachverwendung in der Politik (Holly 1990).

(8) Weiter ist ein stilistisch relevantes Interesse an Rhetorik vielfaltig zu beobachten. Stellvertretend seien nur genannt: Sandig (Hg.) (1988) und Skyum-Nielsen/Schröder (Hg.) (1994).

(9) Analyse von Stilen literarischer Texte ist ein Schwerpunkt britischer Linguistik (z.B. Leech/Short 1981, Van Peer (Hg.) 1988, Fowler 1986, Ehrlich 1990, Simpson 1993). Auch in der DDR war Stil literarischer Texte ein ständiges Thema. ${ }^{30}$ In der alten Bundesrepublik sind vor allem die Arbeiten von Betten zu Stilen in modernen Dramen (z.B. 1983, 1986, auch Lüger 1988) zu verzeichnen und jüngst ein Sammelband von Wellmann (Hg.) (1993). Meist interessiert dabei die Relation von literarischen Stilen und Stilen der Gebrauchssprache, auch die verschiedene Nutzung derselben Mittel in beiden Bereichen (z.B. Dressler 1989, S. 21; Sandig 1989 und 1991).

(10) Im Bereich der Fachsprachenforschung werden vermehrt „Fachstile” untersucht (de Cort 1983) und insbesondere "Fachtextsortenstile". ${ }^{31}$

(11) Im Rahmen einer pragmatischen Stilistik werden „stilistische Handlungsmuster" (Hoffmann 1990/91, Sandig 1991a) ins Gespräch gebracht;

28 Streeck (1988), Kotthoff (1988), (1991), Betten (1989), Gräßel (1991), Frank (1992), Günthner (1992), (1992a) usw.

29 Vgl. auch Sandig (1986): Kap. „Stil als Repräsentant von Werten”.

30 Z.B. Lerchner (1988), Kühn (1991), Müske/Werner (Hg.) (1991), Thormann-Sekulski (1990/91).

31 Z.B. Gläser (1990): „Darstellungshaltung des Textautors” und „Stilqualitāten” im engeren Sinn; Klauser (1992), die neben "textsortentypischen” auch „individualstilistische” Aspekte (d.h. Selbstdarstellungsarten, s.o. Kap. 2) untersucht. Auch Baumann (1992), Sachtleber (1993), Schröder (Hg.) (1993); Kretzenbacher (Hg.) (1992), Stichwort „Stil”. 
sie heißen auch „Stilmuster" 32 oder "Formulierungsverfahren" (z.B. Fix 1991). Stilistische Handlungsmuster sind z.B. GESTALTEN (Püschel 1986 und 1993), ORIGINALISIEREN (Fix 1991b), VERSTÄNDLICH MACHEN (Sandig 1991a), ABWEICHEN (Püschel 1985); es sind auch soziale Orientierung anzeigende Stilisierungshandlungen (Firle 1990/91, Hinnenkamp/Selting (Hg.) 1989) usw. Als Ausdrucksmöglichkeiten für ein Stilmuster gibt es jeweils eine ganze Palette von Stilelementen.

(12) Stilproduktion und Stilrezeption finden Beachtung; es geht nicht mehr nur um Stil als Produkt und damit als Texteigenschaft. Bei Stilproduktion ist zu unterscheiden zwischen der Produktion schriftlicher Texte und der interaktiven Produktion von Stilen im Gespräch (vgl. oben Punkt 4). Stilproduktion schriftlicher Texte ist $z u$ sehen im größeren Rahmen von Textproduktion allgemein und im engeren Rahmen von Stilvorstellungen für Textmuster/Textsorten. Hier ist interessant, was Keseling (1988) herausgefunden hat: Wir bewerten und revidieren im Schreiben unseren Stil nach unseren Kenntnissen der Erfordernisse eines Textmusters und vor allem nach dessen rhythmischer Struktur. ${ }^{33}$ Die Rolle der Redebewertung bei der Stilproduktion hat Fix (1990/91) untersucht. ${ }^{34}$ Die Erforschung von Stilrezeption zeigt die Verschiedenheit der Rezeptionen durch verschiedene Individuen. ${ }^{35}$ Ausgehend von Vorstellungen der Prager Schule zur Literatursprache hat Van Peer (1983) Experimente mit originalen und manipulierten Gedichtzeilen vorgenommen; die Ergebnisse weisen auf verschiedene Arten der Rezeption je nach sozialer Zugehörigkeit und nach Generationszugehörigkeit, d.h. je nach der Art der stilistischen Bildung. Ein interessantes Experiment stammt wiederum von Keseling ${ }^{36}$, der Seminarvorträge von Studierenden in ihrer Wirkung auf die Zuhörenden untersuchte: Es ergaben sich sehr individuelle (Re-)Konstruktionen von stilistischem Sinn. Auch playbackAnalysen eines Gesprächs bei Tannen (1984) ergeben sehr unterschiedliche Interpretationen eines Verhaltens durch verschiedene am Gespräch

32 Sandig (1986, S. 149f.), Püschel (1985), (1986).

33 Dies mag übereinstimmen mnit dem, was Dimter (1981) herausfand, als er Textexemplare inhaltlich verfremdete und trotzdem die richtigen Zuordnungen erhielt, außer bei literarischem Text und Kommentar, die verwechselt wurden.

34 Vgl. auch Püschel (1991).

35 Vgl. Rück (1984).

36 Vortrag auf der Jahrestagung der GAL 1993, erscheint in einem von $M$. Selting und mir herausgegebenen Sammelband zu Sprech- und Gesprächsstilen. 
beteiligte Personen; Hintergrund ist jeweils die unterschiedliche Art der Sozialisation und Herkunft der beteiligten Personen. So haben wir nicht nur bei literarischen Texten eine Offenheit für die Zuschreibung von stilistischem $\operatorname{Sinn}^{37}$ anzunehmen, sondern auch bei nichtliterarischen Tex$\operatorname{ten}^{38}$ und bei mündlichen Sprachproduktionen.

(13) Stilwandel findet Interesse im Rahmen verstärkter Beschäftigung mit Sprachgeschichte (z.B. Lerchner 1990); mit der politischen „Wende” von 1989 ging in der früheren DDR ein Stilwandel einher, der besonders von Ulla Fix aufmerksam beobachtet wurde (1990, 1993, 1994): Die Analyse der ritualisierten Öffentlichkeitssprache der DDR ist Grundlage für Beobachtungen von Veränderungen. „Stilwandel” ist schließlich das Thema der Stilistik-Sektion des IVG-Kongresses in Vancouver $1995 .^{39}$

(14) Stile werden beschrieben als Ganzheiten. Stil ist strukturell ein synthetisches Phänomen: Viele Einzelheiten, Elemente verschiedener sprachlicher Beschreibungsebenen tragen dazu bei. ${ }^{40}$ Hier ist eine Tendenz zu beobachten, nicht nur kleine und kleinste Einheiten zu betrachten, nicht mehr nur von unten, bottom up, vorzugehen, sondern Einheiten, die beschrieben werden, von unten nach oben zu erweitern (vgl. Baumann 1992) und schlieflich von oben, top down, vorzugehen: ganze Texte (vgl. Sandig 1986, Teil 2) oder Gesprächspassagen (z.B. Rauch 1992) zu betrachten. Die Text- und Textsortenlinguistik ist hier ebenso wie die Gesprächslinguistik von Einfluß. Hier sind viele Analysen einzelner Textmuster mit ihren Stilen zu nennen ${ }^{41}$, auch Analysen von Gesprächssorten ${ }^{42}$ und ebenso Analysen von Argumentationsstilen, schriftlich und mündlich. ${ }^{43}$

37 Thieberger (1983).

38 Dies läßt sich für Gebrauchtstexte leicht bei Textanalysen mit Studierenden feststellen.

39 Vgl. auch Stolt (1988) zum Bibelstil, Frese (1987) zu Geburtsanzeigen aus 200 Jahren.

40 Vgl. Sandig (1986, Kap. 1.6.1): „strukturelle Mehrstufigkeit”. Vgl. auch unten 4.

41 Z.B. Antos (1986), (1987), Stolt (1984), Sandig (1985), (1987), Piitulainen (1990), (1993), Schuldt (1992), von Polenz (1989), Böheim (1987), Frese (1987), Baumann (1992) usw.

42 Z.B. Baus/Sandig (1985), Nothdurft (1984), Uhmann (1989), Löning (1985) usw.; die GAL-Sektion Sprech- und Gesprächsstile 1993 und 1994.

43 Kotthoff (1989), Herbig (1992), (1993), Püschel/Sandig (Hg.) (1993). 
(15) Größere Zusammenhänge spielen auch bei der Beschreibung von Stilelementen eine Rolle: Stilelemente werden oft nicht mehr nur als isolierte, isolierbare Einheiten gesehen, die man als solche klassifizieren kann (Plett 1975, Teil II; Küper 1976), sondern sie werden gesehen als Einheiten in größeren Verbänden. ${ }^{44}$

(16) Stil wird vielfach gesehen als Zusammenspiel von sprachlichen und anderen Arten von Zeichen. Bei schriftlich verfaBten Texten kommt das Schriftbild des Textes hinzu: seine komplexe Gestalt, Schrifttypen (Plett 1975, Küper 1976, Pfeiffer-Rupp 1984) und Schrifttypwechsel als ebenfalls sinnherstellende Elemente, auch Typen von Relationen zwischen Text und Bild (Spillner 1982, Muckenhaupt 1986) werden beachtet; semiotisch orientierte Analysen sind hier zu erwähnen. ${ }^{45}$ Bei mündlich verfaBten Texten ist die Art der Stimmführung relevant (vgl. die Arbeiten von M. Selting); Fernsehtexte verlangen auch eine Analyse des Blickverhaltens ${ }^{46}$, der Gestik (Steuble 1986, Weinrich 1992) und Mimik und der visuellen Inszenierung. ${ }^{47}$ Auch bei der Erforschung von Stilwandel und von historischen Stilen (Fix 1992) kann man sich kaum auf das rein Sprachliche beschränken.

(17) Interkulturelle Kommunikation arbeitet Stilistisches heraus, wo sie das unterschwellige Anzeigen von Einstellungen und impliziten Wertungen (Günthner 1988), von Selbst- und Partner-Definitionen, wie auch Beziehungsdefinitionen zum Gegenstand hat (vgl. Tannen 1984, 1985). Wichtig sind unter diesem Aspekt die Definitionen der Situation über unscheinbare „Kontextualisierungshinweise” im Gespräch ${ }^{48}$, die den Mitgliedern einer Kultur ganz selbstverständlich bekannt sind: Konsens oder Dissens darüber, was in der Interaktion gerade geschieht (vgl. oben Punkt 4), sind Ursache für Verständigung oder Mißverständnisse. ${ }^{49}$

(18) Methodische Erwägungen spielen seit dem Sammelband von Spillner (1984) verstärkt eine Rolle; zuletzt in dem bemerkenswerten Beitrag von Fix (1991), in dem der Vergleich als zentrale Methode herausge-

44 Z.B. Blumenthal (1983), Besch (1989), Dittgen (1989). Vgl. auch unten 4.4.

45 Z.B. Schröder (Hg.) (1993, Kap. III); Fix (1991a).

46 Holly/Kühn/Pūschel (1986); Petter-Zimmer (1990).

47 Burger (1991), Holly/Kühn/Püschel (1986).

48 Vgl. Auer (1986); Hinnenkamp/Selting (Hg.) (1989), Teil II; Selting (1991); Schröder (Hg.) (1993); Slembek (1993); Tüittula (in diesem Band).

49 Vgl. Günthner (1988), (1992), Kotthoff (1989). 
stellt wird, weil er eben dem relationalen Charakter von Stil angemessen ist. Dort wird aber auch differenziert zwischen verschiedenen Typen von Gegenständen des Vergleichs. ${ }^{50}$ Auch bei Püschel wird der Methodengesichtspunkt immer wieder aufgenommen. ${ }^{51}$

(19) Stil ist schließlich Gegenstand der Beschreibung von Kompetenz wie auch der Beschreibung von Performanzen. ${ }^{52}$ Im Rahmen von Stilkompetenz spielen z.B. eine Rolle: ${ }^{53}$ Virtuelle Stile wie Soziolekte, Regiolekte, gruppenspezifische Varietäten, Fachsprachen und Fachjargons, Charakteristika der Jugendsprache, spontansprachlicher Umgangsstandard, aber auch Stilebenen und speziellere Stile wie 'feierlicher Stil' (z.B. Antos 1986), Bibelstil (Stolt 1988) und Höflichkeitsstile oder noch spezieller Textmusterstile (vgl. 14). Hierher gehören natürlich auch Beschreibungen von Stilelementen ${ }^{54}$ mit ihren Zusammenhängen.

Bei Stil im Rahmen der Performanzanalyse fragt man danach, wie welche Vorgaben im Bereich stilistischer Kompetenz im konkreten Fall genutzt werden (intensiviert, abgeschwächt ${ }^{55}$, gemischt (vgl. unten 4.3), abweichend usw.) und vor allem auch: wozu sie genutzt werden. Außerdem geht es darum, wie Aspekte sprachlicher Kompetenz, die nicht als solche bereits stilistische Qualität haben, im konkreten Fall genutzt werden, um stilistischen Sinn zu erzeugen (vgl. Kap. 2 und 4).

Stilistik ist also ein weites und lebendiges Arbeitsfeld mit vielfaltigen Überschneidungen zu anderen Bereichen. ${ }^{56}$

50 Vgl. auch Esser (1990).

51 Püschel (1983), (1991a) und (in diesem Band). Vgl. auch unten Kap. 4.1.

52 Vgl. Sandig (1986, Kap. 1.7).

$53 \mathrm{Vgl}$. oben Kap.2.

54 Z.B. zur stilistischen Markiertheit von Lexemen: Püschel (1990), Ludwig (in diesem Band). Vgl. auch oben Punkt 15.

55 Z.B. Koller (1993, S. 80ff.): Nutzung der 'gehobenen' Stilebene, aber nur bezogen auf Satzbau, ohne die Lexik.

56 Vgl. auch die Überblicksartikel von Püschel (1991), Michel (1988), Hoffmann (1988), Spillner (1987), Fix (Hg.) (1990/91), Neuland/Bleckwenn (Hg.) (1991), Sowinski (1991). 


\section{Ganzheitliche ${ }^{57}$ Stilkonzeptionen}

Hier möchte ich, auch anhand von Textbeispielen, auf diejenigen Tendenzen näher eingehen, die ich derzeit für die wichtigsten halte.

\subsection{Inhaltliche Aspekte ganzheitlicher Stilkonzeption}

Die gegebene Stildefinition ist in mehrerer Hinsicht ganzheitlich: Sie ist bezogen auf Handlungen als Ganzheiten und auf Texte (Gesprächstexte wie auch schriftliche Texte) als ganzheitliche Mittel der Handlungsdurchführung. Sprachhandeln wiederum ist eingebunden in Gesamtheiten von historischen, sozialen und situativen Voraussetzungen; diese werden durch die vielfältigen Typen stilistischen Sinns reflektiert; unter diesen Voraussetzungen entfalten die Texte Wirkungen.

Ganzheiten sind auch im Spiel, wenn zu bestimmten Textmustern (oder Textsorten) konventionelle Textmusterstile ${ }^{\mathbf{5 8}}$ gehören (vgl. oben Punkt 14), z.B. bei Todesanzeigen (Reiss 1977/78, Piitulainen 1990, 1993), bei Medikamentenbeipackzetteln (Schuldt 1992, Hoffmann 1983) oder bei Fachtextstilen (Baumann 1992, Klauser 1992). Auch für Gesprächsmuster gibt es Gesprächsmusterstile, allerdings oft mit rollenspezifischen Differenzierungen, z.B. Gesprächspsychotherapie (Baus/Sandig 1985), Interviews (Uhmann 1989), auch für Gesprächsphasen wie Witze erzählen (Kotthoff in Vorb.). Oft sind für Textmuster auch nur einige „textklassenspezifische Kommunikationsmaximen” oder „Formulierungsmuster" charakteristisch (Heinemann/Viehweger 1991, S. 165-169).

Eine Methode, Texte ganzheitlich stilistisch zu analysieren, besteht in folgendem: Man beschreibt ein Textmuster ${ }^{59}$ als Zusammenhang von typischer Verwendungssituation, sozialem $Z$ weck und Strukturvorgaben und fragt dann danach, wie dieses im konkreten Fall realisiert ist: ob maximal, minimal, durchschnittlich, abweichend usw. ${ }^{60}$ Z.B. gehören die

$\overline{57}$ „holistisch”, vgl. Hinnenkamp/Selting (Hg.) (1989, Einleitung).

58 Vgl. Sandig (1986, S. 194-196), Antos (1986).

59 Vgl. Sandig (1985); Antos (1987): „Erwartungsstruktur”; Gülich (1986): Rekonstruktion des explizierten Musterwissens der Beteiligten. Textmuster sind konventionelle Vorgaben zur Lösung gesellschaftlicher Standardprobleme (vgl. Gülich 1986, Antos 1987), die mehr oder weniger große Spielräume zulassen: Es gibt obligatorische (konstitutive) und fakultative Teile; stilistische Vorgaben sind mehr oder weniger fest; bei Alternativen gibt es Präferenzen usw. (vgl. Sandig 1987). Textmuster sind an Typen von Situationen gebunden, und es existiert in der Sprachgemeinschaft mindestens eine Benennung für sie.

Vgl. Sandig (1986, S. 173ff.), Sandig (1987). 
Beispieltexte (s. Anhang, S. 60f.) alle zum Textmuster Anzeigenwerbung, hier speziell Werbung für Werbung.

Das Textmuster Anzeigenwerbung dient dem Aufmerksammachen auf Werbegegenstände im weiten Sinne und ist in seiner Verwendung an Zeitungen, Zeitschriften und andere Druckerzeugnisse gebunden; es wird (nach Sowinski 1979) konventionell aus folgenden Teiltexten gebildet: die Schlagzeile zum Erregen der Aufmerksamkeit; der Haupttext, mit dem der Werbegegenstand benannt, oft auch abgebildet (z.B. mit einem Logo/Signet) und mehr oder weniger explizit beschrieben und bewertet wird; der Liefernachweis o.ä. und der Slogan, „eine oft formelhaft kurze, graphisch und bedeutungsmäBig meist isoliert erscheinende Textzeile, die in der Regel länger benutzt wird, damit diese Aussage und der Produktname bei vielen im Gedächtnis haften bleiben" (Sowinski 1979, S. 81). Das obligatorische Minimum einer Werbeanzeige ist der Produktname in seiner besonderen graphostilistischen (vgl. Pfeiffer-Rupp 1984) Gestaltung. Erwartbar ist eine sorgfältige stilistische Ausgestaltung.

Wir sehen, daß Text $(2)^{61}$ den Namen in seiner charakteristischen Schreibweise präsentiert, aber keine Schlagzeile enthält, und ob Die meisten Leser. Die meisten Anzeigen ein Slogan ist, darüber kann man streiten; diese Äußerungen könnten auch zusammen mit dem 1. Teil der Zeile als Haupttext zählen. Der Text ist in seinem äußeren Format und in seiner Kürze und Sprachökonomie seiner Umgebung, der 1. Anzeigenseite der Zeitung, angepaßt. Bei Text $(1)^{62}$ gibt es die optisch abgesetzte Werbeschlagzeile, den Haupttext, keinen Slogan, dafür aber einen Textteil, der Auskunft über die Zugänglichkeit gibt; diesem Zweck dient auch die Zeile unter der Präsentation des Namenzuges. Es ist in Größe und optischer Gestaltung und ebenso in der sorgfältigen stilistischen Gestaltung eine typische Illustrierten-Anzeigenwerbung. Text (3) enthält außer dem relevanten Namen $Z D F$ Werbefernsehen mit dem Signet eine Schlagzeile, "Vorsicht Falle", den in sich gegliederten Haupttext und den Slogan Mit dem $Z$ weiten Erster sein; der Text paßt sich visuell relativ an die Zeitungs-Textkolumne an, in die er eingelagert ist, ebenso inhaltlich an das Themen-Spektrum der Wochenzeitung. So passen die Schreiber die so unterschiedlichen Realisierungen desselben Musters den jeweili-

61 Text (2) wird so oder angereichert um eine Dachzeile Wer keine Werbung macht, den kennt man nicht. inmer wieder verwendet. Diese Verwendungen dienen offenbar auch dem Zweck, freien Platz sinnvoll zu füllen.

62 Für diesen Text danke ich Martina Lillig, die ihn mir brachte, allerdings ohne Angabe des Fundorts. 
gen Kontexten an: ${ }^{63}$ Im jeweiligen Kontext erfüllen die Anzeigen den spezifischen Zweck. In Relation (vgl. oben Kap. 3, Punkt 2) zum rekonstruierten Muster mit seinen sozialen Zwecken und auch in Relation zur konkreten Verwendungssituation läßt sich der komplexe stilistische Sinn der Musterrealisierungen erfassen. ${ }^{64}$

Ein anderer Aspekt ganzheitlicher Betrachtung ist folgender: Ein schriftlicher Text hat rein äuBerlich oft einen einheitlichen $\mathrm{Stil}^{65}$; bei Gesprächstexten können die aufeinander bezogenen Gesprächsrollen stilistisch jeweils einheitlich gestaltet sein. Die Ganzheit der Handlung und ihres Textes wird durch Einheitlichkeit des Stils unterstützt. Schriftliche Texte und Gesprächstexte ${ }^{66}$ können jedoch auch eine stilistisch in sich differenzierte Gesamtgestalt aufweisen. So ist bei Text (3) das Zitat „frei nach Goethe" nicht nur graphostilistisch abgesetzt, sondern es weist auch im Bereich Orthographie $(\mathrm{Ihm})$ und Lexik (der Irrende, die besondere Verwendung von Wahrheit und Kräfien) als 'historisch' zu interpretierende ${ }^{67}$ Besonderheiten auf, die sich besonders vom nachfolgenden Slogan stilistisch unterscheiden. ${ }^{68}$ Bei Text (1) sind die Stile des Textanfangs und des Textendes deutlich verschieden. Gespräche weisen oft stilistisch unterschiedene Phasen auf, mit denen unterscheidbare Teilhandlungen der Beteiligten kenntlich gemacht werden (z.B. Uhmann 1989). Dieses „aktive Herstellen" von interpretierbarem sozialem Sinn mittels stilistischer Eigenschaften wird besonders in den Überschneidungsbereichen von Soziolinguistik und Ethnomethodologie betont, die zu Stadtsprachenforschung und Analysen von Kommunikation in Institutionen geführt haben; es ist aber für schriftliches Sprachhandeln ebenso wichtig.

63 Vgl. Burger (1991, S. 325).

64 Bei sehr großem Unterschied der Realisierung zum Muster muß die Intention explizit angezeigt werden: Gülich (1986, S. 26, Beispiel 5); Antos (1987, S. 164ff.). Zur stilistischen Realisierung fest vorgegebener Muster vgl. Paul (1989).

Vgl. Sandig (1986, Kap. 1.5.5).

66 Für Gesprächstexte: Selting (in diesem Band): Das Beispiel zeigt, wie die Stilwechsel die Gesamtgestalt der Erzăhlung konturieren; für die thematische Konturierung z.B. Keim (1993).

67 Im Kontext von frei nach Goethe.

68 Ch. Küper machte mich darauf aufmerksam, daß die den Rhythmus verdeutlichende Zeilenschreibung hier nicht eingehalten ist, absichtlich oder irrtümlich. 


\subsection{Strukturelle Aspekte ganzheitlicher Stilauffassung}

Einheiten sehr verschiedener sprachlicher Beschreibungsebenen ${ }^{69}$, aber auch Einheiten anderer Zeichentypen sind als Elemente e in e r stilistischen Struktur zu beschreiben, die als Ganzheit zu interpretieren ist. So wirken bei Gesprächsstilen individuelle sprecherische Qualitäten (Gutenberg 1983, Slembek 1983, Herbig 1992) und soziale Sprechqualitäten wie Rhythmus und Intonation mit lexischen und syntaktischen Mitteln (z.B. Selting in diesem Band) zusammen, ebenso Eigenschaften von Sprecherbeiträgen und Sprecherwechseln, Arten der Themengestaltung usw.; bei schriftlichen Texten sind es Mittel visueller Textgestaltung und graphostilistische Mittel (wie die Beispiel-Texte belegen) im Zusammenspiel mit Lexik und Syntax, wobei die bekannten Typen von Stilelementen jeweils eingeschlossen sind, dazu die Art der Gestaltung des Themas und der Gesamthandlung in bezug auf das Textmuster s.o.).

Auch virtuelle Stile als sozial sinntragende, interpretierbare Einheiten der Kompetenz wie Stilebenen, Fachstile oder Varietäten sind als Zusammenhänge verschiedenartiger Elemente zu beschreiben. Hierbei ist das Prototyp-Konzept hilfreich: Es gibt jeweils Kerneinheiten, an deren Verwendung ein verwendeter Stil deutlich zu erkennen ist wie schön grüßen und mal richtig in Text (1) als Zeichen für 'Umgangsstandard' und ebenda das $e h$ für 'süddeutsch'. Darüber hinaus gibt es jeweils weniger charakteristische Einheiten, die nur in wechselseitiger Unterstützung eindeutig zu interpretieren $\operatorname{sind}^{70}, \mathrm{vgl}$. das Goethezitat in Text (3). Den Rand bilden Einheiten, die auch zu anderen virtuellen Stilen gehören können. ${ }^{71}$ Das heiß, die Elemente eines virtuellen Stils sind graduell mehr oder weniger charakteristisch. ${ }^{72}$

\subsection{Strukturen und inhaltliche Aspekte im Zusammenspiel}

Elemente virtueller Stile als Einheiten der Kompetenz werden bei der Verwendung im sprachlichen Handeln synthetisiert mit Elementen anderer virtueller Stile. Dies hat zuerst Rehbein (1983) gezeigt: An einem Wirtschaftskommentar beschrieb er Lexik und Kollokationen aus

69 Vgl. "strukturelle Mehrstufigkeit" in Sandig (1986, Kap. 1.6.1).

$70 \mathrm{Vgl}$. die Konnotationsbereiche als komplexe Zeichen unterschiedlicher sozialer Praxis bei Maas (1985).

71 Vgl. die Arbeiten von Selting, z.B. (1989).

72 Mehr oder weniger zentral oder peripher. Vgl. auch die noch feinere Abstufung bei Crystal (1991, S. 228ff.). 
dem Überschneidungsbereich von Wirtschaft und Politik ${ }^{73}$ (Inflationsrate, fünf Prozent mehr Arbeitslose usw.) im Zusammenspiel mit alltagssprachlichen Wendungen und mit Kriegsmetaphorik ${ }^{74}$; an der Rede eines Jugendlichen wies er (ebda.) einen Konflikt zwischen Elementen öffentlicher Rede und Berliner Jugendjargon auf. Andere Ganzheiten wie Textmuster können ebenfalls stilistisch genutzt werden, so das Briefmuster in Text (1) und das Muster Richtigstellen ${ }^{75}$ bei Text (3). Weitere Ganzheiten, die für die Herstellung von Stilen verwendbar sind, sind Wissensrahmen (Frames) mit ihren sprachlichen Eigenschaften wie hier 'Körperpflege' in Text (1) mit Nivea, eincremen, pflegen, haut(nah) und das umgangssprachliche Allerwertester im Kontext des Bildes; auch 'Markt' mit Marke und Kundschaft. Text (3) arbeitet mit Wissen über Fernsehen allgemein (Kabelhaushalte, $R T L$ plus) und über das Zweite Deutsche Fernsehen (ZDF) speziell: „Vorsicht Falle” ist der Titel einer Sendung des ZDF; Mit dem Zweiten Erster sein ist der Werbeslogan des ZDF.

Die Stilstruktur kann ${ }^{76}$ deshalb synthetisiert sein aus Elementen verschiedener Muster. Am Beispiel von Text (1): das Briefmuster, 'Süddeutsches' (eh), Umgangsstandard (mal richtig, schön grüßen, Allerwertester) und 'vornehme', geradezu 'devote' Schmeichelrede (eine (Marken)persönlichkeit wie Sie, Ihre allerwerteste Kundschaft), dazu der Wissensrahmen Körperpflege, und dies alles zusammen mit der Verwendung 'normaler' Hochsprache (Auch die Menschen im Süden wollen gepflegt sein). „Konnektiert” (Rehbein 1983), verknüpft sind die Muster 'Körperpflege' und 'Markt' bzw. 'Werbung' durch Doppeldeutigkeiten bei pflegen, hautnah, Ihre allerwerteste Kundschaft und durch die Personifizierung (Fräulein Nivea). Das Briefmuster reicht in der Sequenz von Liebes Fräulein Nivea bis schön grüßen sollen, das Muster 'Werbung' von Sie erreichen bis zum Ende des Textes. ${ }^{77}$

73 "Politökonomische Wissensdomäne".

74 Wichtig sind dabei Konnektoren (Rehbein 1983), die die Integration herstellen. Vgl. auch Selting (1989): Hochsprache, Umgangsstandard und Ruhrdeutsch im Wechsel und in Graden der Kombination; auch Keim (1993).

75 In Abwandlung: Es wird der Fehler von anderen 'berichtigt', nicht ein eigener Fehler, vgl. Sandig (1987).

$76 \mathrm{MuB}$ aber nicht, vgl. Text (2).

77 Das Werbemuster wird fast unmerklich eingefūhrt: „Musterimplementierung” nach Rehbein (1983). Zu Mustermischungen auch Sandig (1989), (1991). 
Interpretiert man diese aus anderen Ganzheiten zusammengesetzte Einheit, so kann die stilistische Deutung etwa folgendermafen lauten: 'Werbungen im neuen Magazin können z.B. so aussehen wie diese, so 'frech', so 'originell', aber auch so 'vielfaltig': von 'bayrisch' bis 'vornehm'; und sie können genauso die Leser erst 'auf eine falsche Fährte locken', denn zuerst versteht man den Text als Werbung für Nivea. Die Art der Handlungsdurchführung, die Art der Themenentfaltung, die Nutzung der Gegebenheiten des Mediums Zeitschrift und der Situationsbezug innerhalb des Mediums, die Nutzung mündlicher Elemente in bezug auf den Schriftkanal - alle diese Aspekte stilistischen Sinns dienen der Imagearbeit (vgl. Schwitalla 1990), d.h. der möglichst positiven Selbstdarstellung der Werbenden.

Virtuelle Stile als Einheiten der Kompetenz sind also Ganzheiten, allerdings solche, die in andere Einheiten wie Text und Gespräch eingelagert verwendet werden. Bezogen auf die Ganzheiten von Texten oder Textteilen, Gesprächen oder Teilen von Gesprächen tragen ihre Elemente zu einer Ganzheit bei, die die Sprachhandlung in die konkreten Handlungsgegebenheiten einfügt, sie auf diese bezieht. Ebenso dienen Elemente virtueller Stile dazu, die Handlung intern zu differenzieren, ihre Teile oder Phasen herauszuarbeiten oder auch erst anzuzeigen, um welche Handlung es gerade geht.

\subsection{Ganzheitliche Beschreibung von Stilelementen}

In diesem Zusammenhang interessieren zunächst Beschreibungen von Typen von Stilelementen, die auf deren mögliche Funktionen in Texten und Gesprächen zielen: z.B. das vielfältige stilistische Funktionspotential von Redewendungen ${ }^{78}$ oder Eigennamen ${ }^{79}$.

Eine andere auf Texte bezogene Tendenz ist die, Typen von Stilelementen so $\mathrm{zu}$ beschreiben, daß sie auf umfassendere Bildungsprinzipien zurückzuführen sind, die dann sehr verschiedenartige Elemente erfassen. Die enorme stilistische Kreativität kann so in Ausschnitten erfaßt werden. Z.B. hat Besch (1989) an Rilkes Gedicht "Das Karussell" die Formen des Wiederholens und Variierens beschrieben: von der Lautung über die Lexik und Syntax bis zur gesamten Textstruktur. Schon Blumenthal (1983) hat sehr verschiedene Typen von Stilelementen auf die Grundprinzipien Ähnlichkeit, Kontrast und Kontiguität zurückgeführt und unterschieden

78 Burger (1987), Sandig (1989), Gréciano (1994), Wotjak (1994).

79 Sandig (in Vorb.); Schwitalla (ebda.) für den Namengebrauch in Gesprächen. Zu Wortbildung im Bereich der Literatur Handler (1993). 
nach solchen, die durch Verwendung von Ähnlichkeiten, Kontrasten und Kontiguitäten der Sprache entstehen („benutzt”) und nach solchen, die im Text erst "geschaffen" werden. Der Vorteil ist dabei, daB auch Überlagerungen mehrerer Prinzipien beschreibbar werden. Vielfältige Formen des Abweichens (graphostilistisch, (ortho)graphisch, morphemisch, syntaktisch, semantisch ...) und deren mögliche Überlagerungen und Funktionen hat Dittgen (1989) an Kurztextmustern herausgearbeitet. ${ }^{80}$ In diesem Licht erscheinen dann die traditionell bekannten Stilfiguren nur als die prototypischsten Stilelemente.

Eine noch einmal ganz andere ganzheitliche Beschreibung zeigen Fiehler (1979) und Ingendahl (1989), die für je einen Situationstyp und die darin gegebene Aufgabe sprachlichen Handelns die sprachlichen Alternativen umfassend erarbeitet haben.

Im Jahr 1989 haben Dressler und Auer zwei Arbeiten vorgelegt, in denen Textbezug (Dressler 1989) bzw. Gesprächsbezogenheit (Auer 1989) kombiniert werden mit semiotischen Zeichenaufassungen und mit einer Natürlichkeitsauffassung, die der Phonologie und der Morphologie entstammt. Die tragende Idee der Natürlichkeitstheorie ist die, die Auswirkungen von Prinzipien leichten Sprachherstellens und leichten Wahrnehmens zu erforschen. Dabei kann eine Eigenschaft, die auf einer Ebene der Beschreibung erleichternd, also 'natürlich' ist (z.B. umgangssprachlich $h a b m$ oder ham statt $h a b n$ ), auf einer anderen Ebene 'nicht natürlich' oder 'markiert' sein ( $h a m$ ist lexikalisch und morphemisch weniger transparent (Dressler 1989) als habn): ${ }^{81}$ Es kommt zu einem Natürlichkeitskonflikt (z.B. Dressler 1989). Außerdem ist Natürlichkeit ein gradiertes Konzept: es gibt jeweils Grade der Natürlichkeit.

Ein Bereich der Natürlichkeit ist der Ikonismus: ${ }^{82}$ Eigenschaften des sprachlichen Ausdrucks bilden Aspekte dessen ab, wie wir das sprachlich Ausgedrückte wahrnehmen. ${ }^{83}$ Es entsteht eine Analogie zwischen dem Signans (Dressler 1989) und der Wahrnehmung des Bezeichneten.

$8 \mathrm{Vgl}$. auch die unterschiedlichen Formen der Mustermischung (Sandig 1989, 1991).

81 Das Natürlichkeitsprinzip, daB einer Form eine Bedeutung entspricht, ist nicht beachtet. Vgl. Dressler (1989), Auer (1989).

82 Genauer: Diagrammatizität: Dressler (1989).

83 Nicht das durch die Sprache Bezeichnete wird abgebildet (z.B. Enkvist 1981), sondern (Dressler 1989, Auer 1989) das für unsere Wahrnehmung der Gegenstände Relevante. 
Hier werden Elemente sehr verschiedener Beschreibungsebenen vom Lautlichen bis zum Text integrierbar. Den stilistischen Pfiff machen dabei oft gerade die Natürlichkeitskonflikte auf mehreren verschiedenen $\mathrm{Be}$ schreibungsebenen aus. Auberdem wird hier etwas von dem beschreibbar, was 'neutraler Stil' ist: ${ }^{84}$ Die natürlichsten Formen sind die neutralsten. Ein Beispiel aus Text (2): Die meisten Leser. Die meisten Anzeigen ist in mehrfacher Weise 'natürlich': Der Parallelismus (Dressler 1989, S. 19ff.) zeigt einen 'Zusammenhang' an, von der rhythmischen Struktur her ${ }^{85}$ folgt die Sequenz dem „Kurzsichtigkeitsprinzip” von Ross (1980): „erst kurz, dann lang"; hier: erst zweisilbig: Leser, dann dreisilbig: Anzeigen.

Interessanter unter dem Natürlichkeitsgesichtspunkt ist aus Text (3) der Werbeslogan Mit dem Zweiten Erster sein. Durch das Ansteigen und Abfallen der Stimme wird eine geschlossene Gesamtgestalt 'natürlich' angezeigt (Auer 1989, S. 19ff.). Zudem bildet der Rhythmus mit unbetonten und betonten Silben eine symmetrische 'harmonische' Figur. Die wichtigsten inhaltlichen Elemente Zweiten und Erster tragen auch die Betonungsstellen (Auer 1989, S. 35ff.). Nach Ross (1980) werden natürlicherweise in Sequenzen höhere Vokale vor niedrigere gestellt: hier Zweiten Erster. Die Sequenz besteht zudem in 'natürlicher' Weise aus einer Abfolge von Thema und Rhema (Dressler 1989, S. 19). Bei Zweiten Erster ist allerdings die natürliche Reihenfolge im Bereich lexikalischer Bedeutung nicht eingehalten: Es heißt nicht Erster mit dem Zweiten sein, was hier die 'natürliche' Reihenfolge wäre; deshalb ist Zweiten $E r$ ster 'markiert'; in dieser Hinsicht besteht also ein Natürlichkeitskonflikt zu den übrigen Eigenschaften des Slogans, und gerade dieser scheint im Zusammenhang der übrigen 'Natürlichkeit' dieses Minitextes die stilistische Würze zu geben. Die Vielfalt der hier beschreibbaren NatürlichkeitsQualitäten scheint auch die höhere stilistische Qualität, die 'Eingängigkeit' gegenüber Text (2) auszumachen. ${ }^{86}$

84 Vgl. Enkvist (1981). Macheiners (1991) verschiedene Beispiele könnten oft durch Natürlichkeitsprinzipien näher erklärt werden.

85 Ross (1980) hat anhand von festgeprägten Wendungen lautlich-rhythmische Natürlichkeitsprinzipien festgestellt.

86 Nicht beschrieben ist dann noch immer die syntaktische Form: der erweiterte Infinitiv als besonderes syntaktisches Muster für Motti, Devisen. Nicht beschrieben ist auch die metaphorische Verwendung von Erster sein, was ein formelhafter Bewertungsausdruck für 'hohen positiven Wert' ist, - in Variation zu dem im Fernsehframe erwartbaren Ersten Deutschen Fernsehen, wodurch ein unausgesprochener Vergleich entsteht (Wettbewerb der beiden Fernsehkanäle). 
Ordo naturalis und ordo artificialis sind seit alters Prinzipien der natürlichen oder markierten Sequenzierung von Themen und Teilhandlungen in Texten ${ }^{87}$ sie können harmonieren oder konfligieren mit Natürlichkeit oder Markiertheit bei den kleineren Einheiten des Textes (Dressler 1989, Auer 1989). Am Beispiel (3): In 'natürlicher Weise' wird erst das Falsche dargestellt als Voraussetzung für das darauf folgende Richtige; beides zusammen bildet als Mitteilung die 'natürliche' Voraussetzung für den nachfolgenden Kommentar (der allerdings in seiner Vermitteltheit, als Goethezitat nicht 'natürlich' ist).

\section{SchluB}

Insgesamt stiften Stile in vielfaltiger Weise sozialen Sinn, der aufgrund der Interpretationshinweise ${ }^{\mathbf{8 8}}$, die Stile mit ihren unterschiedlichen Eigenschaften geben, interpretiert, d.h. aktiv nachvollzogen werden kann.

Die Art der Stile, ihre große oder eingeschränkte Zahl, ihre Verteilung auf soziale Gruppen und Handlungstypen oder ihre freie Verbindbarkeit mit sozialen Handlungsweisen, ihre Bewertung in einer Gemeinschaft, ihre Rigidität oder der Grad ihrer Variabilität und Wandelbarkeit in der Zeit - all das sind Zeichen einer Kultur, verstanden als komplexes Gebilde, nicht nur mit weithin als wohlbewertet angesehenen Kommunikationsgepflogenheiten, sondern auch mit Sub- und Nebenkulturen. Die Frage ist: In welchen Bereichen wird konventionell was wie wozu getan, welche Lizenzen für Abweichungen gibt es jeweils, und wo beginnt jeweils das Fehlerhafte.

Stil ist zwar ein Chamäleon, aber dieses Faktum ist nicht beunruhigend, sondern es ist $\mathrm{zu}$ verstehen als bedingt durch die generelle Funktion von Stil mit seiner Vielfalt von systematisch unterscheidbaren Einzelfunktionen und der Vielzahl von im konkreten Fall sich überlagernden Sinnaspekten. Daß diese Vielfalt mit unterschiedlichen Konzepten angegangen werden muB, ist klar. Verschiedene theoretische und methodische Perspektiven auf den Gegenstand beleuchten jeweils verschiedene Eigenschaften.

\footnotetext{
87 Vgl. Dressler (1989), Asinuth (1991).

$88 \mathrm{Vgl}$. Kontextualisierungshinweise.
} 


\section{Literatur}

Adamzik, K. (1994): Beziehungsgestaltung in Dialogen. In: Fritz, G./Hundsnurscher, F. (Hg.) (1994): Handbuch der Dialoganalyse. Tübingen. S. 357374.

Antos, G. (1986): Zur Stilistik von Grußworten. In: Zeitschrift für germanistische Linguistik 14, S. 50-81.

Antos, G. (1987): Textmusterwissen. Beschreibungsmodelle am Beispiel von Grußworten. In: Engelkamp, J./Lorenz, K./Sandig, B. (Hg.) (1987): Wissensrepräsentation und Wissensaustausch. Interdisziplinäres Kolloquium der Niederländischen Tage in Saarbrücken, April 1986, St.Ingbert. S. 157 189.

Asmuth, B. (1991): Stilprinzipien, alte und neue. Zur Entwicklung der Stilistik aus der Rhetorik. In: Neuland/Bleckwenn (Hg.) (1991), S. 23-38.

Assmann, A. (1986): „Opting in” und „opting out”. Konformität und Individualität in den poetologischen Debatten der englischen Aufklärung. In: Gumbrecht/Pfeiffer (Hg.) (1986), S. 127-143.

Auer, J.C.P. (1986): Kontextualisierung. In: Studium Linguistik 19, S. 22-47.

Auer, P. (1989): Natürlichkeit und Stil. In: Hinnenkamp/Selting (Hg.) (1989), S. 27-59.

Baumann, K.-D. (1992): Integrative Fachtextlinguistik. Tübingen.

Baus, M./Sandig, B. (1985): Gesprāchspsychotherapie und weibliches Selbstkonzept. Sozialpsychologische und linguistische Analyse am Beispiel eines Falles. Hildesheim/Zürich/New York.

Besch, E. (1989): Wiederholung und Variation. Untersuchung ihrer stilistischen Funktionen in der deutschen Gegenwartssprache. Frankfurt/M./Bern/New York/Paris.

Betten, A. (1983): Zwei Mānner reden über eine Frau. Dialogtechniken bei Strauß, Dürrenmatt, Kroetz und Horváth als Beitrag zur Untersuchung von Gesprächsstilen. In: Sandig (Hg.) (1983a), S. 39-68.

Betten, A. (1986): Einige grundsātzliche Überlegungen zur Beschreibung alltagssprachlicher und literarischer Dialoge. In: Hundsnurscher, F./Weigand, E. (Hg.) (1986): Dialoganalyse. Referate der 1. Arbeitstagung Münster 1986. Tübingen. S. 3-12.

Betten, A. (1989): Weiblicher Gesprāchsstil und feministische Gesprächsanalyse? Überlegungen zum Forschungsstand. In: Weigand, E./Hundsnurscher, F. (Hg.). (1989): Dialoganalyse II. Referate der 2. Arbeitstagung Bochum 1988, Tübingen. Bd.2, S. 265-276.

Blumenthal, P. (1983): Semantische Dichte. Assoziativität in Poesie und Werbesprache. Tübingen.

Böheim, G. (1987): Zur Sprache der Musikkritiken. Ausdrucksmöglichkeiten der Bewertungen und/oder Beschreibungen. Innsbruck.

Brinker, K. (Hg.) (1991): Aspekte der Textlinguistik. Hildesheim/Zürich/New York. (= Germanistische Linguistik 106-107). 
Bucher, H.-J. (1986): Pressekommunikation. Grundstrukturen einer öffentlichen Form der Kommunikation aus linguistischer Sicht. Tübingen.

Burger, H. (1987): Funktionen von Phraseologismen in den Massenmedien. In: Burger, H./Zett, R. (1987): Aktuelle Probleme in der Phraseologie. Symposium 27.-29.9.1984 in Zürich. Bern/Frankfurt/M./New York/Paris. S. 1128.

Burger, H. (1990): Sprache der Massenmedien. 2.Aufl. Berlin/New York.

Burger, H. (1991): Das Gespräch in den Massenmedien. Berlin/New York.

Crystal, D. (1991): Stylistic profiling. In: Aymer, K./Altenberg, B. (Hg.) (1991): English Corpus Linguistics. Studies in Honour of Jan Svartvik. London/New York. S. 221-238.

Cort De, J. (1983): Fachsprache und Stil. Ein Überblick. In: Jahrbuch für Internationale Germanistik XV, H.2, S. 40-52.

Dijk van, T. A. (1984): Prejudice in discourse. An Analysis of Ethnic Prejudice in Cognition and Conversation. Amsterdam/Philadelphia.

Dijk van, T. A. (1985): Handbook of Discourse Analysis. Bd.4: Discourse Analysis in Society. London et al.

Dimter, M. (1981): Textklassenkonzepte heutiger Alltagssprache. Kommunikationssituation, Textfunktion und Textinhalt als Kategorien alltagssprachlicher Textklassifikation. Tübingen.

Dittgen, A. M. (1989): Regeln für Abweichungen. Funktionale sprachspielerische Abweichungen in Zeitungsüberschriften, Werbeschlagzeilen, Werbeslogans, Wandsprūchen und Titeln. Frankfurt/M./Bern/New York/Paris.

Dittmar, N. (1989): Soziolinguistischer Stilbegriff am Beispiel der Ethnographie einer Fußballmannschaft. In: Zeitschrift für Germanistik 10, S. 423-444.

Dressler, W. U. (1989): Semiotische Parameter einer textlinguistischen Natürlichkeitstheorie. Österr. Akademie der Wissenschaften. Phil.-hist. Klasse, Bd. 529. Wien.

Ehrlich, S. (1990): Point of View. A Linguistic Analysis of Literary Style. London/New York.

Enkvist, N. E. (1981): Experiential iconism in text strategy. In: Text 1, S. 97-111.

Esser, J. (1990): Norm und Differential bei linguistischen Stilvergleichen. In: Folia Linguistica 24, S. 23-43.

Fiehler, R. (1979): Über das Abgießen von Reis. Ein Kommunikationsbedarfselement und Möglichkeiten seiner Deckung. In: Vandeweghe, W./Van de Velde, M. (Hg.) (1979): Bedeutung, Sprechakte und Texte. Akten des 13. Ling. Koll. Gent 1978. Tübingen. S. 181-190.

Fiehler, R. (1990): Kommunikation und Emotion. Theoretische und empirische Untersuchungen zur Rolle von Emotionen in der verbalen Interaktion. Berlin/New York.

Fiehler, R. (1993): Spezifika der Kommunikation in Kooperationen. In: Schröder (Hg.) (1993), S. 343-357. 
Firle, M. (1990/91): Stil in Kommunikation, Sprachkommunikation und poetischer Kommunikation. In: Fix (Hg.) (1990/91), S. 19-45.

Fix, U. (1990): Der Wandel der Muster - der Wandel im Umgang mit den Mustern. Kommunikationskultur im institutionellen Sprachgebrauch der DDR am Beispiel von Losungen. In: Deutsche Sprache 18, S. 332-348.

Fix, U. (1990/91): Redebewertung-Stilbewertung. Zu theoretischen Fragen der Bewertung sprachlicher ÄuBerungen. In: Fix (Hg.) (1990/91), S. 73-104.

Fix, U. (1991): Stilistische Textanalyse - immer ein Vergleich? In: Brinker (Hg.) (1991), S. 133-156.

Fix, U. (1991a): Vorbemerkungen zu Theorie und Methodologie einer historischen Stilistik. In: Zeitschrift für Germanistik. NF. 1-2, S. 299-310.

Fix, U. (1991b): Unikalität von Texten und Relativitāt von Stilmustern. In: Beitrāge zur Erforschung der deutschen Sprache 10, S. 51-61.

Fix, U. (1992): Stil als komplexes Zeichen im Wandel. Ūberlegungen zu einem erweiterten Stilbegriff. In: Zeitschrift für germanistische Linguistik 20, S. 193-209.

Fix, U. (1993): Medientexte diesseits und jenseits der „Wende”. Das Beispiel 'Leserbrief'. In: Biere, B.U./Henne, H. (Hg.) (1993): Sprache in den Medien nach 1945. Tübingen. S. 30-55.

Fix, U. (1994): Die Beherrschung der Kommunikation durch die Formel. In: Sandig (Hg.) (1994), S. 139-153.

Fix, U. (Hg.) (1990/91): Beiträge zur Stiltheorie. Leipzig. (1990). Tübingen. (1991).

Fowler, R. (1986): Linguistic Criticism. Oxford/New York.

Franck, D. (1984): Stil und Interaktion. In: Spillner (Hg.) (1984), S. 121-135.

Frank, K. (1992): Sprachgewalt: Die sprachliche Reproduktion der Geschlechterhierarchie. Elemente einer feministischen Linguistik im Kontext sozialwissenschaftlicher Frauenforschung. Tübingen.

Frese, K. (1987): Wie Eltern von sich reden machen. Sprachliche Analyse von Geburtsanzeigen in Tageszeitungen zwischen 1790 und 1985. Heidelberg.

Garfinkel, H./Sacks, H. (1976): Über formale Strukturen praktischer Handlungen. In: Weingarten, E./Sack, F./Schenkein, J. (Hg.) (1976): Ethnomethodologie. Beiträge zu einer Soziologie des Alltagshandelns. Frankfurt/M. S. 130-176.

Gerbig, A. (1994): Computergestũtzte Stilanalyse: umweltpolitische Themen im Diskurs. Duisburg: L.A.U.D. Series B. Nr. 253.

Gläser, R. (1990): Fachtextsorten im Englischen. Tübingen.

Good, C. H. (1983): Ideologische Interessen und sprachliche Techniken. In: Sprache und Literatur in Wissenschaft und Unterricht 1, S. 17-29.

Gräßel, U. (1991): Sprachverhalten und Geschlecht. Eine empirische Studie zu geschlechtsspezifischem Sprachverhalten in Fernsehdiskussionen. Pfaftenweiler.

Gréciano, G. (1994): Vorsicht, Phraseoaktivitāt! In: Sandig (Hg.) (1994), S. 203-218. 
Gruber, H. (1991): Antisemitismus im Mediendiskurs. Die Aftāre „Waldheim” in der Tagespresse. Wiesbaden.

Gülich, E. (1986): Textsorten in der Kommunikationspraxis. In: Kallmeyer, W. (Hg.) (1986): Kommunikationstypologie. Handlungsmuster, Textsorten, Situationstypen. Jahrbuch 1985 des Instituts für deutsche Sprache. Düsseldorf. S. 15-46.

Günthner, S. (1988): Interkulturelle Aspekte von Schreibstilen. Zur Verwendung von Sprichwörtern und Routineformeln in Deutschaufsätzen chinesischer Deutschlerner/innen. In: Lieber, M./Posset, J. (Hg.) (1988): Texte schreiben im Germanistik-Studium. München. S. 145-159.

Günthner, S. (1992): Die interaktive Konstruktion von Geschlechterrollen, kulturellen Identitäten und institutioneller Dominanz. Sprechstundengespräche zwischen Deutschen und Chinesen/innen. In: Günthner/Kotthoff (Hg.) (1992), S. 91-125.

Günthner, S. (1992a): Sprache und Geschlecht: Ist Kommunikation zwischen Frauen und Männern interkulturelle Kommunikation? In: Linguistische Berichte 138, S. 123-143.

Günthner, S./Kotthoff, H. (Hg.) (1992): Die Geschlechter im Gespräch. Kommunikation in Institutionen. Stuttgart.

Gumbrecht, H. U./Pfeiffer, K. L. (1986): Stil. Geschichten und Funktionen eines kulturwissenschaftlichen Diskurselements. Frankfurt/M.

Gutenberg, N. (1983): Sprechstile. Ansātze einer sprechwissenschaftlichen Stilistik. In: Sandig (Hg.) (1983a), S. 209-286.

Handler, P. (1993): Wortbildung und Literatur. Panorama einer Stilistik des komplexen Wortes. Frankfurt/M. et al.

Heinemann, W./Viehweger, D. (1991): Textlinguistik. Eine Einführung. Tübingen.

Herbig, A. F. (1992): "Sie argumentieren doch scheinheilig!" Sprach- und sprechwissenschaftliche Aspekte einer Stilistik des Argumentierens. Frankfurt/M. et al.

Herbig, A. F. (1993): Argumentationsstile. Vorschläge für eine Stilistik des Argumentierens. In: Püschel/Sandig (Hg.) (1993), S. 45-75.

Hinnenkamp, V./Selting, M. (Hg.) (1989): Stil und Stilisierung. Arbeiten zur interpretativen Soziolinguistik. Tübingen.

Hoffmann, L. (1983): Arzneimittel-Gebrauchsinformationen: Struktur, kommunikative Funktion und Verständlichkeit. In: Deutsche Sprache 11, S. 138159.

Hoffmann, M. (1988): Kommmunikativ orientierte linguistische Konzepte in der Stilistik seit der kommunikativ-pragmatischen Wende. In: Zeitschrift fūr Germanistik 9, S. 321-221.

Hoffmann, M. (1990/91): Stil und Situation - Stil als Situation. Zu Grundlagen eines pragmatischen Stilbegrifts. In: Fix (Hg.) (1990/91), S. 46-72.

Holly, W. (1990): Politikersprache. Inszenierungen und Rollenkonflikte im informellen Sprachhandeln eines Bundestagsabgeordneten. Berlin/New York. 
Holly, W. (in Vorb.): Secondary Orality in the Electronic Media. In: Quasthoff, U. M. (Hg.) (in Vorb.): Aspects of Oral Communication. Berlin/New York.

Holly, W./Kühn, P./Püschel, U. (1986): Politische Fernsehdiskussionen. Zur medienspezifischen Inszenierung von Propaganda als Diskussion. Tübingen.

Ingendahl, W. (1988): Linguistische Vorarbeiten für eine pragmatische Stilistik. Ein Forschungsbereich $z$ wischen Sprach- und Kulturwissenschaft. In: Muttersprache 98, S. 108-120.

Kalivoda, G. (1988): Stilistik der politischen Ausgrenzung. Diskursstilistische Untersuchung am Beispiel der Sozialistengesetzdebatte des deutschen Reichstags von 1878. In: Sandig (Hg.) (1988), S. 87-101.

Kallmeyer, W. (1987): Stadtsprache als ein Schwerpunkt soziolinguistischer Forschung in Europa. In: Sociolinguistica. 1, S. 80-99.

Kallmeyer, W. (Hg.) (1994): Kommunikation in der Stadt. Exemplarische Analysen des Sprachverhaltens in Mannheim. Berlin/New York. (= Schriften des Institut für deutsche Sprache Bd.4.1).

Kallmeyer, W./Keim, I. (1986): Formulierungsweise, Kontextualisierung und soziale Identität. Dargestellt am Beispiel formelhaften Sprechens. In: Lili 16/H.64, S. 98-126.

Keim, I. (1993): Sprachvariation als konstitutives Merkmal eines sozialen Stils. Am Beispiel einer innerstädtischen Welt „kleiner Leute”. In: Der Deutschunterricht. 45, H.3, S. 44-56.

Keim, I. (in Vorb.): Kommunikative Stilistik einer sozialen Welt „kleiner Leute $^{n}$ in der Mannheimer Innenstadt. (= Schriften des Instituts für deutsche Sprache, Bd.4.3). Berlin/New York.

Keim, I./Schwitalla, J. (1989): Soziale Stile des Miteinander-Sprechens. Beobachtungen zu Formen der Konfliktbearbeitung in zwei Frauengruppen. In: Hinnenkamp/Selting (Hg.) (1989), S. 83-121.

Keseling, G. (1988): Textmuster und Klangstrukturen als Grundlage von Bewertungen beim Schreiben. In: Brandt, W. (Hg.): Sprache in Vergangenheit und Gegenwart. Marburg. S. 219-236.

Klauser, R. (1992): Die Fachsprache der Literaturkritik. Dargestellt an den Textsorten Essay und Rezension. Frankfurt/M./Bern/New York/Paris.

Koller, E. (1993): Peter Handke: Das Umfallen der Kegel von einer bäuerlichen Kegelbahn. In: Wellmann (Hg.) (1993), S. 79-112.

Koller, W. (1994): Phraseologismen als Übersetzungsproblem. In: Sandig (Hg.) (1994), S. 351-373.

Kotthoff, H. (1988): Vom Lächeln der Mona Lisa zum Lachen der Hyänen. Über geschlechtsspezifische Heiterkeit. In: Kotthoff (Hg.) (1988), S. 123153.

Kotthoff, H. (1989): Stilunterschiede in argumentativen Gesprächen oder zum Geselligkeitswert von Dissens. In: Hinnenkamp/Selting (Hg.) (1989), S. 187202.

Kotthoff, H. (1991): Interaktionsstilistische Unterschiede im Gesprächsverhalten der Geschlechter: Unterbrechungen und Themenkontrolle als Stilmittel. In: Neuland/Bleckwenn (Hg.) (1991), S. 131-147. 
Kotthoff, H. (in Vorb.): Die Performanz von mūndlichen Witzen. Zur Erzielung von Komikeffekten über Dialoginszenierungen und soziale Typisierungen.

Kotthoff, H. (Hg.) (1988): Das Gelächter der Geschlechter. Humor und Macht in Gesprächen von Frauen und Männern. Frankfurt/M.

Kress, G. (1985): Ideological Structures in Discourse. In: van Dijk (Hg.) (1985), S. 27-42.

Kretzenbacher, H.-L. (1992): Wissenschaftssprache. Heidelberg. (Studienbibliographien Sprachwissenschaft Bd.5).

Kühn, I. (1991): Beschreibungsansatz der Illokutionsstrukturen im poetischen Text; dargestellt am Beispiel der erlebten Rede. In: Müske/Werner (Hg.) (1991), S. 167-192.

Küper, Ch. (1976): Linguistische Poetik. Stuttgart/Berlin/Köln/Mainz.

Küper, Ch. (Hg.) (1993): Von der Sprache zur Literatur. Motiviertheit im sprachlichen und in poetischen Kode. Tübingen.

Labov, W. (1976): Die Isolierung von Kontextstilen. In: Labov, W.: Sprache im sozialen Kontext. Bd.1. Kronberg/Ts. S. 29-66.

Leech, G. N./Short, M. H. (1981): Style in Fiction. A Linguistic Introduction to English Fictional Prose. London/New York.

Lerchner, G. (1988): Intertextualitāt als ästhetisches Potential: Bobrowskis „34 Sätze über meinen Großvater”. In: Zeitschrift für Germanistik 9, S. 307-320.

Lerchner, G. (1990): Mustermischung und Sprachausgleich im trivialliterarischen Diskurs des 18. Jahrhunderts. In: Zeitschrift für germanistische Linguistik 18, S. 261-272.

Löning, P. (1985): Das Arzt-Patienten-Gespräch. Gesprächsanalyse eines Fachkommunikationstyps. Bern/Frankfurt/M./New York.

Lüger, H.-H. (1988): Ritualität in Gesprächen - untersucht am Beispiel literarischer Texte. In: Sandig (Hg.) (1988), S. 129-145.

Macheiner, J. (1991): Das grammatische Varieté oder Die Kunst und das Vergnügen, deutsche Sätze zu bilden. Frankfurt/M.

Maas, U. (1984): „Als der Geist der Gemeinschaft eine Sprache fand.” Sprache im Nationalsozialismus. Versuch einer historischen Argumentationsanalyse. Opladen.

Maas, U. (1985): Konnotation. In: Januschek, F. (Hg.) (1985): Politische Sprachwissenschaft. Zur Analyse von Sprache als kultureller Praxis. Opladen. S. 71-95.

Michel, G. (1988): Aktuelle Probleme der Linguostilistik. In: Zeitschrift für Germanistik 9, S. 291-306.

Moosmüller, S. (1993): „Wenn eine Frau wirklich gut ist ...” Männliche Argumentationsschemata zur weiblichen Berufstātigkeit. In: Sandig/Püschel (Hg.) (1993), S. 195-213.

Muckenhaupt, M. (1986): Text und Bild. Grundfragen der Beschreibung von Text-Bild-Kommunikationen aus sprachwissenschaftlicher Sicht. Tübingen. 
Müske, E./Werner, H.-G. (Hg.) (1991): Strukturuntersuchung und Interpretation künstlerischer Texte. Interdisziplinäres Kolloquium an der Sektion Germanistik/Kulturwissenschaften der Martin-Luther-Universität HalleWittenberg, Halle. (= MLU Halle Wittenberg, Wissenschaftliche Beiträge. (1991/14). (F 103)).

Neuland, E. (1987): Spiegelungen und Gegenspiegelungen. Anregung für eine zukünftige Jugendsprachforschung. In: Zeitschrift für germanistische Linguistik 15, S. 58-82.

Neuland, E. (1994): Jugendsprache und Standardsprache. Zum Wechselverhältnis von Stilwandel und Sprachwandel. In: Zeitschrift für Germanistik IV NF, S. 78-98.

Neuland, E./Bleckwenn, H. (Hg.) (1991): Stil, Stilistik, Stilisierung. Linguistische, literaturwissenschaftliche und didaktische Beiträge zur Stilforschung. Frankfurt/M./Bern/New York/Paris.

Nothdurft, W. (1984): „...äh folgendes Problem, āh ...”. Die interaktive Ausarbeitung "des Problems" in Beratungsgesprāchen. Tübingen.

OBST (46/1992): Der Diskurs des Rassismus. Ergebnisse des DISS-Kolloquiums November 1991: (Hg.): Jäger, S. und Januschek, F.

Paul, I. (1989): Ritual und Ritualzitat. Die Stilisierung des Rituals durch den pastoralen Diskurs. In: Hinnenkamp/Selting (Hg.) (1989), S. 167-185.

Peer Van, W. (1983): Poetischer Stil, Leserreaktion und Computereinsatz. In: Sandig (Hg.) (1983), S. 191-208.

Peer Van, W. (Hg.) (1988): The Taming of the Text: Explorations in Language, Literature and Culture. London.

Petter-Zimmer, Y. (1990): Politische Fernsehdiskussionen und ihre Adressaten. Tübingen.

Pfeiffer-Rupp, R. (1984): Graphostilistik. In: Spillner (Hg.) (1984), S. 101-119.

Piitulainen, M. (1990): Zum Ausdruck des Sterbens in finnischen und deutschsprachigen Todesanzeigen. In: SKY, S. 159-178.

Piitulainen, M. (1993): Die Textstruktur der finnischen und deutschsprachigen Todesanzeigen. In: Schrōder (Hg.) (1993), S. 141-181.

Plett, H.F. (1975): Textwissenschaft und Textanalyse, Semiotik, Linguistik, Rhetorik. Heidelberg.

Polenz von, P. (1989): Verdūnnte Sprachkultur. Das Jenninger-Syndrom in sprachkritischer Sicht. In: Deutsche Sprache 17, S. 289-316.

Pūschel, U. (1983): Stilanalyse als Stilverstehen. In: Sandig (Hg.) (1993), S. 97-126.

Püschel, U. (1985): Das Stilmuster „Abweichen”. Sprachpragmatische Überlegungen zur Abweichungsstilistik. In: Sprache und Literatur in Wissenschaft und Unterricht 16, S. 9-24.

Pūschel, U. (1986): GESTALTEN als zentrales Stilmuster. In: Kühlwein, W. (Hg.): Perspektiven der Angewandten Linguistik. Forschungsfelder. Kongreßbeitrāge der 16. Jahrestagung der Gesellschaft für Angewandte Linguistik. Tübingen. S. 143-145. 
Püschel, U. (1990): Wortstilistik im Wörterbuch. Zu „Stilfärbung” und „Gebrauchsangaben”. In: Zeitschrift für germanistische Linguistik 18, S. 273-287.

Püschel, U. (1991): Stilistik: Nicht Goldmarie - nicht Pechmarie. Ein Sammelbericht. In: Deutsche Sprache 19, S. 50-67.

Püschel, U. (1991a): Sprachpragmatische Stilanalyse. Überlegungen zur interpretativen Stilistik. In: Der Deutschunterricht 43, S. 21-32.

Püschel, U. (1993): Stilanalyse als interpretatives Verfahren. Stifters Ur- und Studien-Mappe als Beispiel. In: Wirkendes Wort 43, S. 68-81.

Rauch, E. (1992): Sprachrituale in institutionellen und institutionalisierten Text- und Gesprächssorten. Frankfurt/M./Bern/New York/Paris.

Rehbein, J. (1983): Zur pragmatischen Rolle des „Stils”. In: Sandig (Hg.) (1983), S. 21-48.

Reiß, K. (1977/1978): Textsortenkonventionen. In: Le Language et l'homme 35 , S. 46-54 und 36, S. 60-68.

Riesel, E./Schendels, E. (1975): Deutsche Stilistik. Moskau.

Ross, J. R. (1980): Ikonismus in der Phraseologie. Der Ton macht die Bedeutung. In: Zs. für Semiotik 2, S. 39-56.

Rück, H. (1984): Stilanalysen mit Hilfe des theoretischen Ansatzes von Michael Riffaterre. In: Spillner (Hg.) (1984), S. 175-191.

Sachtleber, S. (1993): Textstile in der Wissenschaftssprache. In: Schröder (Hg.) (1993), S. 61-79.

Sandig, B. (1985): Vom Nutzen der Textlinguistik für die Stilistik. In: Schōne, A. (Hg.): Kontroversen, alte und neue. Akten des VII. Internationalen Germanisten-Kongresses Göttingen. Bd.3. S. 24-31.

Sandig, B. (1986): Stilistik der deutschen Sprache. Berlin/New York.

Sandig, B. (1987): Textwissen. Beschreibungsmöglich keiten und Realisierungen von Textmustern am Beispiel der Richtigstellung. In: Engelkamp, J./Lorenz, K./Sandig, B. (Hg.): Wissensrepräsentation und Wissensaustausch. Interdisziplinäres Kolloquium der Niederländischen Tage in Saarbrücken, April 1986, St.Ingbert. S. 115-155.

Sandig, B. (1989): Stilistische Mustermischungen in der Gebrauchssprache. In: Zeitschrift für Germanistik 10, S. 133-150.

Sandig, B. (1991): Literarische Mustermischungen: Formen und Funktionen. In: Müske/Werner (Hg.) (1991), S. 128-151.

Sandig, B. (1991a): Stilistische Handlungsmuster. In: Bahner, W./Schildt, J./Viehweger, D. (Hg.): Proceedings of the Fourteenth International Congress of Linguists, Berlin/GDR, August 10 - August 15, 1987. Bd. III. Berlin. S. 2222-2225.

Sandig, B. (in Vorb.): Namen, Stil(e), Textsorten.

Sandig, B. (Hg.) (1983): Stilistik I: Probleme der Stilistik. Hildesheim. (= Germanistische Linguistik. 3-4/81).

Sandig, B. (Hg.) (1983a): Stilistik II: Gesprächsstile. Hildesheim. (= Germanistische Linguistik. 5-6/81). 
Sandig, B. (Hg.) (1988): Stilistisch-rhetorische Diskursanalyse. Tübingen. (= Forum Angewandte Linguistik. 14).

Sandig, B. (Hg.) (1994): EUROPHRAS 92. Tendenzen der Phraseologieforschung. Bochum.

Sandig, B./Püschel, U. (Hg.) (1993): Stilistik III: Argumentationsstile. Hildesheim. (= Germanistische Linguistik. 112-113/1992).

Schmidt, C. (1988): 'Typisch weiblich - typisch männlich'. Geschlechtstypisches Kommunikationsverhalten in studentischen Kleingruppen. Tübingen.

Schlobinski, P./Kohl, G./Ludewigt, I. (1993): Jugendsprache. Fiktion und Wirklichkeit. Opladen/Wiesbaden.

Schröder, H. (Hg.) (1993): Fachtextpragmatik. Tübingen.

Schuldt, J. (1992): Den Patienten informieren. Beipackzettel von Medikamenten. Tübingen.

Schwitalla, J. (1988): Die vielen Sprachen der Jugendlichen. In: Gutenberg, N. (Hg.) (1988): Kann man Kommunikation lehren? Konzepte mündlicher Kommunikation und ihrer Vermittlung. Frankfurt a.M. S. 167-176.

Schwitalla, J. (1989): Sprachvariation und der Wechsel des Sprechers. Selbstdarstellung, Imagebewahrung und andere Funktionen bei Code-Switching in einer Frauengruppe. In: Pătzold, M./Lindemann, P. (Hg.) (1989): Kommunikationstagung 1989. Internationale Arbeitstagung in Wulkow 18.-20. April 1989. Berlin. S. 55-65. (= Linguistische Studien ZISW. Reihe A: Arbeitsberichte. Nr. 199).

Schwitalla, J. (1990): Sozialstilistische Unterschiede beim Umgang mit dem "positiven Image". Beobachtungen an zwei Frauengruppen. In: Iwasaki, E. (Hg.): Begegnung mit dem 'Fremden'. Akten des VII Internationalen Germanisten-Kongresses Tokyo 1990. Tübingen. Bd.4. S. 473-482.

Schwitalla, J. (in Vorb.): Kommunikative Stilistik von zwei Sozialwelten in Mannheim-Vogelstang. (= Schriften des Instituts für deutsche Sprache, Bd.4.4).

Schwitalla, J./Streeck, J. (1989): Subversive Interaktionen. Sprachliche Verfahren der sozialen Ausgrenzung in einer Jugendlichengruppe. In: Hinnenkamp/Selting (Hg.) (1989), S. 229-251.

Selting, M. (1986): Institutionelle Kommunikation: Stilwechsel als Mittel strategischer Interaktion. In: Linguistische Berichte 86, S. 28-48.

Selting, M. (1989): Konstitution und Veränderung von Sprechstilen als Kontextualisierungsverfahren: Die Rolle von Sprachvariation und Prosodie. In: Hinnenkamp/Selting (Hg.) (1989), S. 203-225.

Selting, M. (1990): Speech styles in conversation as an interactive achievement. In: Hickey, L. (Hg.) (1990); The Pragmatics of Style. London/New York. S. 106-132.

Selting, M. (1991): Prosodie im Gespräch. Aspekte einer interpretativen Phonologie der Konversation. Habilitationsschrift Oldenburg.

Simpson, P. (1993): Language Ideology and Point of View. London/New York. Skyum-Nielsen, P./Schröder, H. (Hg.) (1994): Rhetoric and Stylistics today. An International Anthology. Frankfurt/M. 
Slembek, E. (1983): Individuelle Identifikation und soziale Bewertung von Gesprächspartnern durch Sprechausdrucksmerkmale. In: Sandig (Hg.) (1983a), S. 199-222.

Slembek, E. (1993): Was dem einen sin Uhl, ist dem andern sin Nachtigall. Aspekte interkultureller Argumentation. In: Sandig/Püschel (Hg.) (1993), S. 113-125.

Soeffner, H.-G. (1986): Stil und Stilisierung. Punk oder die Überhöhung des Alltags. In: Gumbrecht/Pfeiffer (Hg.) (1986), S. 317-341.

Sowinski, B. (1979): Werbeanzeigen und Werbesendungen. München.

Sowinski, B. (1991): Stilistik. Stiltheorien und Stilanalysen. Stuttgart.

Spillner, B. (1982): Stilanalyse semiotisch komplexer Texte. Zum Verhältnis von sprachlicher und bildlicher Information in Werbeanzeigen. In: KODIKAS/Code - Ars Semeiotica 4/5, S. 91-106.

Spillner, B. (1987): Style and Register. In: Ammon, U./Dittmar, N./Mattheier, K. J. (Hg.) (1987): Sociolinguistics-Soziolinguistik. Ein internationales Handbuch zur Wissenschaft von Sprache und Gesellschaft. 1. Halbbd. Berlin/New York. S. 273-285.

Spillner, B. (Hg.) (1984): Methoden der Stilanalyse. Tübingen. ,

Steuble, A. (1986): Integrative Konversationsanalyse. Zum Zusammenhang von Sprache, nonverbaler Kommunikation und interaktiver Beziehung. Pfaffenweiler.

Stolt, B. (1978): Die Relevanz stilistischer Faktoren für die Übersetzung. In: Jahrbuch für Internationale Germanistik X, S. 34-54.

Stolt, B. (1984): Pragmatische Stilanalyse. In: Spillner (Hg.) (1984), S. 163173.

Stolt, B. (1988): Revisionen und Rückrevisionen des Luther-NT aus rhetorischstilistischer Sicht. In: Sandig (Hg.) (1988), S. 13-40.

Streeck, J. (1988): Seniorinnengelächter. In: Kotthoff (Hg.) (1988), S. 54-77.

Tannen, D. (1981): New York Jewish Conversational Style. In: International Journal of Social Language 30, S. 133-149.

Tannen, D. (1984): Conversational Style. Analyzing Talk Among Friends. Norwood, New Jersey.

Tannen, D. (1985): Cross-Cultural Communication. In: van Dijk (Hg.) (1985), S. 203-215.

Thieberger, R. (1983): Problematisierung des Begriffes „Text” als Anregung zu einer kritischen Ūberlegung. In: Sandig (Hg.) (1983), S. 49-59.

Thormann-Sekulski, B. (1990/91): Methoden und Methodenkritik in der Stilistik. In: Fix (Hg.) (1990/91), S. 105-124.

Uhmann, S. (1989): Interviewstil. Konversationelle Eigenschaften eines sozialwissenschaftlichen Erhebungsinstruments. In: Hinnenkamp/Selting (Hg.) (1989), S. 125-165.

Weinrich, L. (1992): Verbale und nonverbale Strategien in Fernsehgesprächen. Eine explorative Studie. Tübingen. 
Liebes Fränlein Nivea, cremen Sie cins im Süden mal richtigein. 
Text 2

\section{Frankfurfer Rundschau}

In Frankfurt am Main - Die meisten Leser - Die meisten Anzeigen

Text 3 aus: Die Zeit 19.7.91, S. 20

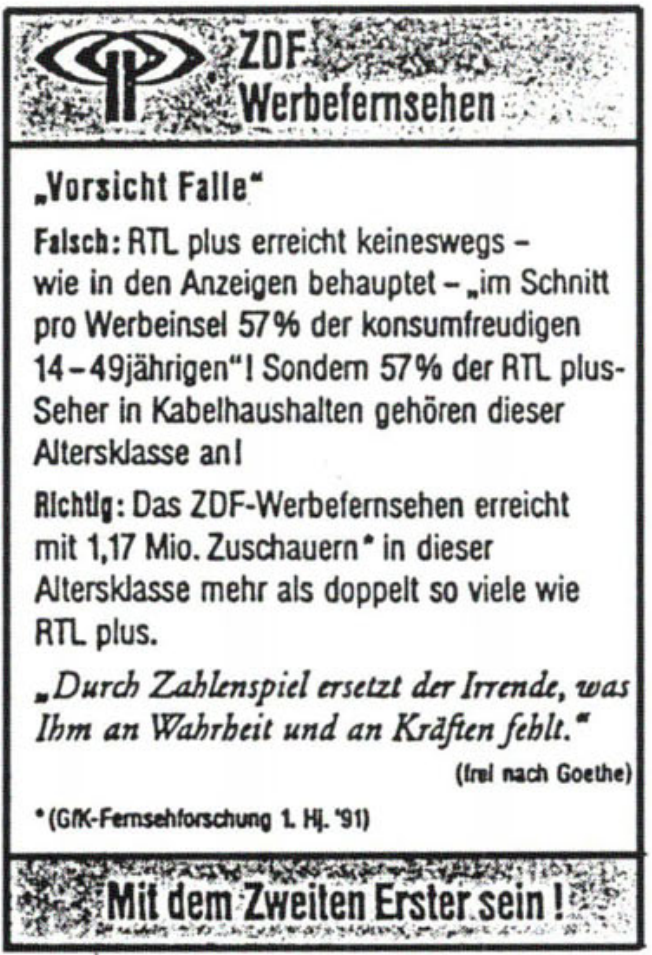




\section{BERND SPILLNER}

\section{Stilsemiotik}

0.1 'Stilistische Semiotik', 'semiotische Stilistik', 'Stil und Semiotik': wie immer man das Kompositum 'Stilsemiotik' interpretieren mag, es bleibt ein mehr als heikles Thema.

Über kaum eine Kategorie wird in der Sprachwissenschaft mehr gestritten als über den Terminus $S \mathrm{t}$ il Definitionsversuche und Theoreme gibt es viele, aber keine konsistente allseits akzeptierte Theorie. Hartnäckig halten sich alte, längst widerlegte Stilauffassungen. Außerdem läuft der Stilforscher regelmäBig Gefahr, satt zwischen zwei Stühle zu plumpsen.

Neben den Metallhocker einerseits der Hardcore-Linguisten, die Stil souverän ignorieren oder - wie ihre generativistische Subspecies - zum Abfallhaufen erklären, auf dem alle abweichenden Sätze einer Sprache landen, die der Algorithmus nicht erzeugt.

Andererseits neben den flauschigen Plüschsessel der literaturwissenschaftlichen Kollegen, die genüßlich konstatieren, daß das linguostilistische Analyseresultat ja längst nicht hinreiche zu dem, was man hermeneutisch und intuitiv $\mathrm{zu}$ interpretieren gedenke.

Steht es besser auf seiten der Semiotik? Mitnichten. Man muß nur einmal an einem Semiotiker-Kongreb teilgenommen haben, um sich ergriffen zu erinnern, dab dort alle über alles nach allen möglichen Kategorien disputieren.

Begriffsverwirrung steckt in der Stilistik, in der Semiotik herrscht das Chaos.

0.2 Dennoch gibt es gute Gründe dafür, $S$ tilis tik und $\mathrm{S}$ e $\mathrm{m}$ i o t i k aufeinander zu beziehen, sich in Stiltheorie und Stilanalyse zeichentheoretischer Kategorien $2 u$ bedienen. Es wird dabei nicht darum gehen, die Stilforschung in eine Meta-Wissenschaft - oder gar Mega-Wissenschaft - 'Semiotik' einzubringen. Im gegenwärtigen Stand der Theoriediskussion und Methodenerklärung ist davon ebensowenig Gewinn zu erwarten wie von Überlegungen, die Linguistik in einer 'Allgemeinen Semiologie' zu verankern. Es kann auch nicht darum gehen, das komplizierte terminologische Instrumentarium der Semiotik unbesehen und mehr als erforderlich in die Stilforschung zu übernehmen. 
Trotz aller Theoriediskussion ist die Stilistik schließlich eine anwendungsorientierte, eine praktische Disziplin. Es geht ihr um Textproduktion und Textanalyse.

Wie, d.h. mit welchen stilistischen Mitteln, lassen sich angemessene, wirkungsvolle, ästhetische Texte herstellen?

Wie lassen sich stilistisch relevante Textmerkmale isolieren, analysieren und in ihrer potentiellen - ggf. vom Textproduzenten intendierten - Stileinwirkung auf den Rezipienten beschreiben und interpretieren?

Beide Seiten - stilistische Textproduktion und stilistische Textanalyse - müssen prinzipiell lehr- und lernbar sein - im Sinne der $\tau \dot{\varepsilon} \chi \nu \eta$ der klassischen Rhetorik.

Bedarf an semiotischem Beschreibungsaufwand besteht dafür nur soweit unumgänglich.

Zwei wichtige - und ganz unterschiedliche - Gründe gibt es, Semiotik und Stilistik miteinander zu korrelieren.

Einmal könnte es nützlich sein, zur Lösung des stilistischen Theorie- und Konzeptionsstreites mit Argumenten aus der Semiotik beizutragen. Dabei geht es um die Frage einer semiotischen Fundierung oder Ergänzung der Stiltheorie, der Stilforschung, der Stilanalyse und vielleicht auch der präskriptiven Stilistik.

Zum anderen gibt es multimediale Texte, z.B. kommunikative Einheiten, in denen Sprache und Bild aufeinander bezogen sind - Texte also, die mit linguistischen Mitteln allein nicht zureichend beschrieben und nicht stilistisch analysiert werden können.

Hier geht es um die Frage, ob verbale und non-verbale Elemente auf einer semiotischen Ebene korrelieren und gemeinsam konsistent beschrieben werden können.

Folglich wird eine Untersuchung der Beziehungen zwischen Semiotik und Stilistik zwangsläufig aus zwei deutlich unterschiedlichen Teilen bestehen.

Im ersten geht es um Relevanz der Semiotik für die Theorie und Praxis, für die Produktion, Rezeption und Analyse von Stil schlechthin, von Stil in sprachlichen Texten.

Im zweiten Teil geht es um die semiotische Analyse von multimedialen Texten, um Stilsemiotik von zeichentheoretisch komplexen Texten. 
Nach einem kurzen Überblick über die Vielfalt möglicher Kommunikationsformen und Texttypen aus unterschiedlichen Zeichensystemen sollen aus dem unübersehbaren Problemkreis exemplarisch zwei engere Fragestellungen herausgegriffen werden und kurz illustriert werden:

- Wie lassen sich stilistisch unkonventionelle Sprache-Bild-Relationen in schriftlichen Texten semiotisch beschreiben?

- Gibt es stilistische Funktionen verbaler Elemente in non-verbalen Texten?

1. Im Jahre 1920 klagt Aronstein: 'Was ist Stil und was ist Stilistik? Die Worte sind sehr vieldeutig.' (Aronstein 1920, S. 251) 1987 gesteht Crystal in seiner 'Cambridge Encyclopedia of Language':

'Style is one of the thorniest concepts to be dealt in this encyclopedia.' (Crystal 1987, S. 66).

Dazwischen werden in Darstellungen zur Stilforschung immer wieder Sammlungen unterschiedlicher Stildefinitionen wiedergegeben.

Dazwischen wird auch immer wieder auf unzulängliche Stilkonzeptionen zurückgegriffen, die sich trotz theoretischer und methodischer Defizite oft hartnäckig halten.

Eine der am gründlichsten widerlegten Stilkonzeptionen ist die Abweichungsstilistik, die Stil als Deviation von einer prätextuellen Sprachnorm definiert. Sie scheint aber gegen alle Einwände resistent zu sein, jedenfalls dann, wenn sie zu grammatiktheoretischen Positionen paßt oder sich in die traditionelle Textinterpretation einfügt. Erstaunlicherweise hält sich die Abweichungskonzeption - in ihrer auf einem mißverstandenen 'Ornatus'-Begriff beruhenden rhetorischen Variante - gerade auch bei renommierten Semiotikern - von Roland Barthes bis Umberto Eco.

1.1 Einen ersten Schritt zur Klärung der vieldeutigen Worte 'Stil' und 'Stilistik' kann man gehen, wenn man sich klarmacht, dab mit den Termini ganz unterschiedliche Objektbereiche bezeichnet werden (vgl. Spillner 1987, S. 276): 


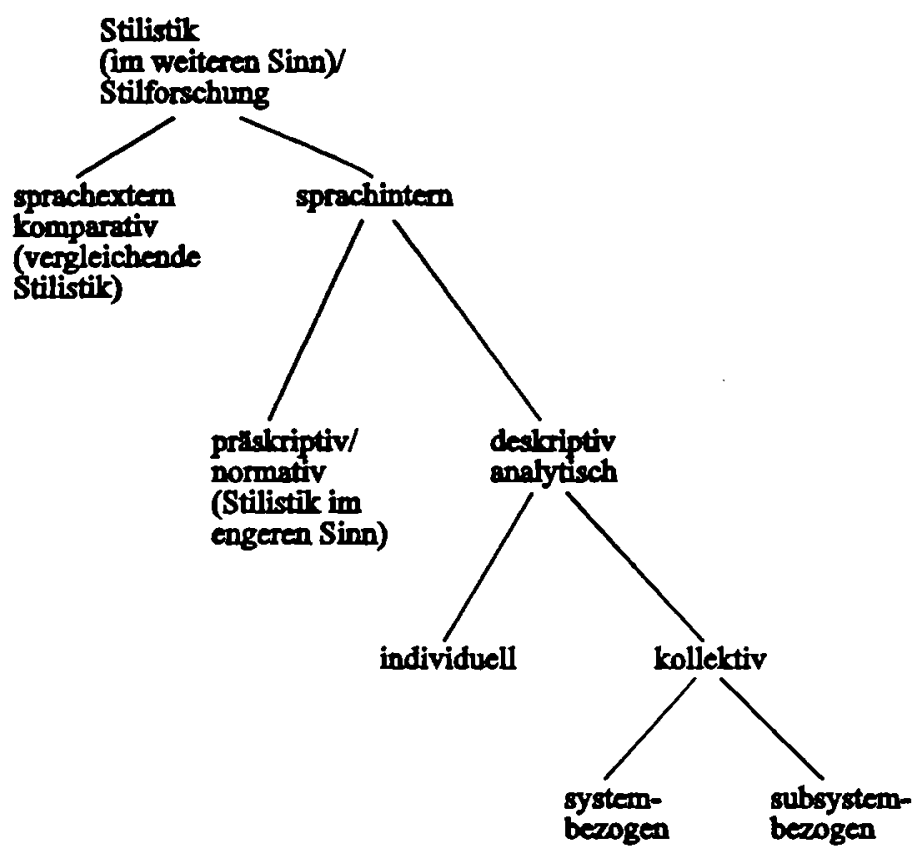

Um den stilorientierten Objektbereich zu differenzieren, kann zunächst die 'Vergleichende Stilistik' ausgegrenzt werden.

Sie versucht, durch systematische Komparation der grammatischen und lexikalischen Inventare zweier Sprachen die spezifischen Besonderheiten einer Sprache zu ermitteln (cf. Strohmeyer 1910; Vinay/Darbelnet 1958; Malblanc 1961).

Streng genommen, wird der Terminus 'Stilistik' für diesen Bereich irreführend verwendet. Die 'Vergleichende Stilistik' gehört in den Bereich der Sprachvergleichung bzw. der kontrastiven Linguistik, wobei der Vergleich eine Methode zur besseren Deskription einer Einzelsprache ist bzw. im Dienst der übersetzungswissenschaftlichen Theorie und Praxis steht.

Alle anderen Konzeptionen von Stilistik betreffen eine Einzelsprache bzw. Teilbereiche einer Einzelsprache. Nach ihrem Zweck lassen sich deskriptive, analytische von der präskriptiven, normativen Stilistik abgrenzen. 
Präskriptive Stilistiken gehen davon aus, daB stilistische Wirkungen an konkrete sprachliche Einheiten geknüpft sind und sich vorhersagen lassen. Sie stellen also als sprachliches Inventar auf 'langue'-Ebene sprachliche Ausdrucksmittel zusammen (Verben, nominale Ausdrucksweise, Funktionsverbgefüge, Parallelismus, Metapher, Passiv, Adverb, Apposition) und schreiben ihnen Stilwerte und Stilwirkungen zu. In der Regel sind sie didaktisch orientiert und lehren - ausgehend von einem Stilideal oder apriorischen Stiltugenden in der Tradition der Rhetorik (Klarheit, Kürze, Anschaulichkeit, Angemessenheit, Wechsel des Ausdrucks), wie man sich stilistisch gefällig und angemessen ausdrücken soll (z.B. Bally [1909] ${ }^{3}$ 1951; Marouzeau [1941] 1965; Riesel 1954, [1959] ${ }^{3}$ 1963, 1964; Faulseit/Kühn [1965] 41969; Crystal/Davy 1969; Gáldi 1971; Sumpf 1971; Sowinski 1973; Turner 1973).

Soweit die Stilistik deskriptiv angelegt ist, läBt sich unterscheiden, ob sie sich als Individualstilistik versteht oder von vornherein überindividuelle Stileigenschaften beschreiben will.

Die traditionelle Stilanalyse, vor allem dann, wenn sie literarische Texte untersucht hat, hat Stil überwiegend als Individualstil verstanden, der sich in Texten eines Schreibers/Sprechers manifestiert. Dabei interessiert allerdings nicht das textproduzierende Individuum. Es geht bei der Konzeption von 'Individualstil' vielmehr um die Tatsache, daß Stil auf der Gebrauchsebene der 'parole', in der 'Performanz', am konkreten Text, auf der Ebene des Diskurses analysiert wird:

„(...); die Stilistik hat es primär mit dem Gebrauch der sprachlichen Mittel seitens des Sprechers zu tun, nicht mit der systeminternen Semantik der sprachlichen Mittel einschließlich ihrer emotionalen Komponente." (Michel 1969, S. 275)

Im Gegensatz zur 'parole'-orientierten Individualstilistik gibt es jedoch auch Versuche, 'Stil' als kollektives Phänomen entweder auf der Ebene des Sprachsystems oder eines Subsystems anzusetzen.

Zum einen läßt sich Stil also auf der Ebene der 'langue', der 'Kompetenz', des Sprachsystems situieren. Auf solche Ansätze hatte Hatzfeld (1929, S. 66) bereits verwiesen:

"Eine ganz neue stilistische Disziplin dürfte die Sprachstilforschung an den Schriftsprachen bilden, deren Wesenszüge als Ausdrucksformen einer nationalen Kultur ähnlich jenen der Kunstsprachen festgestellt werden wollen."

Eine Situierung von Stil auf 'langue'-Ebene scheint auch bei einigen pragmatisch orientierten Konzeptionen vorzuliegen, die die 'Beschreibung von Stilistischem als Regelhaftem' (Sandig 1978, S. 19) intendie- 
ren. Diese scheinen - obwohl dies nicht immer deutlich wird - zumindest dann systemorientiert zu sein, wenn sie von Stilinventaren, konventionellen Stilmustern ausgehen oder sogar ein 'Stilsystem' intendieren:

„Der Versuch einer umfassenden Differenzierung einer Einzelsprache müfte es sich also zum Ziel setzen, ein Stilsystem dieser Sprache zu entwickeln." (Püschel 1976, S. 228)

Obwohl diese stilistischen Ansätze durchaus deskriptiv-analytisch angelegt sind, kommen sie in ihrer Stilkonzeption der systembezogenen präskriptiven Stilistik nahe.

Die meisten überindividuellen deskriptiven Stilistiken beziehen sich auf Subsysteme der Sprache. Hierher gehört einerseits die Konzeption, daß das Sprachsystem in eine begrenzte Anzahl von in sich relativ homogenen $F$ u $\mathbf{k} t$ i o n a l s t il e n gegliedert ist, die sich als sprachliche Subsysteme durch ihren Verwendungsbereich definieren.

Andererseits gehört zu diesem stilistischen Bereich die Annahme, daB innerhalb des Sprachsystems in sich geschlossene und je nach Kommunikationssituation auszuwählende $R$ e $g$ is $t$ e $r$ bereitgestellt werden (vgl. Spillner 1987, S. 282). Beiden Richtungen gemeinsam ist, daB mit stilistischen Beschreibungsmethoden mehr oder weniger wohlgeschiedene Subsysteme der Sprache differenziert werden können. Dabei werden Typen von Kommunikationssituationen Bündel von rekurrierenden Stilmerkmalen, Registern zugeordnet.

1.2 Eine Annäherung an eine linguistisch (und semiotisch) zu fundierende Stiltheorie ist am ehesten möglich, wenn eine natürliche Sprache nicht mit der Kategorie 'Homogenität' konzipiert wird, sondern mit dem Merkmal 'Varietät'. 'Stil' ist dann gebunden an die Existenz unterschiedlicher Ausdrucksmöglichkeiten.

Tatsächlich liegt eine solche Annahme - explizit oder implizit - den meisten linguistischen Stilkonzeptionen zugrunde, z.B.:

"Roughly speaking, two utterances in the same language which convey approximately the same information, but which are different in their linguistic structure, can be said to differ in style: 'He came soon' and 'He arrived prematurely'." (Hockett 1958, S. 556)

Dieser Einstieg in die Stilproblematik zeigt einerseits wichtige Definitionsmerkmale - grammatische Varietät bei semantischer Invarianz -, andererseits aber auch Vagheit der semantischen Beschreibung ('approximately the same information').

Es stellt sich die linguistisch heikle und umstrittene Frage nach der S y n o n y $\mathrm{m}$ i e. Ein Stilunterschied ist eine formale Varietät 
zweier oder mehrerer synonymer paraphrastischer ÄuBerungen. Wenn es gelänge, die semantische Analyse so zu verfeinern und zu differenzieren, daB jedweder sprachlichen Varietät eine je differente semantische Interpretation zugeordnet werden könnte, wäre eine eigenständige Kategorie 'Stil' überflüssig geworden; die Stilistik wäre in die Semantik integriert. Solange dies nicht geschehen ist, kann als 'Stil' diejenige Differenzierqualität alternativer AuBerungen angesetzt werden, denen die linguistische Semantik keine unterschiedlichen Bedeutungen zuordnet bzw. die von den Sprechern der Sprache nicht als bedeutungsdifferent aufgefaBt werden.

Tatsächlich beruhen auf diesen Grundannahmen eine ganze Reihe von Stildefinitionen, z.B.:

Die Stilistik ist

"(...) die Lehre von den synonymischen Ausdrucksmöglichkeiten im schriftlichen und mündlichen Verkehr (...) unter konkreten, gesellsch aftlich und individuell bedingten Umständen." (Riesel [1959] 1963, S. 40)

Wenn man in der Stilistik von synonymen bzw. quasi-synonymen Varietäten ausgeht, heißt dies für die Sprachproduktion, daß der Sprecher/Schreiber unter fakultativen Möglichkeiten des Sprachsystems eine Auswahl trifft.

Diese Auswahl kann bewußt oder unbewußt geschehen (vgl. Spillner 1974 , S. 45-49); sie ist auch nie völlig frei, sondern bis zu einem gewissen Grade durch gesellschaftliche Normen, sprachliche Regeln, stilistische Konventionen determiniert (vgl. u.a. Asmuth/Berg-Ehlers 1974, S. 28; Sandig 1978, S. 39-42).

Sprachliche Varietät, die semantisch nicht differenziert wird, Auswahlmöglichkeiten unter alternativen Varietäten des Sprachsystems sind also wichtige Komponenten für eine kohärente Stiltheorie.

1.3 Nach den getroffenen Abgrenzungen und Vorüberlegungen lassen sich nun einige Anforderungen an eine linguistisch fundierte Stiltheorie formulieren.

1.3.1 'Stil' muß für sprachliche Texte ohne Einschränkungen konzipiert werden und darf sich in einer Stiltheorie nicht auf spezifische Texttypen, Textsorten, Genera beschränken (z.B. auf literarische Texte).

Stil läßt sich an alltagssprachlichen, fachsprachlichen, literarischen Texten - gesprochen und geschrieben - analysieren. 
Diese Anforderung schließt die Annahme von 'Nulltexten', d.h. stilistisch unmarkierten Texten aus (cf. u.a. Barthes 1953).

1.3.2 Eine Stiltheorie muB 'Stil' prinzipiell auf allen Sprachebenen zulassen (phonetisch, syntaktisch, graphisch etc.).

Obwohl daher alle linguistischen Teilkomponenten gleichermaßen relevant sind, kommt der Semantik wegen der Bedeutungsäquivalenz konkurrierender Ausdrucksmöglichkeiten eine zentrale Rolle in jeder Stiltheorie zu.

1.3.3 Eine Stiltheorie muB kommunikativ konzipiert sein. Stil läßt sich dabei auffassen als Epiphänomen an Texten im KommunikationsprozeB. Diese Anforderung ist insbesondere in der pragmatischen Stilistik wiederholt konsequent formuliert worden, z.B.

„Unter 'pragmatischer' Stilanalyse wird im folgenden eine Stilanalyse verstanden, die den gesamten Kommunikationsprozeß berücksichtigt. Der Text, der den Untersuchungsgegenstand bildet, wird untersucht im Hinblick auf den Sender, den Empfänger, die Situation und die Senderabsicht." (Stolt 1984, S. 163)

Ähnlich werden diejenigen Fragen gestellt, auf die eine pragmatische Stilistik zu antworten hat:

„Wie kann Stilabsicht auf der Sprecherseite und Stilwirkung auf der Hörerseite beschrieben bzw. rekonstruiert werden? Welchen Einfluß haben Bedingungen der Kommunikation, der Handlungskontext, auf die Wahl und die Wirkung von stilistischen Texteigenschaften?" (Sandig 1984, S. 137)

Umso erstaunlicher ist, daß diese Anforderungen in landläufigen Stilkonzeptionen nicht oder nur teilweise erfüllt werden.

Selbst wenn man von einem sehr vereinfachten Kommunikationsmodell ausgeht, muB festgestellt werden, daß die meisten Stilkonzeptionen nicht einmal die rudimentären Komponenten eines Kommunikationsmodells (wie Sender, Text, Empfänger) berücksichtigen.

1.3.4 Aus dem zuvor getroffenen Befund ergibt sich, daB eine Stiltheorie integrativ sein muB. Sie sollte alle konstitutiven Komponenten des Kommunikationsprozesses berücksichtigen und miteinander korrelieren. Ein Definitonsversuch von 'Stil', der diese Komponenten berücksichtigt, kann etwa wie folgt lauten: Stil wird aufgefaBt als das Resultat aus der Auswahl des Sprechers/Schreibers aus den konkurrierenden Möglichkeiten des Sprachsystems und der Rekonstituierung durch den textrezipierenden Hörer/Leser. Stileffekte ergeben sich erst im dialektischen Wech- 
selspiel zwischen den im Text kodierten Folgen der durch den Autor getroffenen Auswahl und der Reaktion durch den Leser. Stil ist eine Erscheinung an Texten, die im Kommunikationsprozeß konstituiert wird. Daher ist Stil keine statische Eigenschaft eines Textes, sondern eine virtuelle Qualität, die im Rezeptionsvorgang rekonstruiert werden muß. Am Text erkennbar sind nur die Folgen der einmal erfolgten Auswahl und die Voraussetzungen für die durch die Rezipientenerwartung determinierte Reaktion des Lesers/Hörers.

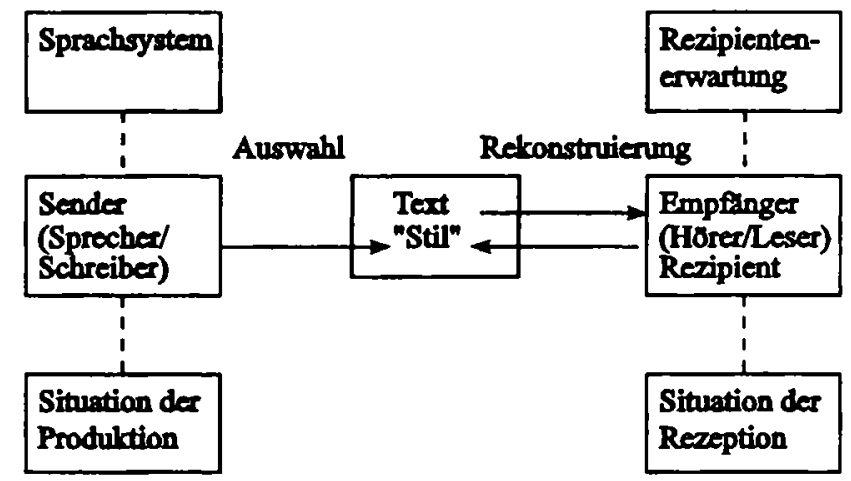

(vgl. dazu Spillner 1974)

Es wird dabei von der Auffassung ausgegangen, daß das Phänomen 'Stil' nicht losgelöst von den Kategorien 'Autor des Textes' und 'Rezipient des Textes' definiert werden kann. Gewiß kommt Stil nur zustande, wenn im Text formal beschreibbare (syntaktische, lexikalische etc.) Merkmale enthalten sind, die Stileffekte auslösen können. Wichtig aber ist, daß diese Merkmale auf eine - bewußte oder unbewußte - Auswahl des Autors unter den ihm zur Verfügung stehenden sprachlichen Realisierungsmöglichkeiten zurückgehen und dab man der gewählten Sprachform im Vergleich zu anderen Möglichkeiten gegebenenfalls eine Hypothese über die stilistische Absicht des Autors zuordnen kann. Wichtig ist ebenso, daB ein virtuelles Textmerkmal nur dann Stilqualität erlangen kann, wenn es im Rezeptionsvorgang vom Leser/Hörer bemerkt und durch seine Reaktion aktualisiert wird.

1.3.5 Vor dem Hintergrund der skizzierten kommunikativ-stilistischen Konzeption läBt sich als weitere Anforderung ableiten, daß eine Stiltheorie die Kategorie 'Stil' als dynamisch auffassen sollte. Stil ist nicht 
als statisch, ein für allemal invariabel im Text kodiert zu konzipieren, sondern als historisch veränderlich und in jedem Rezeptionsprozeß prinzipiell je anders rekonstruierbar. Dabei ist auch mit der Möglichkeit zu rechnen, daB virtuelle Stilelemente bei der Rezeption nicht rekonstruiert werden.

1.3.6 Eine Stiltheorie sollte potentiell stilistische Textelemente nie eindeutig festen Stilwirkungen zuordnen, sondern wegen der Kontextualität, der situativ-kommunikativen Einbettung und der prinzipiell möglichen Individualität der stilistischen Rezeption und Rekonstruktion von der Polyvalenz der stilistischen Merkmale ausgehen.

1.3.7 Eine Stiltheorie sollte auch auf nicht rein sprachliche Texte applikabel sein. Fachtexte enthalten beispielsweise sehr häufig non-verbale Textelemente (Abbildungen, Skizzen, Tabellen, numerische Formeln etc.). Hinzu kommen sehr unterschiedliche multimediale Textsorten (Comics, Artikel in Illustrierten, Werbeanzeigen, Opernarien, Hörspiele usw.). Stileffekte ergeben sich oft erst im Zusammenspiel verschiedener Zeichensysteme. Eine Stiltheorie muB für ihre Analyse leistungsfähig sein.

1.3.8 Eine Stiltheorie sollte nach Möglichkeit semiotisch sein, um die Zeichenhaftigkeit des Textes und der potentiell stilistischen Textmerkmale zu erfassen und den 'Hinweisakt' (Eco 1987, S. 215) eines Zeichens für den Textrezipienten analysieren zu können.

Die oben skizzierte Stilkonzeption läßt sich beispielsweise problemlos semiotisch interpretieren.

2. Unter den in der Semiotik traditionell unterschiedenen Zeichenrelationen

Zeichen - Zeichen (Syntaktik)

Zeichen - Denotat (Semantik)

Zeichen - Benutzer (Pragmatik)

ist unter stilsemiotischen Gesichtspunkten die Zeichen-Benutzer-Relation besonders relevant. Unter kommunikativen Aspekten sind als 'Benutzer' grundsätzlich der Zeichenproduzent (Sender, Textautor, Sprecher/Schreiber) und der Zeichenrezipient (Empfänger, Textrezipient, Hörer/Leser) zu unterscheiden. Intermediäre Textbenutzer (z.B. Drucker, Verleger, Übersetzer, Vorleser, Kopist, Herausgeber) können in diesem Zusammenhang auBer acht bleiben. 
2.1 Die Relation zwischen Zeichen und Zeichenproduzenten ist implizit in der Auswahlstilistik enthalten und relativ gut elaboriert (vgl. u.a. Spillner 1974, S. 45ff.). Es wird dabei eine stilistische Intention des Textautors bei der - bewuBten oder unbewuBten - Wahl unter unterschiedlichen Ausdrucksmöglichkeiten des Sprachsystems postuliert.

Um Hypothesen über mögliche Stilintentionen zu gewinnen, sind für die Stilanalyse u.a. folgende stilsemiotische Methoden vorgeschlagen worden (vgl. dazu: Spillner 1974, S. 80f. u. S. 86ff.):

- der Variantenvergleich (Vergleich unterschiedlicher Textfassungen, insbesondere bei literarischen Texten, aber auch bei korrigierten handschriftlichen Textänderungen; wobei ggf. aus Textkorrekturen auf stilistische Absichten geschlossen werden kann),

- die Rekonstruktion der Autorenintention (insbesondere bei literarischen Texten kann versucht werden, aus Tagebuchaufzeichnungen oder anderen autobiographischen Zeugnissen Rückschlüsse auf Stilabsichten im Hinblick auf den intendierten Leser zu gewinnen)

- die Produktion der alternativen Möglichkeiten des Sprachsystems und ihr Stilvergleich (zu einem Textfragment werden Paraphrasen konstruiert, wobei Zeitpunkt der Textabfassung, Textsorte, Textthematik, Sprachkonventionen, ggf. literarische Strömungen, Epochenstil, zeitgenössische Poetik zu berücksichtigen sind).

Die Wahl des Textautors läßt sich spezifischen Äußerungsabsichten, Stilebenen, Metaphernbereichen etc. zuordnen und zeichentheoretisch als Verstehenshinweis, als Handlungsangebot an den Rezipienten interpretieren.

So wird z.B. in einer Restaurantkritik die Beschreibung des Speiseraums, des Speiseangebotes und der Bedienung durch lexikalische Wahl mit einer nicht zu erwartenden Metaphernkette korreliert:

Giuseppe Verdi

In geschmackvollem Farbenakkord eingerichtet, dunkles Holz und rote Decke und weiße Gardinen, weiße Rauhputzwände - dazu üppiger Blumenschmuck in zarten Tönen- wir sind wahrhaftig bei Meister Verdi (und nicht bei der Gianna Nannini der Pizzabäcker). Und Adriano bedient ebenso sanft wie ein Klarinettensolo in Adagio... Da aber läßt Pasquale Messere aus der Küche Fanfarenstöße hören: sehr gute Gānsestopfleber an Romandorlo-Sauce, und gleich darauf marschieren bißfeste Lasagne mit sehr gut pariertem Kalbsbries. Piano: zauberhafte Zucchiniblüte gefüllt mit Lachs und Steinbutt (fest und gut), dazu kontrapunktisch eine fast schrille Safran/Schnittlauch-Sauce (nicht jedermanns Geschmack). Pause: Maculan, Lungarotti oder doch den schönen Pinot grigio aus Friaul? 
Auftakt adagio im zweiten Akt mit harmonischem Salat von warmen Scampi auf Löwenzahn, Fenchel und grünem Spargel. Herzhafte Kaninchen mit reichlich, überreichlich Rosmarin - Triumphmarsch mit Trompeten.

Warum nur muß das italienische Dessert-Finale fast immer so einfallslosenttäuschend sein, daß man sich statt dessen noch einmal an der Ouvertüre laben möchte? (Gault Millau. Guide Deutschland 1993, S. 183)

Ausgehend vom Namen des Restaurants werden - wo immer es bei der Textthematik möglich ist - Lexeme aus dem Bereich Musik, Oper gewählt. Hinzu kommen textuell ambige Lexeme, die sowohl Musikaufführung wie Küchenprodukte charakterisieren können: geschmackvoll, zauberhaft, harmonisch, warm, marschieren (Terminus der Küchenfachsprache).

Hinzu kommt eine hochfrequente Wahl italienischer Lexeme und Eigennamen. Diese Wahl des Autors kann semantisch als Isotopie oder stilistisch als Metaphernfiliation beschrieben werden. Stilsemiotisch läßt sie sich als Verstehenssupplement, als Handlungshinweis an den Leser interpretieren:

Verstehe die Restaurantbeschreibung wie eine Musikkritik, assoziiere synästhetisch Empfindungen des Gaumens und der Ohren, stell dir einen Aufenthalt in diesem Restaurant wie das Erleben einer italienischen Opernaufführung vor.

Selbstverständlich besagt eine solche Hypothese über die Intention des Textproduzenten nicht, daB das kodierte Verstehenssupplement vom Textrezipienten tatsächlich angenommen wird. Mit anderen Worten: es ist durchaus möglich, daß der semiotische Hinweisakt vom Leser im Lektürevorgang nicht bemerkt, nicht verstanden wird.

Daraus folgt aber nur, daß bei der Stilanalyse Textproduktion und Textrezeption nicht isoliert werden dürfen.

Selbstverständlich läßt sich aus einem semiotischen Verstehenssupplement nicht mit Sicherheit schließen, daß der Hinweisakt intendiert war.

Als Beispiel kann ein Stilkontrast dienen, der im Zeitungsbericht über den Tod eines amerikanischen Dichters auftaucht:

"Charles Bukowski (73, 'Barfly') - der rüde Huren- \& Gossen-Poet ist entschlafen. Es war 13.59 Uhr, Mittwoch nachmittag im weißen Einzelzimmer des Peninsula-Hospital von L.A., als sich sein ausgemergelter Körper noch einmal aufbāumte. Sein Herz zuckte. Dann war alles vorbei, im Zimmer 380 ...." (Bild 11/3/94, S.8) 
Der aus der syntaktischen Kombination zweier unterschiedlicher Stilebenen (rüde, Hure, Gosse vs. entschlafen) entstehende Stilkontrast kann als intendierter Verstehenshinweis interpretiert werden: Widersprüchlichkeit im Leben des Dichters, sanfter Tod nach wildem Leben, oder ähnlich. Die ungewöhnliche lexikalische Wahl (entschlafen statt tot, abgekratzt etc.) kann jedoch auch zufällig sein. Die Quelle des Beispiels und der Kontext könnten auch an Unsicherheit im Umgang mit Stilinventaren der Autoren (am Bericht haben gleich zwei Journalisten gewerkelt) denken lassen.

Hieraus folgt, daß der Leser darüber entscheidet, ob ein Stileffekt vorliegt oder nicht und ob der Effekt als subtiler Hinweis oder Stilfehler zu deuten ist.

2.2 Die Relation zwischen Zeichen und Zeichenrezipienten ist in der Stilforschung stark vernachlässigt. Immerhin ist es das Verdienst von Michael Riffaterre (1971), diese Relation in die literarische Stilistik eingebracht zu haben. Allerdings ist hier der Status des 'Lesers' unzureichend geklärt, die Methodik der Analyse erst in Ansätzen entwickelt und die Textproduktionsseite ausgeblendet (vgl. zur Kritik Spillner 1974, S. 50-56).

Die Stilsemiotik hat davon auszugehen, daß durch Stilphänomene in Texten über die Textsemantik hinausgehende Verstehenssupplemente an den Textrezipienten übermittelt werden können. Für den Leser/Hörer sind potentielle Stilelemente zeichenhafte Hinweise dafür, wie ein Text zusätzlich zur semantischen Bedeutung, möglicherweise aber auch entgegen der semantischen Bedeutung verstanden werden kann. So kann in literarischen Texten z.B. der Reim Handlungshinweis an den Leser sein, zwischen den sich reimenden Lexemen begriffliche Verknüpfungen herzustellen. Selbstverständlich haben längst nicht alle Reime phonostilistische, stilsemiotische Funktion. Sie haben formale Aufgaben (z.B. Strophenbildung) und gehorchen poetischen $\mathrm{Zwängen,} \mathrm{insofern} \mathrm{erfüllen}$ sie nur ein schwaches Angebot an Verstehenssupplement. Daher wäre es töricht, Beziehungen zwischen ad hoc-Reimen zu suchen, wie in dem bekannten Extremfall: „Jeder weiß, was so ein Maikäfer für ein Vogel sei.” (Wilhelm Busch). Es besteht aber immerhin die Möglichkeit, jenseits von paradigmatischen und syntagmatischen Relationen durch Reim assoziative/konnotative Beziehungen zwischen ansonsten beziehungslosen Textsegmenten herzustellen. Erstaunlicherweise gilt dies gerade für triviale, konventionelle Reime, die - einmal bekannt - von Poeten peinlich gemieden werden, z.B.: 
$\begin{array}{lll}\ldots \text { Herz } & - & \ldots \text { Schmerz } \\ \ldots \text { Morgenrot } & -\end{array}$

Unter spezifischen semantischen/thematischen Voraussetzungen lassen sich Reime als Verstehenshinweis an den Leser/Hörer verwenden, die Reimlexeme assoziativ in Beziehung zu setzen. Solche Reimpaare können innerhalb einer Kultur topisch werden und gelten dann poetisch als trivial.

Die Beispiele zeigen auch, wie unterschiedlich die Stilrekonstruktion im LektüreprozeB je nach Leseerfahrung sein kann. Wer zum ersten Male den Reim 'Herz-Schmerz' liest, mag ihn für einen genialen, kreativen Stileffekt halten. Wer den Reim wiederholt in unterschiedlichen Texten lesen mußte, wird ihn für konventionell, einfallslos, unzumutbar einstufen.

2.2.1 Bei der Analyse stilsemiotischer Verstehenssignale an den Leser/Hörer ist zu beachten, daß sie erkannt/verstanden werden können oder auch nicht.

Dies kann z.B. bei komplizierten syntaktischen Strukturen und stilsemiotischen Ironiesignalen leicht der Fall sein:

..., eine gute Kinderstube. An dieser hatte es mir nicht gefehlt, denn ich stamme aus feinbürgerlichem, wenn auch liederlichen Hause; mehrere Monate lang standen meine Schwester Olympia und ich unter der Obhut eines Fräuleins aus Vevey, das dann freilich, da sich ein Verhältnis weiblicher Rivalität $z$ wischen ihr und meiner Mutter - und zwar in Beziehung auf meinen Vater - gebildet hatte, das Feld räumen muBte; mein Pate Schimmelpreester, mit dem ich auf sehr innigem Fuße stand, war ein vielfach geschātzter Künstler, den jedermann im Städtchen 'Herr Professor' nannte, obgleich ihm dieser schōne, begehrenswerte Titel von Amts wegen vielleicht nicht einmal zukam; und mein Vater, wiewohl dick und fett, besab viel persönliche Grazie und legte stets Gewicht auf eine gewählte und durchsichtige Ausdrucksweise." (Thomas Mann)

Wer die vierfache Konstruktion aus Hauptsatz und konzessivem Nebensatz nicht bemerkt, wird auch die vierfache Opposition aus positiven Aussagen und relativierendem Gegenteil nicht wahrnehmen. Wer den Stilkontrast durch den syntaktischen Wechsel ( e r s t Konzessivsatz, d a n n Hauptsatz) in der letzten Konstruktion nicht erkennt, dem wird die argumentative Umkehrung in der Beschreibung der letzten Person nicht auffallen. Wer die euphemistischen Paraphrasen (z.B. ein Verhältnis weiblicher Rivalität ... in Beziehung auf meinen Vater, von Amts wegen vielleicht nicht einmal, eine gewählte und durchsichtige Ausdrucksweise) nicht als Understatements einschätzt, wird nicht auf die Ironie des Textes schlieben. 
2.2.2 Stilsemiotische Verstehenshinweise können - wie die meisten Zeichen - ambig/polyvalent sein.

Das non-verbale Zeichen 'Blinken links beim Kraftfahrzeug' kann mindestens drei verschiedene Hinweisakte haben:

- ich (Fahrer) will gleich nach links ausscheren,

- ich (Fahrer) will links abbiegen,

- Hinweis an nachfolgendes Fahrzeug: nicht überholen, weil Gegenverkehr.

Ebenso können stilistische Figuren (Metapher, Parallelismus, Litotes etc.) sehr unterschiedlichen Verstehenshinweisen entsprechen.

2.2.3 Die Intention stilsemiotischer Verstehenshinweise kann interkulturell different (d.h. einzelsprachlich unterschiedlich kodiert) und historischem Wandel unterworfen sein. Ein klassisches Beispiel für interlingualen/interkulturellen Kontrast ist die unterschiedliche Kombination von Kopfnicken/Kopfschütteln mit Affirmations- bzw. Negationshandlungen (ja/nein). Im rein sprachlichen Bereich hat etwa der syntaktische Parallelismus unterschiedliche stilistische Funktionen in der hebräischen Prosa (z.B. Stil des Alten Testamentes), der karelischen Volksdichtung, in der deutschen Anzeigenwerbung und in der französischen Rechts- und Verwaltungsfachsprache.

Historisch gesehen ändern sich Metaphernspender, Ironiesignale, Epitheta (Attribut, Kompositionselement, Partizipialkonstruktion, Apposition, Relativsatz) usw.

2.2.4 Das Erkennen von stilsemiotischen Verstehenshinweisen kann interkulturell und historisch unterschiedlich sein. Graphostilistische Zeichenkomplexe sind selbstverständlich je nach Schriftsystem unterschiedlich. Die stilistischen Möglichkeiten zur Hervorhebung sind je nach Syntax und Prosodie schon bei den einzelnen europäischen Sprachen sehr unterschiedlich und werden entsprechend unterschiedlich wahrgenommen.

Insbesondere scheint historisch - je nach Hör- und Lesegewohnheiten, je nach Medien - ein großer Unterschied in der Wahrnehmung von stilistischen Textphänomenen möglich zu sein. Es ist z.B. erstaunlich, welche Textmerkmale an der - mündlich (z.T. gesungen) vorgetragenen spätmittelalterlichen Lyrik ein literarisch gebildetes Publikum offenbar wahrgenommen hat: 
Sumer, nû wil dîn gewalt

walt den anger und die heide

beide kleiden: dast dien kleinen vogeln $\mathrm{n}$ ô $\mathrm{t}$.

man siht bluomen manicvalt,

valt an manger stolzen meide:

reide löcke tragents unde mündel $r$ ô $t$.

seht, der fröide was vil nâch zergangen.

ach mîs herzen! jâ muoz mich belangen

nâch dem triutelehten lîbe. owê wan waere er mîn!

Wil si daz mich leit verber

ber mir fröide von ir munde.

wunde von der minne wirt vil schiere $\mathrm{h}$ e il.

daz ir güete mich gewer,

wer ist der mir des verbunde?

kunde ich fuochen, dem wunscht ich daz im un h e il

waere bî vil lange unz an sîn ende.

süeziu Minne, süeze helfe sende.

des ist nôt, sît ich von dînen schulden sorge ie leit.

Ach wie ist si gar liep guot.

guot maem ich niht für diech meine.

seine troestet mich, daz ist der Minne $h$ a $z$,

ir munt roeter dann ein bluot.

bluot des meien fröit mich kleine.

reine saelic wîp, nu troestet mich noch b a z.

tuot irs niht, sô muoz ich gar verderben.

sol ich niht den rôten kus erwerben

und den triutelehten lîp, sô wirde ich fröiden bar.

(...)

(Götfrit von Nifen, $130 \mathrm{C}-132 \mathrm{C}$ )

Es ist davon auszugehen, daß die Zuhörer die komplizierten Reimbeziehungen (durch Unterstreichung, Sperrung, Kursiv- und Fettdruck markiert), Schlagreim, Waise, Assonanzen, Alliterationen und Responsionen (z.T. über gröbere Textabstände hinweg) erkannt und stilistisch eingeschätzt haben.

Mit unterschiedlichen Rezeptionsgewohnheiten ist bei jeder Stilanalyse älterer Texte zu rechnen.

3. Semiotische Ansätze in der Stilforschung sind nicht neu. In manchen Fällen wird damit allerdings lediglich ein modisches Schlagwort in die Stildiskussion eingebracht (Busse 1964, Thoma 1976, Klinkenberg 1985). Meist handelt es sich um Versuche einer literarischen Semiotik, denen Sandig (1978, S. 57 und 1986, S. 331f.) zu Recht vorwirft, daB sie 
dem Ziel, Stil als Eigenschaft sprachlicher Handlungsarten zu beschreiben, nicht gerecht werden. Eine Analyse der semiotischen Einheiten, die 'semantically redundant, but stylistically necessary' (Hess-Lüttich 1982, S. 7) sind, wird hier nicht geleistet.

Eine kohärente semiotisch fundierte Stiltheorie und Stilanalyse bleibt bislang Desiderat.

Um Argumente für eine Stilsemiotik zu gewinnen und Möglichkeiten für die praktische Stilanalyse zu zeigen, sollen exemplarisch einige Möglichkeiten für stilsemiotisches Verstehenssupplement demonstriert werden zunächst an rein verbalen Texten. Dafür werden als Beispiele graphostilistische und phonostilistische Stilmerkmale gewählt (vgl. zum folgenden Pfeiffer-Rupp 1984 und Spillner 1984). Sie haben den Vorteil, daB sie zunächst einmal nicht semantisch relevant sind und sich daher das semiotische Verstehenssupplement gut demonstrieren läBt. Sie haben den Nachteil, daB sie stilistisch nur mit methodischen Vorbehalten analysierbar sind und daB sie in der literaturwissenschaftlichen Stilanalyse oft unmethodisch über- und fehlinterpretiert worden sind.

3.1 Im graphostilistischen Bereich gibt es zunächst einmal die (auch hier interlingual unterschiedlich genutzte) Möglichkeit der Hervorhebung durch Fettdruck, Sperrung, Kursivdruck etc. Die semantischen Folgen solcher typographischer Mittel werden üblicherweise in der Linguistik nicht beschrieben. Hinzu kommen vielfältige stilistische Möglichkeiten, z.B. der Gebrauch der Anführungszeichen als Ironiesignal (selbstverständlich können die Anführungszeichen auch andere kommunikative Funktionen haben). Es ergibt sich dadurch stilsemiotisch der Verstehenshinweis: nimm das Lexem in Anführungszeichen nicht ernst, nicht wörtlich, interpretiere es ironisch!

Interessanterweise werden die Anführungszeichen des geschriebenen Textes seit einigen Jahren in den mündlichen Diskurs transponiert, indem der Sprecher beide Hände hebt und mit Zeige- und Mittelfinger 'Anführungszeichen' in die Luft 'malt'. Obwohl die gesprochene Sprache über eigene stilsemiotische Ironiesignale verfügt, zeigt sich hier eine auffallige kommunikative Interferenz zwischen Schriftlichkeit und Mündlichkeit.

Graphostilistisch sind auch die Versuche, Eigenschaften eines verbal beschriebenen Gegenstandes sekundär typographisch expressiv abzubilden: 


\section{Det einzig sichere Weg zur schlanken LInle: Wenlger essen! Deshalb: Aul die}

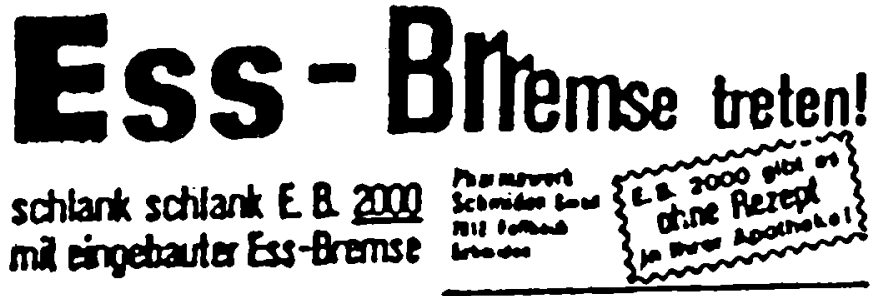

Ein solches typographisches, stilsemiotisches Verstehenssupplement wird - oft in Verbindung mit Farbwirkungen - häufig in Werbeanzeigen genutzt (zur Detailanalyse ähnlicher Beispiele siehe Spillner 1982, S. 9294).

Auch literarisch werden graphostilistische Mittel genutzt, um Textaussagen zusätzlich, also als Verstehenssupplement an den Leser, auszudrücken. Ein berühmtes Beispiel ist die Darstellung einer Flasche von Rabelais (Manuskript, alter Druck, moderne Leseausgabe): 

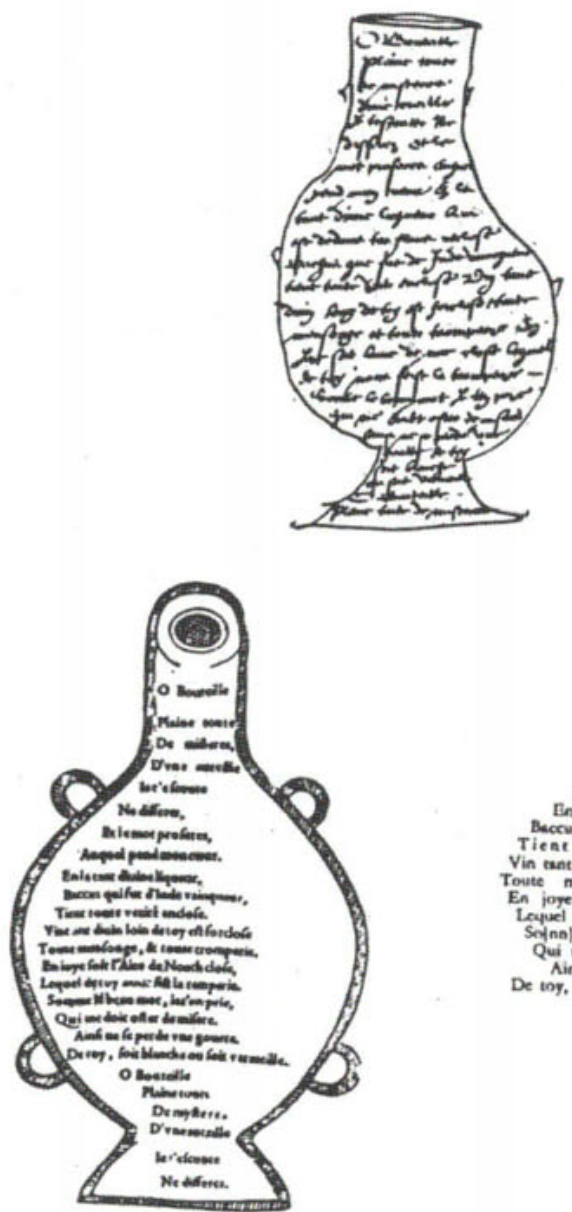

$$
\begin{aligned}
& \text { O Bouteille } \\
& \text { Pleine toute } \\
& \text { De misteres, } \\
& \text { D'une aureille } \\
& \text { Je rescoute : } \\
& \text { Ne differes. }
\end{aligned}
$$

bi le ans proferes

Avquel pend t move corut.

In la tant divine byueue,

Beccus, qui fut d'lade vainqueur'?

Yint teute veritt enclose.

Toute ant divin, loin de toy eat forclose

Toute menannge et toute trnmperic.

En joge soit Taire de Niach"' chase.

Leyuel de toy mou fist to temperiets.

Selnaje' le beau mot, je ten prik.

Qui $m e$ doibe coter de miactes.

Ainsi ne $x$ perde une goutte.

De toy, snit blanche, ow soit vermeille.

$O$ Boureille

Pleine touse

De mysteres

D'une aureille

le teacoute

Ne dificres.

Erstaunlicherweise werden aber solche graphostilistischen Ausdrucksmittel in der 'schönen Literatur' nur in sehr geringem Maße genutzt - auf jeden Fall im Vergleich zu Werbetexten, Fachtexten etc.

Die modernen Gestaltungsmöglichkeiten mit dem Computer, auch unter Rückgriff auf CD-Rom-gespeicherte Graphik, ermöglichen eine Vielfalt 
graphostilistischer Expressivität. Sie wird in Computergraphik und im Layout von Werbezetteln genutzt, kaum jedoch in gängigen literarischen Texten.

Ausnahmen bestätigen die Regel:

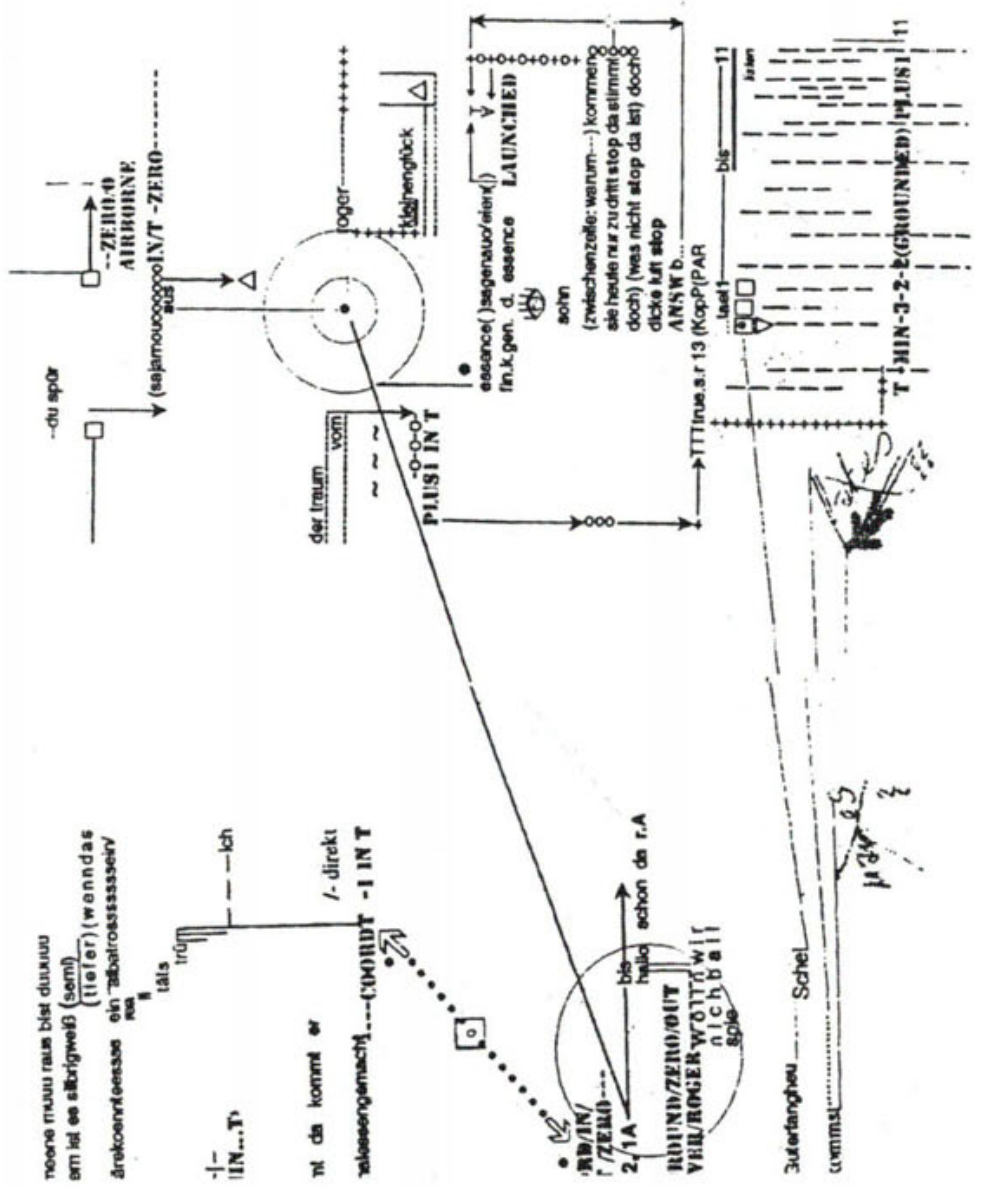

(Michael Sokolowski. In: Van Goghs Ohr. Literarische Zeitschrift no.6 (1993) S. 10f.) 
Die Nutzung typographischer Mittel, die Mischung verbaler und nonverbaler Codes, die Raumaufteilung, die Interferenz von Phonie und Graphie, die Mischung von sprachlicher Sequenzierung und Espacierung sind eine Herausforderung an die literaturwissenschaftliche Textinterpretation. Sie kommt nicht ohne stilsemiotische Analyse aus.

3.2 Phonostilistische Textelemente können - über die bereits erwähnten Reimassoziationen hinaus - in einigen Fällen durch Lautimitation und Lautexpressivität semiotische Verstehenshinweise erbringen:

„Nun hebt sich der Schenkel, nun wackelt das Bein, Gebärden da gibt es vertrackte;

Dann klippert's und klappert's mitunter hinein, Als schlüg' man die Hölzlein zum Takte.

Nur einer, der trippelt und stolpert zuletzt

Und tappet und grapst an den Grüften;

$(\ldots): n$

(Goethe, Der Totentanz)

Als stilsemiotischen Hinweis an den Leser könnte man etwa ableiten:

Assoziiere durch Rhythmus, Metrum, Lautmalerei geräuschvolle Tanzbewegungen. Sofort ergibt sich jedoch die Problematik der Zirkularität:

Der Leser weiß durch Thematik und semantische Beschreibung ohnehin schon, daß sich in Goethes Gedicht 'Der Totentanz' Skelette auf dem Kirchhof hüpfend bewegen.

Immerhin kann die semantische Aussage durch Assonanzen und Alliterationen, durch onomatopoetische Lexeme, durch Rhythmus und Metrum in begrenztem Maße phonostilistisch unterstützt werden, also ein Verstehenssupplement bereitstellen.

Dies wird deutlich, wenn mit wechselndem Thema schlagartig auch die Vokalqualitäten gewechselt werden. Ein schönes Beispiel dafür ist Goethes Hochzeitslied; auch hier geht es zunächst um Tanz und dann um Ballgeflüster:

"So rennet nun alles in vollem Galopp

Und kürt sich im Saale sein Plätzchen.

Zum Drehen und Walzen und lustigem Hopp

Erkieset sich jeder ein Schätzchen.

Da pfeift es und geigt es und klinget und klirrt,

Da ringelt's und schleift es und rauschet und schwirrt; (...)." 
Als dann das beginnende Hochzeitsmahl mit Tischerücken thematisiert wird, ändert sich auch das stilsemiotische Zeicheninventar, ändert sich das Angebot an phonostilistischem Verstehenssupplement:

„Nun dappelt's und rappelt's und klappert's im Saal

Von Bänken und Stühlen und Tischen,

Da will nun ein jeder am festlichen Mahl

Sich neben dem Liebchen erfrischen; (...)."

Für die Phonostilistik gibt es in der Stilanalyse strenge Voraussetzungen und Grenzen:

- die Analyse muß streng auf Lautebene geschehen,

- bei geschriebenen Texten setzt eine Stilwirkung mindestens die Artikulation mit 'innerer Stimme' voraus,

- bei der Textproduktion sind aufgrund lexikalischer Wahl und grammatischer $\mathbf{Z w a ̈ n g e ~ d i e ~ p h o n o s t i l i s t i s c h e n ~ W a h l m o ̈ g l i c h k e i t e n ~ e n g ~ b e - ~}$ grenzt,

- bei Stilinterpretationen ist die Lautfrequenz zu berücksichtigen

- die Phonostilistik der Lautimitation ist auf wenige Fälle onomatopoetischer Lexeme begrenzt,

- die Phonostilistik der Lautexpressivität läBt sich psycholinguistisch nur für wenige Kategorien wie 'klein-groB', 'hell-dunkel', 'spitz-rund' aufrecht erhalten,

- phonostilistische Mittel wie Rhythmus, Reim, Assonanz, Alliteration sind textuell polyvalent.

Dennoch läßt sich die Möglichkeit nicht leugnen, daß durch phonostilistische Textelemente Verstehenshinweise an den Textrezipienten geleistet werden können.

4. Wenn im Fall rein verbaler Texte stilsemiotische Kategorien geeignet sind, eine kommunikative Stilkonzeption besser zu begründen und die textuellen Verstehenshinweise verständlich $\mathrm{zu}$ machen, sind sie unabdingbar zur Analyse von Textkomplexen, an denen unterschiedliche Zeichensysteme beteiligt sind.

In den letzten Jahren hat es eine Reihe von Versuchen gegeben, semiotische Kategorien auf solche Phänomene anzuwenden oder sie als Textsorten sui generis, 'Wort-Bild-Texte', zu beschreiben (siehe u.a. Heimann 1963; Barthes 1964; Bardin 1975; Oomen 1976; Kloepfer 1977; Posner/Reinecke 1977; Moles 1978; Bentele/Hess-Lüttich 1985; Langner 1985; Muckenhaupt 1986; Stegu 1988, 1989; Schröder 1993; vgl. auch Kress/van Leeuwen 1990). 
Zunächst einmal ist festzuhalten, daß die 'Wort-Bild- Rezıprozität' (Helmann 1963, S. 102), das 'Text-Bild-Konglomerat' (Stegu 1989, S 31), die 'Text-Bild-Beziehungen' (Kalverkämper 1993, S 218) mcht die ennzige Möglichkeit von Zeichenprozessen darstellen Genau genommen ist es auch nicht berechtıgt, in diesen Fällen von multımedıalen Texten zu sprechen.

"Streng genommen sind Texte mit Elementen aus einem verbalen und aus einem visuellen Kode nur bimediale Texte: erst wenn weitere Zeichensysteme (auditive, taktile etc.) hinzutreten, scheint es gerechtfertigt zu sein, von multimedialen Texten zu sprechen." (Schröder 1993, S. 195)

Terminologisch fraglıch ist es auch, von Bıld-Text-Bezıehungen zu sprechen, da ein Bild häufig textkonstitutıv, also Tell des Textes ist

Multimediale Texte werden daher hier verstanden als 'semıtısch komplexe Texte', in denen

- verbale und nonverbale Zeichen sich gegenseitig erganzen und wechselseltıg determinieren können (Spıllner 1980b, S 74),

- jedes Zeichensystem spezifisch an der Konstitution von Textbedeutung beteiligt ist (Spillner 1982, S 97),

- der verbale und nonverbale Textteil erst durch den Gesamttext verständlich werden) (Spillner 1980, S 74 und 1982, S 97)

Da multimediale Texte gleichermaßen durch Sprache und Bild sowie durch andere nonverbale Faktoren konstituiert werden, hat auch ene Textanalyse (oder Stılanalyse) auf diese vielschichtigen Beziehungen und Verflechtungen einzugehen (Spillner 1982, S 92)

Trotz mancher semıotıscher Ansätze ist festzustellen, daß bıslang en 'übergeordnetes Raster' (Kalverkämper 1993, S 218) zur Analyse semiotisch komplexer Texte fehlt. Erst recht bleibt eine kohärente stılsemıtısche Theorie Desiderat. Sie müßte die stilistısche Beschreıbung aller denkbaren Text-Zeichenprozesse in allen komplexen Kombinationen le1sten

Aus der Vielfalt der dabeı stılıstısch zu erwartenden Aspekte werden zwel enge Ausschnitte exemplarisch skizziert

4.1 Es gibt sehr unterschiedlıche Relatıonen zwischen verbalen und visuellen Elementen in semiotisch komplexen Texten Komplementaritat, Illustrierung, Exemplifizierung, 'semantischer Kontrast, Informationssupplement, Konkretisierung, Disambiguerung etc 
Ein interessanter Sonderfall ist die Ambiguisierung bzw. Relexikalisierung sprachlicher Zeichen durch ein Bild:

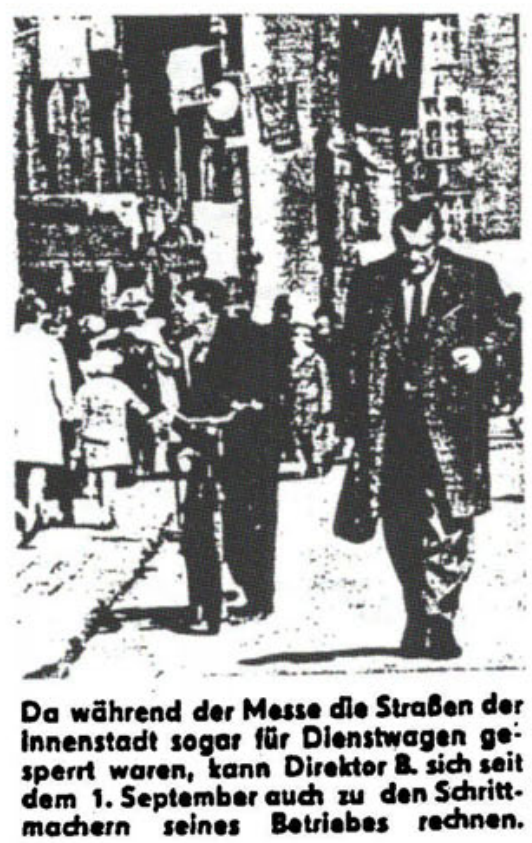

Der Gesamttext ist weder aus dem verbalen noch aus dem visuellen Textteil allein verständlich. Erst recht kann der Stileffekt, der aus der Ambiguisierung der lexikalisierten Metapher 'Schrittmacher' resultiert, aus einem der beiden Zeichensysteme allein nicht rekonstruierbar sein. Das Kompositum wird scherzhaft entmetaphorisiert, in dem bildlich eine Person vorgeführt wird, die 'Schritte macht'. Um den Stileffekt zu verstehen, muB der Leser also den Bildinhalt auf eine ganz bestimmte Art verbalisieren und dann mit dem sprachlichen Textteil korrelieren. Oder umgekehrt: für den sprachlichen Textteil (bzw. für ein Segment daraus) muß im visuellen Teil eine dazu passende verbale Interpretation aufgefunden werden. 
Dies geschieht sehr häufig dadurch, daB Lexeme einer phraseologischen Einheit relexikalisiert, d.h. wörtlich genommen werden, z.B.:

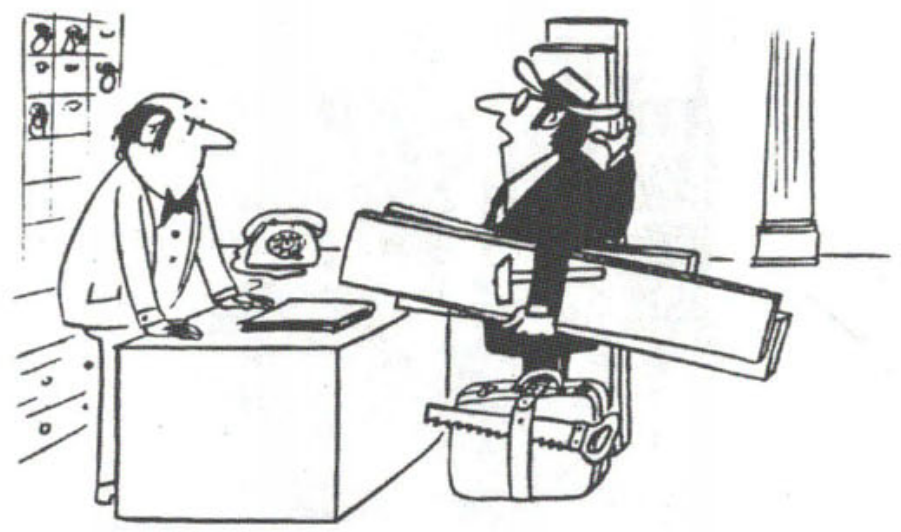

\section{-Aber Sie sagten doch am Telofon, wogen Pursonalmangets mübton div Gästo ihr Bott solber machen"}

Stileffekte dieser Art sind besonders in Werbeanzeigen, in Comics und in Witzzeichnungen beliebt.

Da die semiotischen Rekonstruktionsprozesse kompliziert sind, wird mit Rücksicht auf den Durchschnittsleser oft mit Ambiguisierungen an schlichten Texten und mit leichter Verständlichkeit gearbeitet. Stileffekt und humoristische Wirkung sind daher meistens ähnlich schlicht.

Allerdings können auch - wie in einer Plakatwerbung - in einem semiotisch komplexen Text multiple Ambiguisierungen entstehen, die bilderrätselartig entschlüsselt werden können und unterschiedliche Interpretationen erlauben: 


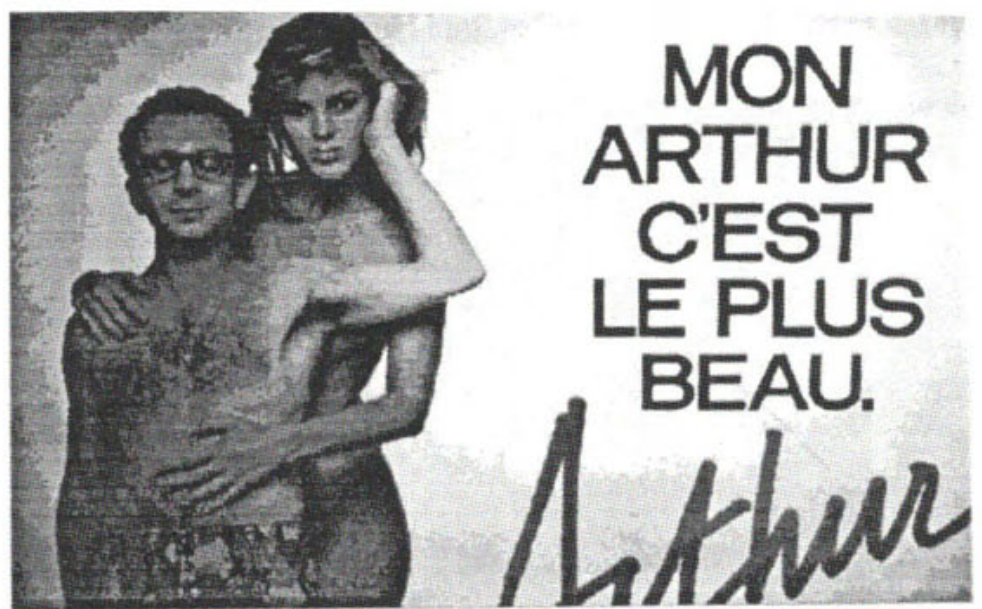

Auch hier sind der verbale und der visuelle Textteil isoliert nicht oder nur eindeutig verstehbar. Der Stileffekt der mehrdeutigen Aussage 'Mein Arthur ist der schönste' entsteht in mehreren semiotisch komplexen Schritten:

- Es ist unklar, wer der Sprecher der Aussage ist. Das Bild bietet zwei Personen an.

- Für den Eigennamen 'Arthur' des sprachlichen Textteils gibt es visuell drei mögliche Denotate: den Firmennamen des Textilproduzenten, metonymisch das Bekleidungsstück, die abgebildete männliche Person (möglicherweise außerdem die Metapher für ein männliches Körperteil).

- Unabhängig vom Sprecher kann das Possessivpronomen unterschiedliche Bezeichnungsfunktion haben.

Durch Kombination dieser unterschiedlichen kommunikativen Mehrdeutigkeiten ergibt sich als Stileffekt eine Fülle divergenter (und z.T. erotischer) Lesarten.

4.2 Ein extremer Sonderfall semiotisch komplexer Texte betrifft den Stileffekt durch verbale Elemente in non-verbalen Texten. Daß Sprache überhaupt eine konstitutive Rolle in rein bildlichen Darstellungen spielen kann, scheint in der semiotischen Forschung bislang übersehen worden zu sein. Der Fall kann aber eintreten, wenn zum Verständnis eines ikonischen Zeichenkomplexes auf Verbalisierung, auf sprachliche Elemente 
rekurriert werden muB. Gar nicht so selten ist dies bei visuellen Darstellungen bzw. Karikaturen vom Typ 'Bild ohne Worte'.

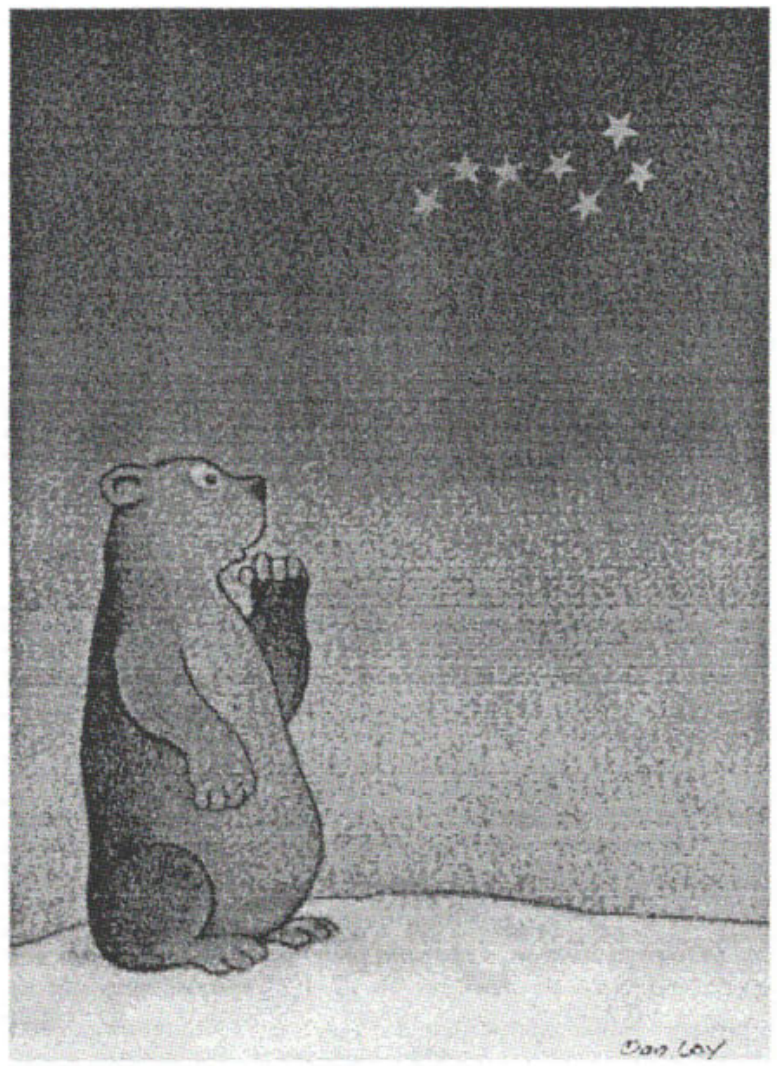

Die Darstellung ist nur scheinbar ein Bild ohne Worte. Tatsächlich handelt es sich um einen Text, dessen Stileffekt auf sprachlicher Homonymie, möglicherweise zusätzlich auf rhetorischer Antithese beruht. Beide Bildelemente - das Tier und das Sternbild - müssen versprachlicht werden, damit der überraschende Stileffekt verstanden werden kann:

Bär - großer Bär

oder genauer, damit eine Antithese entsteht:

Hier der kleine Bär - dort der Große Bär. 
Die Art der Verbalisierung ist nicht beliebig: die Versprachlichung des Sternbildes als 'Himmelswagen' führt nicht zur Entschlüsselung des Gesamttextes. Es versteht sich auch, daB der semiotisch komplexe Stileffekt nur von Sprechern rekonstruiert werden kann, in deren Sprache das Sternbild mit dieser spezifischen Metapher lexikalisiert ist.

Die einzelsprachliche Bindung solcher Texttypen kann besonders deutlich an einem letzten Beispiel demonstriert werden:

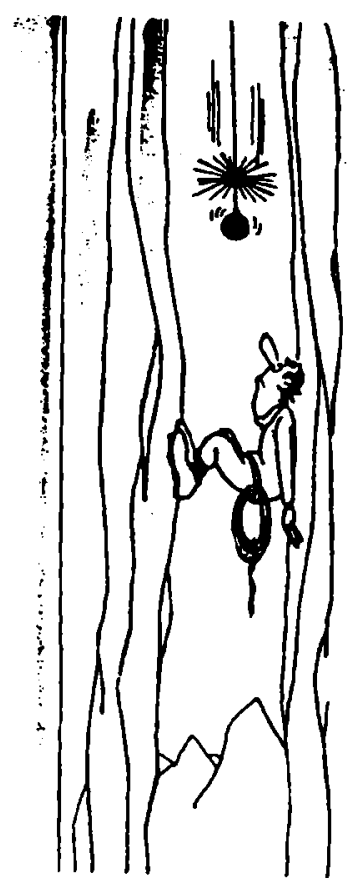

Das Verständnis dieser Karikatur kann nur aufgrund zweier onomasiologischer Voraussetzungen geschehen:

- Man muß wissen, daß ein schmaler Felsspalt, in dem man sich durch Abstemmen mit Rücken und Füßen emporarbeiten kann, in der Fachsprache der Bergsteiger 'Kamin' heißt.

- Man muß wissen, daß das abgebildete Gerät als 'Kaminkehrerbesen' bezeichnet werden kann. 
Erst vermittelt über das mehrdeutige Lexem 'Kamin' kann als Stileffekt der paradoxe Witz des Textes verstanden werden: im Kamin ${ }_{2}$ bemerkt der überraschte Bergsteiger einen Gegenstand, der nur im Kamin 1 vernünftigerweise etwas zu suchen hat.

Der Sprecher einer Sprache, die nicht dieselbe lexikalische Ambiguität enthält wie das Deutsche, kann diese scheinbar sprachunabhängige Karikatur nicht verstehen. Auch ein Deutscher muB mindestens den Fachterminus 'Kamin' kennen. Mehr noch: auch ein norddeutscher Sprecher, dem nur die Bezeichnung 'Schornsteinfegerbesen' geläufig ist, kann den Stileffekt nicht rekonstruieren. Er muB mindestens passiv die süddeutsche Variante 'Kaminkehrer' beherrschen.

5. Semiotische Kategorien sind nicht nur hervorragend geeignet zur theoretischen Fundierung einer pragmatisch-kommunikativ orientierten Stilistik. Sie sind unabdingbar für die Stilanalyse semiotisch komplexer Texte. Diese haben eine lange Tradition: Seit dem 6. vorchristlichen Jahrhundert sind sie in unserem Kulturkreis in den griechischen Vasenbildern mit verbalem Spruchband belegt; die historische Filiation setzt sich in den Schriftbändern der mittelalterlichen visuellen Kunst fort. Heute gibt es die Verbindung unterschiedlicher Zeichensysteme in einer Fülle unterschiedlicher Textsorten: von Pressefotos mit Unterschrift über illustrierte Zeitungsartikel und Werbeanzeigen, Fachtexte und Gebrauchsanweisungen, Comics, Fotoromane und Bilderbücher bis hin zu Hörspiel, Theater, Oper und Multi-Media-Schau.

In allen semiotisch komplexen Texten sind prinzipiell Stileffekte möglich. Alle diese Stileffekte sind nur stilsemiotisch zu beschreiben. Für alle Fälle wird eine stilsemiotische Stiltheorie benötigt.

\section{Literatur}

Aronstein, Ph. (1960): Zur englischen Stilistik. In: Zeitschrift für französischen und englischen Unterricht 19, S. 251-264.

Asmuth, Bernhard/Berg-Ehlers, Luise (1974): Stilistik. Düsseldorf.

Bally, Charles ([1909] 1951): Traité de stylistique française. 2 vol. 3. Auff. Genève/Paris.

Bardin, Laurence (1975): Le texte et l'image. In: Communication et Langages $n^{\circ} 26$, S. 98-112.

Barthes, Roland (1953): Le degré zéro de l'écriture. Paris.

Barthes, Roland (1964): Rhétorique de l'image. In: Communications 4, S. 4052. 
Bentele, Günter/Hess-Lüttich, Ernest W.B. (Hg.)(1985): Zeichengebrauch in Massenmedien. Zum Verhältn is sprachlicher und nicht-sprachlicher Information in Hörfunk, Film und Fernsehen. Tübingen.

Busse, Winfried (1964): La sémiologie littéraire: la glossématique et la stylistique. In: Bulletin des jeunes romanistes 10, S. 36-42.

Crystal, David/Davy, Derek (1969): Investigating English Style. London/Harlow.

Crystal, David (1987): The Cambridge Encyclopedia of Language. Cambridge.

Eco, Umberto (1987): Semiotik. Entwurf einer Theorie der Zeichen. München.

Faulseit, Dieter/Kūhn, Gudrun ([1965] 1969): Stilistische Mittel und Möglichkeiten der deutschen Sprache. 4. Aufl. Leipzig.

Heimann, Paul (1963): Zur Dynamik der Bild-Wort-Beziehung in den optisch-akustischen Massenmedien. In: HeiB, Robert/Caselmann, Christian/Schorb, Alfons O./Heimann, Paul (Hg.): Bild und Begriff. Symposium des Instituts für Film und Bild. München. S. 71-113.

Hess-Lüttich, Ernest W.B. (1982): Multimedial Communication: Semiotic Problems of its Notation. In: Hess-Lūttich, Ernest W.B. (Hg.): Multimedial Communication. Vol. I: Semiotic Problems of its Notation. Tübingen. S. 7-16.

Hockett, Charles F. (1958): A Course in Modern Linguistics. New York.

Kalverkämper, Hartwig (1993): Das fachliche Bild. Zeichenprozesse in der Darstellung wissenschaftlicher Ergebnisse. In: Schröder, Hartmut (Hg.): Fachtextpragmatik. Tübingen. S. 215-238.

Klinkenberg, J.-M. (1985): Essai de redéfinition sémiologique du concept de style. In: Le Français Moderne 53, S. 242-245.

Kloepfer, Rolf (1977): Komplementarität von Sprache und Bild. Am Beispiel von Comic, Karikatur und Reklame. In: Posner, Roland/Reineke, HansPeter (Hg.): Zeichenprozesse. Semiotische Forschung in den Einzelwissenschaften. Wiesbaden. S. 129-145.

Kress, Gunther/van Leeuwen, Theo (1990): Reading Images. Victoria: Deakin University.

Langner, Paul Werner (1985): Strukturelle Analyse verbal-visueller Textkonstitution in der Anzeigenwerbung. Frankfurt a.M./Bern/New York.

Malblanc, Alfred (1961): Stylistique comparée du français et de l'allemand. Paris.

Marouzeau, Jules ([1941] 1965): Précis de stylistique française. 5. Aufl. Paris.

Michel, Georg (1969): Stilnormen grammatischer Mittel. In: Wissenschaftliche Zeitschrift der Humboldt-Universität zu Berlin. Gesellschafts- und Sprachwissenschaftliche Reihe 18, S. 275-279.

Moles, Abraham (1978): L'image et le texte. In: Communication et Langages $n^{\circ} 38$, S. 17-29. 
Muckenhaupt, Manfred (1986): Text und Bild. Grundfragen der Beschreibung von Text-Bild-Kommunikation aus sprachwissenschaftlicher Sicht. Tübingen.

Oomen, Ursula (1976): Wort-Bild-Nachricht: Semiotische Aspekte des Comic Strip 'Peanuts'. In: Linguistik und Didaktik 6, S. 247- 259.

Pfeiffer-Rupp, Rüdiger (1984): Graphostilistik. In: Spillner (Hg.) (1984), S. 101-119.

Posner, Roland/Reinecke, Hans-Peter (Hg.)(1977): Zeichenprozesse. Semiotische Forschung in den Einzelwissenschaften. Wiesbaden.

Pūschel, Ulrich (1976): Überlegungen zu einer Stiltypologie. In: Weber, Heinrich/Weydt, Harald (Hg.): Sprachtheorie und Pragmatik. Akten des 10. Linguistischen Kolloquiums Tübingen 1975. Tübingen. S. 223-234.

Riesel, Elise (1954): Abriß der deutschen Stilistik. Moskau.

Riesel, Elise ([1959] 1963): Stilistik der deutschen Sprache. 3. Aufl. Moskau.

Riesel, Elise (1964): Der Stil der deutschen Alltagsrede. Moskva.

Riffaterre, Michael (1971): Essais de stylistique structurale. Paris.

Sandig, Barbara (1978): Stilistik. Sprachpragmatische Grundlegung der Stilbeschreibung. Berlin/New York.

Sandig, Barbara (1984): Ziele und Methoden einer pragmatischen Stilistik. In: Spillner (Hg.) (1984), S. 137-161.

Schröder, Hartmut (1993): Semiotische Aspekte multimedialer Texte. In: Schrōder, Hartmut (Hg.) (1993): Fachtextpragmatik. Tübingen. S. 189213.

Sowinski, Bernd (1973): Deutsche Stilistik. Beobachtungen zur Sprachverwendung und Sprachgestaltung im Deutschen. Frankfurt a.M.

Spillner, Bernd (1974): Linguistik und Literaturwissenschaft. Stilforschung, Rhetorik, Textlinguistik. Stuttgart/Berlin/Köln/Mainz.

Spillner, Bernd (1980): Semiotische Aspekte der Übersetzung von ComicsTexten. In: Wilss, Wolfram (Hg.): Semiotik und Übersetzen. Tübingen. S. 73-85.

Spillner, Bernd (1982): Stilanalyse semiotisch komplexer Texte. Zum Verhältnis von sprachlicher und bildlicher Information in Werbeanzeigen. In: Kodikas/Code. Ars Semeiotica 4/5, n 1, S. 91-106.

Spillner, Bernd (Hg.)(1984): Methoden der Stilanalyse. Tübingen.

Spillner, Bernd (1984): Grundlagen der Phonostilistik und Phonästhetik. In: Spillner (Hg.) (1984), S. 69-99.

Spillner, Bernd (1987): Style and Register. In: Ammon, Ulrich/Dittmar, Norbert/Mattheier, Klaus J. (Hg.): Sociolinguistics/Soziolinguistik. An International Handbook of the Science of Language and Society. Ein internationales Handbuch zur Wissenschaft von Sprache und Gesellschaft. First Volume/Erster Halbband. Berlin/New York. S. 273-285.

Stegu, Martin (1988): Text und Bild im Wirtschaftsjournalismus (dargestellt anhand der österreichischen Tageszeitung Kurier). In: Bungarten, Theo (Hg.): Sprache und Information in Wirtschaft und Gesellschaft. Referate 
eines internationalen Kongresses, zugleich der XI. Jahrestagung der Internationalen Vereinigung 'Sprache und Wirtschaft' e.V., 30. September 3. Oktober 1985. Tostedt. S. 399-407.

Stegu, Martin (1989): Text und Bild in der Fachkommunikation. In: Dressler, Wolfgang U./Wodak, Ruth (Hg.): Fachsprache und Kommunikation. Experten im sprachlichen Umgang mit Laien. Wien. S. 30-46.

Stolt, Birgit (1984): Pragmatische Stilanalyse. In: Spillner (Hg.) (1984), Methoden der Stilanalyse. Tübingen. S. 163-173.

Strohmeyer, Fritz (1910): Der Stil der französischen Sprache. Berlin.

Sumpf, Joseph (1971): Introduction à la stylistique du français. Paris.

Thoma, Werner (1976): Ansātze zu einer sprachfunktional-semiotisch orientierten Stilistik. In: Lili. Zeitschrift für Literaturwissenschaft und Linguistik 22, S. 117-141.

Turner, G.W. (1973): Stylistics. Harmondsworth.

Vinay, Jean-Paul/Darbelnet, Jean (1958): Stylistique comparée du français et de l'anglais. Paris. 


\section{Stilwandel}

1. Das Vorhaben, über Stilwandel zu sprechen, konfrontiert mit einer langen Reihe von Schwierigkeiten, die einer Realisierung recht hinderlich entgegenstehen; eine schnelle Lösung der Aufgabe - wenn nicht sogar eine Lösung überhaupt - scheint kaum in Sicht:

1.1 Ort und Programm dieser Tagung lassen zwar kaum einen Zweifel daran zu, daB es sich bei dem zu diskutierenden Stilwandel gewiß um Sprachstilwandel handeln soll, aber die Legitimität solcher Einschränkung kann nun doch nicht so ohne weiteres als gegeben angenommen werden, zumal wenn man zumindest für möglich hält, daß da irgendein Zusammenhang zwischen den sehr heterogenen Bereichen sich wandelnden Stils in Literatur und bildender Kunst, in Architektur, Malerei und Musik, nicht zuletzt auch in verschiedenen sozialen Alltagsbereichen besteht und also nicht von vornherein diskussionslos ausgeschlossen werden kann. Wie aber verhält sich ein Sprachhistoriker in einem solchen Falle, und, vor allem, wie soll er Linguisten gegebenenfalls die Zumutung plausibel machen, mehr als nur einen Blick über die wohlbehüteten Grenzen ihrer, zugegeben, ohnehin schon weitläufigen Domänen zu tun? Einen „echten" Linguisten erfüllt der Stilbegriff mit tiefem Mißtrauen und er hat, von seinem Standpunkt aus, damit ohne jeden Zweifel Recht.

1.2 Die bereits in den 70er Jahren allenthalben (was heißen soll: keineswegs auf die Sprachwissenschaft beschränkt) einsetzende Revitalisierung des Interesses an Stil und Stilistik, von der ja schließlich auch das Rahmenthema dieser Tagung zeugt, kann doch nicht darüber hinwegsehen lassen, daB der Stilbegriff selbst nach wie vor eine höchst ungewisse, an den Rändern ihrer Gegenstandsbestimmung diffus verschwimmende Größe darstellt. Zwar werden nur Ignoranz oder Böswilligkeit ihn heute noch zu den „ausgemusterten Beständen geisteswissenschaftlicher Tradition" (Gumbrecht/Pfeiffer 1986, Klappentext) rechnen, aber man muB nicht unbedingt ein Verächter der traditionsreichen Disziplin Stilistik sein, um mehr oder weniger harte Kritik an einem Begriff für berechtigt zu halten, der sich in den Augen seiner potentiellen Anwender als (ich biete zur Illustration nur eine Auswahl von Charakterisierungen) ungenau, unscharf, überdimensional, weitmaschig, schillernd, aufgebauscht, vieldeutig, unsauber, klischeehaft, auf fragwürdigen Analogien beruhend, widerstreitende Strömungen einebnend, harte Gegensätze der Zeit harmonisierend, verschlissen (vgl. Möbius 1988, S. 7) darstellt. Wie aber 
soll, was sich schon in der Statik einer synchronischen Betrachtung offenbar als problematisch, zumindest als komplex und in sich unfest präsentiert, einer Beschreibung im Prozeß einer Veränderung in der Zeit zugeführt werden, ohne daß das Vorhaben zu dann in der Tat klischeehaften Vergröberungen oder unsicheren Pauschalisierungen gerät?

1.3 Niemand wird leugnen können, daß die (Sprach-)Stilistik, nicht zuletzt die der deutschen Sprache, eine ausnehmend differenziert entwickelte, in ihren jüngeren Ausformungen - gleich welcher Richtung theoretisch und methodologisch modernen Anforderungen voll gerecht werdende Wissenschaft ist. Dagegen aber wird schon bei oberflächlicher Zusicht ebenso offenkundig, daB eine Historische Stilistik, in deren Gegenstandsbereich das Phänomen Stilwandel unstreitig gehören würde, gerade einmal in Plädoyers, Vorüberlegungen und - zwar vielversprechenden, aber eben leider doch nur - Ansätzen (vgl. Pöckl 1980; Fix 1991a) existiert. Ist es aber angängig und reicht es aus, das Know-how und das methodische Instrumentarium einer dezidiert synchronisch orientierten (Sprach-)Stilistik einfach auf die diachronische Dimension ihres Gegenstandes zu übertragen?

1.4 Auch wenn man die Verabredung trifft, unter Stilwandel im Kontext der hier stattfindenden Bemühungen fortan (soweit nicht anders angegeben) Sprachstilwandel zu begreifen, bleibt man zwar nicht mehr im Regen interdisziplinärer Verquickungen stehen, gerät dafür aber um so nachhaltiger unter die Traufe fachspezifisch-linguistischer Problemzusammenhänge, in diesem Bezug allen voran zu nennen die Polysemie des Sprachbegrifts. In keiner der mir bekannten empirischen stilgeschichtlichen Untersuchungen zum Deutschen werden Reflexionen angestellt darüber, ob und gegebenenfalls mit welcher Argumentation die praktizierte Homogenitätsidealisierung stilistischer Veränderungen d e r deutschen Sprache (offenbar verstanden als Systemgegebenheit) gerechtfertigt werden kann. Sollte aber die Beschreibung von Stilwandel wirklich vom grundsätzlichen Handlungscharakter von Sprache absehen können? Ist es angängig und gegenstandsadäquat, die diasystematische Organisiertheit einer natürlichen Sprache einfach außerhalb des Beschreibungsradius einer Historischen Stilistik zu belassen? Darf Stilwandel gar außerhalb jeglicher Relation zu sprachlicher Kompetenz und/oder Performanz bleiben?

1.5 Letztere Fragen führen geradewegs zu auf den wohl eckigsten Stolperstein, der auf dem Wege einer wissenschaftlichen Beschreibung von Stilwandel liegt: Sprachstilistische Veränderungen stehen, wie auch ohne 
theoretische Ableitung anmutungsweise jedermann klar zu sein scheint, offenbar in irgendeinem Zusammenhang mit sprachlichen Entwicklungen. Wenn aber historische Prozesse und ihre Ergebnisse im stilistischen Bereich notwendigerweise nicht ohne Beziehung zu historischen Prozessen und ihren Ergebnissen in "der Sprache” gedacht werden können: müssen dann nicht auch die theoretischen Reflexionen zu Stilwandel und Sprachwandel aufeinander Bezug nehmen? Wie verhält sich also Stilwandel zu Sprachwandel?

2. Ich habe bei der - unsystematischen - Auflistung einer Handvoll mir in Hinsicht auf mein Thema relevant erscheinender Fragen bewuft die anspruchsvolle Benennung 'Problemkatalog' vermieden - dazu ist sie viel zu unvollständig und wohl auch zu subjektiv. Immerhin kann sie den Zweck erfüllen, das Feld der Erörterungen abzustecken, auf dem ich mich im weiteren zu bewegen beabsichtige.

2.1 Wenn man nun fest entschlossen ist, die skizzierten Fragen und Schwierigkeiten eher als Herausforderung denn als entmutigende Hindernisse zu verstehen, wird es unumgänglich, sich zur Verdeutlichung des zu vertretenden Standpunktes zuerst dem auf dieser Tagung immer wieder nach vorn drängenden Grundproblem zu stellen, welchem Verständnis von Stil man eigentlich folgen will, bevor man zur Beschreibung seiner Veränderung, seines Wandels eben, übergehen kann.

Das möge man nun nicht dahingehend miBverstehen, als solle hier in Form einer lästigen Doppelung noch einmal eine kritische Revision von Stilbegriffen oder -definitionen aus allen Kulturwissenschaften erfolgen, in denen Stil eine Rolle spielt oder je gespielt hat. DaB das höchst unangebracht wäre, lehrt schon ein flüchtiger Blick auf die Themenliste der Tagesordnung. Für vertretbar und notwendig anzusehen ist aber eine möglichst genaue Kennzeichnung der Position, von der aus die Thematik Stil-W a n d e l angegangen werden soll. Dazu soll die folgende Charakterisierung dienen:

2.1.1 Da der Stilbegriff wissenschaftsgeschichtlich auf sehr verschiedene Bereiche menschlichen Handelns und Verhaltens Anwendung gefunden hat und in einigermaßen heterogenen Wissenschaftsdisziplinen eine Rolle spielt, mag er als anthropologische, kulturwissenschaftliche, kommunikationsgeschichtliche, semiotische oder wie immer zuzuordnende GröBe gelten, auf keinen Fall aber als linguistische Kategorie. Gadamer (1975, S. 466) bezeichnet ihn nachgerade als „eine der undiskutierten Selbstverständlichkeiten, von denen das historische Bewußtsein lebt." Der Artikel Stil im Deutschen Wörterbuch (Bd. 18, 1941, S. 2905-2930) vermag, 
bezogen auf wissenschaftlich-begriffliche ebenso wie alltagssprachliche Gebrauchsweisen und ihre Entwicklungen, einen plastischen Eindruck davon zu vermitteln. Das breite Spektrum seiner Anwendungen als, wie Gumbrecht/Pfeiffer (1986) im Untertitel ihres Sammelbandes formulieren, "kulturwissenschaftliches Diskurselement" begründet indessen zweifellos auch seine "systematische Insuffizienz” (Gumbrecht 1986, S. 772), die jeden Versuch einer vermittelnden Zusammenschau zum schweren Problem werden läßt. Eine solche Zusammenschau erscheint allerdings als unerläßlich, wenn Stilentwicklung oder gar Stilgeschichte, Stil also in historischen Formationen, Beschreibungsgegenstand sein soll. Eine gegenteilige Verfahrensweise, die isolierte Betrachtung nach getrennten Domänen also, hätte hier 2 wangsläufig methodologische Hilflosigkeit und resultative Verzerrungen zur Folge.

2.1.2 Eine Synopse über die Grenzen der Einzelwissenschaften hinweg ist, wie man weiB, verschiedentlich - insbesondere im ersten Drittel dieses Jahrhunderts mit beachtlichen Ergebnissen - unternommen, in der Linguostilistik aber substantiell kaum je zur Kenntnis genommen worden. Leider muB ich es mir im Blick auf mein Thema versagen, an dieser Stelle auf die lange Reihe von Untersuchungen und Darstellungen in Kunstwissenschaft, Architektur, Philosophiegeschichte, vor allem aber in der (deutschen) Literaturwissenschaft analysierend einzugehen, die, ausgehend von Wölfflins „Kunstgeschichtlichen Grundbegriffen” (1915) und Walzels "Gehalt und Gestalt im Kunstwerk" (1923) über Kainz (1926), Nadler (1930), Halbach (1935) Schwietering (1941), bis hin zu Besseler (1931), um nur einige zu nennen, die "wechselseitige Erhellung der Künste" (Walzel 1917) auf der Beschreibungsebene einer Epoche aus gleichem künstlerischen Wollen einer Zeit und vergleichbarer Formbestimmtheit postuliert haben und am Detail nachzuweisen bestrebt waren. So erscheint Halbach $(1935$, S. 543) etwa, um wenigstens andeutungsweise zu markieren, worum es dabei geht, im "heiligen Bildersaal des Bamberger Doms” der Bamberger Reiter als "ein Bruder Parzivals”; in Schwieterings Darstellung der deutschen Literatur des Mittelalters im "Handbuch der Literaturwissenschaft", 8, 1941, gibt es - durchaus nicht nur im Sinne einer schmückenden Illustration - das Nebeneinander von karolingischer Dichtung und Aachener Pfalzkapelle, Otfrid und Lorscher Torhalle, Ezzolied und Hildesheimer Godehardkirche; und der Leipziger Musikhistoriker Besseler vergleicht in seiner "Musik des Mittelalters und der Renaissance" (Handbuch der Musikwissenschaft, 1, 1931, S. 115) die Tonwelt des Pariser Organums mit dem „dunkel-rötlich-violetten Licht gotischer Dome". 
Ich weiß: Dergleichen ist wissenschaftsgeschichtlich lange Vergangenheit, die für manchen vielleicht sogar das Stigma der Verstaubtheit tragen mag, und wenn in aktuellen Stildiskussionen überhaupt einmal, selten genug, Bezug auf dieses Denkmuster genommen wird, dann höchstens im Sinne harscher Ablehnung, von seiten der deutschen Literaturgeschichtsforschung letzthin von Rosenberg beispielsweise (1984/86). Ich vermag mich dem nicht anzuschliefen, und zwar aus folgenden Gründen nicht:

a) Der grundsätzlich kommunikative Charakter und, sozial gesehen, die kommunikative Funktion von Stil oder, wie ich in diesem Zusammenhang zu sagen vorziehe, von Stilistischem zwingt dazu oder legt doch zumindest nahe, auch beim Stilphänomen von einer zeichenbedingten Dichotomie von Inhalts- und Ausdrucksebene auszugehen. Alle Beschreibungsversuche der angeführten Art qualifizieren Stil als Gegebenheit der Form, als Formbestimmtheit unterschiedlicher Materialisierung, in je arbiträrer (aber auch durchaus traditions- oder materialbestimmter) Verknüpfung mit einer Inhaltsebene, die gelegentlich als Denkstil einer Zeit, Richtung o.ä. benannt wird. Wir sollten endlich aufhören damit, geistesgeschichtliche Anwendungen des Stilbegriffs vom linguostilistischen Standpunkt aus nur als eine Art Übertragung aus formbestimmten Bereichen anzusehen, und auch der Organisation von Weltsicht und Weltwissen einer Zeit Stil zugestehen. Es muB gewiß als Mangel des Konzepts einer 'wechselseitigen Erhellung der Künste' angesehen werden - insofern sind die modernen Kritiker sachlich im Recht -, den Vergleich im wesentlichen auf der formalen, der Ausdrucksebene gesucht zu haben. Setzt man aber, zeichentheoretisch problemlos möglich, die (formalen) Stilsysteme der einzelnen 'Künste' zu einem geistesgeschichtlichen oder eben Denkstil einer Epoche in Relation (eben um zu 'Stilzeichen' zu gelangen), ergeben sich über diesen und jeweils auf diesen bezogen zwar keine einfachen Parallelen, wohl aber im Hjelmslevschen Verständnis stilistische Solidaritäten, die aufzuspüren ich für reizvoll und stilgeschichtlich äußerst lohnend halte. Das jedoch erforderte eine Erörterung für sich, die an dieser Stelle unterbleiben muß.

b) Doch auch im gegebenen Zusammenhang darf zumindest ein methodologischer Nutzen aus diesen Erwägungen konstatiert werden: Lassen sich auf ihrer Grundlage doch alle noch so heterogenen Stilbegriffe, -auffassungen und -definitionen, kurz das, was mitunter als hohe Komplexität, Plurivalenz und Facettenreichtum oder sogar Inkompatibilität der unterschiedlichen Stilkonzepte beklagt wird, fernab von allem zu befürchtenden Eklektizismus in Komponenten zerlegen, die ihrerseits ohne nennenswerte Schwierigkeiten als unterschiedliche Perspektiven auf oder Aspekte von jeweils umfänglicheren, prinzipiell gleichen Sachverhal- 
ten interpretiert werden können. Es ergibt sich mithin ein Plädoyer für die grundsätzliche Einheit eines kulturell-kommunikativen Stilbegriffs, der sich in der Unterschiedlichkeit je fachspezifischer oder interessegeleiteter Sichtweisen auf ein zeichenhaftes Phänomen manifestiert, dessen inhalts- und ausdrucksseitige Erscheinungsweisen traditionell in die Gegenstandsbereiche sehr verschiedenartiger, untereinander allerdings kategoriell und methodologisch nicht ohne weiteres kompatibler Wissenschaftsdisziplinen fallen. Es ist, soweit ich sehe, das Verdienst H. Brinkmanns, in seinen Stilstudien von 1932/33 bereits die Ansicht geäußert zu haben, daB die heterogenen begrifflichen Fassungen von Stil in verschiedenen Wissenschaften im Grunde einander eigentlich nur ergänzen „oder von anderem Ausgangspunkt dasselbe meinen"(Brinkmann 1932/33, S. 10); der gleiche Gedanke kehrt später dann, wohl unabhängig von Brinkmann und vor allem im Blick auf die unterschiedlichen literaturund sprachwissenschaftlich bestimmten Stilistikkonzepte geäußert, z.B. bei Anderegg (1977), Fix (1991b) und Sowinski (1991) wieder, verfügt also wohl über eine gewisse methodologische Attraktivität. Denkt man, also ermutigt, auf diesem Weg weiter, müBte sich sogar eine Stildefinition finden lassen, die dieser plurivalenten Komplexität eines interdisziplinär anwendbaren Stilbegriffs nahekommt. Im Sinne eines Gedankenexperiments möchte ich demgemäß sogar, um das Gesagte auf den Punkt zu bringen, etwas dergleichen vorstellen: Demnach wäre Stil aufzufassen als irgendwie geordnet beschreibbare relationale Bestimmtheit der Anwendung je verfügbarer gestalterischer Instrumentarien bei Erzeugung und Aufnahme eines sozial akzeptablen Kommunikats bzw. Klassen von Kommunikaten durch Weltwissen und Weltansichten der jeweiligen Zeit.

2.1.3 Bevor dieses Gebilde dorthin befördert wird, wohin es wegen seiner mangelnden analytischen Praktikabilität und abstrakten Aussageblässe gehört: in den Papierkorb, hat es im Gang dieser Darlegungen jedoch noch eine Funktion zu erfüllen: Wenn es denn richtig ist, daß alle, wirklich alle Stilerscheinungen einer Zeit semiotisch zusammengehören, dann liegt es nahe, ja eigentlich sogar zwangsläufig auf der Hand, sie untereinander in irgendeinem regelhaften und, mit Blick auf die Produzenten und Rezipienten solcher Zeichen, in einem Funktionszusammenhang im Rahmen einer Kommunikationskultur (bzw. deren jeweiliger Synchronie) zu sehen. Der literarische bzw. sprachliche Stilwert der formal gleichen Textsorte, Gattung, Stilfigur oder sonstigen Stereotypen bestimmt sich eben signifikant anders je nach Epoche (Zeitebene), in der diese Verwendung finden. Ein Liebesgedicht des Mittelalters beispielsweise "funktioniert" hinsichtlich seiner sprachstilistischen Gestaltung völlig anders als ein Liebesgedicht des Rokoko, selbst wenn, einen idealisier- 
ten Fall angenommen, Stilfiguren, Reimschemata und Strophenformen völlig gleich wären; das kann man sehr eindrücklich an neuhochdeutschen Übersetzungen oder besser noch Nachdichtungen historischer Texte studieren. Und andersherum gesehen: Die Dorfkirchen des 13. Jahrhunderts etwa, kunsthistorisch weithin kaum besonders bedeutsam, haben, wie der Jenenser Kunstwissenschaftler F. Möbius (1988) gezeigt hat, eine unleugbare stilistische Beziehung zu den vielbewunderten zeitgenössischen Kathedralen, auch wenn das zunächst nicht sehr augenscheinlich ist, eben als struktureller Ausdruck einer gleichen Weltsicht, Realisierung übereinstimmender "Sehformen" und einheitlichen „Kunstwollens” mit je anderen Mitteln. Möbius bezeichnet seine Abhandlung im Untertitel als ein „Plädoyer für eine strukturgeschichtliche Vertiefung des Stilbegriffs" (Möbius 1988). Und genau dies ist es, was die Überlegung für Belange der Beschreibung von Stilwandel außerordentlich attraktiv macht: strukturgeschichtliche Vertiefung des Stilbegriffs. Dieser wird damit zur "Integrationsformel für Existenz schlechthin” (Möbius 1988, S. 5) oder, wie man von einem sprach- bzw. kommunikationswissenschaftlichen Standpunkt aus auch sagen könnte, zur Normierungs- oder besser Markierungsinstanz kommunikationskultureller Spezifik. Denn das je besondere zeitlich-kulturelle "Gefüge einer Ordnungseinheit" wirkt sich in der Sprache aus (Brinkmann 1932/33, S. 28), wie die Literatur ihrerseits ,in der jeweiligen Ordnungseinheit verschiedenen Ort" habe (ebenda, S. 27): So lasse sich - aus literarhistorischer Sicht - die Sprache literarischer Epochen in "gemeinsamen Formzügen" erkennen, die der Aufklärung gekennzeichnet durch philosophisch determinierte Begrifflichkeit, die im Sturm und Drang durch Irrationalität, in der Romantik, der "Zeit der Malerdichter", durch Anschaulichkeit usw. Für den heutigen Leser bemerkenswert, gewinnt man von dieser Sichtweise Brinkmanns aus sachlich mühelos AnschluB an im gegebenen Zusammenhang hochbedeutsame Forschungen der Russischen Formalisten bzw. der Prager Schule, hier besonders an den von Jakobson in seiner Prager Zeit entwickelten Begriff der (epochengeschichtlichen) Dominante, d.h. einer jeweils 'führenden', für andere im Rahmen einer Epoche vorbildhaften bzw. diese bestimmenden Kunstgattung, die den ästhetischen Wert aller kultureller Äußerungen auf einer bestimmten Zeitebene entscheidend prägt, und zwar ohne daß sich dies in materiellen Elementen auf der Ausdrucksebene niederzuschlagen braucht, einfach als Funktion des jeweiligen Systems, als „Summe aller kulturellen Einheiten, die das Signifikans dem Empfänger institutionell ins Gedächtnis rufen kann", wie Eco (1968, S. 111) seinen Konnotationsbegriff (der m.E. hier unmittelbar einschlägig ist) definiert. Die mit der von Por/Radnóti (1990) vorgelegten Anthologie von Texten berühmter Autoren zu Theorie und Begriff 
der Stilepoche neuerdings erfreulicherweise wieder initiierte Diskussion zum (künstlerischen) Epochenverständnis wird diese Zusicht zu berücksichtigen haben, insbesondere im Blick auf die historische Abfolge von Epochen. Denn die strukturelle Änderung des kulturell-künstlerischen Gesamtgefüges und/oder der Wechsel der jeweiligen Dominante haben, so gesehen, unmittelbare Auswirkungen auf veränderte ästhetische und stilistische Wertvorstellungen bzw. Bewertungen im BewuBtsein einer Kommunikationsgemeinschaft. Die stilgeschichtliche Relevanz dieser Beobachtung bedarf keiner weiteren Nachweise.

2.1.4 Natürlich ist es im Blick auf das sprachstilistische Anliegen dieser Ausführungen schließlich noch erforderlich, die Folgen des entwickelten Stilverständnisses für die zu vertretende Auffassung von Sprachstilwandel, um den es ja vorrangig gehen soll, zu bedenken. Das kann ziemlich knapp geschehen, da sie eigentlich auf der Hand liegen und außerdem, wie bereits angedeutet, auch in der Linguostilistik die Empfehlung existiert, die Fülle konkurrierender Stildefinitionen als unterschiedliche Aspektualisierungen gleicher Sachverhalte zu interpretieren; die sehr zeitaufwendige kritische Diskussion von Vorzügen und Nachteilen einzelner Konzepte darf also entfallen.

In diesem Verständnis seien die folgenden relevanten Standpunkte markiert:

a) Das vertretene semiotisch-zeichenhafte Stilverständnis findet selbstverständlich auch auf sprachstilistische Sachverhalte Anwendung. Da die Ausdrucksebene hier ihrerseits durch Zeichen bzw. Zeichenkombinationen gebildet wird, funktioniert Sprache, um mit Ju.S. Stepanov (1971, S. 21, S. 94) zu formulieren, auf der zweiten Stufe der Zeichenhaftigkeit, Stil also als Zeichen von Zeichen oder, bezogen auf Resultate der Stilerzeugung, als Parasitär- bzw. Sekundärstruktur(en), die über (sprachlichen) Primärstrukturen operieren.

b) Da Stil jeglicher Bereiche immer nur im Bezugsverhältnis sozialer Interaktion funktioniert und daher auch nur in interaktionalen Relationen existiert, erscheint die Applikation des Konzeptes stilistischen Handelns soziohistorischer Subjekte für eine Historische Stilistik zwingend. Ich befinde mich mit dieser Ansicht in Übereinstimmung mit U. Fix (1991a, S. 300f.), die in ihren 'Vorbemerkungen' zu einer Historischen Stilistik eine „tätigkeitsorientierte kommunikativ-pragmatische Stilauffassung, die das Spannungsfeld von Überindividuellem und Individuellem dezidiert einbegreift", für eine "geeignete Basis” hält. 
c) Indem sprachstilistisches Handeln nach subjektiven Intentionen von objektiven Handlungsvoraussetzungen mitbestimmt wird, orientiert sich das handelnde Subjekt in der Interaktion an modellhaft verallgemeinerten Handlungsanweisungen, die als Muster von Handlungsabläufen (Stereotypen verschiedener Reichweite) in Erscheinung treten.

d) Sprachstilistisches Handeln ist Textherstellung, das komplexe Zeichen Text mithin die entscheidende Existenzweise von Stil: Die Textäußerung repräsentiert die Schnittstelle zwischen im weitesten Sinne kulturellen Wissensbeständen - also dem, was im Sinne der begrifflichen Diskussion als Inhaltsebene von Stil, als Denkstil, in Anspruch zu nehmen war, und der Ausdrucksebene sprachtextlicher Primärstrukturen.

2.1.5 Die logischen, besser wohl: methodologischen Konsequenzen aus der vorgetragenen stilbegrifflichen Positionierung insgesamt für die Beschreibung stilistischer Veränderungen liegen nun klar zutage:

a) Zum einem wird im weiteren sachlich strikt zwischen $S$ t i l g e$s \mathrm{ch}$ i $\mathrm{ch}$ t e und $\mathrm{S}$ t i l w a $\mathrm{n}$ d e l zu differenzieren sein. Stilgeschichte hat die Abfolge von metachronischen Querschnitten im Sinne kommunikationsgeschichtlicher Formationen zum Gegenstand, Stilwandel die zeitliche Verfolgung von stilrelevanten Veränderungen im Verlauf und im Ergebnis stilistischen Handelns miteinander kulturell kommunizierender Subjekte bzw. Gruppen von Subjekten. Stilwandel dürfte sich, einer ersten Anmutung nach, zu Stilgeschichte etwa verhalten wie Sprachwandel zu Sprachgeschichte.

b) Das für verbindlich erklärte Stilverständnis gibt verschiedene Dimensionen vor, in denen Stilwandel sich vollzieht.

c) Schließlich kann nicht übersehen werden, daß die Applikation eines umfassenden Stilverständnisses im dargelegten Sinn zu erheblichen beschreibungspraktischen Schwierigkeiten führen muB: Die sich aus ihm ergebende Forderung, Veränderungen auf der Zeitachse immer und notwendigerweise im Gesamtgefüge aller Komponenten des postulierten Stilsystems darzustellen, läßt sich analysepraktisch mit den derzeit verfügbaren Mitteln nicht bewerkstelligen. Die Lösung kann also nur in einer 'Narkotisierung' von Variablen dieses Strukturgefüges bestehen, die je nach fachlichem Interesse, Zielstellung und vorgesehenem Beschreibungsradius, abhängig also vom je gewählten Beschreibungsmodus, als Konstanten gesetzt werden. Das darf vor dem Hintergrund der soeben angestellten Überlegungen zum Stilverständnis dann als legitim gelten, wenn es methodisch sauber expliziert, also jeweils genau angegeben wird, in welchem Beschreibungsmodus und, vor allem, 
r e lativ zu we l chen Konstante $n$ die Deskription erfolgen soll. Jede Darstellung von Stilwandel wird bis auf weiteres mit dem Mangel leben müssen, immer nur die e i n s e i t i g e Erfassung eines grundsätzlich $v$ i e ls e it i g e $n$ Problems bieten zu können (vgl. Brinkmann 1932/33, S. 41.)

3. Wenn ein Sprachhistoriker vor Linguisten über Stilwandel spricht, so kann der festzulegende Beschreibungsmodus adressatenspezifisch wohl nur in demjenigen der Sprachhistoriographie bestehen, und zwar, versteht sich am Rande, auf möglichst aktuellem Stand. Erklärtes Ziel ist also, wie bereits eingangs als zu lösende Problemstellung ins Auge gefaßt, den einzubringenden Vorschlag für die deskriptive Erfassung von relevanten stilistischen Veränderungen so auszulegen, daß mit seiner Hilfe AnschluB gewonnen werden kann an Modellierungen von Sprachwandel.

3.1 Durchsucht man die verfügbaren bibliographischen Dateien mit Hilfe der Suchwörter Stilwandel und Stilgeschichte nach thematisch einschlägigen Titeln, so hat das Ergebnis des computativen Schnelldurchlaufs insofern Signalfunktion, als zwar eine relativ stattliche Anzahl von Arbeiten aus Nachbar- und Grenzdisziplinen aufgelistet wird, historischstilkundliche (was ausdrücklich heißt: historisch-sprachstilistische) finden sich dagegen kaum - und wenn, dann in enger Überlappung mit der Literaturgeschichte und eigentlich dieser zugehörig: so in erster Linie die bereits angeführten, noch heute äußerst lesenswerten fünf 'Betrachtungen' über "Grundfragen der Stilgeschichte" von H. Brinkmann $(1932 / 33)$, ansonsten aber vor allem eher methodologisch wenig reflektierte, heutigen Anforderungen gar nicht mehr gerecht werdende ad-hocDarstellungen zu einzelnen Autoren, nur gelegentlich einmal über längere Zeiträume hinweg vergleichend wie die (um wenigstens eine stellvertretend zu nennen) von Gottfried Weber (1928), der im Blick auf das Werk Wolframs v. Eschenbach eine Geschichte des Sprachstils vom Altgermanischen bis auf Wolfram zu beschreiben vorgibt, aber leider nicht tatsächlich bietet. Die im übrigen anzutreffenden großrastrigen Entwürfe stilgeschichtlicher Abläufe und Umbrüche, derjenige Cassirers (1923) etwa in seiner "Philosophie der symbolischen Formen I" mit einer dreigliedrigen Stufenfolge (sinnlicher Ausdruck - anschaulicher Ausdruck - Ausdruck begrifflichen Denkens) oder der E. Staigers (1963) (Stilwandel als Wandel des "Rhythmus", verstanden als „Urfigur geschichtlichen Daseins") sollten zwar dem Sprachhistoriker wie vor allem dem Stilwissenschaftler ob ihrer kühnen Zugriffe und weitgespannten Ausblicke Respekt abnötigen, viel praktisch anfangen kann er bei seiner nun doch auf mehr Sprachdetails abgestellten Interessenausrichtung mit ihnen nicht. An der Beob- 
achtung und Beschreibung empirisch erhobener Sprachdaten orientierte Abhandlungen wie die von U. Fix (1990) oder E. Neuland (1994) sind also auch heute noch eher die Ausnahme - und letztgenannte bemerkenswerterweise nicht eigentlich stilkundlich, sondern deutlich soziolinguistisch intendiert. Überfliegt man daraufhin, stutzig geworden, Inhaltsverzeichnisse und Sachwortregister der gängigen Stilmonographien und -lehrbücher, könnte der Eindruck Gestalt annehmen, Ballys kategorisches Diktum von der absoluten Unmöglichkeit, Stilistik als historische Wissenschaft zu betreiben (vgl. Bally 1909), wirke auf verborgene Weise unverkürzt bis in die unmittelbare Gegenwart weiter, denn in der Regel wird hier auf Stilwandel und Stilgeschichte (wohlgemerkt: ich spreche nicht von der Geschichte der Stilistik, einem ganz anderen Sachverhalt) kaum eine Zeile verwendet; eine Begründung habe ich dafür allerdings nicht ausfindig machen können.

Ganz anders das Bild in Sprachgeschichtsdarstellungen des Deutschen. Diese zeigen, wiederum natürlich nur in der Regel, waches Interesse für Stilveränderungen, allerdings vorwiegend in jüngeren und jüngsten Zeitabschnitten, in denen es bekanntermaßen an verwertbaren Veränderungen im Sprachsystem gebricht und individualstilistische Innovationen vor allem großer oder wenigstens größerer Schriftsteller willkommenen Stoff für die Nachzeichnung insbesondere lexikalischer Entwicklungen in der Standardsprache bieten. Pöckl (1980, S. 195f.) stellt in Hinsicht auf die Sprachgeschichtsschreibung des Französischen nachgerade fest:

„Die meisten Sprachgeschichten ... lehnen sich ab dem 17. Jahrhundert stark an die Literaturgeschichte an und zerfallen so in zwei ungleiche Teile: Den Inhalt der ersten Halfte bilden Lautgesetze und Veränderungen der grammatischen Struktur, während der zweite Abschnitt hauptsächlich der Besprechung von Personal- und Gruppenstilen dient."

Das wird man für Sprachgeschichten des Deutschen, insbesondere die jüngeren Datums, meine ich, so nicht sagen können, unter anderem schon deshalb nicht, weil es z.B. im großen Sprachgeschichtshandbuch von Besch/Reichmann/Sonderegger (1984/85) den respektablen - wenn ich recht sehe: ersten - Versuch gibt, eine zusammenhängende stilgeschichtliche Entwicklung der deutschen Literatur- oder Hochsprache zu skizzieren - wenn auch in starker direkter Abhängigkeit von Gegebenheiten der Systementwicklung und auf der Grundlage eines weniger komplexen als des hier dargelegten Stilverständnisses (Seidler 1985, S. 2026-2038). Wie auch immer, eine deutliche, durch die wissenschaftsgeschichtlichen Zeitläufe hindurch offenbar anhaltende sprachhistorische, möglicherweise rhetorikgeschichtlich beeinflußte Affinität zu stilistischen Phänomen ist unverkennbar, und sie kontrastiert ebenso eindeutig mit dem vorgestell- 
ten stilkundlichen Defizit in dieser Beziehung. Ein wenig überzeichnend, könnte man nachgerade von einem Paradoxon relativ geringer Zuwendung der Stilistik zur historischen Dimension ihres Gegenstandes und relativ starker Affinität der historisch orientierten Geistes- und Sozialwissenschaften zu stilistischen Sachverhalten sprechen.

3.2 Wenn die zunächst anmutungsweise postulierte Kontiguität von Stilentwicklung und Sprachentwicklung, von Stilwandel und Sprachwandel kritischem Hinterfragen standhalten und modellgeleiteter untersuchungspraktischer Handhabung zugänglich gemacht werden soll, gehören nun Begriff und Terminus des Stilwandels selbst auf den Prüfstand, der - das war der strategische Zweck der ermüdenden theoretischen Etüden zum Stilverständnis in Abschnitt 2 - mit der Bestimmung und Beschreibung der Komplexität stilsignifikanter Zusammenhänge aufgebaut worden ist. Es ist zwar trivial, wird aber immer wieder mit großer Selbstverständlichkeit außer acht gelassen: Stilwandel „an sich” kann es schon angesichts des Dilemmas heterogener Stilbegriffe doch wohl nicht geben, obwohl sich, hinreichende Sorgfalt meines Suchens für diese Aussage vorausgesetzt, offenbar bislang niemand zu einer exakten Definition von Stilwandel herbeigelassen hat. Der konstatierten Vagheit des Stilbegriffs entspricht folgerichtig die Vagheit der Begriffe Stilwandel und Stilgeschichte und sorgt für (zusätzliche) MiBverständnisse. Das eine Begriffsklärung von Stilwandel - kann nur auf Basis des anderen - Angabe des applizierten Stilbegriffs - gebessert werden.

Konkret beinhaltet das die Notwendigkeit, die angestrebte Annäherungsprozedur der Vorstellungsgehalte von $\mathrm{St}$ il w a n d el und $\mathrm{S} \mathrm{p} \mathrm{r} \mathrm{a} \mathrm{c} \mathrm{h-}$ w a n d e I entsprechend den festgestellten unterschiedlichen Extensionen des Stilbegriffs vorzunehmen und dementsprechend - hier werden Erfahrungen der langdauernden Sprachwandel-Diskussionen bewußt ausgenutzt (vgl. Mattheier 1984a, 1984b) - zunächst einmal unterschiedliche Gegenstandsbereiche bzw. Beschreibungsdimensionen von Stilwandel anzunehmen; sie werden konsequenterweise jeweils bezogen auf die im Vorangegangenen definitorisch festgelegten Bestimmungsstücke des komplexen Zeichens Stil.

a) Unter P r o z e B a s p k t manifestiert sich Stilwandel als synchronisches Phänomen, insofern stilistisches Handeln immer durch Ausdrucksnotwendigkeiten unikaler situativer Konstellationen der Kommunikation determiniert wird, die Stilhandlungen eines Subjekts, der Stil einer Textsorte, eines Registers oder wie immer also niemals mit sich selbst absolut identisch bleiben können. Die gleiche Aussage gilt natürlich ebenso für Sprachwandel, dessen synchronische Erscheinungsweise, wie 
hinlänglich durch Mattheier expliziert, in der grundsätzlichen Variabilität sprachlicher Entitäten besteht. Wenn aber Sprachwandel und Stilwandel nicht von vornherein gleichgesetzt werden sollen oder können, erscheint die SchluBfolgerung zwingend, stilistische und sprachliche Variabilität als diskrete Kategorien zu behandeln, was wiederum die Angabe von Abgrenzungskriterien erforderlich macht. Diese bestehen in folgender Hinsicht: (1) Variabilität als Eigenschaft natürlicher Sprachen existiert im Bezug auf das Sprachsystem, stilistische Variabilität im Bezug auf die systemhaften Regelungen im Rahmen einer Stilformation, manifestiert in Stereotypisierungen verschiedener Reichweite (im beschriebenen Sinne). (2) Stilistische Variabilität ist ausdrucksseitig unter anderen (aber keineswegs ausschlieBlich!) in sprachlichen Varianten materialisiert (die umgekehrt keineswegs ausnahmslos Relevanz für stilistische Variabilität besitzen). (3) Im klaren Unterschied zu sprachlicher ist stilistische Variabilität in jedem Falle intentional gerichtet. Auch an dieser Stelle sei R. Jakobson zitiert, der, anknüpfend an Detailforschungen der formalen Schule, betont,

„daß die Verschiebung, der Wechsel (in den künstlerischen Mitteln. G.L.) kein bloßes Konstatieren von Geschichte ist - anstelle von A entstand A 1 -, sondern daB die Verschiebung auch eine unmittelbar zu erlebende synchrone Erscheinung darstellt, die Verschiebung ist selbst ein wesentlicher künstlerischer Wert." (Jakobson 1987, S. 264).

Die mangelnde Intentionalität bzw. Finalität von Sprachwandel trifft mithin für Stilwandel (auf synchronischer Ebene) gerade nicht zu.

(4) Die linguostilistische Auffassung, Stil bestehe in der Auswahl sprachlicher Varianten, stellt sich schon deshalb als unzulässige Verkürzung dar, als Stilwandel dann nur in linearer Abhängigkeit von soziolingualen oder sprachhistorischen Veränderungen vonstatten gehen könnte und mit soziolingualem Wandel gleichzusetzen - mithin also als Beschreibungsgröße überflüssig - wäre.

Stilistische Variabilität (als synchronische Erscheinungsweise von Stilwandel) wird demgemäB verstanden als die virtuelle Abweichung, die Möglichkeit des Umspielens von stereotypisierten Anweisungen bzw. Orientierungen stilistischen Handelns, deren (im wesentlichen unveränderte) Einhaltung als Normrealisierung dieser Muster oder Sterotypen fungiert (wenn man so will: in stabilisierender Funktion). In der sprachlichen Äußerung tritt sie in der Dichotomie von (stilistischer) Markiertheit vs. (stilistische) Unmarkiertheit in Erscheinung. Es handelt sich dabei um ein Phänomen, das in der sprachstilkundlichen Literatur natürlich längst beobachtet worden und mit verschiedenen, immer jedoch in gegenüberstellenden Begriffspaaren ausdifferenzierten Bezeichnungen versehen worden ist: in der englischen stilkundlichen Literatur des 18. Jahrhunderts, wie wir dank den Forschungen von Assmann (1986) wissen, 
als 'opting out' vs. 'opting in', in Brinkmanns Arbeit von 1932/33 als 'Besonderung' vs. 'Angleichung', bei Seidler (1985) als 'Differenzierung' gegen 'Tradierung'. Daß dies die Stelle wäre, an der das Problem des Individualstils zu seinem Recht kommen müBte, möchte ich nur eben erwähnen (vgl. Lerchner 1980).

Das Beziehungsverhältnis zwischen sprachsystembezogener, soziolingualer und stilistischer Variabilität sei, abschlieBend zu diesem Punkt, durch eine Übersicht veranschaulicht:

\section{Sprachliche und stilistische Variabilität}

(Sprach)Systemaspekt

soziolinguistischer Aspekt

stilistischer Aspekt

STILSYSTEM

STILHANDLUNG

Neuschöpfung von Varianten
Variabilität als natūrliche Systemeigensch aft

- manifestiert in VARIETÄTEN

„stratigraphisches Spannungsverhältnis”

zwischen Varietäten

- manifestiert in soziokommunikativen

BEWERTUNGEN von VARIANTEN

(durchschnittliche) Zuordnungsbeziehung der stratigraphisch strukturierten Varianten zu STEREOTYPEN/MUSTERN der Sprachverwendung relativ zu Redeintention und Redebewertung in kommunikativ akzeptierten Äußerungen

(konkrete) VARIANTENWAHL und/oder VARIANTEN-SCHÖPFUNG/SPIEL MIT

VARIANTEN bei der Realisierung einer Sprachhandlung zum Zwecke der Markierung von Redeintention und Redebewertung

stilsystemkonforme Wahl stilsystemüberschreitende Wahl

synchronischer Aspekt von Stilwandel 
b) Unter P r od u k t a s p e k t , d.h. bezogen auf die Objektivierungen von sozial approbierten innovativen stilistischen Varianten/Variationen im Rahmen der jeweils geltenden Muster/Stereotypen für Stilhandlungen - und das heiBt zugleich und notwendigerweise unter diachronischem Gesichtspunkt - ist der hervorgehobenen Vagheit des Begriffes Stilwandel auf der Basis des entwickelten Stilverständnisses angemessenerweise durch die folgenden Unterscheidungen zu begegnen:

- Stilwandel kann Veränderungen derjenigen geistig-kulturellen Strukturen in einer Kommunikationsgemeinschaft betreffen, die die Stilhandlungen der Sprecher in analytisch nachweisbarer Weise determinieren, also auf der Inhaltsseite von Stil situiert sind (inhaltsseitiger Stilwandel, „Kulturstil”-Wandel, Wandel in der Verhaltensstilisierung). Einen beschreibungspraktisch nur sehr schwer zu funktionalisierenden - Reflex dieses Sachbestandes kann man m.E. in der Größe des Stilideals einer Epoche und dessen beobachtbaren Veränderungen sehen, etwa wenn im 18. Jahrhundert in ganz Westeuropa eine Abkehr von den Maximen einer auf Galanterie und maskenhafte Höflichkeit (Komplimentierbücher!) abgestellten Konversation erfolgt und stattdessen - speziell in der neuen Gattung der "Moralischen Wochenschriften” - auch im sprachlichen Ausdruck ein ungekünstelter, natürlich-freundschaftlicher Umgang propagiert und (in gewissen Grenzen) auch praktiziert wird. Dabei kann schon deutlich werden, daß Stilideale in den Grenzen von sprachübergreifenden Kulturräumen durch das Vehikel Intertextualität transportiert werden und auf diese Weise durchaus auch eine stabilisierende oder gar konservierende Funktion ausüben können. Man denke nur an das klassische, an Schiller geschulte Stilideal des bildungsbürgerlichen Deutschen im 19. Jahrhundert. Insgesamt betrifft diese Erscheinung des inhaltsseitigen Stilwandels eine Dimension stilistischer Veränderungen, die mit Hilfe linguistischer bzw. traditionell linguostilistischer Instrumentarien nicht oder nur peripher erfaßbar wird: Wissensbestände und deren (möglicherweise sozial differenzierte) Verfügbarkeit, soziopsychische (mentale) Dispositionen (Weltsicht; Ideologie im weiten Sinne von Bewußtseins- und BewuBtheitsbereichen), Einstellungskonfigurationen, Geschmack usw.). Stilwandel kann auf diesem Beschreibungslevel nur in interdisziplinärer Kooperation beschrieben werden (und zwar außerhalb des in der bisherigen Praxis üblichen Dilettantismus). Dies mit Nachdruck betont, muß sofort der Nachsatz folgen, daB es durchaus ausdrucksseitige Indikatoren von Stilwandel dieser Dimension zu geben scheint, deren analytische Sicherstellung, bislang nur in ersten Zugriffen erprobt, zu ebenso unverzichtbaren wie erstaunlichen Ergebnissen zu führen vermögen. So hat J. Erben (1994) in einem vor wenigen Wochen vor der Sächsischen Akademie der Wissenschaften in Leipzig gehaltenen Vortrag über „Sprachliche 
Signale zur Markierung der Unsicherheit oder Unschärfe im Neuhochdeutschen" gezeigt, daß Vagheit des (vor allem mündlichen) Ausdrucks zwar so alt sein dürfte wie menschliche Sprachtätigkeit überhaupt, daB aber seit neuhochdeutscher Zeit, besonders deutlich seit dem 18. Jahrhundert, anhand des signifikant zunehmenden Gebrauchs von grammatischen und semantischen Mitteln zur Signalisierung von Unschärfe (Modalwörter, Partikel, „Hecken"-Ausdrücke, semantische Sterotypisierungen wie ich glaube schon, ich denke einmal, ich gehe davon aus, daß usw.) ein deutliche Veränderung der BewuBtheit von Vagheit bei den Sprechern und ihrer Einstellung zu dem Phänomen erkennbar wird. Letztendlich dürfte gewiß auch die erwähnte Abfolge der Großepochen „symbolischer Formen” Cassirers hierhergehören, und weiteres läßt sich bei genauer Durchprüfung der Literatur mit Wahrscheinlichkeit ausfindig machen. Im übrigen wäre die Wissenschaft vom Stil und seinem Wandel sicher nicht schlecht beraten, wenn sie Jost Hermands Appell an die Geisteswissenschaften auch auf sich bezöge (Hermand 1973, S. 194), sich „als Wissenschaft der Geschichte des sich ständig wandelnden menschlichen Geistes und der diesen Wandel bedingenden Faktoren" zurückzubesinnen.

- Auf der Ausdrucksseite kann sich Stilwandel einerseits in der Dimension der Stilmuster und stilistischen Sterotypen (des Stilsystems) manifestieren, andererseits in derjenigen des Repertoires vorhandener bzw. dem Individuum verfügbarer sprachstilistischer Varianten ("Stilelemente") in Erscheinung treten. Für den ersten Fall schlage ich die Bezeichnung (ausdrucksseitiger) Makrostilwandel vor, für den zweiten die Kategorisierung als (ausdrucksseitiger) Mikrostilwandel. Einen charakteristischen Fall für Makrostilwandel stellt, wie ich meine, der in der Geschichte der Rhetorik beobachtete Paradigmenwechsel von Oralität zu Literalität ebenfalls um die Mitte des 18. Jahrhunderts dar, insofern man, wenn man sich häufiger in dieser Epoche bewegt, schon so etwas wie einen schriftinduzierten Stilwandel (ein grundlegend, eben medial induziertes verändertes Verhalten der Sprachbenutzer gegenüber der Erzeugung sprachlicher Äußerungen generell) ausmachen kann - ein hochinteressanter Vorgang, zu dem es aber hinsichtlich der sprachstilistischen Auswirkungen noch kaum verwertbare Einzelanalysen gibt. Auch die Erscheinungen von Stilmischung auf Grund von Textmustermischungen, etwa in den Texten 'kleiner Leute' im 19. Jahrhundert von S. Grosse (1989) beschrieben, oder, um in dem auffälig gewordenen 18. Jahrhundert zu bleiben, in der Trivialliteratur und in den journalistischen Textsorten dieser Zeit als nachgerade typisch nachweisbar (Lerchner 1990) - eine Erscheinungsweise von text(muster)induziertem Stilwandel also - wären zu nennen. Mikrostilwandel im vorgeschlagenen Verständnis ist demgegenüber mit 
der expansiven Erweiterung des Repertoires verfügbarer Sprachstilvarianten angezeigt, die sich, wiederum zur gleichen Zeit, aus der Vertikalisierung der bis dahin nebeneinander existierenden unterschiedlichen Varietäten der deutschen Sprache im Zuge der jetzt verstärkt wirksam werdenden kulturellen Überdachung durch eine Standardvarietät ergibt (vgl. dazu Bellmann 1986).

Die Beispiele sind in voller Absicht gewählt: Vermögen sie doch in ihrer Gesamtheit anschaulich zu machen, daf es sich bei ihnen in der Tat um die Veränderung zusammengehörender, nicht nur zeitlich aufeinander zu beziehender Erscheinungsweisen oder eben um Dimensionen eines komplexen Zeichens Stil auf einer bestimmten Zeitstufe handelt. „Vor 1750 ... gestaltet der Mensch als überindividuell gebundenes Wesen, aus den Kräften eines Allgemeineren, einer Gemeinsamkeit heraus, die er in sich aufnimmt ..., nach 1750 gestaltet er aus den Kräften des Ich" (Brinkmann 1932/33, S. 23). Die Qualität der wechselseitigen Relationen zwischen den Ebenen entspricht dabei genau der eines Zeichens: sie ist gekennzeichnet durch Arbitrarität. Das heißt, die Erscheinungen von Stilwandel verschiedener Dimension stehen in keinerlei kausalem Verhältnis von Ursache und Wirkung zueinander. Aber sie sind aufeinander abbildbar und in ihrer $G$ e $s t a l t g a n z h$ e i $t$ gegenüber einer einfachen Summierung von zufalligen Einzelerscheinungen, als die sie gewöhnlich in sprachgeschichtlichen Darstellungen mehr oder weniger vollständig aufgelistet werden, signifikant aussagekräftiger für die Charaktersierung der Stilgeschichte dieser Zeit, die sie gestalten.

An dieser Stelle breche ich ab - mit einem gewissen Recht, wie ich glaube, denn hier mündet die Erörterung in Zusammenhänge einer Stilgeschichte, die auftragsgemäb nicht mehr unmittelbar zu meinem Thema gehören und weit über das hinaus, was sich andeutungsweise bereits perspektivisch ergeben hat, verfolgt und ausgebaut werden müßten. Der wichtigste Gesichtspunkt dürfte dabei m.E. unzweifelhaft der sein, daß sich im Beschreibungskontext von Stilformationen, mit denen es Stilgeschichte nach den hier entwickelten Gedanken ja zu tun hat, das Interesse nicht nur auf Stilwandel, sondern mit gleichem Gewicht auch auf Stilkonstanz richten muB. Beide gemeinsam erst ergeben das plastische Bild einer Stilformation, das durch die historische Gleichzeitigkeit von Verläufen unterschiedlichen Alters und unterschiedlicher Morphologie mit je eigenen Zeitmaßen und sozialen Funktionen und darum auch unter Umständen durch das synchronische Nebeneinander divergierender Stiltendenzen (wie sie etwa bei Seidler (1985) und Pöckl (1980) beobachtet worden sind) gekennzeichnet ist. Die Stilidentität einer Stilformation oder Epoche, um wenigstens dies noch zu sagen, dürfte sich mithin 
in der Quasi-Identität eines Kulturraumes manifestieren und letztlich ohne unmittelbaren Bezug auf Kultursemiotik und Kulturmorphologie nicht vollständig beschreibbar sein. Das wäre dann auch die Antwort des Sprachhistoriographen auf die Frage, wozu er den Stilbegriff braucht, und was er ihm bringt.

Anstelle der nun zu erwartenden Zusammenfassung möchte ich den Versuch einer Definition von $S \mathrm{t}$ i l w a n d e l unternehmen: Unter der Bezeichnung sei demnach terminologisch fixiert der synchronisch oder metachronisch beschreibbare Verlust oder Gewinn pragmatischer („perlokutiver”) Markiertheit von dem stilistisch handelnden Subjekt auf einer Zeitebene jeweils verfügbaren sprachlichen oder (anderen) semiotischen Instrumentarien, bezogen auf deren sozial durchschnittlichen Gebrauch in spezifischen Organisationsformen von Kommunikation (bzw. kommunikativer Interaktion).

Man kann das übrigens auch anders sagen - weniger genau zwar und nicht die ganze Breite des Spektrums der behandelten Probleme abdeckend, dafür aber viel, viel anschaulicher und dadurch möglicherweise auch überzeugender:

„Wenn wir in einem Anfall von Zärtlichkeit oder Bosheit einem Menschen liebend zusprechen oder einen Menschen beleidigen wollen, dann genügen uns die verschlissenen, abgenagten Worte nicht, dann ballen und zerbrechen wir sie, damit sie das Ohr treffen, damit man sie sehen kann und sie nicht nur wiedererkennt." (V. Schklowski 1914).

\section{Literatur}

Anderegg, J. (1977): Literaturwissenschaftliche Stiltheorie. Göttingen.

Assmann, A. (1986): „Opting in” und „opting out”. Konformität und Individualität in den poetologischen Debatten der englischen Aufklärung. In: Gumbrecht/Pfeiffer (Hg.) (1968), S. 127-143.

Bally, Ch. (1909): Traité de stilistique française. 1. Bd. Heidelberg.

Bellmann, G. (1986): Zweidimensionale Dialektologie. In: Bellmann, G. (Hg.): Beiträge zur Dialektologie am Mittelrhein. Stuttgart. S. 1-55. (= Mainzer Studien zur Sprach- u. Volksforschung, 10).

Besch, W./Reichmann, O./Sonderegger, St. (Hg.) (1984/1985): Sprachgeschichte. Ein Handbuch zur Geschichte der deutschen Sprache und ihrer Erforschung. 2 Halbbde. Berlin/New York. (= Handbücher zur Sprachund Kommunikationswissensch aft, 2.1/2.2.).

Besseler, H. (1931) (Neudruck 1979): Die Musik des Mittelalters und der Renaissance. Potsdam. (= Handbuch der Musikwissenschaft, 1).

Brinkmann, H. (1932/1933): Grundfragen der Stilgeschichte. Fünf Betrachtungen. In: Brinkmann, H. (Hg.) (1966): Studien zur Geschichte der deutschen Sprache und Literatur. Bd.2. Dūsseldorf. S. 9-57. 
Cassirer, B. (1923): Philosophie der symbolischen Formen. I. Die Sprache. Berlin. 9. Auflage.

Eco, U. (1968): Einführung in die Semiotik. München.

Erben, J. (1994): Sprachliche Signale zur Markierung der Unsicherheit oder Unschärfe von Aussagen im Neuhochdeutschen. Vortrag vor dem Plenum der Sächsischen Akademie der Wissenschaften zu Leipzig am 11.2.1994 (erscheint in den Sitzungsberichten der Akademie).

Fix, U. (1990): Der Wandel der Muster - Der Wandel im Umgang mit den Mustern. Kommunikationskultur im institutionellen Sprachgebrauch der DDR am Beispiel von Losungen. In: Deutsche Sprache 18, S. 332-347.

Fix, U. (1991a): Vorbemerkungen zu Theorie und Methodologie einer historischen Stilistik. In: Zeitschrift für Germanistik (N.F.) 1, H.2, S. 299-310.

Fix, U. (1991b): Stilistische Textanalyse - immer ein Vergleich? Das Gemeinsame von Methoden der Stilanalyse - das Gemeinsame an Stilbegriffen. In: Germanistische Linguistik 106-107, S. 133-156.

Gadamer, H.-G. (1975): Exkurs I. In: Wahrheit und Methode. 4.Aufl. Tübingen.

Gosebruch, M. (1981): Epochenstile - historische Tatsächlichkeit und Wandel des wissenschaftlichen Begriffs. In: Zeitschrift für Kunstgeschichte 44, H.1, S. 9-14.

Grosse, S. (1990): Zu Syntax und Stil in der deutschen Sprache des 19. Jahrhunderts. In: Betten, A. (Hg.): Neuere Forschungen zur historischen Syntax des Deutschen. Tübingen. S. 300-309. (= Reihe Germanistische Linguistik, 103).

Gumbrecht, H.U./Pfeiffer, K.L. (Hg.) (1986): Stil. Geschichten und Funktionen eines kulturwissensch aftlichen Diskurselements. Frankfurt. ( $=$ SuhrkampTaschenbuch Wissenschaft, 633).

Gumbrecht, H.U. (1986): Schwindende Stabilität der Wirklichkeit. Eine Geschichte des Stilbegriffs. In: Gumbrecht/Pfeiffer (Hg) (1986), S. 726-788.

Halbach, K.H. (1935): Der deutsche Mensch in der staufischen Dichtung. In: Zeitschrift für Deutschkunde 1935, S. 531-543.

Hermand, J. (1973): Synthetisches Interpretieren. Zur Methodik der Literaturwissenschaft. 4.Aufl. München.

Jakobson, R. (1987): Die Dominante. In: Mierau, F. (Hg.): Die Erweckung des Wortes. Essays der russischen Formalen Schule. Leipzig. S. 258-264. (= Reclams Universalbibliothek, 1163).

Kainz, F. (1926): Vorarbeiten zu einer Philosophie des Stils. In: Zeitschrift für Ästhetik 20, S. 21-49.

Lerchner, G. (1980): Individualstil und gesellschaftliche Sprachtātigkeit. In: Zeitschrift für Phonetik, Sprachwissenschaft und Kommunikationsforschung 33, H.1, S. 48-55.

Lerchner, G. (1990): Mustermischung und Sprachausgleich im trivialliterarischen Diskurs des 18. Jahrhunderts. In: Zeitschrift für Germanistische Linguistik 18, H.3, S. 261-272. 
Mattheier, K.J. (1984a): Allgemeine Aspekte einer Theorie des Sprachwandels. In: Besch/Reichmann/Sonderegger (Hg.) (1984), Bd.1, S. 720-730.

Mattheier, K.J. (1984b): Sprachwandel und Sprachvariation. In: Besch/Reichmann/Sonderegger (Hg.) (1984), Bd.1, S. 768-779.

Möbius, F. (Hg.) (1984): Stil und Gesellschaft. Ein Problemaufrif. Dresden. (= Fundus-Bücher 89/90).

Möbius, F. (1988): Die Dorfkirche im Zeitalter der Kathedrale (13. Jahrhundert). Plädoyer für eine strukturgeschichtliche Vertiefung des Stilbegrifts. Berlin. (= Sitzungsberichte der Sächsischen Akademie der Wissenschaften zu Leipzig, Phil.-hist.Klasse 128,3).

Nadler, J. (1930): Das Problem der Stilgeschichte. In: Ermatinger, E. (Hg.) (1930): Philosophie der Literaturwissenschaft. Berlin. S. 376-397.

Neuland, E. (1994): Jugendsprache und Standardsprache. Zum Wechselverhältnis von Stilwandel und Sprachwandel. In: Zeitschrift für Germanistik (N.F.) 4, H.1, S. 78-98.

Pōckl, W. (1980): Plädoyer für eine diachrone Stilistik. In: Sprachkunst 1980, II, S. 192-204.

Por, P./Radnóti, S. (Hg.) (1990): Stilepoche: Theorie und Diskussion. Eine interdisziplināre Anthologie von Winckelmann bis heute. Frankfurt/Bern/New York/Paris.

Rosenberg, R. (1984): Stil und Stilauffassung in der Literaturgeschichte. In: Möbius, F. (Hg.) (1984), S. 70-85.

Rosenberg, R. (1986): > Wechselseitige Erhellung der Künste? $<$ Zu Oskar Walzels stiltypologischem Ansatz der Literaturwissenschaft. In: Gumbrecht/ Pfeiffer (Hg.) (1986), S. 269-280.

Sandig, B. (1986): Stilistik der deutschen Sprache. Berlin/New York.

Schklowski, V. (1914): Die Erweckung des Wortes. In: Mierau, F. (Hg.) (1987): Die Erweckung des Wortes. Essays der russischen Formalen Schule. Leipzig. S. 9. (= Reclams Universalbibliothek, 1163).

Schwietering, J. (1941): Die deutsche Dichtung des Mittelalters. Potsdam. (= Handbuch der Literaturwissenschaft, 8).

Seidler, H. (1985): Stilistische Differenzierung des Deutschen in historischer Sicht. In: Besch/Reichmann/Sonderegger (Hg.) (1985), Bd. 2, S. 20262038.

Sonderegger, St. (1990): Grundsātzliche Ūberlegungen zu einer literarischen Sprachgeschichte des Deutschen. In: Besch, W. (Hg.) (1990): Deutsche Sprachgeschichte. Grundlagen, Methoden, Perspektiven. Festschrift für J. Erben zum 65. Geburtstag. Frankfurt/Bern/New York/Paris. S. 31-49.

Sowinski, B. (1991): Stilistik. Stiltheorien und Stilanalysen. Stuttgart. (= Sammlung Metzler, 263).

Staiger, E. (1963): Stilwandel. Studien zur Vorgeschichte der Goethezeit. Berlin.

Stepanov, Ju.S. (1971): Semiotika. Moskva. 
Walzel, O. (1917): Wechselseitige Erhellung der Künste. Ein Beitrag zur Würdigung kunstgeschichtlicher Grundbegriffe. Berlin. (= Vorträge der Kant-Gesellsch aft, 15).

Walzel, O. (1923): Gehalt und Gestalt im Kunstwerk des Dichters. BerlinNeubabelsberg. ( $=$ Handbuch der Literaturwissenschaft, 1 ).

Weber, G. (1928): Wolfram von Eschenbach. Seine dichterische und geistesgeschichtliche Bedeutung. 1.Bd.: Stoff und Form. Frankfurt.

Wölfflin, H. (1915): Kunstgeschichtliche Grundbegriffe. Das Problem der Stilentwicklung in der neueren Kunst. (2. Aufl. Dresden 1983). 


\section{Stil und Stilbegriff in der neueren Literaturwissenschaft}

1.

Die Antwort auf die Frage, die sich im Titel versteckt, läßt sich mit wenigen Worten umreißen: In der Literaturwissenschaft ist es still geworden um Stil und Stilbegriff. Alles deutet darauf hin, daB Stilbegriff und Stiluntersuchung ihre große und gute Zeit hinter sich haben - nämlich die Zeit der sogenannten Werkinterpretation. Wenn die Werkinterpretation sich durch besondere Textnähe auszeichnete, so ist dies in erster Linie der damals dominierenden Frage nach dem Stil zuzuschreiben. Und die Frage nach dem Stil war es auch, die den Zugang zum 'Kern der Sache' zu gewähren versprach, zu dem nämlich, was den Text zum Kunstwerk zu machen schien, zu seinem ästhetischen Wert. Grundlegend war dabei die Vorstellung der Einstimmigkeit des literarischen Texts - ein spätes Kind des klassischen Ideals von der Einheit in der Vielfalt -, und die Stiluntersuchung galt als das Instrument, mit dem sich die Einstimmigkeit erfassen lieb.

Zum Ausbau der Stiltheorie hat die Werkinterpretation wenig beigetragen, und die damaligen methodischen Überlegungen zur Stiluntersuchung nehmen sich aus heutiger Sicht erschreckend bescheiden aus. Was aber die Praxis der Stiluntersuchung betrifft, so sind im Rahmen der Werkinterpretation Arbeiten von hohem, ja höchstem Rang vorgelegt worden. $\mathrm{Zu}$ erinnern wäre etwa an Richard Alewyns Beitrag über Eichendorff, an Walther Rehms Untersuchung von Rumohrs Kochkunst, an Emil Staigers programmatische Aufsätze zu Kleist oder Brentano und - um auch einen Vertreter jüngerer Generationen zu nennen - an Albrecht Schönes Analyse von Musils Konjunktivgebrauch. ${ }^{1}$ Diese und zahlreiche andere auf Aspekte des Stils ausgerichteten Arbeiten haben

1 Alewyn, Richard (1957): Eine Landschaft Eichendorfs. In: Euphorion 51, S. 42-60. Wiederabgedruckt in Stöcklein, Paul (Hg.) (1966): Eichendorff heute. Stimmen der Forschung. Mit einer Bibliographie. Darmstadt.

Rehm, Walther (1964): Rumohrs Geist der Kochkunst und der Geist der Goethezeit. In: ders.: Späte Studien. Bern. S. 97-121.

Staiger, Emil (1957): Kleist, Das Bettelweib von Locarno. In: ders.: Meisterwerke deutscher Sprache. Aus dem 19. Jahrhundert. Zürich. S. 100-117. Staiger, Emil (1953): Die Zeit als Einbildungskraft des Dichters. Untersuchungen zu Gedichten von Brentano, Goethe und Keller. Zürich.

Schöne, Albrecht (1961): Zum Gebrauch des Konjunktivs bei Robert Musil. In: Euphorion 55, S. 196-220. 
sich der Geschichte der Germanistik eingeschrieben und sind für den am Text interessierten Leser noch heute von Bedeutung.

\section{2.}

In den sechziger und siebziger Jahren wuchs das Bedürfnis, die Beschäftigung mit Texten als wissenschaftlich auszuweisen, und das heißt auch: sie zu objektivieren. Die Forderung nach einem kritischen MethodenbewuBtsein, die Frage nach der anzuwendenden Methode, der Wunsch nach einer literaturwissenschaftlichen Terminologie oder doch mindestens nach begrifflicher Klärung, und nicht zuletzt die damals weit verbreitete Auffassung, es bedürfe der Umgang mit Literatur generell der Legitimation und der reflektierenden Absicherung, führten zu einer bis dahin unüblichen Theoretisierung der Literaturwissenschaft.

Je mehr die Theorie an Boden gewann, um so mehr verlor die der Theorie wenig geneigte Werkinterpretation an Bedeutung. Das Ansehen des Stilbegriffs aber blieb vorerst unangetastet. Die literaturwissenschaftliche Praxis hatte seine zentrale Bedeutung in vielfaltiger Weise bestätigt; unbezweifelbar schien es, daß Stilbegriff und Stiluntersuchung bei der Annäherung an Literatur Schlüsselfunktionen hatten. Vielerorts scheint der Stilbegriff damals noch als das eigentliche Rückgrat der Literaturwissenschaft gegolten zu haben; an ihm mußte sich deshalb ihre Wissenschaftlichkeit erweisen. So galt es denn, nachzuholen, was man bisher versäumt hatte: Der Begriff des Stils mußte definiert und in einen Theorierahmen eingefügt werden; die Stiluntersuchung bedurfte der methodologischen Grundlegung.

Aus dem Bedürfnis heraus, den Begriff des Stils und seinen Gebrauch zu klären und festzuschreiben, entwickelte sich bald ein lebhafter Definitionsstreit, und Stiltheorien unterschiedlichster Art traten miteinander in Konkurrenz. Traditionalisten versprachen sich, nicht nur terminologisch unbekümmert, von der Stiluntersuchung den Zugang zur "Gemüthaftigkeit" des Werks" ${ }^{2}$, man bezog den Stilbegriff, den Spuren Ballys folgend ${ }^{3}$, auf den „affektiven Gehalt” von Sprache, und auch Buffons "Le style est l'homme même" erwies sich als revitalisierbar. Bei anderen Definitionsversuchen standen neuere, insbesondere linguistische Entwicklungen oder gerade aktuelle Begriffe Pate: So ließ sich beispielsweise der Gegensatz von Denotation und Konnotation stiltheoretisch

2 Vgl. Seidler, Herbert (1963): Allgemeine Stilistik. 2. Auflage. Göttingen.

3 Bally, Charles (1909): Traité de Stylistique Française I/II. Seconde Edition. Heidelberg/Paris. 
fruchtbar machen. Mit der Bestimmung von Stil als einer Deviation von der Norm kamen frühere theoretische Versuche, insbesondere des Formalismus, zu neuen (und diesmal etwas fragwürdigen) Ehren. Andere liefen sich von Erfahrungen im Bereich der Stillehre leiten und propagierten - unterstützt wohl auch durch damals neuere Entwicklungen in der Grammatiktheorie - einen Stilbegriff, der sich am Prinzip der Wahl orientierte.

Freilich wurde nach kurzer Zeit deutlich, daB mit Einigkeit in der Stilfrage nicht zu rechnen sein würde, die (bald einmal verzweifelten) Anstrengungen, zu einem verbindlichen Stilbegriff zu kommen, erwiesen sich als erfolglos. Der ursprüngliche Optimismus begann angesichts der Vielzahl von Stilbegriffen zu schwinden, und Irritation machte sich breit: Jeder Versuch, das Begriffswirrwarr doch noch zu beseitigen und ihm endlich die stichfeste, gültige Definition entgegenzusetzen, vergrößerte nur das heillose Neben- und Durcheinander.

Gründe für das Scheitern der literaturwissenschaftlichen Bemühungen um den Stilbegriff lagen auf der Hand. Es ließ sich und es läßt sich ohne großen Aufwand zeigen, daB einige der Definitionsversuche zu eng, $\mathrm{daB}$ andere zu weit waren, daB widersprüchlich oder tautologisch argumentiert wurde. Wichtiger ist im hier gegebenen Zusammenhang aber die Erfahrung, daB die stiltheoretische Auseinandersetzung bei allen Fragwürdigkeiten im einzelnen den Sinn für die differenzierte Textbetrachtung zu schärfen vermochte und wichtige Aspekte des Rezeptionsvorgangs bewubt machte. Und auch dies verdient festgehalten zu werden: Zumindest für einige Zeit war die Frage nach dem Stilbegriff Anlaß für einen freundlichen Brückenschlag $\mathbf{z w i s c h e n ~ L i t e r a t u r w i s s e n s c h a f t ~ u n d ~}$ Linguistik.

\section{3.}

Dem stiltheoretischen Sturm der sechziger und siebziger Jahre ist mittlerweile, jedenfalls in der Literaturwissenschaft, die Flaute gefolgt. Wolfgang Kayser hat 1948 in seinem damals grundlegenden und über die Grenzen des deutschen Sprachraums hinaus bekannten Buch „Das sprachliche Kunstwerk" ${ }^{4}$ eines von zehn Kapiteln dem Stil gewidmet. Fünfundzwanzig Jahre später, 1973, finden sich in "Grundzüge der Literatur- und Sprachwissenschaft" 5 neben Ausführungen zu Rheto-

4 Kayser, Wolfgang (1948): Das sprachliche Kunstwerk. Eine Einführung in die Literaturwissenschaft. Bern.

5 Arnold, Heinz Ludwig/Sinemus, Volker (Hg.) (1973): Grundzūge der Literatur- und Sprachwissenschaft. Band I. Literaturwissenschaft. München. 
rik und Poetik immerhin noch zwanzig Seiten zu Stilbegriff und Stiltheorie. In Eagletons "Einführung in die Literaturtheorie”, seit 1988 in deutscher Übersetzung vorliegend, ist dagegen über Stil oder Stiltheorie kein Wort zu finden, und die "Critical Terms for Literary Study" 7 von F. Lentricchia und Th. McLaughlin von 1990 führen zwar 'Structure', 'Discourse', 'Rhetoric' und 'Gender' auf, aber über den Begriff des Stils schweigt sich der Band aus. Gewiß finden sich auch Gegenbeispiele, so die 1991 erschienene "Einübung in die Literaturwissenschaft" 8 von $\mathrm{H}$. Fricke und R. Zymner; es handelt sich dabei aber bezeichnenderweise nicht eigentlich um eine Theorie der Literatur oder der Literaturwissenschaft, sondern um eine praktische Anleitung für den Umgang mit Texten.

Dem Abgesang auf den Stil ist indes ein deutliches „und dennoch!” entgegenzusetzen. Weder das Versagen der Stiltheorie, noch die wiederholte Versicherung, es gäbe keinen Stil und die Stiluntersuchung sei tot, haben in der Praxis die Stiluntersuchung oder allgemeiner die Frage nach dem Stil verdrängen können. So ist fast unvermeidbar von Stil die Rede, wo immer das Lesen gelehrt wird, und dabei fallt auf, daß auch durchaus ungeklärte, ja widersprüchliche Verwendungen des Stilbegriffs zu brauchbaren Resultaten führen und das Textverständnis fordern können. Auch haben sich offenbar wichtige und wichtigste Autoren gerade ihres Stils wegen in das literarische BewuBtsein eingeschrieben - an Eichendorff und Kleist wäre zu erinnern, an Thomas Mann und an Max Frisch -, und es ist schwer denkbar, daß von solchen Autoren kompetent gehandelt wird, ohne daB Stilistisches zur Sprache käme.

Im Zusammenhang mit typologischen Fragen, deren Wissenschaftlichkeit erstaunlich wenig bezweifelt wird, ist die Stilfrage nach wie vor kaum vermeidbar; wenn es um Zuordnungen zu Strömungen und Epochen geht oder zu unterschiedlichen Phasen eines Gesamtwerks, ist uns das Reden über Stil geläufig und unproblematisch. Und auch dann ist vom Stil die Rede, wenn es gilt, Beziehungen zwischen der Literatur und anderen Künsten zu erhellen.

6 Eagleton, Terry (1988): Einführung in die Literaturtheorie. Stuttgart.

7 Lentricchia, Frank/McLaughlin, Thomas (Hg.) (1990): Critical Terms for Literary Study. Chicago.

8 Fricke, Harald/Zymner, Rüdiger (1991): Einübung in die Literaturwissenschaft: Parodieren geht über Studieren. Paderborn. 
DaB Fragen nach Stil und Stilistischem nach wie vor aktuell und sinnvoll sein können, zeigt mit besonderer Deutlichkeit die gegenwärtige Literaturkritik, die in erstaunlich hohem Maße Stilkritik ist - gleichgültig, ob es sich dabei um das traditionelle Besprechungswesen, um öffentliche Jurydiskussionen oder um Fernsehshows handelt. Allerdings ist es wohl gerade die Neigung der Literaturkritik zur Stilkritik, die manchen Wissenschaftler davon abhält, die Literaturkritik als Wissenschaft zu anerkennen: Dem Reden über Stilistisches fehlt es an Präzision; oft klingt es nicht wissenschaftlich, sondern alltäglich. Und wer wollte es bestreiten: Das Reden über Stilistisches gehört durchaus zu unserem Alltag. Im Alltäglichen - und ganz ohne wissenschaftliche Aspirationen - nehmen wir Stil wahr, werden wir von Stilistischem beeinflußt. Oft gilt beispielsweise schon das erste Blättern in einem neuen Buch dem Stil, und aufgrund stilistischer Eindrücke entscheiden wir uns für oder gegen den Kauf. Flüchtige Lektüre genügt, um einen Text dem Stil des Rokoko oder dem des Sturm und Drang zuzuordnen, und wenn wir einen Text, mit erheblicher Sicherheit, diesem oder jenem Autor zuschreiben, Chandler oder Highsmith, Frisch oder Handke, so tun wir dies aufgrund unserer stilistischen Erfahrung und Wahrnehmung. Auch wenn uns das als Wissenschaftler vielleicht nicht genehm ist: Stilistische Aspekte eines Textes drängen sich unserer Wahrnehmung auf, sprechen uns an oder irritieren uns - lange bevor wir angefangen haben, über den Text nachzudenken und lange bevor wir imstande sind, den Text wissenschaftlich zu befragen.

Weithin unentbehrlich in der Praxis - kaum mehr beachtet in der Theorie: So ließe sich der gegenwärtige Status von Stil und Stilbegriff zusammenfassen. Die folgenden Überlegungen gelten denn auch vor allem diesem Gegensatz zwischen Theorie und Praxis. Wie kommt es, daß wir die Frage nach dem Stil aus unseren theoretischen Überlegungen ausklammern, obwohl wir sie tagtäglich in verschiedensten Zusammenhängen stellen? Wie läßt es sich erklären, daß die Wissenschaft einen Begriff unbeachtet läßt, dessen Aktualität sich immer von neuem zu bestätigen scheint?

4.

Im Feld der Praxis, beim unmittelbaren Umgang mit Literatur ist die Frage nach dem Stil vor allem eine Ordnungs- und Orientierungsfrage. Wer nach dem Stil fragt, will sich in der sprachlichen Vielfalt - sei es eines einzelnen Texts, sei es mehrerer Texte oder Textgruppen - orientieren. 
Er sucht nach Zusammenhängen, bemüht sich, sprachliche Erscheinungen zu bündeln, unterscheidet Verbindendes und Trennendes, um so im Vielgestaltigen eine Ordnung zu entdecken oder herzustellen.

Diese Feststellung ist, bei aller Selbstverständlichkeit, insofern bemerkenswert, als der literarische Text dazu angetan ist, bestehende konventionelle Ordnungen in Frage zu stellen, sie zu verändern oder aufzulösen. So zumindest - als Infragestellung unserer konventionellen Wahrnehmungsordnungen - verstehen wir den literarischen Text, wenn wir ihn in seiner Literarität zu erfassen und ernst zu nehmen trachten. Wenn die Stiluntersuchung des literarischen Texts seiner 'Subversivität' oder seiner Widerborstigkeit Rechnung tragen soll, ist es zumindest unwahrscheinlich, da B sie ihm in einer Systematik, in einer bestehenden Ordnung also, einen eindeutigen Ort zuweisen kann, und es erscheint widersprüchlich oder mindestens fragwürdig, ihm einen solchen Ort überhaupt zuweisen zu wollen. Das heiBt aber, daß die Frage nach dem Stil beim literarischen Text an ihre Grenze kommt. Sie entspringt einem dringenden und legitimen Ordnungs- und Orientierungsbedürfnis, aber eine gesicherte Ordnung läßt sie nicht erwarten, und sie kann sie, wenn sie ihrem Gegenstand gerecht werden will, nicht einmal anbieten wollen. Sie wird durch das, worauf sie gerichtet ist, $\mathbf{z w a r}$ nicht aufgehoben, wohl aber wird sie vom literarischen Text gewissermaßen zurückgeworfen.

Wer sich orientieren will, wer, um sich zu orientieren, nach Ordnungen sucht, ist auf das Vergleichen angewiesen. Dabei versteht es sich von selbst, daß das Ziel nur erreicht werden kann, wenn der Bereich des Vergleichbaren begrenzt ist. Eben diese Voraussetzung ist, wenn es um die stilistische Ordnung im Literarischen geht, nicht gegeben: Das Vergleichskorpus ist weder klar umgrenzt noch läßt es sich objektiv festschreiben. Selbst wenn Kanonbildungen zu gesellschaftlichen Gemeinsamkeiten führen oder kulturell bedingte Verhaltensweisen und Werthaltungen die Wahrnehmungen kanalisieren, bleibt die Tatsache bestehen, daB Leser sich bei ihrem ordnenden Vergleichen auf die je eigene Leseerfahrung beziehen. Oder, um es mit den Worten von Barbara Sandig zu sagen: "Was Stil ist, ist abhängig von den Kenntnissen des Rezipienten." 9 Besonders fällt dabei ins Gewicht, daß das Textkorpus, das vergleichend herangezogen werden kann, ständigem Wachstum ausgesetzt ist. Um das Problem mit einem Beispiel zu verdeutlichen: Der wohlgefügte Satz ist nach James Joyce nicht mehr, was er zuvor war. Das Fortschreiben verändert den Stellenwert des Geschriebenen.

9 In ihrem Vortrag "Tendenzen der linguistischen Stilforschung" am 15.3.1994. 
Das heiBt nun aber, daß die Frage nach dem Stil, insofern sie Ordnungsund Orientierungsfrage ist, immer nur zu einer relativen, zu einer vorläufigen Antwort führen kann. Oder anders und härter: Als Ordnungsfrage bleibt die Frage nach dem Stil im Bereich des Literarischen eine grundsätzlich unerledigte Frage. Nicht, då sie deshalb an Bedeutung verlöre. Im Gegenteil: Weil immer wieder Neues geschieht oder Neues entdeckt wird, werden bisherige Ordnungen fragwürdig, bedürfen wir von neuem der Orientierung. Die Fragwürdigkeit der Antwort hält die Stilfrage am Leben.

Die Legitimation der Frage nach dem Stil - und die Legitimation ihrer Repetition - sind augenfällig: Die Frage nach dem Stil entspricht dem grundlegenden Bedürfnis - wenn man so will: dem anthropologischen Grundbedürfnis -, sich im Vielfältigen zurechtzufinden und den verunsichernden Veränderungen durch jeweils neue Orientierung $z u$ begegnen. Zugleich aber dürfte nun auch deutlich geworden sein, dab die Frage nach dem Stil als eine, zumindest im Literarischen, grundsätzlich unerledigte Frage der Wissenschaft suspekt sein muB; sie grenzt sich jedenfalls aus dem Bereich jener Wissenschaft aus, deren Ziel es ist, erworbenes Wissen systematisch geordnet zu kumulieren, die darum als Resultat gelten läßt, was festgeschrieben werden kann, und deren Stärke darin liegt, daß sie das einmal Erworbene nicht mehr in Frage stellen muB.

5.

Die Frage nach dem Stil ist allerdings nicht nur eine Ordnungs- oder Orientierungsfrage, sondern auch eine Identitäts- oder Identifikationsfrage. Sie zielt auf das je Eigenartige und Einmalige - sei es eines einzelnen Texts, sei es einer Textgruppe, eines Gesamtwerks etwa, einer Gattung oder einer historischen Strömung.

Als Identifikations- und Identitätsfrage gründet die Frage nach dem Stil in unserem Bedürfnis, das Konstante im Wechselnden, im Verschiedenen das Identische zu erkennen. Impetus des Fragens ist stets das identifizierende Wiedererkennenwollen, und die Beschäftigung mit dem Stil ist darum immer Beschäftigung mit Wiederkehrendem, mit Wiedererkennbarem. So gesehen ist die Frage nach dem Stil ein Kind des 18. Jahrhunderts: Dem modernen Geschichts- und Zeitbewußtsein verdankt die Frage nach dem Gleichbleibenden, nach dem Identischen in der Zeit, ihre besondere Aktualität.

Die Frage nach dem Stil ist nun freilich, auch als Identifikationsfrage, nicht eine Frage nach der Substanz oder nach Substanzen; sie zielt nicht auf Materielles, sondern auf die Organisation von Texten, auf das Funk- 
tionieren von Textelementen. Insofern ist es durchaus richtig, wenn in der Polemik gegen Stilbegriff und Stiluntersuchung immer wieder behauptet wurde, daß es den Stil nicht gäbe: Das Prinzip einer Organisation, das Prinzip des Funktionierens ist nicht in dem Sinne zu haben, wie man etwa chemische Substanzen haben kann. Und genau darum geht es bei der Frage nach dem Stil: Um das Prinzipielle. Wer nach dem Stil fragt, ist keineswegs an allem interessiert, was dem Problem des Organisiertseins oder des Funktionierens zugeordnet werden könnte. Auch fragt er nicht wahllos nach allem, was in irgendeiner Weise wiederkehrt. Auf das Wiederkehrende zielt die Frage nach dem Stil, insofern es ihr um das Prinzip geht, dem Eigenart oder Einmaligkeit zuzuschreiben sind.

Insofern die Frage nach dem Stil als Identifikationsfrage derart auf das Prinzipielle, auf die Art und Weise, ausgerichtet ist und also das Gleiche im Verschiedenen, das Allgemeine im Besonderen sucht, führt sie den Fragenden in ein beunruhigendes Spannungsfeld. Um zum Eigenartigen zu kommen, klopft sie das Verschiedene auf ein Gleiches hin ab; sie sucht das Besondere - eben die Eigenart oder die Identität - als ein Allgemeines. Oder anders: Das Allgemeine, nämlich das Prinzipielle, das sie beschreibt, gilt ihr als das Besondere, Eigenartige. Die Stilfrage erweist sich als ein Irritans, denn was sie als Identitätsfrage zu Tage fördert, ist gerade das, was die Identität in Frage stellt: Das Prinzipelle ist nicht nur das Wiederkehrende, sondern grundsätzlich auch das Wiederholbare; das rufen uns Stilzitate und Stilparodien immer wieder in Erinnerung.

Das Prinzipielle, das die Stiluntersuchung zu fassen trachtet, macht den Text oder die Textgruppe zu einer Art Ganzheit: Weil im Verschiedenen das eine Prinzip erkennbar wird, läßt es sich als ein Zusammengehöriges begreifen. Dennoch erfaBt die Stiluntersuchung ihren Gegenstand - den Text oder die Textgruppe - gerade nicht in seiner Ganzheit, und dies nicht nur, weil bei unterschiedlich angelegten Stiluntersuchungen jeweils verschiedene Aspekte ein und desselben Texts beleuchtet werden. Immer ist ein Text noch etwas anderes als das, was er stilistisch ist. Der Text, den ich aufgrund seines Stils einem Autor, einer Zeit, einer Gattung zuweise, ist immer mehr als das, was ihn zum Text dieses Autors, dieser Zeit oder dieser Gattung macht. Die Stilfrage ist darum immer nur eine mögliche Frage neben anderen Fragen, und ihre Relevanz muß sie diesen gegenüber durch ihr Resultat allererst erweisen. Wo wissenschaftliche Disziplin den Ton angibt, wird die Frage nach dem Stil darum kaum Anerkennung finden. Wissenschaftliche Disziplinen pflegen zu disziplinieren: Sie geben die zulässige Fragestellung vor.

Die Frage nach dem Stil führt zu einer Identifizierung, die weder als erschöpfend, noch als abschließend gelten kann; sie ist immer nur 
Annäherung an eine Identität, und aller Antwort ist ein "gerade nicht!" mitgegeben. Den Stil eines Textes bestimmen heißt immer: seine Eigenart fassen und nicht fassen. In der Frage nach dem Stil spiegelt sich, so gesehen, die Fragwürdigkeit jeden Bemühens, identifizierend einer Identität habhaft zu werden. Das mindert nicht die Dringlichkeit der Frage; sie bleibt, aller Fragwürdigkeit zum Trotz, so lange bestehen, als wir wahrnehmend und denkend an der Identität interessiert sind. Aber die Tauglichkeit der Frage nach dem Stil für den Dienst im Rahmen wissenschaftlicher Systematisierung läßt sich füglich bezweifeln.

\section{6.}

Im Bereich des Literarischen ist die Frage nach dem Stil nicht nur eine Orientierungs- und eine Identifikationsfrage, sondern immer auch eine Sinnfrage. Wer nach dem Stil fragt, geht davon aus, daß die Art und Weise des Sprachgebrauchs Bedeutung habe, daB sie Sinn mache. Hinter dem Fragen nach Stil steht also - wenn auch freilich in unterschiedlichem Maße (und zuweilen vielleicht gar nicht) reflektiert - die Annahme, oder besser: die Erfahrung, daB Sprache nicht nur aus Zeichen bestehe, sondern daB der Gebrauch dieser Zeichen, daß die Art und Weise des Zeichengebrauchs selbst wieder zeichenhaft, bedeutungsvoll sei; daß Sprache nicht nur ein Instrument sei, um sich in einer vorfindbaren Welt bzw. über eine vorfindbare Welt zu verständigen, daB in ihr vielmehr jene Welt erst konstituiert werde, die wir für die wirkliche halten, oder daB zumindest durch Sprache die Sichtweise bestimmt werde, in der uns das Wirkliche zugänglich wird.

Auch wenn der Frage nach dem Stil im einzelnen recht unterschiedliche Auffassungen sowohl von Sprache als auch von Wirklichkeit zugrunde liegen mögen: als Sinnfrage geht sie davon aus, daß durch die Art und Weise des Sprachgebrauchs die besondere Welt eines Textes konstituiert oder aktualisiert wird. Nach dem Stil fragen heiBt auch nach jener Welt fragen, die durch die Art und Weise des Sprachgebrauchs hervorgebracht wird. So jedenfalls reden wir aufgrund von stilistischen Wahrnehmungen von Schillers hierarchisch-antithetischer Welt, von Rilkes animalisierter Gegenständlichkeit oder davon, daß Max Frisch die Existenz als eine durch und durch temporale erfahre und darstelle.

Die Frage nach dem Stil ist also eine Frage mit hermeneutischer oder semiotischer Perspektivierung. Sie zielt nicht auf wiederkehrende Indizien, sondern auf wiederkehrende Konstitutionen von Sinn. Dabei ist sie - wie dies Szondi schon 1962 im Blick auf alle philologische Tätigkeit 
gezeigt hat ${ }^{10}$ - eine Frage mit zwei Unbekannten. Es gilt zum einen, die Bedeutung von stilistischen Merkmalen oder Zeichen zu erkennen, es gilt zum anderen, stilistische Merkmale oder Zeichen als solche zu identifizieren, und als Merkmal oder Zeichen läßt sich nur das begreifen, was Bedeutung hat.

Insofern die Frage nach dem Stil nicht einfach auf die Wiederholung von Merkmalen, sondern auf die Repetition oder das Prinzip einer Sinnkonstitution ausgerichtet ist, gilt das Interesse nicht eigentlich dem Bleibenden, sondern dem, was immer wieder neu und mit durchaus verschiedenen Mitteln erwirkt wird. Gerade darin besteht der Reiz der Beschäftigung mit Stil, daß der eine Sinn durch sehr unterschiedliche Phänomene oder Zeichen konstituiert werden kann: Die für einen Text oder eine Textgruppe charakteristische Antithetik kann beispielsweise semantisch begründet sein oder aber durch den Satzbau bewirkt werden; die besondere atmosphärische Gestimmtheit eines anderen Textes läßt sich an einer Stelle auf die Denotationen zurückführen, an einer anderen erwächst sie vielleicht aus dem Konnotativen.

Bei derartigen Unsicherheiten und Offenheiten kann es um das wissenschaftliche Ansehen von Stilbegriff und Stiluntersuchung nicht eben gut stehen; dort jedenfalls nicht, wo die Auffassung herrscht oder nachwirkt, es habe sich die Wissenschaft am Kriterium der Eindeutigkeit zu orientieren. Nicht eben gut sind die Chancen für Stilbegriff und Stiluntersuchung auch dort, wo man zur Annahme neigt, Wissenschaft habe zu wissen, wonach sie fragt oder sucht: Die Frage nach dem Stil zeichnet es aus, da $\beta$ sie frei erkunden will, da $\beta$ sie nicht auf von vornherein bestimmte Phänomene ausgerichtet, sonder gewissermaßen auf alles gefaßt ist - auf Affektives oder Rationales, auf Grammatisches oder Rhetorisches etc. - und mit solcher Offenheit auf die Kreativität im Bereich der Textproduktion antwortet.

Wenig Gefallen finden Stil und Stiluntersuchung schließlich auch dort, wo die Wissenschaft bestimmt, was sie als Wirklichkeit akzeptiert, wo sie von der Absicht geleitet wird, das eine Wirkliche zu erforschen und festzuschreiben: Stilbegriff und Stiluntersuchung verdanken ihre Bedeutung ja gerade der Erfahrung und der Einsicht, daß es die eine Wirklichkeit nicht gibt - historisch gesehen wird das Reden vom Stil denn auch gerade

${ }^{10}$ Szondi, Peter (1967): Über philologische Erkenntnis. In: ders.: HölderlinStudien. Mit einem Traktat über philologische Erkenntnis. Frankfurt/Main. S. 9-34. 
dort aktuell, wo der Glaube an die eine Wirklichkeit schwindet -, daB Wirklichkeiten vielmehr konstituiert werden und daß ihre Konstitution mit der Art und Weise oder dem Prinzip des Sprachgebrauchs zu tun habe. Die Stiluntersuchung zielt nicht auf das Festschreiben einer vermeintlich gültigen oder gar endgültigen Wirklichkeit; vielmehr will sie das Festgeschriebene auf seine ihm eigene Wirklichkeit hin befragen.

Freundlichere Aufnahme von Stilbegriff und Stiluntersuchung wäre dort zu erwarten, wo hermeneutische und semiotische Überlegungen an der Tagesordnung sind. Allerdings treten die hermeneutischen Grundprobleme - daB Verschiedenes die gleiche Bedeutung und Gleiches verschiedene Bedeutung haben kann, daB das Merkmal nicht ohne Bedeutung, die Bedeutung aber nicht ohne das Merkmal zu fassen ist - selten so offen zu Tage, wie bei der Beschäftigung mit Stilistischem oder beim Versuch zu beschreiben, was der Begriff des Stils meint und was die Stiluntersuchung leistet; das mag zumindest eine Erklärung dafür sein, daß sich von Stilfragen, vom Nachdenken über Stil und Stilbegriff, manch einer irritieren läßt, dem sonst hermeneutisches Verstehen geläufige Praxis ist.

7.

Bestrebungen, sich im Vielfältigen zu orientieren und im Wechselnden das Konstante zu identifizieren, und Fragen nach dem Sinn von Ordnungen und Konstanten sind in der literaturwissenschaftlichen Praxis nach wie vor häufig mit dem Begriff des Stils verbunden. Stil und Stilbegriff führen hier deshalb ein $z$ war nicht aufregendes aber auch ein nicht ernstlich bedrohtes Leben.

In der Literaturtheorie wirkt dagegen offenbar das Scheitern vieler stiltheoretischer Versuche nach. Dementsprechend gering ist die Bereitschaft, das Problem Stil erneut aufzugreifen. Nur selten werden Versuche gemacht, das Scheitern im Bereich der Stiltheorie (als ein möglicherweise notwendiges) zu begreifen ${ }^{11}$, oder dem Thema aus umfassenderen $\mathrm{Zu}$ sammenhängen heraus neue Erkenntnisse abzugewinnen. ${ }^{12}$ Auch stehen

11 Z.B. Anderegg, Johannes (1977): Literaturwissenschaftliche Stiltheorie. Göttingen.

12 So immerhin Gumbrecht, Hans Ulrich/Pfeiffer, K. Ludwig (Hg.) (1986): Stil. Geschich ten und Funktionen eines kulturwissenschaftlichen Diskurselements. Frankfurt/Main. Und Molinié, G./Cahné, P. (Hg.) (1994): Qu'est-ce que le style? Paris. 
Teile der Literaturtheorie noch immer unter dem Einfluß von Vorstellungen 'harter' Wissenschaftlichkeit; ${ }^{13}$ da ist es denn nicht erstaunlich, daß die Beschäftigung mit Stil und Stilbegriff eine Randerscheinung bleibt. Zwar ließe sich ein Begriff von Stil bei entsprechend einschränkender Definition in Theorien unterschiedlichster Art einbauen, doch verlöre er dabei gerade das, was ihn reizvoll, was ihn zu einer Herausforderung macht. BeläBt man ihn aber in seiner irritierenden Offenheit, bringt er gerade jene Unberechenbarkeiten von Literatur ans Licht (etwa die NichtPrädiktabilität des Kreativen), durch die die Kohärenz von Theorien gesprengt zu werden droht; auch spiegeln sich in ihm jene grundsätzlichen Fragwürdigkeiten des menschlichen Begreifens (schon die Geschichtlichkeit des Verstehens darf dazu gezählt werden), die eine 'harte' Wissenschaft eliminieren möchte.

Es wäre freilich ungerecht und falsch anzunehmen, die Literaturwissenschaft oder auch nur die Literaturtheorie weiche derartigen Problemen oder Fragwürdigkeiten grundsätzlich aus. Neuere Entwicklungen machen diese vielmehr zu ihrem eigentlichen Thema. Für Stil und Stilbegriff scheint der Boden aber auch hier nicht günstig zu sein. Wenn im Poststrukturalismus davon ausgegangen wird, daB Sprache nicht ein mehr oder weniger festes System sei, sondern ganz und gar prozeßhaft gesehen werden müsse, ist die Frage nach Stil oder Stilbegriff obsolet, weil sie ja auf die Art und Weise des Umgangs mit eben jenem System zielt, dessen Existenz oder Relevanz bestritten wird. Und wenn die These vertreten wird, es sei $z$ wischen Literatur und dem Reden über Literatur nicht grundsätzlich zu unterscheiden, es seien Texte überhaupt nicht als Entitäten zu betrachten sondern als Fragmente, als Teile einer eigentlich grenzenlosen Vernetzung, so verliert die Frage nach dem Stil ihren Sinn, denn sie setzt, wie unterschiedlich auch immer Stil im einzelnen definiert wird, die Begrenzung ihres Gegenstandes als sinnvoll voraus.

Gewiß sind bei anderer Ausgangslage und in anderen Zusammenhängen stilistische Phänomene nach wie vor von Bedeutung. Aber wo die Literaturwissenschaft ihre Modernität oder Aufgeschlossenheit zum Ausdruck bringen will, vermeidet sie Begriffe, mit denen jene Geschichte zu Wort kommt, die sie überwunden haben will, und in neuen Diskurstypen haben wo nicht neue, so doch unverbrauchtere oder unbelastetere Begriffe das Sagen. So grüBt aus benachbarten Gebieten ein weitläufiger Verwandter

13 Z.B. Fricke, Harald (1991): Literatur und Literaturwissenschaft. Beiträge zu Grundfragen einer verunsicherten Disziplin. Paderborn. 
des guten alten Stils, das 'Styling'; allen Anfechtungen zum Trotz hat sich bisher die 'Struktur' zu halten vermocht; 'Diskurs' und 'Design' sind - wiewohl auch nicht mehr ganz, was sie einmal waren - in aller Munde; Neues verspricht die 'Signatur'; und wer an Stilistischem interessiert ist, aber nicht vom Stil eines Textes, eines Autors oder einer Epoche reden mag, findet Zuflucht bei einem Allerweltswort: er spricht von ihrer 'Sprache'. Damit ist zwar nicht viel gewonnen, aber auch noch nicht viel verloren. 


\section{Ist [der] Stil meßbar?}

An unbewachten Bahnübergängen warnt in Frankreich ein Schild: $>$ Attention, un train peut en cacher un autre! $<$ Der knappe Titel meiner Ausführungen enthält (zumindest) zwei Fragen: $\gg I s t$ der - namlich <dieser> oder <jener> - Stil meßbar? \& und > Ist Stil - nämlich <an und für sich>bzw. <überhaupt> - meßbar? \&Die Antworten auf diese beiden Fragen lauten verschieden, wenn auch nicht widersprüchlich: $\gg$ Dieser oder jener Stil wird immer meßbarer und $\ll$ Der Stil überhaupt wird immer weniger meßbar $\ll$ bzw. die MeBbarkeit der unterschiedlichen Stile steigt, je leistungsfähiger unsere Apparaturen zur Erfassung und Reproduktion von Strukturen werden. Sie sinkt, je ein-deutiger wir die einmalige Kohärenz des $\gg$ maBgeblichen« Kunstwerkes erschließen.

\section{Zur Begriffsklärung}

In den Kategorien der Ästhetik ist der <generelle> Begriff / Stil/ höher angesiedelt als der <spezielle> Begriff /Sprachstil/ und folgerichtig auch als die partikuläreren Begriffe /Brief-/, /Roman-/, / Traktat-/ oder /Vortragsstil/. In den Kategorien einer umfassenden, weil Logisches, Psychologisches und Pragmatisches einschließenden Grammatik hat denn auch Stilistisches seinen Platz. Der Grammatiker darf sich deshalb der stilistischen Verantwortlichkeit nicht entledigen und etwa den <Stil an und für sich> sozio-linguistisch und psycho-linguistisch als eine unstete Menge von $\gg$ repressiven Konventionen $\ll b z w$, von $\gg$ Kollektiv-Subjektivismen $\ll$ betrachten, deren Analyse sich nur an Außersprachlichem zu orientieren hätte, als ginge es dabei lediglich um $\gg$ Soziokulturelles $\ll$, etwa Gewöhnung, Intoleranz, Prestige, Absonderung, Mode, ja Politik, wobei eine multistilistische [sic] Begabung besonders zu würdigen bzw. mit einem Literaturpreis auszuzeichnen wäre.

\section{Was hat [der] Stil für Attribute?}

Zur methodischen Naivität gehört die Erfassung der <Prädikate>, mit denen der Stil für gewöhnlich von den Kritikern bedacht wird, zum Beispiel akademisch, ausgefeilt, barbarisch, blühend, dunkel, eigenwillig, einfach, elegant, emphatisch, energisch, episch, farblos, gehoben, gepflegt und ungepflegt, geblümt, gewählt, geschliffen, geschminkt und ungeschminkt, geschwollen, harmonisch, hochtrabend, impressionistisch und expressionistisch, kapriziös, klassisch, konzis, langatmig, langstielig, langweilig, lebendig, lichtecht, morbid, mühsam, naiv, ob- 
skur, pittoresk, preziös, quirlig, roh, rhetorisch, romantisch, schlampig, schlecht, schlicht, schwungvoll, streng, stümperhaft, tänzelnd, trocken, überschwenglich, ungeziert, verschleiert und unverschleiert, verschwommen, weitschweifig, und - vielleicht etwas meBbarer? - wortkarg und wortreich, sowie, um es nicht vergessen zu haben: künstlich, natürlich, stilvoll und ... stillos.

Das auf CD-ROM befragte 'Trésor de la Langue Française' brachte das Doppelte zum Vorschein, u.a. déchiré, effacé, épiscopal, lapidaire, miroitant, nerveux, opulent, perspicace, rocailleux, soutenu, tourmenté und villageois, die als nachgestellte Adjektive klassifizierende Ansprüche anmelden, während beau, fier, fort, foutu, grand und haut immer vorangestellt und somit nur zur - übrigens laschen - Bewertung gebraucht werden; nur vier Adjektive erscheinen in beiden Stellungen bzw. Funktionen, nämlich abominable, excellent, long und mauvais.

Komposita wie Amtsstil, Barockstil, Biedermeierstil, Funktionärsstil, Jugendstil, Kanzleistil, Renaissancestil und Übergangsstil oder Stilblüte, Stilbruch, Stilebene, Stilelement, Stilempfinden, Stilfehler, Stilfigur, Stillehre, Stilmittel und Stilmöbel sind jedem geläufig; desgleichen die Stilnote - bei den Olympischen Spielen für eine immer entscheidende und oft bemängelte <Messung> und das Stilwörterbuch als <phraseologisches Wörterbuch, das die korrekte Verwendung der Wörter im Satz darstellen soll>.

Der französische Terminus „stylométrie” bezeichnet seit einem Jahrhundert die <angewandte statistische Stilkunde> als philologische Methode zur Erforschung der Chronologie der Dialoge Platons, um die Jahrhundertwende, und neuerdings zur Echtheitsprüfung aristotelischer (?) Fragmente. Das Programm des Pariser internationalen Kolloquiums Consensus ex machina? (Sorbonne, April 1984) verzeichnet zwei Beiträge zur jüngsten Entwicklung dieser Disziplin, bis an die Schwelle forensischer Verwendung, wie etwa aus den jüngsten Arbeiten von Christian Rutten (Lüttich) und Alfred Noé (Wien) hervorgeht.

\section{Analoga aus der bildenden Kunst}

Vorstellungen von Stil-Arten und Stil-Qualitäten hat nicht nur der literarische Stilkundler. Es sind vermutlich zum Teil nicht immer die gleichen - auch nicht oder gerade nicht bei Zeitgenossen. Dennoch lassen sich in der bildenden Kunst sozusagen formale Atome und Moleküle auflisten, wie dies etwa in der mehrbändigen Sammlung $\gg L a$ Grammaire des formes et des styles $\ll$ im Schweizer Verlag Office du Livre (Fribourg) durchgeführt wurde. Während der Literaturhistoriker in der Regel nur 
zwei oder drei Jahrhunderte überblickt, überbrückt der komparatistische Ansatz der Kunstgeschichte Jahrtausende.

Anhand besonderer Themen, etwa der Darstellung des Pferdes (etwa in Les Chevaux - Un si long compagnonnage von Roger-Louis Thomas, Paris Hatier 1993, und im Kapitel Le Cheval en Chine et ses représentations, von Hubert Delahaye, $\mathrm{CdF}$, in Le petit livre du cheval en Chine, Paris Caracole, nicht datiert) zeigt sich, daB die abstraktesten Formen immer wieder zu Abkehr und Umkehr AnlaB boten, und daß Wechsel und Erneuerung nicht weniger als rituale Schulbildung zur Stilgeschichte gehören, welche sich demnach nicht dichotomisch bzw. einfach in $>$ klassisch $\ll$ vs. $>$ postklassisch $\ll$ oder $\gg$ romantisch $\ll$ vs. $\gg$ vorromantisch $\ll$ bzw. $\gg$ statisch $\ll$ vs. $\gg$ dynamisch $\ll$ oder $\gg$ objektiv $\ll$ vs. >subjektive einteilen läßt. Das Bewegte gehört sozusagen zum Stetigen.

Eine vornehmlich aus dem Buch von Roger-Louis Thomas geschöpfte Auswahl von dreiunddreißig Darstellungen des Pferdes, von der Höhlenmalerei von Lascaux bis zu Théodore Géricault, von altchinesischen Schattenrissen bis Velasquez, von Persien bis zur mittelalterlichen Kaiserchronik, von Vanini bis zu Seurat, von Stubbs bis zu Magritte, vom Cheval bleu von Paul Gauguin bis zur Carriole du Père Juniet vom Douanier Rousseau, folgte einem Wink Platons, der, bevor er eine Definition des Sophisten geben wollte, zunächst irgendetwas definierte, was jeder kannte und von dem jeder wuBte, was es war, und deswegen die Brauchbarkeit der Definitionsprozedur beurteilen konnte, nämlich die Angelfscherei. Wer nicht wüBte, was ein Pferd ist, erführe zum Beispiel aus der Enzyklopädie, daB $\gg$ die weiblichen Tiere nach etwa elfmonatiger Tracht (meist) ein Junges (Fohlen) gebären $\ll$, was ihm zugleich zeigt, was unter / enzyklopädischem Stil/zu verstehen ist. Bei der Betrachtung dieser Bilder sollte man die Mahnung eines französischen Malers nicht überhören, daß sich die Malerei, wie die Literatur, nicht eigentlich an das Auge wendet, $\rightarrow \dot{a}$ l'oeil $\ll$, sondern, wie das auch immer zu übersetzen ist, $\gg \dot{a}$ l'esprit<. Von dieser kurzen, klassischen Kunstfabel hieße die lange, ebenfalls klassische Moral, daßder $\mathbf{S}$ til in der $k$ oh ärenten und stabilisierten Wahl best eht. Auch der Einwand, daB Pferd nicht einfach Pferd, sondern Reit- oder Zugpferd, Renn- oder Arbeitspferd sei, würde der Sache nicht schaden, da $\gg P$ Perderassen $\ll$ wie Stile durch »stabil gezüchtete Merkmale $\ll$ geschaffen werden.

In der bildenden Kunst wird nicht nur vom Stil des einzelnen Werkes oder Künstlers gesprochen, sondern, mit nicht weniger Prägnanz, vom Stil von Schulen, Epochen und Kulturen. Daß eine Stilfibel nur eine engere Grammatik, eine Art 》grammaire choisie«, sein kann, ist eine 
Lappalie. Wie sieht es am anderen Ende der Kette aus: kann eine allgemeine und umfassende Grammatik ohne Stil auskommen bzw. ihre Zuständigkeit aufgeben, wenn es um Ästhetik geht, weil sie sich zur Stilistik so verhielte, wie Pflicht zu Kür? In seinen Grammatischen Gesprächen überlieb Klopstock zwar einen entscheidenen Part der $\gg K u ̈ r \ll$, aber es war sozusagen ein $\gg$ innergrammatischer $<$.

Meine These lautet denn auch, daB Grammatik ohne Stilistik nicht denkbarer und machbarer ist als ein Text ohne Form, als eine Sprachlehre ohne Logik und ohne Pragmatik. Wollte man weiterhin wie gewohnt die Stilistik aus der Grammatik aussiedeln, entstünde ein Niemandsland zwischen einem Katalog von prinzipiellen <Geboten > und mehr oder minder scharfen <Verboten>. Das Prinzip, nach dem alles erlaubt ist, was nicht verboten ist, genügt nicht, um sich einen Stil zu schaffen. Als Merkmale zu England, Preußen, Rußland und Österreich in der napoleonischen Zeit der ersten Belege zu stylométrie, allerdings als $\gg$ Säulenmessung $\ll$, soll für den $\gg$ offentlichen Lebensstilk gegolten haben, es sei jeweils $\gg$ alles erlaubt gewesen, was nicht verboten war; alles verboten, was nicht erlaubt; alles verboten, was erlaubt; alles erlaubt, was verboten war. \& Mit solchen Verfassungen lieBe sich keine Stillehre schreiben. Wegen dieser Lücke in den Sprachlehren haben die Stilpädagogen zwei andere Wege bevorzugt: die korrigierte Spontaneität und das immer empfehlenswerte Abschreiben und Auswendiglernen von Mustertexten, womöglich aus einer Quelle: etwa aus den $\gg$ Wahlverwandtschaften $\ll$, die sich Thomas Mann zu diesem Behufe ausgesucht haben soll.

\section{Stilfragen als grammatische Fragen}

Die Grammatik lehrt zum Beispiel, daß ein Satz beliebig lang sein kann und daß jeder Satz erweitert werden kann. Sie sagt aber nicht, wann welcher Satz wie lange sein darf.

Die Grammatik lehrt zum Beispiel, daß für Nomina Pronomina eingesetzt werden können. Davon abgesehen, daß sie bestimmte Verbotslisten nicht motiviert und nicht zu merken scheint, daß die Unmöglichkeit, ein im Rhema stehendes Substantiv anaphorisch aufzugreifen, nicht als <Ausnahme> zu katalogisieren, sondern als < Regel> zu verstehen ist, sagt sie nicht, wann ein Pronomen eingesetzt werden darf oder soll, und warum.

Die Grammatik lehrt zum Beispiel, daß im unabhängigen sogenannten Kernsatz ein beliebiges Satzglied das Vorfeld besetzen kann, was je nachdem in einem Falle zur geraden und in allen anderen Fällen zur ungeraden Wortstellung führt. Sie bleibt aber die Antwort schuldig auf die 
nicht nur für das <Deutsche als Fremdsprache>, sondern auch für das <Deutsche als Muttersprache> wichtigen Fragen: warum so, warum anders, warum überhaupt?

Das gilt nicht nur für ästhetische Erwartungen, sondern auch für logische Belange. Wenn die Grammatik im Kapitel <Satzbaupläne> lehrt, daß dem <Satzgegenstand > der <Prädikatsverband> gegenübersteht, ohne zu sagen, daB sowohl das Akkusativobjekt wie das Nominativsubjekt zu diesem oder jenem gehören oder auch nicht gehören können, wird sie weder eine ordentliche Syntax axiomatisieren noch die Brücke zur Textgrammatik schlagen können. Insbesondere wird sie nicht sagen können, welche Bereiche die Logikder Stilistikfrei-

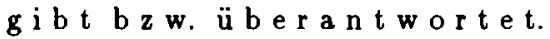

Wenn sie dagegen - schließlich? - meint, die Stilistik sei für alle Verschränkungen, Verwindungen und Verrenkungen zwischen der postulierten <Tiefenstruktur> und den registrierten <Oberfiächenstrukturen> zuständig, sagt sie nicht zu wenig, sondern - schlimmer - z u vi el.

\section{Zur eigentlichen $\gg$ Stilometrie $\ll$}

Die Fragen, ob <der Stil > meßbar ist und ob <Stil überhaupt $>$ meßbar ist, gehen schon deswegen den Grammatiker an, weil alle Stilmittel Sprachmittel und mit geeigneten Mitteln <meßbar> im Sinne von <abzählbar> sind.

Vor bald vierzig Jahren, als bei der Neuauflage des $\gg$ Wegweisers zum treffenden Ausdruck von Wehrle Hans Eggers in Hamburg von den Kastenzetteln zu den Lochkarten überging, habe ich den Brief $\gg$ holleritiert $\ll$, in welchem im Juni 1652 Pascal seine Rechenmaschine der Königin Christine von Schweden erklärte. Inzwischen sind meine Hamburger Lochkarten fast zu Staub verfallen. Unter den geretteten befinden sich diejenigen, die folgende Stelle betreffen: $\gg$ Cet ouvrage, $\mathrm{Ma}$ dame, est une machine pour faire les règles d'arithmétique sans plume et sans jetons. Votre Majesté n'ignore pas la peine et le temps que coûtent les productions nouvelles, surtout lorsque les inventeurs les veulent porter eux-mêmes à la dernière perfection; c'est pourquoi il serait inutile de dire combien il y a que je travaille à celle-ci; et je ne peux mieux l'exprimer qu'en disant que je m'y suis attaché avec autant d'ardeur que si j'eusse prévu qu'elle devait paraître un jour devant une si auguste personne $\ll$ - verdeutscht und postmodernisiert: $\gg$ Dieser Computer ist eine Maschine, die ohne Schreibzeug und Abakus die Grundrechenarten ausführen kann. Wieviel Mühe und Zeit ein perfekter Prototyp kostet, ist Ihnen hinlänglich bekannt. Ich hätte nicht mehr Aufmerk- 
samkeit und Ausdauer daran verwenden können, wenn ich geahnt hätte, $\mathrm{daB}$ dieser mechanische Rechner eines Tages Ihrer lieblichen Hoheit vorgestellt werden dürfte. $\ll$ Aus der gleichen Gründerzeit stammen vergilbte Formulare zur Auszählung von bestimmten Text-Merkmalen wie Satzlänge, Anapher- und Katapher-Gebrauch, Häufung von attributiv verwendeten Adjektiven, Verhältnis von parataktischen und hypotaktischen Strukturen usw. Frequenz-Untersuchungen zum Wortschatz habe ich damals aus zwei Gründen vernachlässigt: einerseits gab es schon anderswo großangelegte und reichdotierte Untersuchungen zur stilistischen Lexikologie bzw. $>$ Lexikometrie<; andererseits verfügte ich über keinerlei sogenannten Projektgelder und hatte mir die stilometrischen Experimente sozusagen als analytische Fingerübungen ausgedacht, bei denen meinen zur Aufmerksamkeit gezwungenen Studenten fast nebenbei allerhand auf- und einfallen könnte. Damals gab es weder Projektgelder noch Beiräte: die privat zu begleichende Monatsmiete der Lochmaschine betrug $5 \mathrm{DM}$.

Die damalige schlechthin experimentelle Methode halte ich heute weiterhin bzw. wiederum für sinnvoll, denn es ist gar nicht so leicht, zu wissen, w o r a n Originalität und Qualität eines Stils liegen. Nur könnte man heute durch Computereinsatz viel mehr Aspekte berücksichtigen und etliche nicht intuitive Frequenzwerte, Abweichungen und Schwankungen schneller berechnen. Die angewandte Statistik - wenn dies kein Pleonasmus ist - hat seit den Untersuchungen zu den Nachtwachen des Bonaventura große, wenn auch noch nicht abgeschlossene Fortschritte gemacht, welche insgesamt die eingangs formulierte Ansicht nicht <falsifizieren>: $>$ Meßbar ist dieser oder jener Stil sehr wohl, Stil überhaupt dagegen nichtK.

\section{Zu den Stil- $\gg$ Gestalten $\ll$}

Aus verschiedenen Zählungen diverser vermuteter Stilmerkmale hatten wir einige ausgewählt, bei denen sich bei Textmengen im Umfang von 50.000 Wörtern im Kontinuum - erprobte und gutausgerüstete Statistiker kommen längst mit weniger aus - bestimmte Konstanten errechnen ließen, die je nach dem Autor für ein Buch, für eine Schaffensperiode oder für das Gesamtwerk brauchbar waren. Eine Schilderung der Stilogramme befindet sich in der Vergleichenden Grammatik, FranzösischDeutsch, Band 2, L'économie de la langue et le jeu de la parole, B.I. 1984, 》Läßt sich Stil messen, beschreiben, nachahmen?《, (S. 614-626)

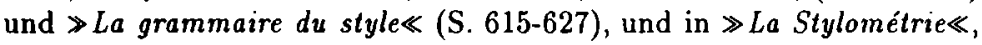
Cahiers du C.R.A.L. n², Nancy 1966 (S. 36-40), von Pierre Girault in 
La Stylistique übernommen, Initiation à la Linguistique A1, Klincksieck Paris 1970 (S. 214-221).

DaB am Ende nur acht Angaben selegiert wurden, lag zum Teil natürlich daran, daß gerade diese charakteristisch zu sein schienen. Dieser Minimalismus hatte auch mit der instinktiven Ahnung etwas zu tun, daB der Stilsich nicht einfach auf eine Anhäufung von Einzelformen zurückführen $l \ddot{a} B t$, sondern irgendwie einer $>$ Gestalt<entspricht, nat ürlich in dem Sinne, in dem die Wahrnehmungslehrevon/Gestalt/spricht. Die Selektion von nur acht Werten erleichterte die Darstellung der verschiedenen Messungen als Dimensionen. Um Sinnfälliges und Augenfälliges zu vereinen, übersetzten wir diese Dimensionen in Strahlen. Je nach ausgezählten Daten (etwa die Zahl der Adjektive in attributischer Funktion und die Zahl der Satzartikel /daß/ im Nominativ) waren Werte zu erhalten, deren Proportion zueinander den Vergleich unnötig erschwerte: eine Schwankung von $2 \%$ ist bei einem Mittelwert von $18 \%$ fast uninteressant, während sie bei einem Mittelwert von $1 \%$ ganz enorm bzw. abnorm wäre. Infolgedessen wurde jeder Dimension ein eigener Maßstab zugeordnet. Der Schnittpunkt der Strahlen mit dem Kreis bestimmte, über einen errechneten Mittelwert, die jeweilige Einheit bzw. den Kurswert.

Die Umwandlung von ursprünglich aus Qualitativem bezogenem Quantitativem in abermals Qualitatives beruhte $\mathrm{zwar}$ auf Konventionen, erleichterte aber die Charakterisierung von Stil-Profilen und -Profilfamilien. Das Verbinden der auf den verschiedenen Skalen eingetragenen Größen und das Schraffieren der so entstandenen Figuren zu Stilgestalten war dann wirklich kein Kunststück mehr. Der Unterschied zwischen den $<$ Gestalten> bzw. <Stilogrammen> entsprach der empfundenen Differenz und fand sich denn auch in Parodien wieder. Darauf, da $B$ die Plagiatoren zünftige angewandte empirische, wenn auch intuitive $<$ Stilometrie> betreiben, ist hier nicht weiter einzugehen, zumal im Anhang das 'Preisrätsel' Anlaß zu einigen Bemerkungen zum Themenkreis Parodie und Fälschung gibt.

Die wissenschafliche Stilometrie hat sich natürlich nicht um die Übersetzung ihrer Messungen in solche $\gg$ Stilogramme $\ll$ bemüht, sondern, wie jede Feinst-Statistik, jenseits aller visuellen 'Gestalten', Konstanten höheren Grades errechnet, $\gg$ Derivate $\ll$, wie bereits in der 1964 vorgelegten und von C.F. v. Weizsäcker und D. Gerhardt betreuten Dissertation von Joachim Thiele nachzulesen ist: Verfahren der statistischen Aesthetik (VVG Hamburg-Altona 1966). Dennoch dürfte gerade das Intuitive und Grobschlächtige der primitiven $\gg$ Stilogramme $\ll$ richtig gelegen haben, 
denn die detaillierten Einzeldaten führen nur dann zu den gesuchten holistischen $\gg$ Gestalten $\ll$, wenn der Statistiker sie rechnerisch so betreut, daB ihre $>$ Streuungen $<$ sich in $\gg$ Kraftlinien $<$ verwandeln, wie sich Eisenfeilspäne auf dem Blatt Papier, das der Lehrer über den Magneten hält, zu eindeutigen Figuren sammeln.

\section{Was nicht meßbar ist}

Abzählen und messen lassen sich offenbar formale Einzeldaten, <dieser oder jener Stil $>$, in Wortlaut meiner Frage also $>\mathrm{d}$ e r S t il «. Wie steht es mit dem Stil überhaupt? Kurzum: $>$ Ist Stil meßbar?

Diesen oder jenen meßbaren Stil nannte Goethe nicht $\gg$ Stil $\ll$, sondern $>$ Manier $<$. Dem Vierzigjährigen lag daran, $>$ das Wort Stil in den höchsten Ehren zu halten, damit uns ein Ausdruck übrig bleibe, um den höchsten Punkt zu erreichen, welchen die Kunst je erreicht hat und je erreichen kann. Diesen Grad auch nur zu erkennen, ist schon eine große Glückseligkeit.\& Wie die Ethik ist auch die Ästhetik in der Aufklärung problematisiert worden. Die Problematik des Stils wurde schneller ausgelebt als ausgedacht, wenn man auf so komplexe Umwälzungen einen so flüchtigen Blick werfen kann.

Als Georges Louis Leclerc, Graf von Buffon, genau ein halbes Jahrhundert vor 1789, im Alter von 32 Jahren in die Académie française aufgenommen wurde, meinte er mit seinem Satz, $\gg$ le style, c'est l'homme même«, weder den Stil überhaupt, noch den Menschen überhaupt, sondern eben, für beide, diesen oder jenen. Buffon war ein Naturalist. Wie hätte er vor lauter Individualität und Originalität der Ausführungen die Zugehörigkeit zu Art und Wesen vergessen können?

Der nur 5 Jahre jüngere Diderot vernahm hinter Senecas (wahrscheinlich des Vaters und des Sohns) $\gg$ talis oratio qualis vita《 die Forderung, die Universalität in der Persönlichkeit zu erreichen. Es wurde ihm bekanntlich vorgeworfen, von der Literatur $\gg$ Moral $\ll$ zu erwarten bzw. zu verlangen. Wie die meisten Denker der Zeit war er von der Malerei fasziniert. Wenn er so von Chardin begeistert war, könnte es an einer solchen <objektiven Relativität> gelegen haben. 15 Jahre nach Diderots Tod, 25 Jahre nach dem Abschluß der Encyclopédie, 10 Jahre nach der Pariser Wende, 7 Jahre nach der Schlacht von Valmy, noch während der Vorbereitung des Staatsstreiches, von dem der dreißigjährige Napoleon - er war 20 Jahre jünger als Goethe - träumt, und derenthalben er in Ägypten sein siegreiches, aber aussichtsloses Expeditions-Korps verläßt, vertieft Goethe diesen <objektiven Relativismus> Diderots: die beschreibbare und meßbare Form allein kann die erstrebte Vollkommen- 
heit der Substanz nicht garantieren. Er schreibt: $\gg$ Das Resultat einer echten Methode nennt man Stil, im Gegensatz der Manier. Der Stil erhebt das Individuum zum höchsten Punkt, den die Gattung zu erreichen fähig ist; deswegen nähern sich alle großen Künstler einander in ihren besten Werken. [...] Dieses gilt so gut vom Sittlichen als vom Künstlichen; denn da alle Handlungen des Menschen aus e i n e $\mathrm{r}$ Quelle kommen, so gleichen sie sich auch in allen ihren Ableitungen. $\ll$ Offenbar ist der $\gg$ Stil $\ll$ das Erstrebte, wenn nicht Unerreichbare, und steht deshalb, wie alles Ideale, außerhalb der Meßbarkeit. Eben im Gegensatz zur bloßen $\gg$ Manier $\ll$. DaB Goethe diese $\gg$ Manier $\ll$ jedoch nicht verachtete, etwa im abwertenden Sinne von $\gg$ Manierismus $\ll$, geht schon daraus hervor, daB er die $\gg$ Manier $\ll$ nicht in eine binäre Opposition zum $\gg$ Stil $\ll$ stellt. Es gebe ein Drittes, die $\gg$ Nachahmung $\ll$, gewissermaßen eine Vorstufe, wie aus einem Vergleich der Verhältnisse dieser drei Formen zur Natur erhellt: $\gg$ Wie die einfache Nachahmung auf dem ruhigen Dasein und einer liebevollen Gegenwart beruhet, die Manier eine Erscheinung mit einem leichten, fähigen Gemüt ergreift, so ruht der Stil auf den tiefsten Grundfesten der Erkenntnis, auf dem Wesen der Dinge, insofern es uns erlaubt ist, es in sichtbaren und greiflichen Gestalten zu erkennen $\ll$. Zehn Jahre später kommt er darauf zurück. Nachdem er, in Anlehnung an Diderot, wiederholt hat, daß der Stil das Individuum zur edelsten Humanität führt, schreibt er: $\gg$ Die Manier hingegen in $\mathrm{d}$ i id u a $\mathrm{l}$ is i e t wenn man so sagen darf, noch das I $\mathrm{n} d \mathrm{i} v \mathrm{i} \mathrm{d} u \mathrm{u} m$ Der Mensch, der seinen Trieben und Neigungen unaufhaltsam nachhängt, entfernt sich immer mehr von der Einheit des Ganzen, ja sogar von denen, die ihm allenfalls noch ähnlich sein könnten; er macht keine Ansprüche an die $\mathrm{M}$ e $\mathrm{ns} \mathrm{ch}$ h i $\mathrm{t}$ und so trennt er sich von den $\mathrm{M}$ e $\mathrm{n} \mathrm{s} \mathrm{ch} \mathrm{n} . \ll$ Drei Jahre, nachdem Napoleon Bonaparte im Alter von dreiundfünfzig Jahren gestorben war, sagt der fünfundsiebzigjährige Goethe sozusagen abschließend zu Eckermann: \Im ganzen ist der Stil des Schriftstellers ein treuer Abdruck seines Innern: will jemand einen klaren Stil schreiben, so sei es ihm zuvor klar in seiner Seele: und will jemand einen großartigen Stil schreiben, so habe er einen großartigen Charaker. $\ll$ Werden die Eigenschaften /klar/ und /großartig/ in der klassischen Stilistik nicht als geeichte Prädikate vergeben?

Der Altmeister Jean Fourquet [dessen beim Goethe-Institut erhältliches Video-Porträt in Mannheim vorgeführt wurde] machte mich darauf aufmerksam, daB auch /Nachahmung/ etymologisch mit /Meßbarkeit/ zu tun hat, und daß sogar, kurioserweise, das nomen Ohm zu omen wurde. Im Rahmen seiner 1922 in Weimar und in Dresden geschriebenen Diplomarbeit über Anton Raphael Mengs hat sich Jean Fourquet übrigens 
auch mit der von Goethe schon vor der Italienischen Reise praktizierten Unterscheidung $\mathrm{zwischen} \gg$ Stil $\ll$ und $\gg$ Manier $\ll$ befaßt.

In der französischen Geistesgeschichte ist übrigens die Humanisierung der Objektivität, wie man diesen $\gg$ objektiven Relativismus « auch nennen kann, bereits in den $\gg$ Essais $<$ von Michel de Montaigne zu erkennen.

\section{Lösung des Paradoxes?}

Hinsichtlich der Meßbarkeit scheint aber diese Akzeption von /Stil/ aus der Perspektive des ERGON in die der ENERGEIA gerückt zu sein. Wenn es nur um die - mit Verlaub pleonastisch zu insistieren $-\gg$ formale Gestalk geht, ist man versucht, zur Ergon-Perspektive zurückzukehren, um sie nicht mehr zu verlassen, zumal nach der nicht zu Ende gedachten Problematik der 》objektiven Relativität《 diejenige der 》subjektiven Relativität《 alias des $\gg$ Nihilismus $\ll$ getreten ist - mit anderen Worten: nicht die von einigen sorgenvoll erhoffte Umwertung aller Werte, sondern ihre beschleunigte $A b$ wertung. Die $\gg$ absolute Unverbindlicheit $\ll$

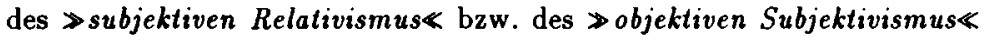
hat jedoch ein paar schwache Nähte, wie der Stil-Wechsel (?) im ModeGeschäft der Haute Couture - ein anderes, ergiebiges Analogon vorzuführen bestrebt ist: $\mathrm{St}$ il se $\mathrm{i}$, was $\mathrm{m}$ a $\mathrm{n}$ wolle, auch wenn der Produzent es anders meine als der Rezipient oder der Käufer, pardon!, der Händler.

Man werfe dieser Fehde gegen die herrschende - suizidäre - Verwechslung von Stil und Mode keinen $\gg$ Archaismus $\ll$ vor. Die $\gg$ radikale Subjektivität« ist nämlich so umwerfend neu nicht. Von Protagoras bis zur scholastischen Epistemologie, in welcher der Grundsatz der Prägung des Empfangenen durch das Empfangende galt: $\gg$ wie das Wasser die Form der Karaffe annimmt $\ll$ - doch schöpft der Frankenwein seinen Geist aus der Form des Bocksbeutels? -, wurde der Aspekt der $\gg$ Kreativität $\ll$ immer nur von Schulen vergessen, die nicht nur $\gg$ Stil $\ll$, sondern sogar $>$ Manier $\ll$ mit $>$ Nachahmung $<$ verwechselten, weil sie überhaupt die störende Relativität vergessen hatten ... Vielleicht hängt die Tragik des Revolutionären damit zusammen, daß es ursprünglich seine Kraft aus Zuwendung bezieht, sich aber seinen Weg von Abwendern diktieren läßt.

Dem Grammatiker sind allgemeine historische und philosophische Überlegungen wohl aufgezwungen, sind doch längst linguistische $\mathrm{Ge}$ meinplätze in philosophische Traktate und Manifeste aufgenommen worden, etwa das Axiom des 》arbitraire du signe«. Dabei ist es wie mit dem gespannten Gummiseil gegangen - ich meine die verbindliche $\gg$ Relativität《 bzw. die verbindenden $\gg$ Relationen $\ll-$, das über einen 
Abgrund an zwei Bäumen festgebunden war. Seit Jahrzehnten seufzen moderne und jetzt auch postmoderne Analytiker und Dekonstruktivisten über eine Relativität ohne Relation. Wann wieder verstanden wird, daB die Intelligenz nicht im Nichts das Höchste und Klügste und Schönste findet, weiB niemand. DaB aber das abgerissene Gummiseil nicht von alleine über den Abgrund auf das gegenüberliegende - und höhergelegene - Cañon-Ufer um den anderen Baum zurückschnellen wird, ahnt jeder. Genau, wie er weiß, daB wir über den Abgrund hinaus müssen und im Grunde auch wollen. Nur machen wir uns so ungern lächerlich ...

\section{$<$ Stil $>$ wie $<$ Stile $>=$ stetige Wahl}

Nun könnte man meinen, ich berufe mich auf ein geheimnisvolles, nicht falsifizierbares, angstlösendes zum Axiom erhobenes Als-ob-Postulat, daß der jenseits der Manier angesiedelte Stil nicht nur nicht mehr meßbar wäre, sondern mit der Ästhetik überhaupt nichts mehr zu tun hätte. Freilich wäre dann die These gesichert, daß nur dieser oder jener Stil meßbar ist, nicht aber Stil an und für sich! Die Ironie würde, natürlich unverbindlich, beipflichten: $\gg$ Stil überhaupt $\ll$ sei nicht meßbar, da er ja $>$ überhaupt kein Stik sei. Einen solchen Einwand würde ich nicht für unzulässig halten. Mehr noch, ich teile ihn gern, denn es liegt nicht in meinem Verständnis, daß man sich einfach ein Undefinierbares gibt, das in jedem Glasperlen-Spiel - mit Verlaub, stilzubrechen - zugleich als Libero und als Schiedsrichter eingesetzt werden dürfte.

Nicht nur von $\gg$ diesem oder jenem Stil $\ll$, sondern auch vom $\gg$ Stil überhaupt«, ist m.E. das doppelte, manchmal schwer verträgliche Hauptmerkmal die $\gg$ s t e t i g e W a h l «: Wahl zwischen vielen Möglichkeiten bzw. Varianten und zugleich kohärentes und konstantes, aufgeklärtes Verharren. Parodien und Plagiate werden meistens am Inhalt erkannt. D i e ser I n hal t is t a u c h Form. Er ist es sogar auf mehrfache Weise, was ich mit statutären Kategorien andeuten möchte:

1. Daß Inhalt auch Form ist, gilt zunächst für alles Rhematische. Der Inhalt der Prädikate ist <Konzept>, Bedeutung, in einem bestimmten Sinne also <subjektiv> bzw. <objektiv-subjektiv>.

2. DaB Inhalt auch Form ist, erhellt sich weiterhin aus dem Umstand, daB die bezeichnenden thematischen Koordinaten einen 'Lokalaugenschein' aus unserem <Perzept $>$ exzerpieren.

3. Die phematischen Brücken, die wir zwischen Konzept und Perzept schlagen, tragen noch stärker als das Rhematische und das Thematische, fast bis in die logischen Modalitäten hin, aber zweifellos in den epistemi- 
schen und den affektiven Modalitäten, das Merkmal des Ausgesuchten, Wählerischen, Persönlichen, Relativen.

4. SchlieBlich sind der jeden einzelnen Satz affizierende Weg des Argumentations-Schemas bzw. die Gangart des erzählenden oder darstellenden Textes wie jede Methode formale Angelegenheiten.

Wie bereits mehrfach erwähnt, halte ich diese vierfache Relativität für einen Aspekt der Objektivität, und zwar in doppelter Hinsicht: so ist Stil weder als kohärente und konstante Auswahl von Begriffen und Daten noch als Ausdruck der eigenen Freiheit $\gg$ gleichwertig $\ll$ bzw. $\gg$ gleichgültig《.

Deswegen ist $>$ Stil an sich - dem Stil-Begriff von Diderot und Goethe durchaus entsprechend - nicht meßbar. Denn, im Unterschied zu den doch ziemlich begrenzten ausdrucks-grammatischen, kasuellen, meßbaren Fügungen, sind die inhaltlich-formalen Potentialitäten wirklich 》unendlich $\ll$ oder mindestens $\gg$ unbegrenzt $\ll$. Den EntschluB, den Usus der Sprache auf die ästhetische $\gg$ Oberflächenstruktur $\ll z u$ beschränken, kann ich nicht nachvollziehen, denn auch die nicht meBbare Qualität des Stils hängt auch an seiner ästhetischen $\gg$ Tiefenstruktur $\ll$. Kurzum, <dieser oder jener Stil> verdient seinen Namen nur, wenn er auch $<$ Stil überhaupt $>$ ist. Ein Sophisma hieße nun, meßbar sei der Stil also nur, wenn er nicht meßbar ist! Aber Protagoras läßt sich auch anders verstehen. An der Schwelle von a posteriori und a priori-Urteilen, verstehe ich den Satz, $>$ der Mensch sei das Maß aller Dinge\&, nicht als Forderung einer $\gg$ subjektiven $\ll$ Relativität, sondern als Einsicht in die \objektive $\ll$ Relativität des Daseins, als Einsicht in seine rettenden Relationen.

$\gg$ Stil an und für sich $\ll$ ist weder meBbar noch kalkulierbar. Es stehen immer nicht nur unendlich viele Möglichkeiten ex parte objecti zur Wahl, sondern es gibt auch ex parte subjecti unendlich viele Wahlmöglichkeiten. [Mehr Möglichkeiten als der gute Stil hat wohl nur noch - freilich der schlechte Stil bzw. die Stillosigkeit.] Nichtsdestominder scheint mir in den kommenden Jahrzehnten eine Verbindung von Stilometrie und Lexikometrie den Bereich der Meßbarkeit über die Regularitäten der bloßen Manier hinaus erweitern zu können.

Dennoch dürfte niemals von der Angemessenheit auf die Einzigartigkeit geschlossen werden. Angenommen, jeder Teilnehmer dieser Jahrestagung über Stilfragen oder sonstige Leser dieser Zeilen müßte - problemgerecht, aber in beliebiger Länge und Form - darstellen, daß - um ein Beispiel zu nehmen, das uns Heutigen so bekannt ist wie es den Griechen in der Blütezeit der Akademie das Angeln war - die Stadt ursprünglich der 
Versuch des Menschen gewesen sei, sich den RAUM untertänig zu machen, und daB in vielen Städten und besonders in Vor- und Schlafstädten heute das Gegenteil eingetroffen sei, daf also die Stadt dem Menschen nicht Freiheit, sondern Sklaverei bringe, bestünden nicht mehr Möglichkeiten als Darsteller, denn jeder von uns würde sich überlegen, was er nun verfassen sollte: einen Artikel, eine Fabel, eine Epistel, ein Haiku, ein Manifest, ein mehrbändiges Geschichtsbuch, einen Dialog, eine Satire, eine Abhandlung, einen Roman, ein Drama, oder, was in diesem Falle den Grammatiker reizen dürfte, eine Utopie?

Eine andere, leichtere und dennoch vielgestaltige Aufgabe besteht in der angemessenen inventio und expositio, ohne circulus vitiosus, der nicht widersprüchlichen Thesen, d a $B$ dieser und jener Stil sehr wohl ziemlich meßbar ist, de $\mathrm{r} \mathrm{St}$ il a $\mathrm{n}$ i c h dage ge n let zten Endes überha upt $n$ ich t.

\section{Anhang}

Den Teilnehmern wurden die folgenden zwanzig Texte ausgeteilt, zu denen jeweils die Frage zu beantworten war, ob die Signatur stimmt (I) oder nicht (0). Von den am folgenden Tag eingereichten Antworten erreichte diejenige von Nicky Anders (Pseudonym von Marie-Anne Durand, Universität Grenoble) mit dreizehn richtigen I bzw. 0 die höchste Punktzahl und gewann damit eine Flasche Burgunder mit dem Prix d'excellence.

[Der Himmlische Lehrsaal]

Hätte ein Engel oder ein himmlischer Geist die Sprache erfunden: wie anders, als daß ihr ganzer Bau ein Abdruck von der Denkart dieses Geistes sein müßte; denn woran könnte ich ein Bild von einem Engel gemalt kennen als an dem Englischen, Überirdischen seiner Züge? Wo findet das aber bei unserer Sprache statt? Bau und Grundriß, ja selbst der ganze Grundstein dieses Palastes verrāt Menschenheit! In welcher Sprache sind himmlische, geistige Begriffe die ersten? Jene Begriffe, die auch nach der Ordnung unseres denkenden Geistes die ersten sein mūssen - Subjekte, notiones communes, die Samenkōrner unserer Erkenntnis, die Punkte, um die sich alles wendet und alles zurückführt, sind diese lebenden Punkte Elemente der Sprache? Die Subjekte müBten doch natürlicherweise vor dem Prädikat und die einfachsten Subjekte vor den zusammengesetzten, was da tut und handelt, das Wesentliche und Gewisse vor dem Ungewissen, Zufälligen vorhergegangen sein; - ja, was man nicht alles schließen könnte; - und in unsern ursprünglichen Sprachen findet durchgängig das offenbare Gegenteil statt. 
2 [Das eigentliche Grundgesetz]

Unsere Gesetze sind Versuche, aus Papier den weisen Mann zu machen, der allen Umständen gewachsen ist, und dessen Gerechtigkeit so groß ist wie seine Unerschrockenheit; - ach, wo ist das ehrfurchterweckende Gesicht des Gesetzgebers hin, welcher mehr bedeuten muß als das Gesetz, nämlich den Wunsch es aus Liebe und Ehrfurcht heilig zu halten?

Friedrich Nietzsche ??

3

[Der arme Dichter]

Ein Dichter, rund und feist bei Leibe,

Mit einem Antlitz', lang wie breit,

Und glänzend, wie des Vollmondes Scheibe,

Sprach einst von seiner Dürftigkeit,

Und schimpite brav auf theure Zeit.

$\gg$ Das thun Sie blob zum Zeitvertreibe,

Rief einer aus dem Kompanie;

Denn dieß Gedeihn an ihrem werthen Leibe,

Und ihr Gesicht, die schöne Vollmondscheibe,

Herr Kläger, zeugen wider Sie! «-

$\gg$ Das hat sich wohl! seufzt der Poet geduldig;

Doch, Gott gesegn'ihn! meinen Bauch -

Sanft strich er ihn - und diesen Vollmond auch -

Bin ich dem Speisewirth' noch schuldig. $\ll$

Gottfried August Bürger ??

[Der Unentbehrliche]

Könnt' ich tausendfach mich theilen,

Schnell mit allen Winden eilen,

Überall zugleich $\mathrm{zu}$ walten,

Wo's die Welt gilt zu gestalten!

Würden nicht durch meine Kräfte

Rasch gedeihn der Zeit Geschäfte?

Doch, so läßt mir mein Geschick

Schauen nur im Zeitungsblick

Ohne mich in fernen Reichen

Die verlassnen Völker schleichen! -

Von den Sternen möcht' ich wissen,

Ob sie mich nicht schwer vermissen?

Friedrich Rückert ??

5 [Die Mittagszeitung]

Korf erfindet eine Mittagszeitung, welche, wenn man sie gelesen hat, ist man satt. 
Ganz ohne Zubereitung irgendeiner andern Speise. Jeder auch nur etwas Weise hält das Blatt.

Christian Morgenstern ??

6 [Faust]

Was bist du denn? gier'ger Allumfasser

Des Universums kühner Freuer du.

Der blind, in Nacht, in zwiefach ew'gem Dunkel

Gebannt $2 u$ irren, nichts erkennen kannst,

Ein ewig ungelöstes Rätsel dir;

Erschaffer deiner Welt nach ewigen

Gesetzen, selbst von ihr erschaffen,

Was bist du mächt'ger, nicht'ger Erdenwurm?

Ein Gott in Banden, oder nur ein Staub?

Was ist des Denkens, was der Sinne Welt?

Die Zeit, der Raum, die Allumfassenden,

Und ihre Schöpfungen, durch die sie werden?

Was auBer ihnen, das Unendliche?

Was ist die Gottheit, jeder großen Kette

Ein erstes ewig unbegriffnes Glied,

Das, nicht getragen, alle Glieder trägt? -

Es wirft das Licht, das innre, dort hinaus

Auf ausgespannte Nacht die Bilder hin,

Ein leerer Widerschein des eignen Ichs,

Und so entsteht die Welt, die ich erkenne.

So hat - vielleicht der Zufall es geordnet,

Der große Bildner, den sie Gottheit nennen.

Und wenn, nicht bloß gedacht, dort Geist und Körper

Und Gottheit sind, - wie fass' ich sie? - umsonst!

Es treten ewig $\mathrm{z}$ wischen sie und mich

Der Sinne Lügen, der Vernunft Gesetze.

Theodor Körner ??

7 [Der Barfüßer]

Unterm Thor der Schenke lag

Trunken ein Barfüßer,

Von Gerichts- und Schöpfungstag

Sprach der fromme Büßer.

Sprach von Kaisern, Königen,

Fürsten, Grafen, Freien,

$\mathrm{DaB}$ sie seine frönigen

Unterthanen seien.

Und er ließ aus voller Hand

(Brauchte nicht zu sparen) 
Stāuben als wie Spreu und Sand

Kronen und Tiaren.

Und er gab das Diadem

Nur entschloßnen Trinkern,

Drohte mit dem Anathem

Allen matten Sinkern.

Über Bogen so und Bausch

Ordnet' er das Welttheil,

Und ihm war allein sein Rausch

Nicht ums Geld der Welt feil.

Nicolaus Lenau??

8 [Jenseits von Argument-Struktur und Rollenplan]

Auch Adverbiale stehen im Bannkreis des Verbs.

Judith Macheiner ??

9

[Entdeckung und Deduktion]

Um der Urbegriffe willen ist also noch zu bemerken: daß die Kategorien, als die wahren Stammbegriffe der reinen Vernunft, auch ihre eben so reinen abgeleiteten Begriffe haben, die in einem vollständigen System der Transzendental-Philosophie keineswegs übergangen werden können, mit deren bloßer Erwähnung aber ich in einem bloß kritischen Versuch zufrieden sein kann. Es sei mir erlaubt, diese reinen aber abgeleiteten Begriffe die Prādicamente (im Gegensatz der Prädikabilien) zu nennen. Wenn man die primitiven und ursprünglichen Begriffe hat, so lassen sich die subalternen und abgeleiteten leicht hinzufügen, und der Stammbaum der reinen Begriffe völlig ausmalen. Da es mir hier nicht um die Vollständigkeit des Systems, sondern nur der Principien zu einem System zu thun ist, so erspare ich die Ergänzung auf eine andere Beschäftigung. Man kann aber diese Absicht ziemlich erreichen, wenn man die Ontologischen Lehrbücher zur Hand nimmt, und z.B. der Kategorie der Causalitāt, die Prädikamente der Kraft, der Handlung, des Leidens, der der Gemeinschaft, die der Gegenwart, des Widerstandes, den Prädicabilien der Modalitāt, die des Entstehens, Vergehens, der Veränderung u.s.w. unterordnet. die Kategorien mit den modis der reinen Sinnlichkeit oder auch nur untereinander verbunden, geben eine große Menge abgeleiteter Begriffe und eine noch größere Menge unableitbarerer Begriffe, die zu verzeichnen eine nützliche, aber unerfüllbare, glücklicherweise aber zur Deduction der Urteilstafel entbehrliche Aufgabe wäre. Der Definition dieser Kategorien überhebe ich mich in dieser Abhandlung geflissentlich, ob ich gleich im Besitz dersellben sein möchte. Ich werde die Prädicabilien und die Prādicamente in der Folge bis auf den Grad zergliedern, welcher in Beziehung auf die Methodenlehre, die ich bearbeite, hinreichend ist. 
Ein Barde hieß, aus frommer Pflicht, Ein ganzes Heer von Sylben ringen.

Ich will nur $z$ wo zur Sprache $z$ wingen, Weil doch in Fabeln alles spricht.

Es sind die, so ich reden lasse, Machtwörter von der ersten Classe, Die in der Welt was rechtes schreyn, Die alten Feinde: Ja und Nein.

Es rüsten beide sich zum Streit.

Sie wollen nun als Helden fechten, Und nicht, wie kleine Hadrer, rechten. Kurz: sie bestimmen Ort und Zeit. Nein trotzt auf kriegerische Freude; $\mathrm{Ja}$ täuscht, verlockt, besticht die Feinde. Nein pocht auf Faustrecht und Gewalt; Ja traut auf seinen Hinterhalt.

Wir wollen, in gewissen Fällen, Uns beyde meisterlich verstellen, Am Hofe soll das Ja oft Nein, Und Nein ein wuchernd Jawort seyn.

Nein, das den Werth des Vorschlags sah, Beschloß, von nun an leeren $H a ̈ n d e n$ Den Beystand nimmer zu verpfänden, Und sprach zum erstenmale: Ja.

Die ganze Fehde war geschlichtet, Aus Eigennuz ein Bund erreichtet; Und beyde dienen izt der Welt, Nach Schweizerart, um baares Geld.

Friedrich von Hagedorn??

Was uns die ersten Silben freundlich nennen, Das ist dem Menschen wunderbar verwandt, Einst werden wir das Rätselbild erkennen, Von oben sonst den Vätern oft gesandt, Wenn sich die Seele wird vorn Körper trennen Und einzieh' $n$ in das alte Vaterland:

Da mag es freundlich, in der Jugend Prangen, Mit zarten Liebestōnen uns empfangen.

Die dritte Silbe baut sich auf der Erde Und ist dem Menschen immer wert und lieb; Und leichter trägt es seines Tags Beschwerde, Wenn's drin nur so froh und ohne Kummer blieb. Ach! wie so gern er zu ihm wiederkehrte, 
So ihn das Schicksal in die Ferne trieb;

So er hinaus muB in das wilde Leben,

Er scheidet still, doch bleibt er ihm ergeben.

Das Ganze prangt auf steilen Felsenhöhen

Als ein Vermächtnis der Vergangenheit;

Durch seine Mauern flüstert Geisterwehen

Wie stille Träume jener bessern Zeit.

Und wo hinaus die trunk'nen Blicke sehen,

Hat die Natur den Brautschmuck ausgestreut,

Als sollte hier die dritte Silbe prangen,

Die beiden ersten würdig zu empfangen.

Adalbert Chamisso??

[Monolog eines jungen Mannes von vierzig Jahren]

Das sind die Tage, über denen allen

Flamingoblaues Dämmern liegt.

- Und hören sehr perverse Orgeln schallen

Und Traueraffen aus den Bäumen fallen

Und sind sehr satt.

Und sind sehr matt und alt.

Und tragen uns mit kränklichen Gebärden

Und wissen, daß wir waren, was wir werden.

Und es ist gut.

Und schreiben ofter matte Operntexte.

Und zählen still vom ersten bis ins sechste.

Und sagen: "Wien".

Und sind noch immer wie vor $z$ wanzig Jahren.

Und wissen, daß wir werden, was wir waren.

Und wedeln sanft.

Und wandeln in der guten Abendröte.

Und spielen gern und sehr den alten Goethe.

Und sind sehr fein.

Und schreiben edle Auf- und Niedersätze.

Und stellen uns auf sehr belebte Plätze.

Und denken nichts.

Und haben einen sehr gepflegten Stil.

Und nicken mit dem Kopfe ganz und viel.

Und wirken ganz ornemental.

Und sind in dieser Welt wie in der Fremde.

Und tragen in der Nacht ein seidnes Hemde.

Und werden nächstens wohl katholisch werden. 
Der Muskel wird durch starken Gebrauch gestärkt, der Nerv hingegen dadurch geschwächt. Also übe man seine Muskeln durch jede angemessene Anstrengung, hūte hingegen die Nerven vor jeder, also die Augen vor zu hellem, besonders reflektiertem Lichte, von jeder Anstrengung in der Dämmerung, wie auch vor anhaltendem Betrachten zu kleiner Gegenstände, ebenso die Ohren vor zu starkem Geräusch, vorzüglich aber das Gehirn vor gezwungener, zu anhaltender oder unzeitiger Anstrengung; demnach lasse man es ruhen während der Verdauung, weil dann eben dieselbe Lebenskraft, welche im Gehirn Gedanken bildet, im Magen und in den Eingeweiden angestrengt arbeitet, Chymus und Chylus zu bereiten, ebenfalls während oder auch nach bedeutender Muskelanstrengung. Denn es verhält sich mit den motorischen wie mit den sensiblen Nerven, und wie der Schmerz, den wir in verletzten Gliedern empfinden, seinen wahren Sitz im Gehirn hat, so sind es auch eigentlich nicht die Beine und Arme, welche gehn und arbeiten, sondern das Gehirn, nämlich der Teil desselben, welcher mittelst des verlängerten und des Rückenmarks die Nerven jener Glieder erregt und dadurch diese in Bewegung setzt. Demgemäß hat auch die Ermūdung, welche wir in den Beinen oder Armen fühlen, ihren wahren Sitz im Gehirn, weshalb eben bloß die Muskeln ermūden, deren Bewegung willkürlich ist, d.h. vom Gehirn ausgeht, hingegen nicht die ohne Willkür arbeitenden wie das Herz. Offenbar also wird das Gehirn arbeiten wie das Herz. Offenbar also wird das Gehirn beeinträchtigt, wenn man ihm starke Muskeltätigkeit und geistige Anspannung zugleich oder auch nur dicht hintereinander abzwingt. Hiemit streitet es nicht, daß man im Anfang eines Spaziergangs oder überhaupt auf kurzen Gängen oft erhōhte Geistestātigkeit spürt; denn da ist noch keine Ermüdung besagter Gehirnteile eingetreten, und andererseits befördert eine solche leichte Muskeltätigkeit und die durch sie vermehrte Respiration das Aufsteigen des arteriellen, nunmehr auch besser oxydierten Blutes zum Gehirn.

Arthur Schopenhauer??

[Windgespräch]

Hast nie die Welt gesehn?

Hammerfest - Wien - Athen?

"Nein, ich kenne nur dies Tal, bin nur so ein Lokalwind -

kennst du Kuntzens Tanzsaal?"

Nein, Kind.

Servus! Muß davon!

Köln - Paris - Lissabon.

Christian Morgenstern ??

Der ergraute Mentor ungezāhlter Befragter, der Unermüdliche, dem es geglückt war, in zäher Bewußtheit die wenig wirtliche Landschaft sich gefügig zu ma- 
chen, der erfahrene Zuerkenner und väterlich gerechte Verteiler vorhandener Gelegenheit zu Rest und Erquickung, der Erzeuger endlich (und damit sind die Werke seiner Reifezeit kurz bezeichnet) jener aus Sahne bereiteten Alpenspeise, die unter dem Namen Käse Weltruf gewonnen hat: Peter Haslacher also, der Schutzhauswirt, rief der auf glatt gehobelten Schienen edel gewāhlten Holzes über die Schneefläche eilends Nähergleitenden eben noch ein warnendes Wort zu, als das Unheil schon seinen Lauf nahm. Erzeugt aus einer sanften Blendung des Auges in Verfolg der ungeahnt beschwingten Bewegung, erstanden aus einer leichten Berückung des Hirns, die das glückhafte Bewußtsein schwereloser Befreitheit auf nervlichen Bahnen zum rascher durchbluteten Herzen hinabtrug, aufgestiegen aus einer leichten Ermattung in jener Gegend des Knies, die ein nordischer Betrachter und durch ungekannt tiefe Vertrautheit gewichtiger Zeuge als die schönste des weiblichen Körpers zu bezeichnen sich nicht entbrechen zu sollen vermeint, hatte die Unsicherheit von den Schenkeln der Fahrtbeflissenen unversehens Besitz ergriffen, war höher kletternd in ungebührlich jäher Verbreitung über den unteren Leib bis in die Gegend des Zwerchfells gelangt und hatte den Schwerpunkt weit hinter die Linie lotrechten Standes zurück, ja die Wendende selbst bis zu schlechtweg unmittelbarer Berührung mit dem kristallisch weißen Elemente niedergedrängt: sie saß im Schnee.

Thomas Mann??

16

[Schiller]

Was wälzt sich dort mit Sprachgewalt

Von Pathos Tempel zur Tirade?

Ein Ungeheuer von Gestalt,

Das bald sich bãumet, bald sich ballt -

Hier wird Getümmel zur Ballade.

Wie schade.

Friedrich Torberg ??

17

Den Adler laß verschwenden

An Erben, Lamm und Frau

Das Salböl aus den Hānden

Des toten alten Pfau ...

Anonym ??

18 [Die Kristallschale]

Der Reichsfreiherr Eusebius horchte. Das Morgengrauen erhellte schon den westlichen Himmel. Es war kein Amselruf, erkannte der nun vollends erwachte Eusebius. Es kam aus der Kate drüben am Rande des Moores. War da ein Lebendiges in Bekümmernis, kreißte da eine werdende Mutter oder dergleichen? Sein war die Verantwortung für Alles.

Er eilte hinüber und fühlte sich erleichtert, als er nur ein etwa zweijähriges Mädchen antraf. Es war allein, er kannte es wohl, es war das Kind Krcyscz, 
die Mutter war wohl schon vor Morgengrauen aufgebrochen, um in der von Eusebius eingerichteten Sonnengoldspinnerei zu arbeiten, und einen Vater hatte es nie gehabt.

Das Kind blickte den Reichsfreiherrn Eusebius an, ganz ohne Scheu.

"Wie heißest du?" fragte er es.

"Pi", sagte es schlicht.

Pipistrella? dachte er leise. Die Fledermaus? Oder hat es auf der Wanderschaft wie so viele die Aussprache des Pi verlernt und heißt Philomela, die Nachtigall? Es wäre schön, wenn du Philomela hießest, fuhr er an das Kind hin zu denken fort.

Das Kind erriet seinen Gedanken sofort. „Glaubst du nicht auch, Herr Reichsfreiherr”, sagte es, „daß es noch ziemender für mich wäre, wenn ich die Lerche hieße statt der Nachtigall, da diese doch mehr der Liebenden Vogel ist?"

Er schickte sich an, einem wundersamen Erstaunen über die Seelenweisheit des Kindes nachzuhängen, aber eine zarte Unruhe nistete in seinem Herzen und ließ sich nicht mehr bannen. Pi, dachte er grübelnd, Pi? Erinnerte ihn nicht etwas an diesem Klange an seine eigene, unwiederbringlich vergangene Jugendzeit?

Ernst Wiechert??

[Dialektisch völlig verfahren]

Ich gebe der Genossin Seghers vollkommen recht in allem, was sie über die derzeitige Notwendigkeit der Herausstellung klassischer Formen sagt; aber stofflich liegt die Szene des verewigten Nationalpreisträgers falsch. Die propagandistische Linie ist korrekt, aber zu direkt. Wir müssen uns, ganz andere Methoden kopierend, viel langsamer heranpirschen. Vor allem ist zu bekämpfen die lächerliche westliche Vorstellung, daß wir (a) prüde und (b) humorlos seien. Das, in Kombination mit der von der Genossin mit Recht geforderten Form, kann am besten an einem völlig unpolitischen, dabei aber zugleich humoristischen und bourgeois-frivolen Thema unter Beweis gestellt werden. Ich habe mich daher entschlossen, die berüchtigten Verse der $\gg$ Wirtin an der Lahn $\ll$ in meine eigenen proletarisch-klassischen Metren umzudichten.

Stephan Hermlin??

[Das Gewissen und das Bewußtsein]

Die Antinomie der moralischen Weltanschauung, daß es ein moralisches Bewußtsein gibt und $d a \beta$ es keines gibt, - oder daß das Gelten der Pflicht ein Jenseits des Bewußtseins ist und umgekehrt nur in ihm stattfindet, war in der Vorstellung zusammengefaßt worden, worin das nichtmoralische Bewußtsein für moralisch gelte, sein zufälliges Wissen und Wollen für vollwichtig angenommen und die Glückseligkeit ihm aus Gnade zuteil werde. Diese sich selbst widersprechende Vorstellung nahm das moralische Selbstbewußtsein nicht über sich, sondern verlegte sie in ein ihm anderes Wesen. Aber dies Hinaussetzen dessen, was es als notwendig denken muß, außer sich selbst, ist ebenso der Widerspruch der Form nach, wie jener es dem Inhalte nach ist. Weil aber an sich eben das, was als widersprechend erscheint und in dessen Trennung und Wiederauflōsung die moralische Weltanschauung sich herumtreibt, desselbe ist, die reine Pflicht nämlich als das reine Wissen nichts anderes ist als das Sein des 
Bewußtseins, und das Selbst des Bewußtseins das Sein und die Wirklichkeit, ebenso was jenseits des wirklichen BewuBtseins sein soll, nichts anderes ist als das reine Denken, also in der Tat das Selbst ist, so geht für uns oder an sich das Selbstbewußtsein in sich zurück und weiß dasjenige Wesen als sich selbst, worin das Wirkliche zugleich reines Wissen und reine Pflicht ist. Es selbst ist sich das in seiner Zufäligkeit Vollgültige, das seine unmittelbare Einzelheit als das reine Wissen und Handeln, als die wahre Wirklichkeit und Harmonie.

Johann Gottlieb Fichte??

Für gewöhnlich enthalten satirisch gemeinte Parodien Elemente, meist inhaltlicher Art, an denen sie vom Leser erkannt werden sollen. Computer könnten es da wohl schwerer haben. Bei Fälschungen ist es umgekehrt: der Leser soll an der Echtheit des Textes nicht 2weifel. Möglicherweise hat es der mit Feinststatistik gespeiste Computer leichter, an der Echtheit des Schriftstückes Zweifel aufkommen zu lassen. Nichtsdestoweniger haben viele Autoren Texte verfaßt, die mit dem Bild nicht übereinstimmen, die andere Schriften von ihnen geben. Insbesondere sind verwechselte Autoren nicht leicht auseinanderzuhalten. Von epistemologisch großem Interesse ist indessen das Gefühl, das wohl jeder hat, sobald sich die Überraschung der Korrektur gelegt hat: a posteriori ist man nicht nur gescheiter, sondern meint auch, mit etwas mehr Aufmerksamkeit, Gedächtnis und List wäre man schon a priori nicht auf solche Vexierfragen hereingefallen.

[Lösung: 1, 1, 1, 0, 1, 0, 0, 1, 0, 1, 0, 0, 1, 1, 0, 1, 1, 0, 0, 0] 


\title{
HARTMUT SCHRÖDER
}

\section{Der Stil wissenschaftlichen Schreibens zwischen Disziplin, Kultur und Paradigma - Methodologische Anmerkungen zur interkulturellen Stilforschung*}

\begin{abstract}
„Wenn man hāufig Gelegenheit hat, deutsche und französische Hochschullehrer auf wissenschaftlichen Tagungen und Konferenzen zu beobachten, wenn man gleichsam mit zerstreutem Ohr zuhört, weniger auf den Inhalt achtend, dafür mehr auf die Form, auf das Gestisch-Mimische des Vortrags und das Musikalische der Rede, dann drängen sich unweigerlich einige Unterschiede auf, zum Beispiel: Die französischen Wissenschaftler, mit kleinem Spickzettel bewaffnet, den sie in der Hand balancieren, aus dem sie ein ganzes Exposé hervorzaubern, scheinen zu improvisieren; die deutschen dagegen mit einem ausformulierten Konzept, das abgelesen wird, das wesentlich Schriftsprache ist mit hoher Substantivierung, Hypotaxen, Adjektivhäufungen; [...] die Franzosen, die entsprechend der Lehre der Rhetorik zunächst die Sprechsituation bedenken, also ausführlich auf Zuhörer, Anlaß und Umstände reflektieren und es auch an Höflichkeiten nicht fehlen lassen, während die Deutschen medias in res sofort zur Sache kommen; - die Franzosen, die mit dem Publikum über Blick, Stimme und Körpersprache kommunizieren, [...]; die Deutschen, die auf die Sache selbst sich versteifen, als ob diese von der Form ablösbar wäre, die im Zweifel ihren Vortrag auch ohne Publikum hielten, nur sich selber und dem wissenschaftlichen Ethos verpflichtet; $-[. .$.$] der spielerische Einstieg in die Thesenexposition bei$ Franzosen, induktiv verstreute Beobachtungen sammelnd, aus denen dann en passant Schlüsse gezogen werden; dagegen der theoretischmethodologische Impetus deutscher Forscher, die als Präludium ihrer Darlegungen geschichtsphilosophische oder erkenntnistheoretische Voraussetzungen härtesten Kalibers servieren, in der Meinung, daß dies zur Durchsichtigkeit ihrer Argumentation hilfreich sei [...]." (Meyer-Kalkus 1990, S. 694-695)
\end{abstract}

\section{Einleitung}

In meinen folgenden Ausführungen möchte ich mich weder im allgemeinen mit der Problematik einer „antithetischen Nationalitätencharakteristik" (Meyer-Kalkus 1990, S. 695) auseinandersetzen, noch möchte ich im besonderen auf Unterschiede in den deutschen und französischen Wissenskulturen eingehen. Vielmehr werde ich zwei entgegengesetzte Thesen aus der angewandten Linguistik diskutieren, die sich insbesondere aus der Sicht des Fremdsprachenunterrichts und der Überset-

* Ich danke Frau Dagmar Zimmer für ihre Mitarbeit bei der Recherchierung und Auswertung der einschlägigen Literatur sowie für ihre wertvollen Hinweise in den wichtigsten Phasen der Entstehung der vorliegenden Arbeit bis hin zur kritischen Durchsicht der verschriftlichten Fassung meines Vort-ags. 
zungspraxis mit der Frage der Universalität einerseits und der Kulturgebundenheit des wissenschaftlichen Diskurses andererseits beschäftigen. Die Universalitätsthese, vertreten u.a. von dem britischen Linguisten Henry Widdowson, stieß zunächst im Bereich der Fachsprachenforschung und der didaktischen Überlegungen zu einem fachbezogenen Fremdsprachenunterricht kaum auf Widerspruch und galt lange als eine wichtige Prämisse, die nicht weiter hinterfragt wurde. Die in den $60 \mathrm{er}$ Jahren von dem Amerikaner Robert Kaplan, dem Pionier der kontrastiven Rhetorik, vorgetragenen Gedanken zu kulturspezifischen Abweichungen vom anglo-amerikanischen Vertextungsmuster der 'Linearität' in von NichtAmerikanern geschriebenen Essays wurden dem Kreis der Germanisten erst relativ spät durch die Arbeiten des australischen Linguisten Michael Clyne bekannt, der in zahlreichen Aufsätzen den Ansatz von Kaplan referiert und weiterentwickelt hat. Seitdem wurden mehrere Untersuchungen vorgelegt, die den wissenschaftlichen Diskurs - und damit den Stil wissenschaftlichen Schreibens - ausdrücklich als „einen Gegenstand kulturund nationalspezifischer Normen" (Schlieben-Lange/Kreuzer 1983, S. 12) behandeln. Ich werde unter Punkt 2 beide Positionen, d.h. die Universalitäts- und die Relativitätsthese, genauer referieren und mögliche Determinanten des Stils diskutieren. Unter Punkt 3 werde ich mich vor allem mit methodologischen Fragen interkultureller Stilforschung im Bereich der schriftlichen Fachkommunikation beschäftigen und unter Punkt 4 auf Aspekte der Zukunft des wissenschaftlichen Schreibens eingehen. Dabei soll insbesondere diskutiert werden, wie sich die zunehmende Internationalisierung und Medialisierung auf den Stil wissenschaftlichen Schreibens auswirkt bzw. auswirken kann. Anspruch des vorliegenden Beitrages ist es indes nicht, fertige Lösungen und originelle Untersuchungsergebnisse zur Thematik des Stils wissenschaftlichen Schreibens vorzulegen. Vielmehr beabsichtige ich, einen kurzen Aufriß zur Problematik Kultur und Stil zu leisten sowie einen Überblick über die methodologischen Schwierigkeiten einer interkulturellen Stilforschung zu geben.

\section{Wissenschaftliche Fachkommunikation und interkulturelle Stilforschung}

\subsection{Fachtext und Stilbegriff}

„Stil: Jede mündliche oder schriftliche Äußerung hat stilistische Qualitäten [...]. Es gibt keinen 'Null-Stil'." (Weinrich 1988, S. 105)

„Stil ist [...] Weltsicht durch Sprache und nicht nur sprachliche Formbetontheit." (Stolze 1992, S. 233)

„Stil ist ein sinnstiftender Faktor im Rahmen der Multiperspektivität von Texten." (Stolze 1994, S. 201) 
Was hat Wissenschaft überhaupt mit Stil zu tun?' ${ }^{1}$ Steht die Wissenschaftssprache nicht für 'Sachlichkeit' und 'Inhaltsbezogenheit', d.h., ist die 'Abwesenheit von Stil' nicht gerade charakteristisch für die wissenschaftliche Kommunikation? Hans-Martin Gauger führt hierzu in seinen theoretischen Überlegungen zum Stilbegriff aus, daß in der Wissenschaft aufgrund der Inhaltsdominanz das Wie, d.h. die sprachliche Gestaltung des Textes, eigentlich völlig frei von Formvorgaben sein müßte, da die Bedeutung durch das Was bereits vorgegeben sei. In der Praxis - so Gauger - ist das Wie jedoch durch bestimmte Schreibkonventionen (den sogenannten 'Sachstil') genau festgelegt (siehe hierzu den Beitrag von Gauger in diesem Band).

Im folgenden gehe ich - hinsichtlich der Fragestellung nach dem Was und Wie in einem Text - davon aus, daß Wissenschaft nicht nur Inhalt ist, d.h. Wissenschaftstexte nicht nur objekt- und sachverhaltsbezogene 'Informationen' vermitteln, sondern darüber hinaus immer auch Wirkung erzielen sowie ein Publikum ansprechen und überzeugen wollen, so daß "die landläufige Dichotomie von Form und Inhalt schon vom theoretischen Ansatz her zu vermeiden” wäre; denn: „In der Stilistik erweist sich einmal mehr, daß die Form nichts ist als die Fortsetzung des Inhalts mit anderen Mitteln" (Graubner 1978, S. 185). Die (stilistische) Gestaltung eines wissenschaftlichen Fachtexts erschöpft sich daher auch nicht in der Komponente des Pragma. Aus der Sicht der Rhetorik (siehe Ueding/Steinbrink 1986, S. 195) enthalten wissenschaftliche Texte Charakteristika des docere (belehren und informieren), des delectare (unterhalten) und des movere (bewegen, mitreißen). Neben dem „Eingehen auf die Sache” (Pragma) soll durch eine adäquate Vertextung die „Verläßlichkeit" des Senders (Ethos) unterstrichen und der Empfänger emotional disponiert werden (Pathos). Die beiden zuletzt genannten Aspekte Ethos und Pathos - sind dabei außer an die Stoffauswahl (inventio) und die Anordnung des Stoffs (dispositio) in besonderer Weise an verbale Vertextungsmittel (elocutio) und an die Verwendung nonverbaler Vertextungsmittel (pronuntiatio und actio) gebunden. 'Stil' - verstanden als Auswahl, „daß dasselbe so oder so gesagt werden kann" (Gauger 1988, S. 81) - ist somit ein Phänomen, das auch den Fachtext in allen Phasen der Textproduktion (und -rezeption) begleitet.

1 Eine begriffsgeschichtliche Begründung findet sich bei Rainer Wimmer, der darauf hinweist, daß der Begriff Stil "seit dem 16./17. Jahrhundert u.a. auch verwendet (wird), um berufsbezogene, professionalisierte Schreibarten zu benennen, und in dieser Tradition rechtfertigt sich auch der Gebrauch eines Ausdrucks wie 'Wissenschaftsstil', 'wissenschaftlicher Stil'." (Wimmer 1987, S. 83) 
'Stil' wird im folgenden als ein sehr weites (textlinguistisch und semiotisch fundiertes) Konzept, d.h. als die gesamte „Art und Weise der Konstitution von Texten" (Harweg 1972, S. 71) verstanden. Mit Carter/Nash bin ich der Meinung, daB Stil nicht in bezug auf nur eine Sprachebene (wie die der Grammatik oder der des Vokabulars) erklärt werden kann, sondern daB Stil aus einem Wechselspiel der Sprachorganisation auf verschiedenen Ebenen resultiert, Stil also als „textuelles Phänomen” gesehen werden muB (Carter/Nash 1990, S. 15). ${ }^{2}$

Des weiteren wird Stil als ein Phänomen nicht nur der Textproduktion, sondern auch der Textrezeption verstanden, d.h.:

„Stil wird aufgefaßt als das Resultat aus der Auswahl des Autors aus den konkurrierenden Möglichkeiten des Sprachsystems und der Rekonstituierung durch den textrezipierenden Leser. Stileffekte ergeben sich erst im dialektischen Wechselspiel zwischen den im Text kodierten Folgen der durch den Autor getroffenen Auswahl und der Reaktion durch den Leser. Stil ist eine Erscheinung an Texten, die im literarischen KommunikationsprozeB konstituiert wird. Daher ist Stil keine statische Eigenschaft eines Textes, sondern eine virtuelle Qualität, die im Rezeptionsvorgang rekonstituiert wird." (Spillner 1974, S. 64; Hervorhebungen H.S.)

Die Trennung von Form und Inhalt, eine der wichtigsten Ausgangspunkte der Stilforschung, ist theoretisch zwar durchaus nachvollziehbar, läBt sich in der Praxis der Stilanalyse von Fachtexten aber nur schwer einhalten, da die Grenze zwischen Form und Inhalt fließend ist. ${ }^{3}$ Bei Gauger heißt es zu dieser Problematik:

„Einerseits können Was und Wie eines Texts tatsächlich getrennt werden; vorsichtiger gesagt: sie sind nicht untrennbar. Gerade auf solcher Trennbarkeit beruht, zu einem Teil, was wir Stil nennen: eine der Bedingungen seiner Möglich keit ist, daß dasselbe so oder so gesagt werden

2 Bei H. Vermeer heißt es: „Stil bilden potentiell alle Textphänomene. Zum Stil gehört also nicht nur das Außergewöhnliche, das Seltene, das (sogleich) ins Auge fallende. Ein anderes ist es, was man wozu analysieren möchte. Und von Textphänomenen reden heißt auch: von Phänomenen reden, die zusammen einen Text konstituieren (helfen). Erst eine skoposorientierte Analyse jedes einzelnen Phänomens als Element eines Ganzen ergibt eine vollstāndige und brauchbare Analyse." (Vermeer 1992, S. 332)

3 U. Pōrksen bemerkt zur Stilkritik: „Kritik an der Sprache ist nahezu unlösbar mit Kritik an der Sache verquickt, sie meint oft in der Kritik an einem neuen Sprachgebrauch die Kritik an den neuen Auffassungen und Realitäten - sie scheint den Esel zu schlagen und den Herrn zu meinen" (1989, S. 429). Weiter heißt es bei Pörksen: „Es ist freilich nicht immer leicht zu entscheiden, ob wir an einer falschen Sache oder an einer falschen Sprache Anstoß nehmen" (1989, S. 430). 
kann. Wenn es nur eine Möglichkeit gäbe, etwas bestimmtes Vorliegendes zu sagen, wie dies in den Kunstsprachen, den Logikkalkülen, der Fall ist, gäbe es für Stil keinen Raum. Andererseits liegt natürlich in dem Begriff 'dasselbe sagen' die ganze Schwierigkeit: sagt man dasselbe, wenn man es so sagt oder so? Ist das bestimmte Vorliegende klar zu trennen von der Art, wie es gesagt wird? Gewiß sind Form und Inhalt nicht in jeder Hinsicht auseinanderzuhalten." (Gauger 1988, S. 81-82)

„Stil ist somit keineswegs nur ein sprachliches Phänomen. In ihm kommt Vieles und Verschiedenartiges zusammen. Er hängt zwar, wenn es um Texte geht, immer am Sprachlichen; er äußert sich in dessen Medium, aber er geht im Sprachlichen nicht auf. Zum Stil tragen, insbesondere bei einem 'fiktionalen' Text, Elemente des rein Inhaltlichen bei, dann formal-inhaltliche Elemente, dann nicht-sprachlich formale Elemente, schlieflich sprachliche Elemente." (Gauger 1988, S. 85)

Lassen sich diese - von Gauger auf fiktionale Texte bezogenen - Kategorien auch in der Analyse eines wissenschaftlichen Fachtexts anwenden? Gauger antwortet in einem Beitrag zum Stil des Historikers Golo Mann folgendermaßen:

„Schließlich gehören zum Stil inhaltliche Elemente. Der Begriff des Stils bezieht sich zwar auf das Wie des Geschriebenen, aber zu diesem Wie tragen auch inhaltliche Züge bei. Was den Historiker betrifft, so läßt sich, wie gesagt, bei ihm das Inhaltliche seiner Darstellungen von deren Wie leichter trennen als beim 'freien' Schriftsteller, auch bei ihm gehört Inhaltliches zu seiner spezifischen Schreibweise, schon allein deshalb, weil er auswählen kann - und muß - aus dem 'chaotischen Stoff', der sein Gegenstand ist: zum Stil eines Historikers gehört nicht zuletzt, was er auswählt, worauf er sich konzentriert." (Gauger 1988, S. 249)

Ausgehend von dieser Position Gaugers sowie in Anlehnung an die o.g. rhetorischen Kategorien wird meiner Meinung nach 'stilistische Bedeutung' im wissenschaftlichen Fachtext auf verschiedenen Ebenen und durch unterschiedliche Vertextungsmittel signalisiert:

1. durch die Auswahl des Stoffes (Ebene der inventio): Was wird explizit gesagt? Was wird vorausgesetzt? Was wird nicht gesagt? Was steht zwischen den Zeilen?

2. durch die Anordnung des Stoffes (Ebene der dispositio): Wie wird der Stoff angeordnet? Welche Rolle spielen Redundanzen und Ellipsen? Welche metatextuellen Elemente werden verwendet? Was sind die wichtigsten Argumentationsmittel?

3. durch die Art und Weise der Darstellung des Stoffes (Ebenen der elocutio, pronuntiatio und actio): Wie wird der Leser angeredet? Werden Aussagen nur angedeutet oder expliziert? Welche Kohärenzmittel werden genutzt? 
Alle genannten Erscheinungen stellen im wissenschaftlichen Fachtext 'Stilpotential' dar. In Anlehnung an Radegundis Stolze kann daher festgestellt werden, daß der "rhetorische Stil” im Fachtext entscheidend zum 'Gesamtsinn' beiträgt und nicht einfach „ein dekorativer Zusatz in einem idealtypisch 'informativen Text"' ist (Stolze 1986, S. 153):

„Hermeneutisch gesehen sind die rhetorisch-stilistischen Mittel, von denen eine leserbeeinflussende Wirkung ausgeht, nur ein Teil der Form, die mit dem lediglich analytisch abzutrennenden Inhalt eine unlösbare Einheit bildet. Texte lassen sich zwar didaktisch in diese beiden Elemente aufteilen, aber weder der Inhalt noch die pure Form hätten für sich eine Substanz, welche jene Wirkung hervorbringen könnte." (Stolze 1992, S. 232)

„Stilistische Merkmale sind linguistisch beschreibbare Sprachstrukturen, die keine statische, ein für allemal unverānderlich festgelegte $\mathrm{Er}_{\mathrm{r}}$ scheinung an Texten sind, sondern eher eine virtuelle Qualitàt, welche im RezeptionsprozeB erst rekonstruiert werden muß. Der dem Rezipienten sinnfällig werdende Stil eines Textes kann 'je nach Lesergruppe prinzipiell unterschiedlich sein' (Spillner)." (Stolze 1992, S. 231-232)

Zusammenfassend komme ich zu dem SchluB, daB das hier vertretene Konzept von Stil als 'textuelles Phänomen' (Carter/Nash 1990, S. 15) und als 'virtuelle Qualität' (Spillner 1974, S. 64) gerade für eine interkulturelle Stilforschung ein geeigneter Ausgangspunkt zu sein scheint: Stil ist demnach zwar in jedem Text omnipräsent und auf allen Ebenen der Vertextung zugegen, dennoch aber keine inhärente Eigenschaft eines Textes; ein Text hat nicht Stil, sondern ihm wird Stil zugesprochen; Stil entsteht erst im Rahmen und durch die Autor-Leser-Kommunikation, wobei „bis zu einem gewissen Grade jeder Leser aufgrund seiner individuellen Lesererwartung Stil anders rekonstruiert" (Spillner 1974, S. 67). Diese Subjektivität der Leserreaktion hält sich jedoch innerhalb einer Kultur gewissermaßen in Grenzen, da „sich die Angehörigkeiten einer Sprachgemeinschaft durch Erziehung, Bildungskanon, gesellschaftlich determinierte ästhetische Ideale etc. weitgehend gleich verhalten" (Spillner 1974, S. 67). Anders ist es jedoch in der interkulturellen Kommunikation, wo sich der Autor und die Rezipienten aufgrund abweichender Normvorstellungen, Erwartungshaltungen etc. unterschiedlich verhalten (können) und die 'Rekonstituierung von Stil' durch den Leser geradewegs Mißverständnisse und Fehlkommunikation provoziert.

4 So heißt es bei Rainer Wimmer: „Wissenschaftliche Stile sind ambivalent: Für die Eingeweihten sind sie ungeheuer hilfreich. Aber für die anderen sind sie Ausdruck des Nicht- Gewußten, des Nicht-Erreichten, des Scheiterns, des Ausgeschlossen-Seins, des Fremden und des letztlich auch Abzulehnenden." (Wimmer 1987, S. 93) 


\subsection{Determinanten des Stils wissenschaftlichen Schreibens}

"Die Kultur der Wissenschaft, die der Wahrheit verpflichtet ist und da-
mit auf das Universale zielt, erweist sich als in besonders hartnäckiger
Weise national geprägt. Sie beharrt in kulturspezifischen Kommunikati-
onsformen und damit einer Vorstrukturierung der Inhalte, die weiterhin
erheblich voneinander abweichen." (Picht 1987, S. 17)
"Both the content and the form of various functions of writing are
culturally determined." (Cooper/Greenbaum 1988, S. 7)

Eine Diskussion nach den Determinanten des Stils wissenschaftlichen Schreibens führt zunächst zur Problematik des Verhältnisses von Stil und Kultur, d.h. zur Frage, ob der Stil wissenschaftlichen Schreibens kulturgebunden oder universal ist. Die Universalitätsthese von Henry Widdowson (1979) geht von der Existenz sogenannter "fachsprachlicher Universalien" aus und galt in der fachsprachendidaktischen Diskussion lange als unumstritten. Ausgangspunkt ist die Annahme, daß jedes Fach bestimmte „Forschungs- und Darstellungsmethoden” hat, die zusammen mit den Begriffen der jeweiligen Disziplin ein „sekundäres kulturelles System" bilden: Begriffe und Methoden erzeugen gemäß der Universalitätsthese "eine bestimmte, für jede naturwissenschaftliche Disziplin charakteristische Art und Weise, über die Gegenstände der Wissenschaft zu kommunizieren, die man als wissenschaftlichen Diskurs bezeichnet" (Buhlmann o.J., S. 17). Bezogen auf die internationale Wissenschaftskommunikation bedeutet diese These, „daß die Wissenschaften und Technologien generell durch die sogenannte Transkulturalität gekennzeichnet seien, und daB in der interlingualen Fachkommunikation kaum Verständigungsprobleme auftauchen könnten, wenn die entsprechende Fachkompetenz und die notwendigste Fremdsprachenfähigkeit vorhanden sind" (Liang 1993, S. 153).

Die Bedeutung von kulturbedingten Stilspezifika wird dagegen in der Relativitätsthese ${ }^{5}$ betont, die insbesondere von Robert Kaplan - aufgrund jahrzehntelanger Beobachtungen im Bereich des Schreibens in der

5 Mit Relativitätsthese ist hier nicht das aus der Sapir-Whorf-Diskussion bekannte gleichlautende Konzept gemeint, wie es etwa von Hartmann auf das Verhältnis von Sprache und Wissenschaft übertragen wurde; Hartmann meint u.a., „daß ein unmittelbarer Zusammenhang zwischen wissenschaftlich-objektivem Denken und der Struktur indogermanischer Sprachen besteht [...] die altgriechische Sprache das relativ vollkommenste wissenschaftliche Instrument darstellte ${ }^{n}$ (1960, S. 51). Eine solche Ansicht wird heute in der Forschung nicht mehr vertreten; des weiteren hat sich der Schwerpunkt der Betrachtungen von dem Verhältnis Sprache - Denken auf das Verhāltnis Kultur - Diskurs verlagert. 
Fremdsprache - vertreten wird. Seine Grundthese hinsichtlich des Stils wissenschaftlichen Schreibens lautet:

${ }_{n}$ Science writing, as seen through the product - the finished text appears to conform to certain well-documented generalizations said to represent the scientific 'style' of writing. The underlying assumption concerning this style is that it faithfully and accurately reflects the experimental process as it occurs in the laboratory. In fact, however, recent research in the sociology of science indicates that the relationship between the experimental method of the laboratory and the text in which it is reported is anything but straightforward. The shaping of a written text by a writer reflects deeply embedded cultural and rhetorical assumptions about what material may be presented, how it is to be organized, and how it may be presented in a maximally acceptable way - not necessarily in a way which is objectively most transparent. [...] In sum, science writing constitutes a value-laden rhetorical activity." (Kaplan/Grabe 1991, S. 200, 213; Hervorhebungen H.S.)

Zu einer ähnlichen Sichtweise kommt Robert Picht aus der Sicht des Übersetzens wissenschaftlicher Literatur:

"Wer in die Lage gekommen ist, wissenschaftliche Literatur zu übersetzen, kennt die Unterschiedlichkeit der Diskurse aus der Arbeit am Text: wie oft zerbröckelt das Gebäude der Argumentation, wenn man es in die andere Wissenschaftssprache zu übertragen sucht, wirken imponierende Demonstrationen plötzlich banal, scheinbar evidente Verkettungen geschraubt. Bis in die Feinstruktur wissenschaftlicher Texte hinein erweist sich also, daß Evidenz auf kulturellen Traditionen beruht, die von Land zu Land divergieren." (Picht 1987, S. 17; Hervorhebungen H.S.)

Picht meint des weiteren, daß

"die Grundlagen wissenschaftlichen Arbeitens [...] kulturell bedingt (sind), selbst 2 wischen westlichen Ländern bestehen erhebliche Unterschiede hinsichtlich so elementarer Ansatzpunkte: wie bezeichnet man ein Problem, was gilt als Information, was gilt als Lösung, welches Produkt wird als wissenschaftliche Leistung anerkannt? Zugleich ist offenbar, daf diese Bausteine von Wissenschaft eng mit dem (sic!) Kommunikationsformen des Wissenschaftsbetriebes und der akademischen Lehre zusammenhängen." (Picht 1987, S. 22; Hervorhebungen H.S.)

In dem von Ruth Eßer, Hans Jürgen Krumm und Johannes Wagner geplanten Projekt "Cultural Relativity in Academic Production in the Humanities" wird schließlich davon ausgegangen, daB a) wissenschaftliche Arbeitsformen, b) wissenschaftliche Ausdrucksformen, c) Gütekri- 
terien, d) Aufbau und Stil von Wissenschaftstexten und e) akademische Unterrichts- und Lernformen durch die Ausgangskultur geprägt sind. ${ }^{6}$

Eine Durchsicht der vorliegenden einschlägigen Literatur zur Universalität bzw. der Kulturbedingtheit des Schreibstils zeigt, daß sowohl für die Stützung der Universalitätsthese als auch der Relativitätsthese wichtige Argumente und Forschungsergebnisse angeführt werden können, die sich - so meine ich - eigentlich auch nur scheinbar widersprechen; denn beide Thesen beziehen sich auf jeweils unterschiedliche wissenschaftliche Disziplinen: die Universalitätsthese in erster Linie auf die Naturwissenschaften - die Relativitätsthese vor allem auf die Human- und Sozialwissenschaften. Ich stimme daher Claus Gnutzmann zu, der die Relativitätsthese unter Bezug auf den Faktor Disziplin einschränkt und eine Ergänzungshypothese aufstellt:

„Je mehr ein Fachgebiet kulturübergreifenden Charakter hat, d.h. sein eigentlicher Gegenstandsbereich nicht in der Primärkultur liegt und somit eher 'gesellschaftsbezogen' ist, desto grōßer ist die Tendenz zur Verwendung āhnlicher bzw. identischer Diskursmuster. [...] Je mehr der Gegenstandsbereich eines Fachgebietes in der Primärkultur verankert ist, je mehr er also 'gesellschaftsbezogen' ausgerichtet ist, desto wahrscheinlicher ist die Tendenz, daB sich bei der Versprachlichung wissenschaftlicher Sachverhalte kulturspezifische Diskursmuster herausbilden." (Gnutzmann 1989, S. 1-2)

Laut dem Fächerkatalog des Hochschulverbandes gibt es heute bereits mehr als 4.000 wissenschaftliche Fächer, und es ist anzunehmen, daß deren Stilorientierungen mehr oder weniger unterschiedlich ausgeprägt sind, d.h., für jedes einzelne Fach wäre eine Position auf dem Kontinuum $\mathrm{zwischen}$ kulturspezifischen Diskursmustern einerseits und kulturübergreifenden Diskursmustern andererseits konkret auszumachen. Aus Gründen der Forschungsökonomie ist dies natürlich nicht möglich. Dennoch sollte in der Forschung zukünftig stärker die Kategorie Disziplin berücksichtigt werden, die ohne Zweifel (neben dem Faktor Kultur) eine wichtige Determinante des Schreibstils in der Wissenschaft darstellt.

In ähnlich dominanter Weise wie der Faktor Disziplin kann das wissenschaftliche Paradigma zwischen Stil und Kultur treten, dem ein Textverfasser sich verpflichtet fühlt. Paradigma verstehe ich in Übereinstimmung mit Kurt Bayertz als

6 Liang geht sogar von der Existenz verschiedener kulturbedingter Erkenntnismodi aus und spricht am Beispiel Chinas und des Westens von einem „induktiv-synthetischen Erkenntnismodus” in China, der „im Gegensatz zum kausal-analytischen im Westen" stehe (1993, S. 162). Des weiteren meint Liang, daß „auch kognitive Prozesse kulturpragmatisch geprägt” seien $(1993$, S. 166). 
„die Gesamtheit dessen [...], was eine wissenschaftliche Gemeinschaft verbindet. Dabei ist zu beachten, da $\beta$ die durch das Paradigma hergestellten Gemeinsamkeiten zwischen den beteiligten Forschern auf zwei Ebenen liegen: insofern das Paradigma einen Grundstock an wissenschaftlichen Überzeugungen über das Wesen des Forschungsgegenstandes und die methodischen Wege seiner Erforschung bereitstellt, sind die Gemeinsamkeiten kognitiver Natur; insofern auf der Basis des Paradigmas bestimmte Beziehungen zwischen den betreffenden Wissenschaftlern entstehen, die sich von den Gemeinschaftsstrukturen der 'vorparadigmatischen' Frühphase des jeweiligen Fachgebietes unterscheiden, sind die durch das Paradigma gestifteten Gemeinsamkeiten sozialer $\mathrm{Na}$ tur." (Bayertz 1981, S. 21)

Anders als in den Naturwissenschaften ist in den Human- und Sozialwissenschaften die Gleichzeitigkeit verschiedener Paradigmen zu einem bestimmten Zeitpunkt möglich und stellt in der Regel sogar den Normalfall dar, wobei Paradigmen kulturübergreifend oder kulturregional sein können. Es sind daher unterschiedliche Stilkonventionen innerhalb einer Disziplin möglich, und es ist weiterhin durchaus denkbar, daß sich eine Paradigmengemeinschaft auch durch kulturübergreifende Stilkonventionen konstituiert. Zu dieser Frage gibt es bislang aber leider so gut wie keine Untersuchungen. ${ }^{7}$

In einem Modell lassen sich nun folgende Faktoren als mögliche Determinanten des Stils wissenschaftlichen Schreibens nennen, die auf einen beliebigen Textproduzenten einwirken und in entsprechender Weise auch bei der Rezeption beteiligt sind:

- Kultur und Gesellschaft, in der der Textproduzent seine primäre Sozialisation erfahren hat;

- das jeweilige Fach und die Sachverhalte, über die der zu erstellende Text handelt;

- das Paradigma (Argumentations-, Darstellungs- und Forschungsverfahren), dem der Autor zuzurechnen ist und in der er seine sekundäre Sozialisation erhalten hat;

- die Perspektive (Kommunikationssituation, Textsorte), aus der sich der Textproduzent seiner Aufgabe nähert;

7 Im Zusammenhang von Paradigma und Stil bemerkt Rüdiger Weingarten, daf der Stil durch die wissenschaftliche Sozialisation gebildet wird und in „engem Zusammenhang mit dem spezifischen Habitus eines Paradigmas" steht, woraus sich eine "sprachliche Form der Selbstdarstellung" ergibt, "die über die jeweilige wissenschaftliche Theorie hinausgeht und weniger der kognitiven als vielmehr der sozialen Funktion der wissenschaftlichen Kommunikation zuzurechnen ist" (1994, S. 134). 
- die Person des Autors selbst (u.a. seine Stellung in der wissenschaftlichen Gemeinschaft).

Der Stil eines konkreten Textes ist in diesem Modell immer als Individualstil zu verstehen, d.h. als konkrete autorbezogene Vertextung auf der Grundlage und im Rahmen der Einbettung des Autors in einen bestimmten Funktional-, Gruppen-, Fach- und Denkstil. Bei aller Freiheit seiner Darstellung ist jeder Autor durch bestimmte (meist ungeschriebene, aber stark internalisierte) Konventionen, Normen und Wertvorstellungen geprägt. Obwohl es solche für jede Fachgemeinschaft zu geben scheint und deren Kenntnis zumindest aus der Sicht des Fremdsprachenunterrichts und des Übersetzens von großer Bedeutung ist, bleibt das wissenschaftliche Schreiben letztendlich aber ein kreativer und individuenbezogener Vorgang, so daB eindeutige Abhängigkeitsverhältnisse zwischen Ausgangskultur und Stil kaum auszumachen sind. ${ }^{8}$

\section{Methodologische Aspekte interkultureller Stilforschung}

\subsection{Forschungsperspektiven}

"Last but not least, descriptions and comparisons of discourse in general, and of academic writing in particular, are troublesome for lack of an explicit theoretical framework and a proper meta-language that would allow us to specify and accommodate the various parameters of discoursal relevance." (Duszak 1994, S. 292)

Einschlägige Arbeiten, die sich mit Aspekten des Stils wissenschaftlichen Schreibens im Kulturkontrast beschäftigen, liegen nur sehr verstreut vor und sind nicht einfach zu recherchieren. ${ }^{9}$ Neben den verschiedenen Teilgebieten der Sprach- und Übersetzungswissenschaft sowie der Fremdsprachendidaktik beschäftigen sich u.a. Teilgebiete der Psychologie, die Wissenschaftssoziologie, die Philosophie und natürlich die Rhetorik (sowohl die allgemeine als auch praktische Rhetoriken bis hin zu Stil-Ratgebern) sowie die jeweiligen Einzelwissenschaften mit der Problematik des Stils wissenschaftlichen Schreibens. DaB Ergebnisse, Methoden und Begriffe anderer Disziplinen nicht oder nur sehr unzureichend zur Kenntnis gekommen werden, ist ein generelles Problem der modernen

8 'Kultur' kann freilich auch anders verstanden werden, wenn mit dieser Bezeichnung nicht die Nationalkultur angesprochen wird, sondern eine bestimmte Disziplin (vgl. z.B. den Begriff "die drei Kulturen” bei Wolf Lepenies) und/oder ein Paradigma gemeint ist.

9 Einige Hinweise bietet Kretzenbacher (1992) in seiner Studienbibliographie zur Wissenschaftssprache. Vgl. außerdem die Bibliographie in der Monographie von James E. Martin (1992). 
wissenschaftlichen Kommunikation überhaupt und hängt, was die Erforschung kulturspezifischer Varianten des Schreibstils betrifft, von den unterschiedlichen Perspektiven ab, von denen aus man sich der Problematik "Wissenschaftliches Schreiben" nähert. Ausgangspunkt der Untersuchungen zu Fragen des Stils wissenschaftlichen Schreibens kann

1. der Text als Produkt (der sogenannte 'fertige Text') sein, wobei die textinterne Seite im Mittelpunkt steht;

2. der Text als Prozeß (bzw. als Kommunikationsmittel des Autors) interessieren, so daB die Kommunikationssituation, d.h. textexterne bzw. pragmatische Faktoren und der SchreibprozeB (die Nutzung der dem Textproduzenten zur Verfügung stehenden stilistisch relevanten Vertextungsmittel unter Berücksichtigung der potentiellen Adressaten) thematisiert werden;

3. der Text als Interaktion, d.h. heißt die Einbeziehung der Textrezeption, des Lesers und der Kategorie Wirkung, das Ziel der Analyse sein.

Neben der einschlägigen kontrastiven Fachsprachenforschung (hier insbesondere die Funktionalstilistik und die Fachtextlinguistik) beschäftigen sich u.a. folgende Forschungsbereiche jeweils aus einer oder aus mehreren der genannten Perspektiven mit Aspekten des Stils wissenschaftlichen Schreibens:

a) die (mehr oder weniger traditionelle) kontrastive Linguistik (mit ihrer Orientierung auf strukturelle Aspekte von Texten) sowie die vergleichende Stilistik (mit dem dazugehörigen Beschreibungsapparat der Stilmittel);

b) die Übersetzungswissenschaft und -praxis mit u.a. folgenden Fragestellungen: Produktion zielsprachenadäquater Texte; Wirkungsäquivalenz, Textsortenproblematik in verschiedenen Kulturen, 'Nullstellen';

c) der fremdsprachendidaktisch orientierte Forschungsbereich Schreiben in der Fremdsprache einschließlich der kontrastiven Rhetorik (Vergleich von kulturbedingten Vertextungskonventionen);

d) die Interkulturelle Germanistik bzw, der Forschungsbereich Interkulturelle Kommunikation (Rezeption fremdsprachiger Texte und damit verbundene Rezeptionsprobleme, 'Lakunen');

e) die Verständlichkeits- und Lesbarkeitsforschung (mit Orientierung auf den Textproduzenten und stark normativen Zügen).

Alle genannten Forschungsbereiche tragen auf spezifische Weise zur Fragestellung bei, stehen teilweise in einem komplementären Verhältnis zu- 
einander und sollten - im Idealfall eines neuen Paradigmas der Fachsprachenforschung - in ein integratives Gesamtmodell überführt werden, das die Kategorien der antiken Rhetorik einerseits sowie der modernen Pragmatik und Semiotik andererseits als Ausgangspunkt nutzen könnte.

\subsection{Fragestellungen und Wege der Forschung}

"In sum, the general trend in contrastive rhetoric research, particularly in the past ten years, has been a move away from a narrow articulation of CR [Contrastive Rhetoric; H.S.] (even by Kaplan himself over the years) toward a broader, more complex notion." (Martin 1992, S. 17)

3.2.1 Aufgrund des oben entwickelten weiten Stilbegriffs unterscheide ich im folgenden nicht zwischen Text-, Diskurs- und Stilanalyse im engeren Sinn (oder anderer Analysemethoden, wie sie z.B. innerhalb der Rhetorik, Semantik, Semiotik und Inhaltsanalyse entwickelt wurden), sondern ich verstehe Stilmittel und Vertextungsmittel in gleicher Weise: Durch die Prämisse der Omnipräsenz von Stil ist jedes Vertextungsmittel stilistisch relevant und daher eine kumulative Analyse gefordert.

Eine in diesem Sinn verstandene interkulturelle Stilforschung steht vor schwerwiegenden methodologischen und methodischen Problemen, wobei ich ein Hauptproblem darin sehe, Korrelationsbeziehungen zwischen dem Faktor Kultur und Stil zu überprüfen: Bedingt durch das komplexe Bedingungsgefüge, das dem Stil eines konkreten Textes zugrundeliegt, ist es sehr kompliziert, die einzelnen Faktoren in der Analyse zu isolieren und den - auch theoretisch noch unzureichend definierten - Begriff des Kulturunterschieds zu operationalisieren. Methodologische und methodische Lösungen für den Bereich der interkulturellen Stilforschung können und sollen auch im folgenden nicht beansprucht werden. Vielmehr begnüge ich mich damit, einige - z.T. bereits erprobte bzw. leicht durchzuführende - Analyseverfahren vorzustellen und sie in bezug auf ihre Gültigkeit und Zuverlässigkeit zu hinterfragen. Es handelt sich um folgende sechs Wege der Forschung:

(1) Selbst- und Fremdbeobachtungen sowie verallgemeinerte Erfahrungen aus der Übersetzungspraxis, der Praxis des Fremdsprachenunterrichts und der Praxis der wissenschaftlichen Kommunikation.

(2) Vergleiche von kodifizierten Stil- und Schreibkonventionen sowie von Kriterien für 'guten Stil' im Bereich der akademischen und wissenschaftlichen Kommunikation.

(3) Befragungen nach nicht-kodifizierten Kriterien für 'guten Stil' und Qualitätskriterien für wissenschaftliche Texte. 
(4) Kontrastive Untersuchungen konkreten Textmaterials am Beispiel ausgewählter Textsorten der wissenschaftlichen Fachkommunikation in Form von Fallstudien und/oder Korpusanalysen.

(5) Analyse in der Fremdsprache geschriebener sowie übersetzter Texte.

(6) Beschreibung und Vergleich fremdkultureller und eigenkultureller Rezeption von Wissenschaftstexten.

3.2.2 Selbst- und Fremdbeobachtungen sowie verallgemeinerte Erfahrungen aus der Übersetzungspraxis, der Praxis des Fremdsprachenunterrichts und der Praxis der wissenschaftlichen Kommunikation stellten nicht nur den eigentlichen Beginn der Beschäftigung mit Kulturspezifika in der Wissenschaftskommunikation dar, sondern gehören auch heute noch zu den verbreitetsten Verfahren der interkulturellen Kommunikationsforschung überhaupt. Bekannt und beliebt war dieses Verfahren übrigens schon in der Romantik, auf deren Hang zu -einer "antithetischen Nationalitätencharakteristik" Meyer-Kalkus für Deutschland und Frankreich hingewiesen hat. Den Anfang der linguistisch orientierten Forschung bildeten in den $60 \mathrm{er}$ Jahren die von Robert Kaplan veröffentlichten Erfahrungen mit im Fremdsprachenunterricht Englisch verfaßten Essays von Nicht-Amerikanern, die mittlerweile einen ganzen Forschungszweig ("contrastive rhetoric"; Kaplan 1966) nach sich gezogen haben. Einen weiteren wichtigen Impuls gab der international bekannte norwegische Sozialwissenschaftler Johan Galtung, der sich durch seine umfangreichen Forschungsreisen dazu veranlaßt sah, Beobachtungen und Erfahrungen in und mit anderen Kulturen in einer Typologie der „intellektuellen Stile” in unterschiedlichen Wissenschaftskulturen zu systematisieren (Galtung 1983). Schließlich sind aus der Übersetzungswissenschaft und insbesondere aus der Übersetzungspraxis Berichte bekannt, die ausgehend von Beobachtungen und Erfahrungen zu Verallgemeinerungen über den Stil in der eigenen und jeweils anderen Kultur gekommen sind. Ein aktuelles Beispiel dafür findet sich jüngst z.B. bei der schwedischen Germanistin Astrid Stedje, die - ausgehend von eigenen Beobachtungen und Erfahrungen - versucht, das Charakteristische der schwedischen Wissenschaftskommunikation darzustellen:

„Ein schwedischer akademischer Vortrag zeichnet sich einmal dadurch aus, daß er oft von konkreten Beispielen ausgeht. Empirie ist bevorzugt, und lieber experimentell belegbare Untersuchungen als phänomenologische Vorgehensweisen. Ausländern fält vielfach auf, daß der theoretische Überbau dabei in den Hintergrund rückt. Weiter ist die sprachliche Form meist nicht elaboriert. Wichtig ist noch die didaktische Zielsetzung: Die Botschaft muß jeden erreichen." (Stedje 1990, S. 30) 
Ausgehend von diesem Beispiel, das hier nicht weiter diskutiert werden soll, möchte ich auf einige methodologischen Probleme des Verfahrens der Selbst- und Fremdbeobachtung im allgemeinen hinweisen:

- Der komplexe Bereich Wissenschaftskommunikation mit all seinen Fächern, Paradigmen, Verzweigungen, nationalen und internationalen Einflüssen, wird als mehr oder weniger homogenes Feld behandelt, d.h., die Ebene der Disziplin, des Paradigmas sowie des Autors (Alter, Geschlecht etc.) wird übersprungen.

- Unterschiede werden meist auf dem Hintergrund der eigenen Kultur bzw. der Erfahrungen mit fremden Kulturen festgemacht.

- Die aus den Sozialwissenschaften bekannte Problematik der SubjektObjekt-Identität und des Ethnozentrismus wird nicht oder nur unzureichend problematisiert.

- Die Frage nach der Verallgemeinerbarkeit wird häufig nicht gestellt, so dab das Problem der Stereotypisierung bzw. der Stereotypenverfestigung (sowohl im Hinblick auf Heterostereotype als auch auf Autostereotype) evident wird.

Trotz dieser offensichtlichen Schwächen war und bleibt das Verfahren der Selbst- und Fremdbeobachtung aber eine wichtige Erkenntnisquel'e und könnte auch in Zukunft zumindest als Grundlage für die Hypothesenbildung dienen.

3.2.3 Ein relativ einfaches Verfahren stellen Vergleiche von kodifizierten Stil- und Schreibkonventionen dar, wie sie z.B. in einschlagigen Lehrbüchern, in den Hinweisen für Autoren bei wissenschaftlicher Zeitschriften und Schriftenreihen sowie in Stilführern für die meister Wissenschaftssprachen (bisweilen sogar für einzelne Disziplinen) vor.iegen. Hierzu gehören des weiteren ausformulierte Gütekriterien (z.B. von Redaktionen und Beiräten bei Verlagen und Zeitschriften) für die Gestaltung wissenschaftlicher Publikationen sowie allgemein Kriterien für 'guten Stil', wie sie häufig in den - meist auf ein konkretes Fach bezogenen - Hinweisen für wissenschaftliches Arbeiten zu finden sind. Nicht vergessen werden sollten darüber hinaus einschlägige Veranstaltungen im Hochschulbereich selbst, d.h. z.B. fachspezifische Übungen zum vissenschaftlichen Schreiben, die in Nordamerika als völlig selbstverständlich gelten, in Deutschland aber wohl nur selten anzutreffen sind.

Im Vergleich mit dem ersten Verfahren (Selbst- und Fremdbeobachtungen) bietet dieses Verfahren den Vorteil, daß sich Einschätzıngen, Schlußfolgerungen und damit evtl. verbundene Wertungen auf explizite Aussagen der entsprechenden Kultur selbst beziehen und somit intersubjektiv nachprüfbar sind. Gleichzeitig zeigen sich aber folgende Projleme: 
- Die in den Stilführern und anderswo eingeforderten Soll-Bestimmungen müssen nicht unbedingt der Stilrealität entsprechen, d.h., es bleibt bei diesem Verfahren unklar, inwieweit die kodifizierten Stilund Schreibkonventionen eingehalten werden bzw. überhaupt realiter normative Kraft besitzen.

- Es ist anzunehmen, daB Stil- und Schreibkonventionen einem permanenten Anpassungsdruck unterworfen sind und daher zumindest ein allmählicher Wandel stattfindet, aktuelle Entwicklungen also viel $\mathrm{zu}$ wenig berücksichtigt werden.

- SchlieBlich ist es nicht ausgeschlossen, daB auBer den kodifizierten Stil- und Schreibkonventionen auch nicht-kodifzierte vorliegen, die gegebenenfalls sogar wichtiger als die kodifizierten sein können.

3.2.4 Die genannten Mängel des zweiten Verfahrens können u.a. durch Befragungen zu nicht-kodifizierten Anforderungen an den sogenannten 'guten Stil' und Qualitätskriterien für wissenschaftliche Texte ausgeglichen werden. Das Ziel sollte eine Analyse der gesamten wissenschaftlichen Sozialisation sein, die spätestens im Grundstudium an einer Hochschule beginnt und sich bis in den Eintritt in eine Paradigmengemeinschaft (einschließlich der Bindung an 'Autoritäten') erstreckt.

Methodisch möglich sind z.B. a) direkte Befragungen von Fachvertretern und b) die Analyse von Korrekturen wissenschaftlicher Qualifizierungsarbeiten sowie von Korrekturvorschlägen, die von Zeitschriften- und Reihenredaktionen vorgenommen wurden. Des weiteren wäre es interessant, Übersetzungen $\mathrm{zu}$ untersuchen ${ }^{10}$ und $\mathrm{zu}$ ermitteln, was an den von Nicht-Muttersprachlern verfaBten Arbeiten korrigiert bzw. beanstandet wird.

M. Clyne kommt in diesem Zusammenhang aufgrund eigener Untersuchungen (zum deutschen und zum angelsächsischen Bereich) zu der SchluBfolgerung,

„daß das Verfassen wissensch aftlich glaubwürdiger Texte in den beiden Kulturen nach verschiedenen formellen Kriterien beurteilt wird - im angelsächsischen Bereich läge es an der Textstruktur, im deutschsprachigen Raum an der Beherrschung eines akademischen Registers mit hoher Abstraktionsebene." (Clyne 1984, S. 93)

10 Interessieren würde hier insbesondere, ob die Ebenen der inventio und der dispositio in dem übersetzten Text verāndert werden. Denkbar ist außerdem eine kritische Analyse von übersetzten Texten durch kompetente Fachvertreter aus dem jeweiligen Sprach- und Kulturbereich, die sprachliche und fachkommunikative Kompetenz miteinander vereinen. 
In einem Test hat Michael Clyne Deutsche und Australier verschiedene Textversionen bewerten lassen und ebenfalls nach den Kriterien wissenschaftlicher Texte und deren Gewichtung gefragt. Als Kriterien wurden von Clyne vorgegeben: a) der Informationsgehalt, b) die Organisation/Präsentierung des Arguments bzw. der Information, c) der geeignete Gebrauch technischer Termini und wissenschaftlicher Stile, d) der theoretische Rahmen, e) die Literaturübersicht und f) die Lesbarkeit des jeweiligen Artikels (Clyne 1991, S. 380ff.). Die Ergebnisse von Clyne, auf die hier nicht weiter eingegangen werden kann, bestätigen die Hypothese von der Kulturgebundenheit der Kriterien wissenschaftlicher Texte und sollten Anlaß sein, größere und repräsentativere Untersuchungen in diese Richtung durchzuführen.

Doch ist auch dieses Verfahren nicht ganz unproblematisch, da insbesondere die Repräsentativität solcher Untersuchungen bisweilen in Frage gestellt werden muB und damit verbunden die Verallgemeinerbarkeit zweifelhaft bleibt. Auf der anderen Seite könnte dieser Ansatz bei Beachtung der einschlägigen sozialwissenschaftlichen und statistischen Methoden aber durchaus interessante Ergebnisse erbringen.

3.2.5 Kontrastive Untersuchungen konkreten Textmaterials am Beispiel ausgewählter Textsorten der wissenschaftlichen Fachkommunikation in Form von Fallstudien und/oder Korpusanalysen bilden die häufigste und wohl auch wichtigste Methode der interkulturellen Stilforschung. Forschungstheoretischer Ausgangspunkt können dabei die kontrastive Textlinguistik (hier vor allem Gnutzmann 1989 und 1991), die kontrastive Pragmatik (Clyne 1993) ${ }^{11}$ und die kontrastive Rhetorik (Kaplan 1966, Martin 1992, Mauranen 1993) sein.

In einer Textanalyse können - in gleicher Weise wie in der von B. Spillner geforderten Stilanalyse - drei Komponenten unterschieden werden:

"1. eine linguistische Komponente: es handelt sich um sprachliche kodierte Äußerungen

11 Graefen sieht - anders als M. Clyne - als Aufgabe einer pragmatischen Textanalyse, daß sie „Text nicht als Bestandteil eines Faktorengefüges auffaBt, sondern als Mittel, eine Verständigung des Autors mit seinen Lesern über bestimmte (Wissens-)Inhalte herzustellen. Komplexere Zusammenhänge $z$ wischen mentalen Tätigkeiten und sprachlicher Produktion eines Autors beim Schreiben eines Wissenschaftstextes rücken dann in den Vordergrund." (Graefen 1994, S. 139) In einer Untersuchung zur Kodierung der Akteure der Wissensproduktion versucht Weingarten eine solche pragmatische Textanalyse und unterscheidet in dieser Hinsicht $z$ wischen einem Objektivitāts- und Handlungsstil (1994, S. 133). 
2. eine pragmatische Komponente: sie ermöglicht es, die Kategorien Autor, Leser, historische Situation, Redegegenstand etc. einzubeziehen 3. eine literaturwissenschaftlich-ästhetische Komponente: sie stellt die Beziehungen zur Wirkung auf den Leser und zur literaturwissenschaftlichen Interpretation und Wertung her." (Spillner 1974, S. 15-16; Hervorhebungen H.S.)

Für eine interkulturelle Stilforschung im Bereich der Fachkommunikation sollte die Forderung von Liang ernstgenommen werden:

„Da der (Fach-)Text als strukturelle Einheit und funktionale Ganzheit eine hohe Komplexitāt aufzeigt, muB eine kontrastive Fachtextanalyse, methodologisch und methodisch gesehen, interdisziplinär und integrativ erfolgen, um die textinternen und auch textexternen Charakteristika der Fachtexte möglichst umfassend erfassen und behandeln zu können." (Liang 1993, S. 167)

Die entscheidende Frage ist nun, welche Parameter in der Textanalyse zu nutzen wären, um den Zusammenhang von Kultur und Stil zu bestimmen. Die bei Liang genannten Parameterbündel (1993, S. 167) ${ }^{12}$ scheinen mir in dieser Hinsicht nicht ausreichend zu sein. Geeigneter für einen interkulturellen Vergleich scheinen mir die von Clyne verwendeten Parameter, mit denen bereits mehrere Untersuchungen durchgeführt wurden, auf die hier aber nicht weiter eingegangen werden soll. Die wichtigsten von Clyne entwickelten Kategorien sind:

- formelle Orientierung vs. inhaltliche Orientierung

- verbale Orientierung vs. schriftliche Orientierung

- Digressivität vs. Linearität

- Rhythmus

- allgemeine Kulturkontraste (z.B. Höflichkeitsregeln).

Obwohl Clynes Parameter durchaus für die interkulturelle Stilforschung richtungsweisend waren, sprechen einige Kritikpunkte für eine „Relativierung der Beurteilungskriterien Clynes” (Graefen 1994, S. 148), wie sie jüngst u.a. von Graefen (1994) und Sachtleber (1993, S. 32f.) vorgeschlagen wurden. Problematisch scheinen insbesondere die Operatio-

12 Liang nennt u.a. folgende Parameterbündel: Textsorten und ihre Varianten, dominante Textfunktionen, typische Verwendungssituationen von Fachtexten, „Forschungsverfahren und Denkweisen sowie ihre Repräsentationsformen in Fachtexten, unter Berücksichtigung der sogenannten kulturellen Domination in der jeweiligen Fachwelt einerseits und der kulturellen Konvention und Tradition andererseits,”, „Vertextungsstrategien und -konventionen der jeweiligen Diskursgemeinschaft im Hinblick auf den intellektuellen Stil,", textsortenspezifische Makrostrukturen, semantische und pragmatische Kohärenz, Isotopienketten und -elemente etc. etc. (Liang 1993, S. 167). 
nalisierung der Kategorie Linearität, die zu enge Trennung der Kategorien Form und Inhalt sowie eine unzureichende Beachtung der SubjektObjekt-Identität in der Forschung zu sein. Die Parameter von Clyne müBten durch weitere Parameter ergänzt werden, deren Fragestellungen dazu geeignet wären, konkrete Stile in ein Kontinuum von Merkmalen einzuordnen; zu nennen wären insbesondere folgende Fragestellungen, die teilweise ineinander übergehen:

- Ist der Text eher interaktions- oder eher missionsbezogen? Wird die Sinnerschliebung durch eine implizite Vertextungsstrategie dem Leser in der Interaktion mit dem Text überlassen oder wird dem Leser durch eine explizite Vertextung eine bestimmte Mission aufgedrängt?

- Ist der Text eher leser- oder eher autorbezogen? Trägt der Leser oder der Autor die Verantwortung für die Verständigung (vgl. das Konzept „writer vs. reader responsibility" von Hinds 1987)? Wird dem Leser ein Zwischen-den-Zeilen-Lesen abverlangt?

- Erfolgt die Vertextung eher indirekt oder eher direkt? Welche Rolle spielt die Metakommunikation, und durch welche textuellen Mittel wird sie realisiert? Wie ist das Verhältnis von Präsuppositionen und Redundanzen?

Des weiteren sollten in einer interkulturellen Stilanalyse Interaktionsrituale verglichen werden, und zwar insbesondere Einleitungen, die Anrede des Adressaten und die Selbstbezeichnung bzw. die „Kodierung des Akteurs in wissenschaftlichen Texten” (Weingarten 1994).

SchlieBlich soll - um noch einmal die Komplexität einer Textanalyse aufzuzeigen - mit Gyde Hansen darauf hingewiesen werden, daß Stilmittel in allen Bereichen der Vertextung zur Verfügung stehen. Hansen nennt im einzelnen den Textaufbau, den Wortschatz, den Satzbau, die Wortstellung sowie Bilder, Stilfiguren und suprasegmentale Faktoren, wie Akzent und Rhythmus (Hansen 1989, S. 17). Zur Charakterisierung des "wissenschaftlichen Forscherstils" benutzt Hansen (1989, S. 241-243) folgende 15 Kategorien, zu denen in jeder Kultur bestimmte Merkmalsausprägungen zu finden wären: 1. Situationen, 2. Medium, 3. Sender und Empfänger, 4. Funktion, 5. Themen, 6. Aufbau, 7. Stilzüge (Klarheit, Logik, Abstraktheitsgrad), 8. Stilschicht, 9. Stilfärbung (neutral, manchmal auch emotional), 10. Wortwahl, 11. Wortarten und ihre Kategorien, 12. Syntax, 13. Bilder und Stilfiguren (Antithese, Wiederholung), 14. Referenz (generische Referenz, Artikelgebrauch), 15. Sprechakte (informieren, definieren).

Methodologische Probleme ergeben sich bei kontrastiven Textanalysen u.a. hinsichtlich der Grundsatzentscheidung, ob eine Fallstudie oder eine 
Korpusanalyse durchzuführen ist, wie umfangreich Korpora sein sollten und wie repräsentativ sie sein können, ob für die Analyse ganze Texte heranzuziehen sind oder Teiltexte ausreichen und wie längere Texte (z.B. ganze wissenschaftliche Monographien) forschungsökonomisch sinnvoll untersucht werden können. SchlieBlich ist dem Problem der SubjektObjekt-Identität zu begegnen, die Parameter hinreichend zu operationalisieren und Methoden zu entwickeln, die es erlauben, den EinfluB der einzelnen Determinanten (Kultur, Disziplin, Paradigma, Medium, Textsorte) für den Stil zu bestimmen. Trotz zahlreicher Anstrengungen und wichtiger Erfolge steht aber auch bei diesem Verfahren eine zufriedenstellende Methodologie noch nicht in Aussicht.

3.2.6 Der relativ junge (interdisziplinäre) Forschungszweig Schreiben in der Fremdsprache nutzt einerseits die Methoden der Textanalyse, geht andererseits aber über die Kategorie Text im engeren Sinn hinaus und wendet sich dem SchreibprozeB zu, wobei insbesondere nach dem EinfluB der muttersprachlichen Vertextungsmuster auf das Schreiben in der Fremdsprache gefragt wird. Insofern stehen dieser Forschungsbereich und die kontrastive Rhetorik in einem engen Verhältnis zueinander. Aus der Sicht der kontrastiven Rhetorik stellt James Martin als (enge) Basisannahme vor, "that the rhetorical organization of L2 written texts is the result of the transfer of $L 1$ rhetorical forms for any language, and that these forms are discoverable by analysis of written texts."; die neuere und weiter gefabte Grundthese lautet hingegen,
„that $\mathrm{L} 1$ rhetorical norms and strategies, while undoubtedly infiuential for the shape of L2 written texts, are but one factor influencing the text shape [...]. As challenging as this broad version is, it strongly sup- ports the basic premise of CR that texts produced by L2 writers are in some ways influenced by the cultural/linguistic/rhetorical norms of the writer's L1." (Martin 1992, S. 3).

Alan Purves weist im gleichen Zusammenhang darauf hin, daß die Vertextung durch rhetorische Mittel zwar von der Kultur abhänge, nicht jedoch unbedingt von der Sprache des Verfassers; auBerdem spiele die jeweilige Disziplin eine gewisse Rolle (Purves 1988, S. 13). In Anlehnung an Purves/Purves (1986) zählen Rubin/Goodrum/Hall (1990) zur Charakterisierung kulturbedingter Schreibstile folgende Merkmale auf: „1. personal-impersonal; 2 . ornamented-plain; 3 . abstract-concrete; 4. single-multiple aspects of topic; 5 . prepositional-appositional connectives; 6 . characterizing-narrating-dramatizing; and 7. message focusedreader focused" (Rubin/Goodrum/Hall 1990, S. 71). Die Ausprägung dieser Merkmale in verschiedenen Kulturen kann man sich wie auf einem 
Kontinuum vorstellen, d.h., eine konkrete Kultur neigt entweder mehr zu dem einen Merkmal oder mehr zu dem anderen.

Methodisch wäre es interessant, neben Texten von Studierenden in der Fremdsprache auch Texte von (mehr oder weniger) bilingualen Wissenschaftlern (in beiden Sprachen) zu untersuchen und Übersetzungen von Wissenschaftstexten in die Fremdsprache heranzuziehen, in denen sich häufig - trotz vorhandener fremdsprachlicher Kompetenz - aufgrund mangelnder fremdkultureller Kompetenz Belege für die dominante Rolle des Faktors Kultur finden lassen. Eine (praxisorientierte) Fragestellung von M. Clyne lautet in dieser Hinsicht,

„inwieweit ein Text in Sprache A umstrukturiert werden muB, wenn er in Sprache B übersetzt wird, oder inwieweit der Text, den ein ASprecher in Sprache B verfaBt hat, umstrukturiert werden muB, um die Wirkung eines muttersprachlichen Textes zu haben. Denn Textstrukturelles wird selten verbessert; es wird aber häufig zur Ursache von Vorurteilen über Individuen und Gruppen." (Clyne 1990, S. 1)

Ein Problem hinsichtlich der Aussagefähigkeit der Arbeiten zum Schreiben in der Fremdsprache sehe ich vor allem darin, dab oftmals die Beziehung zwischen Ausgangskultur und Schreibstil als zu eindeutig und unvermittelt dargestellt wird, die Bedeutung der Disziplin, des Paradigmas und der Textsorte hingegen vernachlässigt bleibt. Dadurch ist es bislang unklar, ob sich ein konkreter Schreibstil eher durch die Forschungslogik einer Disziplin und/oder eines Paradigmas oder eher aufgrund der Schreibkonventionen in der Ausgangskultur konstituiert.

3.2.7 Beschreibung und Vergleich eigen- und fremdkultureller Rezeption werden zwar immer wieder eingefordert, stellen für Wissenschaftstexte jedoch ein außerordentliches Desideratum dar. Die Hauptaufgabe wird von Wimmer wie folgt gesehen: „Die Rezeption wissenschaftlichen Tuns und Schreibens, sowohl die Rezeption im Inland wie auch die Rezeption im Ausland, müBte erforscht, beschrieben, erfaßt werden" (Wimmer 1987, S. 95). Möglich und denkbar wäre hier u.a. das aus der Interkulturellen Germanistik bewährte Verfahren des Perspektivenwechsels, das bisher fast ausschließlich in literaturwissenschaftlichen Studien verfolgt wird. Außerdem wäre die Einbeziehung der Ebene der Wirkung zu nennen bzw. - wie es bei Spillner heißt - die „literaturwissenschaftlichästhetische Komponente: sie stellt die Beziehungen zur Wirkung auf den Leser und zur literaturwissenschaftlichen Interpretation und Wertung her" (1974, S. 16). Methodisch kann mit Spillner

„prinzipiell davon ausgegangen werden, daß auch subjektive Vorgänge objektiv beschreibbar sind. Die Stilanalyse sollte daher versuchen, durch empirische Erforschung der Rezeptionsprozesse und ihrer Be- 
dingungen, d.h. hier der Rekonstituierung von Stil, die subjektiven Vorgänge so genau wie möglich zu analysieren", wobei Spillner u.a. auch die Methode der Informantenbefragungen vorschlägt. (Spillner 1974, S. 67)

Des weiteren sei in dieser Hinsicht auf Untersuchungsverfahren hingewiesen, die von Christiane Nord im Rahmen der Übersetzungswissenschaft entwickelt wurden (1991, S. 149ff.) sowie auf eine relativ einfache Methode, die Clyne in seinen frühen Studien praktizierte: Der Vergleich von Rezensionen wissenschaftlicher Monographien (originalsprachig und/oder übersetzt) in der eigenen Kultur des Verfassers sowie in fremden Kulturen.

3.2.8 Die kurzen Ausführungen sollten deutlich gemacht haben, daB keines der genannten Verfahren ausreicht, die unter Punkt 2.2 genannten Hypothesen von Kaplan/Grabe, Picht und anderen Forschern hinreichend $\mathrm{zu}$ überprüfen. Gefordert ist eine integrative und multidimensionale Textanalyse, die durch interdisziplinäre und internationale Forschergruppen zu leisten wäre. Eine besondere Aufgabe dürfte es dabei sein, Methoden zu begründen, die eine Operationalisierung von Kategorien erlauben, die bisher in der Forschung eigentlich so gut wie gar nicht beschrieben werden konnten, wie z.B. die bei Picht als kulturbedingt vermuteten Begriffe der Evidenz, Information, (wissenschaftliche) Lösung und Leistung.

Solange es der interkulturellen Stilforschung nicht gelingt, ihre methodologischen Probleme zu lösen, sollten bereits vorliegende Ergebnisse mit äußerster Vorsicht aufgenommen werden. Der Stil wissenschaftlichen Schreibens wird generell durch das Zusammenspiel zahlreicher Faktoren (Kultur, Disziplin und Paradigma) konstituiert und steht immer im Zusammenhang mit einer konkreten Kommunikationssituation, so daB sich Verallgemeinerungen über den wissenschaftlichen Stil ohnehin verbieten.

\section{Neue Herausforderungen an eine interkulturelle Stilforschung}

„Das Hauptproblem liegt daher lāngst nicht mehr darin, wie wir die Annāherung der Kulturen befördern, sondern darin, wie wir ihre Differenziertheit bewahren." (Lepenies 1993, S. 22)

Im folgenden möchte ich bereits vorliegende Forschungsergebnisse über kulturbedingte Stilunterschiede in der wissenschaftlichen Fachkommunikation vor dem Hintergrund der Dimension Zeit, d.h. eines möglichen Wandels, relativieren. Mit Blick auf die Zukunft frage ich mich, ob die festgestellten (kulturbedingten) Unterschiede nicht lediglich Ausdruck 
einer bestimmten Phase in der Entwicklung des Stils wissenschaftlichen Schreibens sind und mit zunehmender Internationalisierung und Medialisierung des Wissenschaftsbetriebs mehr oder weniger verschwinden werden, sich also ein universaler Schreibstil auf Kosten der nationalkulturellen Stile durchsetzen wird. Gleichzeitig frage ich mich, in welche Richtung ein postmodernistischer Wissenschaftsbegriff und die damit verbundenen 'neuen Diskurse' diese Entwicklung beeinflussen werden.

Der Wissenschaftsbetrieb ist heute ohne Zweifel eine internationale Institution, die die nationalen Grenzen durchbricht und zunehmend (nicht zuletzt aufgrund harter ökonomischer Fakten) durch eine Amerikanisierungstendenz geprägt wird. John Swales geht davon aus, daB sich aufgrund der Existenz von 'invisible colleges' und von 'transnational discourse communities' universalistische Tendenzen in den einzelnen wissenschaftlichen Stilgattungen durchsetzen werden (Swales 1990, S. 65). Dennoch mub - so Swales - differenziert werden: Die primäre Sozialisation von Studierenden im Rahmen eines Grundstudiums an ihren jeweiligen Heimatuniversitäten kann noch nicht als universalistisch aufgefaßt werden und ist vermutlich - wie z.B. auch die Textsorten Lehrbuch, Vorlesung, Tutorium etc. - noch sehr stark durch die Ausgangskultur geprägt (Swales 1990, S. 66). Anders verhält es sich mit der sekundären Sozialisation, wo Swales - mit Bezug auf die islamische verbale Tradition auf der einen Seite und die säkularisierte pragmatische Welt in Europa und Nordamerika auf der anderen Seite - zwei unterschiedliche Stadien einer Entwicklung unterscheidet und annimmt, daß man in den zuerst genannten Kulturen erst auf dem Weg dorthin ist, wo man sich jetzt schon in Europa und in Nordamerika befindet (Swales 1990, S. 66). ${ }^{13}$

An dieser - meiner Meinung nach ethnozentrischen - Position Swales' vermisse ich eine gewisse Sensibilität für Leistungen der anderen Wissenschaftssysteme (z.B. in der arabischen und in der chinesischen Welt) und eine Erklärung für das Vorhandensein von Unterschieden zwischen dem anglo-amerikanischen Diskurs einerseits und den deutschen, französischen und russischen Diskursen andererseits, die doch wohl nicht als "Nordamerika zeitlich hinterherhinkend" charakterisiert werden können.

13 Unter Bezug auf eine Untersuchung von Eggington heißt es in diesem $\mathrm{Zu}$ sammenhang bei Swales, daß es gegenwārtig zwei rhetorische Stile für das akademische Schreiben in Korea gibt: einen traditionellen und einen durch das Englische beeinflußte. Swales folgert daraus, daß es auch zwei discourse communities innerhalb Koreas gibt: eine Elitegruppe, die in den USA studiert hat und Mitglied der international community of researchers ist und eine größere nationale Gemeinschaft, die noch in der traditionellen koreanischen Rhetorik verhaftet ist. (Swales 1990, S. 67). 
Dennoch spricht manches dafür, daß Swales in einigen Punkten seiner Einschätzung durchaus recht zu haben scheint; denn wenn man beobachtet, welche Prozesse in den letzten Jahren im Bereich der wissenschaftlichen Zeitschriften und Verlage real bereits abgelaufen sind, so wird überaus deutlich, in welche Richtung sich die internationale scientific community bewegt. Als Ausdruck dieser Entwicklung könnte man wie EBer/Krumm/Wagner (o.J.) es in ihren Thesen annehmen - für die Zukunft davon ausgehen,

„daf sich diejenigen Disziplinen am ehesten behaupten werden, die am angloamerikanischen Textstandard und Relevanzkanon orientiert sind. Disziplinen, die das nicht sind, müssen mit zunehmender Diskriminierung rechnen. Anstelle eines auch in Forschung und Ausbildung multikulturellen Europas wird sich der Trend zu einer durch angloamerikanische Standards geprägten Forschungs-Monokultur weiter verstärken."

Dennoch ist der ProzeB der Internationalisierung der Wissenschaften aber nicht einfach gleichzusetzen mit einer allgemeinen Amerikanisierungstendenz, da sich gleichzeitig ja auch in bestimmter Weise das Englische als internationale lingua franca selbst verändert und in der Tat internationalisiert. Dies hat z.B. Wolf Lepenies in einem Vortrag für die englischsprachige Literatur der Gegenwart nachgezeichnet:

„Gleichzeitig vollzieht sich eine dramatische Erneuerung der englischen Sprache durch Autoren, die englisch schreiben, von denen einige auch englische Staatsbürger sind, deren Muttersprache aber nicht das Englische ist. [...] So ist heute eine Literatur entstanden, die auf spezifisch nationale Schreib- und Lesetradition kaum mehr zurückführbar ist, eine neue Art des grenzenlosen Schreibens, dessen Heimat die angloamerikanischen Megacities, die transnationalen Stadtmetropolen mit ihrer aggressiv gemischten Kultur sind - New York, London, Toronto." (Lepenies 1993 , S. 12-14)

Daß für die Wissenschaften ganz Ähnliches angenommen werden kann, ergibt sich aus einem anderen Zitat von Lepenies:

„Nehmen Sie als ein Beispiel das Schicksal der Gestaltpsychologie. Hier muß nach der Machtübernahme der Nazis eine ganze Theorie aus Deutschland emigrieren und gelangt auf dem Umweg über Japan in die USA. Um intellektuell überleben zu können, muß sich diese Theorie ihrem jeweils neuen Kontext anpassen. Sie läßt sich nicht einfach transferieren, sondern ist darauf angewiesen, ihre Grundannahmen jeweils umwelttypisch zu übersetzen. Die Gestaltpsychologie liefert das vielleicht auffallendste Beispiel der Disziplinen- und Theoriewanderung in diesem Jahrhundert, aber es ist bei Leibe nicht das einzige. Gerade die Traditionen der deutschen Wissenskultur sind heute nur noch in Mischformen vorhanden. Dies ist auch eine Spātfolge des Nationalsozialismus: Die Unterdrūckung von Disziplinen und die Vertreibung von Gelehrten haben zu einer. Vermengung vor allem deutscher und angelsächsicher Wissensbestände geführt, die nationaltypische Ausfil- 
terung kaum mehr gestattet. [...] Vor allem in den Vereinigten Staaten und in Deutschland entstanden auf diese Weise übersetzte Wissenskulturen." (Lepenies 1993, S. 17-18)

Einen weiteren Grund für die mögliche Nivellierung von kulturbedingten Stilunterschieden in der wissenschaftlichen Kommunikation sehe ich in der fortschreitenden Medialisierung des Wissenschaftsbetriebes, $d . h$. in der Entwicklung neuer Informations- und Kommunikationstechnologien, die engstens mit dem ProzeB der Internationalisierung und Amerikanisierung zusammenhängen. Die moderne Computertechnologie bietet schon heute qualitativ neue Möglichkeiten für die Gestaltung von Fachtexten. In computererstellten (und auf CD-ROM-Disketten gespeicherten) Enzyklopädien werden $z . B$. verbaler Text, visuelle und auditive Zeichenträger sowie Animationen zu einem harmonischen Ganzen zusammengefaft und eine qualitativ neue Form der Interaktion zwischen Medium und Benutzer ermöglicht. Da die Produktion elektronischer Publikationen sehr hohe Kosten verursacht und die meisten internationalen Netzwerke im Bereich der wissenschaftlichen Kommunikation ohnehin nur in englischer Sprache operieren, wird der bereits auf einem hohen Niveau liegende ProzeB der Amerikaniseriung noch weiter intensiviert. ${ }^{14}$

Zumindest eine Tendenz scheint allerdings der Universalisierung des wissenschaftlichen Diskurses entgegenzuwirken, wenngleich es sich bei dieser Tendenz auch um eine übereinzelsprachliche Tendenz handelt, die in fast allen Wissenschaftskulturen zu beobachten ist. Ich meine damit die Entwicklung eines postmodernistischen Wissenschaftsverständnisses und den damit im Zusammenhang stehenden sogenannten 'neuen Diskurs'.

Uwe Geist kritisiert in diesem Zusammenhang, daß die gegenwärtige Fachsprachenforschung sich noch immer an einem Wissenschaftsverständnis mit den Stichworten Ökonomie, Präzision und Eindeutigkeit orientiert, obwohl sich parallel zur Fachsprachenforschung längst eine "neue Einstellung zu Wissenschaftlichkeit” abzeichnet, die durch die Stichwörter 'Komplexität', 'Unsicherheit' und 'Mehrdeutigkeit' zum Ausdruck gebracht wird. Geist konstatiert eine paradoxe Situation: eine

14 Hier zeigt sich auf jeden Fall, dab das weite Feld der neuen Informationsund Kommunikationstechnologien eine enorme Herausforderung für die fachsprachliche Stilforschung darstellt; denn sowohl in der Alltags- als auch in der Fachkommunikation werden die neuen Technologien zukünftig eine immer wichtigere Rolle spielen, die schließlich unsere Vorstellungen von der Textproduktion, -distribution und -rezeption, ja sogar darüber, was überhaupt ein Text ist, grundlegend verāndern werden. Hier scheint sich ein neuer radikaler Stilwandel anzudeuten, der in seiner Bedeutung vielleicht vergleichbar ist mit dem, was sich im Zusammenhang mit Gutenbergs Erfindung der Druckkunst vollzogen hat. 
„stark expandierende Fachsprachenforschung, die fest in einem Verständnis von Fachlichkeit verankert ist, das im wissenschaftlichen Denken der 80er Jahre in steigendem Maße problematisiert wird" (Geist 1992, S. 243). Ein Problem wird darin gesehen, daß sich unser Verständnis von „Wirklichkeit und damit unsere Vorstellung von Wissenschaftlichkeit in den 80er Jahren tiefgreifend verändert hat" und eine „umfassende Neuorientierung” stattgefunden hat: ein "Umbruch von Kultur, Lebensund Selbstgefühl und damit auch von alltäglichen Denkschemata" (ebd., S. 243). Bei Geist heißt es hinsichtlich dieser neuen Tendenzen: „Ein wesentlicher Teil wissenschaftlichen Arbeit besteht jedoch genau im Gegenteil von Ökonomisieren und Reduzieren. Er besteht im Aufbauschen, Umwege-machen, im Problematisieren von landläufig Akzeptiertem" (ebd., S. 247). Von hier aus ist es kein weiter Weg mehr zum Phänomen Stil im Fachtext und zu einer „Rehabilitierung der Rhetorik” (ebd., S. 263), wie sie von Geist auch audrücklich angesprochen wird.

Der in diesem Zusammenhang entstehende 'neue Diskurs' scheint nun das genaue Gegenteil dessen zu sein, was bislang als Selbstverständlichkeit anglo-amerikanischer Vertextungskonventionen galt. Klaus Laermann (1991) ist in seiner Auseinandersetzung mit diesem sogenannten neuen Diskurs in geisteswissenschaftlichen Büchern zu dem SchluB gekommen, daß hier Frage, Argument und Beweis nicht mehr zählen:

„Bis über die Schmerzgrenzen der Sinnlosigkeit entfernen sie sich von 2 elementaren Voraussetzungen tradioneller Wissenschaft: von Themen und von Argumenten. Über lange Passagen hinweg verzichten sie zum einen darauf, sich nur einem Thema zu widmen. Statt dessen wenden sie sich eher Problemkomplexen zu, die kaum eindeutig zu umreißen sind. Dabei werden solche Bereiche bevorzugt, in denen Geisteswissenschaftler mit einer eher traditionellen Ausbildung die dargebotenen Zitate als Belege schwer ūberprüfen können. Das nāhrt den Verdacht, daß es sich bei diesen Zitaten weniger um Beweismittel handelt als um leeres Verpackungsmaterial. Wenn der herrschende Betrieb (oft fragwürdig genug) Prämien für Interdisziplinarität verteilt, dann sind die neuen Unklaren darüber jeweils schon hinaus; denn sie bewegen sich in den Sphären einer Transdisziplinarităt, die keinerlei Grenzen anerkennt. [...] Die innere Organisation undeutlicher Texte ist zum anderen gekennzeichnet durch einen weitgehenden Verzicht auf Argumentationen."

Im gleichen Zusammenhang spricht Wolf Lepenies auch von einer „Fusion oder Mischung der Genres und von einem Verschwimmen der Genres." (Lepenies 1993, S. 18):

„Philosophische Abhandlungen ähneln immer mehr der Literaturkritik, wissenschaftshistorische Fallstudien erscheinen in Romanform, ganze Schulen der Geschichtswissenschaft laufen in das Lager der Statistik über, die kūhnsten Novellen beruhen auf wahren Begebenheiten, und weitreichende Theorien der Human- und Sozialwissenschaften verber- 
gen sich hinter beiläufigen Reiseberichten. Man wartet nur noch auf die Quantentheorie in Reimen oder auf eine Biographie, die nichts mehr als algebraische Gleichungen enthält. Die wechselseitige Übersetzung wird zur Hauptaktivität der wissenschaftlichen Disziplinen. Daß die Grenze zwischen den Kunstgattungen und den Wissenschaftsdisziplinen durchlässiger wird, ist eine Tendenz der Moderne, die bis in die Frühromantik zurückreicht." (Lepenies 1993, S. 19)

Für die interkulturelle Wissenschaftskommunikation bedeutet dies, da $B$ die Anforderungen an die Qualität der Fremdsprachenkenntnisse sowie der Kenntnisse über fremdkulturelle Diskurse weiter ansteigen werden. Herausgefordert ist dadurch nicht nur der fachbezogene Fremdsprachenunterricht, sondern auch und gerade eine interkulturelle Stilforschung, die hier wichtige Vorleistungen erbringen könnte.

\section{Schluß}

"(Es) weist gegenwärtig vieles darauf hin, daB wir uns auf dem Weg zu einem transkulturellen, zivilisatorischen 'Weltstil' befinden. [...] Aufs Ganze gesehen werden wir mit vielen gegenläufigen Tendenzen rechnen müssen." (Liang 1993, S. 154)

Zusammenfassend komme ich zu dem SchluB, daB für den Stil wissenschaftlichen Schreibens - ausgehend von den hier dargelegten Überlegungen - eine starke Fassung der Relativitätsthese nicht unterstützt werden kann. Allerdings spricht vieles dafür, daB die Sprache über ihre kognitive und kommunikative Funktion durchaus eine aktive Rolle im ProzeB der wissenschaftlichen Erkenntnistätigkeit und bei der Darstellung von Forschungsergebnissen spielt. Die Ausgangskultur, die Disziplin und das Paradigma bilden wichtige Determinanten des Stils. Durch die zunehmende Internationalisierung des Wissenschaftsbetriebes, die wachsende Medialisierung der wissenschaftlichen Kommunikation und durch die Herausbildung eines postmodernistischen Wissenschaftsverständnisses sind klare Abhängigkeitsverhältnisse aber nur schwer auszumachen. Hinsichtlich der Auslotung von Invarianten und Varianten im Rahmen eines Kulturvergleichs möchte ich Elmar Holenstein zustimmen:

„Bei Kulturvergleichen paart sich die Bestreitung von interkulturellen Invarianten mit einem inkonsequenten Übersehen von intrakulturellen Varianten, das sich in pauschalen Gegenübersetzungen von abendländisch und orientalisch, von europäisch und asiatisch oder chinesisch, japanisch usw. verrät. Beides, interkulturelle Invarianz und intrakulturelle Variation, sind im AnschluB an sprachwissenschaftliche Pionierforschungen neu einzuschätzen." (1985, S. 104)

Gerade wegen der zunehmenden Internationalisierung des Wissenschaftsbereiches wird eine interkulturelle Stilforschung immer wichtiger: Für Zwecke einer ungestörten internationalen Fachkommunikation und ei- 
ner effektiven Informationsvermittlung benötigen wir weiteren Aufschluß über Fachtexte-in-Funktion-und-Kultur. Daß es dabei auch „ein schwieriges Dilemma" sein kann, daß die interkulturelle Stilforschung Vorurteile und Stereotype bekräftigt, läßt sich freilich nicht bestreiten, doch können wir mit Michael Clyne davon ausgehen,

„daß diese vermieden oder wenigstens vermindert werden, indem 1. die Datensammlung umfangreich genug ist, um individuelle und subkulturelle Fakktoren von kulturellen abzugrenzen,

2. die Untersuchungen von bikulturellen bzw. interkulturellen Gruppen durchgeführt werden,

3. womöglich mehr als zwei Kulturen Gegenstand der Forschung sind und daher Vergleiche differenziert formuliert werden können." (Clyne 1993, S. 15)

Abschliebend bleibt zu unterstreichen, daB in der interkulturellen Wissenschaftskommunikation „Universalisierung und Partialisierung zwei Phasen eines Zyklus (sind), der grundsätzlich immer wieder von neuem durchlaufen werden kann" (Holenstein 1985, S. 175).

\section{Literatur}

Bayertz, Kurt (1981): Wissenschaftstheorie und Paradigmabegriff. Stuttgart. (Sammlung Metzler Bd. 202).

Buhlmann, Rosemarie (o.J.): Merkmale geschriebener und gesprochener Texte im Bereich naturwissenschaftlicher-technischer Fachsprachen. München.

Carter, Ronald/Nash, Walter (1990): Seeing Through Language. A Guide to Styles of English Writing. Oxford.

Clyne, Michael (1984): Wissenschaftliche Texte Englisch- und Deutschsprachiger: Textstrukturelle Vergleiche. In: Studium Linguistik 15, S. 93-97.

Clyne, Michael (1990): Zur kontrastiven Analyse lāngerer Texte und deren Anwendung. Unverōffentlichtes Vortragsmanuskript.

Clyne, Michael (1991); Zu kulturellen Unterschieden in der Produktion und Wahrnehmung englischer und deutscher wissenschaftlicher Texte. In: Informationen Deutsch als Fremdsprache, 18, 4, S. 376-383.

Clyne, Michael (1993): Pragmatik, Textstruktur und kulturelle Werte: Eine interkulturelle Perspektive. In: Schröder, Hartmut (Hg.): Fachtextpragmatik. Tübingen. S. 3-17.

Cooper, Charles R./Greenbaum, Sidney (1988): Preface. In: Purves, Alan C. (Hg.): Writing Across Languages and Cultures. Issues in Contrastive Rhetoric. Newbury Park. (Written Communication Annual, Volume 2). S. 7-8.

Duszak, Anna (1994): Academic Discourse and Intellectual Styles. In: Journal of Pragmatics 21, S. 291-313. 
EBer, Ruth/Krumm, Hans Jürgen/Wagner, Johannes (o.J.): Cultural Relativity in Academic Production in the Humanities (Crap-Projekt). O.O. Unveröffentlichtes Manuskript.

Galtung, Johan (1983): Struktur, Kultur und intellektueller Stil. Ein vergleichender Essay über sachsonische, teutonische, gallische und nipponische Wissenschaft. In: Leviathan 2, S. 303-338.

Gauger, Hans-Martin (1988): Der Autor und sein Stil. Zwölf Essays. Stuttgart.

Geist, Uwe (1992): Allez-Hopp! Fachsprache und Paradigmenwechsel. In: Grindsted, Annette/Wagner, Johannes (Hg.): Communication for Specific Purposes - Fachsprachliche Kommunikation. Tübingen. S. 243-266.

Gnutzmann, Claus (1989): Sprachliche Indikatoren zur Explizierung von 'Zielsetzungen' im Englischen und Deutschen. Vortrag auf dem 9. IDV-Kongreß in Wien. Unveröffentlichtes Vortragsmanuskript.

Gnutzmann, Claus (1991): 'Abstracts' und 'Zusammenfassungen' im deutschenglischen Vergleich: Das Passiv als interkulturelles und teiltextdifferenzierendes Signal. In: Mūller, Bernd-Dietrich (Hg.): Interkultuelle Wirtschaftskommunikation. München. S. 363-378.

Graefen, Gabriele (1994): Wissenschaftstexte im Vergleich. Deutsche Autoren auf Abwegen? In: Brūnner, Gisela/Graefen, Gabriele ( $\mathrm{Hg}$.): Texte und Diskurse. Methoden und Forschungsergebnisse der funktionalen Pragmatik. Opladen. S. 136-157.

Graubner, Hans (1978): Stilistik. In: Arnold, H.L./Sinemus, V. (Hg.): Grundzüge der Literatur- und Sprachwissenschaft. Band 1. 5. Auflage. München. S. 164-187.

Hansen, Gyde (1989): Textlinguistische Analyse von Gebrauchstexten. Kopenhagen.

Hartmann, Hans (1960): Die Struktur der indogermanischen Sprachen und die Entstehung der Wisenschaft. Vorträge gehalten auf der Tagung der Joachim-Jungius-Gesellschaft der Wissenschaften. Göttingen.

Harweg, Roland (1972): Stilistik und Textgrammatik. In: Zeitschrift für Literaturwissenschaft und Linguistik 2, 5, S. 71-81.

Hinds, John (1987): Reader Versus Writer Responsibility: A New Typology. In: Connor, Ulla/Kaplan, Robert B. (Hg.): Writing across languages: Analysis of L2-texts. S. 138-159.

Holenstein, Elmar (1985): Menschliches Selbstverständnis: IchbewuBtsein, intersubjektive Verantwortung, interkulturelle Verständigung. Frankfurt. (Suhrkamp Taschenbuch Wissenschaft).

Kaplan, Robert (1966): Cultural Thought Patterns in Inter-Cultural Education. In: Language Learning 16, S. 1-20. Hier nach dem Wiederabdruck in: Croft, Kenneth (Hg.): Readings on English as a Second Language. Cambridge. S. 245-262.

Kaplan, Robert/Grabe, William (1991): The Fiction in Science Writing. In: Schröder, Hartmut ( $\mathrm{Hg}$.): Subject-oriented texts. Berlin/New York. S. 199217. 
Kretzenbacher, Heinz Leonhard (1992): Wissenschaftssprache. Heidelberg. (Studienbibliographien Sprachwissenschaft, Band 5).

Laermann, Klaus (1991): Fiat Nox! In: Die Zeit, Nr. 32, S. 42.

Lepenies, Wolf (1993): Die Übersetzbarkeit der Kulturen - Ein europäisches Problem, eine Chance für Europa. Eröftnungsvortrag des Winterprogramms 1993/94 der Wittheit zu Bremen. Kunsthalle Bremen, 5. November 1993. Unveröffentlichtes Vortragsmanuskript.

Liang, Yong (1993): Zur Fremdheitsproblematik in der interkulturellen Fachkommunikation. In: Wierlacher, Alois (Hg.): Kulturthema Fremdheit. Leitbegriffe und Problemfelder kulturwissenschaftlicher Fremdheitsforschung. München. S. 153-172.

Martin, James (1992): Towards a Theory of Text for Contrastive Rhetoric. New York. (American University Studies, Series XIII, Linguistics Vol. 19).

Mauranen, Anna (1993): Cultural Differences in Academic Rhetoric. A Textlinguistic Study. Frankfurt am Main. (Nordeuropäische Beiträge aus den Human- und Gesellschaftswissenschaften, Bd. 4).

Meyer-Kalkus, Reinhart (1990): Fortgesetzte Mißverständnisse, produktiver Kontakt. Zu Unterschieden der Sprach- und Wissenskulturen in Frankreich und Deutschland. In: Merkur, 44, 8, S. 694-700.

Nord, Christiane (1991): Textanalyse und Übersetzen. Theoretische Grundlagen, Methode und didaktische Anwendung einer übersetzungsrelevanten Textanalyse. 2., neu bearbeitete Auflage. Heidelberg.

Picht, Robert (1987): Universaler Anspruch und kulturelle Bedingtheit. Probleme interkultureller Verständigung in der Wissenschaft. In: Materialien Deutsch als Fremdsprache 27, S. 17-25.

Pörksen, Uwe (1989): Thesen zur Sprachkritik und zur Wissenschaftssprache. In: Barner, Wilfried/Müller-Seidel, Walter ( $\mathrm{Hg}$. ): Jahrbuch der Deutschen Schillergesellschaft. Stuttgart. S. 429-433.

Purves, Alan C. (1988): Introduction. In: Purves, Alan C. ( $\mathrm{Hg}_{\mathrm{g} .) \text { : Writing }}$ Across Languages and Cultures. Issues in Contrastive Rhetoric. Newbury Park. (Written Communication Annual, Volume 2). S. 9-21.

Purves, Alan C./Purves, W.C. (1986): Viewpoints: Cultures, text models and the activity of writing. In: Research in the Teaching of English 20, S. 174197.

Rubin, Donald L./Goodrum, Rosemarie/Hall, Barbara (1990): Orality, OralBased Culture, and the Academic Writing of ESL Learners. In: Issues in Applied Linguistics 1, S. 56-76.

Sachtleber (1993): Die Organisation wissenschaftlicher Texte. Eine kontrastive Analyse. Frankfurt am Main. (Europäische Hochschulschriften Reihe XXI, Bd. 127).

Schlieben-Lange, Brigitte/Kreuzer, Helmut (1983): Probleme und Perspektiven der Fachsprachen- und Fachliteraturforschung. Zur Einleitung. In: Zeitschrift für Literaturwissenschaft und Linguistik 51/52, S. 7-26.

Spillner, Bernd (1974): Linguistik und Literaturwissenschaft. Stilforschung, Rhetorik, Textlinguistik. Stuttgart. 
Stedje, Astrid (1990): Sprachliche Handlungsmuster und interkulturelle Kommunikation. In: Spillner, Bernd (Hg.): Interkulturelle Kommunikation Kongrefbeiträge zur 20. Jahrestagung der Gesellschaft für Angewandte Linguistik GAL e.V. Frankfurt am Main et al. S. 29-40.

Stolze, Radegundis (1986): Zur Bedeutung von Hermeneutik und Textlinguistik beim Übersetzen. In: Snell-Hornby, Mary (Hg.): Übersetzungswissenschaft. Eine Neuorientierung. Tübingen. S. 133-159.

Stolze, Radegundis (1992): Hermeneutische Übersetzen. Linguistische Kategorien des Verstehens und Formulierens beim Übersetzen. Tübingen.

Stolze, Radegundis (1994): Übersetzungstheorie. Eine Einführung. Tübingen.

Swales, John (1990): Genre Analysis. English in Academic and Research Settings. Cambridge.

Taylor, Gordon/Tingguang, Chen (1991): Linguistic, Cultural, and Subcultural Issues in Contrastive Discourse Analysis: Anglo-American and Chinese Scientific Texts. In: Applied Linguistics 12, 3, S. 319-336.

Ueding, Gert/Steinbrink, Bernd (1986): GrundriB der Rhetorik. Stuttgart.

Vermeer, Hans (1992): Skizzen zu einer Geschichte der Translation. Frankfurt. (thw-Translatorisches Handeln Wissenschaft, Bd. 6.1, Schriftenreihe der allgemeinen Übersetzungs- und Dolmetschwissenschaft der Universităt Heidelberg).

Weingarten, Rüdiger (1994): Zur Stilistik der Wissenschaftssprache: Objektivitäts-und Handlungsstil. In: Brünner, Gisela/Graefen, Gabriele ( $\mathrm{Hg}$.): Texte und Diskurse. Methoden und Forschungsergebnisse der funktionalen Pragmatik. Opladen. S. 115-135.

Weinrich, Harald (1988): Einige Maximen heutiger Sprachkultur. In: Meyer, Martin (Hg.): Wo wir stehen. Dreifig Beiträge zur Kultur der Moderne. München. S. 102-107.

Widdowson, Henry (1979): Explorations in Applied Linguistics. Oxford.

Wimmer, Rainer (1987): Der fremde Stil. Zur kulturellen Vielfalt wissenschaftlicher Textproduktion als Problem interkultureller Germanistik. In: Wierlacher, Alois $(\mathrm{Hg}$.): Perspektiven und Verfahren interkultureller Germanistik. Akten des I. Kongresses der Gesellschaft für Interkulturelle Germanistik. München. S. 81-98. 


\section{Prinzipien und Parameter als Grundlagen einer allgemeinen Theorie der vergleichenden Stilistik}

Unsere allgemeine stilistische Fähigkeit wird von einigen universellen Prinzipien bestimmt, die aufgrund der grammatischen Parametrisierung der Einzelsprachen unterschiedlich umgesetzt werden. Universelle Prinzipien erfolgreicher Sprachverwendung, wie das Relevanzprinzip, werden sprachspezifisch umgesetzt. Präferiert werden vor allem jene Formen, die den Verarbeitungsaufwand bei der Analyse von Sprachstrukturen minimieren, indem sie eine (den grammatischen Parametern der jeweiligen Sprache) angemessene Verteilung der Information auf die syntaktischlexikalische Struktur von Sätzen und Satzfolgen ermöglichen.

Bis heute gibt es in der Linguistik und der (linguistischen) Stilistik einen 'blinden Fleck': die vielen unauffäligen, unmarkierten, neutralen Formen der Sprachverwendung werden an sich nicht thematisiert, allenfalls vorausgesetzt. Wir können aber nicht nur auffällige, markierte Stilformen erkennen, sondern ganz allgemein, über die im weitesten Sinne grammatisch akzeptablen/inakzeptablen Formen der Sprachverwendung hinaus, zwischen stilistisch mehr oder weniger gelungenen Sätzen/Texten unterscheiden. Das heißt, wir können erstens sagen, welche Sätze in einer Sprache grammatisch möglich sind und einander bedeutungsmäBig so ähnlich sind, dab sie im jeweiligen Kontext als Paraphrasen voneinander gelten können. Diese beiden Fähigkeiten sind bekanntlich die wichtigsten Bestandteile unserer grammatischen Kompetenz. Und wir können zweitens sagen, welche Sätze aus dieser Menge von Paraphrasen mehr, welche weniger gelungen sind. Man kann sich das am schnellsten, weil im wesentlichen kontextfrei, an Aphorismen und Sentenzen klar machen. Der Satz:

Denn immer ist der Text, wenn er etwas taugt, der Forschung und ihrer Methode voraus.

(Hans Magnus Enzensberger, 1988, S. 206)

kann auf vielerlei Weise paraphrasiert werden:

Denn immer ist der Text, der etwas taugt, der Forschung und ihrer Methode voraus. 
Denn immer ist der Text der Forschung und ihrer Methode voraus wenn er etwas taugt.

Der Text, der etwas taugt, ist ja immer der Forschung und ihrer Methode voraus.

Wenn der Text etwas taugt, ist er ja immer der Forschung und ihrer Methode voraus.

Denn immer hat der Text, wenn er etwas taugt, der Forschung und ihrer Methode etwas voraus.

Wenn der Text etwas taugt, hat er ja immer der Forschung und ihrer Methode etwas voraus.

usw.

Je weiter wir uns vom Original entfernen, umso schlechter werden die Paraphrasen. Die Version, die Enzensberger gewählt hat, ist zweifelsohne die gelungenste Form, in die dieser Gedanke gekleidet werden kann. Das erstaunliche an diesem stilistischen Urteil ist, daB wir es alle teilen. Und dies, obwohl mit Sicherheit niemand zuvor diese Menge von Paraphrasen miteinander verglichen haben dürfte. Auch an ad hoc Erklärungen, warum die erste Paraphrase weniger gut ist als das Original und die zweite noch weniger gut und die letzte die schlechteste, dürfte nun nachdem wir einmal mit dieser Paraphrasenmenge konfrontiert worden sind - kein Mangel bestehen. Stichhaltige Erklärungen setzen allerdings eine größere Datenmenge voraus und eine systematische Überprüfung der linguistischen Alternativen, die in den Paraphrasen verwendet werden. Zur empirischen Basis für derlei Untersuchungen gehören jedenfalls, wie das Enzensberger-Zitat verdeutlicht hat, nicht nur die sprachlichen Daten, sondern auch unser Urteil über ihre stilistische Wohlgeformtheit. Und eben in diesem Punkt, in unseren stilistischen Urteilen, stellen wir ein erstaunliches $\mathrm{Maß}$ an Übereinstimmung fest - wenn wir uns erst einmal auf die hier demonstrierte 'generative' Methode der schrittweisen Veränderung einer Ausgangsstruktur einlassen.

Unsere Urteilsfähigkeit über grammatische und semantische Eigenschaften sprachlicher Strukturen erstreckt sich bekanntlich auf beliebig viele Sätze und damit auch und größtenteils auf Sätze, denen wir zuvor noch nie begegnet sind. Wir urteilen in den meisten Fällen nicht aufgrund direkter sprachlicher Erfahrung, sondern aufgrund unserer kompositionellen Fähigkeit, das einmal erworbene sprachliche Wissen in immer neuen Kombinationen zusammenwirken zu lassen. So wissen wir zum Beispiel, daß eine Umstellung der ersten beiden Wörter aus dem Zitat grammatisch unmöglich ist, weil wir etwas über die Wörter denn und immer wissen, das diese Abfolge ausschließt. (Wir wissen dies, obwohl wir kaum sagen können, um welche Eigenschaften es sich handelt - wegen der Menge der Kombinationsmöglichkeiten gilt letzteres in den meisten 
Fällen und selbst dann noch, wenn wir Sprachwissenschaftler und ihr linguistisches Wissen einbeziehen.)

Aber die Kompositionalität von Sprache allein kann die enorme Leistung sprachlicher Kompetenz nicht erklären. Über die Form des Wissens, das die grammatische Urteilsfähigkeit begründet, werden deshalb heute Modelle entwickelt, deren anspuchsvollere Versionen nicht nur eine Computersimulation von rezeptiver und produktiver Sprachverarbeitung sondern zugleich eine systematische, prinzipienbasierte Erklärung der sprachlichen Kompetenz anstreben. Hierfür spielen psycholinguistische Gesichtspunkte, vor allem Fragen des Erstspracherwerbs, keine geringe Rolle. Die Tatsache, daß ein Kind in relativ kurzer Zeit mit vergleichsweise wenig positiver und so gut wie keiner negativen Evidenz zunächst jede beliebige Sprache erwerben kann, spricht nicht nur für eine sprachliche Prädisposition im allgemeinen, sondern für eine eng begrenzte Menge von Prinzipien und Parametern, mit deren Hilfe sich trotz der relativ geringen und eher zufalligen sprachliche Erfahrung des Kindes rasch jede beliebige Einzelgrammatik zu einer der vielen Sprachen dieser Erde entwickeln läBt. ${ }^{1}$

Was für die Entwicklung unserer grammatischen Fähigkeiten, trotz des Unterangebots an Evidenz gilt, gilt nicht weniger für die Entwicklung unserer allgemeinen stilistischen Urteilsfähigkeit - auch wenn diese erst so richtig mit dem Ausbau unseres lexikalischen Wissens erfolgt. Daß die Entwicklung der stilistischen Fähigkeit von der der lexikalischen abhängig ist, ist offensichtlich, wenn man sich die Rolle der lexikalischen Elemente bei der Paraphrasenbildung vergegenwärtigt.

Wir entwickeln unsere stilistische Urteilsfahigkeit mit und in Bezug auf eine bestimmte Sprache und einige ihrer regionalen, sozialen und funktionalen Subsysteme. Was in einem Subsystem grammatisch akzeptabel ist, kann in einem anderen inakzeptabel sein; oft handelt es sich aber nur um mehr oder weniger präferierte Ausdrucksformen. Dasselbe läßt sich bezüglich der vergleichbaren Ausdrucksformen in verschiedenen Sprachen sagen. Unterschiede in den Präferenzen werden dabei eher zufällig registriert, etwa im Fremdsprachenunterricht, wenn es heißt, „das sagt man eben (nicht) so." Im Alltag begegnet einem derlei nicht selten im Bereich pragmatischer Stereotype, wie zum Beispiel, wenn wir in einem un-

1 Eine tiefergehende Auseinandersetzung mit dem Problem der Parameterfixierung im Spracherwerb findet sich in Haider (1993), der die Universalgrammatik als eine biologisch determinierte Berechnungskapazität für spezifische Datenstrukturen auffaßt, die im Zusammenwirken mit anderen kognitiven Kapazitäten die jeweilige Einzelgrammatik erzeugt. 
garischen Bus die Aufforderung lesen: Bitte die Billetten löchern zu wollen (die selbst mit dem Verb lochen bzw. entwerten und den bei uns üblicheren Fahrkarten noch nicht unseren Erwartungen entsprechen würde). In die Fremdsprache übersetzte (bzw. in der Fremdsprache geschriebene) Werbeprospekte, Gebrauchsanweisungen, Touristenführer und dgl. sind eine Fundgrube für solche grammatischen und stilistischen Mißgriffe. Beispiele wie dieses bleiben jedoch wegen ihrer Idiomatizität notwendigerweise anekdotisch.

Aber auch in fortlaufenden Texten scheint vieles ideosynkratisch oder von den individuellen Vorlieben des Autors diktiert - eine Sache des Zufalls und damit nichts, was sich mit einem prinzipien- und parameterbasierten Ansatz erfassen ließe. Und dennoch - wenn wir von der oben demonstrierten Methode der schrittweisen Variation sprachlicher Strukturen Gebrauch machen, entdecken wir gerade beim Übersetzen, wo wir einen Text auf dem Hintergrund eines anderssprachigen Texts betrachten, daB trotz potentiell analoger Ausdrucksformen in Ausgangs- und Ziel-Sprache überwiegend andere, nicht-analoge Strukturen präferiert werden.

Wie die folgenden Beispiele von Übersetzungen aus dem Englischen ins Deutsche zeigen, reicht die Palette der unterschiedlichen Präferenzen von der Wortstellung über Kasus und andere grammatische Kategorien, Wortarten und strukturelle Explizitheit bis hin zu Satzverknüpfungen und Satzgrenzen, kurzum über alles, was bei einer Paraphrasenbildung verändert werden kann. Trotz der vielen formalen Unterschiede zeichnen sich dabei einige grundlegende Unterschiede ab zwischen den dem Original analogen bzw. ähnlichsten sprachlichen Strukturen (AV) und den im Deutschen präferierten Zielvarianten (ZV).

$\mathrm{Zu}$ den häufigsten Präferenzunterschieden zwischen Englisch und Deutsch gehören Unterschiede in der Art und Abfolge von Satzgliedern, also das, was in verschiedenen linguistischen Modellen unter 'Perspektive' figuriert. $^{2}$ Sie werden von verschiedenen anderen Phänomenen überlagert

2 Die bekannteste Version aus der traditionellen Sprachwissenschaft, die 'Funktionale Satzperspektive' der Prager Schule, hat dabei sicher zur Verbreitung des Perspektive-Konzepts das meiste beigetragen. In generativen Darstellungen findet sich der Begriff selten (oder, wie z.B. in Wunderlich und Stechows über 900 Seiten starken Semantik-Handbuch in einer anderen, eher marginalen Verwendung); das Kapitel 3.4 'Perspective and information structure' in Levelt (1989) stellt da eher eine Ausnahme dar. Für die hier thematisierte allgemeine stilistische Fähigkeit ist der Begriff nützlich, da sich in ihm die für Paraphrasierungen so relevanten Phänomene von Reihenfolge- und Kasusrahmenpräferenzen zusammenfassen lassen. 
und lassen sich als gleiche oder ähnliche Muster oft nur erkennen, wenn man eine 'projektive' Blickrichtung wählt und von der im Lexikon fixierten 'natürlichen' Ordnung ausgeht. Die im Deutschen und Englischen präferierten Perspektiveunterschiede stehen in auffallendem $\mathrm{Zu}$ sammenhang mit dem Parameter der Direktionalität, insbesondere der nach rechts bzw. links gerichteten Erweiterungsmöglichkeit des Verbs in einer SOV- und einer SVO-Sprache. ${ }^{3}$ Der Unterschied zwischen den im Deutschen und Englischen präferierten Satzgliedern ist darüber hinaus noch am Konfigurationalitätsparameter, vereinfacht gesagt: an der unterschiedlichen Beweglichkeit der Satzglieder, festzumachen. ${ }^{4}$ Die Präferenzunterschiede werden aber, anders als die - im Lexikon und in den syntaktischen Bewegungsmöglichkeiten - verbindlich festgeschriebenen grammatischen Parametrisierungen, erst über den zusätzlichen 'Transport-Riemen' eines allgemeinen Prinzips für Sprachverwendung wirksam.

Ein großer Bereich neutraler Sprachverwendung wird von Sperber und Wilsons Relevanzprinzip (1986) erfaßt, das - vereinfacht gesagt - erfolgreiche Sprachverwendung von einer Optimierung des Verhältnisses zwischen kognitivem Gewinn und Verarbeitungsaufwand abhängig macht. Jede ÄuBerung sollte an bereits vorhandenes 'Wissen' anknüpfen (es bestätigen, korrigieren und/oder weitere Inferenzen ermöglichen) und mit einem vertretbaren Aufwand verstehbar sein. Letzleres kann vieles Verschiedenes bedeuten - es muB sich aber (über die von Sperber und Wilson thematisierten Bedingungen hinaus) in jedem Fall auch auf die sprachliche Form einer Information beziehen. Und diesbezüglich kann

3 Eine präzisere Formulierung des Parameters würde, folgt man den Annahmen Haiders (1993) über eine universelle rechtsrekursive Form von Basisstrukturen, als entgegengesetzte Lizensierungsrichtung für die internen Positionen in der Projektion lexikalischer Köpfe, wie V, möglich sein.

4 Grob gesehen, ist Englisch - vermutlich wegen seines Kasussynkretismus - eine konfigurationelle Sprache, in der Satzglieder in wesentlichen über ihre Stellung gegenüber dem Verb identifiziert werden; dies schränkt - im Vergleich zu einer morphologisch differenzierteren, nicht-konfigurationellen Sprache, wie dem Deutschen - die Beweglichkeit der Satzglieder ein. Wahrscheinlich handelt es sich aber bei diesem Unterschied weniger um einen grammatischen als um einen pragmatischen Zusammenhang. Vgl. dazu Czepluchs kritische Ausführungen (1992) zu mehr oder weniger konfigurationellen Bereichen der englischen und deutschen Satzstruktur und Dohertys Annahmen (1994 und im folgenden) über eine parametrisierte Sprachverarbeitung. 
es eben auch, aufgrund der Parametrisierung von Einzelgrammatiken, Verschiedenes bedeuten. ${ }^{5}$

Das Relevanzprinzip mit seinem Kriterium der Verarbeitbarkeit ist eines, vermutlich das wichtigste der universellen Prinzipien, die unsere allgemeine stilistische Fähigkeit bestimmen. Wie an den folgenden Beispielen demonstriert werden soll, lassen sich mit seiner Hilfe bereits viele der Präferenzunterschiede zwischen einer SOV- und einer SVO-Sprache erfassen. Optimale Verarbeitbarkeit alleine reicht aber sicher nicht aus, um alle Präferenzunterschiede zu erklären. In der Folge wird deshalb noch von einem zweiten, einem (prosodisch-) ästhetischen Stilprinzip die Rede sein: dem Prinzip des informationellen Gleichgewichts. (Dabei ist allerdings nicht ausgeschlossen, dab sich dieses Prinzip im Rahmen einer noch zu entwickelnden Gesamttheorie der Verarbeitung von Sprache auf allen Ebenen - also auch der prosodischen - letztendlich doch auf das Relevanzprinzip reduzieren läßt.)

Die Beispiele stammen aus einem Korpus von 10 Texten wissenschaftlicher Sachprosa mit insgesamt ca. 1000 Sätzen, für die in einer Art offenem Übersetzungsverfahren (nach der eingangs demonstrierten generativen Methode) über viele Jahre die bestmöglichen Zielvarianten ausgewählt wurden. Die prinzipielle Korrigierbarkeit der Daten erlaubt es, weitere Verbesserungsmöglichkeiten zu berücksichtigen - ein methodischer Vorteil, der sich bei der Überarbeitung von scheinbar inkonsistenten Teildateien bereits ausgezahlt hat. Die häufigsten Unterschiede wurden (1992/93) im Rahmen eines DFG-Projekts ("Parametrisierte Perspektive”) in thematisch geordnete Teildateien zusammengefaBt: zum Perspektivewechsel durch Satzgliedwechsel (insbesondere durch Adverbialisierung des Subjekts) und durch Strukturveränderungen bei satzwertigen Modifikatoren (insbesondere satzfinale Adverbial-/Attributsätze und Spaltsätze).

5 In der psycholinguistischen Literatur stehen die relative Autonomie der syntaktischen Verarbeitung, wie sie in den berühmten Holzweg-Phänomenen zutage tritt, und ihr Zusammenspiel mit den anderen Komponenten spachlicher Information im Zentrum der Aufmerksamkeit (vgl. Altmanns konzise Ūbersicht (1989) über die Entwicklung der letzten Jahrzehnte). Die derivationelle Komplexitätstheorie der frühen siebziger Jahre ist zusammen mit dem zugrundeliegenden Grammatikmodell einem prinzipienund parameterbasierten Erklärungsansatz gewichen, dessen konsequenteste Hypothesen allerdings mehr in der Grammatiktheorie selbst als in den psycholinguistischen Arbeiten entstehen (wie etwa bei Fukui (1993), der mit seinem parameterwerterhaltenden $\mathrm{Maß}$ optionale Bewegungen erklärt). 
Der zur Demonstration ausgewählte Ausschnitt erweitert das Thema eines Textes über Bioelektrizität von den Wachstums-Vorgängen innerhalb der Eizelle auf Fragen des (embryonalen) Nervenwachstums; die Sätze bilden einen relativ geschlossenen Abschnitt; mit dem Klammerausdruck schließt der vorangegangene Absatz:

(electrical studies could be the starting point for explaining all the controls of a number of critical, hitherto mysterious events in morphogenesis.)

One of the most spectacular of these mysteries is the formation of the nervous system. The questing, migratory tips of nerve cells - growth cones - creep throughout the body, often for distances that are immense compared with the size of the nerve cell, to innervate their various target organs. What tells the growth cone where to go? Here we leave the domain of changes within individual cells, and enter extracellular space.

Wie ein erster Vergleich der gesamten Übersetzung des Abschnitts zeigt, liest sich die Zielvariante (die als bestmögliche Paraphrase ausgewählte Übersetzung), ZV, um einiges flüssiger als die (dem Original formal nächste) Analogvariante, AV:

(könnte die Erforschung der Elektrizität zum Ausgangspunkt für die Erklärung einiger entscheidender, bisher rätselhafter Erscheinungen der Morphogenese werden.)

AV: Eines der spannendsten dieser Rätsel ist die Bildung des Nervensystems. Die aussprossenden Nervenzellen - die Wachstumszonen - krie. chen durch den ganzen Körper, oftmals über Entfernungen, die gemessen an der Größe einer Nervenzelle riesig sind, um ihre verschiedenen Zielorgane mit Nerven zu versorgen. Was sagt der Wachstumszone, wo es hingeht? Hier verlassen wir das Gebiet von Veränderungen innerhalb einzelner Zellen und betreten extrazellulären Raum.

ZV: Zu den spannendsten dieser Rätsel gehört die Bildung des Nervensystems. Um ihre Zielorgane mit Nerven zu versorgen, wandern die Wachstumszonen aussprossender Nervenzellen durch den ganzen Körper, wobei sie, gemessen an der Größe einer Nervenzelle, oftmals riesige Entfernungen überwinden. Wodurch wird dieses Wachstum gesteuert? Mit dieser Frage verlassen wir das Gebiet zellinterner Veränderungen und wenden uns dem extrazellulären Bereich zu.

Die strukturellen Unterschiede zwischen $\mathrm{AV}$ und $\mathrm{ZV}$ verteilen die Information jeweils so, wie sie in einer SVO- bzw. einer SOV-Sprache besser verarbeitbar ist. So simpel diese Behauptung scheint, so komplex ist das Zusammenspiel der verschiedenen Faktoren in jedem Satz. Dies gilt auch für den scheinbar so einfachen ersten Satz, dessen Übersetzung einen typischen Unterschied zwischen den im Englischen und Deutschen präferierten Kasusrahmen illustriert. Hier noch einmal die Gegenüberstellung von Original bzw. AV und $\mathrm{ZV}$ : 
(1) One of the most spectacular of these mysteries is the formation of the nervous system.

AV: Eines der spannendsten dieser Rätsel ist die Bildung des Nervensystems.

ZV: Zu den spannendsten dieser Rätsel gehört die Bildung des Nervensystems.

Der wichtigste Unterschied zwischen AV und ZV ist der mit dem nichtanalogen, 'relexikalisierten' Verb ${ }^{6}$ einhergehende Satzgliedwechsel, der anstelle des Subjekts ein Präpositionalobjekt an den Satzanfang bringt. Die Tatsache, daB in AV und ZV derselbe Referent in derselben Position erscheint, verdeckt einen Linearisierungs-Unterschied, der bei einem Satzgliedwechsel dieser Art meist auftritt: Das Präpositionalobjekt ist aus seiner grammatischen Grundposition innerhalb der VP an den Satzanfang verschoben worden. Gerade diese Möglichkeit der 'Topikalisierung' betrifft einen systematischen Unterschied zwischen Deutsch und Englisch. Sie fehlt nämlich nicht nur für das Verb belong to, sondern unterliegt ganz allgemein im Englischen wesentlich größeren Einschränkungen als im Deutschen. Während im Deutschen nahezu jedes Satzglied in die initiale Position, vor das finite Verb, geschoben werden kann, ist die Position vor dem englischen Verb - von wenigen Ausnahmen abgesehen - für das Subjekt reserviert. Zusätzliche Erweiterungen am Anfang des englischen Satzes stellen deshalb in fast allen Fällen zusätzliche Anforderungen an die Verarbeitung der sprachlichen Struktur. Gerade dies dürfte der Grund dafür sein, daß die englische Lexik bekanntlich so viel mehr Möglichkeiten entwickelt hat, Ergänzungen, die im Deutschen zum Beispiel als Adverbial oder Objekt erscheinen, ins Subjekt zu projizieren. Eine Rückübersetzung der deutschen Zielvariante ist nicht möglich:

* To one of the most spectacular of these mysteries belongs the formation of the nervous system.

Auch andere lexikalische Varianten sind allenfalls marginal, unter besonderen, entsprechend markierten Bedingungen zu haben, wie etwa durch den Einschub eines Expletivums:

Among the most spectacular of these mysteries, there is the formation of the nervous system.

6 Das formal ähnlichste Verb ist wurde durch das nur im Kontext äquivalente Verb gehören zu ersetzt, wodurch eine lexikalische Paraphrase von einer Kopula $z$ wischen $z$ wei nominativen Subjekt-NPs, eine davon mit genitivus partitivus, zu einem Vollverb $z$ wischen einer Subjekt-NP und einer präpositionalen Objekt-NP entsteht. 
Das Englische ist auf eine schlichtere Struktur angewiesen, wenn es den Verarbeitungsaufwand nicht grundlos erhöhen will.

Nun könnte man natürlich erwarten, daß eine einfachere Struktur generell einen geringeren Verarbeitungsaufwand hat und folglich auch im Deutschen die einfachere Analogvariante der komplexeren Zielvariante vorzuziehen sein müBte. In Wirklichkeit ist uns aber die Kopulavariante von AV mit dem Subjekt am Satzanfang zu 'simpel' - wir ziehen das lexikalisch etwas spezifischere Prädikat mit seiner präpositionalen Ergänzung vor. Die Gründe hierfür sind nicht weniger parametrisiert als die für die englische Präferenz. Sie lassen sich aber nicht so gut an diesem einzelnen Beispielsatz festmachen, sondern erfordern Überlegungen, die das Deutsche als SOV-, das heiBt als Verbend-Sprache insgesamt betreffen.

Die Annahme, daB der verbale Kopf der deutschen VP eigentlich rechtsperipher ist, wird gerade von den Sätzen widerlegt, die man als die grundlegenden Sätze einer Sprache ansehen möchte: selbständige, einfache Sätze und Hauptsätze verlangen das finite Verb in der zweiten Position - nur bei Nebensätzen steht das Verb rechts außen. Dennoch gibt es gute Gründe dafür, daß Deutsch eine Verbend-Sprache ist. Der wichtigste ist die Tatsache, daß die Richtung, in der die Ergänzungen des Verbs neutralerweise aneinander gereiht werden, generell - also auch im Hauptsatz - nach links geht. Wäre das Deutsche insgesamt oder auch nur im Hauptsatz eine SVO-Sprache, müBte die natürliche Reihung zumindest im Hauptsatz - nach rechts verlaufen.

Diese linksdirektionale/rechtsperiphere Eigenschaft des Deutschen hat entscheidende Konsequenzen für das, was wir in Bezug auf die Verteilung der Information im Satz präferieren - hierzu werden das zweite und dritte Beispiel noch reichliches Anschauungsmaterial liefern. Für die Verarbeitung von Sätzen ergibt sich aber ganz allgemein in allen Sätzen, in denen das Verb tatsächlich am Ende steht, eine mehr oder weniger große strukturelle Distanz zwischen dem Satzglied am Satzanfang und dem Verb. Da die Bedeutung des Verbs letztendlich über die semantischen Relationen entscheidet, in der die Ergänzungen des Verbs zueinander stehen, kann die Verbendstellung beträchtliche Verarbeitungsnachteile mit sich bringen.

Entscheidungsunsicherheiten oder falsche Entscheidungen bei der Interpretation des Satzanfangs können unter Umständen lange auf eine Lösung oder Korrektur warten müssen. In dem $\mathrm{Maße}$, in dem beides von der Bedeutung des Verbs abhängig ist, besteht der Verarbeitungsnachteil auch in Hauptsätzen mit komplexen Verbformen. Das finite Verb sagt - 
ausgenommen vielleicht das Passivmorphem - nicht viel über die Bezie'hungen zwischen den Ergänzungen aus. Das bedeutungstragende Verb steht ja auch in allen Sätzen mit komplexen Verbformen am Satzende.

Unter dieser Bedingung scheint sich nun ganz generell eine Präferenz für grammatisch eindeutigere Satzanfänge herausgebildet $z u$ haben, für Satzglieder, die ihre Beziehung zu den anderen Ergänzungen des Verbs, ihre semantisch-thematische Rolle, formal etwas deutlicher anzeigen. Die präferierten Strukturen haben gewissermaBen eigene, morphologische Indikatoren: Präpositionen, Affixe, durch die Verarbeitungsnachteile des späten Verbs teilweise ausgeglichen werden.

Ein solcher Ausgleich erübrigt sich in einer SVO-Sprache, wie dem Englischen, wo das Verb in jedem Satz sofort zur Verfügung steht, um eventuelle Unklarheiten oder Fehlinterpretationen bei der Interpretation des Satzanfangs zu beseitigen. Englisch kann sich als Verbzweit-Sprache einen - thematisch freieren - Subjektanfang leisten und muß sich ihn leisten, wegen der Topikalisierungsbeschränkungen einer konfigurationellen Sprache. Das Deutsche kann und muß die größeren Topikalisierungsfreiheiten einer nicht-konfigurationellen Sprache nutzen, um durch formal differenziertere Satzanfänge gegen die Verarbeitungsnachteile einer Verbendsprache aufzukommen.

Die Kopulastruktur der Analogvariante zu (1) offeriert in dieser Hinsicht keine formale Interpretationshilfe; eben deswegen wird ihr die Zielvariante mit dem formal differenzierten, präpositionalen Satzanfang vorgezogen.

Das zweite Beispiel, der zweite Satz aus dem Textabschnitt oben, demonstriert einen Präferenzunterschied zwischen Deutsch und Englisch, der sich - weil er nicht durch positionale und referentielle Analogien verdeckt ist - leicht erkennen läBt.

(2) The questing, migratory tips of nerve cells - growth cones - creep throughout the body, often for distances that are immense compared with the size of the nerve cell, to innervate their various target organs.

AV: Die aussprossenden Nervenzellen - die Wachstumszonen - kriechen durch den ganzen Körper, oftmals über Entfernungen, die, gemessen an der Größe einer Nervenzelle, riesig sind, um ihre verschiedenen Zielorgane mit Nerven zu versorgen.

$\mathrm{ZV}$ : Um ihre Zielorgane mit Nerven zu versorgen, wandern die Wachstumszonen aussprossender Nervenzellen durch den ganzen Körper, wobei sie, gemessen an der Größe einer Nervenzelle, oftmals riesige Entfernungen überwinden. 
Der Unterschied zwischen AV und ZV besteht zunächst einmal in einer Topikalisierung des finalen Infinitivs. Der Kasusrahmen bleibt unverändert erhalten. Die Umstellung hilft ganz offensichtlich, einen Teil der 'schwerfälligen' Struktur auf der rechten Seite abzubauen. Der Eindruck von Schwerfälligkeit entsteht vor allem durch die asyndetische Reihung von Adverbialen in der medialen Position von AV - der gewichtige Relativsatz des zweiten Adverbials ist hier besonders schwer zu verarbeiten. Auch eine Paraphrase, nennen wir sie eine Intermediär-Variante (IV), die sich mit der Vorstellung des Infinitivs begnügen würde, scheint aufgrund der asyndetischen Verknüpfung zwischen den beiden Adverbialphrasen noch immer etwas schwerer zu verarbeiten als die Zielvariante:

IV: Um ihre Zielorgane mit Nerven zu versorgen, wandern die Wachstumszonen aussprossender Nervenzellen durch den ganzen Körper, oftmals über Entfernungen, die gemessen an der Größe einer Nervenzelle riesig sind.

ZV: Um ihre Zielorgane mit Nerven zu versorgen, wandern die Wachstumszonen aussprossender Nervenzellen durch den ganzen Körper, wobei sie, gemessen an der Größe einer Nervenzelle, oftmals riesige Entfernungen überwinden.

Der Unterschied mag subtil sein - aber auch eine Vielzahl geringfügiger Präferenzunterschiede kann, wenn man sie nicht berücksichtigt, die stilistische Qualität eines Textes beträchtlich mindern. Und die Beschreibung und Erklärung dieses Unterschieds führt uns in einen zentralen, vermutlich den zentralen Bereich unseres parameter-basierten Versuchs einer allgemeinen Theorie für vergleichende Stilistik: in den Bereich sprachspezifischer Informationsstrukturen. ${ }^{7}$

Die Zielvariante hat das zweite Adverbial zu einem Satz erweitert und diesen dem vorangegangen Satz mithilfe der Konjunktion wobei subordiniert. Die Information des zweiten Adverbials ist auf diese Weise auf eine

7 Als Informationsstruktur bezeichnen wir die Verteilung der nach ihrer Relevanz bewerteten Informationselemente auf eine bestimmte sprachliche Struktur: eine Informationseinheit. Sie könnte am ehesten dem entsprechen, was Nunberg (1990) einen Textsatz ('a textual sentence') nennt. Textsãtze entwickeln die Argumentationsstruktur von Texten und werden durch die Textgrammatik generiert so wie grammatische Sätze durch die lexikalische Grammatik; Textsätze kōnnen grammatischen Sätzen entsprechen, brauchen dies aber nicht; sie können aus textuellen Teilsātzen und -phrasen bestehen, die für die Syntax des Textes Kopf- oder Adjunktfunktion haben usw. usf. Eine Theorie der Informationsstrukturen, die über den Bereich von Fokustheorien hinaus ganz generell die sprachspezifische Enkodierung von Informationswertehierarchien an dieser Schnittstelle zwischen Textgrammatik und lexikalischer Grammmatik erfaßt, steht immer noch aus. 
größere Menge sprachlicher Formen verteilt - das Satzglied weist eine geringere Informationsdichte auf ${ }^{8}$, die Struktur ist flacher und zudem als untergeordnet charakterisiert. Damit tragen beide Veränderungen - die Vorstellung des Infinitivs und die Erweiterung zum Adverbialsatz - zu einer Entlastung der Struktur nach dem ersten Adverbial bei.

Dem ersten Adverbial kommt aber nun ein ganz besonderes informationelles Gewicht zu: es ist, wenn man den Informationswert aller Ergänzungen miteinander vergleicht, der informationelle Schwerpunkt des Satzes. Aus dem Kontext wissen wir, daB es um Zellwachstum und dabei um die Entwicklung des Nervensystems geht, und mit der Angabe durch den ganzen Körper können wir aus unserem Weltwissen über das Größenverhältnis zwischen Zelle und Körper leicht noch die riesigen Entfernungen ableiten. Der Träger des informationellen Schwerpunkts, nennen wir ihn den (pragmatischen) Fokus(exponenten) ${ }^{9}$, steht in ZV am Ende eines Hauptsatzes. Was folgt, ist informationell und syntaktisch untergeordnet.

In IV und AV ist dies anders. In IV besteht syntaktische Gleichwertigkeit zwischen den beiden Adverbialen; in AV scheint darüber hinaus dem finalen Infinitiv am Satzende noch ein besonderes Gewicht zuzukommen. ${ }^{10}$

8 Der Grad der Informationsdichte nimmt entgegengesetzt zum Grad der Explizitheit zu oder ab: wo vieles nur noch implizit ausgedrückt wird, ist die Informationsdichte am gröBten. Dies ist aber relativ zum Textsatz zu sehen: eine infinite Verbphrase kann zum Beispiel im Hinblick auf das implizite Subjekt als strukturell weniger explizit, 'dichter' als die voll ausbuchstabierte, finite Verbphrase bewertet werden, im Satzzusammenhang aber als 'flacher' - etwa gegenüber einer Paraphrase mit einem verblosen prāpositionalen Komplement anstelle des nicht-finiten.

9 In der Regel wird der Fokusexponent als Träger der prosodischen Prominenz, des Satzakzents, gesehen und seine semantisch-pragmatische Interpretation als weiter (globaler, projizierender) Fokus in Abhängigkeit von bestimmten, kanonischen Stellungen der involvierten Satzglieder (so zum Beispiel bei Abraham (1993), Drubig (1994)). Die Notwendigkeit einer modularen Sicht, die den prosodischen Fokus unabhängig vom pragmatischen Fokus variieren läßt, (bei Jacobs (1992), angedeutet) wird neuerdings nachdrücklich von Vallduvi (1994) vertreten. Die Präferenzunterschiede zwischen deutschen und englischen Informationsstrukturen betreffen den Exponenten des pragmatischen Fokus, der mit dem des prosodischen Fokus nicht übereinstimmen muß. Der Ausdruck 'Endfokus' bezeichnet in diesem Sinne die Stellung des pragmatischen Fokusexponenten in etwa an der rechten Peripherie des Satzes, eben da, wo nach der 'kanonischen' Fokustheorie im neutralen Fall der prosodische Fokusexponent steht.

10 Komplexe Sätze weisen in Abhängigkeit von der semantisch-syntaktischen Relation zwischen ihren Teilsātzen spezifische Informationsstrukturen auf. 
Da unsere pragmatischen Überlegungen eine Informationshierarchie ergeben haben, die in $\mathrm{ZV}$ angemessen realisiert schien, muß der Eindruck in IV und AV gerade durch die Strukturunterschiede zu ZV entstehen. Das Deutsche präferiert also eine Informationsstruktur, in der weniger relevante Informationen entweder noch vor dem Informationsschwerpunkt erscheinen oder formal, wie im Fall des wobei, als weniger wichtig ausgewiesen werden. In anderen Worten, das Deutsche präferiert Sätze mit Endfokus und Indikatoren für 'Gegenfälle'.

Wie ein Vergleich zwischen dem Original und einer Rückübersetzung von ZV zeigt, sind die Präferenzen im Englischen so gut wie entgegengesetzt:

(2) The questing, migratory tips of nerve cells - growth cones - creep throughout the body, often for distances that are immense compared with the size of the nerve cell, to innervate their various target organs.

RV: To innervate their various target organs, the questing, migratory tips of nerve cells - growth cones - creep throughout the body, where they often cover distances that are immense compared with the size of the nerve cell.

Die Rückübersetzung zeigt deutlich, daß die im Deutschen angemessene Informationsverteilung im Englischen anders bewertet wird - sowohl die Voranstellung des Infinitivs wie die Erweiterung zum Adverbialsatz suggerieren höhere Informationswerte. Anders das Original: hier nimmt die Hierarchie der Informationswerte nach dem Informationsschwerpunkt kontinuierlich ab. Das Englische ist - im Unterschied zum Deutschen (und entgegen anderslautender Ansichten) - keine Endfokussprache. ${ }^{11}$ Der Unterschied $z$ wischen der deutschen und der englischen Informationsstruktur entspricht - so die Daten aus den präferierten Übersetzungen - der entgegengesetzten Direktionalität deutscher und englischer Verbphrasen. Auf den SVO-/SOV-Unterschied bezogen, heiBt dies: der (pragmatische) Fokus (exponent) wird im allgemeinen in unmittelbarer Nähe des Verbs erwartet/präferiert. Der Präferenz-Unterschied macht sich bei einer Ergänzung des Verbs kaum bemerkbar, wohl aber,

Es gibt Anhaltspunkte dafür, daß es auch diesbezüglich sprachspezifische Unterschiede gibt, die zum Beispiel bewirken, daß satzfinale Infinitivstrukturen im Deutschen anders bewertet werden als im Englischen.

11 Dies wird - wegen der mangelnden Unterscheidung $\mathrm{z}$ wischen prosodischem und pragmatischen Fokus - offensichtlich erst so richtig in Übersetzungen deutlich. Wo zugunsten präferierter Zielvarianten Umstellungen notwendig werden, handelt es sich fast in allen Fällen um informationell weniger relevantes Material, das in der Analogvariante (und damit im englischen Original) nach dem Informationsschwerpunkt steht und zur Sicherung des Endfokus im Deutschen nach links verschoben wird. 
wenn mehrere Ergänzungen vorliegen und ganz besonders in komplexen Sätzen. In solchen Fällen liegt der Informationsschwerpunkt im Englischen, vereinfacht gesagt, in der Mitte des Satzes, und Analogübersetzungen ins Deutsche sind stilistisch entsprechend mangelhaft. Eine Theorie, die der Modularität von prosodischem vs. pragmatischem Fokus gerecht wird, steht immer noch aus. Sie ist aber nach allem, was bisher erkennbar ist, Dreh- und Angelpunkt für eine parameterbasierte Modellierung sprachspezifischer Präferenzen.

Die Annahme einer direktional entgegengesetzten Informationsstruktur reicht allerdings noch nicht aus, um den Präferenzunterschied im zweiten Beispiel 'lückenlos' zu erfassen. Schließlich könnte Endfokus im Deutschen auch durch eine entsprechende 'Permutation' der Adverbiale erreicht werden:

IV': Um ihre Zielorgane mit Nerven zu versorgen, wandern die Wachstumszonen aussprossender Nervenzellen oftmals über Entfernungen, die - gemessen an der Größe einer Nervenzelle - riesig sind, durch den ganzen Körper.

Das Ergebnis ist wegen des schwerfälligen Mittelfelds deutlich schlechter als IV. Aber auch wenn wir das Mittelfeld noch etwas entlasten, läßt sich die permutierte Variante nicht leichter verarbeiten:

IV": Um ihre Zielorgane mit Nerven zu versorgen, wandern die Wachstumszonen aussprossender Nervenzellen oftmals über - gemessen an der Größe einer Nervenzelle - riesige Entfernungen, durch den ganzen Körper.

IV'": Um ihre Zielorgane mit Nerven zu versorgen, wandern die Wachstumszonen aussprossender Nervenzellen oftmals über für sie riesige Entfernungen durch den ganzen Körper.

Obwohl die riesigen Entfernungen aus dem Weg durch den ganzen Körper erschlossen werden können, sind die Modifikatoren beider Adverbiale fokussiert. Auch wenn sich die Foki, pragmatisch gesehen, in einen Primär- und einen Sekundärfokus hierarchisieren lassen, dürfte ihre 'Massierung' am rechten Satzrand den Eindruck einer zu hohen Informationsdichte hervorrufen. Die strukturelle Entlastung in ZV, die durch die Erweiterung in einen Adverbialsatz erzielt wird, gewährleistel ganz offensichtlich eine ausgewogenere Informationsverteilung.

Sicher trägt eine ausgewogene Verteilung von Foki im einfached und im komplexen Satz auch zur besseren Verarbeitbarkeit der sprachlichen Strukturen bei. Soweit sich dieses 'Gleichgewicht' aber auch rhythmischprosodisch auswirkt, dürfte neben dem universellen Relevanzprinzip und seiner Forderung nach optimaler Verarbeitbarkeit auch noch eir eher ästhetisches Stilprinzip wirksam werden - eine Art übergreifender pro- 
sodischer Parallelismus. Dieses 'Gleichgewichts-Prinzip' wird, nicht anders als das Relevanzprinzip, in Abhängigkeit von den grammatischen Parametern sprachspezifisch unterschiedlich umgesetzt. Die Bedingungen, unter denen wir zum Beispiel zwei Foki auf clausale oder phrasale Strukturen verteilen, sind eben in einer SOV-Sprache andere als in ejner SVO-Sprache. Das zweite Beispiel war ein Fall, in dem das Deutsche eine explizitere Struktur präferiert; das dritte Beispiel illustriert das Gegenstück dazu, einen Fall, in dem das Englische expliziter ist.

Zunächst treffen wir aber noch einmal auf den Kasusrahmenunterschied, von dem schon im ersten Beispiel die Rede war.

(3) What tells the growth cone where to go?

AV: Was sagt der Wachstumszone, wo es hingeht?

ZV: Wodurch wird dieses Wachstum gesteuert?

Aus der Perspektive des Deutschen sieht das englische Original wie eine Metapher aus. Sicher können wir da aber nicht sein; wir kennen bereits die größere thematische Freiheit englischer Subjekte, und deutsche Sätze wie Die Kiste enthält Schrauben würden wir ja auch nicht als Stilfiguren ansehen wollen. Der Personifizierungseffekt in AV mag also eine Interferenzerscheinung sein, ungewollt und zugunsten neutraler Varianten aufzugeben. Dies ließe sich allerdings auch schon mit einem wesentlich weniger aufwendigen Schritt erreichen:

IV: Was steuert die Wachstumszone?

So verkürzt, mißfällt uns das Ergebnis fast noch mehr - die Zielvariante ist tatsächlich um ebenso viel besser wie sie aufwendiger ist. Der Präferenzunterschied betrifft den alternativen Kasusrahmen und die Fokusverteilung zugleich. In IV stehen die beiden Fokusträger des Satzes Fragewort und Verb - zusammen auf der linken Seite. Die Passivierung bietet nicht nur ein Kausaladverbial anstelle des Subjekts am Satzanfang sondern auch eine ausgewogenere Verteilung der beiden Foki, am Anfang und Ende des Satzes.

Diese Variante steht dem Englischen grammatisch zur Verfügung, aber nicht, um die stilistisch ebenso wenig überzeugende Rückübersetzung von IV zu verbessern:

R-IV: What regulates this growth?

$\mathrm{R}-\mathrm{ZV}$ : What is this growth regulated by?

Die passivierte Variante würde zwar eine ausgewogene Verteilung der Foki gewährleisten - sie stellt aber, vor allem wegen der Kasusrah- 
menpräferenzen für aktive Subjektanfänge im Englischen, eine deutlich aufwendigere Form dar als im Deutschen.

Wie der Vergleich mit dem Originalsatz zeigt, läßt sich das Gleichgewichtsprinzip mit dem eines minimierten Verarbeitungsaufwands durch eine explizitere, eine Teilsatz-Lösung besser in Einklang bringen. In:

(3) What tells the growth cone where to go?

hat jeder Fokusträger: what/where seinen eigenen Teilsatz und der präferierte aktive Subjektanfang ist ebenfalls gewährleistet. Selbst wenn es sich beim Original um eine Metapher handeln sollte, trägt diese auf jeden Fall dazu bei, den beiden Stilprinzipien im Rahmen einer konfigurationellen SVO-Sprache gerecht zu werden. ${ }^{12}$

Wie die Beispieldiskussion zeigt, ist der Weg zu einer ausformulierten allgemeinen Theorie der vergleichenden Stilistik noch weit. Dies umso mehr, als die angenommene Interaktion von universellen Stilprinzipien und grammatischen Parametern eine voll ausformulierte Prinzipien- und Parameter-Grammatik voraussetzt. Daran wird aber in der Linguistik immer noch gearbeitet und da die Ansätze laufend revidiert werden, sind bisher nur Teilmodelle im Angebot. Dennoch kann man auch mithilfe solcher Teilmodelle, so man sie wirklich zur Kenntnis nimmt, ein gutes Stück weiter kommen bei dem Versuch, den blinden Fleck zwischen Linguistik und Stilistik zu beseitigen.

12 Da Metaphern einen Text 'auflockern' und über ihre Bildhaftigkeit lesbarer, weil abwechslungsreicher, machen, bieten sie über den Aspekt grammatisch parametrisierter Verarbeitbarkeit hinaus Vorteile, die es zu nutzen gilt. Aber selbst hier machen sich die grammatisch bestimmten Prăferenzunterschiede bemerkbar, etwa wenn dem Subjekt- ein Adverbialanfang und der aktivischen eine - mit dem Perzipienten im Subjekt - eher passivische Perspektive vorgezogen wird:

(i) Was sagt der Wachstumszone, wo es hingeht?

(ii) Wie erfährt die Wachstumszone, wo es hingeht?

(zur Präferenz einer passivischen Perspektive vgl. Doherty 1994). Aussagen über die Interaktion zwischen der allgemeinen, grammatisch basierten stilistischen Kompetenz und anderen, markierten Bereichen unserer stilistischen Fāhigkeit setzen allerdings detailliertere Annahmen als die in diesem Beitrag skizzierten voraus. 


\section{Literatur}

Abraham, Werner (1992): Structural properties of information packaging in German and in universal grammar. In: Groninger Arbeiten zur germanistischen Linguistik 35, S. 37-71.

Altmann, Gerry (1989): Parsing and interpretation. In: Language and Cognitive Processes 4, S. 1-19.

Czepluch, Hartmut (1992): Non-Configurational Properties in a Configurational Language: The Case of English. In: Tracy, Rosemarie ( $\mathrm{Hg}_{\mathrm{g}}$ ): Who Climbs the Grammar-Tree. Tübingen. S. 339-373. (= Linguistische Arbeiten 281).

Doherty, Monika (1994): Passive perspectives; different preferences in English and German - a result of parametrized processing. Berlin. (= Arbeitsbericht zum DFG-Projekt 'Parametrisierte Perspektive').

Drubig, Bernhard (1993): Locality and licensing in the grammar of focus. Tübingen. (= Arbeitsbericht zum Teilprojekt A 4 des SFB 340 'Sprachtheoretische Grundlagen für die Computerlinguistik').

Enzensberger, Hans Magnus (1988): Erinnerung an die Zukunft. Leipzig.

Fukui, Naoki (1993): Parameters and Optionality. In: Linguistic Inquiry 24, 3, S. 399-420.

Haider, Hubert (1993): Deutsche Syntax - generativ. Tübingen. (= Tübinger Beiträge zur Linguistik; 325).

Jacobs, Joachim (1991-92): Neutral Stress and the Position of Heads. In: Linguistische Berichte, Sonderheft 4, S. 220-244.

Levelt, Willem (1989): Speaking: From Intention to Articulation. Cambridge, Mass./London.

Nunberg, Geoffrey (1990): The Linguistics of Punctuation. Stanford. (= CSLI Lecture Notes 18).

Sperber, Dan/ Wilson, Deirdre (1986): Relevance. Cambridge.

Vallduvi, Enric (1993): Information packaging: A survey. Edinburgh. (= Research Paper HCRC/RP-44).

Wunderlich, Dieter/Stechow, Arnim von (Hg.) (1991): Semantik. Berlin/New York. (= Handbücher zur Sprach- und Kommunikationswissenschaft; Bd. 6). 


\section{Stile in interkulturellen Begegnungen*}

\section{Zum Begriff Stil}

Das in letzter Zeit rege Interesse an Kulturunterschieden hat viele wichtige Ergebnisse über Unterschiedlichkeiten im Kommunikationsverhalten zwischen verschiedenen Kulturen und ethnischen Gruppen an den Tag gebracht. Die Kehrseite der Medaille bei der Beschäftigung mit Kulturunterschieden ist jedoch, daf alte, vorhandene Stereotype verfestigt und neue geschaffen werden. Die Gefahr der Übergeneralisierung ist groß: Die Vielfalt der kommunikativen Stile innerhalb einer Gesellschaft tendiert zu verschwinden, wenn der globale Vergleich in den Blick rückt: Die Verallgemeinerung zu einem "nationalen Typ" (der Deutsche/der Finne) läßt alle übrigen Eigenschaften sozialer Gruppen wie Geschlecht, Alter oder Schichtzugehörigkeit in den Hintergrund treten oder ganz verschwinden.

Die Typisierung der Stile impliziert zum einen Stilvergleich, zum anderen das Hervorragen bestimmter Stilzüge, die in interkulturellen Kontakten Fremdheitserlebnisse hervorrufen und somit für den interkulturellen Vergleich als relevant angesehen werden können. Dabei erscheint der kulturspezifische Stil als ein Komplex, dessen einzelne Elemente den Interaktionsteilnehmern oft unbewußt bleiben. Der intuitive Gesamteindruck von kulturspezifischen Eigenschaften ist oft, wie in Stereotypen ausgedrückt, einfach und klar, wenn aber einzelne Ausschnitte der Realität näher untersucht werden, wird das Bild komplexer und die Abgrenzungen werden unschärfer.

Die Phänomene, die in Untersuchungen zu interkultureller Kommunikation als eventuelle Störquelle der Interaktion identifiziert worden sind, reichen von verschiedenen sprachlichen Ebenen bis zum nonverbalen Verhalten. Beispielsweise hat man folgende kulturbedingte Unterschiede festgestellt:

- in der Art der „Verpackung” von Informationen (u.a. Günther 1993)

- in der Realisierung von Sprechhandlungen (u.a. Blum-Kulka/House/ Kasper 1989, Muikku-Werner 1993)

- in den Regeln für Nähe und Distanz, beim Ausdrücken von Höflichkeit (u.a. Barnlund 1975, Pavlidou 1994)

- Für viele hilfreiche Kommentare danke ich Ewald Reuter, Mitarbeiter des Projektes „Deutsch-finnische Kulturunterschiede in der Wirtschaftskommunikation". 
- in der Behandlung von Nichtübereinstimmung (u.a. Byrnes 1986, Kotthoff 1989)

- in der Organisation der Interaktion, wie im Sprecherwechsel, im Hörerverhalten und im Blickkontakt (u.a. Erickson/Shultz 1982, Tannen 1984)

- und in den Diskursmustern (u.a. Gumperz/Roberts 1991, Günther 1993).

Ethnischer bzw. kultureller Stil kann mit den kulturspezifischen Kommunikationsformen gleichgesetzt werden, die auch die zugrunde liegenden Normen, Konventionen und Muster der jeweiligen Kultur umfassen. Was jedoch bei der Typisierung der Stile nicht berücksichtigt wird, ist der dynamische Charakter des Stils - daB Stile nicht etwas vorher Festgelegtes sind, sondern wie Selting und Hinnenkamp $(1989$, S. 6) betonen, „in der Situation selbst immer wieder erneut hergestellte, gegebenenfalls modifizierte und auf den Rezipienten zugeschnittene Mittel der Signalisierung und Herstellung gemeinsam geteilter, relevanter sozialer und interaktiver Bedeutungen". Dies beinhaltet nicht nur Bestätigung, sondern auch Veränderung und Auflösung der Normalformen. ${ }^{1}$

Kulturspezifischer Stil bedeutet, daß verschiedene Kulturen unterschiedliche Mittel und Verfahrensweisen zur Lösung der Anforderungen der kommunikativen Aufgaben benutzen bzw. bevorzugen. Andererseits werden mit diesen Lösungsstilen kulturelle Zugehörigkeit und Differenzen immer wieder konstituiert, wobei also der Begriff Kultur nicht auf nationale Kulturen beschränkt bleibt, sondern auch verschiedene Teilkulturen innerhalb einer Gesellschaft umfaßt.

\section{Stilisierung und Vorstellungen von Stilen}

Typisierte Stile sowie Vorstellungen und Normen in bezug auf das Eigene und Fremde sind nicht mit dem faktischen Verhalten in einer konkreten Situation gleichzusetzen, das sich von den Typisierungen und Idealisierungen stark unterscheiden kann. Dennoch sind die Vorstellungen häufig Bestandteile des Interpretationsschemas bei interkulturellen Kontakten und somit relevant.

Sandig (1986, S. 24,61) hat festgestellt, daß Urteile über Stil häufig wertend sind, und daß dieses Bewerten zum Teil nach verschiedenen gruppenspezifischen Wertmaßstäben geschieht. Dies gilt insbesondere für ethnische Stile, wobei das andere, von den eigenen Stilnormen abweichende Verhalten tendenziell negativ bewertet wird. Darüber hinaus wird der

1 Siehe genauer Kallmeyer (1994). 
beschriebene Stileffekt, der durch unterschiedliche Kommunikationskonventionen hervorgerufen ist, leicht auf nationale und persönliche Charakteristika des anderen zurückgeführt.

Befragungen zu Kulturunterschieden bringen nicht unbedingt tatsächliche Verhaltensweisen zum Vorschein, können aber aufweisen, welehe Erscheinungen als fremd empfunden werden und welches die Leitbilder sind, an denen sich die Interaktionspartner orientieren und nach denen sie das zu beobachtende Verhalten interpretieren und bewerten. Als Beispiele für Vorstellungen über kulturspezifische Stile möchte ich nun Auszüge aus Interviews mit deutschen und finnischen Geschäftsleuten anführen und danach auf die Frage eingehen, welche Stilzüge hinter den Bewertungen stehen und zur Konstituierung des Stils beitragen können.

\subsection{Anredeverhalten}

Wenn nach Kulturunterschieden zwischen Deutschen und Finnen gefragt wird, ist eine der häufigsten Antworten, daß der gröBte Unterschied die Förmlichkeit sei: Deutsche seien formell, hierarchisch, Finnen dagegen weniger formell, sogar demokratisch (dies bezieht sich vor allem auf das Verhalten in Betrieben). So drückte ein deutscher Befragter dies aus: ${ }^{2}$

2 Die Interviews stammen aus dem Korpus des Projekts "Deutsch-finnische Kulturunterschiede in der Wirtschaftskommunikation". Um die Formulierungsarbeit beim Sprechen über Kulturunterschiede zu verdeutlichen, sind die Interviewausschnitte in möglichst authentischer Form wiedergegeben.

Transkriptionserläuterungen:

(.) ganz kurzes Absetzen innerhalb einer Äußerung

/// kurze Pause, längere Pause

ein: Dehnung

.,=' fallende, leicht fallende, gleichbleibende, steigende Intonation

dumm auftallige Betonung

(...) unverständlich

A... Auslassung

$>\quad$ schneller

$<\quad$ langsamer

$<<>$ auftällige Prosodie

SIE lauter

[] gleichzeitiges Sprechen

Die Sprecher sind wie folgt markiert: $I=$ Interviewer/in, $B=$ Befragte/r, $d=$ deutsch, $f=$ finnisch. 
(1)

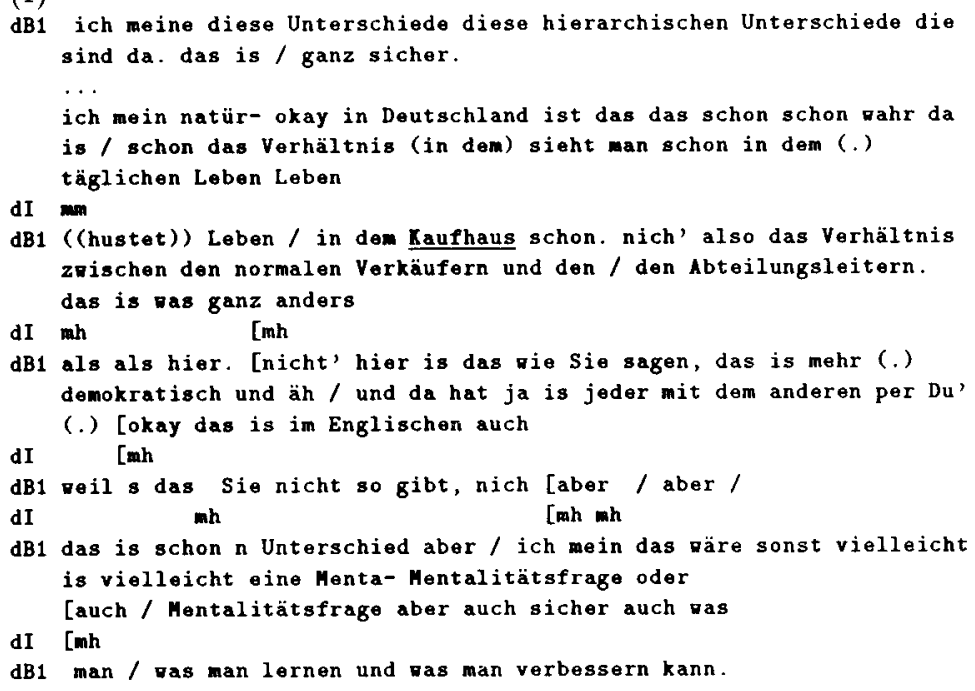

Hierzu noch zwei finnische Meinungen:

(2)

fB1 das is ihre// ihre gevisse / steifheit dort / dort also // äh im Büroleben grad daß man im gleichen Zimmer zranzig Jahre sitzt und sich siezt

fB2 das ist schon sehr hierarchisch all diese Zeremonien ... nun das vird ja auch natürlich sicherlich freier/geht die ganze Zeit in diefreiere Richtung / aber es ist doch / ganz deutlich / steifer als hier also all diese äußeren formen .....

... grad dieses Siezen und dieses ganze äußerliche / äußerliche Anreden und ... das ist immer Herr sehr geehrter Doktor und Herr Doktor

Wertungen wie 'förmlich' und 'hierarchisch' werden vor allem mit den Unterschieden im Anredeverhalten (in Deutschland wird im allgemeinen gesiezt, in Finnland geduzt) begründet, was wiederum mit der Mentalität verbunden wird. Das andersartige Verhalten ist auffällig und wird durch die eigenkulturellen Normen interpretiert, in diesem Fall dadurch, welche Bedeutung die jeweilige Anredeform im eigenen System hat. Dabei wird jedoch übersehen, daß die ungefähr gleichen grammatischen Formen in den beiden Sprachen funktional gar nicht äquivalent sind, sondern soziale Beziehungen unterschiedlich markieren. Das finnische Du hat einen viel weiteren Anwendungsbereich als das deutsche Du. Umgekehrt verhält es 
sich mit Sie: Das deutsche Sie kann auch in vielen persönlichen Situationen verwendet werden, das finnische dagegen nicht, weil es immer hohe Distanz und Förmlichkeit oder aber eventuell auch Altersunterschied signalisiert. Hinzu kommt, daß es neben den Pronomina auch andere Mittel, sprachliche und nicht-sprachliche, zur Markierung von Distanz und Nähe gibt (im Finnischen z.B. Vermeidung der Anrede).

Die Fehlinterpretation der Anredeformen führt nicht nur zur Typisierung, sondern kann auch das Mißverstehen der Kommunikationsabsichten des Gesprächspartners zur Folge haben, wie ein deutscher Befragter gemerkt hatte:

(3)

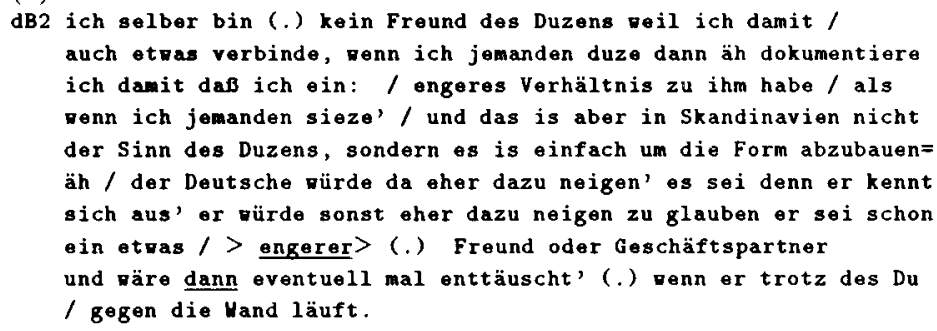

Zum Eindruck der Förmlichkeit der Deutschen trägt finnischerseits neben den Anredeformen auch die unterschiedliche Namensverwendung bei. Wie das vorhin gegebene Zitat (2) andeutet, empfinden Finnen solche deutschen Anredeformen wie Herr Müller oder Herr Dr. Müller als sehr formell. Der Unterschied liegt zum einen in der Häufigkeit der Namensnennung, zum anderen im Gebrauch des Titels. Im Deutschen dient die Namensnennung u.a. der Kontaktherstellung, der Adressierung, der Segmentierung des Gesprächs, der Regelung von Nähe und Distanz sowie der Indizierung von Höflichkeit. ${ }^{3}$ Im Finnischen scheint die Namensverwendung viel eingeschränktere Funktionen zu haben, in erster Linie dient sie dem Aufmerksamkeitsappell. ${ }^{4}$

\subsection{Gesprächsstile}

Ein weiterer wichtiger Punkt, der in den Interviews häufig zu Sprache gebracht wurde, sind die Gesprächsstile. Als finnische und deutsche Geschäftsleute nach Unterschieden in Verhandlungsstilen gefragt wurden, beschrieben sie die Eigenschaften oft mit nicht-sprachlichen Merk-

\footnotetext{
3 Siehe genauer Schwitalla (1994).

4 Zur Namensverwendung im Finnischen siehe Yli-Vakkuri (1989).
} 
malen. Für die Wahrnehmung der Stilunterschiede zunächst ein paar finnische Beispiele:

(4)

fB3 der Deutsche ist / vielleicht schon etras aggressiver und dann geht er so furchtbar viel in die Details, der kann also schon so lange darauf herumreiten, das das bei uns / den entsprechenden / Verhandlungspartnern, denen geht das dann manchmal schon etras auf die Jerven

Ein wesentlicher Unterschied bestand also für finnische Befragte darin, wie eingehend Argumente begründet werden. Hierzu noch eine sehr bildhafte Beschreibung eines finnischen Befragten, in der er den skandinavischen Stil mit dem deutschen vergleicht:

(5)

fB4 es gibt ja immer noch deutliche Kulturunterschiede

fD $m h$

fB4 also das ist ja so unvahrscheinlich viel leichter mit Schveden und / Dänen CGeschäfte zu machen. /

fD $\quad$ man

fB4 also [ganz bestimnt

fI [als zum Beispiel mit rem? [mm

fB4 als zum Beispiel sagen vir mal mit irgendzelchen / Italie[nern oder // oder auch venn wir da keine Schoierigkeiten [gehabt haben

$\mathbf{f} \mathbf{I}$

fB4 aber [doch also / auch sogar mit Deutschen, $/$ und also renn f I [unterschiedlich $\mathrm{mm}$

fB4 // man nun nach Schreden telefoniert dann / geht das mit einem Satz / so / beide sagen also okay und dann / ist die sache erledigt. /

[un un den Deutschen] muß man's erklären / erklären ist also

fI [gibt, s hier Unterschiede (...)]

fB4 das Wenigste was man tun muß auch venn es noch so ein alter Kumpel ist also/ also dem mus man zumindest sagen / in zehn Sätzen

fI mun

fB4 daß / daß ich das heute vill und nicht / nächste Woche.

fI $\mathrm{mm} m \mathrm{~mm}$

fB4 und warum ich das heute will / und warum ich das ausgerechnet um drei Uhr haben will und ger denn das warun auch überhaupt haben [rill und so veiter. ((lacht))

fI $[($ (1acht $))$

$f$ man wuß grün[dlich sein

fB4 [ja man muß Gründe haben ((lachend:)) immer ja.

$\ldots \ldots$

fB4 und voran bei uns meistens / viele Sachen scheitern, ist daß man meint, das ist ja selbstverständlich. das kommt einem so dumm

$\mathbf{f} \mathbf{I}$ $\mathrm{mm}$

fB4 vor / also nach unserer / unserer Mentalität / daf zrei Fachleute Begründungen für etras [suchen / pas eigentlich klar [ist.

fB4 aber dort gehört das dazu. du mußt [das so machen] venn du 
fI

fB4 [vorankommen rillst.

fI $[\mathrm{mm}$

Ein paar Bemerkungen zur Formulierungsweise: Unterschiede werden häufig als etwas Negatives empfunden. So ist es typisch, daß die Befragten, wenn sie Unterschiede feststellen, eine negative Interpretation der Aussage in Abrede stellen (wir haben da keine Schwierigkeiten ge$h a b t)$. Das Lachen im obigen Beispiel ist wohlwollendes Lachen, weniger über den Stil der anderen, eher vielleicht über die eigene Darstellungsweise, insbesondere ist es aber hier ein Mittel, Gemeinsamkeit, kulturelle und situative Zusammengehörigkeit aufzubauen.

Das Beispiel macht deutlich, daß Stereotype kaum vermeidbar sind, wenn über Kulturunterschiede gesprochen wird. Kommunikationsunterschiede tragen zur Stereotypisierung bei, und sie werden andererseits mit Stereotypen erklärt, wie aus der Äußerung der Interviewerin (man muß gründlich sein) zu ersehen ist: Deutsche untermauern ihre Argumente mit detaillierten Begründungen, weil sie gründlich sind.

Nehmen wir nun hierzu eine deutsche Perspektive, aus der die Gründlichkeit des Formulierens etwas anders aussieht:

(6)

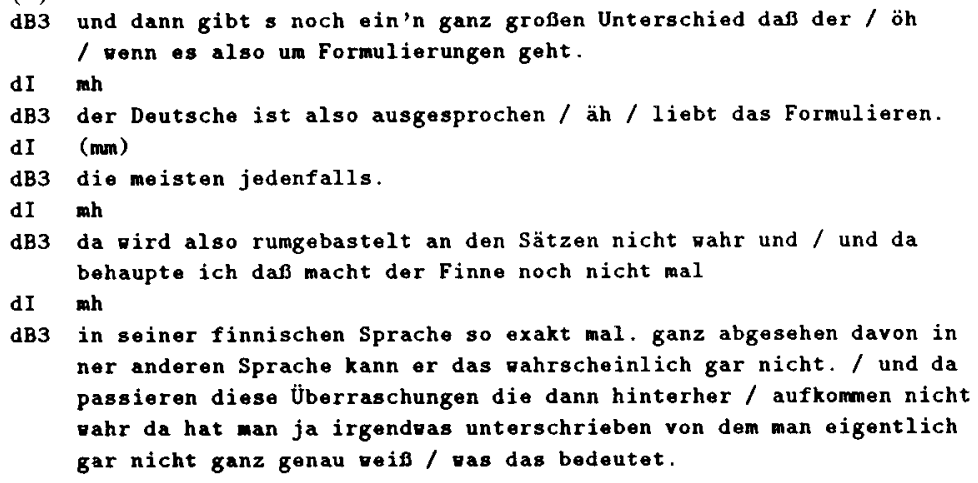

Unterschiedliche Stile können also zu Mißverständnissen führen und schlimmer noch - darüber hinaus Folgen für die sozialen Beziehungen haben. Wenn ein Finne z.B. in einer Geschäftsverhandlung von einem Deutschen zu einem Auftrag überredet wird, kann die Stilwirkung sein, wie ein lange in Finnland lebender deutscher Befragter dies ausdrückte, daß sich der Finne als „in die enge Ecke gedrängt” fühlt. Wenn aber der Kommunikationsstil des deutschen Partners von Finnen als aggressiv und rechthaberisch empfunden wird, so kann umgekehrt die Stilwirkung 
des finnischen Verhaltens bei Deutschen genau so negativ sein, so da $\beta$ Finnen als indirekt, zurückhaltend, wenig aktiv, vielleicht auch zu wenig involviert angesehen werden. Auch die sehr komplexe Frage, wie Direktheit und Indirektheit zum Ausdruck gebracht werden, trägt zu dieser Typisierung bei. Vgl.:

(7)

dB4 also ich habe // relativ venig Finnen / erlebt die

/ ha- ((räuspert sich)) Entschuldigung die hart / verhandeln oder oder sagn wir mal auch bereit sind das Risiko zu laufen und in ner Verhandlung dab / der Verhandlungspartner oder Gegner je nachden / plötzlich aufsteht und sagt $<<$ so. / also / das var s dann. $>>/$ das is im Grunde immer so $n$ bißchen / sehr diplowatisch / äh nicht zu stark festlegend immer eher erst mal zustimen und / dann / äh sehen vas / vie man so an die Sache an Schluß dann / erretten kann.

dI $m$

dB4 es is eigentlich ich hab selten erlebt daß jemand sagt nein also das is wirklich völlig / indiskutabel. da brauchen vir gar nicht erst darüber sprechen. / so was hab ich in Finnland noch nicht gehört es is dann $<<$ ja ah ja mh / ja aber vergleichsweise ist das ja doch / ziemlich // na ich will nicht sagen schlecht aber / da liegen wir doch sehr niedrig vergleichsqeise $=>>$ so das [geht so $n$ bibchen

dI

dB4 (.) freundlich [äh] diplomatisch // und

dI [mm] auch weniger zielgerichtet (also) ruhig oder?

Die unterschiedlichen Verhaltensweisen der Deutschen und Finnen werden in diesem Auszug nicht nur verbal, sondern auch prosodisch beschrieben: deutsche Ordentlichkeit durch straffe Intonation, finnische Laxheit durch Dehnungen. Die Reaktion des Interviewers am Ende des Ausschnitts zeigt, wie man die nun beschriebene Art von Indirektheit aus der Fremdperspektive negativ interpretieren und bewerten kann: freundlich, diplomatisch, also weniger zielgerichtet.

Es ist schwer zu sagen, inwieweit es faktische Unterschiede in der Direktheit, Explizitheit und in der Art der Konfliktausstragung zwischen den finnischen und deutschen Kommunikationsstilen im geschäftlichen Bereich gibt, so wie die Aussagen der Befragten vermuten lassen. Dazu fehlt es uns einfach am empirischen Material von Situationen, in denen die Befragten ihre Erfahrungen machen. Eine Vergleichsmöglichkeit bieten jedoch Geschäftsbriefe, bei denen die Ausdrucksformen stark konventionalisiert sind und die deutliche Unterschiede in den Konventionen 
aufweisen. Um diese Unterschiede zu veranschaulichen, haben Honkavaara, Kuronen, Ojanen und Steuer (1992) ein finnisches Original, eine Antwort auf eine Reklamation, ins Deutsche, Französische und Russische übertragen, wobei sie den entsprechenden Konventionen und Gepflogenheiten der jeweiligen Sprache und Kultur gefolgt sind. Der finnische Originalbrief, eine wörtliche Übersetzung sowie die deutsche und französische Fassung befinden sich im Anhang. In den Übertragungen sind die ÄuBerungen, die im finnischen Original fehlen, fett gedruckt, und die unterstrichen, die im Finnischen $z$ war enthalten, aber ein bißchen anders formuliert sind.

Vergleicht man die verschiedenen Fassungen, so fält zunächst auf, daß der finnische Brief kürzer ist als der deutsche und der französische. Honkavaara et al. stellen fest, daB die finnische Geschäftskorrespondenz zur kurzen Ausdrucksweise zu tendieren scheint, während in den anderen Sprachen zum einen mehr Höflichkeitsphrasen enthalten sind, zum anderen der Anteil der werbenden und zukunftsorientierten Äußerungen größer ist. Hinzu kommt, daß der deutsche und der französische Brief mit Hintergrundinformationen beginnen, während die Verfasserin des finnischen Briefes von einem gewissen AusmaB gemeinsamen Wissens ausgehend sofort zur Sache kommt. Der finnische Brief enthält somit auch weniger explizite Informationen. Weitere Unterschiede sind beim Ausdrücken von Bedauern und Dank zu finden. In allen Briefen wird Bedauern zum Ausdruck gebracht, im deutschen und französischen jedoch viel wortreicher als im finnischen. Nach Honkavaara et al. wäre eine solche Einräumung wie Sie haben Recht in einem finnischen Brief unüblich: Die Tatsache wird festgestellt, und daraus geht hervor, daß der Kunde mit seiner Beanstandung Recht gehabt hat. Auch der Dank dafür, daß der Lieferant über den Fehler informiert wurde, ist im finnischen viel kürzer formuliert als in dem deutschen oder dem französischen Brief.

Um herauszufinden, ob es tatsächlich Unterschiede in den Argumentationsstilen gibt, können wir auch öffentliche Diskussionen in die Analyse einbeziehen, die jedoch ganz anderen Normen unterliegen als nichtöffentliche Geschäftsverhandlungen. An diesen läßt sich jedoch u.a. untersuchen, wie direkt Nichtübereinstimmung zumı Ausdruck gebracht und inwieweit Dissens in der Öffentlichkeit toleriert wird.

Hierzu möchte ich einen Vergleich einer finnischen und einer deutschen Fernsehdiskussion und exemplarisch einige Stilzüge darstellen, die zu der Vorstellung „aggressiv” bzw. „zurückhaltend" beitragen können. Im Anhang ist ein längerer Auszug aus beiden Diskussionen wiedergegeben, die die zu behandelnden Eigenschaften verdeutlichen. Der äußere Kontext 
war in beiden Diskussionen sehr ähnlich: ein Moderator und 4 bzw. 5 Teilnehmer diskutieren über das Thema „Asylanten”. Im Ablauf wiesen die Diskussionen jedoch deutliche Unterschiede auf.

In der deutschen Diskussion (s. Auszug 1 im Anhang) wurde explizit für die eigene Meinung und gegen die Positionen der anderen Teilnehmer argumentiert. In der finnischen Diskussion schienen sich dagegen alle Teilnehmer einig zu sein, obwohl sie ursprünglich verschiedene Positionen vertraten; persönliche Stellungnahmen wurden weitgehend vermieden bzw. sehr vorsichtig formuliert. Sprachliche Mittel der Indirektheit waren u.a. die Vermeidung des direkten Bezugs auf die Partneräußerung und auf den Gesprächspartner (s. Auszug 2 im Anhang). So wurde z.B. statt der direkten Anrede die 3. Person verwendet, vgl. Eero (Vorname des Bürgermeisters einer kleinen Stadt, die die Aufnahme von Asylanten verweigert hatte) erzählte von diesem ihrem Beschluß ...daß da ziemlich viel Gefühl dabei ist bei diesem Beschluß statt Sie haben rein emotional beschlossen. Der Vermeidung des direkten Bezugs dienten auch generische Formen (man, wir), die das Gesagte mit anderen Abschwächungen (sollte, meiner Meinung nach) abmilderten. Dies zeigt, wie in einer Sprache, in der ein Anredepronomen (das Du) einen sehr weiten Anwendungsbereich hat, mit anderen sprachlichen Mitteln Distanz geschaffen werden kann.

Auch wenn man aufgrund dieser beiden Diskussionen keine Verallgemeinerungen treffen kann, so weisen diese Belege doch in die gleiche Richtung, wie sie u.a. aus den Untersuchungen von Kotthoff (1989) und Byrnes (1986) über deutsch-amerikanische Argumentationsstile hervorgeht. So hat Kotthoff festgestellt, da $B$ in Deutschland eine relativ starke Markierung von Dissens in vielen Situationen als weniger problematisch empfunden wird als in einigen anderen Kulturen, z.B. in den USA.

Zum Eindruck der unterschiedlichen Involviertheit bzw. Konfrontationsbereitschaft tragen in der analysierten finnischen und deutschen Diskussion sehr stark die Prosodie, d.h. Intonation, Lautstärke, Sprechrhytmus und -tempo, sowie die Gestik bei. Prosodische Eigenschaften scheinen sich im übrigen sehr stark auf die kulturelle Stilwahrnehmung auszuwirken (vgl. Beispiel 7) und sind auch eine der wichtigsten Ursachen für interkulturelle Mißverständnisse.

In der deutschen Diskussion kamen häufig Überlappungen und Unterbrechungen vor (vgl. Auszug 1). In der finnischen waren sie dagegen kaum zu finden, da die Redeverteilung und Themenentwicklung dort sehr stark vom Moderator gesteuert wurden (vgl. Auszug 2). Andererseits waren die einzelnen Redebeiträge kürzer als in der deutschen Diskussion. Der in 
dem finnischen Gespräch beobachtbare Gesprächsrhytmus muß an sich nicht unbedingt dem kulturspezifischen Stil zuzuschreiben sein: Er kann nämlich auch als eine Strategie der Vermeidung von Dissens dienen.

Ein weiterer Unterschied zwischen den beiden Diskussionen ergab sich daraus, daB die Deutschen häufiger und zum Teil sehr direkte metakommunikative Äußerungen über ÄuBerungen der anderen Teilnehmer verwendeten (z.B. da liegen Sie falsch; da sind wir uns einig, das muß man zunächst sagen; das ist doch ne Scheindiskussion; das sollte man 'n bißchen fairer diskutieren; gehen Sie doch bitte auf die Frage ein ... und auch längere Sequenzen: Ich finde das ne ziemlich ärgerliche Sache, daß man hier diejenigen, die für diese Partei den Kopf hinhalten und für sie auch arbeiten und versuchen das umzusetzen, die von den Mitgliedern dieser Partei gewählt worden sind und zwar auf Mitgliederversammlungen, daß man die so anredet und denunziert, ich finde das keine gute Umgangsart, ich muß das offen sagen.). In der finnischen Diskussion waren solche Äußerungen kaum zu finden. Auch metakommunikative Äußerungen über die Redeverteilungen kamen in der deutschen Diskussion häufiger vor (z.B. also es reicht doch jetzt; lassen Sie ihn doch mal zu Ende reden; gut aber darf ich da jetzt mal nachfragen). Beide Arten der Metakommunikation bringen die vorhin erwähnten Unterschiede in der Argumentation und im Gesprächsrhytmus deutlich zum Ausdruck.

Der Begriff Stil impliziert Wahl, Alternativen. Auch bei kulturspezifschen Stilen handelt es sich häufig um Präferenzen bei der Auswahl der Mittel. So hat z.B. Muikku-Werner (1993) in ihrer Untersuchung über die Realisierung solcher gesichtsbedrohenden Sprechhandlungen wie Aufforderungen und Fragen in deutschen und finnischen Fernsehdiskussionen festgestellt, daB sich die beiden Sprachen trotz der strukturellen Unterschiede wenig in den verwendeten Strategien unterschieden. Das heißt, daß es kaum Mittel gab, die nur in der einen Sprache zu finden gewesen wären, nicht aber in der anderen. Die Unterschiede waren in der Präferenz der einzelnen Strategien zu finden. So wurden im Deutschen mehr analytische Strategien (d.h. lexikalische Mittel wie z.B. Abtönungspartikeln, Gebrauch des Sie sowie verschiedene konventionalisierte Höflichkeitsphrasen) verwendet, im Finnischen dagegen synthetische Strategien (wie z.B. Gebrauch des Konjunktivs/Konditionals, des sog. Höflichkeitsimperfekts und des Passivs sowie Vermeidungsstrategien der direkten Anredeformen).

\section{Interkulturelle Kontaktsituationen}

Kulturspezifische Stile können untersucht werden, indem Konventionen und Muster zunächst in verschiedenen Kulturen analysiert und die Er- 
gebnisse dann miteinander verglichen werden, wie es z.B. von der kontrastiven Pragmatik gemacht wird. Aber auch wenn wir auf diese Weise ethnische Stile erfassen können, können wir aus dem Vergleich nicht erschließen, was in interkulturellen Kontaktsituationen geschieht.

In interkulturellen Begegnungen scheinen häufiger Probleme zutage zu treten als in intrakulturellen Kontakten. Die Störungen liegen darin, daB Angehörige verschiedener Kulturen in interkulturelle Kontaktsituationen mit unterschiedlichen kommunikativen Konventionen und Hintergrundwissen kommen, was zu unterschiedlichen Handlungsweisen und ihrer Interpretation führt. Stil bedeutet nicht Alternativen mit gleichbleibenden Bedeutungen, sondern mit unterschiedlichen Stilen werden soziale Bedeutungen unterschiedlich signalisiert und hergestellt. Hinzu kommt, daß der Stil für die Mitglieder der Gruppe häufig den Status von selbstverständlichen und stillschweigenden Voraussetzungen hat. ${ }^{5}$ Mißverständnisse, die durch unterschiedliche Kommunikationskonventionen entstehen, werden von den Interagierenden vielfach gar nicht als solche wahrgenommen, sondern die Erlebnisse werden der Persönlichkeit des anderen zugeschrieben. Gumperz (u.a. 1982, 1992) hat anschaulich gezeigt, wie die Verwendung unterschiedlicher kommunikativer Kodes, verschiedener Kontextualisierungshinweise zu Störungen und Fehlinterpretationen und sogar bis zur Diskriminierung ethnischer Minderheiten insbesondere in bestimmten Schlüsselsituationen wie z.B. in Jobinterviews führen kann.

Die Auffassung, daß interkulturelle Kontakte fast unausweichlich zu Konflikten führen, liegt vielen interkulturellen Trainingsprogrammen zugrunde, in denen insbesondere für sog. critical incidents sensibilisiert wird, wobei zunächst über irgendwie auffallige Begegnungen mit einer fremden Kultur berichtet wird, die dann mit der Maßgabe interpretiert werden, kulturbedingte Verhaltensregeln zu erkennen und zu erlernen. Die Auffassung "des Zusammenstoßes der Kulturen" wird jedoch u.a. von Blommaert (1991, S. 20) stark kritisiert, weil dabei die Kultur als monolitisch und undifferenziert gesehen wird. Im Sinne der critical incidents ist immer die Kultur das Ausschlaggebende. Jedes Merkmal der Kommunikation wird ihr zugeschrieben, wodurch sie auch allein verantwortlich ist für jegliches kommunikatives Mißlingen. Alternative Erklärungsmöglichkeiten geraten erst gar nicht ins Blickfeld. Folglich ist die Beherrschung der fremdkulturellen Handlungsregeln für kommunikatives Gelingen $z$ wingend. Ein weiterer Fehlschluß ist nach Blommaert die

5 Vgl. Kallmeyer (1994). 
Annahme, daß sich der Interaktionspartner der Situation nicht anpaßt und daB er sich immer benimmt wie ein typischer Vertreter seiner Kultur.

Wenn sich Angehörige zweier Kulturen treffen, ist das Auftreten von Fehlinterpretation und Störungen der Interaktion jedoch nur eine Möglichkeit. In der schriftlichen Kommunikation, in der die unmittelbare Interaktion fehlt, ist dies sicher der Fall, wenn unterschiedliche Stile nicht berücksichtigt werden. Ein Geschäftsbrief, der den Konventionen des Empfängers nicht entspricht, erfüllt kaum die beabsichtigte Funktion.

Ebenso gut wie in intrakulturellen Interaktionen sind auch in interkulturellen Begegnungen Anpassungen und Angleichungen der Stile möglich. Die Untersuchung von Erickson und Shultz (1982) zeigt, daß ein Angleichungsproze $B$ zwischen den Interaktionsteilnehmern möglich ist, wenn anstelle der Ethnizität etwas Gemeinsames in den Vordergrund rückt, so daß der Partner als ein Individuum mit gleichen Interessen gesehen wird und nicht in erster Linie als Vertreter einer ethnischen Gruppe.

Aber auch wenn Mißverständnisse auftreten, sind sie nicht unbedingt irreparabel, sondern können u.a. durch metakommunikative Reparaturmechanismen aufgeklärt und ausgeräumt werden.

Als Beispiel für eine interkulturelle Situation und ihre Analyse sei ein Ausschnitt aus einer finnisch-deutschen Verhandlung vorgeführt. ${ }^{6}$ Es handelt sich um eine Besprechung in der Lufthansa-Niederlassung in Helsinki, bei der ein finnischer Student mit dem deutschen Geschäftsleiter über einen Gruppenflug nach Deutschland verhandelt. An der Besprechung nimmt auch ein finnischer Angestellter teil. Auffallend in dieser Situation ist, da $B$ der finnische Kunde zum Teil nur sehr begrenzt Feedback gibt. An übergangsrelevanten Stellen, an denen also Rückmeldesignale erwartbar wären, führt das Fehlen dieser Signale dazu, daß der Gesprächspartner seine Äußerungen reformuliert. In Beispiel (8) erläutert der finnische Angestellte die Sonderkonditionen für den Jugendtarif. Die Bedingung, daß man den Rückflug nach der Buchung nicht mehr ändern kann, wird zweimal erklärt. Nach beiden Äußerungen folgt eine lëngere Pause, da aber kein deutliches Signal für das Verstehen bis auf kaum wahrnehmbares Nicken gegeben wird, greift der deutsche Leiter ein und erklärt das noch einmal, worauf der Kunde mit seiner Reaktion $z_{1}$ verstehen gibt, daß er das schon längst begriffen hat. Auf diese Sejuenz folgt eine zweite Sequenz, in der das gleiche Phänomen nochmals zu beobachten ist.

6 Zur Analyse dieses Gesprächs siehe genauer Lenz (1990). 
(8)

Besprechung in der Lufthansa Niederlassung in Helsinki ${ }^{7}$

$\mathrm{M}=$ deutscher Leiter, $\mathrm{I}=$ finnischer Student, $\mathrm{H}=$ finnischer Angestellter

H und äh / die Sonderkonditionen für Jugendtarif wie ich schon (.) ervähnt habe / sind erstes Mal daß Sie einen Tag vor der vor dem A(b)flug buchen dürfen sitzplatz reservieren dürfen //

I

mh

$\rightarrow$ H das gilt übrigens auch für den Rückflug dann. /// dann / äh / Sie

$\rightarrow$ müssen so fliegen vie Sie gebucht haben. /// Sie müssen auch gleichzeitig / wenn Sie buchen / bezahlen.

$\rightarrow$ M ((atmet)) äh Entschuldigung der (.) Punkt davor bedeutet daß Sie / Änderungen nicht (.) vornehmen können. venn Sie gebucht haben dann muß der Flug so ab-geflogen verden wie Sie ihn vorher bestimat und be- gebucht haben.

I ja. das ist schon klar

H

H

mh

Reiseversicherung. / sollte irgend jemand kurzfristig so krank verden das er nicht fliegen kann / gibt es leider / keine

$\rightarrow \quad$ Ermäsigung oder keine Möglichkejt für eine Rückzahlung. / nämlich venn Sie die Reise mal angetreten haben / äh gibt es / nicht (.) eine Möglichkeit für die Rückzahlung.

peder für Änderungen noch

für äh Ausfall oder Stornierung durch Krankheit (.) oder (.) andere Gründe und das kann man durch eine Versicherung abdecken.

Was kann man nun aus diesem Befund erschließen? Inwieweit kann man anhand einer interkulturellen Kontaktsituation bestimmen, ob die zu beobachtenden Eigenschaften dem kulturspezifischen, situationsspezifischen oder individuellen Stil zuzuschreiben sind? Liegt hier z.B. unterschiedliches kulturspezifisches Rezipientenverhalten zugrunde, das nach vielen Untersuchungen zu interkultureller Kommunikation eine typische Störquelle ist? ${ }^{8}$ Ein bekanntes Stereotyp über Finnen lautet, daß sie (wir) verschlossen sind, oder wie eine deutsche Geschäftsfrau dies formulierte: „Es gibt kein Rankommen an diese [Finnen], die sagen nichts." Dem Stereotyp vom schweigsamen Finnen entsprechend gibt der Student wenig Feedback, macht lange Pausen und hat eher einen monologischen als dialogischen Gesprächsstil. Wenn nun im analysierten Gespräch die geringe Häufigkeit der Rückmeldesignale auf den finnischen Kommunikationsstil zurückgeführt wird, wird die Kultur als einziger ausschlagge-

7 Quelle: Osterspaziergang 1991, Wirtschaftsuniversität Helsinki.

8 Vgl. u.a. Erickson/Shultz (1982), Tannen (1984), Miller (1991), Günther (1993). 
bender Faktor angesehen. Außer acht bleibt die mehrfache Asymmetrie der Situation:

- Der Finne spricht eine Fremdsprache, der Deutsche seine Muttersprache.

- Der Finne ist ein Student, der kaum über Verhandlungserfahrung verfügt, der Deutsche ein älterer, erfahrener Geschäftsmann mit hohem Status.

- Die Besprechung (wenn auch authentisch) ist Teil des Deutschunterrichts, sie wird auf Video aufgezeichnet mit dem Ziel, das Video später im Unterricht einzusetzen.

An dieser Situation läßt sich einerseits sehr gut beobachten, was in einer interkulturellen Begegnung passiert, wenn das Kommunikationsverhalten des Gesprächspartners von der gewohnten Norm abweicht, wenn wie hier z.B. erwartbare Reaktionen ausbleiben, und andererseits wie sich die Beteiligten bemühen, sich an die Verstehensvoraussetzungen des Gesprächspartners anzupassen. Paraphrasierungen müssen nicht ausschließlich als Signal für Störungen gesehen werden, sondern auch als ein wichtiges Mittel der Verständnissicherung. Aus dem bereits Gesagten folgt, daß man aufgrund dieses Einzelfalls kaum auf einen finnischen Kommunikationsstil rückschließen kann.

Betrachten wir noch ein weiteres Beispiel für die gegenseitige Anpassung in interkulturellen Begegnungen: Es handelt sich um eine ähnliche Situation wie die der Lufthansa-Besprechung, um Reisevorbereitungen. Diesmal findet das Gespräch in einem finnischen Reisebüro statt, beteiligt sind der Leiter des Reisebüros, ein Finne mit recht bescheidenen Deutschkenntnissen und als Kunden ein muttersprachlicher Deutschlehrer sowie zwei finnische Studenten, die jedoch eine geringere Rolle spielen. Im Vergleich zum ersten Beispiel ist die Situation symmetrischer: Die beiden Hauptbeteiligten sind etwa im gleichen Alter, beide sind Experten: der eine auf dem Gebiet des Tourismus, der andere im Bereich der Sprache, die gesprochen wird.

(9)

Besprechung in einem finnischen Reisebüro ${ }^{9}$

$\mathrm{H}=$ deutscher Lehrer, $\mathrm{C}=$ finnischer Leiter

H vir haben hier= äh ich hab leider das Prospekt nicht dabei' / ein äh

Schloßhotel entdeckt, das ist nicht neit von Irier entfernt' /

C aha

$\mathrm{H}$ in Bollendorf', /

${ }^{9}$ Quelle: Osterspaziergang 1991, Wirtschaftsuniversität Helsinki. 


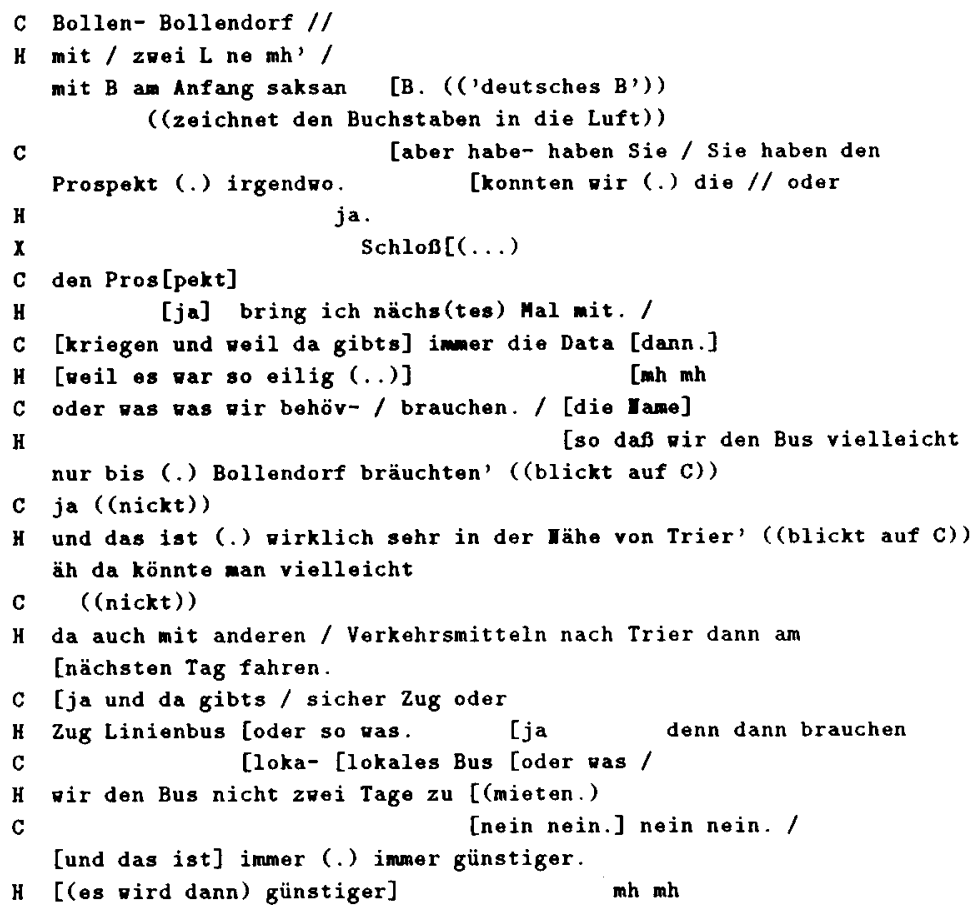

Der Auszug veranschaulicht den häufigen Gebrauch von auffälligen Mitteln der Verständnissicherung in einer interkulturellen Kontaktsituation. Von seiten des deutschen Muttersprachlers sind das:

- langsames Sprechtempo, viele Pausen

- kurze Redebeiträge

- Verfolgung des Verstehens des Gesprächspartners durch Blickkontakt

- Einholen der Verständnissicherung mit Signalen wie $h \ddot{a}^{\prime}, j a^{\prime}, n e^{\prime}$

- Abwarten bis der Gesprächspartner entweder verbal oder non-verbal reagiert

- und verdeutlichende Gestik.

Der finnische Geprächspartner benutzt ebenfalls deutliche Verständigungsmittel: häufige Rückmeldesignale, Wiederholung der Partneräußerungen, Fragen beim Nicht-Verstehen und Äußerungsergänzungen.

Was ist nun in diesem Gespräch jeweils der kulturspezifische Stil? Ist die Frage überhaupt relevant? Die Kommunikation gelingt, weil das Verstehen nicht einfach unterstellt, sondern dauernd in die Frage gestellt wird. 


\section{Zum Schluß}

Unterschiedliche Kommunikationsstile erschweren interkulturelle Begegnungen. Die Erforschung von Unterschieden und Gemeinsamkeiten im Kommunikationsverhalten hat somit nicht nur linguistische, sondern auch soziale Relevanz. Ebenso wichtig ist es aber zu untersuchen, wie in interkulturellen Situationen trotz dieser Unterschiede, trotz verschiedener Wert- und Wissensbestände Bedeutungen ausgehandelt werden und Verständigung erreicht wird. Als Beispiel hierfür möchte ich abschließend noch einen deutschen Befragten zu Wort kommen lassen, der gleich wie Erickson und Shultz (1982) die Bedeutung der partikulären Identitäten statt ethnischer, kollektiver Identitäten für das Gelingen der interkulturellen Kommunikation hervorhebt:

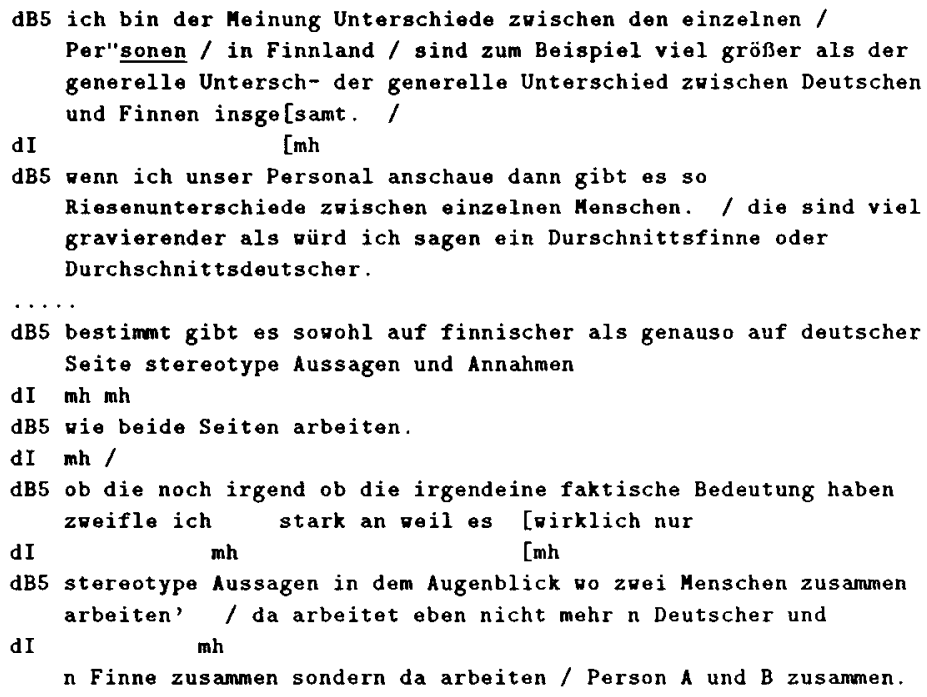

\section{Literatur}

Barnlund, Dean C. (1975): Communicative styles in two cultures: Japan and the United States. In: Kendon, Adam/Key, Mary Ritchie (eds.): Organization of Behavior in Face-to-Face Interaction. The Hague. S. 427-456.

Blommaert, Jan (1991): How much culture is there in intercultural communication? In: Blommaert/Verschueren (eds.) (1991), S. 13-31.

Blommaert, Jan/Verschueren, Jef (eds.) (1991): The Pragmatics of Intercultural and International Communication. Selected papers of the International Pragmatics Conference, Antwerp, August 17-22, 1987 (Vol. III), and the 
Ghent Symposium on Intercultural Communication. Amsterdam/ Philadelphia. (= Pragmatics \& Beyond, new ser. 6:3).

Blum-Kulka, Shoshana/House, Juliane/Kasper, Gabriele (eds.) (1989): CrossCultural Pragmatics: Requests and Apologies. Norwood, N.J. (= Advances in Discourse Processes, Vol. XXXI).

Byrnes, Heidi (1986): Interactional style in German and American conversation. In: Text 6 (2), S. 189-206.

Erickson, Frederick/Shultz, Jeffrey (1982): The Counselor as Gatekeeper: Social Interaction in Interviews. New York.

Günther, Susanne (1993): Diskursstrategien in der interkulturellen Kommunikation. Analyse deutsch-chinesischer Gespräche. Tübingen. (= Linguistische Arbeiten 286).

Gumperz, John J. (1982): Discourse Strategies. Cambridge.

Gumperz, John J. (1992): Interviewing in intercultural situations. In: Drew, Paul/Heritage, John (eds.): Talk at Work. Interaction in Institutional Settings. Cambridge. S. 302-327.

Gumperz, John/Roberts, Celia (1991): Understanding in intercultural encounters. In: Blommaert/Verschueren (eds.) (1991), S. 51-90.

Honkavaara, Kirsti/Kuronen, Marja-Liisa/Ojanen, Sirkka-Liisa/Steuer, Outi (1992): Kulttuurit kohtaavat kirjoitusviestinnän opetuksessa. In: Nuolijärvi, Pirkko/Tiittula, Lüsa (Hg.): Talous ja kieli 1. Helsinki. (= Helsingin kauppakorkeakoulun julkaisuja D-169). S. 75-100.

Kallmeyer, Werner (1994): Zur Darstellung von kommunikativem sozialem Stil in soziolinguistischen Gruppenportrāts. In: Kallmeyer, Werner (Hg.) (1994): Kommunikation in der Stadt, Bd. 3: Kommunikative Stilistik einer sozialen Welt "kleiner Leute" in der Mannheimer Innenstadt. Berlin. (Schriften des IdS, Bd. 4.3). S. 1-25.

Kotthoff, Helga (1989): Pro und Kontra in der Fremdsprache. Pragmatische Defizite in interkultureller Argumentation. Frankfurt/M.

Lenz, Friedrich (1990): Der wortkarge Finne und der beredte Deutsche? oder: Die Angst des Geschäftsmanns vor dem Muttersprachler. Helsinki. (= Helsinki School of Economics, Working papers F-244).

Miller, Laura (1991). Verbal listening behavior in conversations between Japanese and Americans. In: Blommaert/Verschueren (eds.) (1991), S. 111-130.

Muikku-Werner, Pirkko (1993): Impositiivisuus ja kielellinen variaatio. Joensuu. (= University of Joensuu Publications in the Humanities 14).

Pavlidou, Theodossia (1994): Contrasting German-Greek politeness and the consequences. In: Journal of Pragmatics 21, S. 487-511.

Sandig, Barbara (1986): Stilistik der deutschen Sprache. Berlin. (= Sammlung Göschen 2229).

Schwitalla, Johannes (1994): Namen in Gesprächen. Erscheint in: Löffler, H. (Hg.): Namenforschung. Berlin/New York.

Selting, Margret/Hinnenkamp, Volker (1989): Einleitung: Stil und Stilisierung in der Interpretativen Soziolinguistik. In: Hinnenkamp, Volker/Selting, 
Margret (Hg.): Stil und Stilisierung. Arbeiten zur interpretativen Soziolinguistik. Tübingen. (= Linguistische Arbeiten 235). S. 1-23.

Tannen, Deborah (1984): Conversational Style: Analyzing Talk Among Friends. Norwood, N.J.

Yli-Vakkuri, Valma (1989): Suomalaisen puhuttelun piirteitä. In: Kauppinen, Anneli/Keravuori, Kyllikki (Hg.): Kielen käyttö ja käyttäjä. Helsinki. (= Äidinkielen opettajain liiton vuosikirja XXXVI). S. 42-74.

\section{Anhang:}

Auszug (1)

aus der Sendereihe „Deutschland-Gespräche” (N3)

M Moderator

B Herr B. (Oberbürgermeister von Pforzheim)

S Frau S. (MdB-SPD)

A Frau A. (Justizministerin Niedersachsen)

H Sie haben Erfahrung gesamelt ehe Sie Oberbürgermeister vurden als Jurist [(..)]

B

$\mathbf{A}$

fragen darf veil Justizminister alle n ganz anderes Bekenntmis zu der Frage ablegen daß ihre Verraltungsrichter in der Lage sind dieses Thema längst zu lösen.

gehen sie [doch bitte auf [die Frage ein

A Die lang diese Verfahren im Vervaltungsverfahren liegen un nicht im gerichtlichen Verfahren.

$\mathbf{B}$

folgendes sagen, beim Bundesamt für Zirndorf $/$ zveitausend stellen nicht besetzt.

$[(\ldots)$

Choment [die Frage man findet niemanden. man hat

A Verralt [ungsdefizit

B jetzt achthundert [vierundzranzig bitte?

[eigentlich nicht

B [reil niemand bereit ist diese Aufgabe zu erledigen,

$S$ [aber nein]

A [können sie] doch durch Abordnung machen weil in de[in die ehemalige DDR [jeden Tag

B [nein [sie können- darf ich Ihnen sagn

[sie können das nicht machen venn die Tür auflgeht

H [kann ich mir auch nicht vorstellen 
$\boldsymbol{A}$

B und es komen tausend Asylbererber und sie müssen sie praktisch vervaltungsmäßig behandeln vie das so schön heißt [is es nicht

A Herr Becker [uir haben bei jedem

M lassen Sie ihn [doch mal (argu-) aus- zu Ende reden

B

M und argumentieren]

B gigantische.

A Grundrecht

venn Sie bei fünfhundert- / äh tausend anhängigen Verfahren in diesem Jahr / ein'n Dolmetscher brauchen sind das 1,5 Millionen (.) Befassungen mit einem Dolmetscher. / es gibt nicht so viele. venn Sie pro Dolmetscher mal hundert Mark rechnen sind das 150 Millionen' / um beispielsteise Menschen aus Rumänien anzuhören von denen sie ab (0vurf) von Anfang an vissen daß sie nicht in den Schutz des artikels 16 gehören. das Problem das $\nabla i r$ haben und das nicht lösbar ist mit praktischen Maßnahmen ich kann Ihnen das als / es gibt nicht nur Regierungskunst es gibt auch eine Vervaltungskunst. eben die fehlt

B zu bevältigen ist auch nicht sinnvoll. (.) ich habe mal ausgerechnet / wenn Sie sich vorstellen / Verraltungsgerichte // Polizei (.) Verfassungsschutz (.) Bundesgrenzschutz ordentliche Gerichtsbarkeit Strafvollzug

? ((deutlich hörbares Ausatmen))

B Sozialhilfe Unterbringung Personalkosten (.) das ist eine Größenordnung in ich sag das mal so pie ich das empfinde ein Skandal gegenüber einfachen Rentnern das Geld so kaputt zu machen (.) durch Bürokratie' das ist völlig unvertretbar (.) und man hat noch die Dimension dieser Größenordnung noch nicht äh begriffen. stellen Sie vor die- in den neuen in den alten Bundesländern beträgt die Förderung für den sozialen Wohnungsbau

A alle selbst $[(\ldots)$

aber das rissen iir doch [zqei Milliarden Mark. /

das rissen [uir >sagen (Sie) plädieren Sie für [und hier

eine Abschaffung des Artikels 16 [dann sollten Sie] das [ich bin]

hier deutlich [sagen reil das näm]lich das gesamte [ja das natürlich]

[Argument dafür ist.] (.) denn venn Sie sagen

[natürlich. ja] selbstverständlich

eine gigantische Verschrendung von [Steuergeldern'] dann

$[j a / j a]$

haben Sie sich bereits jetzt von Artikel 16 [erheblich]

[natürlich] 
A entfernt, das heißt Sie stehen in diesem Teil nicht mehr

B ich

$A$ auf dem Boden der Verfassung die derzeit noch Gültigkeit

hat. das möcht ich [damit erst mal festhalten.)

nein nein. [das das ist völlig richtig

[<denn wenn Sie / penn Sie an dem Grundrecht vas nur]

ich [bin der Meinung daß Artikel 16 geändert werden muß']

Ausländern gilt vorperfen [daßs sie dafür]

ich verf das [nicht vor]

A Steuergelder Sie haben gesagt gigantische Verschuendungen und [haben dann die Dolmetscherkosten (.) die ja

[ja

A das minimale der minimale Konsens für eine / Verständigung untereinander ist / venn Sie das schon

angrei[fen dann denke ich] sollten Sie es hier klar und [(das seh ich anders)]

A deutlich sagen daß Sie noch nicht mal mehr auf den

Petersberger Beschl[üssen stehen] (.) sondern daß Sie eine $B$ [nein ich bin]

A [Abschaffung] des Artikels 16 pollen damit hier

B [richtig]

A die Zu[hörer und Zuschauer] das auch nissen und auch wir

B [ja selbstrerständlich]

A rissen über vas Sie diskutieren.

$\mathbf{B}$

ja ja jch habe das

vorausgesetzt $\ldots$

Auszug (2)

aus der Sendereihe "Wort um Wort"

V Herr V. (Moderator)

AV Frau V. (Leiterin des Flüchtlingsbüros des Finnischen Roten Kreuzes)

MP Herr P. (Innenminister)

AS Herr S. (Hauptvertrauensmann)

aV ... ihmiset / jotka tänne tulee niin eivät ehkä ole

... Leute / die hierher kommen haben vielleicht auch nicht tienneetkään näitä eroja että / että

gerußt ras diese Unterschiede sind also mikä on pakolainen mikä on siirtolainen ja ja was heift Asylant was heift Einvanderer und und niinku näkyy näistä romanialaisista jotka Suolmeen vie man sieht an diesen Rumänen die nach Finn[land

V

[mu-m

mh

AV halusivat ja yrittivät tulla niin he ilmottivat rollten und zu kommen versuchten, so gaben sie an ihan (h') suoraan et he tulevat töitä tänne hakemaan / 
ganz (h') offen an daß sie hierher kommen um Arbeit zu suchen mut öö ehkä olivat sitten niinku / väärällä

aber öh vielleicht raren sie dann sozusagen / unter einer falschen

nimikkeellä niitä töitä etsimässä täältä. /

Bezeichnung auf Arbeitsuche hier./

$v ?$ niin (kyllä)

ja (schon)

MP tähän ehkä vielä vois jatkaa sen että / että

aran könnte man vielleicht noch anschließen daß / daß

kyllä Suomi ottaa / tänne / sellaset henkilöt / jotka

Finnland nimet schon / hierher / solche Personen auf / die

täyttävät pakolaisuuden tunnusmerkit. // mutta [ei /

die Merkmale eines Flüchtling "erfüllen.// aber [nicht

MP ilman muta sella[sia jotka tulevat tänne / rajalle ohne veiteres solch[e die hierher kommen / an die Grenze

$[\mathrm{mh}$

MP ja ilmottavat että että he ovat turvapaikan tarpeessa ja und angeben daß daß sie Asyl suchen und tosiasiassa ovat todella nii / työnhaussa täällä.

in Wirklichkeit tatsächlich also / hier sind um Arbeit zu suchen.

$\checkmark$ voit- voitko sää hyvin lyhyesti öö kertoa mikä on

kann- kannst du ganz kurz öh erzählen was ist

se raja millon millon saa turvapaikan ja millon saa öö

die Grenze, vann wann bekommt man Asyl und vann bekommt man öh oleskeluluvan. onko se helposti ilmastavissa lyhyesti.

eine Aufenthaltserlaubnis. läßt sich das leicht kurz erklären?

MP no / voi sanoa näin että / että sillon jos kansalainen

na / man kann so sagen daß / daß dann wenn eine Person

vaatii öö suojelua hän ei häntä ei voida palauttaa

verlangt / öh Schutz, dann kann man sie nicht zurückschicken

( (räuspert sich)) siihen maahan mistä hän on tullu ni

in das Land roher sie gekommen ist dann

hänelle myönnetään joko turvapaikka tai oleskelulupa, /

vird ihr entreder Asyl oder ne Aufenthaltserlaubnis gevährt, $/$ ja oleskelulupa sillon jos jos öö ratkasu on

und ne Aufenthaltserlaubnis dann wenn wenn öh die Entscheidung tilapäisempi / syystä taikka toisesta tila[päisempi. /

provisorischer ist / aus dem einen oder anderen Grund provi[sorischer

hän [voisi joskus palata kotim-]

das heißt es rird angenommen daß sie [irgendwann zurückkehren könnte in das Heim-

[ETT̈̈ нÄI VOISI jossakin vaiheessa palata takasin

omaan kotimaahansa. /

[DASS sie zu irgendeinem Zeitpunkt in ihr eigenes

Heimatland zurückkehren könnte. /

$\checkmark$ Ari sulltoli nyt

Ari du hattest jetzt

S niin mä en o (.) kovinkaa huolestunu tästä että (.) 
ja ich bin nicht besonders besorgt desuegen veil (.)

täst keskus >tai> (.) käydään tätä keskustelua et

gegen dieser Diskus- >oder> (.) daßs darüber diskutiert vird ob

elin- taso- pakolainen tai ei mää luotan kyl

Wirt- schafts- flüchtling oder nicht ich hab schon Vertrauen in viranomaisiin täs suhtees et se valinta tehdään siellä,

die Behörde in der Hinsicht das die Entscheidung dort getroffen wird / ja: vaikeet mun on sitä arvioida et mitä nää ihmiset

/ und: ich kann es ja nicht beurteilen uas diese Leute sit on. / mutta jos saa keskustelus palata vähän

dann sind. / aber nenn man in der Diskussion ein bißchen taaksepäin nin / täs / ku Eero / kerto tästä heidän zurückkomen darf auf / hier / was Eero / erzählte von diesem ihrem päätöksestä ni / nin nin (.) täs kuvastu ihan selvästi Beschlub so/so (.) zeigte sich hier ganz deutlich et siinto aika paljon tunnetta mukan siinä päätöksessä daß da zienlich viel Gefühl dabei ist bei diesem Beschluß ja ja täst mun miest pitäs enemmän keskustella meidän (.) und und darüber sollte man denk ich viel mehr diskutieren über unsere (.)

asenteesta ja suhtautumisesta et miks se on tällainen. / Haltung und Einstellung also varum ist die denn so./ elikkä mm mää laittasin näin että me ollaan erittäin also äh ich vürd sagen øir können sehr huonoi sietämään erilaisuutta keskuudessamme / ja: ja mä schlecht Anderssein unter uns tolerieren / und: und ich uskon et meillto aika huono itsetunto (.) peräti / glaube daß vir ein ziemlich schlechtes Selbstberußtsein haben (.) sogar kun me kohdataa jotain jotain uuta, niin niin venn vir mit etwas etras Ieuem konfrontiert verden, so so [nää tausta-asetelmat tässä niin nää ois mun miest syytä diese Hintergründe hier ich meine die sollten

V [(ja kai-) (und vielleicht-)

S keskustella ihan niinkun julkisuudessa so ganz in der öffentlichkeit diskutiert verden 
VALLAN MAINIO OY

Keksikatu 5

00000 KAUPUNKI

Keksiosasto/Luoto

24.4.1992

Kaisa Ketonen

Länsitie 5

00500 HELSINKI

Lähetyksenne 5.4.92

Arvoisa asiakkaamme

Olemme tutkineet rinkelistänne löytyneen rautalangan alkuperää ja saaneet selville, että rautalanka on peräisin pellistä, jollaisilla rinkelit kohoavat tehtaallamme.

Rinkelipeltien kuntoon kïnnitetään kyllä erityistä huomiota, koska pellit jatkuvasti kuumassa uunissa kiertävinä haurastuvat helposti. Tässä tapauksessa vahinko on kuitenkin päässyt sattumaan, ja pala rautalankaa on painunut rinkelin sisälle.

Kaikeksi onneksi tuo vaarallinen esine ei saanut aikaan mitään vahinkoa.

Kiitokseksi asian esille tuomisesta lähetämme erillisenä nävtepaketin tuotteitamme.

Toivomme luottamuksenne Vallan Mainiota kohtaan säilyvän.

Ystävällisin terveisin

VALLAN MAINIO

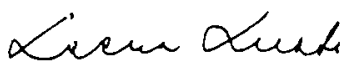

Leena Luoto

talousopettaja 
VALLAN MAINIO OY

Keksikatu 5

00000 KAUTUNKI

Keksiosasto/Luoto

24.4.1992

\section{Kaisa Ketonen}

Länsitie 5

00500 Helsinki

Ihre Sendung vom 5.4 .92

Sehr geehrter Kunde

Wir sind der Herkunft des Eisendrahtstücks in dem Kringel nachgegangen und haben herausgefunden, daß der Eisendraht von einem Rost stammt, auf dem die Kringel in unserer Fabrik aufgehen.

Auf den Zustand der Roste wird bei uns selbstverständlich [deshalb] sorgfältig geachtet, weil die Roste im Backofen ständiger Hitze ausgesetzt sind und deshalb leicht brüchig werden. In diesem Fall ist es jedoch zu einer Panne gekommen, und ein Eisendrahtstück ist in einem Kringel stecken geblieben.

Zum Glück hat dieser gefährliche Gegenstand keinen Schaden angerichtet.

Als Dank für die Meldung des Vorfalls übersenden wir mit getrennter Post ein Musterpäckchen unserer Produkte.

Wir hoffen, daß Ihr Vertrauen zu Vallan Mainio erhalten bleibt.

Mit freundlichen Grüßen

VALLAN MAINIO

Leena Luoto

Hauswirtschaftslehrerin 
Lebensmittelhandlung Greiner

Herrn Baumann

Unter den Linden 24

D-W-3250 Hameln

Helsinki, 24.04.92

Unsere Kringellieferung vom 03.04.92

Ihr Brief vom 14.04 .92

Sehr geehrter Herr Baumann.

daB Sie AnlaB hatten, unsere Kringellieferung zu beanstanden, bedauern wir sehr.

Wir sind der Sache sofort nachgegangen, um die Herkunft des Eisendrahtstūcks in dem Kringel zu ermitteln. Dabel hat sich herausgestellt, daß das Drahtstūck von einem Rost stammt, auf dem die $\mathrm{Kr}$ ingel in unserer Fabrik aufgehen und gebacken werden.

Auf den Zustand dieser Roste wird bel uns sehr sorgfältig geachtet. Die Roste werden aber mit der Zeit brüchig, da sie im of en ständiger Hitze ausgesetzt sind. In unserer Fertigung kam es dann leider zu dieser Panne: Ein Eisendrahtstück löste sich und blieb unbemerkt in einem kringel stecken.

Wir sind erleichtert, daß dieser gefährliche Gegenstand keinen Schaden angerichtet hat.

Wir sind ihnen sehr dankbar dafūr, daß sie uns auf diesen Fehler aufmerksam gemacht haben und stimmen Ihnen zu: Solche Māngel dürften be i VALLAN MAINIO -Kringeln nicht aurtreten. Als Dank lassen wir innen mit separater Post ein Musterpäckchen unserer Produkte zugehen, damit Sie die Geschmacksvielfalt unseres Sortiments ausprobieren können.

Dürfen wir damit rechnen, daß sie uns auch weiterhin als kringellief eranten vertrauen?

Mit freundlichen Grüßen

VALLAN MAINIO

Leena Luoto

Produktleiterin 
V/ref.: $v /$ lettre du $18 / 4 / 92$

\section{Monsieur.}

Nous acousons réption de votre lettre oitêe en réference qui a retenu toute notre attention.

Il ressort de nos examens que le fil de fer que vous aviez trouvé dans un croissant VALIAN MAINIO provient d'un des plateaux de cuisson utilisés dans notre boulangerie. Ces plateaux, malgré un contrôle severe auquel ils sont soumis, risquent en effet d'êtro détériorés a la longue. sous l'effet des hautes temperatures nécessaires au processus de cuisson.

Hous 8 ommes heurenx d'apprendre que cet objet inopportun. voire dangereux, a ete repere a temps et que les degâts ont ainsi étévités.

Nous vous remercions d'avoir porté à notre connaissance cet incident qui, nous l'esperons, n'altérera pas la confiance que vous avez en la marque VALIAN MAINIO, connue, de generation en génération, comme garantie d'ane qualite superieure.

Nous vous faisons parvenir, sous pli separé, un assortimentcadeau de nos produits et vous prions d'agréer, Monsieur, l'expression de nos sentiments devoués.

Le chef de produit

Leena LUOTO 


\section{Sprechstile als Kontextualisierungshinweise}

Die sprechstilistische Kontextualisierung konversationeller Aktivitäten am Beispiel mündlicher Erzählungen in Gesprächen

\section{Einleitung}

Gegenstand meines Beitrags sind mündliche Sprechstile, v.a. mündliche Sprechstile in konversationellen Erzählungen. Meine These ist, daB die Beschreibung konversationeller Erzählungen die systematische Berücksichtigung des sie gestaltenden Sprechstils, insbesondere der prosodischen Gestaltungsmittel, erfordert.

Meine Analyse fuBt auf interaktionistischer Grundlage. Ich werde die Konversationsanalyse mündlicher Erzählungen um eine Kontextualisierungsanalyse ergänzen, in der linguistische Strukturen als Kontextualisierungshinweise interpretiert werden.

Zur kommunikationstheoretischen Verortung können die wichtigsten Prämissen meiner Analyse vorab wie folgt zusammengefaßt werden.

(1) Unter konversations- und kontextualisierungsanalytischer Perspektive ist Kommunikation zwischen Sprechern und Hörern bzw. Rezipienten kein je monologischer Austausch von Informationen, sondern Kommunikation ist ein wechselseitig hergestellter und aufeinander bezogener Interaktions- und Interpretationsproze $B \mathrm{z}$ wischen Sprechern und Rezipienten (vgl. Mead 1934, Schütz 1974, Goffman 1967 usw.).

(2) Sprachliches Handeln ist eine interaktive Leistung, an deren Herstellung und Aushandlung sowohl die Sprecher als auch die Rezipienten beteiligt sind (vgl. Garfinkel 1967, Sacks 1992). - Das gilt prinzipiell auch für konversationelle Erzählungen, bei denen zunächst einmal der Erzähler das (primäre) Rederecht hat (vgl. Sacks 1971, Quasthoff 1980 u.a.).

(3) Konversationelle Interaktion ist sequentiell geordnet und wird von den Interaktionspartnern lokal und auf die jeweiligen Rezipienten zugeschnitten geregelt und ausgehandelt (siehe v.a. Sacks/Schegloff/Jefferson 1974 u.a.). - Die Analyse dieser sequentiellen Organisation konversationeller Aktivitäten ist das Hauptanliegen der Konversationsanalyse. Als Validierungsverfahren gilt dabei der Rückgriff auf Rezipientenreaktionen (Sacks/Schegloff/Jefferson 1974, Levinson 1983 u.a.).

(4) Die interaktive Bedeutung konversationeller Aktivitäten ist jedoch nicht $n$ u r sequentiell bedingt, sondern der kontextspezifische Interaktions- und Interpretationsproze $B$ wird auch durch Kontextuali- 
sierungshinweise gesteuert. Konversationelle Aktivitäten werden durch Kontextualisierungshinweise erkenn- und interpretierbar gemacht; diese legen in der Sprachverwendung erst die für die Interpretation relevanten Interpretationsrahmen nahe. Genau ein solcher Hinweis ist auch der Sprechstil. - Der Kontextualisierungsansatz, der von John Gumperz (1982, 1990, 1992; vgl. auch Auer 1992) entwickelt wurde, bietet die Möglichkeit, linguistische Strukturen systematisch als Kontextualisierungshinweise mit Bezug auf Interaktionsprozesse zu analysieren und somit Gesprächsanalysen auch systematisch linguistisch zu fundieren.

Bevor ich die spezifischen Stilmittel konversationeller Erzählungen behandele, möchte ich zunächst zeigen, weshalb eine solche Analyse notwendig ist bzw. weshalb eine Analyse ohne die Berücksichtigung der spezifisch mündlichen Gestaltung der Erzählung nicht ausreicht.

\section{Die Grenzen der Konversationsanalyse konversationellen Erzählens}

Die Konversationsanalyse betont die interaktive Herstellung konversationeller Erzählungen. Einerseits schneiden die Erzählenden ihre Erzählung auf die Zuhörer und deren Rezipientenreaktionen $\mathrm{zu}$, andererseits sind genau solche Rezipientenreaktionen wiederum auch konstitutiv für das Zustandekommen und die Entwicklung von Erzählungen. In der Konversationsanalyse ist immer wieder gezeigt worden, wie Erzählungen von ihrer Ankündigung an, über ihre geordnete Durchführung bis hin zu ihrer Beendigung auf die beständige Interaktion zwischen dem Erzähler bzw. der Erzählerin und dem bzw. den Rezipienten angewiesen sind und durch diese Interaktion geformt werden. Dabei kümmert sich konversationsanalytische Forschung vor allem um die Analyse der sequentiellen Organisation konversationeller Aktivitäten: Der „Erzähltext” wird in seine konstitutiven Teilaktivitäten segmentiert und als Produkt interaktiver Leistung rekonstruiert. Auf diese Weise kann man z.B. feststellen, daß Erzählende ihre Erzählungen auf eine Pointe, einen Höhepunkt oder einen Relevanzpunkt hin organisieren und daß nach der Präsentation der Pointe eine Rezipientenreaktion erwartbar ist. Bleibt eine solche Rezipientenreaktion aus, wird die Erzählung als „gescheitert” empfunden und gegebenenfalls repariert. Nach konversationsanalytischer Methodologie wird die erwartbare Rezipientenreaktion als retrospektive Evidenz herangezogen, um zu zeigen, daß überhaupt eine Pointe oder ein Höhep̧unkt produziert und verstanden worden ist. (Vgl. Sacks 1971, Jefferson 1978, Kallmeyer/Schütze 1977, Kallmeyer 1981, Gülich 1980, Quasthoff 1980, Michel 1986 u.v.a.m.) 
Diese Vorgehensweise möchte ich anhand des Beispiels (0) verdeutlichen. 1

(0) Rohtranskript K0:457-468

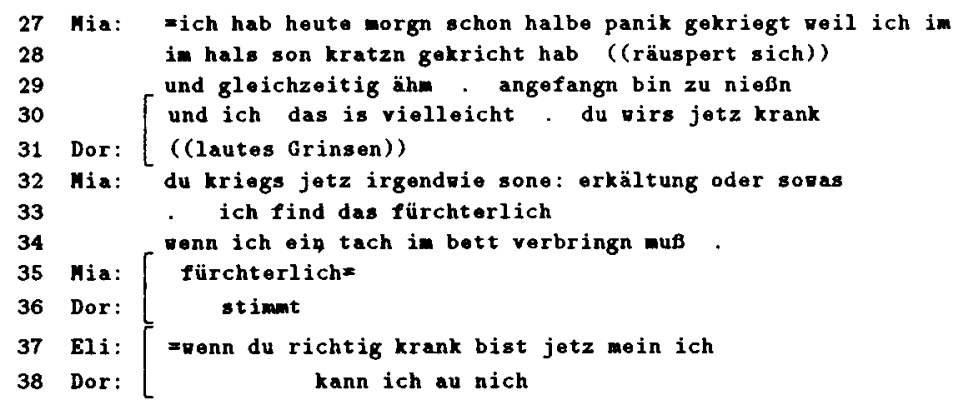

In diesem Beispiel wären nach konversationsanalytischer Methodologie außer der Analyse der Einbettung der Erzählung in das umliegende Gespräch vor allem die Reaktionen von Dor und Eli in den Zeilen 3638 als Evidenz dafür heranzuziehen, daß sie Mias vorherige Äußerung a ls Höhepunkt verstanden haben, der ihre Rezipientenreaktionen verlangt und genau hier relevant macht. Erst die Reaktion der Rezipienten liefert Evidenz für die Interpretation der interaktiven Bedeutung der Vorgängeräußerung.

Aber auch, wenn wir als Analysierende rekonstruiert haben, daß es sich um eine Belegerzählung handelt, mit der Mia ihre Angst vor dem Kranksein-müssen illustriert, und daß Mias Äußerung in Zeile 35 als Höhepunkt behandelt wird, stellt sich hier ein Problem: Wie können die Rezipientinnen überhaupt erkennen, daß die Bewertung fürchterlich ein Höhepunkt sein soll? Diese Bewertung könnte doch vom Wortlaut her ebensogut Teil einer Hintergrunddarstellung sein, mit der Mia erst einen Höhepunkt vorbereiten wollte, z.B. daß sie - weil sie Krank-sein als so fürchterlich empfindet - aus Panik irgendeine Dummheit begangen hat. Wieso interpretieren dennoch Dor und Eli übereinstimmend Mias fürchterlich als Höhepunkt und reagieren sofort auf ihn, ohne z.B. eine mögliche Fortsetzung abzuwarten? Die Konversationsanalyse nimmt hier quasi einen „textlinguistischen” Standpunkt ein, indem sie aus retrospektiver Sicht

1 In diesem Rohtranskript steht ein Punkt für ca. 0.5 Sekunden Pause, eckige Klammern, wie vor den Zeilen 30-31 usw, zeigen den Übergang in eine Partiturschreibweise für die Darstellung gleichzeitigen Sprechens an: die in den geklammerten Zeilen untereinander stehenden Textsegmente werden gleichzeitig produziert. 
den "Gesprächstext" analysiert. Die Frage, weshalb die Teilnehmerinnen selbst aber überhaupt in der Lage sind, beinahe zeitgleich und ohne Überblick über das Folgende, eine Äußerung - wie im Beispiel - im Rahmen der Erzählung als Höhepunkt zu interpretieren und entsprechend zu reagieren, kann die Konversationsanalyse nicht erklären. ${ }^{2}$

Um eine Erzählung für den Rezipienten rasch genug verstehbar zu machen, so daB dieser auch rechtzeitig reagieren kann, muB also offenbar der Erzähler die Teilaktivitäten seiner Erzählung bereits während ihrer Produktion interpretierbar machen. Er muß also, wie John Gumperz es nennt, seine Äußerungen 'kontextualisieren'; d.h., er muß signalisieren, in welchem Zusammenhang, in welchem Rahmen, als welche Aktivität sie verstanden werden sollen.

Ich möchte im folgenden zeigen, daß und wie Sprecherinnen und Sprecher ihre Erzählungen kontextualisieren. Konkret: wie sie sprechstilistische Mittel verwenden, um die Teile ihrer Erzählungen als Komplikationen und als Höhepunkte verstehbar zu machen.

\section{Die Analyse von Sprechstilen als Kontextualisierungs- hinweisen}

Unter 'Sprechstil' verstehe ich allgemein die sozial und interaktiv relevante und interpretierte Art und Weise des Sprechens in sozialen Interaktionen. Damit will ich sprachliche Variation unter stilistischen Gesichtspunkten analysieren, d.h. als sozial und interaktiv bedeutsamen/bedeutungsvollen Gebrauch von Sprachvariation als Ressource der Gesprächs- und Interaktionsorganisation, als aktiv verwendetes und sozial und interaktiv interpretiertes Gestaltungsmittel in der kommunikativen Interaktion. ${ }^{3}$

2 Zudem liegt nach den z.T. sehr engen Kriterien für die Definition von Erzählungen in der Literatur, z.B. Quasthoffs (1980) Kriterium der minimalen Ungewöhnlichkeit, hier allein vom Wortlaut her zumindest keine unproblematisch erkennbare und vollausgebaute Erzählung vor. Vgl. aber dazu kritisch Michel (1986), die den Erzählbegriff weiter faft, um Alltagsaktivitäten, die Interaktionspartner selbst als 'Erzählen' kategorisieren, zu erfassen. Zu unterschiedlichen Erzählbegriffen in der Wissenschaft und im Alltag vgl. auch Ehlich (1983).

3 Vgl. dazu auch Sandigs Stilbegriff: „Mit Stil wird die sozial relevante (bedeutsame) Art der Handlungsdurchführung in die Perspektive genommen" (1986, S. 23). Insofern als Stil als „d a s Mittel der Situationsanpassung von Handlungen” erkannt wird, mit dem „im konkreten Handeln durch die Art der Durchführung weitere(r) intersubjektiv erkennbare(r) Sinn zum generell gegebenen Handlungstyp" hinzugebracht wird (ebd., S. 31f.), trifft sich die neuere Stilistik genau mit der interpretativen Soziolinguistik (vgl. 
Als Kontextualisierungshinweise werden vor allem prosodische Signale in Kookkurrenz mit morphophonologischen, syntaktischen und lexikalischen Signalisierungsmitteln verwendet ${ }^{4}$, um u.a. auch 'Sprechstile' der Alltagskommunikation zu konstituieren. Mit diesen machen Sprecherinnen und Sprecher kommunikative Aktivitäten erkennbar und gestalten sie in sozial und interaktiv relevanter Weise.

Ich möchte im folgenden zwei Gesprächsausschnitte aus informellen Gesprächen zwischen jeweils drei Personen ${ }^{5}$ analysieren, in denen Erzählerinnen mit Hilfe eines Wechsels von einem unmarkierten Ausgangsstil zu einem markierten, auffälligen Stil die Höhepunkte ihrer Erzählungen kontextualisieren und gestalten. In den Beispielfällen verwenden Sprecherinnen vor allem den Wechsel zu einer besonders auftälligen prosodischen Markierung in Kookkurrenz mit speziellen syntaktischen und lexikalischen Signalisierungsmitteln, um einen Sprechstil zu signalisieren, den wir im Rahmen kontext- und aktivitätstyp-spezifisch zugeschriebener Interpretationen als 'emphatisch' bezeichnen. Mit Hilfe der Konstitution dieses Sprechstils legen die Sprecherinnen die Interpretation von 'Emphase' bzw. emphatisch erhöhter Emotionalität nahe. Der emphatische Stil wird nicht für die gesamte Erzählung verwendet, sondern nur lokal zur Signalisierung und Kontextualisierung der Pointen bzw. Höhepunkte der konversationellen Erzählungen. Die Analyse wird deutlich machen, daf die Herstellung solcher Höhepunkte eine interaktive Organisation aufweist: sie werden vom Sprecher vorbereitet und sie machen lokale Reaktionen der Rezipienten relevant. Die Veränderung des Stils läuft parallel mit der sequentiellen Entwicklung und kontextualisiert diese, macht diese erkenn- und interpretierbar.

Zusammengefaßt möchte ich im folgenden drei Punkte zeigen:

(1) wie die Erzählerinnen innerhalb einer sequentiell analysierbaren konversationellen Erzählung Bündel linguistischer Strukturen verwenden, um damit ihren Sprechstil herzustellen und zu verändern;

insbes. die Beitrăge in Hinnenkamp/Selting 1989; Selting 1989) und der neueren Kontextualisierungsforschung (Gumperz 1982, 1990, 1992; Auer 1986, 1992).

4 Ich verstehe 'Prosodie' als Oberbegriff für suprasegmentale Phānomene wie Intonation/Tonhöhenverlauf, Lautstärke, Länge, Pause, sowie die damit zusammenhāngenden komplexeren Phānomene Sprechgeschwindigkeit, Tempo und Rhythmus (Selting 1995).

5 Für eine genauere Beschreibung der hier verwendeten Daten siehe Selting (1995). 
(2) wie sie damit die erzählte Entwicklung der Ereignisse erkennbar machen und die relevanten Interpretationsrahmen nahelegen;

(3) wie sie damit zugleich die Kooperation zwischen sich und ihren Rezipienten koordinieren und sichern. Nach der Analyse der Erzählungen und einem Fazit werde ich das methodologische Problem des Nachweises von Stilwirkungen andiskutieren und einen Ausblick geben.

Die Darstellung der Daten in den Feintranskripten orientiert sich an folgenden generellen Konventionen: Die Anordnung der Text-Zeilen orientiert sich entweder soweit wie möglich an den prosodisch signalisierten (Äußerungs-)Einheiten der Gesprächspartner, wie im ersten Transkript, oder an rhythmischen Einheiten, wie z.T. im zweiten Transkript; auf letztere gehe ich an gegebener Stelle ein. Für die Darstellung gleichzeitigen Sprechens wird, wie bereits im Rohtranskript, in die durch Klammerung angezeigte Partiturschreibweise übergegangen.

Unter den Textzeilen sind die Tonhöhenverläufe und ggf. weitere prosodische Parameter in einer von mir selbst entwickelten Notation angegeben (siehe Selting 1995 für eine genauere Erläuterung und Begründung der verwendeten Kategorien). Diese sind nach dem folgenden

Notationsschema für die Intonationsnotation

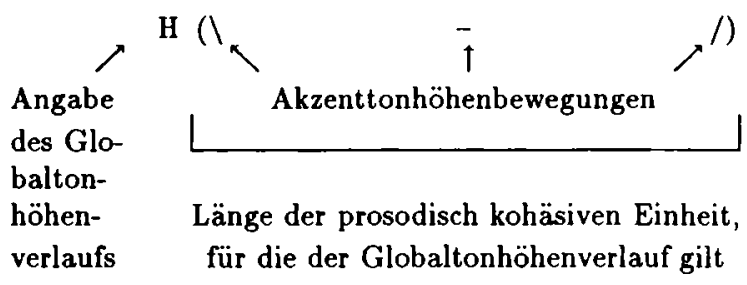

aufgebaut: Die runden Klammern geben die Länge einer prosodisch kohäsiven Äußerungs-Einheit an. Der Großbuchstabe vor der runden Klammer gibt den Globaltonhöhenverlauf der gesamten ÄußerungsEinheit an, und die Zeichen in der Klammer stehen für fallende, gleichbleibende und steigende Akzenttonhöhenbewegungen. Bei auffalligen Realisierungen von Akzenten oder Einheiten, im Vergleich zu unauffalligen und in diesem Sinne unmarkierten umliegenden Akzenten oder Einheiten, spreche ich von „prosodischer Markierung”. (Weitere Erläuterungen zu den verwendeten Transkriptionskonventionen sind im Anhang dieses Beitrags zusammengestellt.) 


\subsection{Erstes Beispiel}

Im ersten Beispiel, das in Abschnitt 2 bereits als Rohtranskript präsentiert wurde, erzählt Mia über ihre Angst davor, krank sein zu müssen. Anhand dieses Beispiels möchte ich zeigen, daß die Rezipientinnen nur aufgrund der von Mia hergestellten Sprechstile die Erzählung so interpretieren können, wie sie es offenbar tun.

(1) „FÜRCH:TER:LICH”

KO: 431-432 und 453-476 (Laufnr. ca. 170ff.)

(Gesprächspartnerinnen: 3 Frauen: Dor, Eli und Mia)

1 Eli: NEIN aber ich (.) *aso wenn, ICH zum Beispiel KRANK bin $M(\backslash)$ -

〈all all

$\mathrm{M}(\mathrm{i}$

kann ich das UNglaublich geNIEßn ne (.)

$\mathrm{F}(\backslash \quad \backslash \quad /)$

$((\ldots))$

23 Mia: $F$ ich find das zum KOTzN (.)

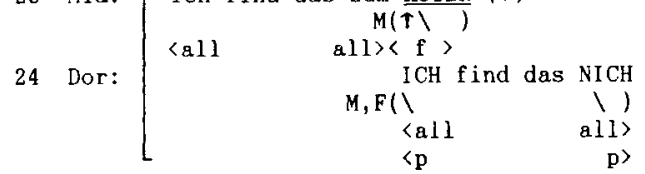

25 Mia: e mir das überhaupt voRzustelln

$M(T)$

$\langle\mathbf{f}\rangle$

26 Dor: STIMMT=

$M(\backslash)$

27 Mia: =ich hab heute MORGN schon halbe PAnik gekriegt weil ich im $M(\backslash$

28

in HALS son KRATzn gekricht hab ((räuspert sich))

29

und GLEICHzeitig ähm (.) ANgefangn bin zu NIEßn $\mathrm{M}(\mathrm{V}$

30 Mia: [ und ICH das IS vielleicht (.) du wirs jetz KRANK

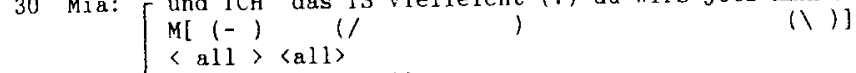

31 Dor: $[$ (lautes Grinsen))

32 Mia: du kriegs jetz IRgendwie sone: erkAltung oder sowas 


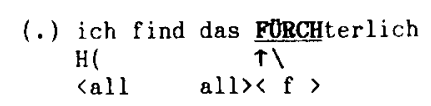

Mia geht in Zeile 35 in einen deutlich markierten Sprechstil über, der mit Hilfe lexiko-semantischer, syntaktischer und-prosodischer Signalisierungsmittel hergestellt wird. Diese Mittel können im Detail wie folgt expliziert werden.

Das lexikalische. Wort fürchterlich wurde schon einmal vorher, in Zeile 33, verwendet. In Zeile 35 wird es in eigener Ein-Wort-Einheit wiederholt. Es ist ein deutlich bewertendes Adjektiv. 
Prosodisch ist auffallig, daß das Wort FŨRCH:TER:LICH maximal dicht akzentuiert wird, nämlich mit einem deutlichen Akzent auf jeder einzelnen Silbe; die ersten Silben werden gelängt; zusätzlich wird die erste akzentuierte Silbe noch mit einem extra hohen Tonhöhengipfel und mit höherer Lautstärke als die umliegenden akzentuierten Silben produziert. Besonders die maximal dichte Akzentuierung kontrastiert mit der Akzentuierung in den umliegenden Einheiten: In den vorherigen Einheiten in den Zeilen 27-34 folgen einer akzentuierten Silbe meist drei bis fünf unakzentuierte Silben; und auch in den Folgeeinheiten ab Zeile 39 folgen einer akzentuierten Silbe meist eine ganze Reihe unakzentuierter Silben.

Eine derartig hohe Akzentdichte wie in Zeile 35 mit der Akzentuierung jeder einzelnen Silbe gilt auch in der Phonologie als höchst markierte Struktur. Vor dem Hintergrund, daß eine Alternation akzentuierter und unakzentuierter Silben die unmarkierte Struktur ist, werden dort Strukturen, in denen direkt aufeinanderfolgende Silben akzentuiert werden, als 'accent elashes' analysiert (vgl. Liberman/Prince 1977, Selkirk 1984, Nespor/Vogel 1989, Couper-Kuhlen 1992, 1993, Uhmann, in press). Eine solche phonologisch markierte Struktur, bzw. eine Erhöhung der Akzentdichte in diese Richtung, eignet sich offenbar gut für die Signalisierung eines markierten Stils (vgl. auch Uhmann 1992).

Schon vorher waren das Wort FÜRCHterlich wie auch das Wort BETT mit markiert hohen Tonhöhengipfeln produziert worden. Die zweite Version des FÜRCH: TER:LICH in Ein-Wort-Konstruktion mit zusätzlicher prosodischer Markierung durch die maximal dichte Akzentuierung eskaliert demgegenüber noch. Sie signalisiert einen klaren Höhepunkt mit der nahegelegten Interpretation von emphatisch erhöhter Emotionalität.

Insgesamt ist die Situation hier jedoch kompliziert, weil Mia diese Bewertungen als Teil einer Erzählung bringt, die selbst eine gegenläufige Bewertung gegen Elis vorherige positive Bewertung des Zustands 'krank sein' in den Zeilen 1-2 darlegt. Der Höhepunkt der Bewertungssequenz fällt hier also zusammen mit dem Höhepunkt einer Erzählung. Genauer: die prosodisch markierte Bewertung is $\mathbf{t}$ der Höhepunkt der Erzählung. Gleichwohl macht die prosodische Markierung diesen Höhepunkt erst als solchen erkenn- und interpretierbar.

Dieser Höhepunkt wird - wie Dors und Elis Reaktionen zeigen - auch sofort von den Zuhörerinnen erkannt und verstanden: Dor reagiert unmittelbar, nachdem sie offenbar erkannt hat, daß Mia nun eine prosodisch markierte Wiederholung des bewertenden Adjektivs fürchterlich produziert, mit der überlappenden Zustimmung STIMMT; und Eli bringt ei- 
nen schnell angeschlossenen Einlenkungsversuch, um Mias und ihre eigene Position aneinander anzunähern.

Eine ähnliche Art der prosodischen Markierung wird auch im zweiten zu analysierenden Gesprächsausschnitt verwendet.

\subsection{Zweites Beispiel}

Da im zweiten Beispielfall Rhythmus als wichtiges weiteres Stilmittel verwendet wird, präsentiere ich dieses Transkript ab Zeile 9, wenn relevant, in der von Couper-Kuhlen/Auer (1991) entwickelten Rhythmusnotation. Hierbei werden die einzelnen Akzenteinheiten (oder Kadenzen) aus Akzentsilbe mitsamt ihrer jeweils folgenden unakzentuierten Silben untereinander angeordnet. Wenn die Begrenzungsquerstriche $(/ /)$ zweier Akzenteinheiten untereinander stehen, zeigt dies einen wahrgenommenen gleichmäßigen, d.h. isochronen, Rhythmus mit ungefähr gleich langen Akzenteinheiten an, wie in den Zeilen 12-17; ein Versetzen oder Fehlen der Striche zeigt an, daß eine Einheit gegenüber der vorherigen Einheit den Rhythmus verändert oder bricht. Meine auditive Rhythmus-Interpretation habe ich durch die Messung der Länge der Akzenteinheiten mit einer Stoppuhr überprüft; die Durchschnittswerte der Messungen sind am rechten Rand in Zehntelsekunden angegeben.

Die nun folgende Erzählung wird von der Erzählerin als Belegerzählung innerhalb einer Argumentation präsentiert, um die These zu stützen, daß nach Ehescheidungen Frauen meistens besser mit ihren Problemen zurecht kommen als Männer. Ida bringt das Beispiel ihrer Nachbarn und erzählt deren Geschichte. Am rechten Rand des Transkripts ist die Segmentierung der Erzählung in ihre Teilaktivitäten nach der Analyse und Begriffichkeit von Kallmeyer/Schütze (1977) und Kallmeyer (1981) angegeben.)

(2) „Der widerliche Kerl, der von seiner Frau verlassen wurde” (K3: 495-550, Laufnr. Uher 220-256, Dauer: ca. 2 Minuten;

Gesprächspartner: 3 Studierende: Ida und Nat (weibl.), Ron (männl.))

1 Nat: $\underset{M(-)}{J A}($.$) da die vIERziger generation so=$

2 Nat: [ =das is WA:HNsinnich viele die sich da habm SCHEIdn lassn

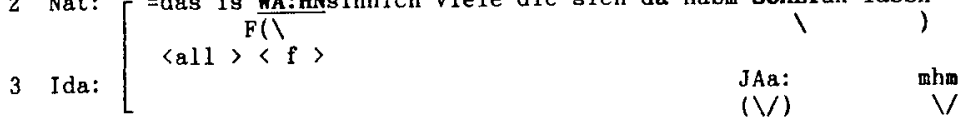




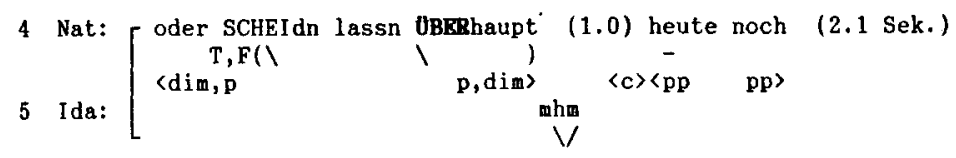

6 Nat: $\$$ is der UMbruch

〈p $\quad F(\backslash) \quad$ p $>$

Ankündigung

der Erzählg

7 Ida: $n$ besonders Gutes beispiel das warn mal unsre MaCHbarn (1.0) $\mathrm{M}, \mathrm{F}(\mathrm{)}$ $<1$

1)

Ereignisträger

ähm (1.0)

Ereigniskette:

Hintergrund,

Vorgeschichte

9 / DREIBich jahre ver

/ $10.7 /$

10 $M()$

\%.7\%

/ HEIratet $(0.5)$

11

das letzte kind (.)

12

/ ENDlich ausm

$10.7 /$ M(I

13

Haus zum stu
$/ /$

$10.7 /$

DI ERN $(0.5)$ $\mathrm{M}(/)$

$10.7 /$

14

/ WEGgegangn ne $\mathrm{M}(/) /$

$10.7 /$

15

$/(0.5)$ nach ber

$10.7 /$

16

$/ \operatorname{LIN}(0.5)$

$10.7 /$

$\mathrm{M}(/)$

$10.6 /$

$/$ und (.) die

/

$10.8 /$

/ ALtere tochter is

/

(1)

AUCH in berlin ge

$10.8 /$

20 I

und: der 
23

24

25

26

27

28

29

30

31

32

33

34

35

36

37

38

39

40

KER:L: das war aber ein pene $M(\backslash /)<t$

\section{/ H:IDERl ing=}

$\langle$ f

$10.6 /$

$=\mathrm{also}(1.0)$

der

$$
\text { / } \operatorname{HAT}_{\text {(l) }}(\text { ) ä sein }
$$

/ GARtn wie (.)

10.81

\langle

As $(0.5) \mathrm{ge}$

10.81

/ FLEcht ne (.)

/ $\underline{\text { EEIN }}$ 

1,1

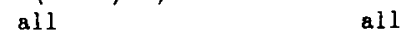

all

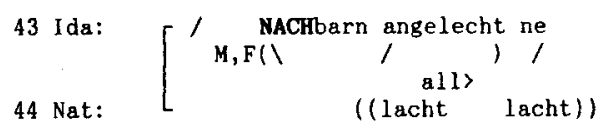

45

(1.2)

46 Ida: und

47

/ WENN da: M()

48

/ EINmal:

$/ 0.3 /$

48

49

/ JEmand zum 1

50

/ ABschied ge

I

51

$/$ HUPT hat da

i /

52

/ WAR der in M()

53

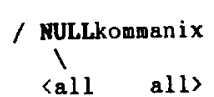

〈all all>

54

$/$ DRAUBen un: $d$ hat da

56 Ida: $[/$ ZBI : un so

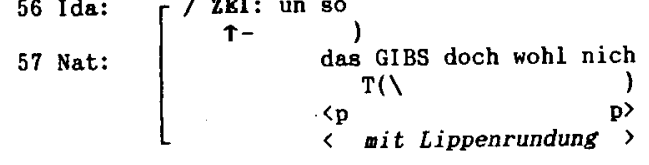

Bew. 2

58 Ida: ja (.) V:OLLkommn WIderlich ne (0.6)

Bew. 3 
59 un: $2(0.5)$ denn HAT er doch son (.) son KLEIY BA:rt: Mi

60 Ida: [ hier ne (.) un ham wir immer gesacht HITler ne M( <all

schub

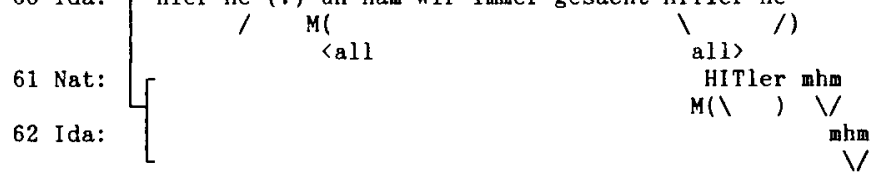

63 Ida: [ ((lacht verstohlen, ca. 1.2 Sek. ))

64 Nat: [( (3acht verstohlen, ca. 1.2 Sek. $))$

Ereignissituation

65 Ida: ja un DANN PLOTZlich $(0.6)$ is seine FRAU abgehaun ne= (a) $F(/ \quad T)$

68

$$
/ \underset{\text { M( }}{\text { LIN }} \text { zu den }
$$

69

$$
\text { / } \mathbf{M I N d e r n}
$$

70

$/(0.4)$ un

$10.5 /$

71

$$
\underset{M(-}{\mathrm{DA}:(.)}
$$

/ NEUes

$$
/ \text { JAHRN ne }
$$

76 Nat: / Mhm

77 Ida: und ER: alLEIne (1.1) 
78

79

80

81

82

83

84

85

86

87

88

89

90

KONNte das HaUs nich mehr (.) haltn $M(\backslash$

mußte das verkaUfn glaub ich (1.0)

M( $),$

daß er das verKAUFT hat (.) GLAUB ich wohl (0.5)

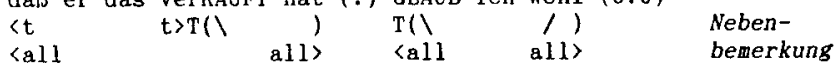

un is

SEI :Tdem:
$<1$

$10.7 /$

/ TA:L zer

F( 1

$10.7 /$

/ FALLN=irgnwie so richtich

$1)$ (all all)

$11>$

/ FORMlich

10.41

/ ZER:

$<1$

$10.4 /$

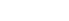

$$
\text { / FaLLN ne }
$$

$10.4 /$

$/ 1.1 /$

$(0.6)$

der hats überHAUPT nich (.) vk (.)

()

von alLEIne wär der nie wieder aufe beine gekommn ne $(0.6)$

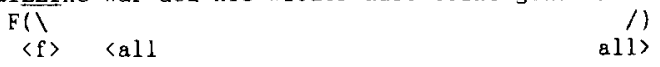

all)

91 Ida: [ JETz wohnt er nämlich mit seiner SCHWster zusammn (0.7)

92 Nat: 〈all all> (( lacht $))$

93 Ida: [ un die

94 Nat: [ ( lacht

95 Ida: $\left[\begin{array}{c}/ \text { LAUfen: } \\ \text { F( }\end{array}\right.$

10.51 


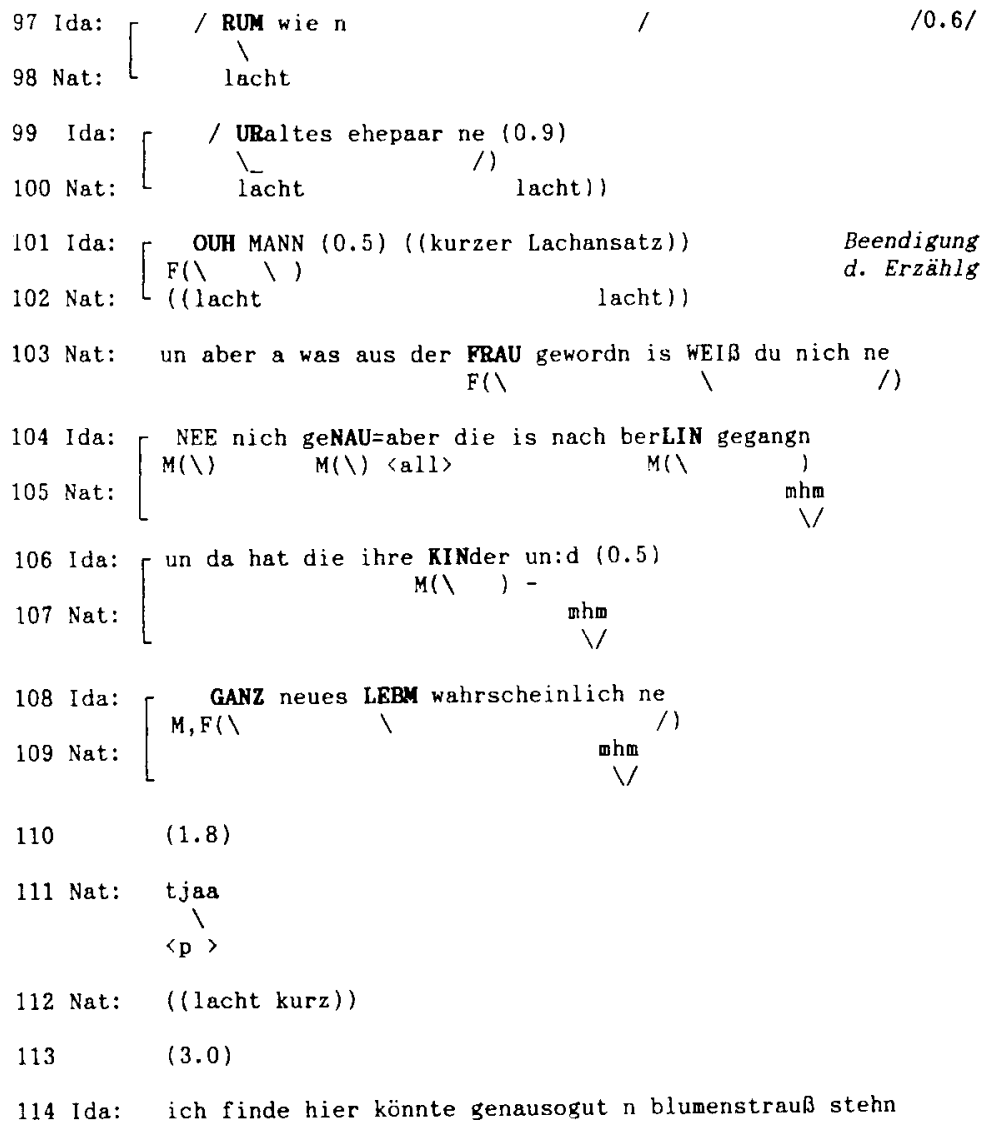

Die Erzählung ist eine Belegerzählung, in der Probleme und Problembewältigungen eines Paares dargestellt werden. Sie läuft nicht, wie viele belustigende Alltagserzählungen, auf einen e in z ig e n Höhepunkt zu. Vielmehr stellt Ida zuerst die Zuspitzungen und Höhepunkte der Entwicklung für die beiden Ereignisträger dar, bevor sie den Relevanzpunkt der Erzählung im Rahmen der Argumentation mit weiteren Höhepunkten gestaltet. Diese Höhepunkte sind keine sequentiellen Strukturerfordernisse der Erzählung, sondern signalisierte Höhepunkte emotionaler Beteiliģung durch die Erzählerin. 
Die Erzählung besteht aus folgenden Teilaktivitäten: Nach der Ankündigung einer Belegerzählung in Zeile 7 stellt Ida in den Zeilen 9-21 die allgemeine Familiensituation vor der Ereignissituation dar, bevor sie in den Zeilen 22-23 den Familienvater als ersten Ereignisträger fokussiert und in den Folgezeilen 23-57 genauer charakterisiert. Diese Charakterisierung bildet die Vorgeschichte zu der in Zeile 65 erzählten Ereignissituation, daB die Frau dieses Mannes als zweite Ereignisträgerin ihn dann plötzlich verlassen und ein ganz neues Leben begonnen habe. Als Nachgeschichte stellt Ida dann den eigentlichen Relevanzpunkt dieser Belegerzählung dar, nämlich daB in der Folge der Mann "total zerfallen" sei und seine Probleme schlechter bewältigt habe.

Um zu verdeutlichen, wie die Erzählerin die Entwicklung mit Hilfe ihres Sprechstils kontextualisiert, werde ich die Verwendung der sprechstilkonstitutiven Signalisierungsmittel aus den Bereichen Lexiko-Semantik, Syntax und Prosodie in den aufeinander folgenden Teilaktivitäten wiederum explizieren und miteinander vergleichen. Meine Analyse wird sich vor allem auf die Beschreibung des Verhaltens des Mannes und die darauf folgende Reaktion der Rezipientin richten. Aus Platzgründen muB ich die anderen Teile kursorischer behandeln.

\section{Der Anfang der Erzählung}

Nach der Ankündigung der Erzählung beschreibt Ida in den Zeilen 921 die allgemeine Familiensituation ihrer Nachbarn. Hier verwendet sie eine ganz normale, unauffälige Lexik. Syntaktisch ist diese Beschreibung schon ungewöhnlicher: Nach der Erzählankündigung verwendet Ida nämlich zunächst fünf infinite Phrasen, bevor sie als letzte Phrase dieses Teils wieder einen syntaktisch vollständigen finiten Satz formuliert. ${ }^{6}$ Diese Konstruktionen stellen die Trägerkonstruktionen für einen sehr regelmäBig organisierten Rhythmus her. Die akzentuierten Silben folgen in regelmäßigen Zeitintervallen aufeinander und bilden somit einen isochronen Rhythmus mit Akzenteinheiten von um die 0.7 Sekunden Länge. Intonatorisch werden zunächst zwei Konturen mit einer fallenden und einer steigenden Akzenttonhöhenbewegung produziert, daran anschließend dann drei jeweils prosodisch selbständige Nachträge zu den Vorgängereinheiten, die die steigenden letzten Tonhöhenbewegungen der Konturen wiederaufnehmen, bevor wieder eine Einheit mit einer fallen-

6 Die infiniten Phrasen sind nur bedingt als Konstruktionsübernahmen (Rath 1979) mit Bezug auf die Erzählankündigung zu analysieren. Vielmehr wird hier einfach ein Zustand stichwortartig umrissen; die Explikation inferierbarer Ereignisträger und finiter Hilfsverben ist hier offenbar meist unnötig. 
den und einer steigenden Akzenttonhöhenbewegung formuliert wird. Die unauffällige Lexiko-Semantik, die syntaktisch infiniten Phrasen und der regelmäßige, aber unauffällige Rhythmus mit sich wiederholenden Akzenttonhöhenbewegungen bilden den unmarkıerten Ausgangssprechstıl, mit dem die allgemeine Ausgangssituation kontextualısiert wird.

\section{Die Beschreibung des Verhaltens des Mannes}

Geändert wird der Sprechstıl für die Fokussierung und Charakterisierung des Mannes ab Zelle 22 Nach der Fokussierung und ersten negativen Bewertung in den Zellen 22-25 gliedert sich die Elaboration der Charakterısıerung in zweı Teıle, nämlıch die Beschreibung seines Verhältnısses zu seinem Garten in den Zellen 26-38, und die Beschreıbung seines Verhaltens gegenüber seinen Nachbarn in den Zeilen 39-56 Die genaue Gestaltung dieser Telle wird im folgenden beschrieben

Entgegen den unauffälligen lexikalischen Ausdrücken Im Ausgangsstil geht Ida ab Zeile 22 zur Verwendung stılıstisch auffälligerer Lexeme über, wie der Bezeichnung Kerl und penetranter Widerling, der Redewendung seinen Garten wie Pık As pflegen, den hyperbolıschen, übertreıbenden, Ausdrücken in keın Blätchen, und nichts, ber jeder Gelegenheıt, in den Formulierungen wenn da einmal jemand, in Nullkommanix und hat da rumgeschrieen. Wir finden hier, neben den infiniten Phrasen in den Zellen 33-38, finite Verben, mit denen habituelle Handlungen bezeichnet werden, sowie das Quasi-Zitat wörthcher Rede ıch hol die polıZEI in den Zeilen 55-56. Die allgemeine hyperbolssche Beschreibung zieht sich also über die gesamte Charakterisierung des Mannes in den Zellen 22-56 hın

Die Einhettlichkeit und Kohäsıon der Charakterısıerung des Mannes wird auch mit Hilfe der Akzenttonhöhenbewegungen signalısiert Vor allem die letzten fallend-steıgenden Akzenttonhöhenbewegungen nehmen jewells vorhergegangene Akzenttonhöhenbewegungen wieder auf und sıgnalisıeren Anknüpfung und Wetterführung

Rhythmisch ist die Charakterısierung des Mannes nicht so einheitlich Hier ist auffällig, daß nach der Fokussierung des KERLs, beı der in den Zellen 21-23 der vorherige Rhythmus gebrochen wurde, der alte Rhythmus in etwa wiederangestrebt wird Die Akzentemheiten in den Zeilen 24-32 liegen meist zwischen 06 und 08 Sekunden, werden aber auch durch eine Pause und durch eine sehr kurze Einhelt von nur 03 Sekunden Länge gebrochen Dıe alté, nahezu vollständige Regelmäßigkelt des Rhythmus wird zwar nicht wieder erreicht, dennoch sind die meisten Akzenteınheiten ungefähr gleich lang wie zuvor und bilden einen immer noch relatıv gut wahrnehmbaren Rhythmus In Zelle 33, wo auch die 
syntaktisch infiniten Phrasen wieder beginnen, wird aber dieser Rhythmus nun deutlich verändert: die Akzenteinheiten in den Zeilen 33-37 sind deutlich kürzer, nämlich zunächst dreimal 0.4 , dann je einmal 0.3 und 0.5 Sekunden. Die Akzentdichte, d.h. die Anzahl akzentuierter Silben im Verhältnis zu unakzentuierten Silben, wird sehr hoch: Z.T. werden direkt aufeinander folgende Silben akzentuiert.

Die kürzeren Akzenteinheiten mit der gröBeren Akzentdichte werden hier in Kookkurrenz mit den genannten lexiko-semantischen und syntaktischen Mitteln gebraucht, um eine Stilverschiebung zu signalisieren, die die Interpretation erhöhter 'Emphase' nahelegt. Auf diese Weise wird innerhalb der Beschreibung des Gartens die vorherige allgemeine Beschreibung der HAT sein GARtn wie PIK AS geflecht bei der Beschreibung der konkreteren Einzelheiten KEIN BLÄTTchen un NICHTS ENGlischer $R A S N$ zugespitzt und dramatisiert.

Eine ähnliche, rhythmisch angezeigte Entwicklung finden wir dann erneut bei der Beschreibung des Verhaltens des Mannes gegenüber seinen Nachbarn in den Zeilen 39-56. Nach einer kurzen Akzenteinheit von 0.4 Sekunden in Zeile 40 geht Ida für die allgemeine Beschreibung bei $J E$ der geLEgenheit hat er die poliZEI gerufen und sich mit den NACHbarn angelecht zunächst wieder zu längeren Akzenteinheiten von 0.9 und 1.0 Sekunden über; auf eine akzentuierte Silbe folgen 5-7 unakzentuierte Silben. Für die Konkretisierung und WENN da: EINmal: JEmand zum ABschied geHUPT hat da WAR der in NULLkommanix DRAUßen konstituiert sie jedoch wieder deutlich kürzere isochrone Akzent-Einheiten von zuerst einmal 0.3 und dann sechsmal 0.4 Sekunden Länge; auf eine akzentuierte Silbe folgen meistens nur noch eine bis zwei unakzentuierte Silben. Im Vergleich zur vorherigen Stilverschiebung liegt hier ein krasserer und abrupterer Stilwechsel vor: nach den einheitlich längeren Akzenteinheiten und einer Pause wird zu den einheitlich kurzen Akzenteinheiten gewechselt. Im Unterschied zu den vorherigen Konturen aus fallenden und steigenden Akzenttonhöhenbewegungen werden nun auch vorwiegend Konturen mit nur fallenden Akzenttonhöhenbewegungen konstituiert. Auch mit Hilfe dieses Stilwechsels wird die vorherige allgemeine Beschreibung bei der Konkretisierung zugespitzt und dramatisiert.

Nach dieser Zuspitzung bricht Ida in Zeile 54 den Rhythmus und geht wieder zu zwei längeren Akzenteinheiten über. Sie formuliert hier aber eine stilisierte Wiedergabe wörtlicher Rede des Mannes, die sie mit einer gleichbleibenden hohen Akzenttonhöhenbewegung zum Ausdruck der Stilisierung enden läßt. Dieses stilisierte Zitat wirkt nun wie ein durch den markierten emphatischen Stil vorbereiteter und „auf die Spitze ge- 
triebener" Höhepunkt der Vorgeschichte. Mit Hilfe des Sprechstils wird also die Charakterisierung des Mannes zu einem Höhepunkt gebracht; die Bewertung ist eindeutig negativ.

Die Reaktion der Zuhörerin

Im AnschluB an diese Signalisierung eines Höhepunktes reagiert Nat in Zeile 57 mit ihrer Bewertung das GIBS doch wohl nich. Diese ist zwar einerseits durch tiefe globale Tonhöhe und geringe Lautstärke als nicht das Rederecht beanspruchende Nebenbemerkung kontextualisiert, sie ist aber andererseits kein einfaches Rezeptionssignal, sondern eine explizite Bewertung, die eine ganze Nebensequenz auslöst. Die Frage, die sich hier stellt, ist: Wieso erfolgt an dieser Stelle eine derartige Reaktion, obwohl doch Ida erst die Vorgeschichte und noch gar nicht den "eigentlichen” Höhe- und Relevanzpunkt der Erzählung geliefert hat? Handelt es sich dabei um eine zufällige Reaktion oder ist sie das Resultat koordinierter Interaktion?

Nats Reaktion an dieser Stelle ist durch zwei Faktoren zu erklären: (1) eine offene Bewertungssequenz und (2) eine fällige Reaktion auf die Signalisierung erhöhter Emotionalität. In Konversationen machen nämlich erste Bewertungen eine zweite Bewertung des Rezipienten erwartbar, vorzugsweise eine gleichlaufende (vgl. Pomerantz 1978, 1984). Im vorliegenden Fall wurde jedoch die erste negative Bewertung des Mannes bereits in den Zeilen 22-25 von Ida formuliert und durch die Erzählung der Vorgeschichte plausibilisiert. Nun ist also eine zweite Bewertung durch Nat erwartbar. - In ähnlicher Weise macht auch eine erste Zurschaustellung erhöhter emotionaler Beteiligung durch einen Sprecher ebenfalls eine Reaktion des Rezipienten relevant, vorzugsweise eine, die Übereinstimmung ausdrückt (Selting 1994; vgl. auch Kallmeyer 1979, Fiehler 1990). Andernfalls gerät das rituelle Gleichgewicht (Goffman 1967) aus dem Lot, mit der Gefahr, daß sich der Sprecher "hängen gelassen" fühlt.

Beim signalisierten Höhepunkt der Vorgeschichte kommen also zwei Strukturstellen zusammen, die beide eine Reaktion von Nat verlangen. Mit der Art der Formulierung ihrer Reaktion wird Nat dabei diesen Strukturerfordernissen im spezifischen Rahmen der noch nicht beendeten Erzählung gerecht: Sie liefert eine mit Idas Bewertung gleichlaufende zweite Bewertung und signalisiert dabei eine mit Ida übereinstimmende 
emotionale Haltung, beansprucht aber nicht das Rederecht - Nats Reaktion ist mithın von Ida "hervorgelockt” und sie stützt Idas Erzählprozeß.

Nats Reaktion löst dennoch eine ganze Nebensequenz aus: Sie zieht eıne Bestätigung durch Ida und einen Einschub zwecks Spannungssteigerung nach sich. Diese Einheiten sind nicht rhythmisch organısıert

Die Darstellung der Reaktion der Frau

Die Erzählung wird mit Idas Präsentation der Ereignissituation in Zelle 65 und deren Elaboration in den Folgezeilen fortgesetzt Nun ist die Frau Ereignisträgerin. Die Ereignissituation selbst wird lexıkalisch mit Hilfe des Schlüsselbegriffs $P L O ̈ T Z l ı c h$ und der Ereignisbeschreıbung is seıne FRAU abgehaun benannt, die weitere Angabe von HEUT auf MORgen in Zeile 66 hebt noch einmal die Unerwartetheit der Ereignissituation hervor Die Formulierung der Ereignissituation un DANN PLÖTZlich (0.6) is setne FRAU abgehaun hat zwar z.T. dicht aufeinander folgende Akzente, wird aber nicht rhythmisch organisiert. von HEUT auf MORgen wird sehr schnell an de Vorgängereinheit angeschlossen, als solle auch mit prosodischen Mitteln noch einmal ikonısch die Unerwartetheit der Ereignissituation ausgedrückt werden.

Diese allgemeine Darstellung der Ereignissituatıon wird in den Folgezellen 67-75 mit immer detaillierteren Angaben zum Ziel und zur Bedeutung der Flucht für die Frau konkretısıert Syntaktısch gebraucht Ida dabei wieder infinite Phrasen, die in einzelnen prosodischen Einheiten organlsiert werden. In den Zeılen 67-72 konstıtuiert sie eınen Akzentrhy thmus mit zunächst kurzen Akzenteinheiten von 04 bzw 05 Sekunden Länge, bricht diesen Rhythmus jedoch in Zelle 73 mit einer sehr langen Einheit, um in den Zeilen 74-75 den alten Rhythmus wieder aufzunehmen und fortzusetzen. In den kurzen Akzenteinheiten folgen einer akzentuierten Silbe zuerst noch zwel, dann eine akzenturerte Silbe Die Tonhöhenbewegungen variieren. - Auch bei dieser Konkretisierung konstituieren vor allem die syntaktisch infiniten Phrasen und der Akzentrhythmus mit z.T. einer hohen Akzentdıchte einen Wechsel zu einem markıerten, emphatischen Sprechstil Damit werden diese Einheiten erneut als eine Art Höhepunkt dargestellt, nun aber ein Höhepunkt im Verhalten der Frau, die implizıerte Bewertung durch die Erzählerın ist eindeutıg posıtıv Nats Reaktion $M h m$ erfolgt genau integriert in den von Ida etablierten Rhythmus. ${ }^{7}$

7 Vielleicht reicht hier wegen der Nähe der Reaktion zu Idas positiver Bewertung ein einfaches $M h m$ aus. 
Die Darstellung der Nachgeschichte

Ab Zeile 77 erzählt Ida dann die Nachgeschichte für den Mann. Sie beginnt in den Zeilen 77-80 mit der materiellen Folge, daß er das Haus verkaufen mußte, schildert danach in den Zeilen 81-87 die persönlichpsychologische Folge, daß er toTA:L zerFALLN sei, und karikiert ab Zeile 89 seine heutige Situation.

Die ÄuBerungen in den Zeilen 77-80 sind weder lexiko-semantisch, noch syntaktisch bemerkenswert; allerdings werden auch hier syntaktisch kohäsive Einheiten prosodisch „zerstückelt"; die ausgerechnet hier wieder fehlende rhythmische Organisation könnte man vielleicht, wie schon bei den Zeilen 65-66, als ikonische Nahelegung der Interpretation auffassen, daB der Mann durch das Handeln seiner Frau auch aus seinem Lebens-Rhythmus geraten sei.

In den Zeilen 81-87 stellt Ida die persönlich-psychologischen Folgen für den Mann dar. Lexikalisch verwendet sie hier wieder hyperbolische und intensivierende Ausdrücke, nämlich die Abverben toTA:L und so richtig FÖRMlich und auch das Verb zerfalln. Das erste to TA:L zerFALLN wird wiederholt und auch noch verstärkt zum irgnwie so richtig FÖRMlich ZER:FALLN. Die zweite Version des ZER:FALLN wird dabei durch eine zusätzliche Dehnung und einen zusätzlichen Akzent gegenüber der ersten Version noch weiter prosodisch markiert.

Hier werden zunächst längere und dann kürzere Akzenteinheiten und hohe Akzentdichte mit auffällig langsamer Artikulationsgeschwindigkeit kombiniert. Die Akzenteinheiten sind hier zunächst zweimal 0.7 Sekunden lang, der Rhythmus wird dann durch eine lange nicht-rhythmische Einheit gebrochen, bevor sich ein neuer Rhythmus mit drei 0.4 Sekunden kurzen Akzenteinheiten etabliert. Obwohl die ersten Einheiten noch relativ lang sind, ist die Akzentdichte hoch: auf eine akzentuierte Silbe folgen in Zeile 82 zwei und in Zeile 83 nur eine unakzentuierte Silbe; in den kurzen Akzenteinheiten folgen auf eine akzentuierte Silbe in Zeile 85 eine, in Zeile 86 keine und in Zeile 87 wieder eine unakzentuierte Silbe. Eindeutig ist wieder die Signalisierung emphatischen Stils, jedoch ist die nun nahegelegte weitere Interpretation aufgrund der andersartigen Lexik ganz anders als die vorherige: eine ikonische Darstellung und Nachzeichnung des Zerfalls mit prosodischen Mitteln.

Im Rahmen der gesamten Belegerzählung ist dieser Sachverhalt der angekündigte Beleg für die These, daß Männer nach einer Ehetrennung schlechter zurecht kommen als Frauen. Mit den genannten sprechstilistischen Mitteln wird diese Beschreibung auch als ein Höhepunkt der Nachgeschichte präsentiert, jedoch ist dieser Höhepunkt als das genaue 
Gegenteil der vorherigen Höhepunkte kontextualisiert. Plakativ könnte der nahegelegte Gegensatz wie folgt formuliert werden: Während die vorherigen Höhepunkte die Interpretation von Zuspitzungen und Höhepunkten energischer Aktion und Reaktion nahelegten, legt die Gestaltung des letzteren Höhepunktes die Interpretation kraftlosen Absinkens in den Zerfall nahe.

Auf diesen Höhepunkt folgt keine verbal explizite Rezipientenreaktion; vermutlich weil auf der Grundlage des als gemeinsam unterstellten kulturellen Wertesystems einerseits Mitleid mit einem zuvor als sehr negativ charakterisierten Menschen unangebracht ist, andererseits aber ein Lachen als Reaktion auf den erzählten Zerfall eines Menschen, und sei er noch so ein peneTRANter WIDERling, moralisch als anstößig gilt und der Lacherin selbst einen $z$ weifelhaften Ruf einbringen könnte. - Im weiteren faBt Ida die Situation des Mannes zusammen und erzählt die Nachgeschichte weiter. Nach einigen nicht-rhythmischen Äußerungen in den Zeilen 89-91, in denen Ida erzählt, daB der Mann nun mit seiner Schwester zusammenlebt, geht sie in den Zeilen 95-99 erneut zu drei rhythmischen Akzenteinheiten über, mit denen sie quasi einen neuen Lebens-Rhythmus des neuen Paàres nahelegt und karikiert. Darauf kann ich nicht mehr im Detail eingehen. Beginnend mit Idas Erwähnung der Schwester des Mannes als seiner neuen Partnerin in Zeile 91 liefert Nat durchgängig das für belustigende Erzählungen erwartbare Lachen als Rezipientenreaktion und signalisiert damit ihr Verständnis dieses nun letzten, belustigenden Höhepunktes von Idas Erzählung.

\section{Fazit der Analysen}

Ich habe zu zeigen versucht, wie die Erzählerinnen ihren Sprechstil einsetzen und verändern, um ihre Erzählungen und deren Teile intern zu gestalten und interpretierbar zu machen. Dabei müssen sowohl das Konstitutionsschema des Aktivitätstyps Erzählen mit seinen konstitutiven Teilaktivitäten, als auch der je konstituierte Sprechstil als voneinander unabhängige Ressourcen der Handlungs- und Gesprächsorganisation aufgefaßt werden. Mit Hilfe des Sprechstils können Erzählungen und ihre Teilaktivitäten je unterschiedlich und auf die konkrete Erzählsituation und die konkreten Gesprächspartner zugeschnitten gestaltet werden, z.B. auch mit nur einem oder mehreren Höhepunkten. Im zweiten Beispiel wird innerhalb jeder der Teilaktivitäten Darstellung der Ereigniskette, der Ereignissituation und der Nachgeschichte eine interne Entwicklung zu einem Höhepunkt hin kontextualisiert. Dabei ist die interne Entwicklung und Zuspitzung innerhalb der einzelnen Teilaktivitäten des Erzählens nur anhand des Sprechstils erkenn- und rekonstruierbar. An 
diesen Höhepunkten signalisiert die Erzählerin mit Hilfe des emphatischen Sprechstils erhöhte emotionale Beteiligung, die eine Rezipientenreaktion relevant macht.

In den Beispielfällen verwenden die Erzählerinnen lexiko-semantische, syntaktische und prosodische Mittel, um ihren Sprechstil herzustellen und zu verändern. Obgleich die Herstellung und Veränderung von Stilen von Rezipienten holistisch wahrgenommen und funktional interpretiert wird, können sie analytisch in ihre konstitutiven Einzelparameter dekomponiert werden. Mit Bezug auf diese Einzelparameter können Stile wie auch Stilveränderungen als aktiv hergestellte und flexibel veränderbare linguistische Signalisierungsmittel beschrieben werden.

Die Erzählerinnen verwenden Bündel markierter Stilmittel, um einen auffäligen, markierten Sprechstil herzustellen, den ich 'emphatischen Stil' genannt habe. 'Emphatischer Stil' wird durch die Verwendung einer markierten Prosodie, vor allem einer gegenüber den umliegenden Einheiten auffälig erhöhten Dichte akzentuierter Silben, gegebenenfalls in rhythmisch isochronen Akzenteinheiten, in Kookkurrenz mit syntaktischen und lexikalischen Signalisierungsmitteln konstituiert. 'Emphase' ist dabei eine kontextspezifische Interpretation der konstituierten Sig nalbündel bei bestimmten sequentiellen Aktivitäten in Konversationen; die gleichen Signale können bei anderen Aktivitätstypen gegebenenfalls auch die Interpretation 'Erstaunen' nahelegen (siehe Selting 1994 und im Druck).

Die Kontextualisierungshinweise, mit denen 'emphatischer Stil' hergestellt wird, können kurz in einem Bündel konstitutiver Signale wie folgt ausgedrückt werden:

entweder [+ (maximal) dicht akzentuierte Silben] oder[ + rhythmisch isochrone kurze Kadenzen/Akzenteinheiten];

[ \pm markierte lokale und/oder globale Tonhöhenbewegungen und/oder Lautstärkeveränderungen und/oder Länge]

[ \pm syntaktische und lexikalische Signalisierungsmittel]

Je mehr hyperbolische Ausdrücke und infinite Phrasen verwendet werden und je dichter die Akzentuierung wird, gegebenenfalls bei rhythmisch isochronen kurzen Akzenteinheiten, um so mehr wird eine Interpretation in Richtung 'emphatisch' nahegelegt. Andere prosodisch markierte Signalisierungsmittel, wie markierte Tonhöhenbewegungen, können hinzukommen, um die Höhepunkte weiter zu gestalten und/oder Beziehungen von Einheiten zueinander prosodisch zu kontextualisieren.

Die Beschreibung der Stilveränderungen könnte man quantifizieren, indem man Anzahl und Gewicht der Stilmerkmale in den jeweils aufein- 
anderfolgenden Einheiten auch quantitativ vergleicht. Man käme dann zu Aussagen wie: Je mehr und je klarere Stilmerkmale für einen 'emphatischen Stil' gewählt werden, um so deutlicher wird eine Äußerung als 'emphatisch' kontextualisiert. Stilveränderungen sind dann als entweder abrupte 'Stilwechsel' von einem Stil zum anderen oder als langsamere 'Stilverschiebungen' von einem Stil zum anderen zu beschreiben (vgl. hierzu auch Selting 1989).

Eine Stilveränderung in Richtung eines 'emphatischen Sprechstils' signalisiert im Rahmen der Erzählung Zuspitzungen und Höhepunkte mit der nahegelegten Interpretation erhöhter Emotionalität. Eine Zurschaustellung von Emotionalität durch einen Sprecher macht aber eine vorzugsweise Übereinstimmung ausdrückende Reaktion des Rezipienten relevant. Deshalb eignet sich im Rahmen einer konversationellen Erzählung eine Stilveränderung zum emphatischen Stil als hervorragende Technik der Anforderung von Rezipientenreaktionen. Die Herstellung eines emphatischen Sprechstils kann als konversationelle Technik verwendet werden, die Demonstration interaktiver Reziprozität zu organisieren. ${ }^{8}$ Das heiBt, daß die analysierte Art der sprechstilistischen Gestaltung der zweiten konversationellen Erzählung durch Ida als Technik interpretiert werden kann, ihre Rezipientin Nat beständig zu Rezipientenreaktionen und mithin einer kooperativen Begleitung ihrer Erzähltätigkeit zu veranlassen.

Emphatischer Stil löst keine eigenen Sequenzen aus, sondern kontextualisiert lediglich Höhepunkte a I s solche. Danach scheinen die aktivitätstyp-spezifischen Rezipientenreaktionen lokal relevant zu werden. Die Rekonstruktion der interaktiven Organisation von Höhepunkten, d.h. ihrer Vorbereitung durch den Sprecher wie auch ihrer Implikationen für die danach relevanten Rezipientenreaktionen, liefert gleichwohl Evidenz, daB Sprecher und Rezipienten sich tatsächlich an den mit Hilfe des emphatischen Stils kontextualisierten Höhepunkten orientieren.

Für die Beschreibung der Oberflächenstruktur mündlicher Erzählungen legt dies nahe, neben den bisher v.a. erforschten Teilaktivitäten und Prinzipien der kontextspezifischen und auf den Rezipienten bezogenen Präsentation und Linearisierung der kognitiven Geschichte auch die sprechstilistischen Techniken der Gestaltung der Erzählung genauer

8 Dies erklärt auch, weshalb wir manchmal das Gefühl haben, im Anschluß an einen bestimmten Punkt einer Erzählung unseres Gesprächspartners lachen zu müssen, obwohl wir vielleicht den Inhalt der Erzählung gar nicht gehört oder verstanden haben: wir reagieren offenbar lokal auf die Technik der Kontextualisierung einer Pointe mit Hilfe des Sprechstils. 
zu untersuchen: damit schneiden Erzähler ihre Erzählung genau auf den konkreten Zuhörer zu und organisieren den Interaktionsprozeß.

Bei diesen Signalen handelt es sich um keine zusätzlichen, aber im Prinzip vernachlässigbaren, sondern um konstitutive Signale, mit denen die entsprechenden Aktivitäten in der mündlichen Kommunikation erst als solche erkenn- und interpretierbar gemacht werden. In den vorliegenden Beispielen waren die Höhepunkte der Erzählungen nur aufgrund ihres Sprechstils als solche erkennbar; mit anderem Stil wären die betreffenden Einheiten durchaus noch als weitere Elemente der Ereigniskette interpretierbar. Wenn das Ziel linguistischer Forschung darin besteht, die Grundlagen unseres Verstehens gesprochener Sprache als sprachliche Handlungen und Aktivitäten in Interaktionskontexten zu explizieren, dann folgt aus meiner Analyse, daß eine solche Explikation nicht ohne die systematische Berücksichtigung prosodischer und anderer sprechstilistischer Signalisierungsmittel möglich ist.

\section{Das methodologische Problem des Nachweises von Stilwirkungen}

Der 'emphatische Stil' macht also Rezipientenreaktionen im Rahmen konversationeller Erzählungen relevant, eröffnet aber $k$ e i n e eigenständige Sequenz. Diese Eigenschaft teilt er mit anderen Stilen. Sandig (1986) spricht auch von Stil als 'Gleichzeitighandlung'. Die Folge dieses Stellenwertes von Stil ist jedoch das methodologische Problem der Stilforschung, den empirischen Nachweis für die zugeschriebene Stilwirkung oft schuldig zu bleiben.

Als stärkste Form der Evidenz für Stilwirkungen müßten im Rahmen einer konversations- und kontextualisierungsanalytischen Untersuchung Einklagungen und ähnliche Rezipientenreaktionen herangezogen werden. In den vorliegenden Gesprächsausschnitten reagieren die Rezipienten aber nur mit den im Rahmen von Erzählungen relevanten Rezipientenreaktionen auf die Höhepunkte. Die Höhepunkte wurden mit Hilfe des markierten Stils signalisiert und als solche erkennbar gemacht. Für die Stilanalyse besteht nun das Problem darin, daß die Rezipienten aber eben nicht auf den $S \mathrm{t}$ i l s e l b s t reagieren, sondern auf die mit Hilfe des Stils kontextualisierten Höhepunkte. Wie kann man dann aber die interaktive Relevanz und die Wirkung der „unselbständigen” 'Gleichzeitighandlung' Stil systematisch nachweisen?

Ich habe zu zeigen versucht, daß man insbesondere die systematische empirische Analyse von Stilveränderungen für die Analyse der Relevanz und der Wirkung von Stil nutzen kann. Wenn Stile und Stilveränderun- 
gen systematisch für Aktivitäten wie die Gestaltung konversationeller Erzählungen verwendet und die je konstituierten Stile von den Sprecherinnen s e l b s t systematisch lokal kontrastiert werden, dann kann ihre Verwendung nicht zufälig sein. Stile kontextualisieren konversationelle Aktivitäten und Stilveränderungen kontextualisieren den Übergang von einer zur anderen Teilaktivität oder Modalitätsveränderungen innerhalb derselben Teilaktivität, die unterschiedliche Interpretationen nahelegen. Wenn Rezipienten sich am Stil von Aktivitäten orientieren, dann hat der Stil zumindest eine aktivitäts-kontextualisierende Funktion und Wirkung, die systematisch und empirisch nachweisbar ist.

Im einzelnen können bei der Suche nach Evidenz für die interaktive Relevanz von Stil und Stilwirkungen mindestens folgende Verfahren herangezogen werden (vgl. Wootton 1989 für Details zu einigen dieser Verfahren):

(1) die Analyse der Kookkurrenz prosodischer und syntaktischer Stilmittel mit verbal expliziteren lexikalischen Signalisierungsmitteln,

(2) die Analyse der erwartbaren Verwendungsweisen und Verwendungsrestriktionen von Stilen in Relation zu Aktivitäten,

(3) der Vergleich des Stils einer Aktivität mit einem (unmittelbar) zuvor verwendeten Sprechstil als einem dynamischen und von den Teilnehmern selbst produzierten tertium comparationis, an dem sich Interaktionspartner orientieren (siehe Selting 1989),

(4) die Rekonstruktion der Funktion, des nahegelegten Interpretationsrahmens, und der interaktiven Organisation der Verwendung und/oder Veränderung des Stils im Gesprächskontext,

(5) die Rekonstruktion der Interpretation und Behandlung des Stils bzw. der damit kontextualisierten Aktivitäten durch die Rezipienten im nachfolgenden Kontext,

(6) die Rekonstruktion der Interpretation und Behandlung abweichender Fälle, in denen der Stil entgegen den Erwartungen verwendet wird.

In der hier verfolgten Sichtweise ist Stil ein aktiv hergestelltes, flexibles, dynamisches, auf den Zuhörer/Rezipienten zugeschnittenes sprachliches Gestaltungsmittel, an dessen Herstellung, Aufrechterhaltung und Veränderung Sprecher und Hörer-Rezipient gleichermaßen beteiligt sind. 'Stil' ist ein komplexes, holistisches Gestaltungsmittel, das Sprecherinnen und Sprecher durch die Wahl kookkurrierender Stilmittel aus unterschiedlichen linguistischen Subsystemen, sowie durch die Herstellung spezifischer Sprechhandlungstypen und Sprechhandlungssequenzen signalisieren. Wenn man das holistische Gestaltungsmittel Stil jedoch in seine einzelnen konstitutiven Stilmittel dekomponiert, dann ist mit Bezug auf diese Stilmittel Stilwahl wie auch Stilveränderung als aktiv und 
situativ veränderbares Signalisierungsmittel analysierbar. Stil wird als Kontextualisierungshinweis verwendet, d.h. mit Stil werden Interpretationsrahmen für die Interpretation von Aktivitäten in Situationskontexten nahegelegt. In dieser Perspektive ist Stil dann nicht nur eine Varietät, die entsprechend oder aber entgegen den mit spezifischen Situationen, Aktivitätstypen, Gesprächsmustern, Institutionen, Textsorten, Rollen oder Sprechern verbundenen Erwartungen gewählt wird, sondern Stil ist das Resultat einer interaktiv relevanten und aufeinander abgestimmten Interaktion zwischen Sprecher und Hörer-Rezipient, mithin eine 'interaktive Leistung'.

\section{Anhang: Transkriptionskonventionen}

Transkriptionszeichen in der Textzeile der Transkripte:

aber DA kam

aber DA kam

SIcher

si:cher

s:i:ch:er:

(.)

((lacht))

(? er kommt?)

a(l)so

*

n, $\mathbf{m}$

$=$

ich gehe

jaha primär akzentuierte Silben einer Einheit sekundär akzentuierte Silben einer Einheit auffällig starker Akzent Längung/Dehnung eines Lautes Dehnung eines ganzen Wortes kurzes Absetzen

Pause mit Längenangabe in Sek. para- und/oder auBersprachliche Vorgänge vermuteter Wortlaut

nicht mit Sicherheit identifizierter Laut

deutlicher Glottalverschlu $B$

silbische Laute wegen Sonorität und Länge schneller Anschluß

simultanes Sprechen

Intonationsnotation in der Intonationszeile:

Globaltonhöhenverläufe: (vor der "(" Klammer notiert)

F,S,H,M,T( )

Angabe des globalen Tonhöhenverlaufs vor der durch die Klammer angegebenen Akzentsequenz: $\mathrm{F}=$ fallend, $\mathrm{S}=$ steigend, $\mathrm{H}=$ hoch, $\mathrm{M}=$ mittel, $\mathrm{T}=$ tief (Klammern stehen i.d.R. vor dem ersten Akzent und am Ende der kohäsiven Einheit, bei Veränderungen zu global tiefen oder hohen Einheiten, wo auch der Vorlauf einbezogen ist, steht die erste Klammer dort, wo der Globaltonhöhenverlauf beginnt) 


$\begin{array}{ll}\mathbf{H}, \mathbf{F}() & \text { Kombination von globalen Angaben } \\ {[()()]} & \begin{array}{l}\text { zusanmengesetzte Kontur mit nur schwachen } \\ \text { oder keinen internen Grenzen zwischen unter- } \\ \text { schiedlichen Globalverläufen }\end{array} \\ & \text { "eingefügte" Kontur/Redepassage, nach der } \\ \text { die vorherige Kontur wiederaufgenommen wird }\end{array}$

Akzent(proto)typen: (immer innerhalb der „()" Klammern stehend)

fallender Akzent: F0 Gipfel im Silbenkern
bzw. kurz davor und Rest der Silbe bzw. des
Wortes und danach fallend:
steigender Akzent: F0 Tal im Silbenkern bzw.
kurz davor und Rest der Silbe bzw. kurz da-
nach steigend:
gleichbleibender Akzent: wird v.a. durch Laut-
heit und/oder Dauer konstituiert und wirkt
ggf. wie etwas gegen den Globaltonhöhenver-
lauf gehalten:
fallend-steigender Akzent: wie fallender Ak-
zent auf einer akzentuierten Silbe plus stei-
gende F0 auf einer späteren unakzentuierten
Silbe
steigend-fallender Akzent: wie steigender Ak-
zent auf einer akzentuierten Silbe plus fallende
F0 auf einer späteren unakzentuierten Silbe

Akzentmodifikationen:

$\uparrow \uparrow, \downarrow /$

lokal größere Tonhöhenbewegungen bei einem Akzent, höherer Gipfel und/oder größere Bandbreite als bei den umliegenden Akzenten Folge von schwachen Akzenten bzw. unakzentuierten Silben innerhalb des Globalverlaufs

Andere prosodische Parameter, die lokal oder global vorkommen und deren Länge durch die Position der $"<>$ angegeben wird:

$\begin{array}{ll}<\mathrm{f}\rangle & \text { forte, laut } \\ <\mathrm{l}\rangle & \text { lento, langsam } \\ <\mathrm{p}\rangle & \text { piano, leise } \\ <\mathrm{pp}\rangle & \text { pianissimo, sehr leise } \\ <\mathrm{all}\rangle & \text { allegro, schnell } \\ <\mathrm{dim}> & \text { diminuendo, leiser werdend }\end{array}$




\section{Literatur}

Auer, Peter (1986): Kontextualisierung. In: Studium Linguistik 19, S. 22-47.

Auer, Peter (1992): Introduction: John Gumperz' appraoch to contextualization. In: Auer, Peter/di Luzio, Aldo (eds.) (1992): The Contextualization of Language. Amsterdam. S. 1-38.

Couper-Kuhlen, Elizabeth (1992): Metrical hierachies and the rhythm of conversational English. KontRI-Arbeitspapier Nr. 16, Mai 1992, Fachgruppe Sprachwissenschaft, Universität Konstanz.

Couper-Kuhlen, Elizabeth (1993): English Speech Rhythm. Form and function in everyday verbal interaction. Amsterdam.

Couper-Kuhlen, Elizabeth/Auer, Peter (1991): On the contextualizing function of speech rhythm in conversation: Question-answer sequences. In: Verschueren, Jef (ed.) (1991): Levels of Linguistic Adaptation. Selected papers of the 1987 International Pragmatics Conference. Vol II. Amsterdam. S. 1-18.

Ehlich, Konrad (1983): Alitägliches Erzählen. In: Sanders, Willy/Wegenast, Klaus (Hrsg.) (1983): Erzählen für Kinder - Erzählen von Gott. Stuttgart. S. 128-150.

Fiehler, Reinhard (1990): Kommunikation und Emotion. Berlin etc.

Garfinkel, Harold (1967): Studies in Ethnomethodology. Englewood Clifs, N.J.

Goffman, Erving (1967): Interaction Ritual. New York. (dt.: (1978) Interaktionsrituale. Frankfurt/M.)

Gumperz, John J. (1982): Discourse Strategies. Cambridge.

Gumperz, John J. (1990): Contextualization and understanding. In: Duranti, Alessandro/Goodwin, Charles (eds.) (1990): Rethinking context. Language as an interactive phenomenon. Cambridge. S. 229-252.

Gumperz, John J. (1992): Contextualization revisited. In: Auer, Peter/di Luzio, Aldo (eds.) (1992): The Contextualization of Language. Amsterdam. S. 39-54.

Gülich, Elisabeth (1980): Konventionelle Muster und kommunikative Funktionen von Alltagserzāhlungen. In: Ehlich, Konrad (Hrsg.) (1980): Erzählen im Alltag. Frankfurt/M. S. 335-384.

Hinnenkamp, Volker/Selting, Margret (Hrsg.) (1989): Stil und Stilisierung. Arbeiten zur interpretativen Soziolinguistik. Tübingen.

Jefferson, Gail (1978): Sequential aspects of storytelling in conversation. In: Schenkein, Jim (ed.) (1978): Studies in the organization of conversational interaction. New York. S. 219-248.

Kallmeyer, Werner (1979) " (Expressif) Eh ben dis donc, hein'pas bien'" - Zur Beschreibung von Exaltation als Interaktionsmodalität. In: Kloepfer, Rolf (Hrsg.) (1979): Bildung und Ausbildung in der Romania. München. S. 249-268. 
Kallmeyer, Werner (1981): Gestaltungsorientiertheit in Alltagserzählungen. In: Kloepfer, Rolf/Janetzke-Dillner, Gisela (Hrsg.) (1981): Erzählung und Erzählforschung im 20. Jahrhundert. Stuttgart etc. S. 409-429.

Kallmeyer, Werner/Schütze, Fritz (1977): Zur Konstitution von Kommunikationsschemata der Sachverhaltsdarstellung. In: Wegner, Dirk (Hrsg.) (1977): Gesprächsanalysen. Hamburg. S. 159-274.

Levinson, Stephen C. (1983): Pragmatics. Cambridge.

Liberman, Mark/Prince, Alan (1977): On stress and linguistic rhythm. In: Linguistic Inquiry 8, S. 249-336.

Mead, George Herbert (1934): Mind, Self and Society. From the standpoint of a social behaviorist. Chicago.

Michel, Gabriele (1986): Biographisches Erzāhlen. Tübingen.

Müller, Frank E. (1991): Metrical Emphasis: Rhythmic Scansions in Italian Conversations. KontRI Arbeitspapier Nr. 14, Februar 1991. Fachgruppe Sprachwissenschaft, Universitāt Konstanz.

Nespor, Marina/Vogel, Irene (1986): Prosodic Phonology. Dordrecht.

Nespor, Marina/Vogel, Irene (1989): On clashes and lapses. In: Phonology 6, S. 69-116.

Pomerantz, Anita (1978): Compliment Responses. Notes on the co-operation of multiple constraints. In: Schenkein, Jim (ed.) (1978): Studies in the Organisation of Social Interaction. New York. S. 79-112.

Pomerantz, Anita (1984): Agreeing and disagreeing with assessments: some features of preferred/dispreferred turn shapes. In: Atkinson, J. Maxwell/Heritage, John (eds.) (1984): Structures of Social Action. Studies in Conversation Analysis. Cambridge etc. S. 57-101.

Quasthoff, Uta (1980): Erzāhlen in Gesprächen. Tübingen.

Rath, Rainer (1979): Kommunikationspraxis. Göttingen.

Sacks, Harvey (1971): Das Erzāhlen von Geschichten innerhalb von Unterhaltungen. In: Kjolseth, R./Sack, F. (Hrsg.) (1971): Zur Soziologie der Sprache. Opladen. S. 307-314.

Sacks, Harvey (1988): On the Preferences for Agreement and Contiguity in Sequences in Conversation. In: Button, Graham/Lee, John R.E. (eds.) (1988): Talk and Social

Sacks, Harvey (1992): Lectures on Conversation. 2 volumes. Edited by Gail Jefferson. With an Introduction by Emanuel A. Schegloff. Oxford. Organisation. Clevedon/Philadelphia. S. 54-69.

Sacks, Harvey/Schegloff, Emanuel A./Jefferson, Gail (1974): A Simplest Systematics for the Organisation of Turn-taking for Conversation. In: Language 50, S. 696-735.

Sandig, Barbara (1986). Stilistik der deutschen Sprache. Berlin etc.

Schütz, Alfred (1974): Der sinnhafte Aufbau der sozialen Welt. Eine Einleitung in die verstehende Soziologie. Frankfurt/Main.

Selkirk, Elizabeth O. (1984): Phonology and syntax: The relation between sound and structure. Cambridge, Mass. 
Selting, Margret (1989): Speech styles in conversation as an interactive achievement. In: Hickey, Leo (ed.) (1989): The Pragmatics of Style. London/New York. S. 106-132.

Selting, Margret (1994): Emphatic (speech) style - with special focus on the prosodic signalling of heightened emotive involvement in conversation. In: Journal of Pragmatics, 22, S. 375-408. ('Special Issue: Involvement in Language', hrsgg. von Richard W. Janney und Claudia Caffi).

Selting, Margret (1995): Prosodie im Gespräch. Aspekte einer interaktionalen Phonologie der Konversation. Tübingen.

Selting, Margret (in Druck): Prosody as an activity-type distinctive signalling cue in conversation: The case of socalled 'astonished questions' in repair-initiation. Erscheint in: Couper-Kuhlen, Elizabeth/Selting, Margret (eds.) (in press): Prosody in Conversation. Interactional Studies. Cambridge.

Uhmann, Susanne (1992): Contextualizing relevance: On some forms and functions of speech rate changes in everyday conversation. In: Auer, Peter/di Luzio, Aldo (eds.) (1992): The Contextualization of Language. Amsterdam. S. 297-336.

Uhmann, Susanne (in press): On rhythm in German everyday conversations: Beat clashes in assessment utterances. Erscheint in: Couper-Kuhlen, Elizabeth/Selting, Margret (eds.) (in press): Prosody in Conversation. Interactional studies. Cambridge.

Wootton, Anthony (1989). Remarks on the methodology of conversation analysis. In: Roger, Derek/Bull, Peter (eds.) (1989): Conversation. An Interdisciplinary Perspective. Clevedon/Philadelphia. S. 238-258. 


\section{Stilphänomene der Mündliçhkeit und Schriftlichkeit im Wandel}

\section{Einführende Überlegungen}

Vergleichende Untersuchungen über Phänomene der Mündlichkeit und Schriftlichkeit sind seit über zwei Jahrzehnten keine Seltenheit, ja in den letzten Jahren sogar ein bevorzugtes Forschungsgebiet der Linguistik. Der Akzent bei der folgenden Behandlung dieses Themas liegt darauf, zu zeigen, wie sich das Verhältnis der Stilistica, die als typisch für geschriebene bzw. gesprochene Sprache gelten, gewandelt hat, seit wir die eine, viel jüngere der beiden Erscheinungsformen, nämlich die Schriftlichkeit, an Textzeugnissen in ihrer Entwicklung beobachten können. Das Problem für einen derartigen Vergleich bleibt jedoch, daB wir für die andere Erscheinungsform, den an sich primären Bereich der mündlichen Kommunikation, bis in unser Jahrhundert hinein auf komplizierte Rekonstruktionsversuche angewiesen sind, durch die wir uns der wirklichen Sprechsprache vergangener Epochen nur punktuell und unter Vorbehalten annähern können. Ob das Hauptaugenmerk solcher vergleichender Betrachtungen auf den Übergängen von der Mündlichkeit zur Schriftlichkeit liegt, wie z.B. in einem Teil der Projekte des Freiburger Sonderforschungsbereichs 'Übergänge und Spannungsfelder zwischen Mündlichkeit und Schriftlichkeit', oder ob Spuren oder 'Reflexe' der Mündlichkeit in mittelalterlichen Texten im Zentrum stehen, wie etwa in einer Reihe von Artikeln des Handbuchs 'Sprachgeschichte' (Besch/Reichmann/Sonderegger 1984f.): immer muß zunächst einmal eine Vorstellung von den sprachlichen Phänomenen zugrunde gelegt werden, die die mündlichen und schriftlichen Kommunikationsformen charakteristisch unterscheiden. Diese aber sind, nicht nur forschungsgeschichtlich, sondern wohl auch forschungslogisch bedingt, zunächst anhand kontrastiver Analysen der Gegenwartssprache ermittelt worden. Hieran hatten die Forschungen zur gesprochenen Sprache einen entscheidenden Anteil, die seit Mitte der sechziger Jahre durch die Analysemöglichkeit von Tonbandaufnahmen spontaner Kommunikationssituationen stark intensiviert wurden. ${ }^{1}$

Im Gegensatz zu der viel längeren Tradition der Auswertung gesprochener Sprache in der Dialektologie, die vorwiegend phonologischen und morphologischen Charakteristika galt, trat hier vor allem die syntak-

1 Man vgl. u.a. ausführlich Betten (1977f.), aktualisierter Rath (1989). 
tische Gestaltung spontan formulierter mündlicher Texte in den Vordergrund. Die natürlich nicht ganz neue Erkenntnis, daß die stilistisch besonders relevanten Unterschiede in der syntaktischen Struktur gesprochener und geschriebener Spracherzeugnisse medial bedingt und daher notwendig seien, wurde zum Ausgangspunkt eines differenzierten Nachdenkens über die situativen Rahmenbedingungen der beiden Kommunikationsformen in all ihren Varianten. In den siebziger Jahren bezogen sich viele der einschlägigen Arbeiten auf den Katalog sog. Redekonstellationsmerkmale, die an der damaligen Freiburger Forschungsstelle des Instituts für deutsche Sprache unter Leitung Hugo Stegers als Grundlage einer Textsortendifferenzierung für die gesprochene Sprache erstellt worden waren. ${ }^{2}$ Der Großteil dieser Merkmale findet sich unter der Bezeichnung 'Kommunikationsbedingungen' auch im folgenden Schema von Peter Koch und Wulf Oesterreicher (1985, S. 23):

1) Kounmunikasionsbedingunger:

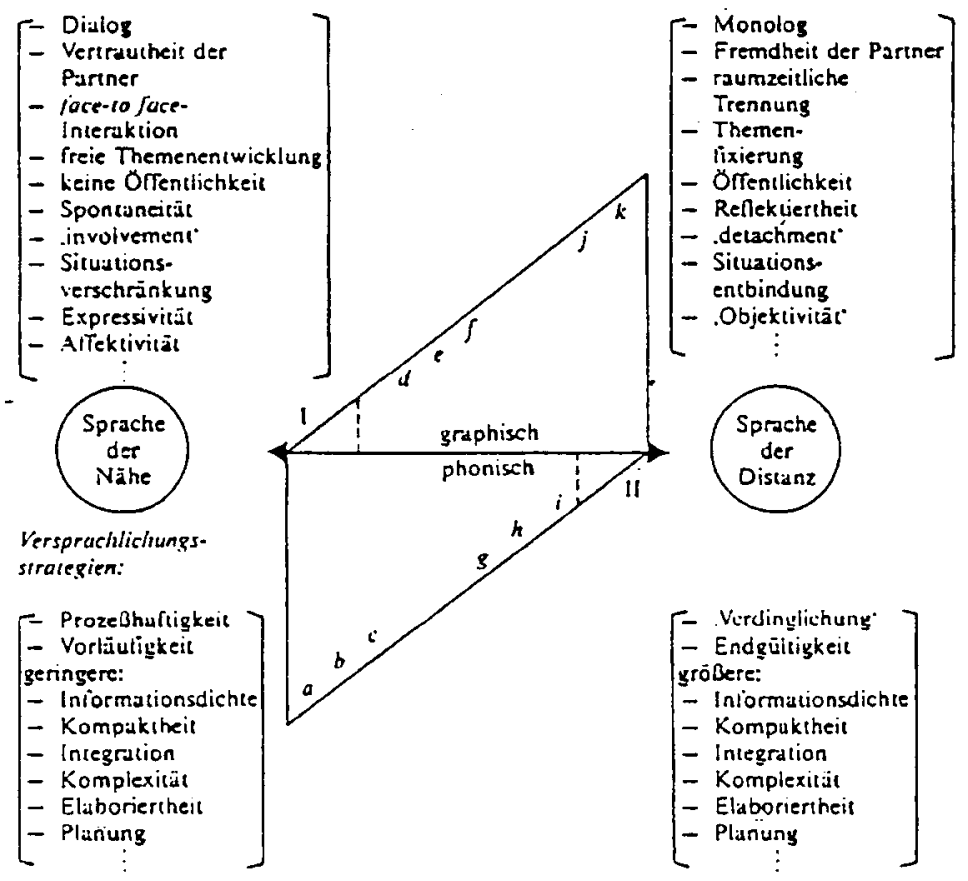

2 S. z.B. Schank/Schoenthal (1983, S. 29ff.). 
Die meisten Publikationen des derzeitigen Freiburger Sonderforschungsbereichs legen dieses Modell zugrunde. Es führt Ludwig Sölls (1974) Unterscheidung zwischen dem Medium der Realisierung (phonisch oder graphisch) und der Konzeption (gesprochen oder geschrieben), die den sprachlichen Duktus von Äußerungen betrift, weiter und integriert auch Impulse der neueren amerikanischen Dialogforschung. Das Schema verdeutlicht, daB Kommunikationsbedingungen wie Vertrautheit, 'faceto-face', freie Themenentwicklung, keine Öffentlichkeit, Spontaneität, 'involvement', Situationsverschränkung, Expressivität, Affektivität etc. korrespondieren mit Versprachlichungsstrategien der ProzeBhaftigkeit und Vorläufigkeit, was weniger Informationsdichte, Kompaktheit, Integration, Komplexität, Elaboriertheit, Planungsaufwand etc. zur Folge habe als in Situationen kommunikativer Distanz. Ähnlich hat in der amerikanischen 'discourse analysis' Elinor Ochs (1979) die Hauptunterschiede auf 'planned' und 'unplanned discourse' zurückgeführt und Wallace Chafe (1982) 'integration' und 'fragmentation' als deren wichtigste Struktureigenschaften gekennzeichnet. Wolfgang Raible (1992) wiederum modifizierte 'fragmentation' zu 'aggregation', somit werden Integration vs. Aggregation als die zwei Extrempole der Textorganisation betrachtet.

Von Koch/Oesterreichers Ansatz wird vor allem übernommen, daß sie die Merkmale der linken Spalte nicht unbedingt mit gesprochener und die der rechten mit geschriebener Sprache gleichsetzen, sondern vielmehr im konzeptionellen Bereich nach kommunikativer Nähe und Distanz differenzieren. $^{3}$ Für ihre systematische Verwendung in Koch/Oesterreichers Schema ist ferner von Bedeutung, daß Nähe und Distanz als Kontinuum mit graduellen Abstufungsmöglichkeiten gesehen werden, wie es schon zu Beginn der achtziger Jahre Deborah Tannen in Arbeiten zum 'oral/literate continuum in discourse' forderte. ${ }^{4}$ Und schließlich ist noch hervorzuheben, daß Koch/Oesterreicher die hier im Schema aufgezeigte Abhängigkeit zwischen Kommunikationsbedingungen und Versprachlichungsstrategien als universal betrachten, während die einzelsprachlichen Realisierungen unterschiedlich sein können. Von universalen Merkmalen, die durch bestimmte Kommunikationsbedingungen verursacht sind, ist jedoch nicht nur eine synchrone, sondern auch eine gewisse diachrone Stabilität zu erwarten.

3 Begriffe wie 'Nähestil', 'Distanzstil' o.ä. sind allerdings schon vorher verwendet worden, so etwa von Werner Holly (1983, S. 134ff.) bei der Analyse therapeutischer Dialoge.

4 U.a. in dem gleichnamigen Beitrag in Tannen (1982). 
Von diesen Überlegungen ausgehend, werde ich mich im folgenden auf drei Aspekte konzentrieren, die zwar das mit dem Titel gesetzte Thema nicht ausschöpfen, aber doch einige grundsätzliche Phasen in dem sich ständig wandelnden Verhältnis von Schriftlichkeit und Mündlichkeit im Deutschen repräsentieren sollen. Zunächst werde ich den sog. 'Spuren der Mündlichkeit' in mittelalterlichen Texten folgen (2.), sodann auf das Verhältnis von mündlichen und schriftlichen Stileigentümlichkeiten im literarischen Dialog eingehen und diesen Befund mit dem spontaner Alltagsdialoge vergleichen (3.) und mit Anmerkungen zum Wandel der gesprochenen Sprache im 20. Jahrhundert anhand von Belegmaterial aus einem eigenen Projekt schlieBen (4.).

\section{Spuren bzw. Strukturen der Mündlichkeit in hoch- und spätmittelalterlichen Texten}

In der Germanistik war Barbara Sandig (1973) eine der ersten, die auf die "historische Kontinuität normativ diskriminierter syntaktischer Muster in spontaner Sprechsprache" hinwies. Sie machte auf eine Reihe syntaktischer Parallelen zwischen heutiger spontaner Sprechsprache und mittelalterlichen Texten aufmerksam, vor allem auf Herausstellungen, Ausklammerungen, Hauptsatzstellung in Nebensätzen, Tendenz zur $\mathrm{Pa}$ rataxe, Parenthesen und Anakoluthe. Sandig führte das auf von der heutigen Schriftsprache abweichende Regeln zurück, „die funktional geeignet sind für spontane Sprechsprache": Es handle sich um „automatisierte Muster mit starker Appell-Wirkung”, die sich "besonders [!] für die direkte mündliche und spontane verbale Interaktion" eignen und das Kurzzeitgedächtnis von Sprecher und Hörer nicht belasten. ${ }^{5}$

In der Forschung hatte man sich lange vor allem auf die sog. 'oral poetry' konzentriert. Nach Definition des Freiburger Sonderforschungsbereichs handelt es sich dabei um „künstlerisch-ästhetische Diskurse”, die unter den Bedingungen einer mündlichen Kultur entstehen, jedoch in den Bereich der kommunikativen Distanz hinüberreichen. ${ }^{6}$ Um hier "nicht von 'Schriftlichkeit' reden zu müssen", wählten Koch/Oesterreicher (1985, S. 30) für derartige distanzsprachliche Ausprägungen von Mündlichkeit

5 Zitate Sandig (1973, S. 48f.).

${ }^{6}$ Mit Literaturangaben s. Koch/Oesterreicher (1985, S. 30f.). Innerhalb des Sonderforschungsbereichs beschäftigt sich mit dieser Thematik besonders das Projekt von Willi Erzgräber und Ursula Schaefer 'Übergänge und Spannungsfelder zwischen Mündlichkeit und Schriftlichkeit im englischen Mittelalter'; man vgl. zur Projektbeschreibung und bisherigen Publikationen den Bericht 'Sieben Jahre Sonderforschungsbereich 321', S. 80-83. 
den Begriff 'elaborierte Mündlichkeit'. Spezielle ästhetische Techniken der 'oral poetry' wie Formelhaftigkeit, Wiederholungen, Reim, Rhythmus etc. dienen nicht zuletzt der Memorierung. Ich halte es für nützlich, gerade diese nicht, wie bisher häufig geschehen, als 'Spuren der Mündlichkeit' zu bezeichnen, sondern allenfalls, wie Koch/Oesterreicher (1985, S. 31), als "Spuren distanzsprachlicher, elaborierter Mündlichkeit".?

Die von Sandig angesprochenen syntaktischen Merkmale sind hingegen charakteristisch für fast alle im weitesten Sinne als narrativ einzustufenden Texte des Mittelalters, und hier sind besonders die seit dem Hochmittelalter immer mehr zunehmenden Prosa-Textsorten gemeint, von der Bibel über die Legende zur Chronik und zum Roman, um nur einige zu nennen. Schon vor der Konzentration auf die Frage, welcher Art die Beziehung der mittelalterlichen Schriftlichkeit zur Mündlichkeit sei, gab es viele Detailuntersuchungen zu einzelnen dieser Phänomene, sowohl aus grammatischem Interesse an der Entwicklung der deutschen Syntax als auch aus stilistisch-rhetorischem. Im folgenden kann nur auf einige wenige ausgewählte Phänomene hingewiesen werden. ${ }^{8}$

Besonders zahlreich sind seit langer Zeit die Diskussionen über die Ausbildung der Satzklammer, zusammen mit der Überlegung, welche Satzglieder in welchen Sprachepochen und in welchen Textsorten bevorzugt ausgeklammert wurden. Auffälig, und damit als Stilmittel interpretierbar, ist vor allem der sog. Nachtragsstil, zum Beispiel bei den großen Predigern des Mittelalters. Er ist stets entweder als Nähe zur oder gar fälschlich als direkter Ausdruck von Mündlichkeit oder aber als besonders kalkuliertes rhetorisches Mittel interpretiert worden, was nicht unbedingt als Widerspruch zu sehen ist, da simulierte Mündlichkeit, unter die die Predigtschriften ja gefaßt werden könnten, immer bestimmte Charakteristika des Mündlichen ganz gezielt verwendet.

Charakteristisch für mittelalterliche Prosatexte ist auch die schwierige Abgrenzung von Sätzen. Der erste deutsche Prosaroman, die LancelotÜbertragung aus dem 13. Jahrhundert, weist $\mathrm{z}$ war bereits sehr komplexe Satzgefüge auf; doch u.a. wegen der Häufigkeit kausaler wann-Sätze, deren Status als Haupt- oder Nebensatz oft nicht klar ist, sowie wegen der vielen Satzreihungen mit und oder Anschlüssen mit Demonstrativa

7 Daß hier von Sprachhistorikern bislang hāufig zu wenig differenziert worden ist, zeigt ein Blick auf die ganz heterogenen Ansātze in den oben schon genannten Artikeln 'Reflexe gesprochener Sprache' zu den einzelnen Sprachepochen des Deutschen in Besch/Reichmann/Sonderegger (HSK 2.2, 1985, Art. 85, 94, 103, 114).

8 Mit ausführlicheren Darstellungen der Forschungslage s. Betten (1987a). 
schwebt die Satzstruktur vielfach zwischen Parataxe und Hypotaxe, und die Satzgrenzen können verwischt sein $^{9}$ - und dies, obgleich schon in den frühesten Texten des Althochdeutschen die Fähigkeit zur abgestuften Hypotaxe nachweislich vorhanden ist, was etwa Admoni in seiner 'Historischen Syntax des Deutschen' (1990) ausdrücklich betont. Als Beispiel dafür gibt er den folgenden Satz aus Notkers Prolog zur Übersetzung von Boethius' 'Consolatio':

(2) Tô uuard taz ten cheiser lusta, daz er Dioterichen vriuntlicho ze hove ladeta, tara ze dero mârun Constantinopoli, unde in dâr mit kûollichên êron lango habeta, unz er in des biten stûont, taz er imo ondi mit Otachere $z e$ vehtenne; unde ube er in uberuuunde, Romam iôh Italiam mit sınemo danche zehabenne.

„Da geschah es, daß der Kaiser Lust bekam, daß er Dietrich freundlich $2 u$ Hof lud, zu der berühmten Stadt Konstantinopel, und ihn dort lange mit großen Ehren verweilen ließ, bis er ihn zu bitten begann, daß er ihm gönne gegen Odoaker zu kämpfen; und falls er ihn überwinde, Rom und Italien mit seiner Erlaubnis zu verwalten". (aus: Admoni 1990, S. 68)

Gerade der bevorzugt aggregative Charakter hoch- und spätmittelalterlicher Erzähltexte und verwandter Genera - außer den Urkunden - hat seine Parallelen im Mündlichen und gilt als eines der Hauptmerkmale der sog. Nähesprache. Es ist wichtig festzuhalten, daß es sich dabei eben nicht um einen strukturellen Zwang, sondern seit Beginn der Schriftlichkeit um eine stilistische Alternative handelt, die durch Tradition und bestimmte Rezeptionsbedingungen im Bereich der narrativen Textgestaltung noch weiterhin dominant bleibt. Die Gründe dafür werden heute vor allem in der Informationssteuerung gesucht. Hierzu sind interessante Analysen auf satzübergreifender Ebene gemacht worden, vor allem zur Satzverknüpfung. Sie alle ergeben, daß sogar in den für die mittelalterliche Literatur quantitativ so bedeutenden übersetzten Texten auf der makrostrukturellen textsyntaktischen Ebene meistens autochthone Strukturen der eigenen Sprache gewählt werden, und das selbst dann, wenn die Übersetzer im engeren syntaktischen Bereich an den Konstruktionen der Vorlage kleben und recht undeutsch anmutende Interferenzen auftreten. ${ }^{10}$ Die gewählten Sprachmittel sind überwiegend solche, die der heutigen mündlichen Informationssteuerung ähneln. Es ist nur naheliegend, daß diese strukturellen Ähnlichkeiten mit der Hörrezeption in Verbindung gebracht werden, die bis zum 16. Jahrhundert überwiegend anzusetzen ist. In der Diktion von Koch/Oesterreicher läBt sich vielleicht sagen, daß hier mit Sprachmitteln der Nähe gearbeitet wird,

9 Vgl. dazu detailliert Betten (1980a) oder (1987a, S. 148ff.).

${ }^{10}$ Ausführlich Betten (1987b, besonders S. 395f., 406f.). 
weil die Rezeptionsbedingungen dieser schriftlich konzipierten Literatur ja weitgehend die der mündlichen Kommunikation sind.

Besonders typisch ist von den Anfängen der Schriftlichkeit bis zum Ende der überwiegenden Hörrezeption die Verwendung der Satzverknüpfungspartikeln, vor allem der Entsprechungen von nhd. da und und, mhd. do und unde, ahd. tho und inti. Auch das ae. pa und das as. tho werden, wie etwa Nils Enkvist ${ }^{11}$ und Terence Wilbur (1988) gezeigt haben, ganz ähnlich verwendet, nämlich als Signale für die Information, die nach dem Willen des Textproduzenten in den Vordergrund treten soll. Enkvist hat ae. $p a$ daher als 'action marker' bezeichnet, Wilbur nennt diese Technik im Heliand 'mise-en-scène', ich habe in Untersuchungen zum ahd. Tatian (Betten 1987b, S. 405) von fokussierender Wirkung gesprochen. Auf jeden Fall ergibt sich hier eine Verbindung mit der sog. 'theory of grounding'. So hat etwa Paul Hopper auch an nicht-indoeuropäischen Sprachen aufgezeigt, daß die Vordergrundsetzung ('foregrounding') häufig durch Partikeln geschieht. ${ }^{12}$ Im Mündlichen herrschen im Deutschen Anschlüsse mit da, und da oder (und) dann bis heute vor und springen an jedem Transkriptionstext sofort ins Auge.

Ein kurzes Beispiel aus der 'Legenda Aurea' möge dies an der Gegenüberstellung der lateinischen Vorlage des Jacobus de Voragine ( 1267) mit der alemannischen Übertragung aus der ersten Hälfte des 14. Jahrhunderts, der 'Elsässischen Legenda Aurea', verdeutlichen.

(3) Jacobus de Voragine:

De sancto Petro martire

Cum autem adhuc septem esset annorum et a scholis rediret a patruo suo qui haeresim sapiebat, quidnam in scholis didicerit, interrogatur. Qui respondit se didicisse: credo in Deum patrem omnipotentem coeli et terrae etc. Et ille:

\begin{abstract}
Elsāssische Legenda Aurea:
Von sant Peter dem brediger
\end{abstract}

Do dis kint wart suben ior alt, do ging es eines moles von der schuilen. Do begegent ime sin vetter, óch ein vnglubiger, vnd frogete daz kint waz es lerte. Antwurt Petrus vnd sprach: 'Ich lere den cristen glöben, vnd ist húte mine lecze, daz ich sol globen an got der himel

11 U.a. in Enkvist/Wårvik (1987).

12 U.a. Hopper (1979, S. 213ff.); vgl. dazu auch Betten (1990, S. 160ff.) mit weiteren Literaturangaben, u.a. zu den Beiträgen in Gerritsen/Stein (1992). 
noli dicere creatorem coeli et terrae, cum ipse visibilium creator non fuerit, sed dyabolus omnia ista, quae videntur, creaverit. vnd erde hat geschaffen.' Do sprach er wider: 'Dis soltu nút sprechen, wenne er hat die fúrborgen heimelichen ding nút geschaffen. So hat der túfel alle ding geschaffen die du sihst.'

(aus: C. Riehl 1993, Anhang)

Beide Textcorpora werden im Vergleich mit $z$ wei weiteren, etwa gleichzeitigen, aber auch mehreren späteren Übertragungen des 16 . und 18. Jahrhunderts von Claudia Riehl (1993) analysiert, um die Kontinuität und den Wandel von Erzählstrukturen im Übergang vom Spätmittelalter zur frühen Neuzeit zu zeigen. Die durch Kursivdruck hervorgehobenen Satzanschlüsse sollen im deutschen Text die typische, stark parataktische Satzstrukturierung mit bevorzugtem Satzanschlu $B$ durch die Konnektoren do und und verdeutlichen, die von der lateinischen Vorlage abweichen, wie es sich schon seit Beginn der volkssprachigen Überlieferung im Althochdeutschen feststellen läßt. Die deutschen Übersetzungen wählen alle eine andere Reliefbildung als die lateinische Vorlage. Interessant ist der schon im Althochdeutschen zu beobachtende Unterschied in der Verwendung von und und do: Und zeigt den Fortbestand der momentanen Grundierung (Vordergrund oder Hintergrund) an, während do die Vordergrundsetzung markiert. Im Lateinischen erfolgt diese Grundierung durch Abstufung von Haupt- und Nebensätzen bzw. durch Wechsel vom Imperfekt (für Hintergrund) zum Perfekt (Vordergrund) oder zum Präsens (vgl. Jacobus Z. 5f.). In den deutschen Texten hingegen sind die Sätze meist parataktisch gereiht, im gleichen Tempus, nämlich der synthetischen Form des Präteritums; und wo im Lateinischen Tempuswechsel erfolgt, steht stattdessen $d o^{13}$ Das hier Gesagte gilt ähnlich für weitere Übersetzungen des 14. Jahrhunderts wie die 'Harburger Legenda Aurea' und 'Der Heiligen Leben', auch wenn deren Qualität und Verhältnis zur lateinischen Vorlage ansonsten anders eingestuft werden. In späteren Übertragungen derselben Legende aus dem 16. und 18. Jahrhundert, also nach dem Umbruch von der Hör- zur Leserezeption, wird die Reliefbildung durch andere Mittel vorgenommen, nämlich ähnlich dem Lateinischen vor allem durch eine Abstufung von Haupt- und INebensatz und durch Tempuswechsel. Es ist jedoch nicht so, daß diese

13 In diesem kurzen Ausschnitt ist dies nicht zu beobachten, sonst aber häufig, vgl. z.B. Riehl (1993, S. 89f., 111). 
Möglichkeiten aufgrund der Entwicklung des grammatischen Systems des Deutschen vorher noch nicht zur Verfügung gestanden hätten. So zeigt etwa der Vergleich mit der 'Harburger Legenda Aurea', daß dort mehr Hintergrundgeschehen gesetzt wird, und zwar u.a. bereits durch Verwendung des Plusquamperfekts. In 'Der Heiligen Leben' tritt do an der Schwelle zum 15. Jahrhundert zwar noch mit besonderer Häufigkeit auf, wie in vielen anderen Erzähltexten des 15. und beginnenden 16. Jahrhunderts, doch wird hier mehr Hintergrund durch Kausalsätze geschaffen. Bei den Übertragungen des 16 . und 18. Jahrhunderts hingegen entdeckt Riehl zuweilen eine den frühen Texten entgegengesetzte Tendenz: sogar Hauptsätze des Lateinischen werden in den Hintergrund gesetzt, und zwar meist durch Tempusdifferenzierungen.

\section{Das Verhältnis von Mündlichkeit und Schriftlichkeit im literarischen Dialog}

Auffallig von der hier skizzierten Satz- bzw. Textgestaltung abgehoben sind im ganzen Mittelalter die Reden. Hans-Gerd Roloff (1970) hat das zur 'Melusine' in seinen 'Stilstudien zur Prosa des 15. Jahrhunderts' besonders herausgearbeitet. Die Reden in Textbeispiel (4) geben nur ganz normale, keine extremen Beispiele dafür:

(4) Do zugent sū mit erlichem schalle zư des kūnigs volck für die statt hienuß. Do nù bede des künigs volck und ouch der zweier brüder volck gesamlet warent und Anthoni und Reinhart beyde uffsitzend und von der schönen fürstin Cristinen urlop nemen wollent, do wünste in die fürstin vil glückes uff ir fartt und sprach zu irem gemachel Anthoni: „Allerliepster gemachel, noch hab ich ein bitt an üch zú tủnd und bitt üch, das ir mich der eren wellent und mir die nit versagen wellent." Anthoni antwurt ir gar früntlich un sprach: „Das were nit möglich, das ich üch dehein müglich bitt versagen solt.” Do sprach sü: „So bit ich üch mit gantzem fliß, sitt das gott gefüget hatt, das wir zủsammen vermehlet und ir here und fürst hie worden sint, das ir mir dan zư liebe und zú eren myns heren seligen und vatters, des erbe ir sint, schilt, helm und wapenkleit füren und üch und üwerm stammen das behalten wellent noch dehein ander wapen noch plasonierung nemen wellent." Harzú antwurte ir Anthoni und sprach: „Allerliebster gemachel, myns vatter und aller myner fordren wapen gebürt mir nit zú lassen. Aber ich han ein warzeichen an düse welt gebracht mit dem löwengriff, so ich an mynem backen han, darumb mich manig mönsch zü wunder beschowet hatt. Darumb so wil ich uff mynem helm zư eynem cryer füren und haben einen löwen, und umb so vil wil ich üch züwillen stan, sid ir in ūwerm wapen ouch den löwen fürent." Do danckete im die hertzogin und sprach: "Uwer und min wapen fürent ir billich beide, denne nit vil unterscheides daran ist." Anthoni nam also das wapen und nam urlop von syner gemachel, der hertzogin Cristinen, und sassent uff und zugent mit starcker macht durch Payern und andre tütsche land biß gan Bohem.

(Thüring von Ringoltingen: Melusine. Hg. v. K. Schneider. Berlin 1958. S. 69f.) 
Die Dialogbeiträge sind komplexer und syntaktisch komplizierter gebaut als die Erzählpassagen. Während letztere im einfachen Erzählstil, parataktisch reihend mit do und $u n d$-Anschlüssen abgefaßt sind, folgen die Reden offensichtlich Stilidealen der Rhetorik; in späteren Romanen geraten sie sogar unter Kanzleistileinfluß. Erst an Wickrams späten bürgerlichen Romanen ('Knabenspiegel' 1554, 'Von guten und bösen Nachbarn' 1556) läBt sich der vielleicht von dem humanistischen Interesse an der Umgangssprache mit beeinflußte Umschwung in der Dialoggestaltung erstmals feststellen, d.h. der Dialog tritt gegenüber dem Erzähltext quantitativ zurück und die Sprechweise wird volkstümlicher. Ingeborg Spriewald (1971) hat auch dies mit der Umstellung auf Leserezeption erklärt. Von nun an verkehrt sich in der Regel das Verhältnis von Autoren- und Figurenrede in der Erzählliteratur, wenngleich beide bis zur Gegenwart mannigfache Wandlungen durchmachen. Auf jeden Fall wird Annäherung an die Mündlichkeit nun zur "bewußten Schreibstrategie" des Autors, wie Paul Goetsch (1985, S. 202) sagt. Sie tritt immer wieder in Richtungen mit realistischem Stilwillen zutage. Alle Analysen kommen zu dem Ergebnis, daß es verschiedene "Macharten" dieser fingierten oder simulierten Mündlichkeit gibt, wobei sich jeder Autor andere Phänomene des Mündlichen auswählt und sie durch gezielten Einsatz wiederum als artifizielle Stilmittel verwendet. Hier sind Vergleiche mit dramatischen Dialogen möglich.

Diese sind allerdings nicht, wie es auf den ersten Blick scheinen möchte, dem spontanen Dialog ähnlicher, weil sie, wie dieser, nur aus direkter Rede bestehen. Vielmehr sind sie gerade deswegen, im Gegensatz zum Dialog in erzählerischen Werken wie auch im Alltag, inhaltlich wesentlich dichter, da der dramatische Autor sämtliche Zusatzinformationen z.B. zur Vorgeschichte, zur Handlung außerhalb der Bühne, aber auch weitgehend zur Sprechsituation selbst und zur inneren Verarbeitung der Interaktion durch die Figuren - in die Rede hineinverlegen muß, was natürlich auch Auswirkungen auf deren formale Gestaltung hat. Grundsätzlich wurde festgestellt (so etwa von Norman Page zum englischen realistischen Roman des 19. Jahrhunderts, von Siegfried Grosse zum deutschen Roman des 20 . Jahrhunderts, von Arthur Kennedy zum englischen und von mir zum deutschen Drama des 19. und 20. Jahrhunderts $)^{14}$, daB es sich dabei stets nur um ein sehr beschränktes Mittelrepertoire handelt, mit dem die Autoren die Illusion der Mündlichkeit erzeugen. Goetsch (1985, S. 213) drückt dies, wieder in Bezugnahme auf Koch/Oesterreicher, folgendermaßen aus: „Nicht die Häufung mi-

$14 \mathrm{Vgl}$. Betten (1985a, spezieller zu den genannten Arbeiten S. 66ff.) sowie Betten (1994). 
metischer Details gibt den Ausschlag, sondern die Tatsache, daß der Schriftsteller durch Planung, Komprimierung, Auswahl und Zuspitzung die Möglichkeiten der Sprache der Distanz dazu benützt, die Merkmale der Sprache der Nähe schärfer herauszuarbeiten".

Die Beispiele 5, 6 und 7 aus Wilhelm Raabe, Friedrich Dürrenmatt und Max Frisch stehen für zwei typische Möglichkeiten: Raabes Dialog zwischen Leutnant und Wirt repräsentiert eine Art des elliptischen Kurzdialogs, in dem Verben, Artikel, Pronomina und alle anderen thematischen, d.h. bekannten Satzelemente ausgelassen sind. Dadurch entsteht eine knappe, zackige Sprache, die nicht nur zur Charakterisierung preußischmilitärischer Milieus beliebt ist, sondern von vielen Autoren bis zur Gegenwart, so etwa stereotyp von Dürrenmatt, auch für inoffizielle rasche Dialogpartien benutzt wird, weil man sie offensichtlich für ungezwungen und privat hält - fälschlicherweise! $!^{15}$

(5) Nimmer wurde ein müder Wanderer unter einem Schenkenzeichen freudiger begrübt als der Leutnant Rudolf Götz unter dem Schilde des Grünen Baumes. [...]

"Das Nest beisammen Lämmert?" fragte der Leutnant.

"Jeder Vogel auf seinem $Z$ weig?" antwortete der Wirt in ordonnanzmäßiger Positur, beide Hände an den Hosennāhten. "Bullau?”

"Auf seinem Zweig im Baum."

"Schön! Stoff?" "Propre?" antwortete der Wirt, den Zeigefinger langsam und bedeutungsvoll über die Lippen ziehend.

(Wilhelm Raabe: Der Hungerpastor. In: W.R.: Sämtl. Werke. Bd. 6. Göttingen 1966. S. 204)

(6) Goethel: Stöhnt eindrucksvoll. Tönt prachtvoll.

Gnägelmann: Und das nach mehr als drei Wochen.

Goethel: Toll. Kammerkomplex phänomenal.

Gäagelmann: Nach einer Herztransplantation und einer Magenresektion.

Goethel: Chapeau. T-Wellen göttlich.

(Friedrich Dürrenmatt: Die Frist. Zürich 1977. S. 79)

In Frischs 'Stiller' ist die wörtliche Rede hingegen stark in den epischen Kontext eingebunden und von ihm gestützt:

$15 \mathrm{Vgl}$. ausführlich zu Dürrenmatt Betten (1980b) sowie zur Tradition dieser Art elliptischen Stils im dramatischen Dialog Betten (1985a, S. 173ff. und passim). Die Dialogpartien aus Raabe und Frisch sind im Vergleich zum epischen Kontext ausführlich behandelt in Betten (1985b). Ich habe hier bewußt auf Textstellen zurückgegriffen, die ich in anderen Zusammenhāngen schon genauer analysiert habe. Im Rahmen dieses Beitrags kann nicht allen Gesichtspunkten intensiv nachgegangen werden, die für die Stilbestimmung und -bewertung wichtig sind, da es hier vor allem darum geht, größere Entwicklungslinien aufzuzeigen. Auf diese Weise hoffe ich jedoch, den Interessierten Hinweise geben zu können, wo ich das hier nur kurz Angedeutete glaube detaillierter nachgewiesen zu haben. 
(7) Lange konnte die arme Julika vor Schluchzen überhaupt nicht sprechen. „Julika?" fragte er endlich mit einiger Ahnung, daß ihr Schluchzen nichts mit der dummen Haarspange zu tun hatte. „Was ist denn los? - Julika? So rede doch! -"

Julika war beim Arzt gewesen.

"Bist du?" fragte er. Sie versuchte sich zu fassen. "Und?" fragte er. Stiller sab auf der Couch neben ihr, Glas und Trockentuch noch immer in der Hand, während die verzweifelte Julika, von neuem Schluchzen geschüttelt, sich mit beiden Händen in das Kissen krallte, derart, daß das Kissen riß. [...] Julika zerriß das Kissen, und Stiller fragte bloß: „Was sagt er denn, der Arzt? -" Die Art seiner Teilnahme (und das findet Julika noch heute) war grauenhaft, seine zärtliche Besonnenheit, seine freundschaftliche Besorgtheit, all dies mit dem Glas von seinem Vorabend in der Hand; ihre gestammelte, immer wieder von Erstickungsnot unterbrochene und von immer neuem Schluchzen verschüttete Eröffnung, daß sie nämlich sobald wie möglich nach Davos gehen müßte, in ein Sanatorium nach Davos, entlockte ihm vorerst nur die trockene Frage: "Seit wann weißt du das?" - "Seit bald einer Woche!" sagte sie in der Annahme, Stiller kōnnte die Grauenhaftigkeit dieser Woche erahnen. "- seit einer Woche schon!" Statt dessen fragte er bloß: "Und warum meldest du es mir erst heute?" Stiller benahm sich unmöglich. "Ist es wahr?" fragte er sogar. "Wahr? Wahr? ..." Erst lachte Julika wohl hellauf, dann schnellte sie empor, blickte ihn an und sah, wie Stiller sie ebenfalls anblickte: als wäre es möglicherweise nur eine Finte von ihr, eine billige Übertreibung, um ihm die fröhliche Erinnerung an den Vorabend zu verderben. Sie schrie: "Geh! Geh! Geh mir aus den Augen?" Stiller schüttelte den Kopf. „Geh! Bitte. Geh hinaus?” - „Julika”, sagte er, "das ist mein Atelier."

(Max Frisch: Stiller. Frankfurt 1973. S. 95f.)

Die Auswahl dieser Äußerungsfragmente ist in ganz anderer Weise der Sprechwirklichkeit angenähert. Dennoch finden sich auch hier nur sehr wenige, geläufige Charakteristika des Mündlichen, und beileibe nicht die Konstruktionsbrüche, Korrekturen, Redundanzen und auch nicht die Häufung von Gliederungs- und Verständnissicherungssignalen, die unsere heutigen spontanen Dialoge so stark kennzeichnen. Als ein Beispiel dafür diene ein schon häufig analysierter Text aus dem Freiburger Corpus, der spontan formulierte Beitrag einer Studentin in einer Unterhaltung zu dritt über die Ehe. Er enthält u.a. viele Anschlüsse mit und. Rainer Rath (1979, S. 107f.) hat diese Anschlüsse in seiner Analyse im Verein mit anderen Signalen kursiv gesetzt, um zu zeigen, wie durch

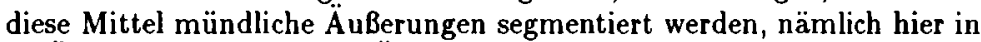
12 ÄuBerungseinheiten $(=\ddot{\mathrm{AE}})$ : 
(8) Gegliederter Text:

ÄE I "Ja, aber das is doch noch nich das is doch noch nich Ehe

ÄE II Ich meine, unter Ehe verstehen wir doch nich nich nur eine Liebe, so ne besondere Liebe zu einer Frau, sondern Ehe is eine ganze Institution mit mit sagenhaft vielen Verpflichtungen, die beide Partner gegenüber haben

ÄE III Und + P [teilweise gefüllt] ich weiß nich (ich müßte) wir können das gar nich so schrecklich schnell abtun

ÄE IV Und + P [gefüllt] meine These, vielleicht is sie falsch, is doch die, daß unsere Vorstellung der abendländische Begriff der Ehe wesentlich geprägt is durch das Christentum $\searrow+P$

$\bar{A} \mathrm{E} V \quad$ Oder durch durch christliche Vorstellungen $\searrow$

$\bar{A} E$ VI Und $($ daß $)$ da wir im Augenblick eine große Wandlung sich vollzieht $\nearrow$

ÄE VII Und + P ich meine, (von von Sākulari) Säkularisierung is das is schon $n$ veralteter Begriff ja $\nearrow$

ÄE VIII Also das Christentum verliert immer mehr an Bedeutung oder verliert seinen Sinn

$\ddot{A} \mathrm{E}$ IX Und es is viel viel schwerer noch noch den christlichen Glauben aufrechtzuerhalten bei Weltraumforschung und bei allen gerade biochemischen Erkenntnissen und man man is fähig irgendwie Plasma zu zeugen, was weiß ich $\searrow+P$

$\ddot{\mathrm{A}} \mathrm{E} \quad U$ Und $+\mathrm{P}$ [gefüllt] in diesem ja großen Wandel, der sich im Augenblick vollzieht, zu dem gehört auch, daß das dich die Vorstellung vielleicht der Ehe neue ja neue Gestalt annimmt.

ÄE XI Und + $\mathrm{P}$ daß daß also also eigenlich aus aus dieser Sicht heraus man sich die vielen Probleme auftun.

ĀE XII Denn wie anders könnten sonst die Chinesen plötzlich quasi die Ehe abschaffen $\searrow / / \ldots$ "..

In der neueren Forschung zur gesprochenen Sprache sind die meisten der hier zu beobachtenden, von den Normen schriftsprachlicher Textgestaltung abweichenden Phänomene positiv, auf ihre kommunikativen Leistungen hin interpretiert worden, nicht als Ergebnis von Planungsschwierigkeiten des Sprechers, sondern eher als sein Entgegenkommen gegenüber dem Hörer: so etwa wenn bei mimisch wahrnehmbaren Anzeichen von Nichtverstehen auf der Hörerseite die begonnene Konstruktion aufgegeben und durch eine neue ersetzt wird (wie z.B. beim Anakoluth) oder durch Parenthese (der häufig ein Anakoluth folgt) eine Erklärung nachgeschoben wird. Korrektur und Präzisierung wurden und werden als notwendige Mittel der linear fortschreitenden Versprachlichung der mündlichen Situation gesehen, die Neigung zur mehr parataktischen Gestaltung sowohl als Resultat der raschen und nur einmaligen Planungsmöglichkeit auf der Sprecherseite wie auch als Einstellung auf die Perzeptionsbedingungen beim Hörer. Fragmentarische Äußerungen gelten in dieser funktionalen Sicht als ökonomisch, die Rede von ablen- 
kendem Ballast freihaltend, den Hörer nicht langweilend, das Wichtigste klar herausstellend etc.

Bei aller Einsicht in diese wünschenswerten Leistungen erhebt sich jedoch die Frage, ob spontanes Sprechen wirklich so sein muB, nicht anders sein kann, also auch immer so bzw. ganz ähnlich war. Der Vergleich etwa mit dem heutigen Englischen oder mit romanischen Sprachen weist zwar auf eine Reihe von Universalien des Mündlichen hin, aber auch auf einzelsprachliche Besonderheiten, wie etwa im Deutschen die hohe Frequenz von Abtönungspartikeln. Auch der Blick zurück in die Geschichte bestätigt, wie ich hier zeigen wollte, gewisse Universalien der Textgestaltung unter Bedingungen der Hörrezeption, wobei allerdings die im spontanen mündlichen Dialog auftretenden Phänomene dort gerade nicht in der stark rhetorisch überformten Dialogwiedergabe, sondern in der Erzähltextstruktur anzutreffen sind. Was sich daher im historischen Vergleich nicht finden läßt, sind die Verständnissicherungsund Gliederungssignale, deren hohe Frequenz beim Lesen eines Transkripts den starken Kontrast $2 u$ den Normen eines schriftlich konzipierten Textes wesentlich verstärkt. In der fingierten Mündlichkeit literarischer Dialoge wird dieser Bereich denn auch meist nur auf ein ganz sparsames Repertoire vereinzelter ja- oder nicht wahr-Formeln zurückgedämmt, da diese Signale ja nur in der 'face-to-face'-Kommunikation eine Funktion haben, außerhalb dieses unmittelbaren Kontaktbereichs aber nur störend und plump wirken. Es ist zwar versucht worden, Aufschlüsse über ihren früheren Gebrauch aus der Dramensprache seit dem Sturm und Drang zu gewinnen, so etwa von Helmut Henne (1980), aber über ihre wirkliche Distribution und Frequenz bzw. Häufung - gerade die 'cluster'-Bildung spielt im spontanen Sprechen eine große Rolle - läßt sich daraus kaum Aufschluß gewinnen. Die bedauernde Feststellung, daß uns die primäre Mündlichkeit früherer Epochen nicht zugänglich ist, scheint alles weitere Fragen nach Sprach- und Stilwandel in diesem Bereich zu erübrigen.

\section{4. Überlegungen zum Wandel der gesprochenen Sprache im 20. Jahrliundert}

In den letzten Jahren war es mir möglich, Sprachmaterial zu erheben, das zumindest weitere Überlegungen über einen Wandel der gesprochenen Sprache zuläßt. Es untermauert die oft geäußerte These vom Untergang des Bildungsbürgerdeutsch nach dem Zweiten Weltkrieg auch für die Sprechsprache. Und zwar habe ich zusammen mit zwei Mitarbeiterinnen in Israel bislang über 150 Gespräche mit jüdischen Emigranten der dreißiger Jahre aus deutschsprachigen Herkunftsländern aufzeichnen können, die dort aus verschiedenen Gründen, nicht zuletzt wegen des für 
viele schwierigen Zugangs zum Hebräischen, das Deutsch der zwanziger Jahre lebendiger bewahrt haben als in anderen Emigrationsländern, weniger beeinfluBt von der neuen Sprache ihrer Umgebung, wie es etwa in englischsprachigen Ländern oft der Fall ist, und kaum oder gar nicht beeinflußt vom Sprachwandel in den deutschsprachigen Ländern. Sie alle zeigen, unabhängig von ihrer Schulbildung und Berufsgruppe, in allen Formen des Mündlichen, beim Erzählen wie zum Teil auch im raschen Dialog, eine wesentlich stärkere Ausrichtung an der Schriftsprache, um nicht zu sagen an der Literatursprache, die für sie alle heute noch eine wichtige Rolle spielt, ihnen als einzige Heimat geblieben ist. ${ }^{16}$ Beispiel (9) stammt von dem zur Aufnahmezeit 84jährigen Franz Krausz, aufgewachsen in Österreich, dann in Berlin Verlagsagent, Emigration mit 29 Jahren, in Israel später ein bekannter Graphiker; Beispiel (10) von der 72jährigen Dalia Grossmann, Arzttochter aus Berlin, emigriert an ihrem 14. Geburtstag, ausgebildet als Kindergärtnerin.

(9) FK: dann kam der erste april $\downarrow^{* *}$ der judenboykott $\downarrow^{*} 3^{*} \mathrm{zu}$ dem die nazis ** zum ersten mal * $3^{*}$ ihre ** judenfeindliche propaganda $\rfloor^{* *}$ nicht in büchern nicht in zeitungen ** tageszeitungen ${ }^{*} 3^{*}$ vertraten ** sondern ** in aufmärschen ** in den straßen berlins $\downarrow$ * $3^{*}$ mit gesängen $\downarrow$ ** mit slogans ** gegen das judentum $\left.\right|^{*} 3^{*}$ mit * $3^{*}$ aufschriften ${ }^{* *}$ an den jūdischen geschäften * die alle geschlossen warn $\uparrow * 3^{*}$ und manchmal warn auch die scheiben * zugeschlagen $\uparrow * * \mathrm{fe} / * *$ und ** alles mit aufschriften versehen $\downarrow^{*} 8^{*}$ juden $\downarrow^{* *}$ ich fahre * (ich hatte * eine dienstreise ${ }^{* *}$ durch ganz berlin zu machen $\downarrow$ ) ** mit dem: * 2 weidecker*autobus! ** ich konnte von oben ** alles sehn ** was sich in den straßen tat $\downarrow$ * $3^{*}$ es gab überhaupt keine polizeil ${ }^{*} 3^{*}$ die: $S^{*} S * S$ nicht $S S \downarrow$ die $S A \downarrow^{* *} j a \uparrow^{*} 4^{*}$ konnte ** auf den straßen machen was sie

$\mathrm{KH}: \mathbf{h m : \downarrow}$

FK: wollten $\downarrow^{*} 6^{*}$ es gab fast keine juden auf der straße $\downarrow^{* *}$ aber wenn sie einen:=ä: $\operatorname{trafen} * j a \uparrow^{*} 3^{*}$ hielten sie an $\downarrow^{*} j a \uparrow^{* *}$ weiß nicht was sie mit ihm gemacht ha:m $\downarrow^{* *}$ ich fuhr ja in de:r* in bus $\rfloor^{*}$ im zweiten stock $\downarrow^{* *}$ und $a::^{*} 3^{*}$ kam zurūck $\downarrow^{* *}$ ins:: ** büro $\downarrow^{*} 5^{*}$ a un: $d^{*} 3^{*}$ sagte ich habe hier keine * existenzberechtigung mehr $\uparrow^{* *}$ ich werde weggehen $\downarrow^{* *}$ so rasch ich kann $\downarrow^{* *}$ aber mein chef zeigte mir einen ** einen:: ** zettel ** ja $\uparrow^{* *}$ von der ä: einem büro von de::r** $\mathbf{a}^{*} \ddot{a}^{*}$ partei ${ }^{* *}$ nazipartei $\downarrow^{* *}$ wo er mich beschäftigen darf $\downarrow * 3^{*}$ ich war ja damals noch österreicher $\downarrow$ * $4^{*}$ ach dir wird gar nichts passiern $\downarrow$ un was willst du $\downarrow^{*} j a \uparrow$

(Gespräch mit Franz Krausz, * 1905 St. Pölten/Österreich, emigriert 1933. Aufnahme Kristine Hecker, Tel Aviv 1989)

16 Mit einer ausführlicheren ersten Skizzierung des Projektes s. Betten (1993a). Die Aufnahmen werden nach AbschluB des Projektes im Institut für deutsche Sprache/Mannheim archiviert und Interessenten zur Verfügung stehen. 
(10) mein vater kam her * am dritten mai * neunzehnhundertdreiendreißich $\downarrow$ ** und warum $\uparrow^{*}$ er war * angestellt * am krankenhaus lankwitz $\downarrow$ ** und hatte * eine ** sehr antisemitische hebamme $\uparrow^{* *}$ und einen * ã: geschmaddeten ** a: direktor des krankenhaus $\downarrow$ ein herr doktor XY $\downarrow^{* *}$ der im grunde mit ihm sehr befreundet war aber doch $\downarrow / /^{* *}$ und eines tages ** sch/ à steckte man meinem vater daß er doch vielleicht * verschwindet $\mathfrak{\downarrow}$ ** daraufhin ** (entsinn ich mich noch * wie heutel) ${ }^{* *}$ is=er über nacht ** getürmt * in die schweiz $\downarrow^{* *}$ am nächsten morgen ** bekamen wir von ihm ein telefon aus freiburg $\downarrow^{* *}$ weil er sorgen hatte um uns $\downarrow^{* *}$ meine mutter hat kurzen prozeB gemacht hat meinen bruder genommen ** hat ihm eine karte gegeben ** und hat ihm gesacht bis du nich siehst daB dein vater ${ }^{*}$ in marseille auf $=m$ schiff is ** läßt du ihn nicht alleine $\downarrow^{* *}$ jetz war es so $\downarrow$ * damals zu jenen zeiten * hat der faruk ** in àgypten sehr * nach jüdischen * spezialisten gesucht $\downarrow$ ** mein vater hatte nich grade die idee nach palāstina zu kommen weil das von ihm weit ** entfernt war $\uparrow^{* *}$ und er wollte im grunde nach ägypten fahrn $\downarrow$ daraufhin hat mein bruder ihm gesagt wenn du schon in der gegend bist * dann fahr doch nach palästina denn ich will dort ganz bestimmt hinfahrn $\rfloor^{* *}$ und so kam es dab vati wirklich ** hier und dort war ** und sich nicht entschließen konnte wo er nun wirklich bleiben wollte $\rfloor^{* *}$ er kam nach tel aviv und die damaligen * ärzte warn nich sehr * erfreut für eine ** große gute konkurrenz so daß der empfang nich so herrlich war $\uparrow^{* *}$ und er ließ meine mutti ** kommen um zusammen zu beschließen $\downarrow$

(Gesprāch mit Dalia Grossmann, geb. Hildegard Sachs, * 1919 Berlin, emigriert 1933. Aufnahme Miryam Du-nour, Jerusalem 1991)

Im Vergleich zu Beispiel (8) fällt auf, daß beide fast nie die Gliederungsund Verständnissicherungssignale benutzen, die dort so häufig sind, ferner nicht die vielen Formeln wie ich meine (Bsp. 8, ÄE II, VII), ich weiß nich ( $\ddot{A} \mathrm{E}$ III), was weiß ich ( $\ddot{\mathrm{A} E} \mathrm{IX}$ ), und ebenso nicht oder kaum die sonst heute so häufigen Wortwiederholungen, Satzabbrüche und Konstruktionswechsel. In Text (9) von Krausz kommen dagegen nur einige Wortkorrekturen vor, in (10) gar keine, und nur in (10) findet sich ein einziger Satzabbruch (Z.5 aber doch $\downarrow){ }^{17}$ Ich möchte behaupten, daß im Vergleich zu den allermeisten Transkriptionstexten heutiger deutscher Sprecher die Texte von Krausz und Grossmann fast literarisch wirken: Asyndetische Reihungen überwiegen gegenüber und-Anschlüssen; wenn, dann steht und meistens allein und zeigt so nur die parataktische Rei-

17 Die Wortwiederholungen und -korrekturen sind in den Texten (9) und (10) kursiv gesetzt, ebenso die Satzanschlüsse mit und und dann und das Verständnissicherungssignal ja. Einschübe sind für meine Zwecke hier durch runde Klammern kenntlich gemacht, Satzabbruch durch //. Die übrigen Transkriptionszeichen entsprechen den (neuen) Konventionen der PhonaiReihe im Niemeyer-Verlag, wo 1995 ein Band mit Texten aus diesem Interviewcorpus erscheinen wird: * steht als Pausenzeichen, $\downarrow$ für fallende und $\uparrow$ für steigende Intonation, : als Längenzeichen, = bei Verschleifungen. 
hung an, ohne in Verbindungen wie und dann, und so zu starke Zäsuren zu setzen. Die Sätze sind fast alle korrekt gebaut, auch nach Einschüben werden die Konstruktionen akkurat wie im Schriftlichen weitergeführt (vgl. Bsp. 9, Z. 8f., Bsp. 10, Z. 7f.). Einfache rhetorische Mittel wie Parallelismus und andere Formen der Hervorhebung werden wirkungsvoll eingesetzt (vgl. Krausz, Z. 2-5 oder Grossmann, Z. 10f.). Neben diesen syntaktischen Stilmitteln zur Intensivierung verwendet Frau Grossmann rhetorische Fragen wie und warum? (Z. 2), Ankündigungsformeln wie jetz war es so (Z. 12f.), klassische Erzähleinleitungen wie damals zu jenen zeiten (Z. 11).

Auch diesem Stil sind die Mittel des Mündlichen nicht ganz fremd. Außer dem reihenden und verwendet Krausz mehrfach das Verständnissicherungssignal $j a$ ? Dies stellt jedoch sowohl quantitativ wie qualitativ eine äußerste Reduktion der für mündliches Erzählen typischen Mittel dar. Die folgende moderne literarische Ich-Erzählung diene hier noch zu einem weiteren Vergleich:

(11) Wenn Gisela morgens nach Naurath fährt, bin ich mit Matthias allein zu Hause. Ich habe Ende Sommersemester 1976 das Staatsexamen für das Lehramt an Gymnasien in den Fächern Geschichte und Philosophie bestanden, aber nun bekomme ich keine Stelle. Es ist völlig hoffnungslos. Ich bin kein Einzelfall. Wenn Gisela weggefahren ist, // wir wohnen hier in Neuweiler, und bis Naurath muB sie ungefähr zwanzig Kilometer fahren über Ehrang, Naurath/Eifel ist sogar Luftkurort, es liegt auf der Höhe, Neuweiler auch, Höhenlage, wir hatten die Wohnung seinerzeit im "Trierischen Volksfreund" gesehen, und Gisela sagte bei der Wohnungsbesichtigung, das sei genau das Richtige, herrlich der Blick in die Landschaft, Grün, nur Grūn, aber diesen Sommer die Wiesen weitherum ausgedörrt, im Winter Weiß, wenn unten in der Stadt der Schnee längst weg ist, ich erkläre den Weg, wenn ich mir bei Horten unten das Bier bestelle, am besten so, es sei hinter dem zweiten Bauernhaus links, rechts ist eine Reihe Einfamilienhäuser, wo auch ein Staatssekretär wohnt, nicht, daß ich ihn persönlich kenne, aber ich sah sein Bild schon im "Volksfreund", die Welt ist hier klein.

(Walter Schenker: Eifel. Zürich 1982. S. 5)

Der Autor und Linguist Walter Schenker hat hier syntaktisch den Stil mündlichen Erzählens durch die Verwendung von Anakoluthen (s. meine Markierung durch $/ /, Z$. 5), Parenthesen und lose Satzreihung, die eine nicht klar segmentierbare Kette bilden (Z. 5 bis Ende) nachgebildet, wenngleich mit der bei der literarischen Verwendung dieser Mittel üblichen „Domestizierung” gegenüber der oft schwer klassifizierbaren Vielfalt ihrer spontanen Erscheinungsformen. Doch selbst hier finden sich diese syntaktischen Merkmale der sog. Nähesprache gehäufter als bei Krausz und Grossmann, obwohl generell eigentlich zu konstatieren ist, daB diese 
Mittel als Signale für Mündlichkeit in der Literatur wesentlich sparsamer gebraucht werden.

Man könnte zusammenfassend zum Erzählstil der beiden Emigranten sagen, er weise nicht viel mehr Anzeichen von Mündlichkeit auf, als man in traditionellen Stilistiken findet, die ihr Mittelrepertoire letztlich aus den gleichen Quellen schöpfen wie Hermann Wunderlichs Beschreibung der „Umgangsprache” von 1884, nämlich dem doch weitgehend an der Schriftnorm orientierten Dialog in der Literatur, in den nur die kleinen Nachlässigkeiten eingestreut sind, von denen der exzellente Dialogschreiber Lessing, der quasi noch als Vorbild dieser Konversationssprache zu denken ist, sagte: „All die kleinen Nachlässigkeiten [...], die dem Dichter so schwer zu finden waren, die er mit so vieler Überlegung dahin und dorthin streuete, um den Dialog geschmeidig zu machen, und den Reden einen wahrern Anschein der augenblicklichen Eingebung zu erteilen". ${ }^{18}$ Die deutsch-jüdischen Emigranten benützen diesen Stil ganz selbstverständlich. Sie haben die Sprache des gebildeten Bürgertums des 19. und beginnenden 20. Jahrhunderts noch internalisiert, trugen sie doch ihre Klassiker bis einschließlich Thomas Mann soweit es möglich war mit in die Emigration und fühlten und fühlen sich auch heute noch als Erben des humanistischen Bildungsideals. Der Sprachstil der Israelis wird von jungen Leuten bei uns manchmal als elitär, prätentiös, ja affektiert empfunden, wie sie selbst berichten. Daneben regt sich aber auch Bewunderung, da $\beta$ diese alten Bildungsbürger fast so sprechen können, wie man schreibt. Oft werden sie als letzte Repräsentanten der Weimarer Kultur bezeichnet, was sie gern hören. Daß auch viele Menschen ohne akademische Bildung an dieser Sprechkultur teilhatten und -haben, zeigt, wie stark die prägende Kraft der damaligen an der Schriftsprache ausgerichteten Idealnorm auf alle Bildungsbeflissenen war.

\section{Resümee}

Abschließend seien die Argumente der drei Teile dieses Beitrags noch einmal in Zusammenhang gebracht. Es gibt eine gewisse Kontinuität mündlicher Textstrukturierung, die sich sowohl in den verschiedensten Sprachen wie auch in frühen schriftlichen, dem Mündlichen nahestehenden Entwicklungsphasen einer Sprache relativ konstant bzw. kontinuierlich zeigt. Gewiß bedarf es weiterer detaillierter Studien quer durch alle deutschen Prosatextsorten des Spätmittelalters, die nicht direkt in lateinischer Stiltradition standen, um noch nuancierter beschreiben zu

$18 \mathrm{Vgl}$. Lessing (1969, S. 520), ausgiebiger auch besprochen in Betten (1985a, S. 151f.). 
können, wie sich mündliche Informationsstrukturierung und Stilprinzipien auf die frühe mediale Schriftlichkeit ausgewirkt haben. Es wird noch genauer zu ermitteln sein, ob diese sog. konzeptionelle Mündlichkeit in Texten medialer Schriftlichkeit ein halbwegs bewuBtes Orientierungsmuster z.B. im Hinblick auf ihre auditive Rezeption war oder ob hier zunächst nur die alten Vermittlungsstrukturen noch nachwirkten. Die Textsortenabhängigkeit ist jedenfalls noch weiter zu klären. Es gibt vermutlich doch nicht nur die komplizierte Hypotaxe bei den Urkunden in Anlehnung an das Lateinische auf der einen Seite und den schlichteren Stil konzeptioneller Mündlichkeit bei allen anderen frühen Prosagenera, wie es Admoni (1990, S. 116ff.), etwas verkürzt gesagt, ansetzt. Schon der Blick auf die andere Entwicklung im Bereich der Dialoggestaltung zeigt, daB es weitere Varianten gab. Auch zwischen Erzähltext und Kommentar - z.B. bei biblischen Nacherzählungen und ihrer anschließenden Auslegung in mittelalterlichen Predigten - und gewiß bei noch vielen anderen Textsorten, gab es seit Beginn der Schriftlichkeit Variationen in der sprachlichen Gestaltung. ${ }^{19}$ Hör- und Leserezeption sind sicher nur e i n Kriterium für solche konzeptionellen Unterschiede - allerdings gewiß eines der grundlegendsten.

In späteren Entwicklungsstadien des Deutschen, in der ausgeprägten Schriftkultur der Neuzeit, erhält die Verwendung der charakteristischen nähesprachlichen Mittel im Schriftlichen eine andere Funktion. Sie ist im Spannungsfeld zwischen dem Prestige der Schrift- und Literatursprache einerseits und der Rebellion gegen die verfestigte Norm andererseits zu sehen. Die literarischen Experimente der Neuzeit, einschließlich ihrer Rückholung konzeptioneller Mündlichkeit in die mediale Schriftlichkeit - etwa im modernen Roman -, bezeugen dieses ständige Wechselspiel. Es ist sicher für alle Etappen des 19. und 20. Jahrhunderts interessant, genauer zu hinterfragen, für welche Kreise bzw. für wieviel Prozent der Bevölkerung die mit der Klassik erreichte Sprachnorm Gültigkeit besaß und in welchen Abstufungen sie in verschiedenen Kommunikationssituationen realisiert wurde. Es gibt nur sehr unzureichende Möglichkeiten, zu erschließen, wieweit sich die Normvorstellungen der konzeptionellen Schriftlichkeit im Bildungsbürgertum als generelles Orientierungsmuster jeglicher Kommunikation, also auch der mündlichen, durchsetzen konnten. Die Dialogsprache in der Literatur ist dabei nur mit äußerster Vorsicht als Quelle heranziehbar. Vor diesem Hintergrund scheinen mir die Befunde der Interviews aus Israel, die die Sprechsprache des gebildeten Bürgertums der zwanziger Jahre widerspiegeln, von Bedeutung für die

19 Vgl. z.B. Betten (1993b, S. 139f.) mit einem Text aus den Altdeutschen Predigten, Oberaltaicher Sammlung, aus dem spāten 12. Jahrhundert. 
Erforschung der Entwicklung der Sprechsprache im 20. Jahrhundert zu sein. Sie belegen auch und vielleicht gerade für den Bereich der Mündlichkeit die von den Sprachhistorikern grob bis zum Zweiten Weltkrieg angenommene Gültigkeit und Akzeptanz standardsprachlicher Normen. Zugleich illustrieren sie im Vergleich mit der Sprechsprache von heute den drastischen Normenwandel in der zweiten Hälfte unseres Jahrhunderts. Die Mehrzahl der Sprachhistoriker heute sieht 1945 oder, unter Einkalkulierung einer kleinen Verzögerung, 1950 einen Einschnitt in der Sprachentwicklung, der von Peter von Polenz (1989) und Stefan Sonderegger (1979) als neue polyzentrische Phase bzw. "Öffnung in sozialer, sprechsprachlicher und regionaler Sicht" bezeichnet wird. Wenn wir die bei den Emigranten konservierte bürgerliche Sprechsprache des ersten Drittels des 20. Jahrhunderts in Koch/Oesterreichers Schema lokalisieren, handelt es sich um eine, je nach Individualstil und Erzählengagement graduell abgestufte 'distanzsprachliche Mündlichkeit', die aber völlig andere Züge trägt als die „Spuren distanzsprachlicher, elaborierter Mündlichkeit" der 'oral poetry', von der ich anfangs sprach, oder auch etwa die distanzsprachliche Mündlichkeit eines ganz oder teilweise schriftlich vorbereiteten Vortrags.

Über die Schriftlichkeit der Neuzeit und ihren Normen- bzw. Stilwandel habe ich hier nicht viel gesagt. Sie steht u.a. im Zentrum von Admonis Aufmerksamkeit im Syntaxband von 1990. Seit Ende des 18. Jahrhunderts sieht Admoni in der Systementwicklung des Deutschen keine wesentlichen Neuerungen mehr: von da an komme es hauptsächlich zu quantitativen Veränderungen aller vom System her möglichen Varianten und vor allem in der Literatur zu Gegenbewegungen gegen die "Zementierung" der schriftsprachlichen Normen. Aber auch im öffentlichen Verwendungsbereich der Schriftsprache begann vor über 100 Jahren eine neue Öffnung zur Mündlichkeit in Form der erst im 18., 19. Jahrhundert neben den Dialekten neu ausgebildeten sog. Umgangssprache. Dieser "säkulare Trend zur Vermündlichung" - wie Johannes Erben (1989, S. 27) es einmal genannt hat - ist in der zweiten Hälfte des 20. Jahrhunderts sicher ebenso beschleunigt vorangeschritten, wie die im Vergleich zur Emigrantensprache hier nur knapp skizzierte heutige Sprechsprache sich von der gebildeten Umgangssprache in den ersten Jahrzehnten unseres Jahrhunderts wegentwickelt hat. Dabei finden heute offenbar die interaktive Gesprächstätigkeit und die situative Eingebundenheit des Spreckens stärkere Berücksichtigung, was sich etwa in dem starken Anschwellen von Gesprächswörtern und ähnlichen Signalen interaktiv bedingter Wiederholungen einerseits und im Verzicht auf syntaktische Vollständigkeit und Normerfüllung andererseits ausdrückt. Dies sei hier nur konstatiert unter Andeutung auch positiver Seiten des Differenzbefundes, denn das 
öfters zitierte Menetekel vom 'Ende der Schriftkultur' bzw, vom 'Ende der Sprechkultur' ist nur e i n e der möglichen Deutungen. Auf jeden Fall aber hat auch die analog zur 'distanzsprachlichen Mündlichkeit' ansetzbare 'nähesprachliche Schriftlichkeit' eine große Vielzahl von Facetten, heute wie auch in stets sich wandelnder Form während ihrer ganzen 1200 jährigen Geschichte.

Wer diesem Wandel von Formen, abhängig vom Wandel von Normen, nachgeht, betreibt auch als Sprachhistoriker meiner Auffassung nach Stilgeschichte, eng gebunden an die strukturellen Voraussetzungen und Variationsmöglichkeiten des sprachlichen Systems in den einzelnen Epochen.

\section{Literatur}

Admoni, Wladimir G. (1990): Historische Syntax des Deutschen. Tübingen.

Besch, Werner/Reichmann, Oskar/Sonderegger, Stefan ( $\mathrm{Hg}).(1984 / 1985)$ : Sprachgeschichte. Ein Handbuch zur Geschichte der deutschen Sprache und ihrer Erforschung. 2 Bde. Berlin. (HSK 2.1/2).

Betten, Anne (1977/1978): Erforschung gesprochener deutscher Standardsprache. In: Deutsche Sprache 5, S. 335-361 (Teil I) und Deutsche Sprache 6, S. 21-44 (Teil II).

Betten, Anne (1980a): Zu Satzbau und Satzkomplexität im mittelhochdeutschen Prosa-Lancelot. Überlegungen zur Beschreibung der Syntax mittelhochdeutscher Prosa. In: Sprachwissenschaft 5, S. 15-42.

Betten, Anne (1980b): Der dramatische Dialog bei Friedrich Dürrenmatt im Vergleich mit spontan gesprochener Sprache. In: Hess-Lüttich, Ernst W.B. ( $\mathrm{Hg}$.): Literatur und Konversation. Sprachsoziologie und Pragmatik in der Literatur wissenschaft. Wiesbaden. S. 205-236.

Betten, Anne (1985a): Sprachrealismus im deutschen Drama der siebziger Jahre. Heidelberg.

Betten, Anne (1985b): Direkte Rede und epischer Bericht in der deutschen Romanprosa. Stilgeschichtliche Betrachtungen zur Syntax. In: Sprache und Literatur in Wissenschaft und Unterricht 16, S. 25-41.

Betten, Anne (1987a): Grundzüge der Prosasyntax. Stilprägende Entwicklungen vom Althochdeutschen zum Neuhochdeutschen. Tübingen.

Betten, Anne (1987b): Zur Satzverknüpfung im althochdeutschen Tatian. Textsyntaktische Betrachtungen zum Konnektor thô und seinen lateinischen Entsprechungen. In: Bergmann, Rolf/Tiefenbach, Heinrich/Voetz, Lothar (Hg.): Althochdeutsch. Bd. I: Grammatik. Glossen und Texte. Heidelberg. S. 395-407.

Betten, Anne (1990): Zur Bedeutung von Textsyntax und Textlinguistik für die Sprachgeschichtsschreibung. In: Besch, Werner (Hg.): Deutsche Sprachgeschichte. Grundlagen, Methoden, Perspektiven. Festschrift für Johannes Erben zum 65. Geburtstag. Frankfurt u.a. S. 159-165. 
Betten, Anne (1992): Sentence connection as an expression of medieval principles of representation. In: Gerritsen, Marinel/Stein, Dieter $(\mathrm{Hg}$.$) : In-$ ternal and External Factors in Syntactic Change. Berlin/New York. S. 157-174.

Betten, Anne (1993a): Die literaturorientierte Dialogsprache der zwanziger Jahre. Beobachtungen an Interviews mit ehemals deutschen Juden in Israel. In: Löffler, Heinrich (Hg.): Dialoganalyse IV. Referate der 4. Arbeitstagung Basel 1992. Teil 1. Tübingen. S. 187-198.

Betten, Anne (1993b): Norm und Spielraum im deutschen Satzbau. Eine diachrone Untersuchung. In: Mattheier, Klaus/Nitta, Haruo/Ono, Mitsuyo (Hg.): Methoden zur Erforschung des Frühneuhochdeutschen. München. S. 125-145.

Betten, Anne (1994): Analyse literarischer Dialoge. In: Fritz, Gerd/Hundsnurscher, Franz (Hg.): Handbuch der Dialoganalyse. Tübingen. S. 519544.

Chafe, Wallace L. (1982): Integration and involvement in speaking, writing, and oral literature. In: Tannen, Deborah (Hg.): Spoken and Written Language. Exploring Orality and Literacy. 2. Aufl. Norwood, N.J. S. 35-53.

Enkvist, Nils/Wårvik, Brita (1987): Old English $p a$, temporal chains, and narrative structure. In: Ramat, Anna G./Carruba, Onofrio/Bernini, Giuliano (Hg.): Papers from the 7 th International Conference on Historical Linguistics. Amsterdam/ Philadelphia. S. 221-237.

Erben, Johannes (1989): Die Entstehung unserer Schriftsprache und der Anteil deutscher Grammatiker am NormierungsprozeB. In: Sprachwissenschaft 14, S. 6-28.

Gerritsen, Marinel/Stein, Dieter (Hg.) (1992): Internal and External Factors in Syntactic Change. Berlin/New York.

Goetsch, Paul (1985): Fingierte Mündlichkeit in der Erzählkunst entwickelter Schriftkulturen. In: Poetica 17, S. 202-218.

Henne, Helmut (1980): Probleme einer historischen Gesprächsanalyse. Zur Rekonstruktion gesprochener Sprache im 18. Jahrhundert. In: Sitta, Horst (Hg.): Ansätze zu einer pragmatischen Sprachgeschichte. Zürcher Kolloquium 1978. Tübingen. S. 89-102.

Holly, Werner (1983): „Die Mutter is wie alt?” Befragungstechniken und Beziehungsstile eines Psychotherapeuten in Zweitinterviews. In: Sandig, Barbara (Hg.): Stilistik. Bd. II: Gesprächsstile. Hildesheim/Zürich/New York. S. 103-147. (Germanistische Linguistik 5-6/81).

Hopper, Paul J. (1979): Aspect and foregrounding in discourse. In: Givón, Talmy (Hg.): Syntax and Semantics 12: Discourse and Syntax. New York/San Francisco/London. S. 213-241.

Koch, Peter/Oesterreicher, Wulf (1985): Sprache der Nähe - Sprache der Distanz. Mündlichkeit und Schriftlichkeit im Spannungsfeld von Sprachtheorie und Sprachgeschichte. In: Romanistisches Jahrbuch 36, S. 15-43.

Lessing, Gotthold Ephraim (1969): Hamburgische Dramaturgie. In: Lessing, Gotthold Ephraim: Werke in drei Bänden. Bd. 2: Kritische Schriften, Philosophische Schriften. Hg. v. Perfahl, J./Mann, O. München. S. 276-o98. 
Ochs, Elinor (1979): Planned and unplanned discourse. In: Givón, Talmy (Hg.): Syntax and Semantics 12: Discourse and Syntax. New York/San Francisco/London. S. 51-80.

v. Polenz, Peter (1989): Das 19. Jahrhundert als sprachgeschichtliches Periodisierungsproblem. In: Cherubim, Dieter/Mattheier, Klaus J. (Hg.): Voraussetzungen und Grundlagen der-Gegenwartssprache. Sprach- und sozialgeschichtliche Untersuchungen zum 19. Jahrhundert. Berlin/New York. S. 11-30.

Raible, Wolfgang (1992): Junktion. Eine Dimension der Sprache und ihre Realisierungsformen zwischen Aggregation und Integration. Heidelberg. (Sitzungsberichte der Heidelberger Akademie der Wissenschaften, Philosoph.histor. Klasse, Bericht 2).

Rath, Rainer (1979): Kommunikationspraxis. Analysen zur Textbildung und Textgliederung im gesprochenen Deutsch. Göttingen.

Rath, Rainer (1989): Zur Erforschung der „Gesprochenen Sprache”. In: Scherer, Hans ( $\mathrm{Hg}$.): Sprache in Situation. Eine Zwischenbilanz. Bonn. S. 10-23.

Riehl, Claudia Maria (1993): Kontinuität und Wandel von Erzählstrukturen am Beispiel der Legende. Göppingen. (= Diss. Eichstätt 1991).

Rolof, Hans-Gert (1970): Stilstudien zur Prosa des 15. Jahrhunderts. Die Melusine des Thüring von Ringoltingen. Köln/Wien.

Sandig, Barbara (1973): Zur historischen Kontinuität normativ diskriminierter syntaktischer Muster in spontaner Sprechsprache. In: deutsche sprache 1,3, S. 37-57.

Schank, Gerd/Schoenthal, Gisela (1983): Gesprochene Sprache. Eine Einführung in Forschungsansātze und Analysemethoden. 2. Aufl. Tübingen.

Söll, Ludwig (1974): Gesprochenes und geschriebenes Französisch. Berlin.

Sonderegger, Stefan (1979): Grundzüge deutscher Sprachgeschichte. Diachronie des Sprachsystems. Bd. I: Einfūhrung - Genealogie - Konstanten. Berlin/New York.

Spriewald, Ingeborg (1971): Jörg Wickram und die Anfänge der realistischen Prosaerzählung in Deutschland. Diss. Potsdam.

Tannen, Deborah (1982): The oral/literate continuum in discourse. In: Tannen, Deborah ( $\mathrm{Hg}$.): Spoken and Written Language. Exploring Orality and Literacy. 2. Aufl. Norwood, N.J. S. 1-16. (Advances in Discourse Processes 9).

Wilbur, Terence (1988): Sentence connectives in ancient Germanic texts. In: Calder, Daniel G./Christy, T. Craig (Hg.): Germania: Comparative Studies in the Old Germanic Languages and Literatures. Wolfeboro, N.H. S. 85-95.

Wunderlich, Hermann (1894): Unsere Umgangssprache in der Eigenart ihrer Satzfügung. Weimar/Berlin. 


\section{Stilkennzeichnungen und Stilbewertungen in deutschen Wörterbüchern der Gegenwart.}

\section{Vorbemerkung}

Es wird berichtet, daß die Mitherausgeberin des "Wörterbuch[es] der deutschen Gegenwartssprache", Ruth Klappenbach, bei einem Besuch in der ČSSR freundlich mit den Worten begrüßt wurde: „Ich glaube, daß ich Ihre Visage schon einmal gesehen habe." Müller (1984) verzeichnet diese Begebenheit im Zusammenhang mit Fehlleistungen in der Wortwahl und bemerkt: „Die korrekte Anwendung der Wörter bereitet sowohl Ausländern als auch Muttersprachlern nicht selten Schwierigkeiten" (S. 366). Korrekte Anwendung wird hier in Verbindung gebracht mit einem "Zusatz", der zu einer im Wörterbuch kodifizierten lexikalischen Einheit steht oder nicht steht.

Schlägt man in allgemeinen einsprachigen Bedeutungswörterbüchern der deutschen Gegenwartssprache nach, so konstatiert man in sieben Wörterbüchern dieses Typs drei unterschiedliche „Zusätze” beim Lemma Visage ('Gesicht'):

"umgangssprachlich" (Wahrig-DW, Knaur),

"salopp" (WDG, Duden-GWB, Duden-UW, HDG),

"derb" (Duden-Bedeutungswörterbuch).

Nimmt man noch die drei letzten Auflagen des Rechtschreib-Dudens hinzu, so begegnet man hier zwei verschiedenen „Zusätzen” bei Visage: "umgangssprachlich" (Duden Mannheim 1986; Duden Mannheim/Leipzig 1991), "salopp” (Duden Leipzig 1985).

Übereinstimmend in allen genannten Wörterbüchern - den sieben allgemeinen einsprachigen und den drei Dudenausgaben - ist der weitere Zusatz „abwertend” (im Duden Mannheim 1986 „verächtlich"; im HDG "/emot. neg./"). Es sei darauf aufmerksam gemacht, daß fünf der genannten Wörterbücher (Duden-GWB, Duden-UW, Duden-Bedeutungswörterbuch, Duden Mannheim 1986, Duden Mannheim/Leipzig 1991) unter der Verantwortung einer Redaktion (an einem Ort) entstanden sind und daß sich in drei dieser fünf Wörterbücher ganz unterschiedliche „Zusätze” bei einem Lemma finden.

Mit diesem Beispiel wollte ich zeigen, worauf das Augenmerk der folgenden Darlegungen gerichtet werden soll: auf "Zusätze” der erwähnten Art, auch „Markierungen”, „Markierungsprädikate” oder "Marker” genannt; Hausmann spricht von "Markierungsetiketten” (1989, S. 649); auf die 
sogenannte "stilistische Charakterisierung des deutschen Wortschatzes" (WDG, S. 011) im Wörterbuch, auf Stilkennzeichnungen und Stilbewertungen - oder besser gesagt - Stilkennzeichnungen durch Stilbewertung.

Während die meisten Beiträge zu „Stilfragen” den Gegenstand „Stil” insbesondere unter theoretischem Aspekt erörtert haben, möchte ich mich ausschlieBlich auf "Stilfragen" der lexikographischen Praxis konzentrieren. Zunächst gilt die Aufmerksamkeit den Markierungskategorien 'Stilschicht'/'Stilebene' und 'Stilfärbung' im allgemeinen (1.). Danach sollen Unterschiede und Veränderungen der stilistischen Charakterisierung von lexikalischen Einheiten in verschiedenen deutschen Gegenwartswörterbüchern dargestellt werden (2.). Schließlich wollen wir thesenhaft einen Ausblick auf eine mögliche Verbesserung sogenannter stilistischer Markierungen in der lexikographischen Praxis geben (3.).

\section{Zu den Markierungskategorien „Stilschicht" / Stilebene” und „Stilfärbung"}

\subsection{Ein Blick zurück}

DaB die lexikographische Methode, in einem Wörterbuch verzeichnete lexikalische Einheiten „relativ zu z w e i Bezugssystemen bewertend zu kennzeichnen" (Wiegand 1981, S. 148), in der germanistischen Lexikographie eine lange Tradition hat, ist weithin bekannt. Dies soll hier nicht im einzelnen wiederholt und dargelegt werden (s. dazu Wiegand 1981; Ludwig 1991). Aber es sei vermerkt, daß nicht erst mit dem „Wörterbuch der deutschen Gegenwartssprache" die systematische „stilistische Bewertung" des in einem einsprachigen synchronischen Wörterbuch erfaßten Wortschatzes begonnen hat. Aussagen, daß man vor Erscheinen des WDG stilistische Markierungen "nur unsystematisch und sporadisch angebracht” habe (Püschel 1989, S. 694; vgl. auch Klappenbach †/MaligeKlappenbach 1978, S. 27), sind $z u$ relativieren. Es waren vor allem Adelung und Campe, die sich nicht mit sporadischen und unsystematischen Hinweisen als lexikographische Angaben zum Stil begnügten. Adelung benutzt ein fünfschichtiges System von Schreib- und Sprecharten, nach dem er die "Würde der Wörter" kennzeichnet (Adelung I, 1774, S. XIV). Es sind die "fünf Classen": "höhere oder erhabene Schreibart", "edle” Schreibart, „Sprechart des gemeinen Lebens und vertraulichen Umganges", "niedrige" Sprechart und schließlich die „ganz pöbelhafte” Sprechart (ebd.) - „Classen”, die mit „Stilschichten” bzw. „Stilebenen” der gegenwärtigen deutschen Lexikographie durchaus vergleichbar sind. "Ich habe mich bemühet, in den nöthigsten Fällen (denn in allen konnte es nicht geschehen) die Classe, in welche jedes Wort, oder jede Redensart gehöret, anzugeben" (ebd.), schreibt Adelung in der Vorrede zur 1. Auf- 
lage seines Wörterbuches, das unter dem Titel „Versuch eines vollständigen grammatisch-kritischen Wörterbuches Der Hochdeutschen Mundart, mit beständiger Vergleichung der übrigen Mundarten, besonders aber der Oberdeutschen" 1774-1786 erschienen ist. Sollte damit etwa eine "Classe" angesprochen sein, zu der Wörter gehören, die gewissermaßen als "neutral” oder "normalsprachlich" gelten - wie die heutigen Lexikographen diese "Stilschicht” nennen? In „allen [Fällen] konnte es nicht geschehen die Classe, in welche jedes Wort, oder jede Redensart gehöret, anzugeben" (s.o.). Adelungs Wörterbuch verzeichnet auch Lexeme, die nicht den "fünf Classen" zugeordnet werden.

Was die Charakterisierung einer „Nullmarkierung” betrifft, so ist Campe im Vergleich zu Adelung genauer. Hatte Adelung von der "Würde der Wörter" gesprochen, so nennt dies Campe "die innern Grade ihres Adels oder ihrer Gemeinheit" (Campe I, 1807, S. XIII), und er ist bemüht, „die Würdigung der Wörter” u.a. auch nach „ihrer Brauchbarkeit für die höhere oder niedrigere [...] Schreibart" zu kennzeichnen (ebd.). Er unterscheidet zunächst "Wörter der höhern Schreibart” und "niedrige Wörter”, die er weiter differenziert in: „Niedrige, aber deswegen noch nicht verwerfliche Wörter, weil sie in der geringern (scherzenden, spottenden, launigen) Schreibart, und in der Umgangssprache brauchbar sind [...]"; „Niedrige Wörter, die ans Pöbelhafte grenzen, und deren man sich daher, sowol in der Schriftsprache, selbst in der untern, als auch in der bessern Umgangssprache, enthalten sollte [...]" (Campe I, 1807, S. XXI). Campe verwendet zur stilistischen Charakterisierung und zur Kennzeichnung landschaftlicher, veralteter und neugebildeter Wörter insgesamt 14 „Kürzungszeichen”, die er in der Vorrede zum ersten Band seines "Wörterbuch[es] der Deutschen Sprache" (1807-1811) einführt und ausführlich erläutert (Campe I, 1807, S. XX f.). Wichtig ist der sich hieran anschließende Zusatz: „Wörter, die allgemein üblich sind, und für jede Schreibart passen, haben gar kein Zeichen" (S. XXI). Einige Beispiele für die Bewertungspraxis in Adelungs und Campes Wörterbuch finden sich in Tabelle 1.

Das zweite Bezugssystem sogenannter stilistischer Bewertung von sprachlichen Ausdrücken im Wörterbuch betrifft Markierungsprädikate, die heute zu den „Stilfärbungen” (WDG) oder "Gebrauchsangaben” (Duden-GWB) gezählt werden. Wir finden sie auch bei Adelung und Campe, z.B.:

Mos [...] ein nur in den niedrigen Sprecharten im $\mathrm{S} \mathrm{ch}$ e $\mathrm{r} \mathrm{z}$ e zuweilen übliches Wort [...] und Geld bedeutet. [...] (Adelung III, 1777, Sp. 587) 


\begin{tabular}{|l|c|c|}
\hline $\begin{array}{l}\text { Lemma- } \\
\text { beispiele }\end{array}$ & \multicolumn{2}{|c|}{ Stilistische Markierung in den Wörterbüchern von } \\
\hline & Adelung & Campe \\
\hline dreckig & in den niedrigen Sprecharten & $X$ \\
\hline duzen & $\begin{array}{c}\text { im gemeinen Leben und in } \\
\text { der niedrigen Sprechart }\end{array}$ & $X$ \\
\hline Fenster & - & - \\
\hline Flügel & - & - \\
\hline Fittich & in der höheren Schreibart & $\Delta$ \\
\hline Schwinge & in der dichterischen Schreibart & $\Delta$ in der höhern Schreibart \\
\hline Gefilde & $\begin{array}{c}\text { in der edlen und dichterischen } \\
\text { Schreibart }\end{array}$ & $\triangle$ \\
\hline Hain & $\begin{array}{c}\text { in der höhern und } \\
\text { dichterischen Schreibart }\end{array}$ & $\begin{array}{c}\text { in der höhern dichterischen } \\
\text { Schreibart }\end{array}$ \\
\hline Scheiße & in den niedrigsten Sprecharten & Xpöbelhaftes Wort \\
\hline
\end{tabular}

Tabelle 1: Beispiele für stilistische Markierungen in Adelungs und Campes Wörterbuch

$$
\begin{aligned}
- & =\text { ohne Markierungsprädikat („Nullmarkierung”) } \\
\triangle & =\text { Wörter der höhern Schreibart } \\
X & =\text { Wörter des gemeinen Lebens } \\
\not{X} & =\text { Pöbelhafte Wörter }
\end{aligned}
$$

X - Der Ehekrüppel [...] im gemeinen $\mathrm{S}$ c h e r z, ein alter gebrechlicher, unfähiger Ehemann; dann überhaupt, ein jeder Ehemann. (Campe I, 1807, S. 818)

Dichterling [...] ein schlechter, niedriger Dichter, im ver ä ch tl i c h e n Verstande. [...] Adelung I, 1774, Sp. 1343)

Der Wanst [...] der Schmerbauch an den Thieren, wie auch, aber in ver $\ddot{a} \mathrm{cht} \mathrm{li} \mathrm{ch} \mathrm{e} \mathrm{m} \mathrm{Verstande,} \mathrm{an} \mathrm{dem} \mathrm{Menschen.} \mathrm{[...]} \mathrm{(Campe} \mathrm{V,}$ 1811, S. 571). 


\subsection{Zur Gegenwart}

Die systematische "stilistische Charakterisierung des deutschen Wortschatzes" (WDG, S. 011) in einem einsprachigen synchronischen Wörterbuch ist nach Campe mit dem WDG wieder aufgenommen worden. Mit dem Erscheinen des „Wörterbuch[es] der deutschen Gegenwartssprache" (1961-1977) hat in der germanistischen Lexikographie die Ära der stilistischen Bewertung von Wörtern und ihren Verwendungsweisen durch die Zuordnung zu sogenannten "Stilschichten” (später auch „Stilebenen” genannt, vgl. HDG) und/oder "Stilfärbungen” (entsprechen den "Gebrauchsangaben" in Duden-GWB und Duden-UW) begonnen. Klappenbach schreibt 1964 über das entstehende Werk: „Es ist ein synchronisches Bedeutungswörterbuch, in dem das Einzelwort nach seinem stilistischen Wert bestimmt, in seinen typischen Fügungen vorgeführt und grammatisch gekennzeichnet wird" (zit. nach Klappenbach 1980, S. 90). Sie hebt hervor: „Das Neue und Besondere an diesem Wörterbuch ist die Einordnung des Wortschatzes in ein stilistisch aufgegliedertes Gefüge" (ebd.). Dieses "Gefüge” besteht zunächst aus vier „Stilschichten”. „Zu den Stilschichten treten Stilfärbungen oder Nuancen, die ein Wort oder eine Redewendung erhalten kann", lesen wir weiter bei Klappenbach (ebd., S. 92) - im WDG sind es elf. SchlieBlich: „Stilschicht und Stilfärbung sind e i n e Ebene, auf der wir den Wortschatz betrachten. Diese Stilanalyse [...] ist noch in keinem bisherigen deutschen Wörterbuch konsequent durchgeführt worden" (ebd.).

Das „stilistisch aufgegliederte Gefüge” des WDG ist Vorbild für andere Wörterbücher der deutschen Gegenwartssprache geworden. Auf die in den verschiedenen Wörterbüchern benutzten Markierungsprädikate für „Stilschichten" / Stilebenen" und „Stilfärbungen" und die dazu gegebenen Erläuterungen - wenn überhaupt vorhanden - soll hier nicht im einzelnen eingegangen werden. Wir haben uns an anderer Stelle ausführlicher zum Status und zur Praxis dieser Markierungen geäußert (vgl. Ludwig 1991).

Als „stilistische Bewertungen von Wörtern und Verwendungsweisen” werden zunächst Markierungsprädikate oder Marker verwendet, die zu „Stilschichten” bzw. „Stilebenen” gezählt werden, metalexikographisch diastratische Markierungen genannt. Ausgangspunkt für die Zuordnung zur Stilschicht sind „die normalsprachlichen Wörter [...], die in ihrem Stilwert neutral sind" (Duden-GWB 1976, S. 15; Duden-GWB 1993, S. 19) und die im Wörterbuch nicht besonders gekennzeichnet werden, also „Nullmarkierung” aufweisen. Die „normalsprachliche Schicht [...] wird bei gefühlsmäßig neutraler Haltung verwendet, erscheint im schriftlichen und mündlichen Gebrauch und ist im öffentlichen Leben (im wei- 
testen Sinne) allgemein üblich" (WDG, S. 012). Im übrigen habe ich bisher in keinem Wörterbuch normalsprachlich als Lemma gefunden. Lexeme, die nicht der "normalsprachlichen Schicht" zugeordnet sind, werden dann mit der entsprechenden Markierung entweder oberhalb dieser Schicht als "bildungssprachlich", „gehoben” oder "dichterisch" gekennzeichnet oder unterhalb der neutralen Schicht als "umgangssprachlich", „salopp", „derb” oder „vulgär” (s. Tabelle 2).

\begin{tabular}{|l|l|l|}
\hline WDG (1961) & $\begin{array}{l}\text { Duden-GWB (1976/1993)/ } \\
\text { Duden-UW (1983/1989) }\end{array}$ & HDG (1984) \\
\hline $\begin{array}{l}\text { Stilschichten } \\
\text { gehoben } \\
\text { (einschl. dichterisch) }\end{array}$ & $\begin{array}{l}\text { Stilschichten } \\
\text { gehobene Sprache } \\
\text { (einschl. dichterisch) } \\
\text { bildungssprachlich } \\
\text { normalsprachlich } \\
\text { normalsprachlich } \\
\begin{array}{l}\text { einschl. umgangs- } \\
\text { sprachlich) } \\
\text { salopp- } \\
\text { umgangsspraclulich } \\
\text { vulgär }\end{array}\end{array}$ & $\begin{array}{l}\text { umgangssprachlich } \\
\text { salopp } \\
\text { derb } \\
\text { vulgär }\end{array}$ \\
\hline
\end{tabular}

Tabelle 2: Markierungen für Stilschichten/Stilebenen in einigen deutschen Wörterbüchern

„Zu diesen stilistischen Bewertungen wie zu den normalsprachlichen Wörtern und Verwendungsweisen können Gebrauchsangaben wie 'scherzhaft, spöttisch, ironisch, abwertend, nachdrücklich, gespreizt, verhüllend, Schimpfwort' u.a. treten", heißt es im "Großen Wörterbuch der deutschen Sprache in sechs Bänden" (1976, S. 15). In der neuen achtbändigen Ausgabe folgt der Zusatz: "die [Gebrauchsangaben] etwas über die Haltung des Sprechers oder die Nuancierung einer Äußerung aussagen" (1993, S. 20) - „Gebrauchsangaben”, die im „Wörterbuch der deutschen Gegenwartssprache" als "Stilfärbungen" in Erscheinung treten, metalexikographisch als (dia)evaluative Markierungen bezeichnet.

Was ist eigentlich mit "Stilschicht" bzw. "Stilebene" und mit „Stilfärbung" gemeint? Anzunehmen wäre, daß beide Markierungskategorien in den Wörterbucheinleitungen bzw. Benutzungshinweisen thematisiert werden, man sie zumindest in den jeweiligen Wörterverzeichnissen als Lemmata mit einer Bedeutungserläuterung finden sollte. Weit gefehlt! Doch kehren wir noch einmal zu der von Klappenbach erwähnten „Stilanalyse" zurück. „Stilschicht und Stilfärbung sind e i n e Ebene”, 
auf der der Wortschatz im WDG betrachtet wird, und diese Betrachtung wird als „Stilanalyse” charakterisiert.

Ohne mich mit dem Terminus "Stil” und mit „Stilanalyse” in diesem Zusammenhang zu befassen, sei dazu nur soviel angemerkt: Klappenbach bezieht "Stilanalyse" nicht auf Texte, sondern speziell auf die Zuordnung der im Wörterbuch verzeichneten Wörter zu Stilschichten und Stilfärbungen. Stilanalyse erscheint als Lemma im WDG mit der Bedeutungserläuterung "Analyse einer sprachlichen (schriftlichen) Ausdrucksform" und den lexikographischen Beispielen: eine $S$. anfertigen; in der S. wurden Verstöße gegen die Syntax aufgezeigt. Im Duden-GWB ist Stilanalyse ohne Erklärung verzeichnet. Bleibt noch die sich hier wohl folgerichtig anschließende Frage: Welche Bedeutungserläuterung finden wir unter dem Lemma Stil, die hier in Frage kommt? Ich bleibe also ausschließlich beim Wörterbuch. Im WDG: „1. für eine bestimmte Epoche, Menschengruppe, Einzelperson, einen Lebens-, Tätigkeitsbereich typische, charakteristische (künstlerische) Ausdrucksform, Erscheinungsweise”, wobei dann differenziert wird „a) /mit Bezug auf Sprache, Literatur/" und „b) /mit Bezug auf bildende Kunst, Musik/". Die unter a) zu Stil angegebenen lexikographischen Beispiele (ein guter, gewandter, gepflegter, manierierter, schwülstiger, geschraubter S.; der Schriftsteller schreibt, hat einen eigenwilligen, lebendigen, glänzenden $S$. u.a.) und ebenso die zu Stilanalyse verzeichneten Beispiele lassen darauf schlieBen, daB Stil bzw. Stilanalyse auf einen Text in seiner Gesamtheit und nicht auf ein Einzelwort bezogen wird.

Aber was bedeuten "Stilschicht” / Stilebene" und „Stilfärbung”? Befragt man auch hierzu die Wörterbücher, die beide Bewertungskategorien benutzen und ihnen Markierungen subsumieren, so ist die Ausbeute der Antworten gering.

Das "Wörterbuch der deutschen Gegenwartssprache”, das die Termini "Stilschicht" und "Stilfärbung" in die lexikographische Praxis des Deutschen eingeführt hat, nach denen der kodifizierte Wortschatz mit deskriptiver Absicht stilistisch bewertet wird, erklärt beide Termini weder in der Wörterbucheinleitung, noch erscheinen sie als Lemmata im Wörterverzeichnis. Duden-GWB (1976/1993) und Duden-UW (1983/1989), die ebenfalls den Wortschatz „Stilschichten” zuordnen, erklären den Terminus "Stilschicht" in den Benutzungshinweisen nicht, erfassen ihn aber im Wörterverzeichnis, und zwar auf folgende Weise: Stilschicht hat die Fachgebietszuweisung "Sprachwissenschaft" und wird auf Stilebene verwiesen („vgl. -ebene"), und bei Stilebene findet man die Zuweisung „bes. Sprachwissenschaft” und die Erklärung „bestimmte Ebene des Stils". Die entsprechende Bedeutungserläuterung zu Stil lau- 
tet in beiden Wörterbüchern: "[durch Besonderheiten geprägte] Art u. Weise, etw. mündlich od. schriftlich auszudrücken, zu formulieren". Fündig in bezug auf eine Erklärung beider Bewertungskategorien wird man eigentlich, was die allgemeinen einsprachigen Wörterbücher des Deutschen angeht, nur im „Handwörterbuch der deutschen Gegenwartssprache” (1984): „Die Stilebene wird als eine innerhalb eines Kommunikationsbereichs wegen ihrer Eignung bevorzugte Möglichkeit der Sprachverwendung definiert. Das Wörterbuch gibt die als dominierend eingeschätzte Stilebene an” (S. XXII); „Die Stilfärbung wird verstanden als eine innerhalb eines Kommunikationsbereichs in Verbindung mit der Stilebene wegen ihrer Eignung bevorzugte Möglichkeit spezieller Sprachverwendung. Stilfärbungen drücken spezielle Nuancen aus, mit ihnen werden zusätzlich Gebrauchshinweise gegeben" (S. XXIII).

Wir finden diese Termini zum Beispiel auch in einigen Nachschlagewerken zur Sprachwissenschaft mit folgenden Erklärungen:

Für Krahl/Kurz (1984) ist im „Kleinen Wörterbuch der Stilkunde” Stilschicht - synonym mit Stilsphäre gebraucht - die „Höhenlage sprachlicher Formen im Verhältnis zur literarischen Norm; ästhetische Qualität. Eine mögliche Einteilung ist z.B. die Schichtung vulgär - umgangssprachlich - einfach-literarisch - gehoben - poetisch" (S. 121). Davon unterschieden wird die Stilebene als „durchschnittliches sprachästhetisches $\mathrm{Ni}$ veau eines Aussagekomplexes, eines Textes. Die Stilebene wird von der allgemeinen Stilschicht der Wörter und ihrer Fügung und durch den gesamten Charakter des Textes, z.B. durch dessen intellektuelle Qualität, bestimmt" (S. 113). Stilfärbung, gleichgesetzt mit Stilkolorit, bedeutet „übliche, d.h. im Wörterbuch bereits fixierte stilistische Nuance von Wörtern und Fügungen" (ebd.). Dabei können nach Krahl/Kurz (ebd., S. 113f.) Wörter und Fügungen z.B. aufweisen: ein "spezielles Kolorit" (sie können abwertend, grob, scherzhaft, spöttisch, übertreibend, vertraulich, verhüllend, zotig sein); ein "landschaftliches (territoriales) Kolorit" (z.B. Wiese/Alm in der Lexik; ist/hat gestanden in der Syntax); ein „politisches und soziales Kolorit” (z.B. Establishment/führende Klasse).

In dem von Conrad (1985) herausgegebenen „Lexikon sprachwissenschaftlicher Termini" werden Stilschicht, Stilebene und Stilsphäre als Synonyme behandelt und erklärt als „allgemeine emotionale Höhenlage sprachlicher Mittel; ausgehend von einer neutralen Grundschicht (normalsprachlicher Schicht mit expressiver Nullfärbung), sind nach oben und unten weitere Stilschichten zu unterscheiden" (S. 232). Bei Stilfärbung steht: „konnotative Qualitäten der Rede, die von sachlich neutraler Aussage abweichen und der sprachlichen Äußerung 
zusätzlich einen bestimmten Grad von Expressivität verleihen" (ebd., S. 231). Hier ist neben den bekannten Stilfärbungen "vertraulich" (Alterchen), "gespreizt" (Beinkleid), "abwertend" (klauen), „spöttisch" (neunmalklug), „übertrieben” (sich vor Ärger die Haare raufen), „verhüllend" (abberufen werden für sterben) auch von nzeitlicher" (veraltet: Eidam, veraltend: Gendarm u.a.), "territorialer" (Schlächter, Metzger; Schrippe) und "sozialer" Stilfärbung (Jargonismen: kesse Biene, Moos für Geld) die Rede.

Im „Sachwörterbuch für die deutsche Sprache” (1989) wiederum werden Stilfärbung und Stilschicht synonym behandelt und aufgefaßt als "die Summe von (sachbedingt oder einstellungsbedingt) wertenden und von situativen Konnotationen sprachlicher Mittel" (S. 240). In neueren linguistischen Nachschlagewerken (z.B. BuBmann 1990, Lewandowski 1990, Metzler-Lexikon Sprache 1993) tauchen Stilschicht/ Stilebene und Stilfärbung als Lemmata nicht auf.

Ich möchte die unterschiedlichen Auffassungen nicht weiter kommentieren, es sollte damit lediglich auf das terminologische Dilemma in bezug auf "Stilschicht" / Stilebene" und "Stilfärbung” im allgemeinen hingewiesen werden. Es gibt keine allgemein verbindliche Definition dieser Markierungskategorien, geschweige denn der ihnen zugeordneten Markierungsprädikate. Hinzu kommt, daß einerseits die Zahl der Markierungen von Wörterbuch zu Wörterbuch schwankt und andererseits die Zuordnung einzelner Markierungen entweder zu „Stilschichten” oder zu "Stilfärbungen" differiert.

\section{Unterschiede und Veränderungen der stilistischen Bewertung von lexikalischen Einheiten in deutschen Gegenwartswörterbüchern}

\subsection{Zur Markierungspraxis in allgemeinen einsprachigen Wörterbüchern}

Es ist auffällig, daß das Markierungsprädikat „derb” im WDG als Stilfärbung, in Duden-GWB und Duden-UW als Stilschicht in Erscheinung tritt. Die Anwendung von "derb" wird im WDG nicht näher erläutert. In Duden-GWB und Duden-UW gehört „derb” zur Schicht unterhalb der normalsprachlichen Schicht und gilt für "Wörter, die einer groben und gewöhnlichen Ausdrucksweise angehören", wie z.B. Arsch, bescheißen, Fresse (Duden-GWB 1993, S. 20; vgl. auch DudenUW 1989, S. 9). Während "umgangssprachlich”, "salopp”, „derb” und "vulgär" in den beiden zuletzt genannten Wörterbüchern gewissermaßen als „Graduierungen” zu einer Schicht unterhalb der normalsprachlichen 
gehören - „reicher gegliedert ist die Schicht unterhalb der normalsprachlichen Stilschicht" (Duden-GWB 1993, S. 20) -, begreift das WDG "urmgangssprachlich" als "Variante der Normalsprache" und "salopp" (hier: „salopp-umgangssprachlich”) und „vulgär” als eigenständige Stilschichten (WDG, S. 012). Die im WDG als "vulgär" gekennzeichnete unterste Ebene erscheint im HDG als "derb”. In Duden-GWB (1976, S. 15/1993, S. 19) und Duden-UW (1989, S. 9) wird oberhalb der normalsprachlichen Schicht "eine gebildete Ausdrucksweise" angesiedelt, "die gewisse Kenntnisse und eine gute schulische Ausbildung voraussetzt" und in den genannten Wörterbüchern mit „bildungssprachlich” gekennzeichnet wird. "Es handelt sich hierbei meist um Fremdwörter, die weder einer Fachsprache noch der Umgangssprache angehören" (ebd.). Im Brockhaus-Wahrig wird „bildungssprachlich” den "Angaben zu Sondersprachen" zugeordnet.

Abgesehen davon, daß sich die Zahl der angenommenen "Stilschichten" / „Stilebenen” von Wörterbuch zu Wörterbuch unterscheidet und die Zuordnung von Markierungen $z u$ diesen unterschiedlich ist, schwankt die Zuordnung von diastratischen Markierungen zu Wörtern bzw. zu einzelnen Verwendungsweisen lexikalischer Einheiten erheblich (vgl. Braun 1981, S. 169ff.; Wiegand/Kučera 1981, S. 141ff.; Hausmann 1989, S. 649ff; Corbin 1989, S. 673ff.). Braun (1981, S. 172) hat beispielsweise bei einem Vergleich der Zuordnung von Wörtern zu Stilschichten im WDG und Duden-GWB (1976) festgestellt, daß „die untere Grenze der Abweichungen [...] bei 30\%, die obere bei 70\%" liegt. Eine zur Zeit laufende, aber noch nicht abgeschlossene Untersuchung der Zuordnung von diastratischen und diaevaluativen Markierungen zu Wörtern im WDG und HDG läßt eine ähnliche Tendenz in der unterschiedlichen stilistischen Markierung erkennen. Nach vorläufiger Auswertung ist innerhalb der Buchstabenstrecke $A$ bis $K$, in der rund 8400 Wörter oder deren Verwendungsweisen eine "stilistische" Markierung aufweisen, eine Differenz der Zuordnung zu Stilschichten von etwa $40 \%$ festzustellen. Das liegt zum Teil daran, daß die von den im WDG als „dichterisch" gekennzeichneten lexikalischen Einheiten, die auch in das HDG übernommen worden sind, hier meist als "gehoben” markiert werden, häufig auch als "veraltend gehoben” (vgl. hierzu Tabelle 3). Als „dichterische Wörter und Redewendungen" werden im WDG lexikalische Einheiten gekennzeichnet, „die im allgemeinen der poetischen Gestaltung eines Werkes vorbehalten sind" (WDG, S. 012). Im HDG werden zur "gehobenen Stilebene" Lexeme gerechnet, „die gewählt, feierlich, erhaben anmuten” (HDG, S. XXII). Im Duden-UW, das bei diesem Vergleich mit herangezogen worden ist, werden diese Lexeme häufig - wie im WDG - als „dichterisch” bewertet. Es sind „Wörter, die vorzugsweise in der älteren Dichtung vorkommen 
und heute fast durchgängig veraltet sind oder altertümelnd gebraucht werden" (Duden-UW 1989, S. 9).

Beim Vergleich der Zuordnung lexikalischer Einheiten zu Stilschichten ist vom WDG zum HDG hin sehr häufig die Tendenz einer "Aufwertung” festzustellen. Das heißt: Wörter bzw. bestimmte Verwendungsweisen lexikalischer Einheiten, die im WDG als "salopp" gekennzeichnet sind, erhalten im HDG das Markierungsprädikat „umgangssprachlich”; im WDG als „umgangssprachlich" markierte Lexeme erscheinen im HDG mit „Nullmarkierung”. Wir haben auch bei diesem Vergleich die jeweils im Duden-UW verzeichneten Markierungen mit herangezogen. 


\begin{tabular}{|c|c|c|c|}
\hline & \multicolumn{3}{|c|}{$\begin{array}{l}\text { Stilistische Markierung } \\
\text { in den Wörterbüchern }\end{array}$} \\
\hline Lemmabeispiele & WDG & HDG & Duden-UW \\
\hline Aar (Adler) & dicht. & veraltend geh. & dichter. veraltet \\
\hline Altvorder(e)n (Vorfahren) & dicht. & noch scherzh. & veraltet, geh. \\
\hline Barke (kleines Boot ohne Mast) & dicht. & - & - \\
\hline beglänzen (Glanz auf etw. werfen) & dicht. & - & dichter. \\
\hline benetzen (anfeuchten) & dicht. & geh. & geh. \\
\hline $\begin{array}{l}\text { Brandmal } \\
\text { (das unauslöschliche } \\
\text { Zeichen) }\end{array}$ & dicht. & geh. & \begin{tabular}{|l} 
nicht in dieser \\
Bedeutung \\
verzeichnet \\
\end{tabular} \\
\hline Busen (Brust des Menschen) & dicht. & veraltend & dichter., veraltet \\
\hline Dämmerschein & dicht. & geh. & geh. \\
\hline dräuen (drohen) & dicht. & veraltend geh. & dichter. \\
\hline Eiland (Insel) & dicht. & veraltend geh. & dichter. \\
\hline $\begin{array}{l}\text { fächeln } \\
\text { (in sanfter Bewegung wehen) }\end{array}$ & dicht. & geh. & geh. \\
\hline Fittich (Flügel) & dicht. & geh. & dichter. \\
\hline Gefilde (Landschaft) & dicht. & geh. & geh. \\
\hline gülden (golden) & dicht. & geh. & $\begin{array}{l}\text { dichter., } \\
\text { sonst meist iron. }\end{array}$ \\
\hline Hain (kleiner Wald) & dicht. & geh. & dichter. veraltet \\
\hline hehr (erhaben) & dicht. & veraltend & geh. \\
\hline Himmelszelt (Himmel) & dicht. & geh. & dichter. \\
\hline Hort (Schatz) & dicht. & veraltend & dichter. \\
\hline $\begin{array}{l}\text { Jungbrunnen (etw., was jmdm. } \\
\text { neuen Schwung verleiht) }\end{array}$ & dicht. & - & - \\
\hline künden (berichten) & dicht. & geh. & geh. \\
\hline Lenz (Frühling) & dicht. & geh. & dichter. \\
\hline Nachen (Kahn, Boot) & dicht. & veraltend geh. & dichter. \\
\hline Odem (Atem) & dicht. & veraltend geh. & dichter. \\
\hline Parnaß (Reich der Dichtkunst) & dicht. & veraltend geh. & dichter. geh. \\
\hline Port (Ort der Geborgenheit) & dicht. & veraltend geh. & dichter. veraltet \\
\hline
\end{tabular}

Tabelle 3: Beispiele für die Zuordnung von Lexemen zu den Markierungsprädikaten "dichterisch" und "gehoben" in drei deutschen Wörterbüchern

$\begin{array}{ll}- & =\text { ohne Markierungsprädikat ( Nullmarkierung") } \\ \text { dicht./dichter. } & =\text { dichterisch } \\ \text { geh. } & =\text { gehoben } \\ \text { iron. } & =\text { ironisch }\end{array}$


Wie bereits erwähnt, wird im WDG eine „Variante der Normalsprache, die im mündlichen Gebrauch erscheint und für die einige Wörter (z.B. kriegen 'bekommen') typisch sind", als "Umgangssprache" bezeichnet. „Schriftlich werden diese Wörter nur in privaten Briefen gebraucht sowie in der Literatur, um eine gewisse Vertraulichkeit auszudrücken”, sie erhalten die "Bewertung umgangssprachlich" (WDG, S. 012). Im HDG werden zur "umgangssprachlichen Stilebene" Lexeme gerechnet, "die in einer zwanglosen Sprache des alltäglichen mündlichen oder (nichtöffentlichen) schriftlichen Gebrauchs verwendet werden" (HDG, S. XXII). Im Duden-UW (1989, S. 9) wird darauf verwiesen, daB der „normalsprachlichen Stilschicht” die "Umgangssprache” nahesteht, „die im alltäglichen, besonders im familiär-vertraulichen, mündlichen Verkehr der Menschen untereinander üblich ist und in Briefen verwendet wird. Sie ist aber heute auch häufig in der Öffentlichkeit anzutreffen und hat Eingang in die Literatur gefunden." Die „saloppumgangssprachliche" Schicht unterscheidet sich nach dem WDG „von der Normalsprache, einschließlich ihrer umgangssprachlichen Variante, durch eine gewisse Nachlässigkeit” und ist ,im*alltäglichen Verkehr der Menschen untereinander heute sehr verbreitet. [...] Sie würde, im öffentlichen Leben verwendet, salopp und leicht anstöBig wirken. [...] Die Wörter und Redewendungen dieser Stilschicht sind mehr oder weniger gefühlsbetont” (WDG, S. 012). Im HDG werden der „saloppen Stilebene” Lexeme zugeordnet, „die eine legere Haltung des Sprechers ausdrücken, oft bildhaft sind und eine starke emotionale Aufladung besitzen" (HDG, S. XXII). Als „salopp” kennzeichnet das Duden-UW $(1989$, S. 9) Wörter und Verwendungsweisen, "wie sie für eine burschikose und z.T. recht nachlässige Ausdrucksweise charakteristisch sind."

Im WDG als „salopp”, in HDG und Duden-UW als „umgangssprachlich” werden z. B. gekennzeichnet:

abdampfen (weggehen, -fahren), abkanzeln (scharf tadeln), Abreibung (scharfe Zurechtweisung; Prügel), sich abstrampeln (sich abmühen), etw. ist amtlich (ganz sicher), angesäuselt (ein wenig betrunken), Bärenhunger (großer Hunger), Bauchkneipen (Bauchschmerz), Bauchladen, Hals- und Beinbruch (alles Gute!), beschummeln (ein wenig betrügen), bibbern (zittern), blümerant (unwohl), bockbeinig (störrisch), einen Bock schießen (einen Fehler machen), dazwischenfunken (dazwischenfahren), dickfellig (gleichgültig), der, die, das Dings (Person; irgend etwas; Ortsname), dösen (mit wachen Augen vor sich hin träumen; leicht schlafen), durchackern (etw. durcharbeiten), durchbrennen (sich heimlich davonmachen), etw. aus dem Effeff (vorzüglich) können, beherrschen; einfädeln (anbahnen), Flittchen, Ganove, Gaudi (Spaß), junges Gemüse (unerfahrene Jugendliche), Job (Beschäftigung), Käfer (hübsches junges Mädchen), knutschen. 
Im WDG als „umgangssprachlich” gekennzeichnete lexikalische Einheiten erscheinen in HDG und Duden-UW in vielen Fällen mit „Nullmarkierung”, z.B.:

abgekämpft (ermũdet), abgemacht! (es gilt), sich abhetzen (sich sehr beeilen), abreagieren (Affekte entladen), adrett (sauber und ordentlich), ahnungslos (völlig unwissend), Akku (Akkumulator), Amüsement (Vergnügen), das ist Ansichtssache (darüber kann man verschiedener Meinung sein), bemuttern (umsorgen), Binsenwahrheit (allgemein bekannte Tatsache), blendend (ausgezeichnet), brühheiß (sehr heiß), brutto (ohne Abzug der Abgaben, Steuern), Bus (Omnibus), Busfahrer, Bushaltestelle, couragiert (beherzt), deplaciert (unangebracht), Desaster (schweres MiBgeschick, Zusammenbruch), dummerweise (ärgerlicherweise; törichterweise), Dummkopf (dummer Mensch), das Eingemachte (eingemachte Lebensmittel), en passant (beiläufig), Faible (Vorliebe), feuchtfröhlich (fröhlich, ausgelassen durch AlkoholgenuB), Flickzeug (Material zum Flicken), fortbringen (wegbringen), fortschaffen (wegbringen), Galgenfrist (Gnadenfrist), Geläster (dauerndes Lāstern), Glückskind (jmd., der immer Glück hat), hänseln (sich über jmdn. lustig machen), herumtollen (ausgelassen umherspringen, -laufen), humpeln (mühsam gehen), Ischias (Schmerzen im Bereich des Ischiasnervs), Jammergestalt (mitleiderregender Mensch), johlen (lärmend schreien), Kalamität (Schwierigkeit), Kalauer (wenig geistreiches Wortspiel), Kleinigkeitskrämer (jmd., der Kleinigkeiten übertrieben wichtig nimmt).

Bemerkenswert scheint mir bei dem Vergleich der Zuordnung von sprachlichen Ausdrücken zu Stilschichten im WDG bzw. Stilebenen im HDG die Tatsache, daB ein Dutzend Mitarbeiter des Autorenkollektivs des HDG auch Autoren des WDG gewesen sind. Haben sich also die Bewertungsnormen vom AbschluB des WDG über die Erarbeitungsphase des HDG verändert?

Weitgehend übereinstimmen die im WDG als "vulgär" markierten Wörter mit denen, die im HDG der Stilebene "derb" zugeordnet sind. Nach dem WDG gehören zur Schicht vulgärer Wörter und Redewendungen solche, "die als ausgesprochen grob empfunden und deshalb im allgemeinen vermieden werden”. Sie sind „nur in beschränktem Umfang in dieses Wörterbuch aufgenommen." (WDG, S. 012). Es wird ausdrücklich darauf aufmerksam gemacht, daß obszöne Wörter, die zur vulgären Schicht gehören, nicht berücksichtigt sind. Im HDG werden der „derben Stilebene" Lexeme zugeordnet, die ,in hohem Grade drastisch, verletzend oder unter Umständen anstößig wirken" (HDG, S. XXII).

\subsection{Zur Markierungspraxis im Duden (Rechtschreibwörterbuch)}

In der in jüngster Zeit geführten Diskussion über die Mikrostruktur der Wörterbuchartikel eines Rechtschreibwörterbuches geht es auch um die Frage, welche Angaben zu einem Lemma bzw. Lemmazeichen aufzunehmen sind. „Grundsätzlich gilt für die Prüfung [...] das Krite- 
rium der rechtschreiblichen Relevanz; d.h., es sollen nur solche Angaben Eingang in einen Wörterbuchartikel finden, die in irgendeiner Weise die Rechtschreibung des jeweiligen Wortes betreffen. Bisher ist nicht endgültig ausgemacht, welche Arten von Angaben dies im Einzelfall sind" (Augst/Schaeder 1991, S. 90). Reichlich Gebrauch gemacht wird heute im Duden von den diasystematischen Markierungen, die nach Herberg (1993, S. 348) im Rahmen des Konzepts von Zentrum und Peripherie zur Peripherie der Informationen eines im Rechtschreibwörterbuch verzeichneten Lemmas zu zählen sind. Ich möchte nicht darüber sinnieren, ob der Duden vom „Universalwörterbuch”, "Mehrzweckwörterbuch”, "Allzweckwörterbuch”, „Überwörterbuch” (Nerius 1988, S. 478f.; 1988a, S. 252f.) wieder zum reinen Rechtschreibwörterbuch zurückkehren sollte. Aber: Sollte der Duden auch zukünftig die vielfältigen nichtorthographischen Kennzeichnungen zu Lemmata beibehalten, so sollten - nein - müßten diese Angaben zu einer präziseren, besser durchschaubaren Praxis führen (vgl. auch Nerius 1988a, S. 253f.). Und das betrifft - und hierauf beschränke ich mich - auch die „stilistische" Kennzeichnung von Wörtern im Duden, die Zuordnung zu "Stilschichten” und/oder "Stilfärbungen” (nach der Terminologie allgemeiner einsprachiger Wörterbücher).

Weder in der letzten Ausgabe des Leipziger Dudens (18. Neubearbeitung 1985) noch in der letzten Ausgabe des Mannheimer Dudens (19. Auflage 1986), noch in dem 1991 erschienenen "wiedervereinigten" Wörterbuch zur deutschen Rechtschreibung (20. Auflage Mannheim/Leipzig) werden stilistische Markierungen in den jeweiligen Hinweisen für den Benutzer thematisiert, wenn man von folgenden allgemeinen Bemerkungen absieht:

Im "Vorwort” zur 18. Neubearbeitung des Leipziger Dudens (1985, S. 5) heiBt es: „Die stilistischen Angaben wurden im gesamten Wörterverzeichnis nach einheitlichen Kriterien bearbeitet." Zum „Aufbau der Stichwortartikel" der "Einführung in Anlage und Aufbau des Wörterverzeichnisses" ist zu lesen: "Die Worterläuterungen stehen in sunden Klammern, wenn nötig, mit kursiven Sachgebiets-, territorialen (landschaftlichen) oder stilistischen Kennzeichnungen versehen. [...] Die stilistischen Angaben wurden häufig relativiert, da eine absolute Kenzzeichnung ohne Kontext oft nicht möglich ist" (S. 9f.). Bleiben die Tragen: Was sind eigentlich stilistische Angaben/Kennzeichnungen? Nach welchen einheitlichen Kriterien wurden sie bearbeitet?

Im „Vorwort” und in den „Hinweise[n] für den Benutzer” des Mannheimer Dudens von 1986 finden sich keine Ausführungen zu den stilistischen Markierungen. Im "Vorwort” der Neuausgabe des Dudens von 1991 wird 
(wohl) zumindest auf derartige Angaben hingewiesen, wenn es heißt: „Da der Duden nicht nur ein Rechtschreibbuch ist, sondern auch die Funktion eines Volkswörterbuchs erfüllt, wurden die Erklärungen schwieriger Wörter, vor allem veraltender, landschaftlicher, umgangssprachlicher und fachsprachlicher Ausdrücke, und die Angaben zum Wortgebrauch beträchtlich erweitert” (S. 6). Keine Erläuterungen dazu, was „Angaben zum Wortgebrauch" sind, inwiefern diese Angaben beträchtlich erweitert wurden und welches Bewertungssystem diesen Angaben, mit denen vermutlich auch "stilistische Kennzeichnungen” gemeint sind, zugrunde liegt.

Nur über das jeweilige Abkürzungsverzeichnis und die im Wörterverzeichnis verwendeten Markierungsprädikate ist $\mathrm{zu}$ erschließen, welche Angaben eigentlich "stilistische Angaben” sind; sie werden nicht systematisch eingeführt. Das betrifft nicht nur Markierungen, die in allgemeinen einsprachigen Wörterbüchern zu "Stilschichten”/ „Stilebenen” gehören (s. Tabelle 4), sondern auch Angaben, die "Stilfärbungen” bzw. "Gebrauchsangaben" zugeordnet werden (z.B. "scherzhaft”, ,spöttisch", "ironisch", „abwertend").

\begin{tabular}{|c|c|c|}
\hline \multicolumn{2}{|c|}{$\begin{array}{c}\text { Markierungen im Duden, die "Stilschichten"/,Stilebenen" } \\
\text { in allgemeinen einsprachigen Wörterbüchern } \\
\text { des Deutschen entsprechen }\end{array}$} \\
\hline $\begin{array}{c}\text { Duden 1985 } \\
\text { (18. Neubearbeitung } \\
\text { Leipzig) }\end{array}$ & $\begin{array}{c}\text { Duden 1986 } \\
\text { (19. Aufl. Mannheim) }\end{array}$ & $\begin{array}{c}\text { Duden 1991 } \\
\text { (20. Aufl. } \\
\text { Mannheim/Leipzig) }\end{array}$ \\
\hline $\begin{array}{c}\text { dichterisch } \\
\text { gehoben } \\
\text { normalsprachlich } \\
\text { umgangssprachlich } \\
\text { salopp } \\
\text { derb }\end{array}$ & $\begin{array}{c}\text { dichterisch } \\
\text { gehoben }\end{array}$ & gehoben \\
\hline
\end{tabular}

Tabelle 4: Markierungen für Stilschichten/Stilebenen in drei Dudenausgaben

Kurios ist, daß im Abkürzungsverzeichnis des Leipziger Dudens (1985) die Angabe „normalsprachlich” auftaucht. Bisher habe ich im Wörterverzeichnis dieser Dudenausgabe kein so markiertes Lemma entdeckt. Sowohl in der Leipziger Ausgabe von 1985 als auch in den Dudenausgaben von 1986 und 1991 haben wir jeweils auch die „Nullmarkierung” bei Lemmata, die nicht explizit (d.h. durch ein verbales Prädikat) markiert sind. Ohne hier auf Einzelheiten unterschiedlicher stilistischer Markierungen von lexikalischen Einheiten in den genannten drei Dudenausgaben ein- 
gehen zu können (vgl. Ludwig 1994), sei zu den bisherigen Ergebnissen einer laufenden Untersuchung nur soviel mitgeteilt:

Die sowohl im Leipziger Duden (1985) als auch im Mannheimer Duden (1986) als "dichterisch" markierten Lemmata werden im "Einheitsduden” (1991) als "gehoben" gekennzeichnet, z.B.: Aar (Adler), Allmutter('Mutter alles Lebenden': Allmutter Natur), Fittich (Flügel), Lenz (Frühling), Odem (Atem).

Die Markierung „salopp” wird nur im Leipziger Duden (1985) verwendet. Die hier so gekennzeichneten Lemmata werden im Mannheimer Duden von 1986 und im Duden von 1991 als "umgangssprachlich" markiert, z.B.: aasen (verschwenderisch umgehen), abgetakelt (heruntergekommen, ausgedient), abhauen (davonlaufen), ausgekocht (durchtrieben), auswischen ( $j m d m$. eins auswischen 'schaden').

Nahezu Übereinstimmung herrscht bei den als „derb” markierten Lemmata, 2.B.: Anschiß (Tadel), Arsch, Arschkriecher, auskotzen, ficken, Scheiße.

\section{Ausblick}

Im Vorwort der annotierten Bibliographie zur Theorie der Lexikographie "Lexicography Today" (1988) macht Zgusta im Zusammenhang mit terminologischen Fragen nachdrücklich darauf aufmerksam, daß die größte terminologische und begriffliche Unklarheit im Bereich der diasystematischen Markierungen im Wörterbuch besteht und innerhalb dieses Gebietes vor allem die stilistischen betrifft (S. XII).

An Überlegungen und Vorschlägen zur Verbesserung der bisherigen Praxis stilistischer Markierung in Wörterbuch mangelt es nicht (vgl. z.B. Rossipal 1973, Wiegand 1981, Schumann 1983, Ludwig 1991). Thesenhaft möchte ich die Problematik der "Angaben zum Stil” im Wörterbuch zusammenfassen und hierbei einen eigenen Vorschlag zur Verbesserung der bisherigen Praxis einbeziehen:

(1) Es gibt bestimmte Wörter und Wendungen, die im Vergleich zu anderen a uffällig sind. Erinnern wir uns an die eingangs erwähnten Wörter Visage - Gesicht, denen wir auch die Synonyme Angesicht Antlitz - Fresse hinzufügen können. Oder nehmen wir Überschrift und Inhalt eines Artikels in der „Zeit” (11. März 1994, S. 93): „Wie flucht Europa? Und wie redet es sich heraus? Ein Brite hat die Unterschiede analysiert. Merde, Scheiße, shit” in der Rubrik "Modernes Leben”. Über das deutsche Wort schreibt die Autorin Roggenkamp: „Das Wort hat selbstverständlich in jedem europäischen Land seine Bedeutung, nimmt 
aber nirgendwo diesen Rang ein" (wie bei den Deutschen). Dies paBt zu der Frage einer Studentin, die nach dem Seminar, in dem wir die hier zur Debatte stehende Problematik erörtert hatten, zu mir kam und mich fragte: „MuB denn dieses Wort im Wörterbuch überhaupt gekennzeichnet werden? Jeder gebraucht es, auch die Professoren!" Es gibt also auffällige Wörter. Hausmann (1989, S. 649) hat darauf hingewiesen, daß mit einer solchen Auftälligkeit eine „unmittelbare Auffälligkeit gemeint” ist und nicht eine, „die erst nach eingehender linguistischer Analyse zutage tritt. Solche Auffälligkeit ergibt sich durch ein gegenüber der Normalität zusätzliches Merkmal, das der sprachlichen Einheit wie ein Etikett anhaftet. Wir sagen, die sprachliche Einheit ist markiert. Dem Durchschnittsphänomen fehlt dieses Merkmal, es ist unmarkiert." Und besonders wichtig ist Hausmanns Zusatz: „Für die Textproduktion ergeben sich aus der Markiertheit Verwendungsrestriktionen, Wortverwendungsgrenzen, um die der Muttersprachler intuitiv weiB, die der Fremdsprachler jedoch, ganz so wie die phonetischen, morphologischen, semantischen, syntagmatischen und paradigmatischen Regeln, eigens lernen muB."

DaB diese Auffalligkeit der Wörter im Wörterbuch kenntlich zu machen ist, ist wohl unbestritten. Die Fragen sind: Wie sind diese „Auffalligkeiten” oder „Zusätze” kenntlich zu machen? Wie sind diese „Etiketten” zu beschriften? Damit im Zusammenhang steht das Problem: Wie viele „Etiketten" sollten verwendet werden?

(2) Meines Erachtens geht es in erster Linie darum, dem Wörterbuchbenutzer Informationen darüber zu vermitteln, ob eine lexikalische Einheit im Rahmen einer kommunikativen Prädisposition als „neutral” anzusehen ist, also keinerlei "Auffäligkeit" und somit auch keinerlei Verwendungsrestriktionen aufweist, oder ob die lexikalische Einheit nach "oben" ("über neutral”) oder nach „unten" („unter neutral”) von der neutralen Ebene abweicht und somit Gebrauchsrestriktionen unterliegt. Mit diesen Informationen in Form von "Markierungsetiketten" soll das im Alltagsverständnis der Sprecher vorhandene Wissen über Verwendungsmaximen von Lexemen lexikographisch erfaßt werden. Was ist mit k o m m u n k t iver Prädis position gemeint? Da die Verwendung der Termini „Stilschicht”/ „Stilebene” und "Stilfärbung" als Stilbewertungskategorien insofern problematisch ist, als "Stil" gewöhnlich als textimmanente Eigenschaft begriffen wird, „Stilschicht"/nStilebene" und "Stilfärbung" jedoch auf ein Einzellexem bzw. eine seiner spezifischen Verwendungsweisen bezogen werden, habe ich vorgeschlagen, anstelle dieser Termini den Begriff der kommunikativen Prädisposition zu verwenden (vgl. Ludwig 1991, S. 222ff.). Damit soll ausgedrückt werden, daß eine lexikalische Ein- 
heit prädisponiert ist, in bestimmten Bereichen der Kommunikation gebraucht zu werden. Lexikalische Einheiten, die dieselbe kommunikative Prädisposition aufweisen, d.h. ohne Einschränkung bzw. nur mit Einschränkung verwendet werden können, gehören dann zur selben $k$ ommunikat iven Prädispositionsebene; sie gibt den allgemeinen Bereich der Kommunikation an, in dem die entsprechende lexikalische Einheit vorwiegend gebraucht werden kann. Die Ebenen dieses dreistufigen Modells stellen zunächst ein grobes, aber grundlegendes Raster für die Einordnung lexikalischer Einheiten in Verwendungsbereiche und die entsprechenden Markierungen damit Hinweise für Verwendungsrestriktionen dar, wobei zu erwägen ist, die Ebene „unter neutral” zu differenzieren in "umgangssprachlich” bzw. „ungezwungen” und "derb”. Hinzu kommen können weitere Markierungen, die spezifische Hinweise für Gebrauchsmöglichkeiten eines Lexems geben, "Gebrauchsangaben”, die „etwas über die Haltung des Sprechers oder die Nuancierung einer Äußerung aussagen" (Duden-GWB 1993, S. 20). So können z.B. Markierungen darauf hinweisen, daß durch die Verwendung dieses Lexems der Sprecherstandpunkt, insbesondere eine emotionale Einstellung des damit bezeichneten Denotats ausgedrückt werden kann. Andere Markierungen weisen darauf hin, daß durch den Gebrauch lexikalischer Einheiten in bestimmten Zusammenhängen insofern die Sprecherintention angedeutet wird, als damit eine gewisse Scherzhaftigkeit oder Distanzierung zum Ausdruck gebracht werden kann.

(3) Um eine ausgewogene und systematische „stilistische” Markierung der Einzellexeme in einem Wörterbuch zu erzielen, ist es unabdingbar, das Einzellexem jeweils mit anderen Lexemen des entsprechenden Lexemfeldes in Beziehung zu setzen, d.h., eine solche ausgewogene und systematische „stilistische” Bewertung kann nur im Feldzusammenhang geschehen, was einen Vergleich kompletter Synonymfelder voraussetzt. Zu prüfen ist ebenfalls, ob zu dem als „über neutral” bzw. „unter neutral" zu markierenden Lexem jeweils ein Synonym vorhanden ist, das der „neutralen” Ebene zugeordnet werden kann.

(4) Man sollte versuchen, die im Wörterverzeichnis verwendeten Markierungen auf eine begründbare Typologie zurückzuführen, damit dem Lexikographen ein $\mathrm{m} \ddot{\mathrm{g}} \mathrm{li} \mathrm{ch} \mathrm{s} \mathrm{t}$ einheitliches Beschreibungsinventar zur Verfügung steht. Daß sich mit „einem geschlossenen Inventar von Prädikatsausdrücken [...] die vielfältigen Nuancen im Wortgebrauch nicht erfassen" lassen (Püschel 1989, S. 698), ist ebenso unbestritten wie auch die Beschreibung dieser Nuancen in Form sogenannter "offener Kommentare”, die Wiegand (1981) vorgeschlagen hat, nicht ausgeschlossen wer- 
den soll. Die wiederholt erhobene Forderung, im Wörterbuch genaue Regelbeschreibungen für den situationsspezifischen Gebrauch von Lexemen anzugeben, besteht sicherlich zu Recht. Sie ist jedoch insofern schwer zu erfüllen, als hierbei von konkreten Situationen zu abstrahieren ist, um zu Typen von Situationen zu gelangen. Es bleibt weiterhin zu bedenken: Je mehr Markierungsprädikate für die stilistische Bewertung verwendet werden, um so größer werden gleichzeitig die Schwierigkeiten der Lexikographen bei der Kennzeichnung von Lexemen. Wichtig ist allerdings: Dem Benutzer muB der Bewertungsmodus von lexikalischen Einheiten in den Benutzungshinweisen erklärt werden, und es müssen sämtliche im Wörterverzeichnis verwendeten Markierungen in der Wörterbucheinleitung eingeführt und umfassend beschrieben werden.

\section{Schlußbemerkung}

Eine endgültige, alle Wörterbuchbenutzer und Linguisten befriedigende Lösung in bezug auf die ,stilistische" Bewertung und Kennzeichnung von lexikalischen Einheiten im Wörterbuch wird es nicht geben. Den Markierungen ist „kein absoluter, wohl aber ein relativer Wert zuzumessen" (Hausmann 1989, S. 650), denn „das Sprachgefühl ist bei den Menschen nicht immer das gleiche, es kann divergieren je nach Alter, Bildung oder Landschaft, aus der ein Sprecher kommt" (Klappenbach 1964/1980, S. 93).

\section{Literatur}

1. Wörterbücher:

Adelung, Johann Christoph (1774-1786): Versuch eines vollständigen grammatisch-kritischen Wörterbuches Der Hochdeutschen Mundart, mit beständiger Vergleichung der übrigen Mundarten, besonders aber der Oberdeutschen. 5 Bde. Leipzig.

Brockhaus-Wahrig (1980-1984): Deutsches Wörterbuch in sechs Bänden. Hrsg. von Gerhard Wahrigt, Hildegard Krämer und Harald Zimmermann. Wiesbaden/Stuttgart.

Bußmann, Hadumod (1990): Lexikon der Sprachwissenschaft. 2., völlig neu bearb. Aufl. Stuttgart.

Campe, Joachim Heinrich (1807-1811): Wörterbuch der Deutschen Sprache. 5 Bde. Braunschweig.

Conrad, Rudi (Hrsg.) (1985): Lexikon sprachwissenschaftlicher Termini. Leipzig.

Duden. Bedeutungswörterbuch (1985): Duden. Bedeutungswörterbuch. 2., völlig neu bearb. und erw. Aufl. Hrsg. und bearb. von Wolfgang Müller. Mannheiun/Wien/Zürich. 
Duden (1985): Der Große Duden. Wörterbuch und Leitfaden der deutschen Rechtschreibung. 18. Neubearbeitung. Leipzig.

Duden (1986): Duden. Rechtschreibung der deutschen Sprache und der Fremdwörter. 19., neu bearb. und erw. Aufl. Mannheim/Wien/Zürich.

Duden (1991): Duden. Rechtschreibung der deutschen Sprache. 20., völlig neu bearb. und erw. Aufl. Mannheim/Leipzig/Wien/Zürich.

Duden-GWB (1976-1981): Duden. Das große Wörterbuch der deutschen Sprache in sechs Bänden. Hrsg. und bearb. vom Wissenschaftlichen Rat und den Mitarbeitern der Dudenredaktion unter Leitung von Günther Drosdowski. Mannheim/Wien/Zürich.

Duden-GWB (1993): Duden. Das große Wörterbuch der deutschen Sprache. In acht Bänden. 2., völlig neu bearb. und stark erw. Aufl. Hrsg. und bearb. vom Wissenschaftlichen Rat und den Mitarbeitern der Dudenredaktion unter Leitung von Günther Drosdowski. Bd. 1-3. Mannheim/Leipzig/Wien/Zürich.

Duden-UW (1989): Duden. Deutsches Universalwörterbuch. 2., völlig neu bearb. und stark erw. Aufl. Hrsg. und bearb. vom Wissensch aftlichen Rat und den Mitarbeitern der Dudenredaktion unter Leitung von Günther Drosdowski. Mannheim/Wien/Zürich (1. Aufl. 1983).

HDG (1984): Handwörterbuch der deutschen Gegenwartssprache. In zwei Bānden. Von einem Autorenkollektiv unter der Leitung von Gūnter Kempcke. Berlin.

Knaur (1985): Knaur. Das deutsche Wörterbuch. Erarbeitet von Ursula Hermann unter Mitarbeit von Horst Leisering und Heinz Hellerer. München.

Krahl, Siegfried/Kurz, Josef (1984): Kleines Wörterbuch der Stilkunde. 6., neubearb. Auft. Leipzig.

Lewandowski, Theodor (1990): Linguistisches Wörterbuch. 5., überarb. Aufl. Heidelberg/Wiesbaden.

Metzler-Lexikon Sprache (1993): Metzler-Lexikon Sprache. Hrsg. von Helmut Glück. Stuttgart/Weimar.

Sachwörterbuch für die deutsche Sprache (1989): Sachwörterbuch für die deutsche Sprache. Von einem Autorenkollektiv unter Leitung von Karl-Ernst Sommerfeldt und Wolfgang Spiewok. Leipzig.

Wahrig-DW (1986): Deutsches Wörterbuch. Mit einem „Lexikon der deutschen Sprachlehre". Hrsg. in Zusammenarbeit mit zahlreichen Wissenschaftlern und anderen Fachleuten. Völlig überarb. Neuausgabe. München.

WDG (1961-1977): Wörterbuch der deutschen Gegenwartssprache. Hrsg. von Ruth Klappenbach und Wolfgang Steinitz. 6 Bde. Berlin. 


\section{Sekundärliteratur:}

Augst, Gerhard/Schaeder, Burkhard (1991): Rechtschreibwörterbücher der deutschen Gegenwartssprache - Analyse, Kritik, Vorschläge. In: Augst, Gerhard/Schaeder, Burkhard (Hrsg.): Rechtschreibwörterbücher in der Diskussion. Geschichte - Analyse - Perspektiven. Frankfurt a.M./Bern/ New York/Paris. S. 31-98. (= Theorie und Vermittlung der Sprache, Bd. 13).

Braun, Peter (1981): Zur Praxis der Stilkennzeichnungen in deutsch-deutschen Wörterbüchern. In: Muttersprache 91, H. 3-4, S. 169-177.

Corbin, Pierre (1989): Les marques stylistique/diastratiques dans le dictionnaire monolingue. In: Wörterbücher (1989), S. 673-680.

Hausmann, Franz Josef (1977): Einführung in die Benutzung der neufranzösischen Wörterbücher. Tübingen. (= Romanistische Arbeitshefte; 19).

Hausmann, Franz Josef (1989): Die Markierung im allgemeinen einsprachigen Wörterbuch: eine Übersicht. In: Wörterbücher (1989), S. 649-657.

Henne, Helmut (Hrsg.) (1975): Deutsche Wörterbücher des 17, und 18. Jahrhunderts. Einführung und Bibliographie. Hildesheim/New York.

Herberg, Dieter (1993): Deutsche Rechtschreibwörterbücher - wie sie sind und wie sie sein sollten. Aus AnlaB des Erscheinens der 20. Duden-Auflage. In: Zeitschrift für germanistische Linguistik 21.3, S. 334-353.

Klappenbach, Ruth (1964/1980): Das Wörterbuch der deutschen Gegenwartssprache. In: Studien zur modernen deutschen Lexikographie. Hrsg. von Werner Abraham unter Mitwirkung von Jan F. Brand. Amsterdam 1980. S. 89-107.

Klappenbach, Ruth†/Malige-Klappenbach, Helene (1978): Das Wörterbuch der deutschen Gegenwartssprache. Entstehung, Werdegang, Vollendung. In: Kopenhagener Beiträge zur Germanistischen Linguistik 14. S. 5-46.

Ludwig, Klaus-Dieter (1991): Markierungen im allgemeinen einsprachigen Wörterbuch des Deutschen. Ein Beitrag zur Metalexikographie. Tübingen (= Lexicographica. Series Maior, Bd. 38).

Ludwig, Klaus-Dieter (1994): Probleme der Markierung im Wörterbuch. In: Symposium on Lexicography VI. Proceedings of the Sixth International Symposium on Lexicography May 7 - 9, 1992 at the University of Copenhagen. Ed. by Karl Hyldgaard-Jensen and Viggo Hjørnager Pedersen. Tübingen. S. 51-71. (= Lexicographica. Series Maior, Bd. 57).

Müller, Wolfgang (1984): Zur Praxis der Bedeutungserklärung (BE) in (einsprachigen) deutschen Wörterbüchern und die semantische Umkehrprobe. In: Wiegand, Herbert Ernst (Hrsg.): Studien zur neuhochdeutschen Lexikographie V. Hildesheim/Zürich/New York. S. 359-461. (= Germanistische Linguistik 3 - 6/84).

Nerius, Dieter (1988): Aufgaben und Möglichkeiten orthographischer Wörterbücher. In: Symposium on Lexicography III. Proceedings on the Third International Symposium on Lexicography May $14-16,1986$ at the University of Copenhagen. Ed. by Karl Hyldgaard-Jensen und Arne Zettersten. Tübingen. S. 469-484. (= Lexicographica. Series Maior, Bd. 19). 
Nerius, Dieter (1988a): Zur Geschichte und Funktion des Dudens. In: Symposium on Lexicography IV. Proceedings of the Fourth International Symposium on Lexicography April $20-22,1988$ at the University of Copenhagen. Ed. by Karl Hyldgaard-Jensen und Arne Zettersten. Tübingen. S. 249-264. (= Lexicographica. Series Maior, Bd. 26).

Pūschel, Ulrich (1989): Evaluative Markierungen im allgemeinen einsprachigen Wörterbuch. In: Wörterbücher (1989), S. 693-699.

Roggenkamp, Viola (1994): Wie flucht Europa? Und wie redet es sich heraus? Ein Brite hat die Unterschiede analysiert. Merde, Scheiße, shit. In: Die Zeit, Jg. 49, Nr. 11 (11. März 1994), S. 93.

Rossipal, Hans (1973): Konnotationsbereiche, Stiloppositionen und die sogenannten "Sprachen" in der Sprache. Hildesheim. (= Germanistische Linguistik 4/73).

Schumann, Hanna Brigitte (1983): Versuch, Konnotativität als kommunikative Präferenz lexikalischer Einheiten mit Hilfe einer Merkmalmatrix zu beschreiben. In: Die Lexikographie von heute und das Wörterbuch von morgen. Analysen - Probleme - Vorschläge. Hrsg. von Joachim Schildt und Dieter Viehweger. Berlin. S. 300-314. (= LS/ZISW/A, H. 109).

Wiegand, Herbert Ernst (1981): Pragmatische Informationen in neuhochdeutschen Wörterbüchern. Ein Beitrag zur praktischen Lexikologie. In: Wiegand, Herbert Ernst (Hrsg.): Studien zur neuhochdeutschen Lexikographie I. Hildesheim/New York. S. 139-271. (= Germanistische Linguistik 3 $-4 / 79)$.

Wiegand, Herbert Ernst/Kučera, Antonín (1981): Brockhaus-Wahrig: Deutsches Wörterbuch auf dem Prüfstand der praktischen Lexikologie. I. Teil: 1. Band (A - BT); 2. Band (BU - FZ). In: Kopenhagener Beiträge zur germanistischen Linguistik 18, S. 94-214.

Wörterbücher (1989): Wörterbücher. Ein internationales Handbuch zur Lexikographie. Hrsg. von Franz Josef Hausmann/Oskar Reichmann/Herbert Ernst Wiegand/Ladislav Zgusta. 1. Teilband Berlin/New York.

Zgusta, Ladislav (1988): Zgusta, Ladislav with the assistance of Donna M.T.Cr. Farina: Lexicography Today. An annotated bibliography of the theory of lexicography. Tübingen. (= Lexicographica. Series Maior, Bd. 18). 


\section{ULRICH PÜSCHEL}

\section{Stilpragmatik - Vom praktischen Umgang mit Stil}

\section{Zum Verhältnis der Stiltheorie zur Analysepraxis}

„Vom praktischen Umgang mit Stil” zu handeln, das heiBt, über Stilanalyse zu reden, ist gewiß eine nützliche Sache. Viel interessanter ist es aber, Stilanalysen zu machen. Denn Überlegungen zur Stilanalyse sind allenfalls ein erster Schritt, die wirkliche Herausforderung bringt erst die Praxis. Trotzdem möchte ich lhnen einige Überlegungen zur Stilanalyse vortragen, von denen Sie sich aber kein abgerundetes Bild erwarten dürfen - schon deshalb nicht, weil sich solch ein Bild für das Problemkind 'Stilanalyse' wohl gar nicht zeichnen läßt.

Es ist längst ein Topos in der Stilistikdiskussion, über die unübersehbare Fülle von Arbeiten zur Stilistik mit ihrer verwirrenden Vielfalt an Konzeptionen zu klagen. Dabei bleibt aber fast unbemerkt, daB die Zahl der Arbeiten, die sich explizit und ausschließlich mit der Analysepraxis beschäftigen, geradezu schmal ausfallt. Allerdings darf bei dieser Feststellung nicht übersehen werden, $\mathrm{da} B$ es in kaum einer stiltheoretischen Arbeit versäumt wird, zumindest einen Seitenblick auf die Analyse zu werfen. Diese mehr oder weniger deutliche Abstinenz gegenüber Fragen der Praxis ist nun nicht ganz einfach einzuschätzen, zumindest berechtigt sie nicht dazu, voreilig mit dem Finger auf die Theoretiker zu zeigen. Denn nach dem Selbstverständnis vieler dieser Theoretiker bilden die stiltheoretischen Überlegungen die Voraussetzung dafür, sich auf angemessene und erfolgreiche Weise mit dem Analysegeschäft zu befassen. Ganz explizit hat diesen Zusammenhang etwa Hans Graubner postuliert, wenn er schreibt, daß die analytische und deskriptive Beschäftigung mit dem Stil einzelner Spracherzeugnisse es erfordere, zuerst einmal eine Theorie über das zu entwickeln, was Stil ist (Graubner 1973, S. 164f.).

Natürlich ist dieses Postulat plausibel, vor allem für Sprachwissenschaftlerinnen und Sprachwissenschaftler. Wer würde schon freiwillig und leichtfertig die Legitimation für das eigene theoretische Treiben in Frage stellen wollen? Trotzdem ist dieses postulierte Fortschreiten von der Theorie zur Praxis nicht ganz so zwingend, wie es manchem von uns erscheinen mag. Drei Beobachtungen, die ich nur andeuten und nicht weiter ausführen möchte, können als Warnschilder vor einem ungebrochenen Optimismus dienen: Zum ersten gibt es Stilanalysen, die auf sehr klaren theoretischen Prämissen beruhen, aber dennoch insgesamt viel zu wünschen übrig lassen. Ich nenne als ein Beispiel die strukturalistische Analyse von Baudelaires "Les chats", die Roman Jakobson und 
Claude Lévy-Strauss in den sechziger Jahren vorgelegt haben. ${ }^{1}$ Zum zweiten gibt es eine enorme Zahl von Analysen - Bernd Spillner (1984, S. 223f.) spricht von hunderten, wenn nicht tausenden -, die interessante und aufschlufieiche Einsichten und Ergebnisse bieten, in denen aber von stiltheoretischer Reflexion wenig bis nichts zu finden ist. Vermutlich muB man sagen: glücklicherweise. Hätten sich die Autoren nämlich auf die Theoriebildung geworfen, dann hätten sie wohl vor allem die Zahl der Arbeiten zum Stilbegriff erhöht, nicht aber die der lesenswerten Analysen. Zum dritten schlieBlich läBt sich beobachten, dab die stiltheoretische Grundlegung und die daraus abgeleitete Analysepraxis sich nicht unbedingt decken müssen. Konkret bedeutet das, daB sich Analysen bei weitem nicht in dem theoretisch abgesteckten Rahmen bewegen. Und auch da kann man in dem einen oder anderen Fall sehr wohl sagen: glücklicherweise, da vielfach die Analysen einfach besser sind als die Theorie, auf der sie fußen sollen. Ich bin diesem merkwürdigen Zusammenhang oder auch Nicht-Zusammenhang an anderer Stelle einmal ausführlicher nachgegangen (Püschel 1983, S. 98ff.) und wurde dafür in einer der jüngeren Monographien zur Stilistik heftig gerüffelt (Sowinski 1991, S, 166). Bei meiner Behauptung bleibe ich aber dennoch!

\section{Zwei Positionen der Stilanalyse}

Wenn es nun im weiteren um Anleitung zur Stilanalyse gehen soll, dann stellt sich als erstes die Frage, was eine solche Anleitung überhaupt leisten soll und kann. Soweit ich sehe, sind auf diese Frage zwei extrem unterschiedliche Antworten gegeben worden. Das eine Extrem bildet die oft zitierte und fast ebenso oft kritisierte ÄuBerung Leo Spitzers, die er im Jahre 1948 vor Studierenden der Universität Princeton gemacht hat; ich zitiere in der deutschen Version:

"Wie oft habe ich, trotz aller in vielen Jahren gesammelten theoretischen Erfahrungen über die Methodik, wie vor den Kopf geschlagen auf eine Seite gestarrt, die ihr Geheimnis nicht preisgeben wollte. Der einzige Weg, der aus diesem Zustand der Unproduktivität herausführt, ist ein geduldiges und zuversichtliches Lesen und Wieder-Lesen." (Spitzer 1969, S. 32)

Spitzer formuliert hier seine hermeneutische Position, die zugleich Quintessenz eines langen Forscherlebens darstellt, in dem der praktische Um-

1 Roland Posner hat in "Sprache im technischen Zeitalter" die Analyse von Roman Jakobson und Claude Lévi-Strauss zusammen mit der (gekürzten) Stellungnahme von Michael Riffaterre und einer eigenen kritischen Stellungnahme abgedruckt (Jakobson/Lévi-Strauss 1969; Riffaterre 1969; Posner 1969). 
gang mit Stil eine dominierende Rolle gespielt hat. Bewegt zu diesem - ich sage einmal - Bekenntnis wurde Spitzer durch die Kritik eines seiner Schüler, der offensichtlich durchtränkt war von behavioristischem Gedankengut und vermutlich auch vertraut war mit dem Analyseinstrumentarium des taxonomischen Strukturalismus. Dieser Schüler klagt nun bei Spitzer das Fehlen einer strengen Technik ein (vgl. Spitzer 1969, S. 30f.). Spitzer dagegen wehrt einen solchen Anspruch $a b$, indem er kategorisch verneint, daß es eine solche Technik gebe.

Mit dem Vorwurf des Spitzerschülers ist aber schon das andere Extrem markiert, die szientifische Position, die sich in der Formulierung von Bernd Spillner folgendermaßen liest:

„An jede Methode der Stilanalyse ist vielmehr der Anspruch zu stellen, $\mathrm{da} B$ prinzipiell jeder imstande sein muB, sie anzuwenden, und daB jede Stilanalyse eines bestimmten Textes mit dieser Methode zu annähernd gleichen, mindestens aber mitein ander vergleichbaren Analyseergebnissen gelangen muß. (Spillner 1984, S. 7)

gelangen muß." (Spillner 1984, S. 7)@@

Damit ist gesagt, was eine Anleitung zur Stilanalyse leisten sollte 'sollte' deshalb, weil es diese Methoden offenbar nicht gibt, wie das große Aber ausweist, das dieser Forderung auf dem FuB folgt:

"Im gegenwãrtigen Stand der Stilforschung sind sichere Rezepte für die Textanalyse nicht zu erwarten; auch eine Didaktik der Stilanalyse ist derzeitig nicht in Sicht." (Spillner 1984, S. 9)

Um nochmal auf den Spitzerschüler zu sprechen zu kommen, auch er wußte offensichtlich nicht, wie diese Anleitung, diese Technik aussehen könnte; denn hätte er es gewußt, dann hätte er sie nicht von Spitzer eingefordert.

Wir sind damit an einem irgendwie fatalen Punkt angelangt. Denn es sollten ja zwei Extrempositionen vorgeführt werden, natürlich in der Erwartung, daß uns das in den Überlegungen zur Stilanalyse weiterbringt. Was wir jedoch im Augenblick in Händen halten, ist fast nichts. Einerseits hat uns Spitzer den hermeneutischen Zirkel als Methode anzubieten - eine Methode, die jedoch von so allgemeiner Natur ist, daß sie von vielen als Nicht-Methode eingestuft wird. Andererseits bekommen wir gesagt, daß es die geforderte strenge Methode zur Zeit nicht gibt und allenfalls von einer besseren, wenn auch nicht absehbaren Zukunft zu erwarten bleibt.

Das war das pessimistische Resümee; doch daneben gibt es noch eine optimistischere Lesart. $Z$ war setzt auch diese bei dem negativen Befund an, aber sie nimmt ihn zum Anlaß für zwei Fragen. Die erste Frage lautet: 
Warum gibt es die sichere Technik, die sicheren Rezepte für die Stilanalyse nicht? Oder anders gewendet: Ist die Spitzersche Aufforderung zum geduldigen und zuversichtlichen Wieder-Lesen nicht doch ein sehr probater methodischer Hinweis für alle diejenigen, die sich mit stilistischer Textanalyse befassen?

Die zweite Frage ergibt sich aus der Feststellung, daß im gegenwärtigen Zeitpunkt keine sicheren Rezepte existieren, was ja nicht impliziert, daß gar keine Rezepte existieren, sondern möglicherweise unsichere. Diese Redeweise von den Rezepten ist ja nicht einfach aus der Luft gegriffen. ${ }^{2}$ Schließlich wissen wir ja alle, daß Stilanalyse durchaus handwerklich betrieben werden kann, und wir scheuen uns auch nicht, beispielsweise im Seminar Anweisungen zu geben wie "Tut dieses oder jenes” oder „Achtet auf dieses oder jenes". Die zweite Frage lautet dann: Welchen Status haben solche Anweisungen, und was können wir erreichen, wenn wir sie befolgen? Mit diesen beiden Fragen werde ich mich jetzt in einem ersten Schritt beschäftigen, wobei ich weiB, daß ich keine neuen Gesichtspunkte in die generelle Diskussion einbringe, aber darum geht es mir auch nicht, sondern um eine Positionsbestimmung in Sachen 'Stilanalyse'. In einem zweiten Schritt werde ich dann versuchen, zumindest einen groben Überblick darüber zu geben, was für den praktischen Umgang mit Stil relevant sein kann.

\section{Leistung und Grenze von Verfahren der Stilanalyse}

Ich bin damit an den Punkt gelangt, an dem ich wie der schon zitierte Graubner sagen müßte: Bevor ich mich weiter zu Fragen der Stilanalyse äußere, muß ich die stiltheoretische Basis skizzieren, von der aus ich operiere. Ich verzichte jedoch auf eine ausführlichere Explikation und versuche nur eine ganz knappe Standortbestimmung in Thesenform, wie ich mich überhaupt im weiteren thesenhaft äußern werden. Meine erste These lautet:

Stil beruht auf dem zentralen Muster GESTALTEN.

Damit schließe ich mich an eine sprachpragmatisch-handlungstheoretisch fundierte Betrachtung von Sprache und Sprachstil an, für die exemplarisch die Handlungssemantik von Hans Jürgen Heringer, Rudi Keller, Rainer Wimmer und natürlich auch anderen steht, die Satzsemantik von Peter von Polenz und die Stilistik von Barbara Sandig. ${ }^{3}$ Den Kernpunkt

${ }^{2}$ Die Bezeichnung 'Rezept' ist allerdings nicht besonders glücklich gewählt, da mit ihr eine mechanische Vorgehensweise suggeriert werden kann.

3 An dieser Stelle müßten nicht nur erheblich mehr Namen angeführt wer- 
bildet die Auffassung, daß das sprachliche Handeln - also alles Sprechen und Schreiben - regelgeleitet ist oder Mustern folgt. Regelgeleitet ist dann auch die Art und Weise, wie eine sprachliche Handlung gemacht ist, wie sie gestaltet ist oder wie Sandig (1986) sagt: wie sie durchgeführt ist. Dementsprechend kann GESTALTEN als das allgemeinste oder zentrale Stilmuster betrachtet werden (Püschel 1986). In der Sprachhandlungsanalyse geht es darum, die Regeln oder Muster anzugeben, nach denen wir die Handlung verstehen. Dementsprechend geht es in der Stilanalyse dann darum, die Gestaltungsmuster anzugeben, nach denen wir das Stilistische an einer Sprachhandlung verstehen. Insofern ist Stilanalyse Textanalyse (Püschel 1991).

Damit bin ich schon bei der zweiten These, die - wenn auch auf sehr pauschale Weise - die Aufgabe der Stilanalyse umreißt; sie lautet:

Stilanalyse beschäftigt sich mit der Gestalt von sprachlichen Handlungen und dem durch die Gestalt bewirkten stilistischen Sinn.

Mit dieser These soll zuerst einmal daran erinnert werden, daß mit dem Sprachstil eine doppelte Sichtweise verbunden ist. Zum einen ist Stil eine Eigenschaft von Texten. Ein kleines Beispiel dafür ist die Art und Weise, wie die Bundeskanzler Schmidt und Kohl in ihren Neujahrsansprachen das Publikum anreden. ${ }^{4}$ Schmidt sagt nämlich Meine Damen und Herren, Kohl dagegen Meine sehr verehrten Damen und Herren, liebe Mitbürgerinnen und Mitbürger. Die Anreden sind also verschiedenartig gestaltet. Schmidt REDET knapp AN, indem er sich einer Minimalformel bedient. Kohl hingegen REDET ausführlicher AN, indem er zwei Routineformeln miteinander koppelt und außerdem die erste mit sehr verehrle ausbaut. Zum andern ist an die Art und Weise, wie ein Text gestaltet ist, stilistischer Sinn geknüpft. So läßt sich für Schmidts Anrede beispielsweise sagen, $d a B$ er die Beziehung zu seinem Publikum als distanzierte Normalbeziehung DEFINIERT; Kohl dagegen DEFINIERT so etwas wie Beziehungsvielfalt und überläBt seinem Publikum die Entscheidung, ob es sich $\mathrm{zu} \mathrm{ihm}$ in einer förmlich-distanzierten Beziehung oder in einer integrierenden und Nähe schaffenden Beziehung sehen will.

den, sondern von den genannten Personen müßten auch mehr Beitrāge aufgezählt werden. Ich beschränke mich auf Heringer (1974), Keller (1976) und (1977), Wimmer (1983), von Polenz (1988), Sandig (1986).

4 Als Beispielmaterial dienen zwei Neujahrsansprachen der Bundeskanzler Helmut Schmidt zum Jahreswechsel 1979/80 und Helmut Kohl zum Jahreswechsel 1985/86. Die beiden Ansprachen finden sich im Anhang. 
Wenn alles Stilistische darauf beruht, daß wir es nach bestimmten Stilmustern und zu einem bestimmten $Z$ weck gemacht verstehen, damn sind wir sehr schnell bei dem Kernpunkt aller Anleitung zur Stilamalyse, nämlich bei der Frage, warum es keine sicheren Rezepte geben kann. Und damit komme ich zur dritten These:

Verstehen passiert uns.

Entweder wir verstehen, oder wir verstehen nicht.

Ich schließe mich mit dieser These einem Verstehensmodell an, das im Widerstreit zu Konzepten steht, in denen Verstehen als Prozeß oder als innere Handlung modelliert ist (dazu Busse 1992, S. 107ff.). Verstehen - auch Stilverstehen - ist nach diesem Modell nicht ProzeB oder innere Handlung, sondern ein Zustand. Dabei heiBt Stilverstehen soviel wie Wissen, was der Stil einer sprachlichen Handlung ist und was er bedeutet (vgl. Harras 1976, S. 212). Wäre Verstehen ein ProzeB, wäre es Handlung, hätte dies unter anderem zur Bedingung, daß wir in der Lage sein müBten, unser Verstehen zu kontrollieren (Heringer 1984, S. 58). Das können wir aber nicht. Denn wir können nicht zu uns selber sagen: „Jetzt will ich den Text verstehen”, und es auch tun, so wie wir morgens zu uns sagen können, „Jetzt will ich aus dem Bett steigen”, und das dann in die Tat umsetzen. Wir können Verstehen weder herbeizwingen, noch können wir es verhindern. Allerdings sind wir nicht ganz zur Untätigkeit verurteilt, wenn es darum geht, etwas zu verstehen; denn wir können sehr wohl einiges dafür tun, um zu einem anderen, weitergehenden, besseren Verständnis zu gelangen. So können wir grübeln, Hypothesen aufstellen oder Lesarten ausprobieren. Aber - und das ist der entscheidende Punkt - das sind alles nur Versuche. Ob wir mit diesen Versuchen erfolgreich sind, unser Ziel also erreichen, entzieht sich unserem Einfluß (vgl. Brennenstuhl 1975, S. 212). Es ist mit dem Verstehen wie bei einem verlegten Gegenstand. Wenn wir nach ihm suchen, haben wir auch eine Chance, ihn zu finden, aber eine Garantie dafür haben wir nicht.

Mit diesem Suchen vergleichbar ist nun die Spitzersche Aufforderung zum geduldigen und zuversichtlichen Lesen und Wieder-Lesen. Nichts anderes können wir im Prinzip für die Stilanalyse tun - in der Hoffnung, daß sich das Stilverstehen schon einstellen wird. Und außerdem zeigt dieses Verhältnis zwischen Lesen und Stilverstehen, $\mathrm{da} B$ es sichere Rezepte für die Stilanalyse überhaupt nicht geben kann, weder zum gegenwärtigen Zeitpunkt noch in einer ferneren Zukunft.

Dennoch sind Anleitungen zur Stilanalyse keineswegs nutzlos und überflüssig. Um noch einmal zu dem Vergleich von Suchen und Finden zurückzukehren: „Nicht das Finden will gelernt sein oder birgt Probleme, 
sondern das Suchen." (Keller 1977, S. 8) Deshalb ist es durchaus vernünftig, sich auf die Suchprobleme zu konzentrieren. Wer seine Findechancen erhöhen will, der sollte beispielsweise seine Anstrengungen verdoppeln und zudem nicht einfach wild herumstöbern, sondern systematisch in allen Ecken suchen. Einem solchen systematischen Suchen sind Verfahren zur Stilanalyse vergleichbar, was mich zu meiner vierten These führt:

Verfahren der Stilanalyse unterstützen den Versuch, zu einem besseren Stilverständnis zu gelangen.

Ich sage ausdrücklich 'unterstützen', denn eine Erfolgsgarantie für das Stilverstehen können sie nicht sein, ebensowenig wie systematisches $\mathrm{Su}-$ chen eine Erfolgsgarantie für das Finden ist. Analyseverfahren sind also nützlich, dennoch sollten wir sie nicht zum Fetisch machen; denn das Ganze hat noch eine Kehrseite, auf die ich zumindest hinweisen möchte: Es kann nämlich durchaus auch erfolgversprechend sein, unsystematisch zu suchen. Der Zufall kann uns viel schneller als systematisches Suchen zum verlegten Gegenstand führen. Auf die Stilanalyse gewendet bedeutet das, da $B$ die eine oder der andere Analysierende mit Intuition und Fingerspitzengefühl mehr erreicht als so mancher mit seinem methodischen Vorgehen. Es bedeutet aber auch, daß wir nicht verzweifeln müssen, wenn wir ein Textproblem nicht lösen. Vielleicht haben wir ja Glück, und es geht uns in einem völlig unvermuteten Augenblick ein Licht auf.

\section{Keine einfache Anleitung zur Stilanalyse}

Bevor ich nun zu einigen Verfahren der Stilanalyse übergehe, möchte ich noch eine Eigenschaft des Sprachstils erwähnen, die mittlerweile ziemlich unstrittig ist. Ich komme damit zur fünften These:

Der Sprachstil ist hochkomplex und unübersichtlich. Das „Chamäleon Stil” (Sandig) begegnet uns in vielfältiger und unterschiedlichster Farbigkeit.

Während sich gerade die linguistische Stilistik bis vor nicht allzu langer Zeit auf die Trias von Laut, Wort und Satz konzentriert hat, gehen wir heute davon aus, daß auch die Satzgrenze transzendierende Erscheinungen stilistische Qualität haben, aber auch umfassendere Textstrukturen - eben alles, was wir an einem Text als gestaltet verstehen können, seien es lokale oder globale, mikrostrukturelle oder makrostrukturelle Erscheinungen (vgl. Sowinski 1991, S. 71ff.). Das hat natürlich Folgen für die Stilanalyse, deshalb These sechs:

Entsprechend der Komplexität und Unübersichtlichkeit des Sprachstils gibt es keine einfache Anleitung für die Stilanalyse. 
Ebensowenig gibt es eine Abfolge von Analyseschritten, die einfach abgearbeitet werden können.

Wir können also nicht sagen: Setze in der Adlerperspektive an und schreite top down zu den mikrostrukturellen Details fort; und auch nicht umgekehrt: Setze in der Froschperspektive an und schreite bottom up zu den Makrostrukturen fort. Stattdessen müssen wir die Details und das Ganze gleichermaßen im Blick haben, wir müssen zwischen beiden Perspektiven hin und her springen, wir müssen sie aufeinander beziehen und zwischen ihnen vermitteln. Wie oft und wann wir die Perspektive wechseln sollen, kann uns aber niemand vorhersagen. Dementsprechend kann eine Anleitung zur Stilanalyse nicht mehr, aber auch nicht weniger leisten, als den Analysierenden Orientierungshilfen für ihr Geschäft zu geben. Kurz gesagt: In einer Anleitung zur Stilanalyse sollten die Ratsuchenden möglichst viele und vielfältige Hinweise finden, aus denen sie einerseits Grundsätzliches über die Voraussetzungen und Probleme des Umgangs mit Sprachstil erfahren und mit denen andererseits ihre Aufmerksamkeit auf Aspekte und Erscheinungen gelenkt wird, deren Beachtung ihnen bei der Analyse unter Umständen weiterhelfen kann. Um es noch einmal zu betonen: Eine solche Anleitung stellt keinen Algorithmus dar, sondern sie ist eher eine Sammlung von Merksätzen, an denen sich zu orientieren, hilfreich sein kann.

Wenn ich hier im übrigen die Komplexität und Unübersichtlichkeit des Sprachstils so betone, in den Augen mancher vielleicht sogar über Gebühr, so hat das seinen Grund darin, daB in der Vergangenheit sehr häufig extrem einfache Lösungen für Stil und seine Analyse angeboten worden sind, mit denen dem Chamäleon seine Vielfarbigkeit entzogen wird. Ein Beispiel dafür ist der "Archileser” Michael Riffaterres, der ausschließlich auf die im Text angelegten Stimuli in Form von Abweichungen reagiert (Riffaterre 1973).

\section{Merksätze für die Stilanalyse}

Im weiteren werde ich nun einige Merksätze für die Stilanalyse aufzählen und auch ansatzweise am Beispiel illustrieren. Dabei enthält diese Aufzählung sehr Allgemeines und recht Spezielles, direkt auf die Arbeit am Text Zielendes und die Voraussetzungen und Begleitumstände der Textarbeit Betreffendes. Damit soll verdeutlicht werden, wie vielfaltig die Gesichtspunkte sind, die für die Stilanalyse eine Rolle spielen. Allerdings kann diese Aufzählung in der vorgegebenen Zeit nicht vollständig ausfallen, einfach weil die Zahl der Gesichtspunkte zu groß ist, die für die Stilanalyse eine Rolle spielen. Außerdem ist die Aufzählung nicht systematisch angelegt. Das ist schon deshalb nicht möglich, weil einzelne 
der Gesichtspunkte wiederholt in verschiedenen Merksätzen auftauchen, dann aber in jeweils spezifischer Beleuchtung; das verdeutlicht auch den chamäleonhaften Farbwechsel, dem der Perspektivwechsel in der Analyse entspricht. Ich komme damit zum ersten Merksatz:

Gehe davon aus, daB zwischen dem Geäußerten und dem, was gemeint sein beziehungsweise verstanden werden kann, prinzipiell Asymmetrie besteht. Einem Text läßt sich erheblich mehr an Sinn zuschreiben, als der bloße Wortlaut erwarten läßt.

Rechne deshalb damit, daß du immer etwas verstehen kannst, das nicht ausdrücklich gesagt wurde, vielleicht sogar verschwiegen werden sollte.

Zwei Bemerkungen zu diesem Merksatz: Man kann ihn zum ersten als eine Paraphrase der Eigenschaften von Stil verstehen, denn dasjenige, was mit stilistischen Mitteln kommuniziert wird, ist ja nie explizit geäußert, sondern immer implizit an die Gestaltung geknüpft. Zum zweiten kann man diesen Merksatz eine Binsenweisheit nennen, auf die jeder stößt, der auch nur für zwei Minuten über seinen eigenen Sprachgebrauch nachdenkt. Doch manchmal müssen auch Binsenweisheiten ausdrücklich gesagt werden, insbesondere im Seminar, wenn Studierende etwas zu einem Satz oder einem Textabschnitt sagen sollen und dann so tun, als ob sie noch nie eine sprachliche ÄuBerung verstanden hätten. ${ }^{5}$

In den nun folgenden Merksätzen geht es jetzt vor allem darum, die genannte Asymmetrie aufzufächern. Nummer zwei lautet:

Nenne stillschweigende Voraussetzungen und Implikationen ausdrücklich.

Diese Aufforderung läßt sich in eine Reihe von Teilaufgaben zerlegen, zu denen unter anderem gehört: ${ }^{6}$

5 Das soll kein Vorwurf sein, da wir ja schließlich alle wissen, wie schwierig es sein kann, dasjenige, das wir irgendwie verstanden haben, in Worte zu fassen. Außerdem sollten wir nicht vergessen, daß diese Asymmetrie in der sprachwissenschaftlichen Diskussion schon viel Kopfschmerzen bereitet hat. Die Versuche, das Gesagte und das Gemeinte sprachtheoretisch sauber auseinanderzudividieren, kōnnen das belegen.

6 In die Formulierung der Merksätze sind viele Aspekte eingeflossen, die sprachwissenschaftliches und stiltheoretisches Allgemeingut sind, daneben aber auch Anregungen, die sich deutlicher auf einzelne Quellen zurückführen lassen. Bei dem zweiten Merksatz fühle ich mich besonders verpflichtet von Polenz (1988) und Holly (1985). 
Löse komprimierte Ausdrücke, zum Beispiel Nominalgruppen oder Wortbildungen, in Sätze mit Verben auf.

Verwandele Passivkonstruktionen in Aktivkonstruktionen. Ersetze unpersönliche Konstruktionen durch persönliche. Verändere die Abfolge der Satzglieder.

Ersetze wertende Ausdrücke durch neutralere und formuliere die Wertung explizit.

Sage bei vagen Quantifizierungen, welche Mengen gemeint sein können.

Sage bei vager Referenz, welche Referenzobjekte gemeint sein können. Ergänze bei Argumentationen fehlende $\mathrm{Zwischenschritte.}$

Obwohl diese Liste noch sehr unvollständig ist, läßt sich an ihr doch eines ablesen: Wer sich an ihr orientieren will, braucht umfassende linguistische Kenntnisse. Deshalb kann an dieser Stelle als dritter Merksatz eingeschoben werden:

Verschaffe dir Kenntnisse auf möglichst vielen Gebieten der Linguistik. Je mehr du über Sprache weißt, desto mehr fällt dir an Texten auf und desto sicherer kannst du das, was dir auffällt, benennen.

Wer also systematisch Stilanalyse betreiben will, sollte sich dafür rüsten, indem er sich aus den verschiedensten Ecken der Sprachwissenschaft sein Rüstzeug holt. ${ }^{7}$

Mit dem vierten Merksatz wird der Blick unmittelbar auf die Komplexität des sprachlichen Handelns gelenkt (vgl. Holly/Kühn/Püschel 1986, S. 43ff.; Holly/Schwander 1987, S. 83ff.):

Gehe davon aus, daß wir eine sprachliche Handlung nach mehreren Mustern zugleich machen. Orientiere dich dabei an den drei Aufgabenfeldern des sprachlichen Handelns mit

- den konstitutiven Mustern, die die Textsorte bestimmen

- den Organisationsmustern, die die Strukturierung und Gliederung von dialogischen und monologischen Texten, die Themenbehandlung, die Verständnissicherung und die Aufmerksamkeitslenkung betreffen

- den Kontakt- und Beziehungsmustern, die der Etablierung, Aufrechterhaltung und Ausgestaltung der kommunikativen Beziehung dienen.

7 Das heißt nicht, daß jeder, der Stilanalysen macht, notwendigerweise auch ein mehr oder weniger perfekter Linguist sein muB. Dagegen spricht schon die eingangs getroffene Feststellung, daß es auch hervorragende Analysen von Leuten gibt, die über keine sprach- und stiltheoretischen Grundlagen verfügen. Aber Kenntnisse auf Gebieten wie Lexikologie, Syntax und Satzsemantik, Textlinguistik, Gesprächsanalyse, Soziolinguistik u.a. können nützlich sein (vgl. Wimmer 1982, S. 303 und Püschel 1994, S. 127f.). 
Gerade die Herausarbeitung der konstitutiven Muster oder wesentlichen Texthandlungen bildet einen guten Ansatzpunkt für die Analyse, da mit ihnen gezeigt werden kann, um was für eine Art von Text es geht (Holly/Kühn/Püschel 1986, S. 84f.; von Polenz 1988, S. 333f.). Der Blick auf die Redesorte 'Neujahrsansprache des Bundeskanzlers' zeigt, daß in der Hauptsache drei Muster konstitutiv sind: Zum ersten ERINNERT der Kanzler sein Publikum an Vergangenes und BEWERTET es POSITIV. So heiBt es bei Schmidt im Satz [4]: Durch Fährnisse und Untiefen, die jenseits unserer Grenzen entstanden waren, sind wir 1979 abermals gut hindurchgekommen. Zum zweiten SAGT der Kanzler Zukünftiges VORAUS und ZEIGT im Hinblick darauf OPTIMISMUS. So spricht Schmidt in den Sätzen [28] und [29] von den Schwierigkeiten in der Welt und schließt mit Satz [30]: Die Aussichten dafür, daß wir Deutschen mit unserem Teil dieser Schwierigkeiten fertig werden, die beurteile ich mit Zuversicht.

Über die bloße Konstatierung der konstitutiven Muster hinaus ist natürlich von stilistischem Interesse, wie diese realisiert werden. Dazu kurze Hinweise zum dritten dieser Muster, bei dem es darum geht, daB der Kanzler SOLIDARISIERT, indem er DANKT, GRÜSST, GEDENKT und APPELLIERT. Schmidt bevorzugt dabei den Appell, der sich an verschiedenen Stellen im Text findet - meist, wenn auch nicht ausschlieBlich auf eher indirekte Weise; Beispiele sind:

wenn ich heute ein weiteres Mal an die Elektrizitätsgesellschaften appelliere (Satz [14])

Denen möchte ich zureden, daß (Satz [19])

sie sind eine große Herausforderung an jeden einzelnen von uns (Satz [22])

Es wäre gut, wenn sich dieses Verantwortungsgefühl verstärkt (Satz [25])

Aber darüber hinaus müssen die Alten auch spüren können, daß die Kinder und Enkelkinder ... sich um sie kümmern. (Satz [27])

Kohl SOLIDARISIERT dagegen vielfach ganz explizit, wobei DANKEN und vor allem GRÜSSEN eine zentrale Rolle spielen:

\footnotetext{
Dafür möchte ich Ihnen allen herzlich danken. (Satz [42])

Ich möchte an uns alle appellieren (Satz [63])

Ich grüße unsere Landsleute im andern Teil Deutschlands (Satz [66])

Ich sende meinen Gruß an alle Landsleute überall in der Welt. (Satz [67])

Ich grüße voller Dankbarkeit unsere älteren Mitbürger (Satz [68])

Mein herzlicher Gruß gilt den Jungen (Satz [69])

Mein Dank gilt unseren Soldaten in der Bundeswehr und den Zivildienstleistenden (Satz [70])

Ich grüße die Gastarbeiter und ihre Familien (Satz [71])
} 
Das Handlungsfeld des Organisatorischen wird in den Neujahrsansprachen recht implizit gehandhabt. So müssen die Zuhörenden es beispielsweise selber merken, daß Schmidt mit Satz [4] von der Einleitung zum Hauptteil übergeht: Durch Fährnisse und Untiefen, die jenseits unserer Grenzen entstanden waren, sind wir 1979 abermals gut hindurchgekommen. Bei Kohl wird dieser Übergang - ebenfalls implizit - durch Satz [6] markiert: Sie haben gewiß noch die Bilder vom Treffen zwischen Präsident Reagan und Generalsekretär Gorbatschow vor Augen. Explizitere organisatorische Arbeit leisten beide Redner dagegen mit den einleitenden Bemerkungen, die dem Exordium des rhetorischen Redeschemas entsprechen. ${ }^{8}$ Hier ORIENTIEREN die Kanzler ihr Publikum über das, was es zu erwarten hat. Schmidt NENNT zu diesem Zweck feierlich den ANLASS, zu dem er spricht: Jahreswende, letzter Abend des SiebzigerJahrzehnts, weiterhin ORIENTIERT er DARÜBER, was er tun will, indem er ein ERÖFFNUNGSSCHEMA benutzt: Was macht man beim AnlaB $x$, was mache ich? Zu diesem Zweck STELLT er der knappen und vagen Darstellung des Üblichen in Satz [2] eine doppelt gegliederte Darstellung der eigenen Absichten in Satz [3] GEGENUBER:

[2] An Betrachtungen zur Jahreswende knüpfen manche Deutschen das Wort von der Besinnlichkeit. [3] Sie werden aber verstehen, daß ich an diesem letzten Abend des Siebziger-Jahrzehnts nicht zu philosophieren versuche, sondern daß ich statt dessen einige Gedanken vor thnen ausbreite, die mit der heutigen Wirklichkeit unserer Bundesrepublik Deutschland und mit der Wirklichkeit der uns umgebenden Welt zu tun haben.

Dabei EXPLIZIERT Schmidt seine THEMEN: Bundesrepublik Deutschland - die uns umgebende Welt, außerdem STRUKTURIERT er VORAUSGREIFEND, indem er eine zweifache Gliederung seiner Ausführungen nach Innenpolitik und Außenpolitik ANDEUTET sowie den Umfang: einige Gedanken und die Darstellungsform: ausbreiten.

Auch Kohl NENNT den ANLASS seiner Ansprache, aber nur gemäßigt feierlich: Silvesterabend, diese Stunde. Ebenso ORIENTIERT er, indem er das ERÖFFNUNGSSCHEMA benutzt. Dabei STELLT er jedoch ganz im Gegensatz zu Schmidt - das Übliche ausführlich und konkret DAR in Satz [3] und [4]:

[3] Am Silvesterabend denken wir zurück an das, was im ausklingenden Jahr unser Leben in Familie und Beruf geprägt hat, und an das, was wir vom neuen Jahr erhoffen. [4] In erster Linie sind es die persönlichen

8 Bei Schmidt handelt es sich um die Sätze [2] und [3], bei Kohl um die Sätze [3] bis [5]. 
Erfahrungen und Hoffnungen, auf die sich die meisten von uns in dieser Stunde besinnen.

Daran SCHLIESST er dann eine knappe Darstellung seiner eigenen Vorgehensweise AN:

[5] Aber ich möchte aus meiner Sicht noch einige Gedanken äußern, die uns alle angehen.

Weiterhin UNTERLÄSST Kohl eine konkrete Themenexplikation und beschränkt sich darauf, den Umfang seiner Ausführungen ANZUDEUTEN: einige Gedanken; allerdings UNTERSTREICHT er dafür die Relevanz dessen, was er zu sagen beabsichtigt: die uns alle angehen.

Bisher wurden einige Beispiele für Gestaltungsmuster auf zwei Handlungsfeldern vorgestellt, die Frage nach dem daran geknüpften Sinn blieb jedoch ziemlich außen vor. Eine Facette des stilistischen Sinns stellt sich jedoch fast wie von selbst ein, wenn wir einen Blick auf das Feld von Kontakt und Beziehung werfen. Denn da zeigt sich, da $B$ die beiden Kanzler sich im Exordium auf unterschiedliche Weise SELBST DARSTELLEN und auch die Beziehung zu ihrem Publikum unterschiedlich GESTALTEN. Schmidt PRÄSENTIERT sich als Realist und Anwalt der Sachlichkeit, der es nicht mit der Besinnlichkeit hat, aber dennoch die Besonderheit des Augenblicks zu würdigen weiß. Er verleiht dem RedeanlaB wie dem, was er zu sagen hat, ein gewisses Gewicht, was sich deutlich in der Wortwahl spiegelt: Betrachtungen zur Jahreswende, knüpfen an, das Wort von, philosophieren, Siebziger-Jahrzehnt, Gedanken ausbreiten, heutige Wirklichkeit der Bundesrepublik Deutschland, Wirklichkeit der uns umgebenden Welt. Im Verhältnis zu seinem Publikum BAUT er DISTANZ AUF, indem er in Satz [3] ausdrücklich den GEGENSATZ von ich einerseits und Sie beziehungsweise vor lhnen andererseits HERAUSSTELLT. Kohl dagegen präsentiert sich eher familiär und als Mensch wie du und ich, der an Silvester das tut, was alle anderen auch tun. Zwar würdigt auch er die Besonderheit des Anlasses, wie seine sorgfältige Wortwahl belegt, aber er vermeidet es, den Anlaß noch zusätzlich AUFZUWERTEN: Silvesterabend, zurückdenken an, Leben in Familie und Beruf, im neuen Jahr, erhoffen, in dieser Stunde, besinnen, Gedanken äußeren, angehen. Zudem versucht Kohl, Nähe zu seinem Publikum zu schaffen und Gemeinsamkeit herzustellen, ebenfalls ganz im Gegensatz zu Schmidt. Kohl macht das, indem er von wir und die meisten von uns spricht. Dabei kann er natürlich seine Rolle als Kanzler, der sich über die Medien an die Nation wendet, nicht hinwegeskamotieren, aber er rückt sie in den Hintergrund, indem er in Satz [5] nur knapp und vage anspricht, was er zu tun beabsichtigt, und dann sofort wieder Gemeinsamkeit mit dem uns alle beschwört. 
Diese unterschiedliche Beziehungsgestaltung läßt sich durch die beiden Texte hindurchverfolgen, zum Beispiel anhand der Referenzausdrücke, mit denen der jeweilige Sprecher auf sich als Individuum BEZUG NIMMT oder auf eine Personengruppe, zu der er dazugehört. Dazu habe ich Ihnen eine kleine Statistik vorbereitet:

\section{Schmidt}

$\begin{array}{lr}\text { ich } & 15 \\ \operatorname{mir} & 1 \\ \operatorname{mein} & 4\end{array}$

Zwischensumme

$\begin{array}{ll}\text { wir } & 22 \\ \text { uns } & 15 \\ \text { unser } & 10\end{array}$

Zwischensumme insgesamt

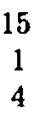

22

15

10
Kohl

$$
\begin{aligned}
& 9 \\
& 0 \\
& 4
\end{aligned}
$$

20

30

9

30

$67 \quad 82$

Wie dieser Überblick zeigt, verwendet Kohl erheblich öfter das Gemeinsamkeit stiftende wir, uns und unser als Schmidt, was vor allem bei unser daran liegt, daß er Bezeichnungen für Staat, Gesellschaft und Bürger sowie für schon Erreichtes, noch zu Erreichendes und bestimmte Eigenschaften und Werte systematisch mit dem Possessivpronomen versieht; ich zähle auf:
unser (deutsches) Vaterland (zweimal) - unser(em) Land(e) (dreimal) unsere Heinat - unserer Nation - unser(es) Volk(es) (zweimal) - un- sere Wirtschaft - unsere (solidarische) Gesellschaft (zweimal) - unsere Landsleute (zweimal) - unsere Familien - unser Leben in Familie und Beruf - unsere älteren Mitbürger - unseren Soldaten - unserer eigenen Sicherheit - unsere Erfolge - unsere kulturellen Leistungen - unseren Beitrag - unsere Hilfe - unsere Standfestigkeit - unsere Kraft - un- sere Chancen - unsere Zukunft - unser Ziel - unsere Sorge - unsere wichtigste innenpolitische Herausforderung

Auch Schmidt verwendet solche Kennzeichnungen, versieht sie aber nur sporadisch mit dem Possessivpronomen unser. Zusätzlich unterscheiden sich noch die Kontexte, in denen Kohl und Schmidt das Personalpronomen ich gebrauchen. Speziell Kohl gebraucht ich meist bei den schon zitierten Mustern DANKEN, GRÜSSEN und APPELLIEREN, also bei solidarisierenden Handlungen, die per se auf Gemeinsamkeit und Nähe zielen.

Bei diesen wenigen Bemerkungen zu Aspekten der Neujahrsansprache haben sich schon zwei weitere Merksätze eingedrängt, die als nächste genannt werden sollen. Der fünfte Merksatz lautet: 
Gehe grundsätzlich davon aus, daß wir eine sprachliche Handlung machen, indem wir eine andere Handlung machen. Bei der Entschlüsselung solcher indem-Verknüpfungen kannst du dich an den Konversationsmaximen von $\mathrm{H}$. Paul Grice und an deinem Wissen orientieren. ${ }^{9}$

Solchen indem-Verknüpfungen sind wir schon bei der Beschreibung der Organisationsmuster begegnet; dort hieB es zum Beispiel:

Schmidt ORIENTIERT DARŬBER, was er tun will, indem er ein ERÖFFNUNGSSCHEMA benutzt, indem er der knappen und vagen Darstellung des Ūblichen die Darstellung der eigenen Absichten GEGENÜBERSTELLT, indem er Satz [2] und [3] ÄUSSERT.

Mit der Aufdröselung solcher indem-Verknüpfungen können wir die Handlungsanalyse nicht nur detaillierter machen, wir können auch im Zusammenhang veranschaulichen, wie die Handlungen konkret GESTALTET sind. Außerdem läßt sich mit indem-Ketten explizieren, daß und wie jemand mit seiner ÄuBerung über das hinaus, was sowieso auf der Hand liegt, weitergehende Zielsetzungen verfolgt. So können wir beispielsweise über die Neujahrsansprache sagen: Indem der Kanzler sie hält, WIRBT er für sich, seine Politik und seine Partei. Das heiBt, er verleiht mit diesem Ritual dem Jahreswechsel nicht einfach eine besondere Weihe, sondern nutzt es für eigene, weitergehende Ziele. Die darf er aber nicht einseitig und plump angehen, weshalb - und das ist wieder stilistisch relevant - der Kanzler vor allem konsensfähige Werte ins Spiel bringt, manchmal aber doch auch deutlicher parteipolitisch Gefärbtes, so etwa Kohl, der in den Satz [10] den CDU-Slogan vom Frieden in Freiheit einfließen läßt und in Satz [15] die seinerzeitige Unionsparole zum NATO-Doppelbeschluß zitiert: Frieden schaffen mit immer weniger Waffen.

Die kleine Statistik zum Gebrauch von ich und wir, mit der der wiederholte Gebrauch dieser Ausdrücke erfaBt wird, führt zu einem sechsten Merksatz:

Achte darauf, wie FORTGEFÜHRT wird: ob Muster WIEDERHOLT, VARIIERT, GEMISCHT, VERSCHOBEN, GEWECHSELT werden, ob von Mustern ABGEWICHEN wird. ${ }^{10}$

9 Zur indem-Verknüpfung Heringer (1974, S. 43ff.) - Zur praktischen Nutzung der Grice'schen Maximen von Polenz (1988, S. 310ff.); Ūberblick über die Rolle von verschiedenen Formen des Wissens (ebd., S. 307ff.).

10 Zum Beispiel Sandig (1978, S. 87ff.); Rehbein (1983); Püschel (1985). Vgl. auch das Kapitel "Art der Handlungsdurchführung" in Sandig (1986). Ein Beispiel für eine mediale Mischtextsorte gibt Püschel (1992). 
Die stilistische Einheitlichkeit wie Uneinheitlichkeit von Texten läßt sich mit dem Muster FORTFÜHREN erfassen, aber auch typische konventionelle Stile und einzelne Stilzüge. Weiterhin betrifft das $\mathrm{Mu}-$ ster FORTFÜHREN auch die Bewältigung einzelner Aufgaben aus den Handlungsfeldern: Wie werden beispielsweise STRUKTURIERUNG oder VERSTÄNDNISSICHERUNG durch den Text hindurch geleistet? Wie werden SELBSTDARSTELLUNG und BEZIEHUNGSGESTALTUNG im Text durchgehalten?

Dieser sechste Merksatz wurde mit der Aufforderung Achte auf formuliert. Das bringt mich noch einmal zu Leo Spitzer zurück, dessen sehr allgemeine Aufforderung zum Wieder-Lesen mit solchen Achte aufHinweisen spezifiziert werden kann. Für Spitzer mit seiner immensen Erfahrung wären Aufforderungen wie die folgenden natürlich überflüssig gewesen:

Achte auf

- die Reihenfolge der Teile im Satz (Satzgliedstellung), aber auch im Text (Sequenzierung von Mustern)

- die personale Deixis

- Verallgemeinerungen und (fehlende) Quantifizierungen

- Vagheit in der Referenz

- Deagentivierung und Subjektschub

- die Wortwahl

- Bilder

- auffällige Ausdrucksweisen

- 'kleine Wörter' (Partikeln)

- den Gebrauch von Kohärenzmitteln.

Diese Achte auf-Liste ${ }^{11}$, aber auch die Liste der Merksätze läßt sich selbstverständlich noch fortsetzen, wobei vor allem die Merksätze

11 Eine solche Aufzällung, vor allem wenn sie noch als unvollständig apostrophiert wird, mag zu dem Vorschlag reizen, sie doch einfach durch "Achte auf alles" zu ersetzen. Das wāre aber wahrhaftig des Guten zuviel, da wir einfach nicht in der Lage sind, auf alles zu achten, selbst wenn wir wollten. Deshalb ein weiterer Merksatz: "Mache dir vor und während der Analyse darüber Gedanken, was du mit deiner Analyse erreichen willst. Entsprechend deiner Zielsetzung achte besonders auf ..." Daran schließt sich noch ganz nahtlos an: "Die Grenzen deiner Analyse setzt du selbst." Und: „Sei offen für Überraschungen." 
noch zu detaillieren und konkretisieren wären. ${ }^{12}$ Doch was mir noch an Zeit übrig ist, möchte ich nutzen, um auf zwei Gesichtspunkte hinzuweisen.

Ich hatte ja schon davon gesprochen, daß es sich für die Stilanalyse auszahlen könne, so viele sprachwissenschaftliche Kenntnisse wie nur möglich zu erwerben. Darüber hinaus sollten sich die Analysierenden zu jedem Text, mit dem sie sich beschäftigen, speziellere Kenntnisse verschaffen, womit ich - nebenbei gesagt - wieder bei den Binsenweisheiten gelandet bin. Dennoch der siebte Merksatz:

Verschaffe dir so viel Informationen wie möglich

- über die Handlungsbeteiligten und ihre Rollen

- über den kommunikativen Zusammenhang, in dem der Text steht, also über Vor- und Nachgeschichte und den Hintergrund

- über die kommunikativen Rahmenbedingungen, zum Beispiel über die

- politischen, ökonomischen, gesellschaftlichen, medialen Bedingungen bei Medientexten.

Der achte und letzte Merksatz betrifft noch eine Erfahrung, die sicherlich so mancher von uns gemacht hat und die ich persönlich nicht missen möchte, daß nämlich die gemeinsame Arbeit am Text nicht nur schneller zum Ziel führen kann, sondern auch $2 u$ reichhaltigeren Ergebnissen; deshalb:

Mache die Analyse gemeinsam mit anderen, spreche zumindest mit anderen über deine Ergebnisse.

Auch hier gilt: Vier Augen sehen mehr als zwei. Zugleich kann es einen heilsamen Zwang bedeuten, sein Stilverständnis für andere formulieren zu müssen. Denn so werden wir dazu genötigt, das, was an unserem Verständnis noch Eindruck, Gefühl, Empfindung ist, soweit abzuklären, daß es sich in Worte fassen läßt.

12 Ein weiterer Merksatz steckt in dem gängigen, auch in diesem Beitrag angewandten Verfahren des Textvergleichs: "Suche dir einen oder mehrere vergleichbare Texte. Wenn du keinen Vergleichstext hast, dann überlege dir selbst Formulierungsalternativen." Die Aufforderung, sich selbst Alternativen einfallen $z u$ lassen, führt direkt zu Verfahren der Textmanipulation: „Spiele mit dem Text, indem du zum Beispiel Paraphrasen bildest, Elemente austauschst, herausstreichst oder einfügst. Du kannst auch die Reihenfolge von Satzgliedern oder Textteilen verändern." (vgl. Spillner 1974, S. 85ff. und S. 89ff.). In eine andere Richtung zielt: "Hole dir Anregungen aus den Analysen anderer." Damit wird an die schulrhetorische Praxis angeknüpft, sich an vorbildlichen Rednern zu schulen (Püschel 1991, S. 26). 


\section{Drei Ingredienzen der Stilanalyse: Begabung, Erfahrung, Glaube}

Abschließend beziehe ich mich noch einmal auf meine Zitierautorität Leo Spitzer $^{13}$, der auch gesagt hat, daß er für die Eindrücke und Überzeugungen, die sich aus seiner Beschäftigung mit einem Text ergeben, keine Garantie geben könne; er betrachtet sie stattdessen als Ergebnis „aus Begabung, Erfahrung und Glauben" (Spitzer 1969, S. 31).

Zum Stichwort 'Begabung' braucht nicht viel gesagt zu werden: Entweder man hat sie, oder man hat sie nicht. Diejenigen, die über ein hohes MaB an Sprachsensibilität und Intuition verfügen, brauchen eine Anleitung zur Stilanalyse allenfalls in Grenzen. Ihnen fliegt zu, was andere sich mühsam erarbeiten müssen. Nur so ist es im übrigen auch erklärlich, daß es interessante und aufschlußreiche Analysen gibt, für die theoretische und methodische Fragen keine Rolle gespielt haben.

Mit dem Stichwort 'Erfahrung' beschwört Spitzer eine Instanz, auf die sich letztlich alle Verfechter von interpretativen Verfahren berufen - nicht nur in der Literatur- und Sprachwissenschaft, sondern auch in Soziologie, Psychologie und Medienforschung, wo qualitativen Verfahren vermehrt Aufmerksamkeit geschenkt wird. ${ }^{14}$ Es geht um die Analysekompetenz, die uns nicht in die Wiege gelegt ist, sondern die wir uns erwerben müssen. Eine Anleitung zur Stilanalyse kann den Weg zu dieser Analysekompetenz ein wenig ebnen helfen, indem sie die Kenntnisse und Fähigkeiten ausbreitet, die sich aneignen sollte, wer Analysen machen will; sie kann diesen Weg auch an der einen oder anderen Stelle abkürzen helfen, indem sie die Erfahrungen anderer zusammenstellt und damit nutzbar macht. Das ändert jedoch nichts grundsätzlich an der eingangs getroffenen Feststellung, daß das wirklich Entscheidende im Umgang mit Stil die Praxis, die Empirie, ist und nicht das Reden über die Praxis.

13 Wenn ich mich wiederholt auf Leo Spitzer berufen habe, dann nicht damit die Zuhörer "leuchtende Augen" bekommen (Heringer in der Diskussion). Wäre das mein Ziel gewesen, hätte ich ganz anders zulangen und viele klingende Namen anführen können. Selbst der Name Jacob Grimms hätte dann - wie auch immer - untergebracht werden können. Mir ging es aber einfach darum, eine Position zu markieren, die auch manche einnehmen, die bei Spitzer keine leuchtenden Augen bekommen. Zugegeben: Es erschien mir allerdings unproblematischer, von Leo Spitzer zu sprechen als etwa von der „objektiven Hermeutik” Ulrich Oevermanns.

14 Vgl, neben Sammelbänden wie Soeffner (1979), Baacke/Kübler (1989), Charlton/Bachmair (1990) und Holly/Püschel (1993) noch beispielsweise Charlton/Neumann (1986), Oevermann (1986), Soeffner (1989). 
Was schließlich den Glauben angeht, so besteht der darin, daß wir das Verständnis, zu dem wir in der Analyse gelangt sind, für das richtige halten. Allerdings darf unser Glaube nicht blind werden, denn trotz aller Überzeugung von der Richtigkeit unserer Ergebnisse dürfen wir nicht verdrängen, da $B$ es immer nur ein mögliches Verständnis ist, auch dann, wenn wir es mit anderen teilen. Wir selbst können zu einem späteren Zeitpunkt sehr wohl zu einem neuen, vielleicht sogar besseren Verständnis kommen. Oder aber andere konfrontieren uns mit ihrem Verständnis, was die Sache erst richtig spannend macht. Doch welche Probleme daraus entstehen, wie wir mit einem solchen Konflik umgehen sollten, das ist ein anderes Thema. ${ }^{15}$

\section{Literatur}

Baacke, Dieter/Kübler, Hans-Dieter (Hg.) (1989): Qualitative Medienforschung: Konzepte und Erprobungen. Tübingen.

Biere, Bernd Ulrich (1989): Verständlich-Machen. Hermeneutische Tradition Historische Praxis - Sprachtheoretische Begründung. Tübingen.

Brennenstuhl, Waltraud (1975): Handlungstheorie und Handlungslogik. Kronberg.

Busse, Dietrich (1992): Textinterpretation. Sprachtheoretische Grundlagen einer explikativen Semantik. Opladen.

Charlton, Michael/Bachmair, Ben (Hg.) (1990): Medienkommunikation im Alltag. Interpretative Studien zum Medienhandeln von Kindern und Jugendlichen. München/New York/London/Paris.

Charlton, Michael/Neumann, Klaus (1986): Medienkonsum und Lebensbewältigung in der Familie. Methode und Ergebnisse der strukturanalytischen Rezeptionsforschung - mit fünf Falldarstellungen. München.

Graubner Hans (1973): Stilistik. In: Arnold, Heinz Ludwig/Sinemus, Volker (Hg.): Grundzüge der Literatur- und Sprachwissenschaft. Band 1: Literaturwissenschaft. München. S. 164-187.

Harras, Gisela (1976): Kellers „Handlungen verstehen” verstehen. In: Zeitschrift für germanistische Linguistik 4, S. 200-212.

Heringer, Hans Jürgen (1974): Praktische Semantik. Stuttgart.

Heringer, Hans Jürgen (1984): Text verständlichkeit. Leitsätze und Leitfragen. In: Zeitschrift für Literaturwissenschaft und Linguistik 14, S. 57-80.

Holly, Werner (1985): Politische Kultur und Sprachkultur. Wie sich der Bürger politische Äußerungen verständlich machen kann. In: Wimmer, Rainer (Hg.): Sprachkultur. Jahrbuch 1984 des Instituts für Deutsche Sprache. Düsseldorf. S. 196-210.

15 Aus hermeneutisch-linguistischer Perspektive hat sich jüngst Bernd Ulrich Biere damit auseinandergesetzt; vgl. Biere (1989). 
Holly, Werner/Kühn, Peter/Püschel, Ulrich (1986): Politische Fernsehdiskussionen. Zur medienspezifischen Inszenierung von Propaganda als Diskussion. Tübingen.

Holly, Werner/Püschel, Ulrich (Hg.) (1993): Medienrezpetion als Aneignung. Methoden und Perspektiven qualitativer Medienforschung. Opladen.

Holly, Werner/Schwander, Michel (1987). Spielen im Deutschunterricht II. Sprachliches Handeln und Kommunizieren. Heinsberg.

Jakobson, Roman/Lévi-Strauss, Claude (1969): „Les Chats” von Charles Baudelaire. In: Sprache im technischen Zeitalter 29, S. 2-19.

Keller, Rudi (1976): Handlungen verstehen. In: Zeitschrift für germanistische Linguistik 4, S. 1-16.

Keller Rudi (1977): Verstehen wir, was ein Sprecher meint, oder was ein Ausdruck bedeutet? $\mathrm{Zu}$ einer Hermeneutik des Handelns. In: Baumgärtner, Klaus (Hg.): Sprachliches Handeln. Heidelberg. S. 1-27.

Oevermann, Ulrich (1986): Kontroversen über sinnverstehende Soziologie. Einige wiederkehrende Probleme und Mißverständnisse in der Rezeption der „objektiven Hermeneutik”. In: Aufenanger, Stefan/Lenssen, Margrit ( $\mathrm{Hg}$.): Handlung und Sinnstruktur. Bedeutung und Anwendung der objektiven Hermeneutik. München. S. 19-83.

von Polenz, Peter (1988): Deutsche Satzsemantik. Grundbegriffe des Zwischenden-Zeilen-Lesens. 2., durchges. Aufl. Berlin/New York.

Posner, Roland (1969): Strukturalismus in der Gedichtinterpretation. Textdeskription und Rezeptionsanalyse am Beispiel von Baudelaires "Les Chats". In: Sprache im technischen Zeitalter 29, S. 27-58.

Püschel, Ulrich (1983): Stilanalyse als Stilverstehen. In: Sandig, Barbara (Hg:): Stilistik. Band 1: Probleme der Stilistik. Hildesheim/Zürich/New York. S. 97-126 (= Germanistische Linguistik H. 3-4. 1981).

Püschel, Ulrich (1985): Das Stilmuster „Abweichen”. Sprachpragmatische Überlegungen zur Abweichungsstilistik. In: Sprache und Literatur in Wissenschaft und Unterricht 16. H. 55, S. 9-24.

Püschel, Ulrich (1986): GESTALTEN als zentrales Stilmuster. In: Kühlwein, Wolfgang (Hg.): Perspektiven der angewandten Linguistik. Forschungsfelder. Kongreßbeiträge zur 16. Jahrestagung der Gesellschaft für Angewandte Linguistik, GAL e. V. Tübingen. S. 143-145.

Püschel, Ulrich (1991): Sprachpragmatische Stilanalyse. Überlegungen zur interpretativen Stilistik. In: Der Deutschunterricht 43. H. 3, S. 21-32.

Pūschel, Ulrich (1992): Von der Pyramide zum Cluster. Textsorten und Textsortenmischung in Fernsehnachrichten. In: Hess-Lüttich, Ernest (Hg.): Medienkultur - Kulturkonflikt. Massenmedien in der interkulturellen und internationalen Kommunikation. Opladen. S. 233-258.

Püschel, Ulrich (1994): Sprachkultur - eine Aufgabe für uns alle. In: Bickes, Hans/Trabold, Annette ( $\mathrm{Hg}$.): Förderung der sprachlichen Kultur in der Bundesrepublik Deutschland. Positionsbestimmung und Bestandsaufnahme. Stuttgart. S. 117-134. 
Rehbein, Jochen (1983): Zur pragmatischen Rolle des „Stils”. In: Sandig, Barbara (Hg.): Stilistik. Band 1: Probleme der Stilistik. Hildesheim/Zürich/New York. S. 21-48 (= Germanistische Linguistik H. 3-4. 1981).

Riffaterre, Michael (1969): Analyse von Baudelaires „Les Chats”. In: Sprache im technischen Zeitalter 29, S. 19-27.

Riffaterre, Michael (1973): Strukturale Stilistik. Mūnchen.

Sandig, Barbara (1978): Stilistik. Sprachpragmatische Grundlegung der Stilbeschreibung. Berlin/New York.

Sandig, Barbara (1986): Stilistik der deutschen Sprache. Berlin/New York.

Soeffner, Hans-Georg (Hg.) (1979): Interpretative Verfahren in den Sozial- und Textwissensch aften. Stuttgart.

Soeftner, Hans-Georg (1989): Auslegung des Alltags - Der Alltag der Auslegung. Zur wissenssoziologischen Konzeption einer sozialwissenschaftlichen Hermeneutik. Frankfurt.

Sowinski, Bernhard (1991): Stilistik. Stiltheorien und Stilanalysen. Stuttgart (Sammlung Metzler. 263).

Spillner, Bernd (1974): Linguistik und Literaturwissenschaft. Stilforschung, Rhetorik, Textlinguistik. Stuttgart/Berlin/Köln/Mainz.

Spillner, Bernd (1984): Methoden der Stilanalyse. Forschungsstand und analytische Bibliographie. In: Spillner, Bernd (Hg.): Methoden der Stilanalyse. Tübingen. S. 223-240.

Spitzer, Leo (1969): Sprachwissenschaft und Literaturwissenschaft. In: Spitzer, Leo: Texterklärungen. Aufsätze zur europäischen Literatur. München. S. 7-33.

Wimmer, Rainer (1982): Überlegungen zu den Aufgaben und Methoden einer linguistischen Sprachkritik. In: Heringer, Hans Jürgen (Hg.): Holzfeuer im hölzernen Ofen. Aufsătze zur politischen Sprachkritik. Tübingen. S. 290313.

Wimmer, Rainer (1983): Sprachkritik und reflektierter Sprachgebrauch. In: Sprache und Literatur in Wissenschaft und Unterricht 14. H. 15, S. 3-14.

\section{Anhang}

Ansprache des Bundeskanzlers zum Jahreswechsel 1979/80 über Rundfunk und Fernsehen

Bundeskanzler Helmut $\mathrm{S} c \mathrm{~h}$ m id t hielt zum Jahreswechsel 1979/80 über Rundfunk und Fernsehen am 31. Dezember 1979 folgende Ansprache:

[1] Meine Damen und Herren,

[2] an Betrachtungen zur Jahreswende knūpfen manche Deutsche das Wort von der Besinnlichkeit. [3] Sie werden aber verstehen, daB ich an diesem letzten Abend des Siebziger-Jahrzehnts nicht zu philosophieren versuche, sondern daß 
ich statt dessen einige Gedanken vor Ihnen ausbreite, die mit der heutigen Wirklichkeit unserer Bundesrepublik Deutschland und mit der Wirklichkeit der uns umgebenden Welt zu tun haben.

[4] Durch Fāhrnisse und Untiefen, die jenseits unserer Grenzen entstanden waren, sind wir 1979 abermals gut hindurchgekommen. [5] Wir haben einen guten konjunkturellen Aufschwung erreicht; die Zahl der nach Arbeit suchenden Deutschen ist merklich zurückgegangen, der Arbeitsmarkt sieht heute besser aus als jemals seit 1974. [6] Wir wollen uns deshalb nicht selber auf die Schulter klopfen, auch die Bundesregierung will das nicht. [7] Richtig ist aber und gesagt werden darf: Wir können auch im kommenden Jahr die Sicherheit der Arbeitsplātze bewahren, wir können auch im kommenden Jahr mit wirtschaftlichem Wachstum rechnen. [8] Das Tempo freilich wird sich verlangsamen. [9] Aber kein Professor der Volkswirtschaft, kein Politiker, keiner von Ihnen, meine Damen und Herren, könnte heute genau vorhersagen, welche $\mathrm{Ri}$ siken und welche Gefahrenmomente uns in den kommenden zwölf Monaten von außen bedrängen werden.

[10] Jeder von uns hat inzwischen verstanden, welche Unsicherheiten für die Energieversorgung der ganzen Welt entstanden sind, für uns, die wohlhabenden Industriestaaten, melır noch für diejenigen Entwicklungsländer der Dritten Welt, die ohne Rohstoffe sind und die wegen der stetig steigenden Energiepreise ihren ohnehin geringen Lebensstandard noch mehr absenken müssen. [11] Mehrfach habe ich in diesem Jahr bei den Regierungschefs der uns befreundeten Länder darauf gedrängt, daß eine gemeinsame Energiepolitik, jedenfalls innerhalb der Europäischen Gemeinschaft, entwickelt wird. [12] Darin werde ich auch künftig nicht nachlassen. [13] Aber natürlich ist das noch nicht genug. [14] Es ist auch noch nicht genug, wenn die Bundesregierung darauf drängt, daß Elektrizităt nicht länger aus Erdöl gewonnen wird, und wenn ich heute ein weiteres $\mathrm{Mal}$ an die Elektrizitätsgesellschaften appelliere, daß sie alle Möglichkeiten nutzen, wenigsten einige neue Kohlekraftwerke zu bauen, damit unsere Stromversorgung auch dann gesichert bleibt, wenn das Öl noch knapper wird. [15] Sorgen vor einem akuten Strommangel sind fürs erste freilich unbegründet. [16] Aber mit vielen von Ihnen finde ich es richtig, da $B$ uns das Thema Energie mehr und mehr beschäftigt. [17] Viele haben diese Sorge begriffen und handeln vernünftig. [18] Andere wollen das Problem noch verdrängen. [19] Denen möchte ich zureden, daß sie sich auf eine veränderte, weithin sich verändernde Weltenergieversorgungslage einzustellen versuchen. [20] Es wäre gut, wenn wir die manches $\mathrm{Mal}$ mißverstandene deutsche Tugend der Disziplin gerade beim Energiesparen erneut beweisen könnten.

[21] Es ist nicht bloß Sentimentalität, wenn ich die Deutschen der mittleren und der älteren Generation daran erinnere, daß wir nach dem Kriege aus eigener Initiative mit gewaltigen Problemen fertig geworden sind, daß wir damals nicht immer nach der Obrigkeit gerufen, sondern vieles in eigener Verantwortung des einzelnen und gemeinsam mit anderen angepackt und geschaftt haben. [22] Diese Fähigkeiten sind uns bestimmt nicht abhanden gekommen. Solche Fähigkeiten können wir mit Gewinn für den einzelnen, mit Gewinn für die Gemeinschaft wieder beleben, neu aktivieren. 
Die Probleme des kommenden Jahrzehnts der 80er Jahre ūbersteigen unsere Kräfte gewiß nicht, aber sie sind eine Herausforderung an jeden einzelnen von uns, der sich für mehr interessiert als nur für sein privates Wohl.

[23] In den allerletzten Jahren hat sich bei vielen ein Gefühl der Mitverantwortung für jene entwickelt, die zu den Gruppen am Rande gehören, die so oder so benachteiligt sind, für jene, die aus eigener Kraft, auch wenn sie sich Mūhe geben, nicht mithalten können. [24] Ich denke an die Kinder ausländischer Arbeitnehmer, ich denke an die große Zahl psychisch Kranker, ich denke an die vielen Landsleute, die aus Osteuropa als Aussiedler zu uns gekommen sind. [25] Es wäre gut, wenn sich dieses Verantwortungsgefühl verstärkt, daß wir alle eine Pflicht haben, uns um diese Menschen zu kümmern, und daß es notwendig ist, daß ihnen auch mit Steuergeldern geholfen wird.

[26] Unsere älteren Bürger haben nur zum geringsten Teil materielle Sorgen, und ich möchte auch keinen Zweifel daran lassen, daß das Renteneinkommen sicher ist, daß keine Abstriche gemacht werden, daß die Lage der Versicherungsträger gut ist und daß die Finanzierung der Renten in Ordnung ist. [27] Aber darüber hinaus müssen die Alten auch spüren können, daß die Kinder und Enkelkinder, daß die Nichten und Neffen sich um sie kümmern.

[28] Meine Damen und Herren, das kommende Jahrzehnt kann schwierig werden, nicht wegen der Unsicherheiten der Energieversorgung. [29] Die ganze Welt ist in Unruhe; denken wir an Afrika, an den Nahen und Mittleren Osten, an die amerikanischen Geiseln in Teheran, mit denen wir uns solidarisch fühlen, denken wir an Südostasien.

[30] Die Aussichten dafür, daß wir Deutschen mit unserem Teil dieser Schwierigkeiten fertig werden, die beurteile ich mit Zuversicht. [31] Über drei Jahrzehnte hat sich unsere Bundesrepublik Deutschland als ein Land von vielfach beneideter Stabilität erwiesen. [32] Mit unserer ganzen Kraft werden wir dafür sorgen, daß uns diese Stabilităt, daß uns der innere und außere Frieden auch im kommenden Jahr erhalten bleiben. [33] Dazu braucht es die enge Partnerschaft mit unseren Freunden im Westen; dazu braucht es auch das ehrliche Bemühen um Zusammenarbeit mit den Nachbarn im Osten. [34] Dabei können wir unsere Beunruhigung über das Vorgehen der Sowjetunion und ihrer Verbündeten in Asien und Afrika nicht verschweigen. [35] Die Zusammenarbeit zwischen Ost und West in Europa wird um so erfolgreicher sein, je stärker der Wille zur Entspannung und zur Zusammenarbeit das politische Handeln auch in anderen Teilen der Welt prägt. [36] Natürlich werden wir keine Berge versetzen können, aber jeder Schritt, auch der kleinste Schritt, der den Frieden in Europa sichern und den Zusammenhalt unserer Nation bewahren hilft, der geht in die richtige Richtung. [37] Wir haben in den letzten Jahren und auch 1979 viele Dinge ein Stück in die richtige Richtung vorangebracht.

[38] Bei mir 2u Hause gibt es dafür ein plattdeutsches Sprichwort, und ich bitte meine westdeutschen und süddeutschen Landsleute um Verständnis. [39] Das heißt so: "Wenn de Mensch don deit, wat he kann, denn kann er nich mehr don, als he deit." [40] Auf Hochdeutsch bedeutet das ungefăhr dieses: [41] Wenn einer alles tut, was er kann, dann kann man nicht noch mehr von ihm verlangen. [42] Wir haben im Siebziger-Jahrzehnt fast alles getan, was wir konnten, deshalb kōnnen wir mit gutem Gewissen in das neue Jahrzehnt gehen und mit sehr viel Selbstvertrauen. [43] Wer selbst seine Pficht tut, der darf 
getrost auf die Zukunft vertrauen, und viele werden sagen, er darf auf Gott vertrauen.

[44] Meine Damen und Herren, lassen Sie uns mit Vertrauen und Hoffnung in das neue Jahr 1980 gehen. [45] Ich wünsche Ihnen ein gutes, ein fröhliches neues Jahr.

Aus: Presse- und Informationsamt der Bundesregierung. Bulletin Nr. 1. Bonn, den 3. Januar 1980, S. 1-2.

Ansprache des Bundeskanzlers zum Jahreswechsel 1985/86 über Rundfunk und Fernsehen

Bundeskanzler Helmut K $\circ \mathrm{h} I$ hielt zum Jahreswechsel 1985/86 über Rundfunk und Fernsehen am 31. Dezember 1985 folgende Ansprache:

[1] Meine sehr verehrten Damen und Herren,

[2] liebe Mitbürgerinnen und Mitbürger!

[3] Am Silvesterabend denken wir zurück an das, was im ausklingenden Jahr unser Leben in Familie und Beruf geprägt hat, und an das, was wir vom neuen Jahr erhoffen.

[4] In erster Linie sind es die persönlichen Erfahrungen und Hoffnungen, auf die sich die meisten von uns in dieser Stunde besinnen. [5] Aber ich möchte aus meiner Sicht noch einige Gedanken āußern, die uns alle angehen.

[6] Sie haben gewiß noch die Bilder vom Treffen zwischen Prāsident Reagan und Generalsekretār Gorbatschow in Genf vor Augen. [7] Die Bundesregierung - und auch jch ganz persönlich haben uns dafür eingesetzt, daß diese Begegnung zustande kam.

[8] Das Treffen in Genf war ein wichtiger Schritt zur Festigung des Friedens in der Welt.

[9] Bei allem was uns politisch bewegt, wissen wir: [10] Alles wãre umsonst, wenn es uns nicht gelänge, für unser Land den Frieden in Freiheit zu sichern. [11] Wir leisten dafür unseren Beitrag: [12] Die Bundesrepublik Deutschland ist ein verläßlicher Partner im westlichen Bündnis. [13] Unsere Standfestigkeit hat mit dazu beigetragen, daß das Gespräch zwischen West und Ost wieder in Gang gekommen ist.

[14] Unser Ziel bleibt: [15] Wir wollen Frieden schaffen init immer weniger Waffen! [16] Das heißt: [17] Vorankommen auf dem schwierigen Weg der Abrüstung.

[18] Wir wollen das um unserer eigenen Sicherheit willen. [19] Aber wir wollen es auch, weil es widersinnig ist, daß die Rüstungsausgaben weltweit steigen, während viele Millionen in der Welt Hunger leiden und in großer Not leben, Menschen, die unsere Hilfe brauchen. 
[20] Und: Wir wollen im Ost-West-Dialog zu Erleichterungen und zu mehr Miteinander kommen - besonders für unsere Landsleute im anderen Teil Deutschlands. [21] Es geht uns um Freiheit und die Achtung der Menschenrechte in Europa und in der Welt. [22] Wir wollen den Zusammenhalt der Deutschen stärken - im Bewußtsein der Einheit unserer Nation.

[23] Im freien Teil Europas haben wir dabei in den letzten Jahrzehnten einen historischen Durchbruch geschafft. [24] Auf dem Weg zu dem immer engeren Zusammenschluß der Völker unseres Kontinents sind wir auch 1985 ein weiteres Stück vorangekommen. [25] Bis Ende 1992 wollen wir den Europäischen Binnenmarkt vollenden - jenen großen freien Wirtschaftsraum, in dem über 300 Millionen leben.

[26] Wir Deutschen werden daraus den gröBten Nutzen ziehen, denn unsere Wirtschaft braucht den frischen Wind des Wettbewerbs nicht zu scheuen. [27] Sie befindet sich wieder auf einem soliden Wachstumskurs: [28] Es geht deutlich aufwärts!

[29] 1985 war ein Jahr harter Arbeit. [30] Wir haben sparsam und solide gewirtschaftet und gute Erfolge erzielt. [31] Wir konnten erste Früchte ernten für Besonnenheit und Opfer in den Jahren zuvor.

[32] Die Preise sind stabil. [33] Viele Millionen Arbeitnehmer gehen mit der Gewißheit ins neue Jahr, daß ihre Arbeitsplätze wieder sicher sind. [34] In diesem und im nāchsten Jahr entstehen eine halbe Million neuer Arbeitsplātze. [35] Die Staatsfinanzen sind gut geordnet. [36] Die Rentner können wieder Vertrauen in ihre Alterssicherung haben. [37] Die MaBnahmen für den Umweltschutz wirken sich positiv für Menschen und Natur aus.

[38] Dankbar blicken wir heute auf ein Jahr zurück, in dem wir die wirtschaftliche und moralische Kraft unseres Volkes weiter stārken konnten.

[39] Dieser Weg war nicht einfach. [40] Er war mit Opfern verbunden, mit Einschränkungen, mit manchem Verzicht. [41] Viele haben dabei geholfen, großartige Leistungen erbracht und vielfälige Anstrengungen unternommen.

[42] Dafür möchte ich Ihnen allen herzlich danken.

[43] Heute sehen wir, daß sich diese Anstrengungen gelohnt haben. [44] Wir verfügen wieder über Gestaltungsmöglichkeiten für mehr sozialen Ausgleich. [45] Am 1. Januar 1986 treten mit der Steuerreform finanzielle Verbesserungen für unsere Familien und viele andere Menschen in unserem Lande in Kraft.

[46] Mit dem ersten Schritt der Steuerreform werden besonders Familien mit Kindern entlastet.

[47] Wir wollen, daß unsere Gesellschaft wieder kinderfreundlicher wird. [48] Wir dürfen die nachwachsende Generation auch nicht dadurch belasten, daß wir heute auf Kosten von morgen leben. [49] Wir schaffen feste Grundlagen für unsere Zukunft - mit wachem Sinn für unsere Kraft und unsere Chancen.

[50] Das geistige Klima in unserem Lande ist heute anders als vor einigen Jahren. [51] Hoffnungslosigkeit und Pessimismus sind überwunden. [52] Zuversicht und Optimismus sind überall spürbar. 
[53] Unser Volk stellt sich wieder selbstbewußt den Herausforderungen in Wirtschaft und Wissenschaft, in Technik und Forschung. [54] Wir dürfen stolz sein auf unsere kulturellen Leistungen.

[55] Mit diesem neugewonnenen Selbstvertrauen werden wir auch künftig im internationalen Wettbewerb Erfolge erzielen, die allen zugute kommen - vor allem bei der Schaffung neuer Arbeitsplätze. [56] So werden wir auch das schwierigste Problem meistern, das uns alle heute noch bedrückt. [57] Denken wir an die Mitbürger, die an der Wende zum neuen Jahr arbeitslos sind. [58] Ihnen fehlt nicht nur ein Stück Sinnerfüllung ihres Lebens, mit ihnen sind auch in Sorge - und manchmal in Not - ihre Familien, ihre Kinder, ihre Angehörigen.

[59] Unsere Sorge gilt vor allem den jungen Menschen, die an der Schwelle zum Berufsleben noch vor verschlossenenen Türen stehen. [60] Mit einem herausragenden Lehrstellenergebnis schon im dritten Jahr hintereinander konnten wir den meisten jungen Menschen auch 1985 die Chance für eine gute berufliche Ausbildung geben.

[61] Die Schaffung und Sicherung von Arbeitsplätzen bleibt auch 1986 unsere wichtigste innenpolitische Herausforderung. [62] Der anhaltende wirtschaftliche Aufschwung und die Zunahme der Beschäftigung zeigen, daß wir auf dem richtigen Weg sind.

[63] Ich möchte an uns alle appellieren, im Alltag, in der Nachbarschaft, im Miteinander Aufgeschlossenheit und Solidarität zu beweisen.

[64] Unsere Erfolge wurden zwar durch politische Entscheidungen ermöglicht, letztlich aber von den Bürgern selbst - von Ihnen allen - errungen. [65] Darauf können wir stolz sein - stolz auf unsere solidarische Gesellschaft, stolz auf Deutschland, unsere Heimat, unser Vaterland, in dem es sich zu leben und zu arbeiten lohnt.

[66] Ich grüße unsere Landsleute im anderen Teil Deutschlands, in Ostberlin, in Rostock, in Magdeburg, in Leipzig, in Dresden, in Jena, in Halle und Weimar und überall in der DDR.

[67] Ich sende meinen Gruß an alle Landsleute überall in der Welt.

[68] Ich grüße voller Dankbarkeit unsere älteren Mitbürger, die unsere Bundesrepublik in schwieriger Zeit aufgebaut haben. [69] Mein herzlicher Gruß gilt den Jungen, die ilhr Leben voller Chancen noch vor sich haben.

[70] Mein Dank gilt unseren Soldaten in der Bundeswehr und den Zivildienstleistenden, die ihre Pflicht für uns alle tun.

[71] Ich grüße die Gastarbeiter und ihre Familien, die mitten unter uns leben und arbeiten.

[72] Ich wünsche Ihnen allen ein friedvolles und glückliches Jahr 1986.

[73] Gott segne unser deutsches Vaterland.

Aus: Presse- und Informationsamt der Bundesregierung. Bulletin Nr. 1. Bonn, den 3. Januar 1986. S. 1-2. 


\section{INGRID KÜHN}

\section{Alltagssprachliche Textsortenstile}

\section{Sprache nach der Wende}

„Unsere Sprache kann man ansehen als eine alte Stadt: Ein Gewinkel von Gäßchen und Plätzen, alten und neuen Häusern, und Häusern mit Zubauten aus verschiedenen Zeiten; und dies umgeben von einer Menge neuer Vororte mit geraden und regelmāBigen Straßen und mit einformigen Häusern.” (Wittgenstein; Philosophische Untersuchungen. §18)

Bleiben wir bei den geraden und regelmäBigen Straßen - gebaut in den alten Bundesländern ebenso wie in der ehemaligen DDR, und lassen Sie sich in den sprachlichen Alltag der neuen Bundesländer führen. Es gehörte zur politischen Symbolik der DDR, massenhaft und massiv Geschichtszeichen zu setzen.

Straßen, Brücken, Plätze ebenso wie Schulen, Kindergärten, Briefmarken und Fahnen dienten der Selbstdarstellung.

Die Neubaugebiete oder neuen Vororte der ehemaligen DDR trugen Straßennamen, wie Straße der Waffenbrüderschaft, Straße des 90. Jahrestages der DDR, Straße des Roten Oktober oder Straße der Neuerer (Kühn 1992).

Die Bewohner muBten damit leben und protestierten sofort nach der Wende dagegen. Neubenennungen, Rückbenennungen, Umbenennungen erfolgten in den letzten Jahren in den neuen Bundesländern. Neue Namen machen heute die Orientierung schwer für den Bürger in seiner Stadt.

So wie die alten Straßennamen wurden auch mühelos andere hochfrequente DDR-Neuwörter aus dem Sprachgebrauch gestrichen: Parteilehrjahr, Klassenfeind, Kombinat, Subbotnik oder marxistisch-leninistische Weiterbildung.

Dafür dringen neue Wörter ein - und nicht nur am Rande oder als neue Vororte, mehr als Gewerbegebiete. Bestimmte Wortfelder der Alltagssprache sind durch häufigen Gebrauch besonders relevant, und der Orientierungsbedarf in einer fremd empfundenen öffentlichen Kommunikation ist groß. Berufsbezeichnungen sind neu und fremd, entsprechen nicht tradierten Formen, angefangen vom stigmatisierten Arbeitgeber und $A r$ beitnehmer zum Bediensteten, Beamten, Referendar, Akademischen Rat, Azubi, Dezernenten, Ministerialdirigenten bis zum Klientel oder Mittelstand. 
Die Bürger sollen sich angesprochen fühlen und die neue Lexik auch in ihren Anträgen und Bewerbungen verwenden, wie etwa Existenzgründer, Neueinrichter, Nebenverdienstsuchender. Es soll über Teamgeist, Laufbahn, Karriereeinbindung, Referenzen, Führungserfahrungen oder Drittmittel berichtet werden.

Die Reihe läBt sich fortsetzen, und die Auswahl beruht auf Erfahrungen mit der Sprachberatung des Germanistischen Instituts in Halle. Traditionelle Denk- und Verhaltensmuster stimmen nicht mehr, bzw. reichen nicht aus.

Alle Lebensbereiche sind von Veränderungen betroffen. Veränderung erfordert Anpassung. Übernahme von angepaBten wirtschaftlichen, sozialen oder wissenschaftlichen Strukturen erfordert Übernahme von Lexik. Neue Lexik und neue Texte in allen Lebensbereichen müssen schnell verinnerlicht werden - das führt zu Verunsicherungen und Fremdheitsgefühl (Hellmann 1990; Schröder 1992).

In den 40 Jahren der Teilung Deutschlands haben sich in beiden Teilen des Landes unterschiedliche Konventionen auch im kommunikativen Bereich herausgebildet. Ein so umfassender, politisch motivierter Sprachund Kommunikationswandel, wie er sich vollzieht, schlieBt den Textsortenwandel mit ein.

Verständigungsprobleme in verschiedenen Bereichen der Alltagssprache sind verschieden stark ausgeprägt. Es bedarf systematischer Analysen zur Darstellung der Andersartigkeit bestimmter Sprach- und Kommunikationsmuster und parallel dazu der Entwicklung von Hilfeleistungen - vor allem für Ost, aber auch für West - im Umgang mit fremd empfundenen Sprachvorbildern auf allen Gebieten des täglichen Lebens. Die mehrfach beschriebenen Selbst- und Fremdbilder Ost und West zeigen den momentanen Trend: Die „Prestigevarietät” Westdeutsch besetzt den sprachlichen Markt (Resendiz 1992; Lux 1993). Oder anders ausgedrückt: Zur neuen Asymmetrie der Kommunikation gehört, daß der bisherige westdeutsche Sprachgebrauch den Geltungsbereich "gesamtdeutsch" erreicht (Pätzold 1992; v. Polenz 1993). Diskussionen zu Sprachproblemen sind in Tageszeitungen und im Rundfunk aktuell und die Reaktionen in Leserbriefen beweisen die Sensibilität der Betroffenen, wie folgende Beispiele zeigen:

- „Es wundert mich, daß sich jemand darüber wundert, daß die Sprache ausschließlich in Richtung West-Ost geht. Hat man noch nicht gemerkt, daf nicht nur die Sprache, sondern überhaupt alles in Richtung West-Ost läuft? Ich gehöre zu der ausgegrenzten Randgruppe der Vorruheständler und damit zu den Bedauernswerten, denen es nun nicht gelingen wird, dank eines schnellen Lernens des neudeutschen Wortschatzes ein richtiger Mensch zu 
werden. Und dazu muß ich sagen: Ich will nicht. Ich sehe überhaupt nicht ein, warum ich, um bei dem Beispiel zu bleiben, 'cash' sagen muB, wenn es dafür das deutsche Wort 'bar' gibt, was auch hierzulande schließlich jeder versteht."

- „Es ist also verdächtig oder sogar 'out', hier im Osten weiter von der 'Kaufhalle', von 'viertel acht' oder vom 'Kollektiv' zu reden. Ich möchte statt der im MZ-Beitrag angeführten Belanglosigkeiten dieses in meinen Augen Sprachterrors einmal ein paar wesentliche neue Vokabeln nennen, die hier hereingebrandet sind: Massenarbeitslosigkeit, Ministergeldskandale, abwickeln, feuern, Obdachlose, Aussteiger, Reps, Rauschgiftszene, Kinderfeindlichkeit, gegauckt werden."

(Mitteldeutsche Zeitung, 26.2.1994)

Momentan ist in der Alltagssprache der neuen Länder eine Mischung von tradierten Wendungen im neuen Diskurs zu beobachten, d.h., alte kommunikative Verhaltensweisen werden auf strukturell vergleichbare modifiziert übertragen. Der gemischte Sprachgebrauch ist gruppenspezifisch und betrift unterschiedliche Textsorten.

Neue Führungskräfte werden schon berufsbedingt sehr schnell situationsspezifische Sprachregister ziehen, neue Muster übernehmen und aktiv und passiv verwenden. Trotzdem muB auch bei ihnen damit gerechnet werden, daB in selbstverständlicher UnbewuBtheit kognitive Muster und ihre sprachliche Umsetzung bewahrt, variiert und differenziert werden, was wiederum bei Kommunikationspartnern aus dem Kommunikationsgebiet „Westdeutsch” je nach Toleranzspielraum, Verwunderung, Fremdheit oder Überheblichkeit auslöst. So gab es eine erregte Leserbriefdiskussion um das Neuwort (DDR) Dispatcher, das ein westdeutscher Unternehmer hier in dieser breiten Verwendungsweise ungewöhnlich fand. Die Reaktion "Ost" zeigt nochmals die momentane Sprachsituation.

„Dispatcher-Unsinn?
Daß wir aus 'Neufünfland' für manche Bürger jenseits der Elbe im all-
gemeinen viel Nachholbedarf haben, ist ja bekannt. Aber daß wir nun
noch der deutschen Sprache unkundig sind und wenig Allgemeinwissen
besitzen und noch Unsinn reden, das haut den stärksten Eskimo vom
Schlitten. Fast jeder weiB, was das Wort Dispatcher bedeutet. Dispat-
cher zum Beispiel ist echt ein Arbeits- und Verkehrskoordinator. Wenn
Herr Overhues bestimmte Wörter nur aus einem Metier kennt, kann
man ihm nur raten, seinen Horizont zu erweitern. Havag-Dispatcher
sind jedenfalls meist Könner ihres Faches." (Mitteldeutsche Zeitung, 2.3.1994)

Andererseits erfolgt zur Zeit ein Funktionswandel DDR-typischer Bezeichnungen oder typischer Wortgruppen, die als alltagsweltliche Wortschätze tief habitualisiert sind, auch wenn sie in bestimmte neue Textmuster eingefügt werden. (Wissenschaftler: Begründung C4-Berufung entspricht den gesellschaflichen Erfordernissen; Arzt: die medizinische Ver- 
sorgung im Territorium; Verkäuferin: Ich wollte in meiner Verkaufsstelle bleiben; Studentin: Wissenschaftliche Hausarbeit - Staatsexamensarbeit; Journalist: Er übernimmt in einem Sanatorium eine leitende Funktion; Betrieb annonciert: In unserem Ferienobjekt sind freie Ferienplätze.)

Bei diesem synonymen Gebrauch von vertrauter Lexik und von neuen Benennungen für gleiche Sachverhalte steht die Frage nach Präferenzen und doch möglichen Bedeutungsdifferenzen. Das temporäre $\mathrm{Ne}$ beneinander gruppenspezifisch unterschiedlichen Sprachgebrauchs bringt zunächst Mischung im ProzeB der Angleichung kommunikativer Verhaltensmuster. Gegenseitige Kenntnisnahme synonymer Lexik als Wortdubletten im Sinne von arealer Spezifik ist für Kommunikationspartner aus Ost und West wichtig (Lerchner 1992).

BewuBt vermieden werden Kaderentwicklung, Kaderakte, obwohl unbewuBte Mischungen zu Stellenanzeigen mit folgender Benennung führen: geeigneten $K$ a de $r$ mit Wohnsitz in Leuna, gesucht ...

Formen von Adaption und Loyalität führen zu stilistischen Veränderungen bei bestimmten Textsorten. Solche Veränderungen sollen am Textmuster "Arbeitszeugnis/Beurteilung" verglichen werden mit konventionell vorgegebenen Rahmen, die sich momentan - wie in diesen einleitenden Bemerkungen angedeutet werden sollte - in den neuen Bundesländern gravierend verändern und bei dieser Textsorte konfliktreich verlaufen. Die hier darzustellenden Stilveränderungen resultieren aus meiner Auffassung von Stil als einem Textphänomen, als einem Teilaspekt des Textes in einer strukturellen Mehrstufigkeit (Sandig 1986, S. 128), wo eine Reihe von Strukturelementen stilistische Funktionen haben.

Hier wird besonders die lexikalische Teilebene untersucht, wobei lexikalische Besonderheiten als Index für Veränderungen im Vergleich stehen und einen besonderen Stilwert bekommen. Die Veränderung stilistischer Durchführungsbestimmungen sind der veränderten sozialen Situation geschuldet. So ist Stil auch zu sehen als ein Mittel der Anpassung sprachlicher Handlungen an Situationen.

Die Konflikthaftigkeit der Stilwirkung kann nur partiell benannt werden und resultiert mit aus den aufzuzeigenden stilistischen Veränderungen, die in der Relation von der Handlungsdurchführung zur Situation und den veränderten sprachlichen Mitteln zu sehen ist. So stehen das Erwartbare und Angemessene - weil bisher konventionell Übliche - den Besonderheiten von neuer Angemessenheit und normativen Vorgaben in einer Mischung gegenüber. Veränderungen der Textstruktur führen zII Veränderungen des Stils - mithin zu Stilwandel. 


\section{Aspekte bei der Beschreibung des Textmusters Arbeitozeugnis/Beurteilung}

\subsection{Alltagssprachliche Textsorten}

Ohne die verschiedenen und vielfach beschriebenen Textsortenklassifikationen zu referieren - die letzte ausführliche Übersicht dazu bietet meines Wissens Rolf (1993) „Die Funktion der Gebrauchstextsorten” sollen hier momentane Veränderungen in der Orientierung von Kommunikationsteilnehmern in der kommunikativen Praxis an Einzelbeispielen benannt werden.

Auf der Grundlage einer funktionalen, pragmatischen Textklassifikation wird von der Textfunktion als einem kommunikativen, handlungsbezogenen Kriterium ausgegangen. Dabei wird die Textfunktion als Typologisierungsbasis für Textklassifikationen verstanden (vgl. auch Brinker 1985; Franke 1987; Gläser 1990).

Textsorten werden aufgefaBt als konventionalisierte Muster für komplexe sprachliche Handlungen. Beschreibbar sind sie auf der Basis ihrer Funktion, ihrer kontextuellen/situativen Bedingungen und ihrer sprachlichen Merkmale. Alltagssprachliche Textsorten gehören zum Alltagswissen, wobei die lexikalisierten Textsortenbezeichnungen häufig der Textfunktionsbezeichnung dienen. Die Textsortenbezeichnung kann als „Präsignal” (Große 1976, S. 20) oder als „explizit performative Formel” (Rolf 1993, S. 146) betrachtet werden und ist als Indikator für die Textfunktion zu berücksichtigen.

Alltagssprachliche Textsorten sind zweckbestimmt und somit pragmatisch orientiert, dazu gehören auch bestimmte Fachtextsorten, die für das Alltagsleben bestimmt sind und von Bürgern in einer bestimmten institutionellen Hierarchie verfaBt werden. Konventioneller Stil und individueller Spielraum sind differenziert ausgeprägt in den verschiedenen Textsorten. Alltagssprachliche Textsorten sind differenziert normiert. Die Normierungskriterien sind hinlänglich bekannt und ihre sprachliche Gestaltung ist je nach Normierungsgrad vorgeprägt. Die Textsorte bildet also einen normierenden Orientierungsrahmen, häufig mit Anleitungen zum Formulieren (Gülich 1985, S. 38/39).

Alltagssprachliche Textsorten sind in der Sprachgemeinschaft historisch gewachsen. Typische Muster sind intersubjektiv verfestigt.

Der gemeinschaftliche Wissensvorrat unterliegt Veränderungen, wenn sich konstitutive Bedingungen, die textextern sind, verändern. Dazu gehört die Kommunikationssituation als eine Form der situativen Beschreibungsebene. Spezielle Handlungs- und Bewertungsnormen gel- 
ten für bestimmte gesellschaftliche Bereiche. Feste Redekonstellationen führen zu festen Sprachhandlungsmustern.

Wie situative Veränderungen zu Veränderungen verschiedener Textsortenstile führen, kann vorläufig nur an einzelnen Textexemplaren gezeigt werden. Fixierte Situationsbedingungen sowie Kenntnis aller Sprachteilhaber über diese Bedingungen führten zu ritualisierten Textmustern. Man kann von einem „Erzeugungszusammenhang” (Franke 1991, S. 168) zwischen der situativen und sprachlichen Ebene sprechen. Situative Bedingungen bilden hier den Hintergrund bzw. die Ursache für die Entstehung von Musterwandel.

Das Wissen davon, daß die kommunikativen Traditionen so nicht weiterexistieren, die partielle Inkompatibilität alltagssprachlicher Textsorten, führt gegenwärtig zu einer Mischung aus Bewahren und Adaptieren von Wissensmustern, realisiert in alltagssprachlichen Textsorten mit gemischten sprachlichen Mitteln aus altem und neuem Diskurs. Anders gesagt - zwischen altem Textsortenwissen und der momentanen Realisierung im Text entstehen Musterkonflikte, die zu Konfliktsituationen in der Kommunikation führen.

Textsorten wie Leserbrief, Kunstkritik, Bewerbungen oder Stellenanzeigen in den Tageszeitungen zeigen diese Veränderungen deutlich.

\subsection{Beurteilung und Arbeitszeugnis - zwei Namen ein Konzept?}

Bei einer Textsortendifferenzierung kann man von personenbezogenen Textsorten sprechen, bei denen neben einer Bescheinigung oder Bestätigung von Tatsachen auch eine Bewertung erfolgt. Eine Bewertung, die Auskunft über eine Person gibt, da eigene Personenkenntnis nicht vorhanden ist. Rolf zählt Texte dieser Art zu "Leistungs-/Eignungsbezogene Textsorten" (Rolf 1993, S. 302). Neben Arbeitszeugnis stehen Dienstzeugnis, Abiturzeugnis, Befähigungsnachweis u.a.m.

Wichtiges Kriterium ist zusätzlich zum Bescheinigen das Bewerten (Impfzeugnis/Arbeitszeugnis). Die Auszählung von Dimter 1981 (S. 33) zu alltagssprachlichen Textklassennamen brachte über $1500 \mathrm{im}$ Duden benannte Namen von Textklassen, von denen 480 für grundlegende Textklassenkonzepte stehen, zu dem auch „Zeugnis” gehört.

Welche alltagsweltlichen Konzepte liegen den konventionellen sprachlichen Ausdrücken Beurteilung und Arbeitszeugnis zugrunde?

Jeder ehemaliger DDR-Bürger kennt Beurteilungen, jeder hat mehrfach Einschätzungen seiner Leistungen gelesen, meist schöngefärbt gefunden, dienten sie doch hauptsächlich zur Prämierung zum 1. Mai, zum Inter- 
nationalen Frauentag, Tag des Gesundheitswesens, Tag des Lehrers, Tag des Bauarbeiters oder zur Aktivistenauszeichnung, zur Auszeichnung als Kollektiv der sozialistischen Arbeit. Aber auch finanzielle Höherstufungen muBten begründet werden, dienstlicher Aufstieg war in Kaderperspektivplänen fixiert und verlangte umfangreiche Beurteilungen, die als "exklusive Kommunikation" dem Beurteilten unbekannt waren (Fix 1993). Ansonsten hat jeder Abteilungsleiter mit oder ohne Hilfe des Arbeitskollektivs, der Gewerkschafts- und Parteileitung Beurteilungen geschrieben.

Ziemlich schnell - im zweiten Jahr nach der Wende etwa - verlangten die ersten Mitarbeiter, die sowohl durch Kündigung oder besser durch Aufhebungsvertrag den Betrieb, die Firma verlassen mußten, ein Arbeitszeugnis. Die Leiter - alte oder neue - aber aus der ehemaligen DDR, hörten den Terminus erstmals, hatten aber zunächst keine Probleme mit der inhaltlichen Zuordnung. Beurteilung als Überschrift blieb meist stehen.

Im Duden (Ost) oder Wörterbuch der deutschen Gegenwartssprache nachgeschlagen, findet man Arbeitsnorm, Arbeitsplan, Arbeitsproduktivität, Arbeits- und Lebensbedingungen und Arbeitszeit. Arbeitszeugnis erscheint nicht. Im Synonymwörterbuch bei Beurteilung zur Vergewisserung nachgesehen, stehen als Synonyme:

Begutachtung, Bewertung, Wertung, Einschätzung, Urteil, Charakteristik.

nicht aber Arbeitszeugnis.

Es ist festzustellen, daß es die Benennung Arbeitszeugnis in der DDR nicht gab, während sie in den alten Bundesländern seit Anfang der 50er Jahre üblich wurde.

Wenn ein Kriterium für ein Textmuster die Benennung und damit Alltagskategorisierung ist, so werden hier als musterbezeichnende Ausdrücke Beurteilung und Arbeitszeugnis synonym verwendet. Strukturell vergleichbare Kommunikationsmuster und entsprechendes Musterwissen müssen zu Abwandlungen bei der Realisierung des Textmusters führen. Intersubjektive Wissensbestände sind unter den veränderten situativen Bedingungen modifiziert $2 u$ realisieren. Solche Veränderungen verlangen zunächst Musterkenntnis. 


\section{Textmusterbeschreibung des Textmusters Arbeitszeugnis/Beurteilung}

\subsection{Norm und Aufbau von Arbeitszeugnissen}

Wichtigster Grund für das Verfassen von Arbeitszeugnissen ist der Arbeitsplatzwechsel. Das Bürgerliche Gesetzbuch benennt die allgemeine Rechtsgrundlage:

„Bei der Beendigung eines dauernden Dienstverhältnisses kann der Verpflichtete (Arbeitnehmer) von dem anderen Teil (Arbeitgeber) ein schriftliches Zeugnis über das Dienstverhältnis und dessen Dauer fordern. Das Zeugnis ist auf Verlangen auf die Leistungen und die Führung im Dienst zu erstrecken.” (BGB 630)

Im Duden (1989) steht unter Arbeitszeugnis:

„dem Arbeitnehmer vom Arbeitgeber über Art und Dauer der Beschāftigung sowie über Führung und Leistungen ausgestelltes schriftliches Zeugnis."

Art des Dienstverhältnisses, Dauer sowie Leistung und Führung im Dienst beschreiben die Textfunktionen des Arbeitszeugnisses. Oberster Grundsatz oder Norm der Einschätzung ist die Zeugniswahrheit. Es darf die Bewertung "nicht wesentlich vom Rahmen der Verkehrssitte abweichen, d.h. von dem, was allgemein üblich ist." (Presch 1991, S. 7)

Ratgeberliteratur für das Schreiben und Lesen von Arbeitszeugnissen ermöglicht allen Sprachteilhabern (Produzenten und Rezipienten von Arbeitszeugnissen), von Bedeutung, Art, Formulierung über Geheimcodes bis zu Rechtsfragen das Wissen über Arbeitszeugnisse zu vervollkommen (Dittrich 1988; Wypijeski 1992; Nasemann 1992; Ruge 1993).

Die verschiedenen Arten von Arbeitszeugnissen werden in der Ratgeberliteratur ausführlich beschrieben. Wichtigste formale Differenzierung ist die $Z$ weiteilung in einfache und qualifizierte Arbeitszeugnisse. Daneben erfolgt noch die Beschreibung von Zwischenzeugnissen, Ausbildungszeugnissen, Probezeugnissen u.a.m. (Dittrich 1988, S. 44).

Das qualifizierte Arbeitszeugnis hat folgenden Aufbau (Presch 1991, S. 2):

1. Angaben zur Person, Beschäftigungsdauer

2. Tätigkeitsbeschreibung

3. Leistungsbeurteilung

4. Führung/Sozialverhalten

5. Führungsqualitäten/Aufstiegseignung

6 . Kündigungsgrund

7. SchluB (Wünsche/Unterschrift). 


\subsection{Norm und Aufbau von Beurteilungen}

Ratgeberliteratur zum Schreiben von Beurteilungen gab es in der DDR nicht. Dafür wurden in sprachwissenschaftlichen Fachbüchern die Anforderungen an Beurteilungen benannt und erläutert. Sie wurden auch in den Berufs-, Ingenieur- und Fachschulen im Fach "Deutsch" unter dem Terminus "Gebrauchsformen des Sachstils" neben dem „Wirtschaftsbrief”, „Aussprache zwischen Bürgern und staatlichen Stellen”, „Bewerbungsschreiben” und "Kadergespräch” geübt (Ausdruckslehre 1969). Für das Schreiben von Schülerbeurteilungen gab es ein Anleitungsbuch, in dem das Ziel der Schülerbeurteilungen einleitend beschrieben wird, und übergreifend für alle Beurteilungen gilt:

„In der sozialistischen Gesellschaft sind kontinuierliche Persönlichkeitsbeurteilungen und Analysen des Kollektivs ein unerläßlicher Bestandteil der wissensch aftlichen Leitungstätigkeit auf verschiedenen Ebenen, und schlieBen eine ständige Analyse und Beurteilung der Persönlichkeit und ihrer Entwicklungsbedingungen ein ... Die Entwicklung muB bewuft und systematisch gelenkt werden. ...” (Erlebach 1983, S. 13).

In der Anleitung zur Ausbildung von Deutschlehrern heißt es:

„Beurteilen beruht auf Bewerten ... Das Bewerten erfolgt auf der Basis von Parteilichkeit, in unserem Falle von sozialistischer Parteilichkeit ..." (Schmidt 1981, S. 159).

In dem Buch „Deutsche Sprache - Handbuch für den Sprachgebrauch” steht:

„Bei Beurteilungen haben wir die Aufgabe, einen Kollegen nach den Forderungen, die wir an eine sozialistische Persönlichkeit stellen, einzuschätzen ... Wir gehen deshalb bei der Beurteilung eines Kollegen von seiner Beziehung zur sozialistischen Gesellschaft aus ..." (Liebsch 1976, S. 437).

Aufbau einer Beurteilung (Liebsch 1976, S. 438)

1. Überschrift

2. Personalangaben

3. Tätigkeit im Betrieb

4. Berufliche Entwicklung

5. Einstellung zur Gesellschaft

6. Einstellung zur eigenen Person

7. Beurteilung besonderer Eigenschaften

8. Zweck der Beurteilung

9. SchluB 
3.3 Dominierende Illokutionen und Handlungshierarchie des Textmusters Arbeitszeugnis/Beurteilung

Als (deklarative) Textsorten mit Leistungs- und Verhaltensbewertung ordnen sich Arbeitszeugnisse und Beurteilungen in das vorgegebene Wertgefüge ein, sind wertende Stellungnahmen auf der Basis der fixierten Normen mit prototypischen Formulierungen im Textmuster. Das gilt so allgemein für beide Varianten des Textmusters, nur daß die Wertmaßstäbe unterschiedlich waren.

Zum Arbeitszeugnis sind konventionelle Vorgaben und Formulierungsmuster in jedem Ratgeber beschrieben, beispielsweise in einer sechsstufigen Leistungsbewertung, in Bausteinen, die Verhalten, Verantwortungsbereitschaft, Vertrauenswürdigkeit oder Führungsqualitäten und Kreativität beschreiben. Gleich dazu werden "Lesehilfen" zur Interpretation vorliegender Zeugnisse gegeben (Dittrich 1989, S. 74ff.).

Wie Norm und Aufbau als Gliederungskriterien zeigen, besteht das $\mathrm{Ar}$ beitszeugnis aus mehreren obligatorischen Teiltexten, die hauptsächlich eine Tätigkeitsbeschreibung, Bewertung von Leistung und Beurteilung von Sozialverhalten geben. In den Teiltexten 1. (Angaben zur Person), 2. (Tätigkeitsbeschreibung) dominiert die Informationsfunktion mit den illokutiven Teilhandlungen Feststellen, Beschreiben, Begründen, Zusammenfassen. Daraus resultiert eine orientierende Funktion für einen neuen Arbeitgeber.

Bewertungen erfolgen in den Teiltexten 3. (Leistungsbeurteilung), 4. (Führung/Sozialverhalten), 5. (Führungsqualitäten/Aufstiegseignung).

Sie werden meist mit Hilfe der vorgegebenen Werteskala ebenso wie in der Bewertung des Sozialverhaltens durch intertextuell fixierte sprachliche Muster realisiert. Die Bewertung der Leistung soll wohlwollend sein und dem Fortkommen dienen.

Die dominierenden Illokutionen, die auch schon in der Gesetzes- und Dudenbeschreibung als Indikatoren für eine Handlungshierarchie gegeben sind, lauten:

Das Beschreiben und Bewerten

- soll dem Beurteilten zum Fortkommen dienen,

- soll dem Beurteilten nicht schaden (Wohlwollen),

- soll zuverlässig unterrichten,

- soll Auslese ermöglichen. 
Als obligatorische Teiltexte für Beurteilungen gelten die bei Norm und Aufbau beschriebenen Gliederungsanweisungen.

Die Teiltexte 1. (Angaben zur Person), 2. (Tätigkeitsbeschreibung und vorherige Tätigkeit) informieren, wobei durch Angaben zur vorherigen Tätigkeit/Entwicklung bereits inklusive, indirekte Einschätzungen erfolgen.

Beispiel:

„Dr. X, geb. 1957, hat nach dem Abitur mit Auszeichnung ein Vollstudium in der Sowjetunion in Rostow am Don absolviert. Auf Grund seiner Studienleistungen (Diplom mit Auszeichnung 1981) und Auszeichnung als Jungaktivist wurde ihm eine Aspirantur in Rostow vorgeschlagen, die er 1984 mit der Verteidigung seiner Kandidatendissertation abschloß. Im Herbst $1984 \mathrm{nahm}$ er seine Tätigkeit auf. Er ist seit 1985 unbefristeter Assistent."

Die Teiltexte 3. (Berufliche Entwicklung/Einstellung zur Arbeit und zum Kollektiv), 4. (Einstellung zur Gesellschaft), 5. (Einstellung zur eigenen Person) haben argumentierenden und bewertenden Charakter.

Beispiele:

(1) „Sein überaus positiver Einfluß auf die Studenten und Führungskader der II. Abteilung war gekennzeichnet von hoher Disziplin, Parteilichkeit und großer Fachkenntnis. In seiner sehr interessant gestalteten politischideologischen Arbeit genoB Gen. Dr. X bei allen hohes Ansehen."

(2) „Dr. X ist verheiratet, hat zwei Kinder im Vorschulalter und lebt in geordneten Familienverhältnissen. Persōnliche Kontakte zu Verwandten im NSW bestehen nicht, gelegentliche wissenschaftliche Kontakte zu Slawisten aus NSW-Ländern dienen der notwendigen wissenschaftlichen Kommunikation."

Die Teilhandlung „Beurteilen” kann als wesentlich gelten. Es kommen aber implizit und explizit noch die Zusatzhandlungen "Erziehen” und „Prognostizieren” (nützliches Mitglied unserer Gesellschaft/potentiell entwicklungsfähig) hinzu (vgl. dazu ausführlich Fix 1993).

Beispiele:

(1) „Nach alldem sind wir der Gewißheit, daß wir in Genossin Dr. $X$ eine sozialistische Hochschullehrerpersōnlichkeit besitzen, die ihre gesamte Kraft für Ausbildung und Erziehung sowohl der Studenten als auch des wissenschaftlichen Nachwuchses einsetzt und die in hohem Maße dazu beiträgt, die gesellschaftliche Wirksamkeit ihres Faches weiter auszuprägen."

(2) „Die Parteigruppe unterstützt und begrüBt die Entscheidung der SL und PL der Kollegin X eine Oberassistentenstelle zu geben und erhofft sich ein stãrkeres Engagement und eine größere Wirksamkeit der gesellschaftspolitischen Arbeit der Kollegin X."

(3) „Es wäre wünschenswert, wenn Kollegin X sich zur Vollschwester qualifizieren würde." 
Obligatorisch ist auch der Teiltext 6. (Zweck der Beurteilung), da die vielfältigsten Gründe für das Schreiben einer Beurteilung vorlagen.

Beispiele:

(1) Aktivist der sozialistischen Arbeit: „Seit November 1978 leistet Genos$\sin \mathrm{X}$ eine verantwortliche Arbeit in der Parteileitung der GO, setzt sich mit Engagement und Selbstlosigkeit für die Verwirklichung der Parteibeschlüsse ein und wird mit Nachdruck ihrer Aufgabe bei der Kassierung der Parteibeiträge gerecht."

(2) Höherstufung: „Die Einstufung von Kolln. Dr. X muß von der Parteileitung vorgenommen werden, da ihre erziehungswirksamen Aktivitäten und ihre groBe Belastung vor allem durch ihre politischen Funktionen zustande kommen."

Die intertextuelle Erfahrung mit dem Textmuster, die jeder arbeitende DDR-Bürger als Beurteilter gemacht hat, lautet: Fachliche und gesellschaftliche Aktivitäten müssen umfassend beschrieben (schöngefärbt) werden. Beurteilungen sind häufig zwei bis vier Seiten lang. Der zweiseitigen Zweckbestimmung von Arbeitszeugnissen (Fortkommen und Auslese) entspricht eine Mehrdimensionalität von Beurteilungen:

- Information bei Arbeitsplatzwechsel,

- Leistungseinschätzung,

- Einschätzung des Entwicklungsstandes des Werktätigen,

- Mittel der Erziehung und Kritik.

\subsection{Formulierungshilfen für Sequenzmuster im Vergleich}

Entsprechend dem Prinzip der logischen Abfolge sind bei dieser stark normierten Textsorte zu gesellschaftlichen Standardzwecken Sequenzmuster als globale Vorgaben vorhanden. Formulierungshilfen werden als textmusterspezifische Ausdrücke der einzelnen Sequenzen gegeben.

Die Hilfen zum Formulieren von Arbeitszeugnissen sind perfektioniert und bestehen aus einer Zusammenstellung von „Formulierungsbausteinen", die vor allem arbeitsrechtliche Auseinandersetzungen ersparen sollen (Dittrich 1988, S. 66).

Für Beurteilungen sind in den Lehrbüchern Formulierungen genannt, die hier durch auf Häufigkeitsuntersuchungen basierende Standardformulierungen ergänzt werden. Beispielhaft sollen typische Formulierungsangebote für die einzelnen Sequenzen verglichen werden. Denen lagen ergänzend zu der Ratgeberliteratur und den genannten DDRLehrbüchern 12 Arbeitszeugnisse aus den alten Bundesländern und 85 Beurteilungen aus der DDR-Zeit zugrunde. 


\section{Arbeitszeugnis}

1. Angaben zur Arbeitszeugnis-Person

Anrede: Herr, Frau, auf Wunsch Fräulein

\section{Tätigkeitsbeschreibung}

Bezeichnung von Haupt- und Nebentätigkeiten: „Zu den Aufgaben gehörten ..." "Er leitete die Abteilung ..." (Dittrich 1988, S. 70)

\section{Leistungsbeurteilung}

Skala zur sechsstufigen

Leistungsbewertung

(Dittrich 1989, S. 74)

Note/Bedeutung/Wortbeurteilung (z.B. in Berufzeugnissen):

1 = sehr gut: ... erfüllte stets seine Aufgaben zu unserer vollsten Zufriedenheit ...

2 = gut: ... erfüllte seine Aufgaben zu unserer vollen Zufriedenheit ...

3 = befriedigend: ... erfüllte seine Aufgaben zu unserer Zufriedenheit ...

4 = ausreichend: ... bemühte sich stets, seine Aufgaben zu erfüllen ...

5 = mangelhaft: ... versuchte, den Anforderungen gerecht zu werden ...

\section{Beurteilung}

1. Angaben zur Person

Kollege, Genosse, Jugendfreund

\section{Tätigkeitsbeschreibung}

Neben jetziger Tätigkeit Mitteilung

über vorherige Tätigkeit, z.B.: nach dreijähriger Armeezeit, Studium - vorfristig mit

Diplom abgeschlossen;

3. Berufiche Entwicklung/Einstellung zur Arbeit und zum Kollektiv

- Vorlesung und Seminare zeichnen sich durch immanenten marxistischleninistischen Gehalt aus;

- trägt wesentlich zur gesellschaftspolitischen Erziehung der Studenten bei; - ist ein wertvolles und vielseitig einsetzbares Mitglied des Lehrerkollektivs; Lexeme: verantwortungsbewubt, große Verdienste erwarb er sich, wissenschaftlich fundiert; internationale Anerkennung erworben, vielfältige gesellsch aftliche Arbeit, hohen politisch-erzieherischen EinfluB, Heranbildung politisch bewußter Nachwuchskräfte. 
6 = ungenūgend: ... mühte sich, zu einem Ergebnis zu kommen ...; oder: ... wir wünschen ihm eine Position, die seinen Fāhigkeiten gerecht wird ... (was natürlich sarkastisch gemeint ist!)

\section{Führung/Sozialverhalten} "Stellte stets das Interesse der Firma in den Vordergrund ..." "arbeitet zum Wohle des Unternehmens”, „war für diese Position geeignet", „kollegiale Haltung, Diskretion, Verhalten gegenüber den Vorgesetzten ..." „Kreativität und innovative Fähigkeiten"

(Dittrich 1989, S. 79)
4. Einstellung zur Gesellschaft/ Angaben zur politisch-ideologischen Haltung Zugehörigkeit zu politischen Organisationen: Besucht die Kreisparteischule; leitet ein Kollektiv der sozialistischen Arbeit; Mitglied der SED; Sekretăr der Grundorganisation; als prinzipienfester und verantwortungsvoller Kommunist bewährt; weltanschaulich gefestigtes Engagement; nimmt aktiven parteilichen Anteil an der Kulturpolitik der DDR; Tätigkeit in der sozialistische Presse; als BGL-Vorsitzender hat er sich stets offen zur Politik unserer Partei bekannt; als ein Arbeiterkader hat er ein positives Verhăltnis zur Partei; prägt spürbar die FDJ-Arbeit; nimmt aktiv an der Gestaltung des sozialistischen Wettbewerbs teil; hat einen klaren Klassenstandpunkt - erkennbar durch die fundierte Anwendung theoretischer Kenntnis auf dem Gebiet des M/L bei brennenden Zeitfragen und in der Ũbernahme eines Jugendobjektes; vertritt jederzeit die Position des sozialistischen Staates. 
5. Führungsqualitäten/Aufstiegseignung

„Verhalten bei der Führung seiner Mitarbeiter;

Leistungsfähigkeit unserers

Unternehmens steigern; versteht es zu motivieren; natürliche Autorität;

Führungsfāhigkeit"

(Dittrich 1988, S. 82)
5. Einstellung zur eigenen Person (Leiterpersönlichkeit) Prinzipienfestigkeit, Gründlichkeit, beharrlicher Arbeitswille, genießt hohes Ansehen; Engagement: fand ungeteilte Anerkennung; prägt durch seine Persōnlichkeit die Arbeit; gibt wichtige Orientierungen für die Arbeit; verantwortliche Funktionen; überdurchschnittliche Arbeitsbelastung; größtmögliche Effektivität; sozialistische Hochschulpersönlichkeit; starke Vorbildwirkung; langjährige Leitungstätigkeit; Leiter eines sozialistischen Kollektivs; verantwortungsbewußte Kaderpolitik; Initiative und Tatkraft.

\section{Zweck der Beurteilung} Hōherstufung, Prāmierung; Berufung, Kurantrag, Arbeitsplatzwechsel.

\section{Schluß (Unterschrift}

evtl. Wünsche)

Direktor für Erziehung und

Ausbildung; Sektionsdirektor;

Parteisekreär; BGL-Vor-

sitzender; Chefarzt; Stationsarzt;

AGL-Vorsitzender;

Beurteiler.

(Dittrich 1988, S. 69)

Unterschrift:

Geschäftsfūhrer

Diese Gegenüberstellung zeigt zunächst eine relative Übereinstimmung in den konventionellen Vorgaben, die das Muster bestimmen, was die intuitive Musterkenntnis von Arbeitszeugnis für Beurteilung rechtfertigt.

Die Realisierung unter den veränderten situativen Bedingungen erfordert eine stark modifizierende Ausfüllung des Textmusters. Reicht nun das konventionell unterstellte Musterwissen, das gruppenspezifisch inhomogen ist, aus, um Texte neu-mustergemäß zu formulieren? 


\section{Wissensmuster und ihre sprachliche Realisierung}

Bei der Analyse von Arbeitszeugnissen - geschrieben in den neuen Bundesländern von neuen Vorgesetzten, aber ausschlieBlich ehemaligen DDR-Bürgern - ging es darum, Textmusterrealisierungen $z \mathrm{u}$ beschreiben. Dabei handelt es sich einmal um Analysen von Beurteilungen/Arbeitszeugnissen für Ärzte im Praktikum. Für diese Gruppe standen auch Vergleichsarbeitszeugnisse aus den alten Bundesländern und Beurteilungen von vor der Wende zur Verfügung. Des weiteren wurden Arbeitszeugnisse aus Betrieben und von Universitätsmitarbeitern analysiert. Hinzu kamen noch Beurteilungen bzw. Schullaufbahnempfehlungen aus einzelnen Schulen.

Insgesamt konnten 35 nach der Wende geschriebene Arbeitszeugnisse analysiert werden, so daB hier nur erste Tendenzen anhand des zugrundeliegenden Materials aufgezeigt werden können.

Zunächst wurde jeder Text nach dem Muster in sechs Teiltexten analysiert. Dabei wurde auf die Analysenkenntnisse aus den vergleichenden Untersuchungen von Arbeitszeugnissen und Beurteilungen zurückgegriffen. In einer Tabelle wurden rezeptiv auffällige Formulierungen mit der folgenden Fragestellung eingetragen:

- In welchen Teiltexten gibt es Präferenzen für vertraute Formulierungsmuster?

- In welchen Teiltexten erfolgt selektiv die Übernahme von neuem sprachlichem Inventar?

- Wo wird (ungewollt) individuell formuliert, weil das Textmusterwissen nicht ausreicht?

- Welche Teiltexte wurden eliminiert?

Aufgrund der veränderten situativen Bedingungen und der mehr oder weniger globalen Kenntnis von Musterwissen stehen neue und alte Formulierungsmuster als Synthese für zu dokumentierenden Sprachwandel, der aus einer gesellschaftlichen/soziolinguistischen Drucksituation, verbunden mit außerlinguistischen Begleitumständen, resultiert. Muster befolgen und Improvisieren führen zumindest zu einer vorübergehenden Veränderung des Textmusters bei einer Mischung von Musterwissen.

\subsection{Textmusterbestimmende Typika aus dem alten Diskurs}

Der Begriff Typikum soll vor allem einen Unterschied in der Vorkommensweise, d.h. Seltenheit, eventuelle Beschränktheit auf bestimmte Textsorten implizieren und ist durch die Vorkommenshäufigkeit charakterisiert (Anderson 1984). 
In welchen Teiltexten von Arbeitszeugnissen/Beurteilungen werden alte Muster bewahrt?

Schon die Überschrift wird von einem GroBteil noch mit „Beurteilung” (auch "AbschluBbeurteilung"/ "Gesamtbeurteilung”) angegeben. Im Teiltext 1. Angaben zur Person/Anrede wird deutlich, daß hier fast ausschlieflich DDR-typische Anredeformen übernommen werden: $\mathrm{Kol}$ lege/Kollegin; ohne Titel; ohne Anrede nur Vor- u. Familienname.

Des weiteren fällt auf, daß weibliche Personen sehr häufig mit maskulinen Formen bezeichnet werden, wie etwa:

sie war Lehrer im Hochschuldienst

sie wurde rasch zu einem wertvollen Mitarbeiter im Ärztekollektiv

Frau $X$ arbeitete als Sachbearbeiter in der Vertriebsabteilung.

Die Differenzierung in weibliche und männliche Anrede- und Berufsbezeichnung ist auch im alläglichen Sprachgebrauch erst typisch und bewußt verwendet für die Nachwendezeit. $\mathrm{Zu}$ dem Teiltext 2. Tätigkeitsbeschreibung fallen in den neuen Arbeitszeugnissen hauptsächlich Sachbezeichnungen aus dem alten Diskurs auf: Fachorgan; Publikationsorgane; außerunterrichtliche Aufgaben/Veranstaltungen an der Universität; promovierte mit einer Dissertation A; erbrachte den Nachweis der fakultas docendi.

Aber auch Wendungen wie betriebliche Rationalisierungsmaßnahmen; war organisatorisch bei der Durchführung beteiligt; leistete ab; Aus- und Weiterbildung; Zielstellung und Aufgabenstellung; die daraus resultierenden Erfahrungen; kam ihren Verpfichtungen nach entstammen den normierten, intersubjektiven Wissensbeständen dieser Textsorte in der DDR, manifestiert im Textdenken und in Formulierungsgewohnheiten.

Der Teiltext 3. Leistungsbeurteilung wird vorsichtig formuliert. Hohes Verantwortungsbewußtsein, hohes Pfichtbewußtsein, hohe Einsatzbereitschaft sind durch die verwendeten Kollokationen markiert, im Sinne eines vorgeschlagenen Markiertheitsbegriffes von Anderson (1984, S. 62), entsprechen aber durchaus möglichen Formulierungsangeboten der Ratgeberliteratur, werden jedoch dort nicht in dieser relativen Häufigkeit und in den festen Wortverbindungen wie in den untersuchten VergleichsArbeitszeugnissen verwendet. Der verglichene Umgebungskontext in den Beurteilungen bleibt ebenfalls stereotypisiert, so daß die Relation Sachverhaltsgestaltung und Art der Handlungsdurchführung als "gewohnt" bezeichnet werden kann, wie etwa 
... stelle sich mit großem Engagement und hohem Verantwortungsbewußtsein jeder übertragenen Aufgabe.

... erwarb sich bei der Ausübung dieser Funktion große Verdienste.

Die ihr übertragenen Aufgaben löste sie mit großer Einsatzbereitschaft und hohem Verantwortungsbewußtsein.

Teiltext 4. Führung und Sozialverhalten - beide Lexeme als Schlüsselwörter für den Teiltext sind neu und ersetzen im vertrauten Muster Einstellung zur Gesellschaft, Einstellung zur Arbeit und zum Kollektiv. Deshalb bleibt das Kollektiv auch in fast allen Arbeitszeugnissen als Dublette bestehen:

Arbeitskollektiv, Ärztekollektiv, Stationskollektiv, Lehrerkollektiv, Klassenkollektiv, Schülerkollektiv.

Stereotype Wendungen wie:

machte sie zu einem wertvollen Mitglied des Kollektiv;

leistete einen Beitrag zur Erhöhung des Ansehens;

arbeitete zum Wohle unseres Betriebes;

fügte sich in das Lehrerkollektiv gut ein,

sind typische Kollokationen, die als DDR-markiert gelten können und in den Häufigkeitstabellen in den untersuchten DDR-Beurteilungen einen vorderen Platz einnahmen.

Teiltext 5. Führungsqualitäten und Aufstiegseignung konnten nur in der Umschreibung in ihrer Funktion als Leiterin und einmal, schon angelehnt an neue Denkweisen als ärztliche Laufbahn beschrieben werden. Hier können aber Einschränkungen im vorhandenen Analysematerial begründet sein.

Die für Arbeitszeugnisse in der Ratgeberliteratur vorgeschlagenen Wünsche Teiltext 6. Schluß/Gute Wünsche unterbleiben meist in den hier analysierten neuen Arbeitszeugnissen/Beurteilungen. Als fakultativer Teiltext waren sie in DDR-Beurteilungen in der Regel auch nicht üblich und nicht nötig, da ein Großteil der Beurteilungen zu anderen Zwecken geschrieben wurde als zum Arbeitsplatzwechsel. Falls Wünsche formuliert werden, klingen sie mitunter sehr ungewöhnlich wie in dem folgenden Arbeitszeugnis:

Unabdingbare Struktur- und Rationalisierungsmaßnahmen in unserem Unternehmen zwingen uns dazu, das bestehende Arbeitsverhältnis mit Herrn $X$ zu beenden. Wir bedauern das sehr und hoffen, daß Thre Institution Herrn $X$ eine seinen Fähigkeiten und Kenntnissen entsprechende Arbeitsaufgabe anbieten kann. Wir wünschen Herrn $X$ für weitere berufliche Jahre noch viel Erfolg, Schaffenskraft und Wohlergehen. 
Die Unterschrift, von meist noch mehreren Vorgesetzten, beendet das Arbeitszeugnis, wobei auch die Titel wie Medizinalrat, Diplom-Mediziner, amtierender Direktor, amtierender Abteilungsleiter, Vorstandsvorsitzender oder auch gar keine Berufsbezeichnung DDR-typische Benennungen bzw. Übergangsformen sind.

Wenn man die Sequenzierung als Prinzip der logischen Abfolge der einzelnen Teiltexte betrachtet, die ja als globale Vorgabe in diesem Textmuster kaum zu modifizieren ist, so fält auf, daB, bevor mögliche gute Wünsche zum Schluß formuliert werden, häufig noch eine zusammenfassende Einschätzung gegeben wird, die mit insgesamt, zusammenfassend, abschließend kann eingeschätzt werden beginnt.

Überhaupt wird die logische Abfolge mehrfach durchbrochen, indem besonders nach den Teiltexten 3-5 nochmals auf die Tätigkeitsbeschreibung bezug genommen wird. Das geschieht fast ausschlieflich in den Arbeitszeugnissen/Beurteilungen, die von den neuen Vorgesetzten (Ost) geschrieben werden, während Vergleichs-Arbeitszeugnisse von Personalleitern (West) geschrieben, die Sequenzfolge genau einhalten. Hier kann spekulativ Unkenntnis genauer Musterhierarchien angenommen werden.

\subsection{Adaption neuer normierter Formulierungsmuster}

Es fiel auf, $d a B$ in einzelnen Teiltexten als Implementierung bestimmte Lexeme bevorzugt verwendet werden. Das betriftt Teile der Tätigkeitsbeschreibung, wo eine instabile Mischung von tradierten und neuen Formen vorhanden ist. Dabei kann man davon ausgehen, daß besonders identitätsstiftende und vertrauter werdende Bezeichnungen für die Arbeitsumgebung dazu beitragen.

So werden Benennungen komplementär zu Betrieb gewählt, wie etwa Firma, Unternehmen, Auftraggeber, Unternehmungsführung, MarketingBereich, Management-Bereich.

Das für das Sozialverhalten wichtige Kollektiv im Teiltext 4. wird häufig im gleichen Text auch als Team, (Stationsteam, Ärzteteam) bezeichnet.

Bei der Leistungsbeurteilung wird die vorgegebene standardisierte Ausdrucksweise stets zur vollsten Zufriedenheit fast ausschließlich benutzt. Zielstrebig und engagiert ergänzen die vorgeschlagene Bewertung und gehören zu den typischen Lexemen dieser Textsorte in Ost und West, wenngleich die Wortverbindungen in den untersuchten DDRBeurteilungen vor allem folgende waren: 
politisches Engagement für unseren Staat, weltanschaulich gefestigtes Engagement, fachlich und organisatorisches Engagement, Engagement und Selbstlosigkeit für die Verwirklichung der Parteibeschlüsse.

In den vorliegenden Arbeitszeugnissen aus den alten Bundesländern wird Engagement in folgenden Verbindungen verwendet: reges Engagement; großes berufliches Engagement; Interesse, Fleiß und Engagement, so daß durch die unterschiedlichen Kollokationen Engagement unterschiedlich konnotiert ist, zwar als musterbezeichnender Ausdruck existiert, nun aber für den Rezipienten (Ost) fremd wirkt.

\subsection{Individuelles Formulieren}

Im Zusammenspiel von Musterbefolgen (Leistungsbeurteilung) und Improvisieren, weil das Inventar des Musters im bewuBten Vermeiden von Tradition umgangen werden soll oder nicht so geläufig ist, kommt es zu bewuBter, aber auch ungewollter Kreativität beim Ausfüllen des Musters. Die Möglichkeiten des individuellen Abweichens vom konventionell vorgegebenen Rahmen sind bei dieser Textsorte relativ gering.

Es fällt auf, $\mathrm{daB}$ vorgegebene, fremd empfundene Bewertungsausdrücke wie erfolgsorientiert, innovativ, souverän, Kreativität (Teiltext 3) oder Prestige, kooperativer Führungsstil, Karriere, Autorität, Führungspraxis, Teamfähigkeit, Kommunikationsfähigkeit, Durchsetzungsvermögen (Teiltext 4/5) umgangen werden. Man kann hier von Konnotationen sprechen, die auf konventionellen Gebrauchsrestriktionen beruhen und somit eine stilistische Bedeutung besitzen. Lexeme wie Karriere/Karriereaufstieg gehörten in DDR-Beurteilungen nicht zum Inventar und wurden in alltagssprachlichen Kontexten eher negativ konnotiert, wenn überhaupt gebraucht.

Bei der Realisierung der Teiltexte Führung/Führungsqualitäten werden als Handlungsalternativen individuelle Formulierungen gewählt wie seine Erwägungen waren treffsicher, seine Sensibilität bei der Tätigkeit ist hervorzuheben, ihre diagnostische Strategie (Teiltext 3); aufgeschlossener Gesprächspartner; entwickelt sich zu einer großen Hilfe; gab Denkanstöße zur Veränderung der angetroffenen Realität; erfreut sich hoher Wertschätzung der Kollegen (Teiltext 4/5). 


\subsection{Dominante Teiltextmuster entfallen}

Die soziolinguistische Fragestellung: „Zu welchem Zeitpunkt und in welcher Umgebung ändert sich die sprachliche Struktur aufgrund welcher Verhältnisse?" (Dittmar 1973, S. 157) ist ein zentrales Problem des Sprachwandels und soll hier explizit genannt werden.

Neue Konventionen verlangen andere Muster. Konventionell unverträglich in der neuen sozialen Situation ist der Teiltext Einstellung zur Gesellschaft/Angaben zur politisch-ideologischen Haltung, der prototypisch und zentraler Bestandteil für Beurteilungen war und von stereotypisierten sprachlichen Mitteln dominiert war.

Eine Häufigkeitsstatistik der untersuchten Texte zeigt in Frequenz und Distribution folgende Schlüsselwörter:

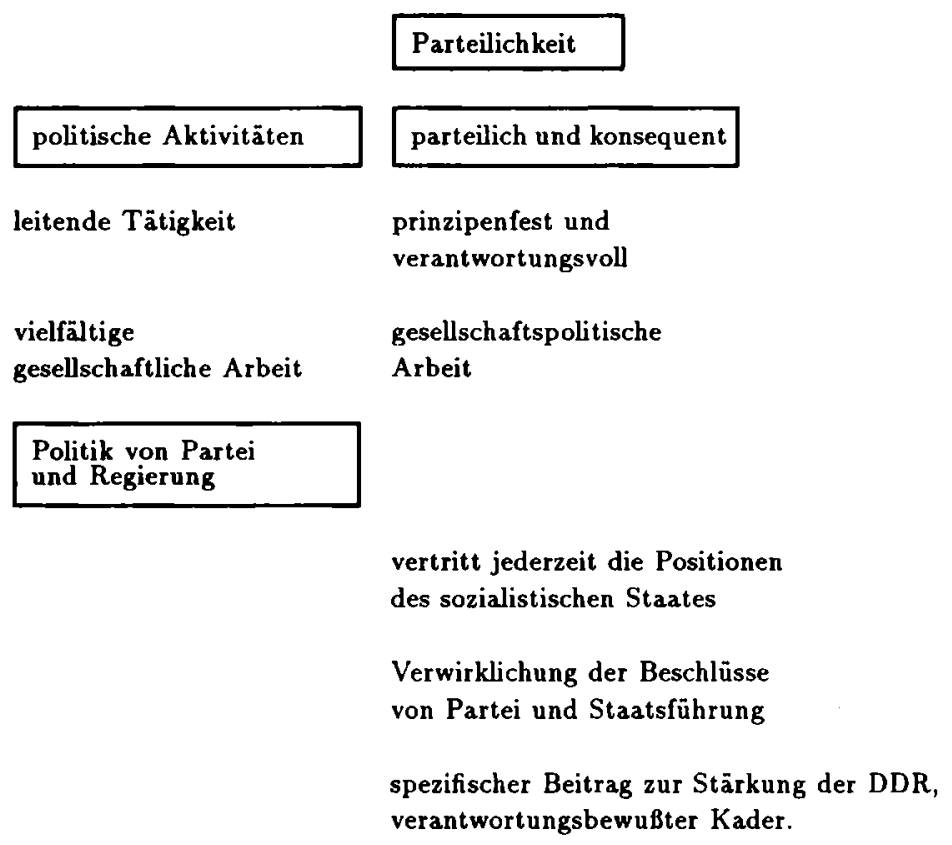

Diese Schlüsselwörter können als prototypische Stilelemente für das Textmuster gelten, die der normativen Vorstellung entsprachen und durch die veränderten normativen Bedingungen im neuen Textmuster entfallen. 


\section{Zusammenfassung}

Anhand der vorliegenden Analysen wird deutlich, daß das Textmuster Arbeitszeugnis unter den situativen Bedingungen modifiziert realisiert wird. Die Veränderungen resultieren aus:

1. Unvollkommene Kenntnis des Textmusters - Ratgeberliteratur ist weitgehend unbekannt/ungewohnt zu benutzen (Anrede, SchluB)

2. BewuBtes Eliminieren tradierter Teiltextmuster (politische Entwicklung, Parteizugehörigkeit)

3. Bewußtes Umgehen fremd empfundener Teiltexte und ihrer vorgegebenen Formulierungsangebote (erfolgsorientiert, Führungspraxis)

4. Fehlende Kompatibilität von Wissensbeständen (Dissertation $A$ )

5. UnbewuBte Verwendung von tradierten Formen in strukturell übereinstimmenden Teiltexten (2/3) (Kollektiv, Aus- und Weiterbildung, außerunterrichtliche Aufgaben)

6. BewuBte Implementierung bzw. Substitution bereits vertraut empfundener neuer synonymer Formulierungsmuster (Firma, Unternehmen).

Als verallgemeinerte Stilwirkung im Vergleich zu Musterarbeitszeugnissen und vorliegenden Arbeitszeugnissen westdeutscher Arbeitgeber erscheinen aus Rezipientensicht die im Musterkonflikt entstandenen synthesehaften gemischten Beurteilungen/Arbeitszeugnisse $\mathrm{k} \mathrm{n}$ a p p. Die Art der Durchführung wirkt oft $u n b$ e h o l f e $n$ aber auch f r e m d a r t ig und $n$ e u a $r$ t i g in Bezug auf tradiertes Musterwissen und weggefallene Standardorientierungen. Die Art der Themenbehandlung wird als notwendig zeitgemäß empfunden. Durch das Weglassen der als fakultativ empfohlenen guten Wünsche zum SchluB wirken die Texte un persönlich, steif und distanziert gegenüber Wohlwollen und Herzlichkeit ausstrahlenden SchluBformulierungen in Arbeitszeugnissen, geschrieben von Arbeitgebern aus den alten Bundesländern. Die Stilzuschreibung ,wohlwollend" wird durch Formulierungen wie: Bedauern über Fortgang; allerbesten Dank; Gesundheit, Glück und Erfolg in der fakultativen GruBsequenz gestützt.

Konflikte zwischen Schreibern und Rezipienten von neuen Arbeitszeugnissen resultieren auch aus der Stilwirkung, besonders der Art der Themenbehandlung und der Art der Durchführung, die in Relation zu dem konventionell Erwartbaren gewertet wird. Hier werden auch Unterschiede im momentanen gemeinsamen Wissen zur Realisierung des Textmusters deutlich. Häufig verfügt der Rezipient über die besseren Kenntnisse.

Abschließend sei noch auf einen Konflikt hingewiesen, der sich aus unterschiedlichen Relationen der Adressiertheit ergibt. Herkunftsort, Wohnort, Arbeitsort und zukünftiger Arbeitsort sind für die Interpretation 
von Arbeitszeugnissen in Zukunft mit zu beachten. Konfliktsituationen entstehen - jetzt und in Zukunft -, wenn Produzent und Rezipient durch traditionelle Verhaltensmuster, beispielsweise die Art und Weise, Beurteilungen zu interpretieren (Fix 1993), die kommunikative Andersartigkeit in einem besonders sensiblen persönlichen Bereich verspürten. Das führt dazu, daß Arbeitnehmer der neuen Bundesländer, die Arbeitszeugnisse fordern, weil ihr Arbeitsverhältnis beendet wird, häufig Vergleiche mit Ratgeberliteratur auf Hinweis westdeutscher Bekannter vornehmen und entsprechende Formulierungen fordern, ja sogar mit dem Arbeitsgericht drohen. Dabei werden Auszüge aus Ratgeberliteratur dem Zeugnisschreiber vorgelegt oder es werden Tätigkeitsbeschreibungen vom Arbeitnehmer selbst formuliert und als Anhang an das Arbeitszeugnis mit Unterschrift vom zuständigen Vorgesetzten angefügt. Um solchen Konfliktsituationen vorzubeugen, haben beispielsweise Lehrer in SachsenAnhalt für das Schreiben von Schülerbeurteilungen und Schullaufbahnempfehlungen Formulierungshilfen von Niedersachsen (Lüneburg) zur Verfügung gestellt bekommen.

Hier sollte an einer Textsorte aus dem Textsortenspektrum der Alltagswelt die Konfliktsituation aufgrund der Divergenz unterschiedlicher Kommunikationskulturen am Fortwirken von kommunikativen Mustern sowie am beginnenden Transfer zum Ausgleich von Differenzen gezeigt werden, was für einen längeren Zeitraum noch, auch bei dieser stark normierten Textsorte, zu einer regionaltypischen Spezifik sprachlicher Ausfüllung des Textmusters Arbeitszeugnis führt, wie das abschließende Beispiel eines Arbeitszeugnisses nach neunjähriger Tätigkeit zeigen soll:

\begin{abstract}
Abschlußbeurteilung
Frau $X$, geb. am 24.03.41, arbeitete vom 1.11.1982 bis zum 31.12.1991 als Sachbearbeiter in der Vetriebsabteilung der Melany-Konfektionsund Handels AG, ehemals VEB Kindermoden. Ihr Aufgabenbereich beinhaltete den ÁbschluB von Vertrāgen zu Messen, Auswertung der Vertragsabschlüsse, eine ordnungsgemāße Durchführung von monatlichen Inventuren sowie eine tägliche Überwachung der termin- und qualitätsgerechten Einhaltung der Lieferverträge und weitere Verkäufe und Angebote zu tätigen. Diese ihr übertragenen Aufgaben löste sie stets zur vollen Zufriedenheit. Fleiß und Verantwortungsbewußtsein gehörte zu ihrer tāglichen Arbeit. Auf Grund von Rationalisierungsmaßnahmen innerhalb des Unternehmens wurde Frau X die Kündigung zum 31.12.1991 ausgesprochen.
\end{abstract}

Vorstandsvorsitzender

Ziel solcher Analysen alltagssprachlicher Textsorten ist es, entstehende und bereits entstandene Mischformen differenziert zu beschreiben, Wissensdifferenzen an Einzelbeispielen aufzuzeigen und Akzeptanz für durch Diffusion entstehende Musterveränderungen zu erwirken. 


\section{Literatur}

Andersson, Sven-Gunnar (1984): Wortwanderung. Zur Beschreibung der deutsch-deutschen Sprachsituation im Bereich des Wortschatzes. In: Deutsche Sprache 12, S. 54-84.

Bauer, Dirk (1990): Zwei deutsche Staaten! - Zwei deutsche Sprachen? Überlegungen zur Entwicklung der germanistischen Forschung und zum Verhältnis von Sprachwissenschaft und Politik. In: Deutsche Sprache 18, S. 218240.

Becker-Mrotzek, Michael (1990): Kommunikation und Sprache in Institutionen. Ein Forschungsbericht zur Analyse institutioneller Kommunikation. In: Deutsche Sprache 18, S. 158-190, S. 241-259.

Bellmann, Günter (1991): Wandlungen im Wortschatz der deutschen Gegenwartssprache: Der Wortschatz und die deutsche Einheit. In: Beiträge zur deutschen Linguistik, Methodik und Didaktik 5. Kyoto 1991, S. 21-32.

Brinker, Klaus (1985): Linguistische Textanalyse. Berlin.

Brinkmann, Bettina/Buder, Andreas/Dawin, Andrea/Osburg, Anke (1992): Ein Staat - eine Sprache? Empirische Untersuchungen zum englischen EinfluB auf die Allgemein-, Werbe- und Wirtschaftssprache im Osten und Westen Deutschlands vor und nach der Wende. Frankfurt.

Burkhardt, Armin/Fritzsche, Klaus Peter (Hg.) (1992): Sprache im Umbruch. Politischer Sprachwandel im Zeichen von "Wende” und „Vereinigung”. Berlin/New York.

Dimter, Matthias (1981): Textklassenkonzepte heutiger Alltagssprache. Kommunikationssituation, Textfunktion und Textinhalt als Kategorien alltagssprachlicher Textklassifikation. Tübingen. (= Reihe germanistische Linguistik, 32).

Dittrich, Helmut (1988): Arbeitszeugnisse schreiben und verstehen. München.

Ehlich, Konrad (1986): Die Entwicklung von Kommunikationstypologien und die Formbestimmtheit sprachlichen Handelns. In: Kallmeyer, Werner (Hg.): Kommunikationstypologie. Handlungsmuster, Textsorten, Situationstypen. Jahrbuch 1985 des Instituts für Deutsche Sprache. Düsseldorf. S. 47-72.

Erlebach/Hoft/Ihlefeld/Zehner (1983): Schülerbeurteilung. 10. Aufl.. Berlin.

Fix, Ulla (1992): Stil als komplexes Zeichen im Wandel. In: Zeitschrift für germanistische Linguistik 20.2, S. 193-209.

Fix, Ulla (1994): Texte mit doppeltem Boden. Erscheint: Wien 1994.

Fleischer, Wolfgang (1987), (Autorenkollektiv): Wortschatz der deutschen Sprache in der DDR. Leipzig.

Franke, Wilhelm (1987): Texttypen - Textsorten - Textexemplare. Ein Ansatz zu ihrer Klassifizierung und Beschreibung. In: Zeitschrift für germanistische Linguistik 15, S. 263-281.

Franke, Wilhelm (1991): Linguistische Texttypologie. In: Brinker, Klaus (Hg.): Aspekte der Textlinguistik. Tübingen. S. 157-182. (= Reihe Germanistische Linguistik, 106/107). 
Gläser, Rosemarie (1990): Fachtextsorten im Englischen. Tübingen.

Good, Colin (1993): Über die „Kultur der Mißverstāndnisse” im vereinten Deutschland. In: Muttersprache 103, 3, S. 249-259.

GroBe, Ernst Ulrich (1976): Text und Kommunikation. Stuttgart.

Gülich, Elisabeth/Raible, Wolfgang (Hg.) (1972): Textsorten. Differenzierungskriterien aus linguistischer Sicht. Frankfurt. 2. Aufl., Wiesbaden 1975 .

Gülich, Elisabeth (1985): Textsorten in der Kommunikationspraxis. In: Kallmeyer, Werner (Hg.): Kommunikationstypologie. Jahrbuch 1985 des Instituts für Deutsche Sprache. Düsseldorf 1986. S. 15-46. (= Sprache der Gegenwart, Bd. 67).

Hannappel, Hans/Melenk, Hartmut (1984): Alltagssprache. München.

Hellmann, Manfred W. (1990): DDR - Sprachgebrauch nach der Wende - eine erste Bestandsaufnahme. In: Muttersprache 100, S. 266-286. Dazu Diskussion: ebd. 101, S. 66-70.

Kießling, Kurt (Hg.) (1969): Ausdruckslehre. 7. Aufl. Leipzig.

Kühn, Ingrid (1992): Straßennamen nach der Wende. In: Namenkundliche Informationen. Leipzig.

Kūhn, Ingrid (1994): Sprachberatung in den neuen Bundesländern - Hilfe bei deutsch-deutschen Sprachproblemen. In: Muttersprache 104, Heft 2.

Lerchner, Gotthard (Hg.) (1992): Sprachgebrauch im Wandel. Anmerkungen zur Kommunikationskultur in der DDR vor und nach der Wende. Frankfurt/M. et al. (= Leipziger Arbeiten zur Sprach- und Kommunikationsgeschichte, Bd. 1).

Lerchner, Gotthard (1992): Broiler, Plast(e) und Datsche machen noch nicht den Unterschied. Fremdheit und Toleranz in einer plurizentrischen deutschen Kommunikationskultur. In: Lerchner (Hg.) (1992), S. 297-332.

Liebsch, Helmut (Hg.) (1976): Deutsche Sprache. Leipzig.

Lux, Peter (1993): Ostdeutsch-Westdeutsch: Zwei Sprachen. In: Leipziger Volkszeitung. 31.12.1993.

Möhn, Dieter/Pelka, Roland (1984): Fachsprachen. Tübingen.

Nasemann, Andrea (1992): Arbeitszeugnisse durchschauen und interpretieren. Niedernhausen.

Oschlies, Wolf (1989): Würgende und wirkende Wörter. Deutschsprechen in der DDR. Berlin.

Pātzold, Jörg (1992): Zwischen Indirektheit und Sprachlosigkeit. Der Umgang der Presse in der DDR zwischen dem Stern-Interview Hagers und Oktober 1989 mit der Wirklichkeit des Real Existierenden. In: Welke u.a. (Hg.) (1992), S. 93-110.

Petersen, Jens (1986): Sprache in der gesellschaftlichen Öffentlichkeit. Frankfurt.

von Polenz, Peter (1988): „Binnendeutsch” oder plurizentrische Sprachkultur? Ein Plädoyer für Normalisierung in der Frage der "nationalen" Varietāten. In: ZGL 16, S. 198-218. 
von Polenz, Peter (1993): Die Sprachrevolte in der DDR. Im Druck: Germanistische Linguistik.

Presch, Gunter/Gloy, Klaus (Hg.) (1976): Sprachnormen II. Stuttgart-Bad Cannstatt 1976.

Presch, Gunter (1991): Arbeitszeugnisse. Informationsbroschüre des Germanistischen Seminars der Universitāt Hamburg. Hamburg.

Püschel, Ulrich (1982): Die Bedeutung von Textsortenstilen. In: Zeitschrift für germanistische Linguistik 10, S. 28-37.

Reséndiz, Julia Liebe (1992): Woran erkennen sich Ost- und Westdeutsche? Eine Spracheinstellungsstudie am Beispiel von Rundfunksendungen. In: Welke u.a. (Hg.) (1992), S. 127-140.

Rolf, Eckhard (1993): Die Funktion der Gebrauchstextsorten. Berlin.

Ruge, Elisabeth (1993): Behördenkorrespondenz. Niedernhausen.

Sandig, Barbara (1987): Textwissen. Beschreibungsmōglichkeiten und Realisierungen von Textmustern am Beispiel der Richtigstellung. In: Engelkamp/Lorenz/Sandig (Hg.): Wissensrepräsentation. St. Ingbert. S. 115155.

Sandig, Barbara (1989): Stilistische Mustermischung in der Gebrauchssprache. In: Zeitschrift für Germanistik 2/1989, S. 133-150.

Schrōder, Marianne (1992): Lexikographische Nach-Wende - Ein Überarbeitungsbericht. In: Lerchner (Hg.) (1992), S. 263-296.

Schmidt, Wilhelm (1981): Funktional-kommunikative Sprachbeschreibung. Leipzig.

Welke, Klaus/Sauer, Wolfgang W./Glück, Helmut (Hg.) (1992): Die deutsche Sprache nach der Wende. Hildesheim usw. (= Germanistische Linguistik 110-111/1992).

Wittgenstein, Ludwig (1953): Philosophische Untersuchungen. Frankfurt.

Wypijeski, Wolfgang (1992): 99 Zeugnisse. München.

Wörterbuch der deutschen Gegenwartssprache, hrsg. v. Klappenbach, Ruth/ Steinitz, Wolfgang. Berlin 1978.

Duden, Deutsches Universalwörterbuch, hrsg. v. Drosdowski, Gūnter. Mannheim 1989.

Rückläufiges Wörterbuch der deutschen Gegenwartssprache, hrsg. v. Mater, Erich, Leipzig 1967.

Synonymwörterbuch, hrsg. v. Görner, Herbert/Kempcke, Günter. Leipzig 1973. 


\section{Warum gibt es normative Stilistiken?}

\section{Sprachtheoretische Überlegungen zu einem scheinbar trivialen Phänomen}

1.

„Sie sind zu allem fähig, aber zu nichts zu gebrauchen!" ${ }^{1}$ Ist dies auf den Punkt gebracht der zentrale Vorwurf der Öffentlichkeit gegenüber Linguisten? ${ }^{2}$ Wenn man sich von einschlägigen Presseartikeln beeindrucken läBt, den öffentlichen Streit um die Rechtschreibreform hinzunimmt oder die Linguistik-Beschimpfung mancher Stillehren in Erwägung zieht - um nur einige Bruchstellen zwischen Öffentlichkeit und Linguistik zu benennen -, dann ist die eingangs zitierte Abwandlung eines Slogans eine fast schon wieder schmeichelhaft zu nennende Formulierung jener Kritik, die die veröffentlichte Meinung an der Linguistik seit langem zu üben nicht müde wird.

Die Gegenkritik der Linguisten an der Öffentlichkeit ist nicht minder grundsätzlich und ebenfalls nicht ganz neu: „Wann ist die Öffentlichkeit endlich bereit, Einsichten der modernen Linguistik zur Kenntnis zu nehmen?" Während ansonsten wissenschaftlichen Ergebnissen öffentliche Aufmerksamkeit zuteil wird, sofern sie nur alltagsweltliche Bedeutung beanspruchen können, scheint ein kontinuierlicher Transfer sprachwissenschaftlicher Ergebnisse in die Öffentlichkeit noch immer die Ausnahme zu sein. Insbesondere normative Stilistiken, Korrespondenz- und Schreibhilfen aller Art sperren sich bisweilen sogar demonstrativ, wenn es um die Berücksichtigung von Einsichten der modernen Sprachwissenschaft geht. Kernpunkt des wechselseitigen Mißvergnügens zwischen Linguistik und Öffentlichkeit ist dabei die nach wie vor unterschiedliche Auffassung von der Rolle der Präskription in Grammatik, Lexik und Stilistik.

Konkret: Weite Teile der Öffentlichkeit erwarten von der Linguistik, was die Linguistik bei Strafe ihres wissenschaftlichen Anspruchs nicht bieten kann - nämlich verbindliche Vorschriften. Dem gegenüber steht jene Position der Linguistik, die André Martinet (1963, S. 14) so auf den Punkt gebracht hat: „Der Sprachwissenschaft geht es um wissenschaftli-

1 In Anlage und Duktus habe ich die Vortragsfassung beibehalten.

2 Es wäre uncharmant, ausgerechnet hier das erwartbare "LinguistInnen" zu schreiben. Daher ist die Bezeichnung „Linguist” etc. immer geschlechtsneutral zu verstehen. 
che, nicht um normative Betrachtung." „Wissenschaftlich' steht (...) im Gegensatz zu normativ." Und mit dieser Formel scheint von seiten der Linguistik die unveränderliche Frontlinie zu Stilistiken und vergleichbarer Literatur eindeutig markiert zu sein.

Gleichwohl: Die im Martinetschen Diktum zum Ausdruck kommende strikte Dichotomisierung von Deskriptivismus und Normativismus muB heutzutage wissenschaftstheoretisch und wissenschaftssoziologisch als antiquiert bezeichnet werden. Die normativen Präsuppositionen (Lorenzen/Schwemmer 1973) ebenso wie die zweckrational-technologischen Implikationen von Wissenschaften ${ }^{3}$ werden mittlerweile wesentlich klarer gesehen als zu Zeiten, in denen sich in Sonderheit die Sprachwissenschaften von den Zumutungen normativer (häufig auch: ideologischer) Vorgaben allererst emanzipieren mußten.

Seit das Verhältnis von Deskriptivismus und Normativismus in den Wissenschaften nicht mehr nur als "fallacy" diskutiert wird, ist es nun auch für Linguisten leichter, ein unvoreingenommenes Interesse für ein geradezu prototypisches Muster normativer Sprach- und Kommunikationsthematisierung, nämlich für Stillehren, zu entwickeln. Dabei setze ich durchaus all das voraus, was Linguisten den Stillehrern seit langem kritisch ins Stammbuch schreiben: Sie betrieben „Verbalartistik” (Sanders 1992), Stilistiken seien unsystematisch, subjektiv gefärbt und propagierten statt begründbarer Normen lediglich Geschmacksurteile. Wenn dies und vieles andere richtig ist, dann bleibt eigentlich nur die Frage: „Warum gibt es überhaupt (noch) normative Stilistiken?”. Ist die Existenz dieses Genres tatsächlich ein Zeichen für eine sich wissenschaftlichen Erkenntnissen sperrende Öffentlichkeit? Sind die in jeder Buchhandlung kaum übersehbaren Angebote zu Themen der Art: „Wie soll ich schreiben?", „Wie soll ich reden?” wirklich historisch überholte Fragen? Und wenn nicht, steckt hinter diesem Bedürfnis nach alltagsweltlicher Sprachreflexion mehr als nur die Befriedigung von sprachpflegerischen, sprachpuristischen oder ästhetisch motivierten Geschmacksurteilen?

Die Antwort läBt sich so zusammenfassen: Während die moderne Linguistik die verschiedenen Wissensbereiche (im Jargon: die verschiedenen Wissensmodule resp. Kompetenzen) des "native (!) speaker” zu explizieren sucht, interessiert die Öffentlichkeit an Stilistiken und entsprechenden Veröffentlichungen gerade die jenseits des „angeborenen" Sprachwissens anzusiedelnden sprachlichen Wissensdefizite bzw. Vervollkomm-

3 Man vergleiche die uns inzwischen schon fast verstaubt vorkommende, einst heiß geführte Finalisierungs-Debatte der 70er Jahre; siehe Böhme et al. (1973). 
nungsmöglichkeiten. Ich werde diese Position als „ImperfektibilitätsThese" erläutern. Zuvor aber ein kurzer Überblick: Im folgenden Abschnitt soll zunächst gezeigt werden, daB normative Stilistiken lediglich besonders ins Auge springende (sog. "saliente”) Exemplare einer weit umfangreicheren, praxisorientierten Thematisierung von Sprache und Kommunikation sind, die ich zusammenfassend als "Laien-Linguistik" bezeichnen möchte. Dabei ist zunächst die soziale Rolle dieser nichtakademischen Literatur zu umreißen. Dazu These 1: Die Laien-Linguistik kann soziolinguistisch als Reflex auf die fortschreitende gesellschaftliche Arbeitsteilung auch in der Muttersprache verstanden werden. Angesichts einer sich sprachlich ausdifferenzierenden Gesellschaft wächst in breiten Kreisen der Öffentlichkeit zunehmend das - privat wie beruflich stimulierte - Bedürfnis nach Wissen, Beratung und Qualifikation, aber auch nach Unterhaltung im Bereich der muttersprachlichen Kommunikation.

Im dritten Abschnitt möchte ich die Frage behandeln, was aus linguistischer Sicht der Gegenstand eben dieser Laien-Linguistik ist. Dazu These 2: Gegenstand der Laien-Linguistik ist jener Bereich des sprachlichen Wissenserwerbs, der anders als der primäre Spracherwerb nicht naturwüchsig und - anders als ein großer Sektor schulisch vermittelten Lernens - primär praxisorientiert und damit soziokulturell relevant ist. Im Gegensatz zu der von Chomsky initiierten Learnerbility-Diskussion (Piattelli-Palmarini 1980) - aber in einem durchaus komplementär distribuierten Sinn dazu - geht es der Laien-Linguistik um die praktisch orientierte Beantwortung der Frage, was man über Sprache und Kommunikation noch lernen kann bzw. soll, wenn man denn schon naturwüchsig Sprache erworben hat. Oder etwas anders akzentuiert: Es geht der Laien-Linguistik im wesentlichen um unzureichende sprachliche und kommunikative Kompetenzen, d.h. um fehlendes, lückenhaftes oder wenig habitualisiertes sprachlich-kommunikatives Wissen des Individuums relativ zu sozio-kulturellen Standards und Anforderungen einer Gesellschaft. Ich möchte daher die These 2 gegenüber Verabsolutierungen der „Kompetenz-Linguistik” - aber durchaus komplementär auf sie bezogen - die „Imperfektibilitäts-These” nennen. Die Laien-Linguistik im allgemeinen und normative Stilistiken im besonderen thematisieren Bereiche imperfektibler sprachlich-kommunikativer Kompetenzen von faktischen Sprechern/Schreibern. Oder terminologisch schlichter: Sie thematisieren Optimierungsmöglichkeiten und Bereiche sprachlich-kommunikativer Defizite.

Dies führt direkt zum vierten Abschnitt, nämlich zu der sprachtheoretischen Problematisierung dieser Defizite und Optimierungsmöglichkeiten. Dazu These 3: Angebote zur "Laien-Linguistik" - und hier vornehmlich 
normative Stilistiken - lassen sich als Lösungsversuche von zugrundeliegenden Sprach- und Kommunikationsproblemen verstehen! Diese Probleme werden in der akademischen Linguistik $\mathbf{z}$ war behandelt, aber eben nicht in einer Systematik, die sie als zentrale alltagsweltliche Sprach- und Kommunikationsprobleme von linguistischen Laien ausweist.

In einem abschließenden fünften Punkt möchte ich dann zeigen, daß die der Laien-Linguistik zugrundeliegenden Problemtypen auf eine bestimmte Klasse sprachtheoretischer Bedingungen zurückzuführen sind. Dazu die These 4: Die meisten der in der Laien-Linguistik schwerpunktmäßig thematisierten alltagsweltlichen Sprach- und Kommunikationsprobleme lassen sich auf bestimmte fundamentale Asymmetrien zurückführen, die als Constraints (als „Zwänge”) der Sprachverarbeitung bei der Diskurs- bzw. Textproduktion und -rezeption eine zentrale Rolle spielen. Sie definieren damit jene allgemeinen Barrieren, mit denen man es beim Formulieren und Rezipieren zu tun hat. Diese Asymmetrien können damit zugleich als Operationalisierungen der sprachlichkommunikativen Imperfektibilität interpretiert werden.

Der skizzierte Zugriff auf die Thematik wird sprachtheoretisch Geschulte verwirren und das aus mindestens zwei Gründen: Der Gegenstand der Explikation, nämlich metalinguistische Aussagen der laien-linguistischen Literatur, ist zum einen - so wird man einwenden - in dieser Form überhaupt kein "ordentlicher" sprachtheoretischer Reflexionsgegenstand. Das methodische Vorgehen scheint zum anderen überdies empirisch zu sein, indem es von mehr oder weniger normativen Aussagen in Stilistiken seinen Ausgang nimmt. Ohne hier den Begriff „sprachtheoretisch” problematisieren zu können, möchte ich dazu zwei methodisch konvergente Entgegnungen machen:

1) Zum einen gehe ich - anders als dominierende Strömungen der Sprachwissenschaft - nicht „diagnostisch”, d.h. nicht von immanent definierten Problemen der Disziplin "Linguistik” aus, sondern von alltagsweltlichen, vorzugsweise praktischen Ansätzen, nämlich von Lösungsversuchen für Formulierungs- und Rezeptionsprobleme. Diese Vorgehensweise möchte ich "therapeutisch" nennen. Sie zielt wie die "reine”, die grundlagenorientierte Linguistik auf "Diagnostik”. Dahinter steht aber eine weitergehende angewandt-linguistische Zielrichtung, nämlich mit Hilfe einer verbesserten „Diagnostik” die "Therapiemöglichkeiten” zu effektivieren. Diese Zielsetzung steht sicher nicht im Gegensatz zu einer diagnostischen, rein grundlagenforschungsbezogenen sprachtheoretischen Analyse, sie geht aber in ihrem Anspruch ersichtlich über sie hinaus. 
2) Der Versuch, die sprachtheoretischen Überlegungen vor den Wagen angewandt-linguistischer Fragen zu spannen, hat darüber hinaus eine ganz konkrete methodische Konsequenz: Ausgangspunkt der Analyse sind die aus linguistischer Sicht mehr als angreifbaren „Therapien” der Laien-Linguistik, die als wenig zureichende Problemlösungsversuche interpretiert werden. Um aber an die alltagsweltlich grundlegenden Sprach- und Kommunikationsprobleme überhaupt heranzukommen, ist es sinnvoll, diese Therapieversuche selbst zum Gegenstand der Analyse zu machen. Mögen die "Therapien” der Laien-Linguistik auch „schlecht” sein, so eignen sie sich zumindest als methodisches Hilfsmittel zur Entdeckung und damit zur „Diagnose” eben jener alltagsweltlichen Sprachund Kommunikationsprobleme, die das Ziel meiner Überlegungen sind.

2.

Ich komme damit zu meinem ersten Punkt, nämlich zur Rolle normativer Stilistiken und verallgemeinert: zur Rolle der Laien-Linguistik überhaupt. Beginnen möchte ich mit einigen spektakulären Fragen zur öffentlichen Relevanz dieser Art von Sprachthematisierung:

- Welcher Linguist hat es bisher auf eine Auflagenhöhe von knapp einer halben Million bringen können - wie beispielsweise der Sprachamateur Ludwig Reiners mit seiner unverwüstlichen "Stilfibel" (Sanders 1992, S. 119ff.)?

- Welche linguistische Sommerschule könnte pro Tag und Person 200 bis $800 \mathrm{DM}$ problemlos in Rechnung stellen, wie dies bei vielen kommerziellen Rhetorik-Trainings inzwischen ganz selbstverständlich ist?

- Welche sprachwissenschaftliche Monographie würde - was die öffentliche Resonanz betrifft - bei einer Stärke von ca. 2800 Seiten und einer geheim gehaltenen, aber realistisch geschätzten Auflage von dreibis fünftausend verkauften Exemplaren mit Wolfgang Manekellers "Textberater" konkurrieren wollen?

Nun ist zweifellos publizistischer Erfolg noch kein Ausweis für Qualität und schon gar kein Beleg für wissenschaftliche Dignität. Gleichwohl, ignorieren kann man solche Zahlen nicht: Sie könnten ansonsten leicht zum Nachweis verwendet werden, wie groß das Interesse der Öffentlichkeit an sprachlich-kommunikativen Fragen ist und wie sehr die akademische Linguistik diese ignoriert. Und in der Tat: Erlaubt sich nicht weithin die Linguistik den Luxus, auf populärwissenschaftliche Darstellungen und damit auf Transfermöglichkeiten ihrer Arbeit zu verzichten? ${ }^{4}$ Was weiß

4 Eines der wenigen vorzeigbaren Gegenbeispiele ist die von D. Crystal (1987) 
die Linguistik von den vermeintlichen, aber eben auch von den tatsächlichen Bedürfnissen der Öffentlichkeit nach Sprachberatung, -qualifikation und -reflexion?

In diese Lücke stößt nun mit einem zum Teil sehr fragwürdigen Angebot das, was ich "Laien-Linguistik” nenne. "Laien-Linguistik” bezeichnet eine Sprach- und Kommunikationsbetrachtung für Laien und häufig genug auch eine, die von Laien betrieben wird. Der Begriff "Laien-Linguistik" deckt sich dabei in weiten Teilen mit dem, was man "normative” oder „präskriptive Linguistik” nennen könnte. Sie umfaßt aber mehr: deskriptive, enzyklopädisch ausgerichtete und/oder unterhaltende Darstellungen zu sprachlich-kommunikativen Themen oder Problemen. Gerade weil die ehedem normative Sprachbetrachtung im Sinne der Briefsteller oder der Stilfibeln dabei ist, sich zu einer thematisch weitgespannten Sprachthematisierung zu wandeln, die sich heute betont zweckrational-technologisch gibt, erscheint mir eine neue Bezeichnung sinnvoll, ja geboten. Die Laien-Linguistik kann also als eine weitgehend außer-wissenschaftlich geprägte Thematisierung von Sprache und Kommunikation auf dem Weg von einer primär normativ-ästhetischen hin zu einer zweckrational-technologischen Ausrichtung aufgefaßt werden.

Deutlich abzugrenzen ist sie jedoch einerseits von einer didaktischen und andererseits von einer populärwissenschaftlichen Beschäftigung mit Sprache und Kommunikation. Beide zielen letztlich auf Transfer wissenschaftlicher Erkenntnisse. Demgegenüber ist. die Laien-Linguistik eher als eine moderne, d.h. nicht-museale Form der "Volkslinguistik" (Brekle 1985) aufzufassen, was nicht ausschlieBt, daf volkslinguistische Sedimente noch in der Laien-Linguistik zu finden sind. Die "Entzauberung der Welt" (Max Weber) - nicht zuletzt durch die Verwissenschaftlichung des Alltags - hat aber auch das alltagsweltliche Verständnis von Sprache und Kommunikation nicht unberührt gelassen. Insofern gibt es inzwischen durchaus popularisierte wissenschaftliche Erkenntnissplitter und kommunikationspsychologische Theoriesegmente auch in der Laien-Linguistik (z.B. den unverwüstlichen Watzlawick 1969).

Zur „Laien-Linguistik” rechne ich Unterhaltungsliteratur zu Fragen von Dialekt, Standard-, Sonder- und Fachsprachen; Literatur und Trainings zu Themen wie Beraten, Debattieren, Telefonieren oder Gesprächsführung; ferner Rede- und Kommunikationstrainings sowie schließlich die breite Palette sprachlicher Ratgeberliteratur (Gebrauchs-

veröftentlichte „Cambridge Encyclopedia of Language” (Cambridge University Press), die inzwischen auch ins Deutsche übersetzt worden ist. 
grammatiken, Lexika für alle sprachlichen Zweifelsfälle des Lebens, normative Stilfibeln, Populär-Rhetoriken, Korrespondenzhilfen, Ausbildungsliteratur für Redakteure, Werbetexter, Anleitungen zum technischen Schreiben usw.).

Erstaunlich ist nicht nur die thematische Breite, sondern auch der Umfang der Literatur, die heute durch eine unüberschaubar große Zahl von kommerziellen Kommunikationstrainings ergänzt wird. Allein die Bibliographie von Blumenthal (1985), die nur Titel zur mündlichen praktischen Rhetorik erfaBt, und die heute als veraltet gelten kann, zählt ca. $400 \mathrm{Ti}$ tel.

Wichtiger als die Zahl der Titel ist aber ihre linguistische Relevanz: Denn diese so umfangreiche Literatur bildet das gröBte natürliche (d.h. nicht experimentell elizitierte) metasprachliche Corpus. Das heiBt: Nirgends sonst in unserer Gesellschaft gibt es so viele auBer-wissenschaftliche Aussagen über Sprache und Kommunikation wie eben in dieser laienlinguistischen Literatur. Auf diesem Hintergrund muB man sich wundern, daB die Linguistik, - die ja schon lange Sprachthematisierungen unter Begriffen wie Metalinguistik, „linguistic awareness”, SprachbewuBtsein bzw. -bewuBtheit oder sprachliches Wissen bzw. Kompetenz untersucht (Haueis 1989) - daß also die Linguistik diesem Corpus noch kaum Aufmerksamkeit geschenkt hat.

3.

Damit komme ich zu meiner zweiten These und zu der Frage nach einer sprachtheoretischen Begründung des Gegenstandes der Laien-Linguistik. Erinnert sei zunächst nochmals an die These: Für unser differenziertes sprachliches Handeln in arbeitsteiligen Gesellschaften - so der Tenor der These - benötigen wir mehr sprachliches Wissen, als uns - etwa im Sinne der Chomskyschen Universalgrammatik - in die Wiege gelegt wurde.

Was sich daher in Stilistiken, Rhetoriken, Wörterbüchern etc. vordergründig als ein Epiphänomen der Linguistik darstellen mag - nämlich Sprach- und Kommunikationsthematisierungen von Laien - ist ein Reflex auf mehr oder weniger ausgeprägte Fähigkeits- und Optimierungsdefizite im Bereich von Sprache und Kommunikation. Dahinter verbergen sich eine Reihe zentraler sprachtheoretischer Fragen:

- Warum scheint es überall da, wo wir es mit literalen Gesellschaften zu tun haben, Schreib-, Normierungs- und Kontrollhilfen zu geben?

- Stile, Register, Berufs-, Fach- und Sondersprachen spiegeln die sprachlich-kommunikative Differenziertheit und Spezialisierung ge- 
sellschaftlicher Strukturen wider. Wie bewältigen aber Gesellschaftsmitglieder diese „innere Mehrsprachigkeit der Einzelsprache” in ganz praktischer Hinsicht?

- Warum entstehen in allen komplexen, d.h. in varietätenreichen Sprachgemeinschaften Wörterbücher in ihren verschiedenen thematischen Ausprägungen?

- Warum scheint es in allen komplexen Gesellschaften ein gesellschaftliches Bedürfnis nach effizienter Kommunikation zu geben? Warum prägen sich diesbezüglich bestimmte stilistische oder rhetorische Standards aus?

- Wie ist die asymmetrische Sprachbeherrschung, zum Beispiel die offenkundige Differenz zwischen aktivem und passivem Wortschatz, zu erklären?

- Welchen Einfluß haben (Rede-, Sprech- oder Schreib-) Routinen auf die Habitualisierung sprachlicher Handlungen?

- Warum spielt selbst in wenig formalen, spontanen Diskursen das Monitoring bzw. das Repair-Korrekturverhalten angesichts der in der Linguistik üblichen Kompetenzzuschreibungen überhaupt eine so wichtige Rolle?

Auf dem Hintergrund dieser und weiterer Beobachtungen stellt sich die weitergehende Frage, ob es nicht eine Menge sehr allgemeiner Sprachund Kommunikationsprobleme gibt, die womöglich immer und überall dort anzutreffen sind, wo eine Sprache bzw. ein Sprachgebrauch eine spezifische, nämlich elaborierte strukturelle Ausprägung erfährt? Diese in Syntax, Lexik und Stilen elaborierten Ausprägungen sind zwar materialiter immer beeinflußt von zugrundeliegenden sozio-kulturellen Determinanten, jedoch formaliter sprach- und kommunikationsimmanent charakterisierbar. Auffällig ist jedenfalls, daß in vielen, womöglich sogar in allen varietäten- und stilreichen Sprachen Wörterbücher, Gebrauchsgrammatiken, Rhetoriken, Stilistiken, Konversationshilfen etc. existieren. Warum ist dies eigentlich so?

Für den Sprachteilhaber hat die Ausdifferenzierung von varietäten- und stilreichen Einzelsprachen eine doppelte Konsequenz für seine Sprachbeherrschung: Er wird in der Regel weder alle Varietäten, Register und Stile einer Sprache passiv noch alle wichtigen, d.h. alle funktional relevanten Sprachausprägungen aktiv beherrschen können.

Fazit: Es gibt offenkundig sprachlich-kommunikative Unsicherheiten, Lücken und Fehler selbst in der Beherrschung und im Gebrauch der Mut- 
tersprache. Gleichberechtigt hinzutreten können stilistisch-rhetorische, medial bedingte oder standardbezogene Optimierungsbedürfnisse. Offenkundig ist der aktuale und habituelle Gebrauch von Sprache kognitiv und im kommunikativen Handeln weit komplexer, aufwendiger und fehleranfälliger, als dies Vorstellungen von einer bloßen 'Performierung' von 'Kompetenzen' suggerieren. Solche in der Sprachbeherrschung sowie in der produktiven wie rezeptiven Sprachverarbeitung auftretenden kognitiven Unvollkommenheiten ebenso wie Korrektheitsund Optimierungsbedürfnisse möchte ich zusammenfassend „sprachlichkommunikative Imperfektibilität" nennen.

Die Imperfektibilitäts-These besagt also, daB der Begriff des sprachlichen Wissens bzw. des sprachlichen Könnens nicht ohne sein Gegenteil sinnvoll ist - nämlich dem des Nicht-Wissens, des Nicht-Könnens, des Nicht-sicher-Wissens bzw. des Nicht-vollständig-Beherrschens einer Sprache. Die inzwischen inflationierte Redeweise von „Kompetenzen” überstrahlt die schlichte alltagsweltliche Erfahrung, daß auch in der Sprache und Kommunikation Wissen und Können begrenzt sind. Solche „imperfektiblen” kognitiven und handlungsrelevanten Begrenzungen können folgende Ursachen haben:

- Grad der Reifung (z.B. bei der Schreibentwicklung),

- noch unausgebildete kognitive Strukturierungsmuster,

- mangelnde Habitualisierung von Fähigkeiten und Fertigkeiten,

- ungleichzeitige Ausbildung einzelner bereichsspezifischer Wissensmodule,

- Koordinationsprobleme zwischen relevanten Wissensbereichen (Anderson 1988),

- mangelnde Berücksichtigung von sozio-kulturell relevanten Sprachund Kommunikationsanforderungen (z.B. Verständlichkeit, Stiladäquanz etc.).

Diese sicherlich nicht exhaustiven Ursachen verdeutlichen: Die LaienLinguistik ist zweifellos durch sozio-kulturelle, d.h. linguistik-externe Randbedingungen geprägt. Trotzdem spricht vieles dafür, dahinter linguistik-internen Bedingungen Priorität einzuräumen. Der Kernpunkt dieser Betrachtungsweise liegt in der sprachtheoretisch relevanten These, daß unser sprachliches Wissen und Können lückenhaft, unvollständig, ergänzungsbedürftig, kurz: „imperfektibel” ist. Um es im Hinblick auf die uns interessierenden Stilistiken, Rhetoriken usw. auf einen einfachen Nenner zu bringen: Sprachliche Qualifikation über den Grad des 
primären Spracherwerbs hinaus ist erforderlich, weil - anders als die gängigen Kompetenzzuschreibungen suggerieren - selbst Muttersprachler ihre Sprache nicht vollständig und nicht vollkommen beherrschen.

Versucht man die Imperfektibilitäts-These in die sprachtheoretische Diskussion einzuordnen, so ist sie zunächst einmal ein notwendiges begriffliches Korrektiv zu den in der Linguistik üblichen Kompetenzzuschreibungen: „Imperfektibilität” als zusammenfassende Bezeichnung von Kompetenz-Grenzen ist also ein Beitrag zu einer realistischen Modellierung von sprachlichen Fähigkeiten und Fertigkeiten.

Im übrigen bringt die Imperfektibilitäts-These nichts anderes zum Ausdruck als das sprachphilosophische "Prinzip der Ausdrückbarkeit” - nur aus einer dazu komplementären Perspektive: Nach Searle besagt dieses Prinzip, „daB man alles, was man meinen, auch sagen kann” (Searle 1971, S. 34). Das heißt einmal: Ich kann "meine Kenntnis der Sprache erweitern", also meinen faktischen Sprachgebrauch verändern. Zum anderen läßt sich eine gegebene Sprache „durch Einführung neuer Begriffe oder anderer Mittel" stets erweitern. Eine aktuelle oder potentielle Erweiterung einer Sprache bzw. eines Sprachgebrauchs setzt jeweils individuelle oder kollektive Begrenzungen der Sprache und des Sprachgebrauchs voraus. Dies ist ja gerade der Sinn des „Prinzips der Ausdrückbarkeit”. Imperfektibilität ist sowohl das empirische "Unterfutter” als auch logisch die „Bedingung der Möglichkeit” für ein Prinzip, das die „Offenheit” von Sprachen postuliert. Wären wir ausgerechnet im Bereich der Sprache und Kommunikation allwissend und omnipotent, so wäre das „Prinzip der Ausdrückbarkeit” witzlos (und Rhetorik, Stilistik, Soziolinguistik, Rezeptions- und Verständlichkeitsforschung, Sprachdidaktik und manches mehr überflüssig).

4.

Damit komme ich zu meiner dritten These: Normativen Stilistiken und vergleichbarer Literatur liegen alltagsweltliche Sprach- und Kommunikationsprobleme zugrunde, für deren Lösung sie mehr oder weniger gute Vorschläge offerieren!

Nun stellt sich aber die sowohl empirische wie theoretische Kernfrage: Welche alltagsweltlichen Sprach- und Kommunikationsprobleme als unterstellte Manifestationen der Imperfektibilität gibt es überhaupt, und welche sind davon aus der Sicht der Laien relevant?

Zur Beantwortung dieser Frage habe ich etwa 70 Publikationen und zwei Kommunikationstrainings der Laien-Linguistik näher untersucht. Die dahinter stehende Hypothese: Trotz des kaum mehr überschaubaren Um- 
fangs und einer erstaunlichen Vielfalt des laien-linguistischen Angebots liegt die Vermutung nahe, daß die Laien-Linguistik auf relativ wenige, dafür aber sehr allgemeine Sprach- und Kommunikationsproblemtypen zurückzuführen ist. Begünstigt wird diese Annahme durch eine überraschend groBe Repetition der behandelten Themen, Tips und Topoi. Bei einer hinreichend breiten und großen Materialauswahl gängiger Angebote zur Laien-Linguistik, die statistisch als Zufallsauswahl interpretiert werden kann, sollten aufgrund der unterstellten „Wiederkehr des Gleichen" alle relevanten Problemtypen erfaBbar sein. Aus dem untersuchten Material lassen sich die in der Graphik (siehe folgende Seite) dargestellten Problemtypen gleichsam "herausdestillieren”.

Dieser Überblick macht deutlich, daß alltagsweltliche Sprach- und Kommunikationsprobleme sowohl aus $\mathrm{dek}$ la $\mathrm{r}$ a $\mathrm{t}$ i ve $\mathrm{n}$ wie aus prozeduralen Wissensproblemen (z.B.: „Wie soll man konkret planen, formulieren oder redigieren?") bestehen. Dabei zeigt sich eine aufschlußreiche Divergenz: Obwohl es Anhaltspunkte dafür gibt, daß prozedurale Wissensprobleme des Formulierens oder Rezipierens faktisch dominieren, überwiegt in den Darstellungen der Laien-Linguistik die Vermittlung deklarativen Sprachwissens. Der Grund hierfür liegt auf der Hand: Sprachliche Fakten, Regeln, aber auch Normen, DIN-Normen oder Geschmacksurteile zu präsentieren, ist allein schon aufgrund der lokalistischen Struktur ihrer Darstellung her leichter, als exemplarisch Fähigkeitsübungen zu präsentieren. Diese Unterrepräsentation prozeduraler Problemlösungsangebote wird von manchen Stillehrern zwar gesehen, aber bisweilen zu einer Frage nach der "Lehrbarkeit von Stil" umgedeutet. Viel naheliegender wäre es zu konstatieren, daß die Vermittlung prozeduralen Wissens sich sehr viel schwieriger gestaltet als die Vermittlung deklarativen Sprach- und Stilwissens.

Damit komme ich zu den Problemtypen, die sich einem bereichsspezifischen Wissensbereich zuordnen lassen. Herauszuheben sind zunächst die s e mi ot is chen Proble m t y pe n. Vor allem in älteren Stilistiken finden sich Semiotik-Auffassungen, die man mit Brekle (1985) getrost der Volkslinguistik zuschlagen kann:

Unter dem sog. A r b i t ra r i t äts-Problem verstehe ich jene Verunsicherung von sprachwissenschaftlichen Laien, die "Sprache als zweite Natur" mit der Betonung auf "Natur” erleben. Verunsichert werden sie vor allem bei der Konfrontation mit Fremdwörtern und mit der Rechtschreibung. „Die Hochschätzung der geltenden Orthographie als maßlose Überbewertung der sekundären, besonders arbiträren graphischen Repräsentation sprachlicher Ausdrucksformen" (Stickel 1987, S. 312) läßt sich daher als kompensatorischer Versuch der Volkslingui- 


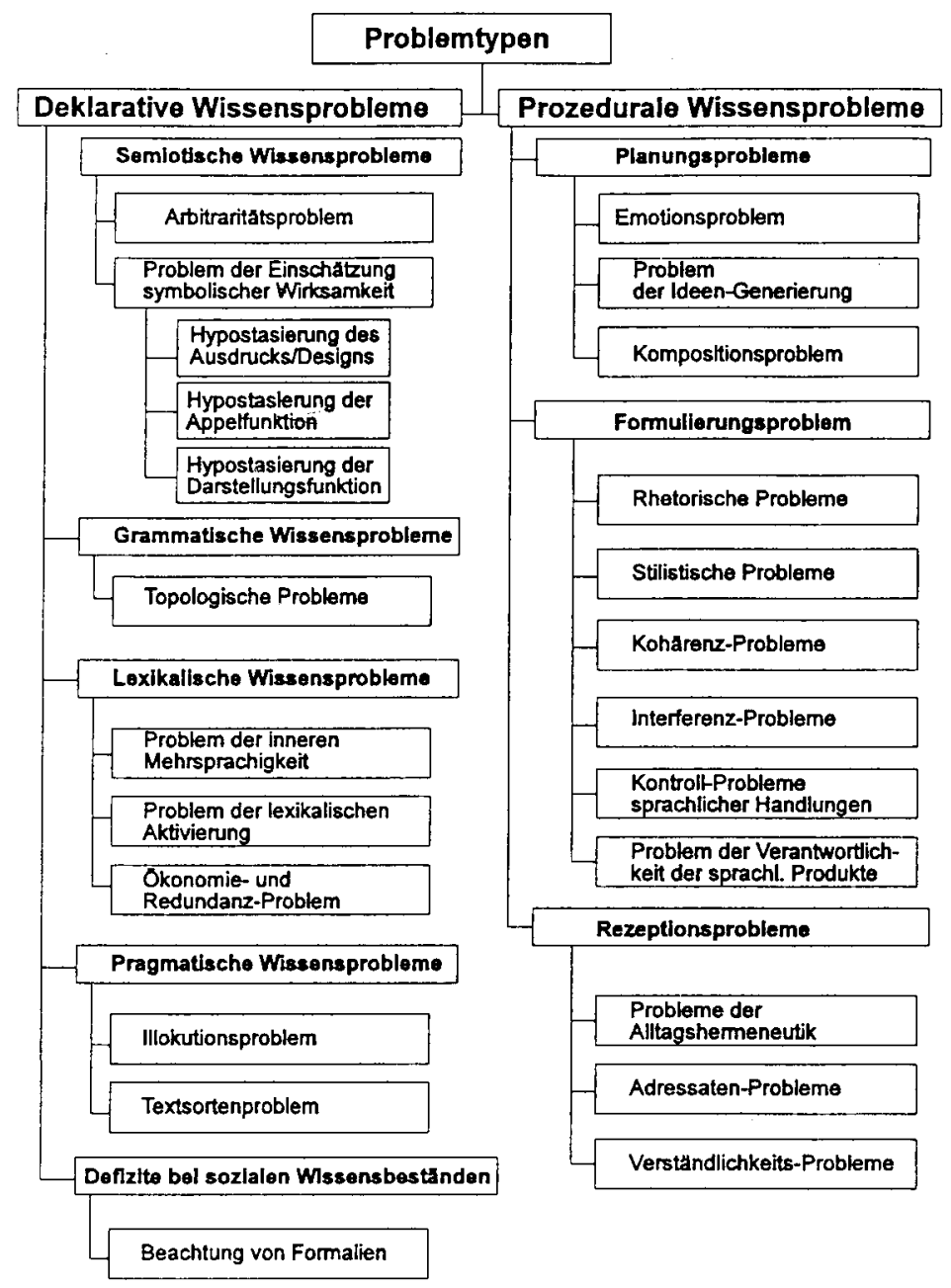

stik erklären, Konventionalität so weit wie möglich zu ignorieren. In der Rechtschreibung führt dies zu einer weithin geschätzten Normrigidität, die die Illusion der scheinbaren Naturhaftigkeit wiederherstellen will. Wo dies nicht möglich scheint - wie etwa beim Fremdwortgebrauch - wird dieser Gebrauch als „unnatürlich” abgelehnt und sanktioniert. 
Naturhafte, genauer: kausale Vorstellungen von der symbolisch begründeten Wirksamkeit von Sprache finden sich ebenfalls als Relikte volkslinguistischer Vorstellung in der untersuchten Literatur. Aus der Überschätzung der körperlichen Präsentation von Sprache in der Rede (man denke an die ziemlich unbegründete verabsolutierende Hochschätzung der sog. Körpersprache in der Laien-Linguistik) einerseits oder aus der Überschätzung von Design-Wirkungen bei Druckerzeugnissen andererseits darf man zum Beispiel auf ein Problem schließen, das ich „H y postasierung des A usdrucks bz. des D e s i g n s" genannt habe. Ohne auf die anderen Teilprobleme näher eingehen zu können (etwa auf Reste magischer Sprachauffassungen) läBt sich das semiotisch zu charakterisierende Wissens-Problem so zusammenfassen: Worauf gründet sich die Wirksamkeit der „Magie und Macht der Sprache"? - so der Untertitel des Buches von Wolf Schneider („Wörter machen Leute”, 1979).

Auf den Bereich der gram mat is chen $\mathrm{W}$ is sens p roble$m$ e möchte ich nur einen flüchtigen Blick werfen. Auffällig ist aber, daß die Laien-Linguistik die Beherrschung der Syntax als unproblematisch unterstellt und - wenn überhaupt - nur in to p o log i s c h e n $S$ t r u k t u r e n Fehlerquellen (Wortstellungs-, Kongruenz- und Skopusfehler) entdeckt und diese als "falsche Bezüge" diskutiert. Vertreter von Chomskys Sprachtheorie werden mit diesem Ergebnis ebenso wenig Schwierigkeiten haben wie mit der sich daran gleichsam kontrastierenden Erkenntnis, daß in der gesamten laien-linguistischen Literatur lexikalische Wissensprobleme eine herausragende Rolle spielen. Das betrifft einmal die Aneignung und den Gebrauch von Wortschätzen, die sich in stilistischer, regionaler und/oder funktionaler Hinsicht unterscheiden und in ihrer Gesamtheit das repräsentieren, was man das "Problem der in eren Mehrsprachigkeit” nennen könnte.

Weil lexikalisches Wissen aufgrund seiner varietätenspezifischen Differenziertheit schwer überschaubar, teilweise außerordentlich umfangreich und daher mnemotechnisch anspruchsvoll ist, muß ferner das Problem der lexikalischen Aktivierung vorgesehen werden. Retrieval- und Aktivierungshilfen in Form verschiedenartigster Wörterbücher für varietätenreiche Sprachen sind Indizien und zugleich Lösungsangebote für dieses Problem.

Aus Platzgründen überspringe ich ein Problem, dem normative Stilistiken einen unverhältnismäßig breiten Raum einräumen. Es handelt sich um Kritik an angeblicher, falsch verstandener Sprachökonomie und falsch gebrauchter Redundanz: Die Ök o n o mi ekritik entzündet 
sich an Abkürzungen, Univerbierungen und an verkürzenden Bezeichnungen (wie z.B. die unvermeidliche "Reitende Artilleriekaserne"). Komplementär dazu gibt es auch eine $R$ ed undanz-Kritik wofür ebenso regelmäBige Beispiele wie „Zusammenaddieren” oder „Attentatsversuch" herhalten müssen. ${ }^{5}$

In der laien-linguistischen Literatur lassen sich ferner zwei nach Bedeutung und Umfang recht unterschiedliche prag mat is $\mathrm{ch}$ e Wiss e n s - P r o b l e me unterscheiden:

1) I 11 ok u t i ons - P r o b l e me: Wie bei der Ökonomie- bzw. Redundanzkritik werden - aber diesmal nicht nur auf lexikalischer Ebene - einerseits sog. „Vorreiter” („Hierzu nehme ich wie folgt Stellung") als überflüssig kritisiert. Andererseits wird - etwa bei Mahnschreiben oder bei der Beantwortung von Reklamationen - darauf hingewiesen, daB die situationsangemessene Deklaration von Illokutionen ( "Hinweisen”, „Bitten”, „Entschuldigen”) in bestimmten Schreibkontexten empfehlenswert bis unabdingbar sei. Entsprechendes gelte auch für die Bekundung innerer Einstellungen wie Freude, Lob, Betroffenheit etc. bei (Mitarbeiter-)Gesprächen, die ich hier ebenfalls den „lllokutionsProblemen" zuordnen möchte. Der Grund hierfür: Die situationsgerechte Deklaration von Sprechakten ebenso wie die inneren Einstellungen ist offenkundig für viele keineswegs unproblematisch, sondern ein Quell von Unsicherheit im Sprachgebrauch.

2) Das zentrale pragmatis che Wissens-Problem ist aber zweifelos das $\mathrm{T}$ e $\mathrm{xt}$ s or t e $\mathrm{n}-\mathrm{P} \mathrm{r}$ ob l e m: Es entsteht aus mangelnder Kenntnis bzw. Beherrschung von Gebrauchs-Textsorten. Um die Bedeutung dieses Problems zu verdeutlichen nur zwei Zahlen: Im „Textberater” von Wolfgang Manekeller werden sage und schreibe 28 Typen von Musterreden und gar 192 (!) Typen von Musterbriefen unterschieden und überraschend umfangreich exemplifiziert. Dieser Aufwand ist ein deutlicher Beleg dafür, daß Textsorten, sowohl was ihre Häufigkeit als auch ihre formalen Unterschiede betriftt, Sprachteilhaber - insbesondere bei der Rede- oder Textproduktion - vor nicht geringe Probleme stellt.

Hingegen nicht überraschen dürfte in Stilistiken die breite Behandlung von Formalien, die ich dem Problemtyp „D ef i z i te be i s o z i ale n W is se ns bestä nde n" zuschlage. Hierzu zählt die vor al-

5 Es ist nicht ganz klar, ob dahinter beispielsweise Probleme mit mangelnder bzw. wortwörtlich interpretierter lexikalischer Durchsichtigkeit stehen, ob Maßstäbe der Logik an Erscheinungen der Sprache angelegt werden oder ob dies nichts anderes als eine Spielart des Sprachpurismus ist. 
lem aus Briefstellern bekannte, geradezu peinliche Beachtung von Titeln und Anredeformen. Wo früher die Demonstration sozialer, insbesondere aber hierarchischer Distinktion im Vordergrund stand, geht es heute um die bürokratisch korrekte Einhaltung von Schreibregeln, wie sie beispielsweise in der DIN-Norm 5008 ("Regeln für Maschinenschreiben”) zum Ausdruck kommt. In vielen neueren Briefstellern wird darüber hinaus wenn auch implizit - die Verdeutlichung sozialer Ordnung thematisiert. Nicht zuletzt mit Blick auf das Telefon geht es beispielsweise um die Frage des angemessenen Gebrauchs von Mündlichkeit und Schriftlichkeit: „Wer schreibt wann und zu welchem Anlaß”.

Damit komme ich gleich zu den prozed u rale $n$ Wis se n sp roblemen: Auf die in Stilistiken weithin unterschlagene Bedeutung dieser Probleme habe ich schon verwiesen. Wenn man die Problemtypen überfliegt, wird sich mancher an die Schreibforschung erinnert fühlen, die sich in dem letzten Jahrzehnt vorrangig mit Planungs-, Formulierungs- und Rezeptionsp r o b l e m e n (Antos/Krings 1989, Eigler et al. 1990, Krings/Antos 1992) beschäftigt hat. Da sich eine ausführlichere Beschreibung dieser prozeduralen Problemtypen in Antos (1994) findet, beschränke ich mich hier nur auf die erläuterungsbedürftigen Problemtypen:

Unter P I a n u $\mathrm{ng} s-\mathrm{P}$ r ob le me n fallt das sog. E motion s$\mathrm{Pr}$ o b le $\mathrm{m}$ ins Auge. Der richtige Umgang mit der eigenen und der Emotionalität des/der Adressaten erweist sich in der laien-linguistischen Literatur als ein doppelt aspektualisiertes Problem: Einerseits stelit sich für Schreiber das Problem der "Desymptomatisierung von Emotionen” im Sinne von Augst/Faigel (1986). Andererseits sollen sie - gemäß den einschlägigen Stilfibeln - „kein Papierdeutsch” produzieren. Diese medial bedingte Domestizierung bei gleichzeitiger Transformierung von Emotionalität ist in Stilistiken der Hintergrund für eine ganze Reihe von (oft hilflos erscheinenden) Regeln.

Im Vordergrund von $\mathrm{Plan}$ u $\mathrm{ngs}-\mathrm{P}$ r o b l e me $\mathrm{n}$ steht aber das Problem der Generierung von Ideen sowie das Problem der textuellen Komposition. Unter den Hilfsmitteln zur Ideen-Generierung finden sich aus der Rhetoriktradition her vertraute Topoi- und Zitatensammlungen ebenso wie (angeblich aus der "modernen Gehirnforschung” entstammende) "Brainstorming"-Methoden, die etwa über eine Vernetzung assoziativ gewonnener thematischer Schlüsselwörter das „kreative Schreiben” befördern sollen. Wie immer man diese Versuche auch einschätzen mag: Offenbar brauchen Leute eine besondere Hilfestellung beim Auffinden, Entwickeln und Strukturieren von Ideen. Entsprechendes gilt 
für das Gelingen textueller Komposition, etwa in Form von Gliederungsvorschriften (bei der Argumentation z.B. der sog. „Fünfsatz”) und Vertextungsempfehlungen. Ein sehr probates Mittel, um diese Komposition s-Probleme für Schreiber zu lösen, sind bekanntlich die umfangreichen Text- und Redemustersammlungen in Briefstellern und Korrespondenzhilfen. Sie werden heute in der modernen Bürokommunikation durch die Entwicklung und den Einsatz sog. „Textbausteine” ergänzt bis verdrängt. Auf die sich daraus ergebenden, vielfältigen Problemen (z.B. Transferfragen bei der Komposition never Texte oder Kohärenz-Probleme zwischen Textbausteinen) kann hier nicht weiter eingegangen werden.

Bei den "Formulierungs-Problemen" stehen in der laien-linguistischen Literatur naturgemäß die $r$ h e tor is che $n, s$ tilis $t$ is $c h$ en und die bereits erwähnten Kohärenz-Probleme im Vordergrund. Da sie weitgehend den in der Linguistk problematisierten Fragen entsprechen, können sie hier unkommentiert bleiben. Anders sieht es mit den restlichen drei Problemfeldern aus: In Stilistiken wird den Benutzern traditionell unter der Behandlung von sog. „Stilblüten” das I $n$ t e r f e r e n z-P r ob l e m bewußt gemacht. Stilbrüche sind aber nur e in Fall von sprachlichen Koordinationsproblemen, deren mangelnde Bewältigung zu unakzeptablen Interferenzen führt. Behandelt werden auch Fälle von Vermischungen zwischen Mündlich- und Schriftlichkeit.

Kont roll-Probleme sprachlicher Handl u $\mathrm{n} g$ e $\mathrm{n}$ : Laien beherrscht offenkundig die Sorge, daß sie sich beim Reden und Schreiben durch „unvorsichtige Formulierungen” und durch dialektale, idiosynkratische etc. Eigenheiten „verraten”. Deshalb unterstellen sie einen kausalen Zusammenhang zwischen Produkten sprachlichen Handelns und bestimmten (vorzugsweise charakterlichen) Eigenschaften des Sprechers/Schreibers. Das heißt: In der Laien-Linguistik ist ein "Primat des symptomatischen Charakters von Kommunikation" unverkennbar. Dies führt zu dem unrealistischen Wunsch nach womöglich perfekter Kontrolliertheit des eigenen Handelns. Ein nicht unbeträchtlicher Teil der Laien-Linguistik (Rhetoriktrainings, Seminare zur Körpersprache, Bewerbungsliteratur etc.) widmet sich (nicht immer seriösen) Anleitungen zur Effektivierung der eigenen Kontrolliertheit.

Der rationale Kern der geschilderten Sorge liegt jedoch in dem Problem der Verantwortlichkeit für eigene s p r a c h li ch e Prod u k t e. Dahinter verbirgt sich die schlichte Tatsache, daß wir für unsere Formulierungen verantwortlich gemacht werden können (Antos 1982). 
Den Formulierungs-Problem e n bei Sprecher/Schreiber entsprechen $R$ e z e t i o n s-P r o b l e m e bei Adressaten. In der Laien-Linguistik treten drei Problem-Typen in den Vordergrund: Laien scheinen das zu haben, was man P r ob le me de r Allt a g s - H e rm e n e u t i k nennen könnte. Dabei geht es um die Frage: „Wo liegen die 'wahren' Absichten des Sprechers/Schreibers?”. Dahinter steht der nicht unproblematische Wunsch vieler Laien, „den anderen durchschauen zu wollen".

Unter Ad ress a t e n - P r o b l e m e $n$ lassen sich in der LaienLinguistik Ratschläge zusammfassen, die einen Perspektivenwechsel vom "Ich" zum „Du” (et vice versa) sowohl aus der Produktions- wie Rezeptionsperspektive problematisieren (wobei Produzenten auch immer ihre ersten Rezipienten sind. Daß trotz der Wechselseitigkeit von kommunikativen Perspektiven und Positionen ein (kulturell, historisch, sozial oder individuell begründeter) Rest an kommunikativer Fremdheit verbleibt, ist ein wenig offensichtliches, aber konstantes Thema der LaienLinguistik.

Zum Verständlichkeits-Problem braucht es-angesichts der großen Publizität dieses Problems - keine weitere Erläuterung. Aus linguistischer Perspekive allenfalls interessant ist die bisher unbeantwortete Frage, warum so unverwüstliche Empfehlungen von Stilfibeln wie "Kurze Sätze” nicht zu dem als selbstverständlich unterstellten Effekt geführt haben.

\section{5.}

Ich komme zum vorletzten Punkt und damit zu der Frage nach einer sprachtheoretischen Verankerung der analysierten Problemtypen. Zugespitzt: Gibt es Prinzipien, die diese sehr verschiedenartigen alltagsweltlichen Sprach- und Kommunikationsprobleme begründen oder gar erklären können? Von dieser Frage abzutrennen sind dabei die beiden semiotischen Problemtypen ebenso wie der Typ "Defizite bei sozialen Wissensbeständen", die eine Sonderrolle zu spielen scheinen: Im ersten Fall könnte man geneigt sein, diesen Typen aus linguistischer Sicht die Beurteilung „vermeintliche Probleme" zuordnen, wobei sich aber der Nachweis der "Vermeintlichkeit" nicht einfach gestalten dürfte. Bei den Defiziten im Hinblick auf externe soziale Normen des Redens und Schreibens ist zumindest klar, daß hier keine sprachtheoretischen Prinzipien wirksam sein können.

Die anderen Problemtypen lassen sich hingegen unter übergreifenden Aspekten zusammenfassen und als Manifestationsweisen der Imperfekti- 
bilitäts-These verankern. Meine Hypothese ist, daß sich die zur Diskussion stehenden Sprach- und Kommunikationsprobleme auf eine Reihe grundlegender Asymmetrien der folgenden Art zurückführen lassen:

Asymmetrien der Textproduktion und -rezeption

1. Asymmetrie zwischen der Anreicherung sprachlich-kommunikativen Wissens in einer (varietäten-reichen) Sprachgemeinschaft und ihrer individuellen Beherrschung ("Langue-Parole"-Differenz)

2. Mediale Asymmetrie ("Prinzip der medialen Differenz”)

3. Asymmetrie zwischen sprachlichem Wissen und Können (Differenz zwischen passiver und aktiver Sprachbeherrschung)

4. Asymmetrie zwischen Produktion und Rezeption (Differenzen im temporalen und kognitiven Aufwand)

5. Asymmetrie zwischen Intention und Verbalisierung ( Meinen-Sagen"Differenz)

6. Asymmetrie zwischen Verbalisierung und Rezeption („Sagen-Verstehen"-Differenz)

7. Asymmetrie zwischen faktischem Sprachgebrauch und sprachreflexiver Bewußtheit über Sprache (Differenz zwischen Sprachgebrauch und Sprachreflexion z.B. in Form der „Regel-Norm”-Differenz)

Die meisten dieser Asymmetrien dürften nicht unbekannt sein. Neu ist allenfalls die durch die Auflistung bewirkte Massierung, die den systematischen Charakter dieser Asymmetrien verdeutlichen soll. Zunächst aber eine kurze Erläuterung dieser Asymmetrien:

1. Asymmetrie zwischen der Anreicherung sprachlich-kommunikativen Wissens in einer (varietätenreichen) Sprachgemeinschaft und ihrer individuellen Beherrschung ( LLangue-Parole”-Differenz)

Diese Asymmetrie liegt auf dem Schnittpunkt des HeterogenitätsPrinzips von Sprachen im Sinne Labovs und der Langue-ParoleDichotomie Saussures. Je varietätenreicher eine komplexe Sprachgemeinschaft wird, um so heterogener wird sie - wie schon hervorgehoben - bezüglich Stilen, Registern und Varietäten. Zugleich verschärft sich damit das Problem einer umfassenden, interferenzfreien und adäquaten Realisierung sprachlicher Systemkonglomerate im Sinne der Parole. Hinzu kommen individuelle Schwierigkeiten, die aus dem Problem der medialen Differenzierung der Sprache rühren. Dies führt zur zweiten Asymmetrie: 


\section{2. "Mediale Asymmetrie”}

In der Mündlichkeit-Schriftlichkeits-Debatte der letzten 15 Jahre ist gezeigt worden, daB die beiden Medien weder strukturell noch funktional äquivalent sind, sondern spezifische Wirkungen in den diversen Kommunikationsformen evozieren.

Auf dem Hintergrund dieser beiden soziolinguistischen gewinnen nun die folgenden fünf psycholinguistischen Asymmetrien ihre besondere Brisanz:

3. Asymmetrie zwischen sprachlichem Wissen und Können (Differenz zwischen passiver und aktiver Sprachbeherrschung)

Diese dritte Asymmetrie ist kognitionswissenschaftlich trivial: Wir wissen passiv immer mehr als wir aktiv können. Wenn der Vergleich mit der Musik erlaubt ist, so könnte man sagen: Man kann die letzten SchubertSonaten sehr wohl kennen (übrigens ohne explizite Kenntnis der Noten), ohne die Sonaten aktiv spielen zu können. Durchaus Vergleichbares zeigt sich z.B. in der Phonetik bei Nachsprechtests, im Wortschatzgebrauch, im Bereich der Syntax, was stilistische und rhetorische Fähigkeiten angeht, oder bei der Textkomposition. Diese Differenz von aktiver und passiver Beherrschung eines Handlungsmusters betriftt sowohl deklarative Wissensbestände, also etwa den Umfang des aktiven und passiven Wortschatzes, als auch der prozeduralen Fähigkeiten der Sprach- und Informationsverarbeitung. Damit leite ich zur vierten Asymmetrie über:

4. Asymmetrie zwischen Produktion und Rezeption (Differenz im temporalen und kognitiven Aufwand zwischen Produktion und Rezeption)

Das heiBt, der zeitliche und damit auch der kognitive Aufwand bei der Produktion übersteigt denjenigen der Rezeption. Besonders ausgeprägt ist dies bei Varietäten, die wir nur unvollkommen beherrschen und natürlich bei vielen Formen schriftlicher Kommunikation.

5. Asymmetrie zwischen Intention und Verbalisierung („Meinen-Sagen”Differenz)

6. Asymmetrie zwischen Verbalisierung und Rezeption („Sagen-Verstehen"-Differenz)

Für diese beiden Asymmetrien verweise ich auf die IntentionalitätsDiskussion in der "Intentionalistischen Semantik" (Harras 1983) und erläutere ansonsten die beiden Asymmetrien in den Worten von Johannes Engelkamp, der lapidar feststellt: „In der Regel wird weniger gesagt, als mitgeteilt wird; und auf der anderen Seite, es wird mehr verstanden, 
als gesagt wird" (Engelkamp 1976, S. 44). Diese doppelte Differenz wird in aller Schärfe erst seit gut anderthalb Jahrzehnten gesehen und hat Ansätze zur Sprach- und Textproduktion ebenso beflügelt wie Analysen der rezeptiven Sprachverarbeitung. Eine Konsequenz der Differenz zwischen Meinen und Sagen habe ich vor Jahren auf die Formel „Formulieren als Problemlösen" (Antos 1982) gebracht und diese in ihren Implikationen näher spezifiziert. SchlieBlich noch die siebte Asymmetrie:

7. Asymmetrie zwischen faktischem Sprachgebrauch und sprachreflexiver Bewußtheit über Sprache (Differenz zwischen Sprachgebrauch und Sprachreflexion z.B. in Form der "Regel-Norm”-Differenz)

Auch diese Symmetrie zwischen faktischem Handeln und der reflexiven Beurteilung eben dieses Handelns ist aus dem Alltag, aber natürlich auch in der Psychologie seit langem bekannt. So als Kritiker-Privileg bei der Beurteilung fremden Handelns (Man kann sehr wohl eine fremde Handlung oder ein Handlungsprodukt kritisch beurteilen, ohne selber in der Lage sein zu können, diese Handlung zu vollziehen) und als Selbsttäuschung bei der Beurteilung eigenen Handelns. Eine linguistische Spielart davon ist die Regel-Norm-Differenz: Der faktische Sprachgebrauch eines Sprechers muB sich bekanntlich nicht mit z.B. seinen Grammatikalitätsurteilen oder Stil-Idealen decken.

Diese sieben Asymmetrien scheinen nun eine entscheidende Rolle bei der Erklärung von alltagsweltlichen Sprach- und Kommunikationsproblemen zu spielen. Unklar bleibt aber der Status dieser Asymmetrien einerseits und ihr Bezug zu den einzelnen Problemtypen. Wie immer man beides bestimmen mag: Zumindest die Postulierung solcher Asymmetrien scheint begrifflich notwendig zu sein: Denn die Definition des Problembegrifts in der Kognitionspsychologie hängt entscheidend davon $a b, d a ß z u$ überwindende „Barrieren” bei dem Übergang von einem „Anfangszustand A" zu einem „intendierten Endzustand B" vorausgesetzt werden müssen (Antos 1982). Diese Asymmetrien bieten sich nun einzeln und in spezifischen Kombinationen als „Barrieren” im Sinne von Problemlösetheorien an, die wir beim Kommunizieren, insbesondere beim Formulieren und Rezipieren überwinden müssen.

Damit stellt sich nochmals die Frage nach dem Status dieser Asymmetrien: Sicherlich fällt es schwer, sie als sprachliche oder kommunikative Prinzipien - etwa im Sinne Chomskyscher universalgrammatischer Prinzipien oder im Sinne von Grice'schen Maximen - zu verstehen. Anders sieht es aus, wenn man sie auf der Folie der cognitive sciences als fundamentale Prinzipien der Sprachverarbeitung bzw. der Prozessierung kommunikativer Akte versteht. 
Meine These ist, sie als Constraints, als globale Beschränkungen der sprachlichen Verarbeitung bei der Produktion und Rezeption zu betrachten. Je nach kommunikationsspezifischen Randbedingungen können die soziolinguistisch definierbaren Anforderungen oder die psycholinguistisch definierbaren Asymmetrien den Charakter der Beschränkung bestimmen. Es ist dabei das Zusammenspiel aus kommunikationsspezifischen Anforderungen (z.B. situative, mediale, stilistische, rhetorische Standards) einerseits und individuellen Sprachfähigkeiten und -fertigkeiten andererseits, das die Grenzen der Prozessierung von Wissen und Können bei der Textproduktion und -rezeption deutlich werden läßt. Wichtig ist aber, gleichsam hinter den individuellen Beschränkungen die sie bedingenden Asymmetrien nicht zu vergessen. Insofern sind die bei der Sprachproduktion und -rezeption auftretenden aktualen wie habituellen „Schwierigkeiten" keine „Privatsache” des einzelnen Sprachteilhabers, sondern Ausdruck der bei der Produktion und der Rezeption auftretenden (allgemeinen kognitiven) Probleme.

Die genannten Asymmetrien, als fundamentale Constraints der Sprachverarbeitung, sind zugleich vorzeigbare Kandidaten für eine Operationalisierung der Imperfektibilitäts-These. Die Asymmetrien in ihrem durch die Imperfektibilitäts-These definierten Status machen deutlich, daß Probleme bei der Sprachbeherrschung nicht nur als individuelle Schwierigkeiten abzubuchen sind, sondern primär Konsequenz jenes Typs von Informationsverarbeitung sind, der ein Problemlösen im Sinne der Kognitionspsychologie erfordert.

6.

Ich komme zum SchluB: Normative Stilistiken als Prototypen der laien-linguistischen Literatur mögen als Therapien unserer sprachlichkommunikativen Imperfektibilität nicht viel taugen. Als Tableau zur Diagnose alltagsweltlicher Probleme im Bereich von Sprache und Kommunikation sind sie jedoch alles andere als triviale Phänomene. Von den Besonderheiten der semiotischen und sozialen Problemtypen einmal abgesehen, lassen sich die meisten Problemtypen auf grundlegende Asymmetrien zurückführen, die ihrerseits als Constraints der Sprachverarbeitung $\mathrm{zu}$ verstehen sind.

Diese Bestimmung führt zur Ausgangsfrage zurück: „Warum gibt es normative Stilistiken?" Die zusammenfassende Antwort: Weil wir bei der Sprach- und Textproduktion aktuale und habituelle Formulierungsund Rezeptionsprobleme zu lösen haben, die sich zwar als individuelle Schwierigkeiten manifestieren können, aber im Kern Konsequenzen von 
Wissens- und Fertigkeitsbeschränkungen sowohl in deklarativer wie prozeduraler Hinsicht sind.

Angebote zur Laien-Linguistik können für eine Sprachwissenschaft, die sich sprachlich-kommunikativen Bedürfnissen von Menschen nicht verschlieBt, als Herausforderung verstanden werden, mit einer eingehenden Diagnose der zugrundeliegenden Probleme zu beginnen, um darauf aufbauend Vorschläge zu einer verbesserten Therapie zu erarbeiten.

Vielleicht ändert sich dann auch bei Stilistiken (im engen und weiten Sinn) die Einstellung der Öffentlichkeit gegenüber der modernen Linguistik. Warum sollte es nicht zukünftig heißen: „Sie sind in ihrem Fache nicht nur zu allem fähig, sondern zu manchem sogar zu gebrauchen!"

\section{Literatur:}

Anderson, J.R. (1988): Kognitive Psychologie: eine Einführung. Heidelberg.

Antos, G. (1982): Grundlagen einer Theorie des Formulierens. Textherstellung in geschriebener und gesprochener Sprache. Tübingen.

Antos, G. (1994): Laien-Linguistik. Studien zu Sprach- und Kommunikationsproblemen im Alltag. Am Beispiel von Sprachratgebern und Kommunikationstrainings. Tübingen.

Antos, G./Krings, H. P. (1989): Textproduktion. Ein interdisziplinārer Forschungsüberblick. Tübingen.

Augst, G./Faigel, P. (1986): Von der Reihung zur Gestaltung. Untersuchungen zur Ontogenese der schriftsprachlichen Fähigkeiten von 13-23 Jahren. Frankfurt/Bern/New York.

Blumenthal, A. (1985): Anleitungen zur Gestaltung von Rede und Gespräch Auswahlbibliographie zur praktischen Rhetorik. In: Bausch K.H./ Grosse, S. (Hg.): Praktische Rhetorik. Beiträge zu ihrer Funktion in der Aus- und Fortbildung. Auswahlbibliographie. Mannheim. S. 188-254.

Bōhme, G. et al. (1973): Die Finalisierung der Wissenschaft. In: Zeitschrift für Soziologie 2, S. 128-144.

Brekle, H.E. (1985): „Volkslinguistik” : ein Gegenstand der Sprachwissenschaft bzw. ihrer Historiographie? In: Januschek, F. (Hg.): Politische Sprachwissenschaft: Zur Analyse von Sprache als kulturelle Praxis. Opladen. S. 145156.

Chomsky, N. (1986): Knowledge of Language: Its Nature, Origin, and Use. New York.

Eigler, G./Jechle, T./Merziger, G./Winter, A. (1990): Wissen und Textproduzieren. Tübingen.

Engelkamp, J. (1976): Satz und Bedeutung. Stuttgart.

Harras, G. (1983): Handlungssprache und Sprechhandlung. Eine Einführung in die handlungstheoretischen Grundlagen. Berlin. 
Haueis, E. (Hg.) (1989): Sprachbewußtheit und Schulgrammatik. (= Osnabrücker Beiträge zur Sprachtheorie 40).

Hirsch, E. Ch. (1976): Deutsch für Besserwisser. München.

Krings, H.P./Antos, G. (1992) (Hg.): Textproduktion. Neue Wege der Forschung. Trier.

Lorenzen, P./Schwemmer, O. (1973): Konstruktive Logik, Ethik und Wissenschaftstheorie. Mannheim/Wien/Zürich.

Manekeller, W. (1984): Der Textberater. Ratgeber für die Textarbeit. Formulierungshilfen und Mustertexte für die Rede und Schreibpraxis. Freiburg.

Martinet, A. (1963): Grundzüge der Allgemeinen Sprachwissenschaft. Stuttgart.

Piatelli-Palmarini, M. (1980): Language and Learning: The Debatte Between Jean Piaget and Noam Chomsky. Cambridge.

Reiners, L. (1963): Stilfibel. München. (1. Aufl. 1951).

Sanders, W. (1992): Sprachkritikastereien und was der „Fachler” dazu sagt. Darmstadt.

Searle, J. (1971): Sprechakte. Ein sprachphilosophischer Essay. Frankfurt.

Frankfurt. Schneider, W. (1979): Wörter machen Leute. Magie und Macht der Sprache. Reinbek.

Stickel, G. (1987): Was halten Sie vom heutigen Deutsch? - Ergebnisse einer Zeitungsumfrage. In: Wimmer, R. (Hg.): Sprachtheorie. Der Sprachbegriff in Wissenschaft und Alltag. Düsseldorf.

Watzlawick, P. et alii (1969): Menschliche Kornmunikation. Formen, Störungen, Paradoxien. Bern/Stuttgart/Wien. 


\section{Aufgaben einer modernen Stilistik}

Vier Statements von

\author{
Birgit Stolt (Stockholm) \\ Willy Sanders (Bern) \\ Ulla Fix (Leipzig) \\ Hans Bickes (Darmstadt)
}

\author{
Moderation und \\ Redaktion der \\ abschließenden \\ Plenardiskussion
}

Siegfried Grosse (Bochum)

\section{SIEGFRIED GROSSE}

Meine Damen und Herren,

Im Unterschied zu früheren Jahrestagungen schließen wir diesmal nicht mit einem resümierenden Referat, sondern mit einem Podium, dessen Teilnehmer in kurzen Statements ihre Sicht einer modernen Stilistik umreißen werden. Die Damen und Herren des Podiums haben vor der Tagung ihre Positionen gegeneinander abgesteckt und dankenswerterweise in Mannheim die Ergebnisse der Tagungsreferate berücksichtigt, also ihre Statements umgeschrieben und aktualisiert. Im Anschluß an die vier Kurzreferate bitten wir Sie um Ihre Teilnahme an der Diskussion. 


\section{Kommunikative Stilanalyse}

1. Die Stilistik war viele Jahre ein Stiefkind der Sprachwissenschaft. Gründe dafür sind leicht zu finden: ihre Position zwischen Sprach- und Literaturwissenschaft; die Auffassung, Stil sei eine ausschließlich ästhetische Dimension, die es mehr mit gutem Geschmack als mit Wissenschaft zu tun habe, Formsache gewisser Beliebigkeit im Gegensatz zum allein wichtigen Inhalt. In den siebziger Jahren kamen dazu Aversionen gegen "herrschende Stilnormen, die die Normen der Herrschenden sind" und als „unsozial” erschienen. ${ }^{1}$ Es bestand ein Widerspruch zwischen Sprachpflegern einerseits, die für "Stilnormen” plädierten, und Wissenschaftlern andererseits, die Stilmittel als "Abweichung von der Norm” definierten - wobei die Crux stets das Erfassen und Beschreiben der jeweiligen „Norm” ausmachte. ${ }^{2}$

2. Die kommunikative bzw. pragmatische Wende in der Sprachwissenschaft der letzten Jahrzehnte hat demgegenüber eine neue Sicht ermöglicht. Im Zusammenhang mit der Lehre von einem "sprachlichen Handlungsspiel" ist der Funktion des Stils neue Aufmerksamkeit und neues Verständnis erwachsen, was eine Neuerfassung des gesamten Stilkomplexes erzwingt.

3. Im folgenden wird „Stil” aufgefaßt als ein System von Möglichkeiten innerhalb eines gesellschaftlich bedingten Rahmens. Der vom Individuum realisierte Stil ist eine Funktion von Konformismus und Originalität. Im Blickpunkt stehen mithin nicht „Abweichungen von einer (wie auch immer beschaffenen) Norm", sondern steht die Kombination von obligatorischen und fakultativen Elementen.

4. Ich konzentriere mich im folgenden auf die Rolle des Stils im Verstehensprozeß (kommunikative Stilanalyse). Der Sender gibt mit

1 Vgl. z.B. Nikisch, Reinhard M.G. (1975): Gutes Deutsch? Kritische Studien zu den maßgeblichen praktischen Stillehren der deutschen Gegenwartssprache. Göttingen, S. 93ff., S. 106f., S. 141.

2 Zur Sprachnorm-Diskussion s. Mogge, Brigitta (Hg.) (1988): Die Sprachnorm-Diskussion in Presse, Hörfunk und Fernsehen. Stuttgart. (= Der Öffentliche Sprachgebrauch Bd. I). Rez. v. B. Stolt in Moderna språk 1981, S. 87-91. 
dem "Stil” dem Empfanger zu verstehen, wie der Text aufgefaßt werden soll. „Verstehen passiert uns” (Püschel) - aber leider: auch falsch Verstehen kommt häufig vor. Mit „uns" meine ich den Durchschnittsmenschen, dem kein Wiederlesen gebräuchlich und kein $\mathrm{Ab}$ arbeiten von Merksätzen - wie während der Tagung demonstriert möglich ist.

5. Welche Funktionen im „sprachlichen Handlungsspiel” sind im Verstehensproze $B$ ausschlaggebend?

Ich gehe das Risko ein, offene Türen einzuschlagen und nehme eine Einordnung von „Stil” in das bekannte "Organonmodell der Sprache" von Karl Bühler vor ${ }^{3}$ (Fig.).

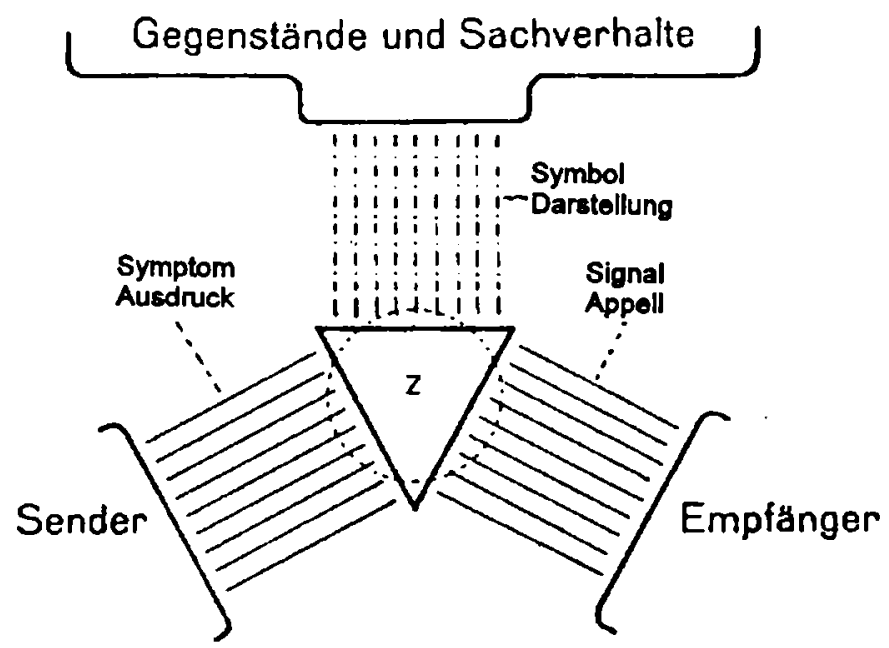

${ }^{3}$ Bühler, Karl (1934): Sprachtheorie. Die Darstellungsfunktion der Sprache. Jena. Neudruck mit einem Geleitwort von Friedrich Kainz. Stuttgart/New York. 1982. S. 28f. (UTB 1159). 
Stil leistet in diesem Modell auf den Sender und den Empfänger bezogene Funktionen von "Ausdruck" und „Appell”; der "Ausdruck” ist ein "Symptom" für die Einstellung des Senders, der "Appell” ein „Signal” an den Hörer/Leser. Während der denotative Inhalt des Textes vorwiegend die „Darstellungsfunktion” erfüllt, informiert der Stil den Empfänger über den "Sinn” der Äußerung im situativen, kommunikativen, personellen und gesellschaftlichen Zusammenhang - mit anderen Worten: wie das, was gesagt wurde, gemeint ist.

Daß gerade auf diesem Gebiet große Kommunikationsschwierigkeiten bestehen, geht aus der Häufigkeit fester Wendungen wie: „Wieso?”, „Wie meinst du das?”, „Warum sagst du mir das?”, „Soll das ein Witz sein?" usw. hervor; ebenso aus dem weltweiten, durchschlagenden Erfolg der amerikanischen Linguistin Deborah Tannen mit ihrem Buch „That's not what I meant!”, das, 1986 erschienen, in mehrere Sprachen übersetzt und in zahlreichen Auflagen weite Verbreitung und großes Echo gefunden hat. Es handelt sich durchgehend um Fälle, wo sehr wohl verstanden wurde, was gesagt war, der kommunikative Sinn aber nicht erfaßt wurde. In einem weiteren Buch: "You Just Don't Understand" beschreibt Tannen Mißverständnisse zwischen Männern und Frauen als Folgen unterschiedlicher, geschlechtsgebundener Stile (eine Sicht, die von feministischer Seite scharfe Kritik hervorgerufen hat ${ }^{4}$ ).

6. Zwei in diesem Zusammenhang besonders relevante linguistische Kategorien seien in diesem kurzen Statement zur Illustration herausgegriffen, eine im schriftlichen, eine vorwiegend im mündlichen Verkehr übliche: a) Textsorten, b) Sprechhandlungen.

a) Zum $\mathrm{T}$ e $\mathrm{x}$ t $\mathrm{s}$ or te $\mathrm{n} \mathrm{s}$ il. Der Textsortenstil signalisiert die Relevanz des Mitgeteilten hinsichtlich seiner Wahrheits- und Wirklichkeitsrelationierung sowie dem gesellschaftlichen Leben: der Romanstil Fiktionalität, der Gesetzstil gerichtliche Autorität, der Fachsprachenstil sachliche Kompetenz. Der Zeitungsstil wiederum differenziert innerhalb der Journalistik: Eine Reportage soll objektiv Fakten bringen; ein Leitartikel soll argumentieren, jedoch nicht objektiv, sondern in Übereinstimmung mit der Haltung der Zeitung; Feuilleton, Anzeigen, Sport usw. haben je eigene Stilmuster, an die der Leser gewöhnt ist und die seine Erwartungen steuern und ihm bei der Einschätzung des Gelesenen Hilfestellung leisten. Kirche und Religion haben ihren eigenen Sakralstil zusammen mit dem

${ }^{4}$ S. Trömel-Plötz, Senta (1991): Review of Deborah Tannen's „You Just Don't Understand" (New York 1990). In: Discourse \& Society 1991, S. 489502. 
Fachwortschatz der Theologie. Dies ist der A u s d r u c k des Textsortenstils im Bühlerschen Sinn: er bedingt den Ton, gibt Aufschluß über die Relevanz des Gelesenen, über die Lebensumstände des Lesers, die berührt oder betroffen werden.

Die Textsortenstilnormen stecken Rahmen ab, innerhalb derer Variationen möglich sind, die jedoch nicht übertreten werden dürfen, da damit das Verständnis gefährdet wird. Eine Reportage in humoristisch-plauderndem Feuilletonstil weckt Zweifel an der Wahrheit des Geschilderten. Wenn ein Prediger in der Kirche seine Predigt mit "Meine Damen und Herren” beginnen würde, würden diese sich aus der Kirche in einen Vortragsraum versetzt fühlen. Wenn stilistische Ironiesignale nicht deutlich genug sind, kommen ernste Mißverständnisse vor (dies geschieht bekanntlich häufig).

Versuche, einen Stilwandel herbeizuführen, können aus eben dem angeführten Grund unerwartet negative Folgen haben. Als im Rahmen des amerikanischen New Journalism Zeitungsreportagen mit den packenden Stilmitteln des realistischen Romans geschrieben wurden, waren anfangs wütende Reaktionen die Folge: „Verdammt nochmal - das haben diese Schufte doch einfach erfunden!" 5 Der Ausdruck des Stils wurde als Symptom (Indiz, Signal) für Funktionalität aufgefaßt.

Wie schwierig es deswegen ist, textsortenlinguistische Änderungen herbeizuführen, sei an einem deutschen Beispiel illustriert.

In der Verwaltungssprache wurde in den achtziger Jahren eine Umformulierung von Vordrucken vorgenommen, unter der Devise "bürgernahe Amtssprache”. Die autoritäre Form von Formularen, die der Bürger auszufüllen hatte, wurde als Relikt des Obrigkeitsstaates angeprangert, und man nahm eine Umformulierung nach dem Muster des Geschäftsbriefes vor. Nicht immer war der Versuch erfolgreich: es kam vor, daß wichtige Fragen nicht ausgefüllt wurden. Man hatte bei der Abfassung des Textes - mit vielen an sich willkommenen "Bitte" und "Danke" - nicht beachtet, da $B$ der Textsortenstil „Amtssprache” Signale enthält, die ein Geschäftsbrief nicht vermittelt: die Legitimierung eines gewissen Zwanges durch eine gesellschaftlich anerkannte Obrigkeit, dem man sich nicht ohne unangenehme Folgen widersetzen kann. Der

5 S. Stolt, Birgit (1990): „Was ist wahr?” Eine alte Kontroverse aus textlinguistischer und rhetorischer Sicht. Vortrag auf dem V1I. Internationalen Germanistenkongreß in Göttingen 1985; jetzt in erweiterter Form in: Textgestaltung - Textverständnis. Stockholm. S. 1-35. (= Stockholmer germanistische Forschungen 42). 
amtlichen Verlautbarung wird stilistisch ein offizieller Stempel aufgedrückt, der signalisiert, daß Belange des Privatlebens überindividuelle gesellschaftliche Relevanz haben und über sie verbindlich Regulierendes ausgesagt wird. Dies ist der „Ausdruck” des Stils, der dem Inhalt der "Darstellung” zur Durchsetzung verhilft, mithin dem "gesellschaftlichen sprachlichen Handlungsspiel" als eine der „Spielregeln” beigegeben ist, ohne die das „Spiel” nicht klappt. 6

b) Sprechhandlungen: Höfliche Bitte bzw. autoritärer Befehl, Lob bzw. Tadel, Vorschlag oder Aufforderung, Trost, mahnender Zuspruch usw. haben in der gesprochenen Sprache alle ihren speziellen Ton (Prosodie). Ihr Stil weist eine hohe Frequenz von Abtönungspartikeln auf. Bei stillem Lesen muB der Leser selbst den Ton in seinem „inneren Ohr” mithören. Ein Mißgriff innerhalb der Sprechhandlungen kann empfindlich verletzen. ("Aber das war doch nur ein Scherz!") In diesen Rahmen gehört die Kontroverse zwischen Deborah Tannen und Senta Trömel-Plötz über männlichen und weiblichen Stil: Mißverständnisse zwischen Männern und Frauen werden von Tannen als Mängel in einer „interkulturellen Kommunikation zwischen zwei verschiedenen Stilen" definiert, von Trömel-Plötz dagegen als "Stil der Machthaber" bzw. "Stil der Untergeordneten” gesehen. Was von Trömel-Plötz aufgezeigt wird, ist, daß Männer die Sprechhandlungen der Macht ausüben (befehlen, unterbrechen, Urteile abgeben ...), Frauen die der Untergeordneten (bitten, danken, einlenken, zustimmen, ermutigen, trösten ...). Trömel-Plötz wirft Tannen eine apolitische Haltung vor ${ }^{7}$, indem sie Machtverhältnisse innerhalb der Gesellschaft auf Stilfaktoren reduziert, die sich durch „besseres gegenseitiges Verständnis” aus der Welt schaffen ließen, mithin nicht zwischen Ursachen und Folgeerscheinungen differenziere.

In vielen Sprechhandlungen steht die Ausdrucksfunktion im Vordergrund. Beispiele sind u.a. Versprechen, Lob bzw. Kritik, Dank, Beglückwünschung etc. In anderen ist es vorwiegend der Appell: Warnung, Drohung, Befehl und Verbot etc. Auf diesem Gebiet sind interkulturelle - und daher auch übersetzungstechnische - Probleme zu bewältigen.

Besonders aus Geschäftsbeziehungen zwischen Schweden und Franzosen sind häufige Mißverständnisse bekannt, die durch einen tra-

6 Stolt, Birgit (1982): Devise „Bürgernah”. Neue Signale in der deutschen Verwaltungssprache. In: Moderna språk 3, S. 243-250.

7 Wie o. Anm. 4. 
ditionellen Sprachunterricht nicht zu beheben sind: die Betroffenen verstehen sehr wohl, was gesagt wurde, aber nicht, wie es - sprechaktmäßig - gemeint war. Von der Arzneimittelfirma Kabi Pharmacia sind diesbezügliche Schwierigkeiten beschrieben. In Schweden gilt es als undemokratisch bzw. unhöflich, etwas zu befehlen. Ein Vorgesetzter kommt jedoch nicht umhin, notwendige Dinge zu veranlassen. In Schweden geschieht dies in der Form einer Empfehlung. Jeder Schwede faßt eine Empfehlung von einem Vorgesetzten als verpflichtende Aufforderung auf. Für einen Franzosen dagegen bedeutet sie lediglich einen Vorschlag, dem er nicht zu folgen braucht - und folgerichtig wird auch nichts getan oder veranlaßt. Für den Franzosen liegt der Schwerpunkt der Äußerung auf der Ausdrucksseite, gemeint ist sie jedoch als Appell. ${ }^{8}$ Im internationalen Umgang sind diese kulturell bedingten Unterschiede im sprachlichen Umgangsstil von mitunter ausschlaggebender Bedeutung und müssen in den fremdsprachlichen Unterricht mit einbezogen werden.

7. Abschließend soll aus dem Bereich der politischen Rede ein Beispiel angeführt werden, wo die ungenügende Beherrschung eines Stilmittels, das der Schönen Literatur entstammt, katastrophale Folgen hatte, indem zwar völlig verstanden wurde, was gesagt wurde, aber gänzlich gegenteilig, wie es gemeint war. Es handelt sich um die bekannte Rede Philip Jenningers am 9.11.1989 im Deutschen Bundestag zum Gedenken an das Datum der "Reichskristallnacht”. Sie scheiterte an einem mißglückten Gebrauch des Stilmittels „erlebte Rede". 9 Bei dieser werden bekanntlich Gedanken oder innere Monologe eines Dritten wiedergegeben. Während ein $\mathrm{Zi}$ tat in Gänsefüßchen Distanz des Autors signalisiert, vermittelt die "Erlebte Rede" in der Schönen Literatur Einfühlung in die Gestalt, die zitiert wird, Empathie und Nähe des Autors. Diese Ausdrucksfunktion des Stilmittels hatte Jenninger nicht beachtet. Das Publikum faßte sie in seiner Rede auf, als identifiziere er sich mit den Gedanken, die er zitierte, was keineswegs der Fall war. Was beim

8 Kempe, Gunilla (1992): Kulturskillnad ett stort hinder. In: Svenska Dagbladet, 27.9.1992.

9 Zuzuki, Yasushi (1991): Erlebte Rede und der Fall Jenninger. In: GRM NF 41, S. 5-12. Dazu Stanzel, Franz K. (1991): Zur Problemgeschichte der "Erlebten Rede". Eine Vorbemerkung zu Yasushi Zuzukis Beitrag „Erlebte Rede und der Fall Jenninger". ebd. S. 1-4. - S. auch Heringer, Hans Jürgen (1990): Jenninger und die kommunikative Moral. In: Sprache und Literatur 21, S. 40-48. Heringer argumentiert mit den Konversationsmaximen von Grice. 
Publikum ankam, war Nähe, nicht Distanz zum Dargestellten. Die „erlebte Rede" wurde als Symptom und Ausdruck der Zustimmung mißverstanden.

8. In unseren Statements sollten „Berechtigung, Problematik und Möglichkeiten der Stilforschungen" angesprochen werden. Es war das Ziel meiner Ausführungen, die hochgradige gesellschaftliche Relevanz von „kommunikativer Stilforschung” zu demonstrieren, in einem Zeitalter, wo der Kommunikationsfähigkeit entscheidende Bedeutung zukommt. Die Zeiten sind vorbei, da "Stil” als rein ästhetisches Element bzw. Gegenstand einer elitären Oberschicht abgewertet wurde. Eine pragmatische Sprachwissenschaft, die sich verstärkt der Rezeptions- bzw. Verstehensproblematik zugewandt hat, kommt nicht umhin, Stilfragen unter diesem Aspekt großes Gewicht zuzumessen. Nicht zuletzt im internationalen Verkehr und als Übersetzungsproblem ist das "Wie sag ich's am besten” von ausschlaggebender Bedeutung.

Die Bühlerschen Kategorien sind bei der Analyse und Beschreibung, wie oben an Beispielen gezeigt, eine gute Handhabe. 


\section{Stil und Stilistik}

„Stil ist einer der schwierigsten Begriffe, die in diesem Buch gebraucht werden."

D. Crystal, 1993, S. 66

\section{Stilfragen}

Ein leicht anzügliches Wort sagt, es bedürfe nur der Teilnahme an einem StilkongreB, um zu wissen, wie man sich die Babylonische Sprachverwirrung vorzustellen habe. Richtig daran ist: Stil und Stilistik werden, was Definition, Terminologie, Prinzipien, Methoden usw. angeht, derart kaleidoskopisch bis kontrovers behandelt, daB sich an der Einheitlichkeit des Stilbegriffs füglich Zweifel einstellen können. Man braucht nur den Sammelband von H.U. Gumbrecht/K.L. Pfeiffer (1986) zur Hand zu nehmen, und schon irrt man zwischen literaturwissenschaftlichen und kunsthistorischen, soziologischen und kulturgeschichtlichen, ja lebensweltlichphilosophischen Stilauffassungen hin und her, die sich allenfalls unter dem sehr weiten Himmel einer universalen Stilsemiotik vereinen lassen. Der Stilbegriff, heißt es dort dezidiert, habe sich in seiner ursprünglichen sprachlich-literarischen Form verschlissen, erziele dafür jedoch in heutiger Zeit Anwendungszugewinne in vielen anderen Bereichen. Zu längst bekannten Stichwörtern wie „offener Stil” oder „Stilpluralismus” gesellt sich die Vorstellung einer „Ubiquität” des Stils, der überall dort - in einer Art Nothelferfunktion - einspringe, "wo andere Begriffe zu versagen drohen" (K.L. Pfeiffer, ebd. S. 693f. und 711). Auch sonst geht, dieses Forum eingeschlossen, nicht selten ein Stilskeptizismus um, dem man nur mit der kühnen Feststellung U. Püschels (1991, S. 65) begegnen kann: "Wenn es den Begriff des Sprachstils nicht gäbe, so müßte er unbedingt erfunden werden."

Die folgenden Bemerkungen beruhen auf Vorarbeiten zu einer 'Studienbibliographie Stil und Stilistik', die im Auftrag des Instituts für deutsche Sprache entsteht. Nur auswahlweise und bestenfalls andeutend geben sie einige Beobachtungen wieder, die aus der Durchsicht von gut anderthalbtausend Titeln stilistischen Gehalts resultieren und - Postskriptum - mit vielen Vorträgen der Tagung erstaunlich korrespondieren.

Vorweg ein doppelter Pauschaleindruck: Quantitativ stammt, erstens, die Mehrzahl der bibliographisch erfaBten Stilpublikationen aus den letzten zwanzig Jahren. Das ist nicht Ergebnis einer Auswahl nach Aktualitätsgesichtspunkten, sondern spiegelt den bemerkenswerten Aufschwung, den die Sprachstilistik seit den 60er Jahren genommen hat, und zwar im 
Gefolge des damaligen Höhenflugs der modernen Linguistik, nachdem bis dahin die literaturorientierte Stilbetrachtung absolut vorherrschte (insofern ist es kein Widerspruch, wenn der Literaturwissenschaftler konstatiert, es sei still geworden um den Stilbegriff, der seine große Zeit hinter sich habe; J. Anderegg, in diesem Band S. 115). Qualitativ läBt sich, zweitens, nach einer Phase starken Theoretisierens gerade in letzter Zeit eine Tendenz zu pragmatischen Anschauungen, verbunden mit praktischen Veranschaulichungen, feststellen. Ein schönes Beispiel für solche Fachmetaphorik ist das seit 1980 durch das stilistische Schrifttum und mehrmals auch durch den Vortragssaal geisternde "Chamäleon Stil”.

\section{Die Stil-Frage}

Nicht nur zur Einleitung von Stiltagungen (H.-M. Gauger, S. 7-26; vgl. ders. 1991, 1993), sondern auch am Anfang unzähliger Stilbücher und artikel wird gefragt: „Was ist (eigentlich) Stil?” - die Stil-Frage schlechthin. Die Antworten verbleiben entweder im Topischen, wie W.G. Müller (1981) des näheren dargelegt hat; beispielsweise das zeitlose, auch jetzt wieder aktuelle Diktum des Grafen Buffon, der Stil sei der Mensch selbst ("le style est l'homme même"). Oder sie sind einerseits, gebunden an spezielle Konzeptionen wie „Stil als Abweichung von der Norm”, zu eng, um Allgemeingültigkeit beanspruchen zu können; andrerseits aber, wenn sie ihr Heil in synthetisierenden Umschreibungen suchen, zu weit, um praktikabel zu sein. Vielleicht ist "Stil" gleich anderen sprachwissenschaftlichen Zentralbegriffen - „Wort”, "Satz”, „Text" usw. - gar nicht exakt definierbar? Ein ebenso beliebter Aufhänger wie die Stil-Frage ist übrigens seine Wortgeschichte, die vom antik-mittelalterlichen "Schreibgriffel”, dann "Schreibart”, zum neuzeitlichen „Stil” führt: vielen erscheint der lateinische stilus in der Hand offenbar sicherer als ein moderner Stilbegriff auf dem Dach.

Die enorme Wichtigkeit des Stils für unseren Umgang mit Sprache wird kaum bestritten, indes bereitet eine klare Abgrenzung von eben dieser Sprache Mühe. In der gegenwärtigen Fachdiskussion hat das problematische Verhältnis von matter und manner, wie es englisch heißt, Ausdruck gefunden in der "vorwissenschaftlichen”, aber anschaulichen Unterscheidung des WAS und des WIE von Sprachäußerungen: das "Was” als Sachgehalt des Geäußerten, das „Wie” als seine sprachlich-stilistische Äußerungsform. Hochinteressant $z u$ verfolgen, wie sich während der letzten zehn Jahre in kleinen, oft beiläufigen Diskussionsschritten eine Entwicklung vollzieht von der Auffassung eines völlig bedeutungsindifferenten WIE über seine Sicht als Einstellungen, Haltungen, Wertungen ausdrückend bis zur heutigen Annahme einer eigenen „stilistischen 
Bedeutung", die direkten Einfluß auf das WAS hat und am Sinn der Äußerung "maßgeblich beteiligt" ist (Thieberger 1992, S. 52). Doch geht es nicht nur um das mittlerweile fast omnipräsente WAS und WIE allein, ihren so oder so formulierten Zusammenhang; vielmehr wird mit weiteren Fragen, etwa nach dem WARUM und WOZU, der bloBe Bedeutungsaspekt um wichtige Gesichtspunkte ergänzt wie Stilabsicht und Stilwirkung. Zugleich erschlieBt sich der Hintergrund jenes auf alte, rhetorische Muster zurückgehenden Katalogs von W-Fragen (WER, WAS, WEM usw.; vgl. Stolt 1984), die als solche den kommunikativen Grundcharakter des Stils offenlegen.

\section{Fragestellungen}

Manche Stilprobleme darf man unterdessen als gelöst ansehen, andere stehen weiterhin zur Diskussion (im Überblick Sowinski 1991). Während mit der kommunikativ-pragmatischen Fundierung der Stilistik im Rahmen von Sprachhandlungstheorie und Semiotik eine tragfähige Grundlage geschaffen scheint (vgl. Sandig 1978, 1986), irritiert - immer vom Bibliographischen her gesehen - neben anderen, gut dokumentierten Stilkonzeptionen wie Individualstil, Funktionalstilistik oder Stilstatistik die keineswegs neue Auffassung von „Stil als Wahl”: genauer die Auswahl aus synonymischen, äquivalenten, konkurrierenden usw. Sprachmöglichkeiten - eine Auffassung, die vielfach geradezu als stilistische Prämisse, d.h. unerläBliche Voraussetzung für die Existenz des Stilphänomens angesehen wird. Um so mehr muB das fast vollständige Fehlen spezieller neuerer Arbeiten auffallen (einschlägig nur Agricola 1957; Milic 1971). Die Auseinandersetzung mit der Selektionstheorie spielt sich nahezu ausschlieBlich in Handbuchartikeln und Gesamtdarstellungen ab, die ihr mehr oder weniger Raum widmen, und sie ist zudem gekennzeichnet durch die zwiespältige Argumentationsfigur des „Zwar - aber”. Umstritten sind vor allem die notwendigerweise anzunehmenden Selektionsbeschränkungen, der Selektionsbegriff im stilistischen Analyseverfahren und der Bewußtheitsgrad der Stilwahl, inwieweit nämlich etwas intentional „zum Ausdruck gebracht wird” oder unreflektiert „zum Ausdruck kommt" (nach Keller 1977, S. 15). Klärung täte zweifellos not.

„Tendenzen der linguistischen Stilforschung". wird man nach der umfassenden Übersicht von B. Sandig (S. 27-61) nicht mehr aufzählen, wohl aber seien einige stilistische Problemfelder angesprochen. Bibliographisch defizitäre Bereiche bilden u.a. die Stilgeschichte, eingeschlossen das Phänomen des Stilwandels (vgl. G. Lerchner, S. 94-114), und ein Konzept von Zeit- und Epochenstilen, das nicht literaturgebunden ist; eine parallel zu Interlinguistik, Interkultureller Kommunikation usw. 
zu postulierende „Interlinguale Stilistik”, die in engster Verbindung mit einer Übersetzungsstilistik zukunftsträchtig erscheint; nicht zuletzt aber die noch junge Makrostilistik: Nachdem schon Asmuth (1974, S. 67f.) vor der "Froschperspektive" der traditionellen Stilistik gewarnt hatte, die nur "die grammatisch, lexisch und phonetisch beschreibbare, im Grunde sekundäre Mikrostuktur" berücksichtige, war es die Moskauer Stilforscherin E. Riesel, die erstmals eine systematische Unterscheidung von Mikro- und Makrostilistik vorschlug - letztere ausdrücklich als damals „noch wenig bearbeitetes Neuland” (Riesel/Schendels 1975, S. 11f.). Seither sind zögernd erste Arbeiten erschienen, in denen sich freilich die angestrebte makrostilistische "Adlerperspektive", so Püschel (1991, S. 64), bestenfalls umrißhaft andeutet. Zumal vor dem Horizont eines kommunikativ-pragmatischen Stilbegriffs stellen die Zusammenschau der "globalen" Textorganisation mit den sie konstituierenden Einzelelementen, die Wechselbeziehung also zwischen dem Ganzen und seinen Teilen, ebenso wie eine Klärung des problematischen "Denkstils" (Sanders 1990, S. 23ff.) vordringliche Forschungsaufgaben dar.

Bleibt noch ein kurzer Blick auf die sog. Praktische (normative, präskriptive) Stilistik, das weite, durchweg populär beackerte Feld von Sprachkritik und Stillehre, denen G. Antos (SchluBvortrag, S. 355-377) ihren Ort im Rahmen einer landläufigen "Laien-Linguistik" zugewiesen hat. Es ist sicher nicht damit getan, über solche „Sprachkritikastereien” (Sanders 1992) zu lamentieren; vielmehr gilt es, auf der Grundlage linguistisch fundierter Stilkritik und Stilbewertung eine wissenschaftliche Stildidaktik zu entwickeln, die sich ernsthaft mit den Möglichkeiten praktischer Stillehre auseinandersetzt und auch nicht vor der Herausforderung des bislang arg vernachlässigten Lehrbuchs zurückschreckt. Zur Bezeichnung dieses Bereichs stilistischer Textgestaltung, ihrer Mittel und Vermittlung, bietet sich der im Soziologischen beheimatete Begriff der "Stilisierung" an, der neuerdings - wie die Titel von Neuland/Bleckwenn (1991) und Hinnenkamp/Selting (1989) zeigen - nicht immer, aber immer öfter auch sprachwissenschaftlich für Stilgebung im weitesten Sinne steht: das „Stilherstellen”, wie es technizistisch heißt.

\section{Nach wie vor frag-würdig?}

Um am SchluB den Bogen zurück zum Anfang der Tagung zu schlagen: Stil sei einer der schwierigsten Begriffe überhaupt, zitierte B. Spillner (hier S. 64) den englischen Sprachenzyklopädisten D. Crystal - das wird vermutlich zum geflügelten Wort künftiger Stilistik werden. H.-M. Gauger (S. 21) hat sich, Buffon variierend, dieser Schwierigkeit des Stilbegriffs geschickt durch eine so nur französisch mögliche Pointe entzogen: 
„Le style (Stil/Griffel), c'est le style (Griffel/Stil) même." Man kann dies deutsch auf die Spitze (französisch pointe) treiben, indem man Karl Philipp Moritz zitiert; in seinen 'Vorlesungen über den Stil' (1793/94; nach R. Campe 1991, S. 75) steht, wie immer das zu interpretieren sein mag: "Der Stil ist - der Stil".

\section{Literatur}

Agricola, Erhard (1957): Fakultative sprachliche Formen. Gedanken zur grammatischen Fundierung der Stilkunde. In: Beiträge zur Geschichte der deutschen Sprache und Literatur/Halle 79, Sonderband für Theodor Frings, S. 43-76.

Asmuth, Bernhard/Berg-Ehlers, Luise (1974): Stilistik. Düsseldorf. (Grundstudium Literaturwissenschaft. Hochschuldidaktische Arbeitsmaterialien, Bd. 5).

Campe, Rüdiger (1991): Die zwei Perioden des Stils. In: Comparatio 2, S. 73-101.

Crystal, David (1993): Die Cambridge Enzyklopädie der Sprache. Frankfurt a.M.

Gauger, Hans-Martin (1991): Zur Frage des Stils - etymologisch gesehen. In: Comparatio 2, S. 3-16.

Gauger, Hans-Martin (1993): Stilfragen. In: Merkur 47, S. 494- 507.

Gumbrecht, Hans Ulrich/Pfeiffer, Karl Ludwig (Hg.) (1986): Stil. Geschichten und Funktionen eines kulturwissenschaftlichen Diskurselements. Frankfurt a.M. (suhrkamp taschenbuch wissenschaft).

Hinnenkamp, Volker/Selting, Margret (Hg.) (1989): Stil und Stilisierung. Arbeiten zur interpretativen Soziolinguistik. Tübingen. (Linguistische Arbeiten, 235).

Keller, Rudi (1977): Kollokutionäre Akte. In: Germanistische Linguistik 1-2/77, S. 3-50.

Milic, Louis T. (1971): Rhetorical Choice and Stylistic Option. The Conscious and Unconscious Poles. In: Chatman, Seymour (Hg.): Literary Style. A Symposium. London/New York. S. 77-88.

Müller, Wolfgang G. (1981): Topik des Stilbegrifts. Zur Geschichte des Stilverständnisses von der Antike bis zur Gegenwart. Darmstadt. (Impulse der Forschung, 34).

Neuland, Eva/Bleckwenn, Helga (Hg.) (1991): Stil - Stilistik - Stilisierung. Linguistische, literaturwissenschaftliche und didaktische Beiträge zur Stilforschung. Frankfurt a.M./Bern/New York/Paris.

Püschel, Ulrich (1991): Praktische Stilistiken - Ratgeber für gutes Deutsch? In: Neuland/Bleckwenn (Hg.) (1991), S. 55-68.

Riesel, Elise/Schendels, Eugenie (1975): Deutsche Stilistik. Moskau.

Sanders, Willy (1990): Gutes Deutsch - besseres Deutsch. Praktische Stillehre der deutschen Gegenwartssprache. 2. Aufl. Darmstadt. 
Sanders, Willy (1992): Sprachkritikastereien und was der „Fachler” dazu sagt. Darmstadt.

Sandig, Barbara (1978): Stilistik. Sprachpragmatische Grundlegung der Stilbeschreibung. Berlin/New York. (de Gruyter Studienbuch).

Sandig, Barbara (1986): Stilistik der deutschen Sprache. Berlin/New York. (Sammlung Göschen, 2229).

Sowinski, Bernhard (1991): Stilistik. Stiltheorien und Stilanalysen. Stuttgart (Sammlung Metzler, 263).

Stolt, Birgit (1984): Pragmatische Stilanalyse. In: Spillner, Bernd (Hg.) (1984): Methoden der Stilanalyse. Tübingen. S. 163-173.

Thieberger, Richard (1992): Das Wie und das Was. In: Hardin, James/Jungmayr, Jörg (Hg.) (1992): „Der Buchstab tödt - der Geist macht lebendign. Festschrift zum 60. Geburtstag von Hans-Gert Roloff. Bd. I. Bern/Berlin/Frankfurt a.M./New York/Paris/Wien. S. 47-54. 


\section{ULLA FIX}

\section{Zur Berechtigung, zu Problemen und Möglichkeiten der Stilforschung}

Mein Ausgangspunkt ist, daB die Stilforschung auf ihrem jetzigen Stand - eine große Zahl vielfältiger Ansätze und Konzepte liegen vor - wieder einmal gesichtet werden sollte - im Sinne einer ZUSAMMENSCHAU (Püschel 1991) und im Sinne einer AUSSCHAU auf Desiderata und Perspektiven.

Ich will Ergebnisse meiner Ausschau in elf, teilweise kommentierten, Thesen vortragen.

1. These:

Als die Hauptkomponenten alltagsweltlicher wie wissenschaftlicher Stilkonzepte gelten allgemein die folgenden drei: GESTALT, SINN und WIRKUNG, allerdings oft - das betrifft besonders GESTALT - nur als stillschweigende, nicht reflektierte und schon gar nicht problematisierte Voraussetzung.

Stil hat im allgemeinen Verständnis immer etwas mit Gestalten und Gestalt zu tun. Daß Stil Gestalten - und zwar einheitliches - ist, macht einen Teil seines Wesens aus. Stil ist nach allgemeiner Auffassung auch immer an der Konstituierung und Vermittlung von Sinn - sozialem und ästhetischem - beteiligt. Und es wird in der Regel vorausgesetzt, daß Stil auf - soziale und ästhetische - Wirkung hin gebildet wird.

2. These:

Die gegenwärtige Stilforschung ist nun dabei, der Eindruck stellt sich bei den Bemühungen um einen Gesamtüberblick über gegenwärtige Stilforschung ein, die Komponente der GESTALT - eine ihrer ureigensten Domänen - aufzugeben.

3. These:

Die heute dominierenden, den SINN hervorhebenden pragmatischkommunikativen Vorstellungen von 'Stil' sind vor diesem Hintergrund - dem der drei Komponenten - gleichzeitig zu we i t und zu e $n g$. Zu diesem Paradoxon:

4. These:

Zu eng sind sie insofern, als ihre bevorzugten Gegenstandsbereiche SINN und WIRKUNG sind und infolgedessen GESTALT und damit auch das 
ÄSTHETISCHE und das INDIVIDUELLE am Stil in den Hintergrund rücken.

Es ist ganz zweifellos ein großer Gewinn, daB im Verlauf der letzten Jahre die Vorstellung von 'Stil' vom System auf den Text und schließlich auf kommunikatives Handeln übertragen wurde. Ein Gewinn deshalb, weil dies der Realität sprachlicher Kommunikation wirklich entspricht. Die damit verbundene Konzentration auf Muster und Konventionen des Handelns brachte es mit sich, daB Sachtexte in das Zentrum der Aufmerksamkeit rückten. Gerade dies aber ließ den Gestaltaspekt bei jeglicher Art von Texten in den Hintergrund treten. Literarische Texte gerieten fast völlig aus dem Blickfeld. Das ist unter dem Gesichtspunkt des Faches Germanistik kein zufriedenstellender Zustand.

\section{These (komplementär zu These 4):}

Zu weit sind solche Stilvorstellungen, weil mit dem Hervorheben des Pragmatischen und dem Zurückstellen der Gestaltkomponente die Grenzen zu anderen Disziplinen zu verschwimmen drohen. Indem die Stilistik auf handlungstheoretische, kommunikationslinguistische, textlinguistische Konzepte bezogen wird, läuft sie Gefahr, von diesen Konzepten "geschluckt" zu werden. Es bleibt dann gelegentlich unklar, was z.B. Sprachhandlungen gegenüber Stilhandlungen, was Textmuster gegenüber Stilmustern sind, wie Stilmerkmale sich zu situativen Bestimmtheiten des Textes verhalten.

Was Stil in einer Handlung, einer Situation, in einem Text ist, kann nur dann erfaßt werden, wenn das Gestalthafte einbezogen wird: gestaltete Handlung, Gestaltmerkmale, Muster des Gestaltens. Die Gefahr der Konturenlosigkeit des Stilbegriffs kann durch den Bezug auf GESTALT überwunden werden.

6. These:

Eine Rückbesinnung auf den Aspekt der GESTALT ist möglich, ohne $\mathrm{da} \beta$ etwas von dem aktuellen Wissen über den sozialen/pragmatischen Aspekt von Stil aufgegeben werden müßte und sollte.

Wenn sowohl zu große Enge als auch zu große Weite des Stilbegriffs durch das Vernachlässigen des Gestalthaften verursacht werden, ist das ein deutlicher Hinweis darauf, daß ausgewogene Relationen aller Komponenten durch den Blick auf GESTALT hergestellt werden müssen. 


\section{These:}

Diese Rückbesinnung auf das Gestalthafte ist möglich, weil die soziale Komponente an GESTALT gebunden ist. Stil ist an Gestalt sichtbar gemachter, also erkennbarer sozialer und/oder ästhetischer Sinn.

Er ist das Ergebnis intentionaler Handlungen des Sichtbarmachens (Luckmann 1986), die einheitsstiftend sind und zu einer homogenen Gestalt mit dem Angebot einer einheitlichen Interpretation führen, einer Gestalt, in der die Ganzheit mehr ist als die Summe der Teile (Kainz 1932). Das alles zusammengefaBt unter den Stichworten SICHTBARMACHUNG und EINHEITLICHKEIT kann - mit Soeffner (1986) - als (ästhetische) ÜBERHÖHUNG gelten.

\section{These:}

Folgen für die Praxis: Die Wiederbelebung der Kategorie GESTALT könnte auf die Analysepraxis anregend wirken: neue Gesichtspunkte, neue Kategorien könnten - auch durch Grenzerweiterung im Sinne interdisziplinären Herangehens - gewonnen werden.

\section{These:}

Folgen für die Theorie: Die Einbeziehung des Gestalthaften macht die Komplexität des Stilbegriffs erneut deutlich. Das von Natur aus komplexe - aber nicht konturenlose - Phänomen 'Stil' verpflichtet zu polyperspektivischer Betrachtung. "Grenzerweiterung” über die Disziplin „linguistische Stilistik” hinaus ist nötig.

10. These:

Grenzerweiterung sollte stattfinden, indem der "stilistische Blick” von der SEMANTIK auf die SEMIOTIK, von der PRAGMATIK, ohne diese aber aufzugeben, auf die ÄSTHETIK gerichtet wird.

Auf die SEMIOTIK deshalb, weil kommunikative Auffassungen von Stil berücksichtigen müssen, daB alle an der Kommunikation beteiligten kulturellen Kodes, also auch die nonverbalen, Mittel des Gestaltens sind. Kommunikation ist nicht nur Sprachliches, auch Nichtsprachliches hat Anteil an der GESTALT. Auf diese Weise würde man sowohl dem Konzept von Stil als Handeln als auch dem Gestaltphänomen gerecht.

Auf die ÄSTHETIK sollte der Blick deshalb gerichtet werden, weil intentionales gestaltendes Stilhandeln zweifellos eine ästhetische Komponente hat. Die Mitteilung von pragmatischem Sinn ohne ästhetische Überhöhung (vgl. Soeffner 1986) ist nicht möglich. Auf diese Weise werden Beschreibungsgegenstände (literarische Texte) und Kategorien (ästhetische) zurückgewonnen. 
11. These:

Grenzerweiterung sollte außerdem stattfinden, indem wir über die Grenzen der Gegenwart hinausgehen und den Blick zurück auf die historische Dimension der Stilforschung in diesem Jahrhundert richten.

Wir werden dann sehen, wie ausgeprägt 'Stil' Gegenstand anderer Disziplinen - der Kunstwissenschaft, Literaturwissenschaft, Philosophie, Psychologie - war und wie wenig er in der Sprachwissenschaft eine Rolle spielte. Es wird außerdem deutlich werden, wie in der ersten Hälfte dieses Jahrhunderts interdisziplinäre Zusammenarbeit als gelebte Beziehung zwischen den Disziplinen die selbstverständliche Basis aller Überlegungen war. Und wir nehmen wahr, daß die Beschäftigung mit 'Stil' immer die Auseinandersetzung mit dem Wesen und der Wahrnehmung von GESTALT, des Ästhetischen, und mit den Möglichkeiten seiner Beschreibung, mit Kategorien des Ästhetischen also, war.

Die im interdisziplinären Austausch entwickelten Beschreibungsvorschläge und Kategorien für GESTALT/ÄSTHETISCHES (Croce 1936, Fechner 1925, Kainz 1932, 1948, Spitzer 1928, Vossler 1904, 1905, Walzel $1917)$ sollten wir prüfend zur Kenntnis nehmen. Wir sollten sehen, daß z.B. in den Bemühungen der werkimmanenten Methode ebenso wie in den nicht beziehungslos daneben stehenden Bemühungen des russischen Formalismus Ansätze liegen für eine genaue Beschreibung des Gestalthaften - Schätze, die es immer noch zu heben gilt.

\section{Literatur}

Croce, Benedetto (1936): La Poesia. Introduzione alla critica e storia della poesia e della letteratura. Bari.

Fechner, Gustav Theodor (1925): Vorschule der Āsthetik. Leipzig.

Kainz, Friedrich (1932): Personalistische Ästhetik. Leipzig.

Kainz, Friedrich (1948): Vorlesungen über Ästhetik. Wien.

Luckmann, Thomas (1986): Soziologische Grenzen des Stilbegriffs. In: Gumbrecht, Hans Ulrich/Pfeiffer, K. Ludwig (Hg.): Stil. Geschichten und Funktionen eines kulturwissensch aftlichen Diskurselements. S. 612-619. Frankfurt am Main.

Püschel, Ulrich (1991): Stilistik: Nicht Goldmarie - nicht Pechmarie. Ein Sammelbericht. In: Deutsche Sprache 19, S. 50-67.

Soeffner, Hans-Georg (1986): Stil und Stilisierung. Punk oder die Überhöhung des Alltags. In: Gumbrecht, Hans Ulrich/Pfeiffer, K. Ludwig (Hg.): Stil. Geschichten und Funktionen eines kulturwissenschaftlichen Diskurselements, S. 317-341.

Spitzer, Leo (1928): Stilstudien. I. Sprachstile. II. Stilsprachen. München. 
Vossler, Karl (1904): Positivismus und Idealismus in der Sprachwissenschaft. Heidelberg.

Vossler, Karl (1905): Sprache als Schōpfung und Entwicklung. Heidelberg.

Walzel, Oskar (1917): Wechselseitige Erhellung der Künste. Berlin. 


\section{HANS BICKES}

\section{Kann denn Sprache Sünde sein?}

Eine schöne, treffende Geschichte hat uns unlängst der amerikanische Philosoph Richard Rorty ${ }^{1}$ erzählt. Seine Geschichte handelt von Kontingenz, von Ironie und von Solidarität. Sie lebt von der Spannung zwischen dem berechtigten Streben der Menschen nach Einmaligkeit und Unverwechselbarkeit auf der einen Seite und ihrer ebenso legitimen Sehnsucht nach sozialer Gemeinschaft und Gerechtigkeit auf der anderen Seite. Diese Spannung spiegelt sich im Bemühen der Menschen um eine unverwechselbare, kraftvolle eigene Sprache einerseits und dem vereinnahmenden Bestreben des Gemeinwesens andererseits, seine Mitglieder zu gut funktionierenden, unauffälligen Mitspielern in den Sprachspielen der Gemeinschaft zu machen. Hier haben wir den Wunsch nach der Unersetzlichkeit des Einzelnen, dort den Primat der Funktion.

Rortys Sympathie gilt dem Individuum. Er zeigt, daß wir uns selbst nur erkennen können, wenn wir uns vor zuviel überkommenem Sprachgebrauch, vor einem zuviel an 'Stammessprache' hüten. Die Erschaffung des Selbst ist mit einem persönlichen Sprachgebrauch - Rorty spricht von Vokabular $^{2}$ - verbunden. Vokabularien verkörpern gewissermaBen Stile der Weltbewältigung. Indem freilich einzelne ihr Vokabular in das Gemeinwesen einbringen, wird Starrheit überwunden und gesellschaftliche Veränderung gefordert. Folgen wir Rorty, so kommt kultureller Wandel dadurch zustande, daB immer mehr Dinge auf andere Art neu beschrieben werden, und zwar so lange, „bis dadurch ein Muster sprachlichen Verhaltens geschaffen ist, das die kommende Generation zur Übernahme reizt und sie damit dazu bringt, nach angemessenen neuen Formen nichtsprachlichen Verhaltens Ausschau zu halten - sich etwa neue naturwissenschaftliche Ausrüstungen oder neue soziale Institutionen zuzulegen" (Rorty 1993, S. 30).

1 Rorty, Richard (1993): Kontingenz, Ironie und Solidarităt. Frankfurt am Main, 2. Auflage.

2 Der Terminus „Vokabular” erhält seine Bedeutung im Sprachgebrauch von Rorty im erwāhnten Buch und ist selbstverstāndlich nicht identisch mit „Wortschatz" im linguistischen Sinn. Gleichwohl sind Wortschätze zentrale Teile von Vokabularien. Vokabularien kann man sich in Annäherung als dynamische Ensembles von sprachlichen Verhaltensweisen, Fähigkeiten, Weltund Lebensentwürfen vorstellen. 
Gesellschaftlicher Wandel, so Rorty, beruht nicht auf dem Prüfen von These und Gegenthese. Vielmehr gründet der Wandel auf einem expliziten oder impliziten „Wettkampf zwischen einem erstarrten Vokabular, das hemmend oder ärgerlich geworden ist, und einem neuen Vokabular, das erst halb Form angenommen hat und die vage Versprechung großer Dinge bietet" (Rorty 1993, S. 30).

Rorty radikalisiert zudem die erkenntnistheoretische Einsicht, daB wir Wahrheit nicht erkennen, sondern daß wir Wahrheit machen. Denn als Eigenschaft von Sätzen ist Wahrheit abhängig von Vokabularien, d.h. von Sprachen. Sprachen aber werden von uns gemacht - und damit auch Wahrheit. Sehr anschaulich, so Rorty, wird der Begriff der Wahrheit daher durch Nietzsches Definition von Wahrheit als einem "beweglichen Heer von Metaphern" wiedergegeben (Rorty 1993, S. 43). Somit ist eine Sprache nichts, was als Medium zwischen einer äußeren Welt der Tatsachen und uns als Subjekten vermittelt. Rorty kann sich dabei auf jüngere Arbeiten Davidsons berufen:

„Davidson bricht konsequent mit der Auffassung, Sprache sei ein Medium, ein Medium der Darstellung oder des Ausdrucks" (Rorty 1993, S. 32).

Und:

„Davidsons Darstellung sprachlicher Kommunikation verzichtet auf das Bild von Sprache als einem Dritten zwischen Selbst und Realität (...) Zu sagen, daß meine frühere Sprache ungeeignet für den Umgang mit manchen Bereichen der Welt war (zum Beispiel dem gestirnten Himmel über oder den heftigen Leidenschaften in mir), heißt nur, daß ich jetzt, wo ich eine neue Sprache gelernt habe, diese Bereiche leicht handhaben kann" (Rorty 1993, S. 39).

Mit dem Zusammenbruch der Vorstellung, daß Sprache ein Medium, ein Mittel sei, fält gleichzeitig die Vorstellung, daß Sprache einen $Z$ weck habe. Sprache ist die Fähigkeit ${ }^{3}$, mit der Welt umzugehen, in der wir leben. Uns steht hierzu ein Repertoire unterschiedlicher Vokabularien zur Verfügung.

3 Vgl. zu ähnlichen Überlegungen auch: Putnam, Hilary (1991): Repräsentation und Realität. Frankfurt a.M.; Putnam, Hilary (1982): Vernunft, Wahrheit und Geschichte. Frankfurt a.M.; Bickes, Hans/Busse, Dietrich (1989): Begriffe im kommunikativen Handeln. Linguistische Begriffsanalyse als Rekonstruktion von Handlungsmustern. In: Conceptus XXIII, 60, S. 81-98. Bickes, Hans (1993): Semantik, Handlungstheorie und Zeichenbedeutung. In: Stachowiak, Herbert (Hg.): Pragmatik. Handbuch pragmatischen Denkens. Band IV: Sprachphilosophie, Sprachpragmatik und formative Pragmatik. Hamburg. 1993, S. 156-187. Busse, Dietrich (1987): Historische Semantik. Stuttgart. 
Diese Sichtweise hat gravierende Konsequenzen: „Wir sollten uns darüber klar sein, daß wir nicht nur die übliche Bestimmung von Sprache aufgeben, sondern die Grenze zwischen der Kenntnis einer Sprache und der Fähigkeit, uns überhaupt in der Welt zurechtzufinden, niedergerissen haben. (...)

So etwas wie eine Sprache gibt es nicht, jedenfalls nicht, wenn eine Sprache irgend etwas der Art ist, wie zumindest die Philosophen es angenommen haben. Es gibt also auch nichts Derartiges, was man lernen oder beherrschen könnte. Wir müssen die Vorstellung von einer klar bestimmten, gemeinsamen Struktur aufgeben, die die Benutzer einer Sprache beherrschen und dann auf Fälle anwenden (...) wir sollten den Versuch aufgeben, durch Hinweis auf Konventionen erläutern zu wollen, wie wir uns verständigen" (Donald Davidson, A Nice Arrangement of Epitaphs” 4 , zitiert in Rorty, 1993, S. 39f.). „Konventionen und Regeln erklären die Sprache nicht, sondern die Sprache erklärt sie" (vgl. Davidson 1990, S. 316 , in Übersetzung zitiert bei Schulte 1993, S. 113). ${ }^{5}$

Für Linguisten und für Sprachlehrer mag das beunruhigend klingen. Es als 'nur von philosophischer Bedeutung' zu verharmlosen, hieße jedoch, die Praxisnähe philosophischer Argumente zu unterschätzen. In einem pointierten Aufsatz mit dem Titel Ist der deutsche Wortschatz lernbar? Oder: Wortschatz ist Chaos ${ }^{6}$ kommt Franz Josef Hausmann zu Ergebnissen, die verblüffend mit den eben zitierten übereinstimmen, und dies, obwohl er mit Wortschätzen ja nur einen Teil dessen untersucht, was oben Vokabular genannt wird": "Hier zeigt sich nämlich, daß zwischen Sprache und Welt nicht zu trennen ist (Hervorhebung H.B.). Die gekochte Kartoffel ist anders hart als die rohe. Das gekochte $\mathrm{Ei}$ ist anders hart als die gekochte Kartoffel. Die weiche rohe Kartoffel ist immer noch härter als die harte gekochte usw. usw. Am Ende muß man alles beschreiben, was irgendwie auf der Welt hart ist" (Hausmann 1993, S. 474). Das dürfte

4 Davidsons Aufsatz ist unter dem deutschen Titel „Eine hübsche Unordnung von Epitaphen" enthalten in Picardi, E./Schulte, J. (Hg.) (1990): Die Wahrheit der Interpretation. Beiträge zur Philosophie Donald Davidsons. Frankfurt a.M. S. 203-227.

5 Schulte, Joachim, (1993): Nachwort zu: Donald Davidson, Der Mythos des Subjektiven. Philosophische Essays. Stuttgart (Reclam). S. 109ff. Engl. Originalbeleg in: Davidson, Donald, (1990): The Structure and Content of Truth. In: The Journal of Philosophy 87, S. 316.

6 Hausmann, Franz Josef (1993): Ist der deutsche Wortschatz lernbar? Oder: Wortschatz ist Chaos. In: Info DaF 20,5, S. 471-485.

7 Vgl. Fußnote 2. 
auch den Nichtphilosophen nachdenklich stimmen - ganz ohne Hinweis auf Davidson oder Rorty. Überall im Wortschatz herrscht Idiomatizität $^{8}$, spitzt Hausmann seine These zu, und damit das Chaos. Wortschätze wollen erobert, erfahren sein. Das nicht Vorhersagbare, Unsystematische, wie es dem idiomatischen Sprachgebrauch eignet, ist freilich etwas, was die traditionelle Sprachbeschreibung allenfalls in bestimmten Nischen, in „sündigen Bereichen der Sprache" (vgl. Hausmann 1993, S. 474) zuläßt. „So konnte sich in den Köpfen die Vorstellung einnisten, Idiomatik sei die Ausnahme, nur eine düstere Rumpelkammer im ansonsten lichtdurchfluteten, klar gegliederten Haus der Sprache". In Wirklichkeit geht alles drunter und drüber. Aus der Sicht der Fremdsprachen ist sogar der gesamte Wortschatz einer Sprache idiomatisch. Hausmann folgert: „Der Wortschatz einer Sprache als Fremdsprache ist nicht beschreibbar und deshalb nicht lernbar. (...) Man kann ihn nicht schwarz auf weiß davontragen" (Hausmann 1993, S. 479) ${ }^{9}$. Das erinnert wiederum sehr an Davidson, und so will ich - nach diesem knappen Exkurs - zum 'philosophischen' Strang meines Argumentes zurückfinden. Wie ist Verstehen angesichts des Chaos, angesichts der Idiomatik und Metaphorik fremder oder neuer Vokabularien überhaupt möglich? Wieviel Sünde verträgt die Sprache?

8 Er beruft sich z.B. auf den französischen Grammatiker Maurice Gross, der nach jahrzehntelangen Forschungen zu dem Schlu $B$ kommt, „daß unter 12.000 franzōsischen Verben nicht zwei ein vollkommen identisches syntaktisches Verhalten haben und meint, das müBte eigentlich allen Theoretikern zu denken geben, die dazu neigen, Idiomatik als Ausnahme zu betrachten" (Hausmann 1993, S. 479). - Hausmann bezieht sich auf: Gross, Maurice (1993): Lexicon Based Algorithms for the Automatic Analysis of Natural Language. In: Beckmann, Frank/Heyer, Gerhard (Hg.): Theorie und Praxis des Lexikons. Berlin/New York, S. 218-236.

9 Es scheint, als habe die Idiomatizität von Wortschätzen bei Hausmann ähnliche Wirkungen wie die Metaphorik von Vokabularien bei Rorty. Denn der Muttersprachler merkt in seiner Sprache „überhaupt keine Idiomatik. Für ihn ist alles selbstverstāndlich, selbst das Kuriosesten (Hausmann 1993, S. 467). Erst der Wechsel der Perspektive, der Blick auf eine Sprache aus der Sicht einer Fremdsprache, läßt uns das Idiomatische erfahren. „Betrachtet man die deutsche Sprache als Fremdsprache aus der Sicht aller Sprachen der Erde, dann bleibt in der Wortkombinatorik überhaupt nichts Universales mehr übrig, und es wird alles idiomatisch”. Und: "Totale Idiomatizität - das ist Chaos" (Hausmann 1993, S. 477). - Bei Rorty ist es die Außenseiterperspektive, die Konfrontation mit einem neuen Vokabular, die erst unseren Sinn für Metaphorik, d.h. neue, ungewohnte Verwendungsweisen, schārft. Der Unterscheidung von Buchstäblichem und Metaphorischem entspricht hier wie bei Davidson die Unterscheidung zwischen vertrautem und unvertrautem Vokabular (vgl. Rorty 1993, S. 43). 
Daß wir uns verständigen können, heißt nichts anderes, als daß zwei Menschen sich in ihren Vokabularien, in ihren "Sprachspielen”, von Fall zu Fall tendenziell und vorläufig einander annähern. Die Welt stattet uns nicht mit Kriterien aus, nach denen wir uns zwischen verschiedenen Vokabularien entscheiden können; es bleibt uns nur, Vokabularien handelnd untereinander zu vergleichen und gegeneinander abzuwägen. Kultureller Wandel, gesellschaftliche Veränderung heißt nichts anderes, als daß wir nach und nach die Gewohnheit aufgeben, bestimmte Wörter und Sätze zu benutzen und daß wir uns dafür allmählich andere Vokabularien angewöhnen.

Neue Vokabularien werden jedoch nicht durch bewuBten BeschluB und gesellschaftliche Willensbildung geschaffen. Neue Vokabularien dringen in die Welt unserer Sprachspiele meist unmerklich, sozusagen von der Basis her ein. Sie entspringen dem Bedürfnis einzelner Menschen, sich jeweils als Selbst, als Individuum zu erschaffen, d.h. die eigene Geschichte sprachlich als einmalige zu beschreiben. Alle Beschreibungen der eigenen Individualität ausschließlich in der 'Stammessprache', der Einsatz überkommener Sprachspiele zum Zweck der Selbsterkenntnis werden indes notwendig scheitern (vgl. Rorty 1993, S. 59). Diese Beschreibungen laufen Gefahr, daß die Wörter, die man hat aufmarschieren lassen, sich als bloße Standardartikel erweisen, die in längst bekannter Routine arrangiert wurden (vgl. Rorty 1993, S. 53).

"Dann wird man der Sprache keine eigene Prägung gegeben, sondern ein
Leben lang nur vorgeprägte Stücke herumgeschoben haben. Man wird
also überhaupt kein eigenes Ich gehabt haben. Die eigenen Schöpfungen,
das eigene Selbst, werden nur mehr oder weniger gelungene Ausprägun-
gen wohlbekannter Typen sein" (Rorty 1993, S. 53).

Was bleibt also? Wir müssen uns an den Dichtern orientieren, als den Vorkämpfern für neue Vokabularien. Sie ermutigen uns zur Sünde am herrschenden Vokabular ${ }^{10}$ im Dienste der Selbsterschaffung. Solange wir umstellt sind von toten Metaphern, d.h. von überkommenen Vokabularien, verliert sich unser Selbst im gut geölten Getriebe eingeübter Sprachspiele. Je mehr wir uns in vorhandene Vokabularien verstricken, desto austauschbarer werden wir als Individuen. Unser Ich verblaßt in alltäglichen Beschreibungen und in faden, vorgefertigten Weltentwürfen. Die verbrauchten Vokabularien der Alltagssprache verstellen den Blick auf das Selbst. Wir werden zu jederzeit ersetzbaren Wortverwaltern am Fließband der Normalsprache.

10 Es erstaunt nicht, daß Rorty als einen seiner Kronzeugen für die Möglichkeit neuer Vokabularien Vladimir Nabokow aufruft. 
Ich komme zu den Folgerungen für die Stilistik - Stilistik sehr allgemein verstanden als eine Variante der Beschreibung und Beeinflussung von Vokabularien.

Viele Ansätze in der Stilistik scheinen implizit auf einem Sprachbegriff zu gründen, der Sprache als Medium begreift. Da ist etwa in Stillehren von der Logik der Sachen gegenüber der Logik der Sprache die Rede, da können Inhalte des Denkens mehr oder minder angemessen formuliert werden. Das erinnert doch sehr an die Auffassung von Sprache als Mittel der Darstellung und des Ausdrucks, die Davidson - wie ich meine überzeugend verworfen hat.

Wie können die Konturen einer Stilistik überhaupt aussehen - nach Davidsons Destruktion des Sprachbegriffs? Allenfalls lassen sich Vokabularien in einer einkreisenden Beschreibung erobern. Erst nachdem sie eine Weile im Gebrauch sind, lassen sie sich in Annäherungen ganzheitlich charakterisieren. Aber wie läßt sich Stil vermitteln, wenn Vokabularien gar nicht lehrbar und lernbar im herkömmlichen Sinn sind? Können und wollen sich Stillehren auf die umfassende Idiomatizität bestehender und auf die Metaphorik neuer Vokabularien, d.h. auf deren 'sündhaften Charakter' einlassen? Ist Stil überhaupt reproduzierbar?

Zugespitzt wird ein Dilemma, das für die Stilistik charakteristisch ist. Eng sind heutige Stilauffassungen mit dem Begriff des Individuellen verknüpft. Dichter, Maler, Modemacher haben ihren persönlichen Stil. Sprachwissenschaftliche Annäherungen an Stil schwanken indes zwischen Betonungen des Unverwechselbaren auf der einen Seite und textsortengemäßer und kommunikativer Funktionalität auf der anderen Seite. Die meisten Stillehren dienen bevorzugt der Verfestigung, der Verfeinerung und Optimierung und der Verbreitung bestehender Vokabularien (im Sinne Rortys). Stilistisch 'wertvoller' Sprachgebrauch wird so zum angepaBten, wenngleich funkelnd verpackten Standardartikel und verschleiert den Blick auf Individualität. Stillehren, die gar normative Tendenzen aufweisen, verhindern geradezu das Entstehen neuer Vokabularien, töten neue Metaphern schon im Ansatz ab. Sie sind 'lustfeindlich', tabuisieren das Sündige in der Sprache. Die Frage nach dem Stil entspringt hier, so scheint es, einem Bedürfnis nach Kontrolle. Stilistik wird zum Versuch der Domestizierung von Vokabularien, die im Aufbruch sind. 
Erinnern wir uns: 1986 hat Helmut Henne ${ }^{11}$ in einer Festschrift für Günther Drosdowski am Beispiel von Arno Schmidts StürenburgGeschichten en detail vorgeführt, wie bereits auf der simplen Ebene orthographischer und stilistischer Korrekturen der Aufbruch zu einem kraftvollen neuen Vokabular durch die Sachverwalter überkommener Vokabularien (sprich: Redakteure und Korrektoren) erheblich behindert werden kann. Henne resümiert (S. 11): „Ich redigiere, also bin ich. Aber bedenken die Redakteure, daß literarische Texte Normen folgen, die nicht notwendig die der Standardsprache sind? Eben weil diese Texte eine Welt entwerfen, die 'Wo-Mögliches' darstellt und also dem kruden Zwang des Wirklichen enthoben ist". - Es wäre indes verfehlt, dies auf literarische Vokabularien beschränken zu wollen. Neue Vokabularien keimen in allen gesellschaftlichen Bereichen, im Sozialen und in der Wissenschaft $^{12}$ ebenso, wie in der Kunst. In Abwandlung eines Satzes von Joseph Brodsky: Es gibt keine andere Zukunft für den Menschen als diejenige, die in diesen 'Vokabularien im Aufbruch' vorgezeichnet ist. Sonst läge nur noch die Vergangenheit vor uns. ${ }^{13}$

Was kann eine moderne Stilistik gleichwohl leisten? 1) Sie kann unser Gespür dafür wecken, wo allzu vertraute und glatte Vokabularien zu erstarren oder leerzulaufen drohen. 2) Sie soll unser Gehör und unseren Blick für neue Vokabularien sensibilisieren und uns ermuntern, uns tentativ auf diese einzulassen. 3) Sie soll anregen, neue Vokabularien zu schaffen. 4) Sie muß - und das scheint mir ihre wichtigste Funktion ${ }^{14}$ zu sein - uns mit Mitteln ausstatten, Vokabularien zu bekämpfen, deren Grundtendenz ist, das Entstehen anderer, neuer Vokabularien zu verhindern. Ich fürchte, daß sie so zunächst einen Teil des eigenen Vokabulars bekämpfen muß.

11 Henne, Helmut (1986): Literatursprache - Normen wider die Norm. Arno Schmidts "Stürenburg-Geschichten" in der Zeitung. In: Sprachnormen in der Diskussion. Beiträge vorgelegt von Sprachfreunden. Berlin/New York, S. 1-20.

12 In sehr vergnüglicher Form führt dies am Beispiel wissenschaftlicher Vokabularien Paul Feyerabend in "Über Erkenntnis. Zwei Dialoge” vor (Frankfurt a.M. 1992).

13 „Sonst läge nur noch die Vergangenheit vor uns, als Massenkrimi und Polizeispiel" hieß es vollständig in der im Hanser-Verlag veröffentlichten Rede Brodskys anläßlich der Verleihung des Literaturnobelpreises.

14 Ich nehme an, daß diese Funktion gegenwärtig eher von einer linguistischen Sprachkritik als von der 'herrschenden' Stilistik erfüllt wird. Insbesondere denke ich dabei an Ansätze zu einer kommunikativen Ethik, wie sie etwa von Rainer Wimmer vorgeschlagen wird. 
Zur Frage gewendet: Gehört das Vokabular der Stilistik zu jenen Vokabularien, die die Verheißung großer Dinge bieten, oder eher zu jenen, die solche verhindern wollen? 


\section{Plenardiskussion}

Es schließt sich eine etwa anderthalbstündige Diskussion mit dem Plenum an, in der die Teilnehmer auf die vorgetragenen vier Statements und die Referate der Tagung eingehen und den offenen Begriff "Stilfragen” des Tagungsthemas zu präzisieren versuchen. Die Wortmeldungen werden verkürzt wiedergegeben; ihre Reihenfolge wurde in der schriftlichen Form nach inhaltlichen Gesichtspunkten geordnet:

\section{Gisela Harras:}

Die Stilistik erscheint in der Darstellung von Herrn Bickes als Basis für Wortbedeutungen, die innerhalb einer Nationalsprache geprägt werden. Sie wäre demnach eine notwendige Voraussetzung der Bedeutungsprofilierung und läge der Sprache zugrunde, sie wäre also keine zusätzliche Aktzentuierung. Ist das richtig?

\section{Hans Bickes:}

Sie ist der Sinnhorizont einer Sprache. Mit "Vokabular” meine ich nicht nur den Wortschatz, sondern die Ganzheit der Sprache.

\section{Rainer Wimmer:}

Ich sehe den Stil als eine Variante der Grammatik an, mit deren Wahl sich der Sprecher oder Schreiber zu erkennen gibt. Das sieht man an Frau Stolts Beispiel der Jenninger-Rede, die nicht an der äuBeren Form gescheitert ist, sondern weil das Wie des sprachlichen Ausdrucks die Person des Sprechers bloßstellt.

\section{Birgit Stolt:}

Man sollte mit Vereinfachungen und gedanklichen Verkürzungen, zu denen uns hier der Mangel an Zeit zwingt, vorsichtig sein. Den stilistischen Varianten der Textproduktion stehen bei der Rezeption stets so viele Meinungen und Deutungen gegenüber, wie es Hörer und Leser gibt.

\section{Gerhard Stickel:}

Alle vier Statements zeigen, wie lohnend die Stilforschung ist. Wäre in Zukunft nicht eine wissenschaftlich fundierte normative Stilistik denkbar? Könnte man sich nicht für die textproduktive Seite etwas Vergleichbares vorstellen, um zu lehren, wie man reden oder schreiben soll, um bestimmte Wirkungen zu erzielen und die gegenseitige Verständigung zu verbessern?

\section{Willy Sanders:}

Die Stillehre ist ein bisher unbebautes Feld der Sprachwissenschaft. Ich halte eine normative Stilistik für möglich; allerdings nicht in absehbarer 
Zeit. Denn dafür ist noch beträchtliche Vorarbeit nötig, die lediglich in ersten Ansätzen erkennbar ist. Man muß zwischen Schreiben und Sprechen unterscheiden. Die Stilistik leitet zum Schreiben an. Herr Gauger hat darauf hingewiesen, daB ein Ende des Griffels zum Schreiben diente und das andere die Veränderung des Geschriebenen ermöglichte. Eine solche Korrekturmöglichkeit gibt es beim Sprechen nicht, dessen Lehre und Übung in andere Bereiche, $\mathbf{z}$.B. in den der Rhetorik, gehört.

\section{Ulla Fix:}

Eine normative Stilistik könnte Konversationsmaximen enthalten, eine Beschreibung des möglichen Stilinventars mit Beispielen und mit Mustern, über die wir vieles aufzunehmen pflegen. Wenn man konventionsund musterbezogen vorgeht und darauf hinweist, daB die Muster auch gebrochen werden können, dann kann man alle aufnehmen, ohne einen negativen Lehreffekt befürchten zu müssen.

\section{Gisela Zifonun:}

Erlauben Sie meine provokative Warnung: Die Linguistik sollte die Finger von einer normativen Stilistik lassen. Frau Fix hat in ihrem Statement eindrucksvoll betont: Der Sinn der Stilistik gehe dann verloren, wenn sie keine ästhetische Komponente hat. Die Linguistik aber ist keine ästhetische Disziplin.

\section{Ulla Fix:}

Auch die Stilistik ist keine ästhetische Disziplin, doch sie kann interdisziplinäre Gesichtspunkte des Ästhetischen mit einbeziehen, ja sie darf diese bei der Beurteilung von Texten nicht ignorieren, und zwar nicht aus elitären Gründen, sondern um Texte besser verstehen zu können.

Heidrun Kämper-Jensen:

Die Stilistik sollte eine ästhetische Wissenschaft bleiben und Linguistik und Literaturwissenschaft wieder zusammenführen.

Hans-Jürgen Heringer:

Es ist traurig, daß die normative Stilistik jetzt wieder zur Sprache kommt. Bisher gab es keinen Widerspruch, wenn von Gestaltungsfreiheit die Rede war. Wir brauchen eine Stillehre, die das Individuum in den Stand setzt, sich kommunikativ selbst zu realisieren.

\section{Willy Sanders:}

Der Bedarf, den es an Stilistiken gibt, läBt sich an den Auflagenhöhen ablesen, die z.B. Ludwig Reiners erreicht, dessen „laienlinguistische” Ratgeber in rund einer Million Exemplaren vorliegen. Solche astronomischen Auflagezahlen dürften linguistische Publikationen noch nie erreicht haben. Die Titel reagieren auf die Mechanismen und Moden des Buchrrark- 
tes: aus den einstigen „Stillehren” oder - „schulen” wurde „Deutsch für Profis" und „Kenner”, neuerdings „Schreib-” oder „Toptraining” usw. Wir brauchen Zeit und Vorbereitung, um dieses Terrain betreten und gewinnen zu können. Der Bedarf und die Aufnahmebereitschaft des Publikums müssen erkundet werden. Wir brauchen unterschiedliche Stilistiken, nicht eine einzelne Stillehre, und wir müssen zielgerichtet vorgehen; sonst laufen die Ratschläge ins Leere und bewirken nichts.

Ulla Fix:

Man sollte den Begriff "normativ" fallen lassen und die individuelle Verwirklichung des Stils betonen, die sich zwischen den Regeln der festen Konvention und der freien persönlichen Wahl bewegt.

Hans Werner Eroms:

Welche linguistischen Gebiete sollen in stilistische Untersuchungen einbezogen werden? Alle oder in verengender Konzentration nur einige? Das von Herrn Bickes genannte Vokabular umfaBt alles, während Frau Doherty sich nur mit der Grammatik und da allein mit der Wortstellung befaBt hat, also gegenläufig zu Herrn Püschel, der empfiehlt, alles abzuarbeiten, was ein Text hergibt. Es ist schwierig und wichtig, die Zentrierung zwischen den Mitteln zu finden, die zur Stilisierung beigetragen haben. Das ist zunächst von der Rezeptionsseite des geschriebenen Textes aus gesehen. Aber man kann die dabei gewonnenen Erkenntnisse auch auf die Produktion eines entstehenden Textes übertragen, damit eine vorgegebene Textsorte ihren Effekt erzielt.

Klaus Mattheier.

Warum arbeiten Textlinguistik und Stilistik nicht miteinander Hand in Hand?

\section{Ulla Fix:}

Das ist durchaus üblich. Die Stilistik ist eine Teildisziplin der Textlinguistik.

\section{Hans Bickes:}

Es sollte auch ein Ziel der Stilistik sein, neue Vokabularien in die Gesellschaft zu bringen. Arno Schmidt hat dies z.B. in der Graphematik der Interpunktion, der Wortbildung und der Syntax getan und erfahren, wie schwer das ist. Bei der Drucklegung haben Redakteure und Lektoren ständig versucht, seine Innovationen nach der geltenden Norm zu korrigieren. Statt einer normativen Stilistik sollte es eine kommunikative Ethik geben, die sprachliches, der Situation angemessenes Handeln lehrt und jedem genügend Freiraum läßt, sich individuell zu entfalten. 
Gerhard Stickel:

Linguisten haben stets gute Gründe, normative Festschreibungen zu scheuen. Warum ersetzt man nicht „normativ” durch "pädagogisch"? Denn Stilistik sollte lehren, wie man sich besser ausdrücken kann und wie man lernt, den anderen besser zu verstehen.

\section{Gotthard Lerchner:}

Ich bin in der Hoffnung nach Mannheim gekommen, zu wissen, was Stil seí; aber ich fahre mit einem recht erschütterten Selbstbewußtsein im Hinblick auf meine Stilkenntnisse nach Leipzig zurück. Der Gegenstand der Stilistik wird laufend erweitert. Ästhetik, Grammatiktheorie, kognitive Linguistik und Sprachhandlungstheorie sollen künftig einbezogen werden. Ist das möglich? Welche Stelle nimmt die Stilistik im Kreis der anderen Geisteswissenschaften ein? Muß man sich nicht zu Eingrenzungen entschließen, damit die Stilistik ihr zwischen den Disziplinen vagabundierendes Dasein verliert und sich stabilisiert?

\section{Heinz Vater:}

Ich möchte zunächst Frau Zifonun widersprechen, die Linguistik solle die Hände von der Stilistik lassen. Das ist nicht möglich; denn Stilistik und Grammatik gehören eng zusammen. Mein zweiter Widerspruch gilt Herrn Bickes: Man kann weder die Grammatik unter das Vokabular subsumieren, noch - wie Herr Helbig vorschlägt - das Lexikon unter die Grammatik. Deshalb lassen sich alle sprachlichen Erscheinungen mit dem Terminus „Vokabular” nicht erfassen. - Stil hat immer mit der Variation sprachlicher Mittel zu tun bei gleichzeitiger Konstanz des Gemeinten. Nicht überall - das gilt für die Grammatik ebenso wie für das Lexikon sind stilistische Varianten möglich. Wir kennen alle die zahlreichen Varianten zu "sterben” oder "Gesicht”; aber der Satz „Heute ist der 17. März" kann nicht abgewandelt werden. Und in der Grammatik sind Perfekt und Präterium in manchem Fall nicht austauschbar. „Das Kind ist eingeschlafen" (mit der Gegenwartsrelevanz) kann nicht ersetzt werden durch „Das Kind schlief ein”. Es gibt Bereiche, in denen lexikalische und grammatische Variationen möglich sind und solche, die Variationen ausschlieBen.

Rainer Kohlmayer:

Auch die funktionale Datenangabe „Heute ist der 17. März” läßt sich in phonologischer Dialektfärbung oder mit Änderung der Wortstellung stilistisch variieren. 
Barbara Sandig:

$\mathrm{Zu}$ den Alternativen von Lexik und Grammatik kommen noch die des sprachlichen Handelns. Alle Komponenten in ihren wechselseitigen Bezügen zu beschreiben, erfordert ein hartes Stück Arbeit.

\section{Bernd Spillner:}

Es gibt eine Unzahl praktischer Stillehren und Redeanweisungen von Gewerkschaften, Firmen, Parteien, Institutionen, die Psychologen, Betriebswirte und Werbefachleute verfaßt haben, aber keine Linguisten. Können wir also unsere Kenntnisse nicht in praktische Handlungsanweisungen umsetzen? Die gesamte Tagung hat gezeigt, wie komplex und schwierig der Stilbegriff ist. Eine Rückkehr zu den vielzitierten Leo Spitzer und Emil Staiger bringt uns nicht weiter. Wir sollten auf den reichen Ergebnissen der Textlinguistik und der Konversationsanalyse aufbauen, um eine praktische Handlungsanweisung zu entwickeln, die lehrt, wie man Texte klar, verständlich, konzise und ästhetisch wirksam konzipiert. Das ist eine lohnende, aber schwierige Aufgabe.

\section{Harald Weinrich:}

Erlauben Sie als Ergänzung einen Satz und ein Zitat. Auf die Begriffe Lust und Sünde aus dem Statement von Herrn Bickes bezieht sich mein Satz: Was immer Stil sein mag, ohne Sinnlichkeit wird das nichts mit dem Stil. Und dieser Feststellung füge ich ein Zitat aus "Mon Faust” von Paul Valery an:

$$
\text { Le style c'est le diable. }
$$




\section{Das Institut für deutsche Sprache im Jahre 1994}

0. Allgemeines

1. Arbeiten der Abteilungen und Arbeitsstellen

2. Tagungen, Kolloquien, Kommissionssitzungen und Vorträge externer Wissenschaftler am IDS

3. Kontakte zu anderen Institutionen, Lehraufträge und Vortrāge auBerhalb des Instituts

4. Studienaufenthalte und Besuche in- und ausländischer Wissenschaftler am IDS

5. Gremien und Mitarbeiter des Instituts für deutsche Sprache

6. Besondere Nachrichten

7. Personalstärke, Anschriften, finanzielle Angaben

8. Verōffentlichungen im Jahre 1994

9. Satzung

\section{Allgemeines}

Für die wissenschaftlichen Arbeiten des Instituts im Berichtsjahr galt vor allem der im März 1993 vom Kuratorium gebilligte Arbeitsplan. Dieser Plan wurde im Herbst 1994 mit Zustimmung des Kuratoriums in einigen Punkten modifiziert. Die Änderungen sind vor allem Anpassungen der Zeitplanung, die sich nach den Erfahrungen in der Anfangsphase einiger der neuen Projekte als unvermeidlich erwiesen hatten. Verzögerungen ergaben sich in einigen wenigen Fällen auch durch die Druckaufbereitung der Ergebnisse schon abgeschlossener Projekte. Die zunehmende Praxis der Verlage, Arbeiten, die früher zu ihren Aufgaben gehörten (Lektorieren, Setzen, Korrekturausführung), den Autoren und Herausgebern zu überlassen, bedingt einen erheblichen Mehraufwand an Zeit, der bei den 'älteren' Forschungsprojekten des IDS noch nicht ausreichend berücksichtigt worden ist.

Bei den derzeit laufenden Projekten des Instituts, über die im folgenden kurz berichtet wird, soll der Zeitaufwand für die Ergebnispublikation realistischer als bei einigen der älteren Arbeiten eingeschätzt werden.

Folgende Personalia (siehe auch Kapitel 6) im Berichtsjahr waren für das Institut besonders wichtig:

- Seit 1. Juni 1994 ist Prof. Dr. Reinhard Fiehler Leiter der Abteilung „Gesprochene Sprache - Analyse und Dokumentation" (als Nachfolger von Prof. Dr. Ludger Hoffmann, nun Universität Hamburg). 
- Am 1. Oktober 1994 wechselte Prof. Dr. Rainer Wimmer nach zwölfjähriger Tätigkeit als Mitdirektor von Prof. Dr. Gerhard Stickel vom IDS auf einen Lehrstuhl für Germanistische Linguistik an der Universität Trier.

- Am 8. September 1994 starb Prof. Dr. Heinz Rupp (Basel), der dem Institut von 1965 bis 1987 in mehreren Funktionen verbunden war: im Wissenschaftlichen Rat, im Kuratorium, in verschiedenen Beiräten und Kommissionen, schließlich von 1975 bis 1981 als stellvertretender Vorsitzender des Kuratoriums und von 1981 bis 1987 als Kuratoriumsvorsitzender, d.h. als Präsident des IDS.

\section{Arbeiten der Abteilungen und Arbeitsstellen}

\subsection{Abteilung Grammatik}

Die Arbeiten der Abteilung galten weiterhin der Grammatik der deutschen Sprache. Die redaktionelle Bearbeitung des Manuskripts dieser Grammatik wurde 1994 weitgehend abgeschlossen; die Lektorierung im orthographisch-grammatischen Bereich wird derzeit durchgeführt. Die Druckfassung des Gesamtwerks einschlieBlich Bibliographie und Register kann voraussichtlich im Frühjahr 1995 abgeschlossen werden.

Im Teilprojekt Validierung der Syntax wird derzeit an einer erweiterten Kategorialgrammatik für das Deutsche gearbeitet; dabei sollen die syntaktischen Ausdrucksmöglichkeiten dieses Grammatiktyps, insbesondere auch zur Behandlung von Stellungsphänomenen, erprobt werden.

Im Rahmen des Teilprojekts Konnektoren wird ein Handbuch vorbereitet, das über verknüpfende Elemente (aber, denn, wenn) und Partikel (nur, auch, doch) in einem systematisch-paradigmatischen Teil und in einem Lexikonteil informieren soll. Im Berichtsjahr wurden Kriterien zur Strukturierung des Gegenstandsbereichs in verschiedene Konnektivklassen erarbeitet und Manuskripte zu übergreifenden Themen des systematischen Teils des Handbuchs - etwa zur Wortklassenbestimmung, zur Abgrenzung zwischen Konjunktoren und Subjunktoren, zur Polyfunktionalität einzelner Einheiten - vorgelegt. Theoretische Vorarbeiten zum Handbuch sind 1994 in den Forschungsberichten des IDS (Nr. 71 und 72) erschienen.

Das Teilprojekt Grundlagen eines grammatischen Informationssystems (GRAMMIS) wurde weiter konkretisiert. In der derzeit laufenden Pilotphase werden Prototypen zu bestimmten Teilbereichen einer „elektronischen Grammatik” entwickelt. So wird in der ersten Phase ein 
Kapitel der "Grammatik der deutschen Sprache” (Wortarten und interaktive Einheiten) in ein Hypertextdokument umgesetzt, erweitert um eine Datenbankkomponente zu Funktionswörtern und eine Lernkomponente zur Wortartenbestimmung. Dieser Prototyp soll mit künftigen Benutzern (Deutschlehrern an Gymnasien) erprobt werden. In der zweiten Phase soll entsprechend ein multimediales Textdokument zu dem Themengebiet "Verbsyntax und -semantik" im Dialog mit Lehrenden und Lernenden des Studienfachs Deutsch als Fremdsprache entwickelt werden.

Mit dem Teilprojekt Modifikation im Deutschen, das das semantische Verfahren der modifikativen Erweiterung bei unterschiedlichen Kategorien von Ausdrücken (Nomina, Verben, Adjektive) zum Gegenstand hat, wurde Ende 1994 begonnen.

\subsection{Abteilung Lexikologie und Wortbildung}

In der Abteilung werden Vorhaben zu speziellen Bereichen des deutschen Wortschatzes sowie zur Wortbildung durchgeführt.

Im Projekt Erklärende Synonymik kommunikativer Ausdrücke des Deutschen (ESKA) wurden die Verbgruppen: Repräsentative, Direktive, Deklarative und Expressive bearbeitet. Die in Zusammenarbeit mit der Linguistischen Datenverarbeitung entwickelte Datenbank wurde fortlaufend optimiert.

Für das Handbuch Deutsche Wortbildung in Grundzügen wurden eine theoretische Grundlage für die Darstellung entwickelt und erste Musterbeschreibungen für Neubildungen in der deutschen Gegenwartssprache vorgenommen. Eine Rohfassung des Kapitels "Adjektivbildung" liegt vor.

Die Bearbeitung des neuen Valenzlexikons deutscher Verben wurde fortgesetzt.

In der Arbeitsstelle Graphie und Orthographie wurde im Anschluß an die im Herbst 1992 publizierten Reformvorschläge ein Wörterverzeichnis erstellt. Konzeptionen zur weiteren systematischen Erforschung der (Ortho)graphie wurden erarbeitet.

Die Arbeit an zwei von der Deutschen Forschungsgemeinschaft (DFG) geförderten Projekten wurde fortgesetzt:

(1) Orthographiedarstellungen des Deutschen, insbesondere im 19. Jahrhundert; 
(2) Die Benutzung von Rechtschreibwörterbüchern mit dem Schwerpunkt auf der Auswertung von Anfragen an Sprachberatungsstellen.

\subsection{Abteilung Historische Lexikologie und Lexikographie}

Die Arbeiten an der historischen Datenbank zur deutschen Wortschatzentwicklung seit 1700 wurden fortgesetzt. Die Datenbank soll die Grundlage zur Behandlung wortgeschichtlicher und anderer Themen der jüngeren Sprachgeschichte bilden. Erste Ergebnisse gehen in Studien über Formulierungstraditionen seit dem 18. Jahrhundert ein.

Das Manuskript zum ersten neubearbeiteten Band des historischen Deutschen Fremdwörterbuchs ist abgeschlossen. Ein Band historischer Untersuchungen über die Lehnwortbildung im Deutschen ist weitgehend fertiggestellt.

Im Rahmen der 1993 begonnenen Beteiligung am Frühhochdeutschen Wörterbuch (Anderson/Goebel/Reichmann) wurde das Manuskript der ersten Mannheimer Lieferung erarbeitet.

\subsection{Abteilung Sprachentwicklung in der Gegenwart}

In dieser Abteilung werden Prozesse der Veränderung der deutschen Sprache in der Gegenwart untersucht. Besonders aktuell ist die Untersuchung von Sprachveränderungen im Zusammenhang mit der staatlichen Vereinigung Deutschlands. Hierzu wurde ein großes Textkorpus aus der Zeit von Mitte 1989 bis Ende 1990 zusammengestellt und im Computer verfügbar gemacht. Die Texte stammen sowohl aus dem Osten wie aus dem Westen Deutschlands. Dieses "Wendekorpus” wird z.Zt. für die Untersuchung von Wortschatzveränderungen wie auch Bedeutungsveränderungen in Texten genutzt.

Im Projekt Sprachwandel in der Wendezeit wurde das „Wendekorpus" in drei aufeinander bezogenen Teilprojekten bearbeitet:

(1) Wendebezogene Wortschatzveränderungen in der DDR 1989/90 (AbschluB: Mitte 1995)

(2) Lexikographische Erschließung des Wende-Korpus (Abschluß: Mitte 1995)

(3) Bedeutungsvariation und -uminterpretation in Texten zur deutschen Einheit

(AbschluB: Mitte 1995)

In dem von der Deutschen Forschungsgemeinschaft (DFG) geförderten Projekt Eurotexte wurden die besonderen Prozesse der Genese von 
Texten unter Bedingungen der Mehrsprachigkeit in Institutionen der EG (Wirtschafts- und Sozialausschuß) untersucht. Die Publikation der Projektergebnisse in einer Monographie wurde zur Veröffentlichung vorbereitet.

Seit August läuft das von der Europäischen Kommission finanzierte britisch-deutsche Projekt Ökologische Innovationen und Unternehmenskommunikation. Partner sind das IDS und die ASTON University, Birmingham. Das Projekt läuft bis Ende 1995.

Im AnschluB an das NERC-Projekt (vgl. Jahresbericht 1993) läuft ab November 1994 das ebenfalls von der Europäischen Kommission finanzierte Infrastrukturprojekt PAROLE, das der Schaffung eines Netzwerks von Sprachinstituten in Europa dient. Beteiligt sind 13 Länder. Das IDS ist deutscher Partner.

Vorbereitet wurde die im CoPERNICUS-Programm der Europäischen Kommission finanzierte konzertierte Aktion Trans-European Language Resources Infrastructure (TELRI, 1995 - 1997), in der 22 Institute in 17 Ländern zusammenarbeiten. Das IDS ist Koordinator.

\subsection{Abteilung Verbale Interaktion}

Die Arbeit konzentrierte sich auf die Erarbeitung eines Handbuchs Rhetorik der Problem- und Konfliktbearbeitung, in dem verbale $\mathrm{Mu}$ ster und Verfahren in Problem- und Streitgesprächen dargestellt werden sollen. Das Projekt schließt an die in den vergangenen Jahren in der früheren Abteilung Sprache und Gesellschaft durchgeführten Projekte zu Beratungs- und Schlichtungsgesprächen sowie zur Kommunikation in der Stadt an und soll die vorhandenen gesprächsanalytischen Ergebnisse unter rhetorischer Perspektive systematisieren und vertiefen.

In das Rhetorikprojekt sind auch die beiden Projekte am Sonderforschungsbereich 245 „Sprache und Situation” integriert: Initiative Reaktionen und Bedeutungskonstitution im Dialog.

Im Zusammenhang mit der Arbeit an der "Rhetorik” wurde eine DiskursDatenbank (DIDA) aufgebaut (siehe auch 1.7).

Ein Sammelband mit Ergebnissen der ersten Arbeitsphase des Projekts liegt in Manuskriptfassung vor und ist zur Veröffentlichung in den "Studien zur deutschen Sprache” vorgesehen (Kallmeyer, Werner (Hg.): Gesprächsrhetorik. Zur Analyse von rhetorischen Verfahren in Gesprächsprozessen). 


\subsection{Abteilung Gesprochene Sprache: Analyse und Dokumentation}

Die Arbeit der Abteilung zielt darauf ab, gesprochene Sprache auf den verschiedenen Beschreibungsebenen (durch den Vergleich mit anderen Kommunikationsformen) in ihren Besonderheiten zu charakterisieren. Dazu werden Zusammenhänge zwischen kommunikativen Funktionen und sprachlichen Formen in der gesprochenen Sprache (einschlieflich ihrer arealen und sozialen Varianten) analysiert. Zu den Aufgaben der Abteilung gehört ferner, gesprochene Sprache in ihrer Vielfalt zu dokumentieren.

1994 wurde an vier Projekten gearbeitet:

Im Projekt Zur sprachlichen Integration von Aussiedlern wurde untersucht, wie sich Aussiedler aus der GUS und Polen in die Sprach- und Kommunikationsgemeinschaft integrieren, die sie in Deutschland vorfinden. Forschungsschwerpunkte waren (a) phonologische, lexikalische und syntaktische Veränderungen, die in der Sprache von Aussiedlern auftreten, wenn sie mit den innerdeutschen Sprachvarietäten konfrontiert werden; (b) die Zweisprachigkeit in Aussiedlerfamilien und ihre Auswirkungen auf den Spracherwerb der Kinder sowie (c) die Kommunikationsbeziehungen zwischen Aussiedlern und Einheimischen.

Das Projekt Grammatik des gesprochenen Deutsch ist wegen des Wechsels in der Abteilungsleitung in eine Phase konzeptioneller Neuorientierung eingetreten. Die gegenwärtigen Planungen, die unter dem Arbeitstitel Besonderheiten gesprochener Sprache laufen, werden Anfang 1995 vorgestellt werden.

Das Deutschen Spracharchiv (DSAv) hat 1994 die seit drei Jahren geplante Modernisierung beginnen können. Aufnahme und Aufbereitung von Sprachdaten, Tonbearbeitung und Archivierung (in einer. CD-Jukebox) erfolgen jetzt auf digitaler Basis. Die Digitalisierung der Bestände konzentrierte sich zunächst auf die z.T. stark gefährdeten Aufnahmen der ehemaligen Akademie der Wissenschaften der DDR und auf rumäniendeutsche Aufnahmen. Neben dem rumäniendeutschen Korpus (284 Aufnahmen) sind weitere sechs externe Korpora übernommen worden und stehen zur Integration an.

Als größte Institution dieser Art kann das DSAv nun mehr und mehr Forschungsarbeiten auf der Basis des reichhaltigen Materials und die Funktion als zentrale Dokumentationsstelle für gesprochenes Deutsch übernehmen. 
Die redaktionellen Arbeiten an der "Dokumentation von Tonaufnahmen zum gesprochenen Deutsch" wurden abgeschlossen. Sie erscheint als Band 40 in der neukonzipierten Reihe PHONAI.

Die Erprobungsphase zum Projekt Sprachwandel im gesprochenen Deutsch steht vor dem Abschluß. Es wurden weitere Aufnahmen transkribiert und verschiedene Analyseansätze erprobt.

Im Arbeitsbereich Sprachkontakt wurde ein Abschlußbericht erstellt, der Recherchen und Literaturauswertungen zur Situation des Deutschen in Lateinamerika zusammenfaßt.

\subsection{Zentrale Arbeitsstelle Linguistische Datenverarbeitung (LDV)}

Die Arbeitsstelle hat drei Aufgabenbereiche:

(1) Grunddienste der Datenverarbeitung im IDS,

(2) Neu- und Weiterentwicklung von Datenverarbeitungssystemen,

(3) Erfassung und Aufbereitung der Textkorpora des IDS und korpusbezogener Service.

Zu den Grunddiensten gehört das Betreiben der Computer, die Pflege der Betriebssysteme, der Benutzer-Software und die Sicherung der Daten. Betrieben werden fünf Mehrplatz-UNIX-Computer vom Typ mx300 (Siemens), ein Unix-Computer vom Typ AViion 6225 (Data General) und $15 \mathrm{PC} /$ Workstation-Computer. Mit dieser Ausstattung stehen im IDS über 130 Bildschirm-Arbeitsplätze zur Verfügung.

Folgende Datenverarbeitungs-Systeme wurden entwickelt und werden zur Zeit weiterentwickelt:

Neben der Abteilung "Verbale Interaktion” transkribiert und bearbeitet jetzt auch die Abteilung "Gesprochene Sprache" ihre empirischen Daten mit dem System Diskursdatenbank (DIDA). Die Leistung dieses Systems wurde so erweitert, daB jetzt alle auf modernen graphischen Oberflächen zur Verfügung stehenden Zeichensätze genutzt werden können.

In das Korpus-Recherche-System COSMAS wurden weitere Funktionen integriert; die Korpora wurden laufend erweitert. Im COSMASGesamtsystem können nun auch auswärtige Benutzer über Internet, DFN und andere Netzwerke on-line recherchieren. $1994 \mathrm{gab}$ es 40 externe Dauerabonnenten u.a. in Tokio, Rom, Trondheim, Oslo, Kopenhagen, Vaasa, New York u.a.m.

Mit einem Projekt Multilingual Environment for Corpusbased Lexicon Building wurde begonnen, in dem COSMAS zu COSMAS-II wei- 
terentwickelt wird. Dieses System kann annotierte Corpora verwalten; es wird zum großen Teil durch Mittel der Europäischen Gemeinschaft finanziert. Beteiligt sind mehrere wissenschaftliche Partner in Deutschland und an fünf europäischen Universitäten. Ziel ist die Weiterentwicklung von Computersystemen im Hinblick auf den Aufbau lexikographischer Datenbanken.

\subsection{Zentrale Arbeitstelle Öffentlichkeitsarbeit und Dokumentation}

In der Arbeitsstelle sind die Bereiche 'Öffentlichkeitsarbeit und Presse', 'Publikationswesen', 'Dokumentation' und die Bibliothek organisatorisch zusammengefaßt.

Im Berichtsjahr wurden die laufenden Aufgaben wie Pressekontakte, Redaktion der Zeitschrift 'Sprachreport', Redaktion der Zeitschrift 'Deutsche Sprache', Gästebetreuung, Besucherprogramme, Betreuung des Vereins der Freunde des IDS, Tagungsorganisation, Druckvorlagenerstellung für die IDS-Publikationen, Zentrale Adreßverwaltung, Vertrieb der Eigenverlagspublikationen, Bearbeitung von Anfragen usw. wahrgenommen. Hinzu kommen Aktivitäten zur Verbesserung der internen Information und Kommunikation.

Neben diesen laufenden Aufgaben waren 1994 Schwerpunkt der Öffentlichkeitsarbeit:

die Jahrestagung zum Thema Stilfragen, die Präsentation des IDS auf dem Germanistentag in Aachen, eine Ausstellung mannheimer und tschechischer Künstler mit dem Titel 'Bilder aus Papier' in den Räumen des IDS sowie zahlreiche Maßnahmen (Pressemeldungen, Sondernummer 'Sprachreport', Interviews) zu Fragen der Rechtschreibreform.

Für die Dokumentation sprachwissenschaftlicher Forschungsvorhaben wurden die erhobenen Projektdaten (In- und Ausland) bearbeitet. Die Dokumentation erscheint im Frühsommer 1995.

In der Bibliothek werden seit der Einführung des Katalogisierungssystems BISLOK (August 1993) sämtliche Neuerwerbungen und - soweit möglich - Altbestände mit diesem System erfaßt und verstichwortet. Durch die zunehmende Zahl von Gastwissenschaftler/innen und der auf das Doppelte angewachsene Zahl von Nutzern aus den umliegenden Hochschulen sind die Beratungsaufgaben der Bibliothek erheblich gestiegen. 
2. Tagungen, Kolloquien, Kommissionssitzungen und Vorträge externer Wissenschaftler am IDS

\subsection{Jahrestagung 1994 „Stilfragen”}

Die Jahrestagung 1994 zum Thema „Stilfragen” fand vom 15. - 17. März im Mannheimer Stadthaus statt. Ein Motiv für die Wahl dieses Themas war der Widerspruch zwischen der "Distanz" der modernen Linguistik zum Phänomen "Stil" und dem besonderen Bedarf bestimmter Berufsgruppen an der Klärung von Stilfragen. Die Anzahl von 600 Teilnehmern aus dem In- und Ausland dokumentierte das große Interesse an der Tagung. Die Heterogenität der Stilistik als Teildisziplin von Literaturwissenschaft und Linguistik spiegelte sich in der Vielfalt von Perspektiven wider, aus denen Stilfragen gestellt und zu beantworten versucht wurden: textlinguistische Fragen nach stilistischen Merkmalen verschiedener Typen von "Gebrauchstexten" oder alltagssprachlichen Textsortenstilen standen neben Fragen nach Stilen in interkulturellen Begegnungen sowie nach der Verwendung von Sprechstilen in Gesprächen; aus einer sprachhistorischen Perspektive wurden Fragen des Stilwandels in mündlicher und schriftlicher Kommunikation thematisiert. Aufgrund dieser Heterogenität ist es nicht verwunderlich, daß am Ende der insgesamt 15 Vorträge keine einheitlichen Antworten zu Fragen nach dem Gegenstandsbereich der Stilistik, nach bestimmten Begriffen wie z.B. „Stil” sowie nach den Methoden der Stilanalyse gegeben werden konnten. Nicht verwunderlich ist ebenfalls, daß der Bedarf der Praxis an der Klärung dieser Fragen damit nicht gedeckt ist, und daß Vertreter der Medien dies als Mangel konstatierten. Es gab jedoch Anregungen von Linguisten für Linguisten, sich stärker dem alltagspraktischen Bedarf an der Klärung von Stilfragen zuzuwenden. Im Rahmen der Podiumsdiskussion zum Thema "Aufgaben einer modernen Stilistik" wurde dazu aufgefordert, sich wieder mehr mit den individuellen Aspekten von Stil zu beschäftigen und das Gespür für die das Individuum hemmende Erstarrung allzu vertrauter "Vokabularien” zu wecken. Dazu müsse man sich wieder stärker an den Dichtern orientieren.

Im Rahmen der Tagung wurde Prof. Dr. Gerhard Helbig der KonradDuden-Preis der Stadt Mannheim verliehen.

\subsection{Kommission für Fragen der Sprachentwicklung}

Mit dem Arbeitsthema „Sprache und Sprachentwicklung unter dem Einfluß der (technischen) Medien" befaßte sich das von der Kommission am 1. und 2. Juli 1994 im Institut für deutsche Sprache veranstaltete Kolloquium mit dem Thema "Oralität und Schriftlichkeit im Fernsehen". 
U.M. Quasthoff (Bielefeld) diskutierte einleitend grundlegende Aspekte mündlicher Kommunikation als "somatische Kommunikation”, die sie insbesondere aus der ethnographisch orientierten amerikanischen Oralitätsforschung ableitete. W. Holly (Chemnitz-Zwickau) zeigte unterschiedliche Erscheinungsformen der Mündlichkeit im Fernsehen (sekundäre Oralität) auf. J. Häusermann (Tübingen) berichtete von Verfahren der Ausbildung im Rundfunk- und Fernsehjournalismus, die im Rahmen des Tübinger Aufbaustudiums "Medienpraxis" erprobt worden sind. H. Burger (Zürich) untersuchte die "Vorführung” von „Laien” im Fernsehen, wie sie sprechen und wie man mit ihnen spricht, während $U$. Püschel (Trier) einen neuen Ansatz der Rezeptionsforschung vorstellte, in dem die gemeinsame Verarbeitung des Gesehenen (während und nach einer Sendung) im Mittelpunkt der Analyse steht. W. Schütte (IDS) stellte schließlich Formen der "Boulevardisierung” von Information im Fernsehen dar, die zu einer Vermischung von Informations- und Unterhaltungsfunktion führen.

In der internen Kommissionssitzung wurden entsprechende Konsequenzen für die weitere Arbeit der Kommission diskutiert. Nach Ablauf der Amtsperiode von Prof. Dr. Rudolf Hoberg (Darmstadt) wurde Prof. Dr. Werner Holly (Chemnitz-Zwickau) zum neuen Vorsitzenden der Kommission gewählt.

Das Kolloquium 1995 (23./24. Juni) wird sich mit dem Thema "Textsorten und Textsortenwahl in den Medien" (Arbeitstitel) befassen.

\subsection{Kommission für Rechtschreibfragen}

Die Arbeit der Kommission war im Berichtszeitraum bestimmt von der Vorbereitung der „3. Wiener Gespräche zur Neuregelung der deutschen Rechtschreibung". Bereits im Januar (20. - 22.1.1994) fand am IDS eine Expertenberatung statt, in deren Mittelpunkt Diskussionen zur Getrennt-/Zusammenschreibung und zum Bindestrich, zu den bisherigen Ergebnissen der Ausarbeitung einer Vorlage zur Modifizierten Großschreibung und zum Wörterteil standen. Verabschiedet werden konnten die Vorlagen zur Laut-Buchstaben-Beziehung, zur Zeichensetzung und zur Worttrennung.

Fortgesetzt wurden die Beratungen auf der Arbeitstagung im März (17. 19.3.1994). Neben der weiterführenden fachlichen Diskussion wurde auch das weitere Vorgehen der staatlichen Stellen beraten. $\mathrm{Zu}$ diesem Tagesordnungspunkt konnten als Gäste Ministerialbeamte aus Österreich, aus der Schweiz und aus Deutschland begrüßt werden. In einer eigens angesetzten Kommissionssitzung am 17. März hatten auch die nicht unmit- 
telbar an der Expertenberatung beteiligten Kommissionäre Gelegenheit, sich ein Bild vom Stand der Vorbereitung zu den Wiener Verhandlungen zu machen. Dazu lagen synoptische Darstellungen des Regelteils aller Reformbereiche sowie eine Probestrecke des Wörterteils vor.

Mitglieder der Kommission waren weiterhin beteiligt an Beratungen der Kultusministerkonferenz und des Bundesinnenministeriums zu den vom Internationalen Arbeitskreis vorgelegten überarbeiteten Reformvorschlägen (Kassel 24.5.1994; Bonn 10.11.1994) sowie an einer Arbeitstagung zu speziellen Problemen der Modifizierten Großschreibung am 8.9.1994 in Erlangen.

Als Mitglieder der deutschen Delegation haben die Kommissionäre Augst (Siegen), Heller (Mannheim), Munske (Erlangen), Nerius (Rostock), Schaeder (Siegen) und Zabel (Dortmund) an den „3. Wiener Gesprächen zur Neuregelung der deutschen Rechtschreibung" vom 22. bis 24. November 1994 teilgenommen, zu denen das österreichische Bundesministerium für Unterricht und Kunst eingeladen hatte.

Die Teilnehmer dieser Konferenz kamen in allen Fragen zu einvernehmlichen Lösungen, so daß nunmehr ein zwischen den Fachwissenschaftlern und Vertretern der zuständigen staatlichen Stellen der betroffenen Länder abgestimmter Neuregelungsvorschlag vorliegt.

\subsection{Vorträge externer Wissenschaftler im IDS 1994}

\subsubsection{Prof. Dr. Daniel Bresson (Aix-en-Provence):} „Nomina in prädikativer Form"

8.2.94 Doz. Dr. Ekaterina Protassova

(Päd. Akademie Moskau):

"Attrition der Muttersprache am Beispiel des Russischen in Finnland und in Deutschland"

10.3.94 Dr. Susanne Hauser (Berlin):

„Die Entfaltung der Diskurse über Müll und Abwasser im 19. Jahrhundert"

12.4.94 Martin Hoeltter (Bochum): „Elektronische Wörterbücher für Mensch und Maschine" 
28.4.94

26.5 .94

13.7.94

22.9 .94

18.10 .94

25.10 .94

13.12 .94
Prof. Dr. Stanley Starosta (Hawaii): "The disunity of the word" ("Die Uneinheit(lichkeit) des Wortes")

Prof. Dr. Manfred Görlach (Köln):

"Mehrsprachiges Anglizismenwörterbuch"

Dr. Michail Kotin (Moskau):

„Probleme bei der Beschreibung der deutschen Verbalmorphologie. Zur Herausbildung der Kategorie des Genus verbi"

Dr. Ioanna Karvela (Athen): "Das sprachlich Fremde und das Eigene"

Kristin Bührig (Hamburg): „Zur Generalisierbarkeit qualitativer Forschungsergebnisse - Erfahrungen aus dem ENFAS-Projekt"

Prof. Dr. Vladimir Pavlov (AdW Rußlands/ St. Petersburg):

„Kann man Grammatik ohne Sprachgeschichte erklären?"

Prof. Dr. Herbert Brekle (Regensburg):

„Die Zähmung pompeijanischer Ausschweifungen. Historische und theoretische Begründungen unserer heutigen Buchstabenform"

Prof. Dr. Ilja Gorelov (Saratov/Rußland):

„Kultur und Sprache der Rußlanddeutschen in der Dynamik der Gesellschaftsumwandlung vom 18 . bis 20 . Jahrhundert"

Prof. Dr. Konrad Ehlich (München): „Deutsch - Ein sprachpolitisches Dilemma” 
3. Kontakte zu anderen Institutionen, Lehraufträge und Vorträge außerhalb des Instituts

3.1 Kontakte zu anderen Institutionen

- Alexander-von-Humboldt-Stiftung

- Arbeitsgemeinschaft Forschungseinrichtungen Blaue Liste (AG-BL)

- Arbeitskreis der Sprachzentren, Sprachlehrinstitute und Fremdspracheninstitute

- Arbeitskreis für siebenbürgische Landeskunde, Gundelsheim

- Arbeitsstelle Deutsches Wörterbuch, Berlin

- Arbeitsstelle Deutsches Wörterbuch, Göttingen

- Arbeitsstelle „Sprache in Südwestdeutschland”, Tübingen

- DANTE. Deutschsprachige Anwendervereinigung TEX e.V., Heidelberg

- Deutsche Forschungsgemeinschaft (DFG), Bonn

- Deutsche Gesellschaft für Sprachwissenschaft (DGfS)

- Deutsche Gesellschaft für Dokumentation (DGD), Frankfurt a.M.

- Deutscher Akademischer Austauschdienst (DAAD), Bonn

- Deutscher Germanistenverband

- Deutscher Sprachatlas, Marburg

- DIN-Normenausschuß Terminologie, Berlin

- Dudenredaktion des Bibliographischen Instituts, Mannheim

- EURALEX, European Association for Lexicography, Exeter

- Fachverband Deutsch als Fremdsprache

- Fachverband Moderne Fremdsprachen

- Fremdsprachenhochschule Tianjin, VR China

- Fritz-Thyssen-Stiftung

- GLDV, Verein zur Förderung der wissenschaftlichen Datenverarbeitung e.V., Frankfurt

- Gesellschaft für angewandte Linguistik e.V. (GAL)

- Gesellschaft für deutsche Sprache (GfdS), Wiesbaden

- Gesellschaft für Mathematik und Datenverarbeitung mbH, Bonn

- Goethe-Institut, München

- Hugo-Moser-Stiftung im Stifterverband für die Deutsche Wissenschaft, Essen

- Institut für Auslandsbeziehungen, Stuttgart

- Inter Nationes, Bonn

- International Association of Sound Archives (IASA)

- Institut für niederdeutsche Sprache (INS), Bremen

- Laboratoire d'Automatique Documentaire et Linguistique (LADL), Paris

- Max-Planck-Institut für Psycholinguistik, Nimwegen 
- Österreichische Akademie der Wissenschaften, Wien

- Robert-Bosch-Stiftung, Stuttgart

- Russische Akademie der Wissenschaften, Institut für russische Sprache, Moskau

- Stiftung Volkswagenwerk, Hannover

- Universitäten Mannheim und Heidelberg sowie zahlreiche weitere germanistische Institute an Universitäten und Hochschulen im Inund Ausland

\subsection{Lehraufträge von IDS-Mitarbeitern}

Prof. Dr. Joachim Ballweg: SS 1994, Modifikation, Proseminar, Universität Stuttgart

Kategorialgrammatik und deutsche Wortstellung, Hauptseminar, Universität Stuttgart

WS 1994/95, Behandlung von Fachwortschatz in einsprachigen Wörterbüchern, Proseminar, Universität Stuttgart

Nebensätze, Hauptseminar, Universität Stuttgart

Priv.Doz. Dr. Bernd Ulrich Biere: SS 1994, Sekundärtextsorten, Hauptseminar, RWTH Aachen

Schreibforschung und Aufsatzunterricht, Hauptseminar, Universität Koblenz

Textverstehen und Textverständlichkeit, Vorlesung, Universität Koblenz

Einführung in die Fachdidaktik, Proseminar, Universität Koblenz Einführung in die Sprachwissenschaft, Proseminar, Universität Koblenz

WS 1994/95, Kolloquium für Examenskandidaten, Kolloquium, RWTH Aachen

Schreiben in der Schule. Aufsatzdidaktische Konzeptionen, Vorlesung, Universität Koblenz

Jugendsprache und Deutschunterricht, Hauptseminar, Universität

Koblenz

Einführung in die Fachdidaktik, Proseminar, Universität Koblenz

Prof. Dr. Reinhard Fiehler: SS 1994, Analyse von Verkaufsgesprächen, Seminar, Universität Bielefeld

Kommunikation im Alter, Seminar, Universität Bielefeld

Prof. Dr. Gisela Harras: SS 1994, Texte, Hauptseminar, Universität Mannheim

WS 1994/95, Kognitive Semantik, Kolloquium, Universität Mannheim

Dictionaries, Undergraduate (Proseminar), University of Florida/Gainesville/Fl. 
The structure of information of german and english sentences, Graduate (Hauptseminar), University of Florida/Gainesville/Fl.

Prof. Dr. Werner Kallmeyer: SS 1994, Formulierungsverfahren, Hauptseminar, Universität Mannheim

WS 1994/95, Fernsehgespräche, Hauptseminar, Universität Mannheim.

Dr. Inken Keim-Zingelmann: SS 1994, Stereotyp und Vorurteil in der interkulturellen Kommunikation, Hauptseminar, PH Heidelberg WS 1994/95, Kommunikative soziale Stile, Forschungsseminar, Universität Saarbrücken

Dr. Klaus-Peter Konerding: SS 1994, Aspekte der kognitiven Linguistik, Proseminar, Universität Heidelberg

WS 1994/95, Syntax des Deutschen, Proseminar, Universität Heidelberg

Priv.Doz. Dr. Katharina Meng: WS 1994/95, Gesprochene Sprache. Grundlegende Eigenschaften und ihre Dokumentation im Transkript, Seminar, Universität Mannheim

Prof. Dr. Wolfgang Motsch: SS 1994, Explosionen im Wortschatz. Mittel und Funktionen der Wortbildung, Proseminar, Universität Mannheim

Pantelis Nikitopoulos, Dipl. rer. pol.: SS 1994, Interkulturelle Kommunikation und Binnendifferenzierung im Unterricht der Regelklasse, Seminar, PH Heidelberg

WS 1994/95, Interkulturelle Kommunikation und Binnendifferenzierung im Unterricht der Regelklasse, Seminar, PH Heidelberg

Dr. Werner Nothdurft, Dipl. Psych.: SS 1994, Ökologische Kommunikation, Hauptseminar, Fachhochschule Essen

WS 1994/95, Interaktionstheorien, Hauptseminar, Fachhochschule Essen

Prof. Dr. Joachim Schildt: WS 1994/95, Das Frühneuhochdeutsche. Funktionale, sprachgeographische und strukturelle Probleme seiner Entwicklung, Seminar, Universität Mannheim

Dr. Rudolf Schmidt: SS 1994, Maschinelle Bild- und Spracherkennung, Vorlesung, Universität Mannheim

Digitale Bild- und Sprachverarbeitung, Vorlesung, Berufsakademie Mannheim

Prof. Dr. Johannes Schwitalla (ab 1.5.1994 beurlaubt)

Vertretung einer Professur für deutsche Sprachwissenschaft, Universität Würzburg

Prof. Dr. Gerhard Stickel: SS 1994, Negation und Negieren, Hauptseminar, Universität Mannheim 
WS 1994/95, 'Sprachreinigung', 'Sprachpflege', 'Sprachkultur' in Deutschland, Hauptseminar, Universität Mannheim

Dr. Angelika Storrer: SS 1994, Metalexikographische Methoden in der Computerlexikographie, Forschungsseminar, Universität Tübingen

WS 1994/95, Korpusgestützte empirische Phraseologie, Proseminar, Universität Heidelberg

Prof. Dr. Rainer Wimmer: SS 1994, Einführung in die neuhochdeutsche Syntax, Vorlesung, Universität Trier

Linguistisch begründete Sprachkritik, Hauptseminar, Universität Trier

Grundbegriffe der Grammatik und Semantik, Proseminar, Universität Trier

Wissenschaftssprache, Oberseminar, Universität Trier

Priv.Doz. Dr. Gisela Zifonun: SS 1994, Valenz in Grammatik und Lexikon, Hauptseminar, Universität Mannheim

\subsection{Kurse und Kurzseminare von IDS-Mitarbeitern}

Dr. Karl-Heinz Bausch: 25.1. - 15.6.1994, Deutsch für Ausländer, Sprachkurs, Volkshochschule Ladenburg

10.5. - 27.5.1994, Textlinguistik, Seminar, Fremdsprachenschule Tianjin, VR China

13.5. - 20.5.1994, Textverstehen, Dozentenfortbildung, Fremdsprachenschule Tianjin, VR China

30.8. - 8.12.1994, Deutsch für Ausländer, Sprachkurs, Volkshochschule Ladenburg

Priv. Doz. Dr. Bernd Ulrich Biere: 17.10 und 24.10.1994, Fachsprachen, Vorlesung und Übung (Kurzseminar), Universität Preßburg, Slowakische Republik, Lehrstuhl für Germanistik und Nordistik 19.10. - 24.10.1994, Textfunktion und Textverstehen, Vorlesung und Seminar (Kurzseminar), Universität PreBburg, Slowakische Republik, Lehrstuhl für Germanistik und Nordistik

25.10.1994, Sprachgeschichtliche Perioden des Neuhochdeutschen (17.-19. Jh.), Vorlesung und Seminar (Kurzseminar), Universität Preßburg, Slowakische Republik, Lehrstuhl für Germanistik und Nordistik

Dr. Manfred W. Hellmann: 23. September 1994, Sprache und Verständigung in Deutschland - Brücke oder Hindernis?, Kurzseminar: Internationaler Sommerkurs für deutsche Sprache und Kultur, Universität Mannheim 
Prof. Dr. Dieter Herberg: 5.3.1994, Rechtschreibreform: letzter Stand, Tendenzen, Kurzseminar auf der Studientagung des Verbandes der Fachlehrer e.V., Königswinter

Dr. Irmtraud Jüttner: 20.10.1994, Fallstudien zu sprachlichen Fragestellungen, COSMAS-Workshop im Rahmen des EU-Projektes MECOLB (Multilingual Environment for Corpus-Based Lexicon Building), Institut für deutsche Sprache, Mannheim

Dr. Inken Keim-Zingelmann: 2. - 6.5.1994, Endredaktion der Beiträge zu: „Selbst- und Fremdbilder im Ost-West-Diskurs” am ZIF, Bielefeld

13. - 22.8.1994, Datenaufnahme in Posen, Polen: Gesprächsmaterialien für das deutsch-polnische Projekt

Dr. Wolf-Andreas Liebert: 16.4. - 17.4.1994, Molekülchimären und Gedankenchimären, Metaphern-Workshop mit einer AIDSforschungsgruppe vom Schwerpunkt angewandte Tumorvirologie des deutschen Krebsforschungszentrums, Institut für deutsche Sprache, Mannheim

Robert Neumann: 17. - 19. Mai 1994, Multimediale, integrierte und hochstrukturierte Spracharchiva als Forschungsinstrument, Workshop, Columbia-University

Ulrich Reitemeier: 5/94 - 12/94, Soziologie für Logopäden, DeuserSchule, Ludwigshafen

Dr. Reinhold Schmitt: 15.6.1994, Kommunikationstraining für Sekretärinnen, Köln

Dr. Peter Schröder: 3.11.1994, Besonderheiten der gesprochenen Sprache, Gastseminar, Høogskole i Øostfold Halden/Norwegen

Helmut Schumacher: 3.12. - 21.12.1994, Einführung in die Valenzgrammatik, Kurzzeitdozentur Havanna/Kuba, Vorlesung, Universität Havanna

3.12. - 21.12.1994, Neuere Tendenzen in Syntax und Semantik des Deutschen, Seminar, Universität Havanna

Prof. Dr. Johannes Schwitalla mit Dr. Inken Keim-Zingelmann: 29.8. - 31.8.1994, Soziale Stile des Sprechens, dargestellt an der "Literaturgruppe”, Arbeitstagung für kontrastive Untersuchungen „kommunikativer Tugenden” im Japanischen und Deutschen, Workshop, Sanda bei Osaka.

Kathrin Steyer: 26.4.1994 Topische Argumente von Westdeutschen über Ostdeutsche, Seminar im Rahmen des Hauptseminars „Sprachliche Verarbeitung der Wende”, Universität IIalle

Doris al-Wadi: 12. - 14.9.1994, (zusammen mit Dipl.Ing. Cyril Belica) COSMAS - Ein Computersystem für den Zugriff auf große Textkorpora, Vorführung im Rahmen der Kulturbörse zum Deutschen 
Germanistentag 1994, RWTH Aachen

20.10.1994, Praktische Einführung in COSMAS; Fallstudien zu sprachlichen Fragestellungen, COSMAS-Workshop im Rahmen des EU-Projektes MECOLB (Multilingual Environment for Corpus-Based Lexicon Building), Institut für deutsche Sprache, Mannheim

\subsection{Vorträge von IDS-Mitarbeitern}

Prof. Dr. Joachim Ballweg: 11.11.1994, Was sind zugelassene Antworten? Fragesätze und Fragen, Universität Freiburg

Dr. Nina Berend: 17.4.1994 Sprachliche Integration rußlanddeutscher Aussiedler, Universität Washington, Washington, USA

22.9.1994, Neuere Tendenzen im muttersprachlichen Deutschunterricht in RuBland, Nordbadischer Caritas-Verband, Mannheim 11.11.1994, Sprachliche Integration rußlanddeutscher Aussiedler, Universität Kopenhagen, Kopenhagen

23.10.1994, Soziale und sprachliche Integration der Wolgadeutschen, Universität Hays, Kansas, USA

Priv. Doz. Dr. Bernd Ulrich Biere: 15.4.1994, Grammatische Korrektheit und Verständlichkeit im Journalismus, Seminar für Journalistik Institut für Pädagogik, Universität Mainz, 5.7.1994, Interpretative Verfahren der Kommunikationsanalyse, Institut für Pädagogik Universität Koblenz,

6.9.1994, Zum Zusammenhang von Rezeption und Produktion im Lernbereich „Schriftlicher Sprachgebrauch”, Germanistisches Institut, Universität Rostock

12.9.1994, Germanistik und Öffentlichkeit, Deutscher Germanistentag, 11. - 14.9.1994, RWTH Aachen

22.9.1994, Die Bedeutung der Mündlichkeit für Verstehenstheorie und Verständlichkeitsforschung, Jahrestagung der Gesellschaft für Angewandte Linguistik, 21 - 24.9.1994, Universität Trier 29.9.1994, Verständlichkeitsforschung und Angewandte Linguistik, Jahrestagung der Vereinigung für Angewandte Linguistik der Schweiz, 27. - 30.9.1994, Universität Bern

11.10.1994, Textverstehen und Textverständlichkeit, Institut für Germanische Philologie, Universität Poznań/Posen, Polen 18.10.1994, Zur Komplementarität von Mündlichkeit und Schriftlichkeit. Ein sprachhistorisches Beispiel und ein konzeptioneller Vorschlag, Institut für Germanistik, Universität Greifswald 22.11.1994, Zum Zusammenhang von Rezeption/Produktion und Mündlichkeit/Schriftlichkeit in sprach- und literaturdidaktischer Sicht, Institut für Germanistik, Universität Koblenz 
Dr. Elke Donalies: 11.10.1994, Wortverknüpfungen und Wortverknüpfungstraditionen in der wirklich gelesenen Literatur des 18. 20. Jahrhunderts, IDS-Kolloquium, Institut für deutsche Sprache, Mannheim

Dr. Mechthild Elstermann: 29.10.1994, Zur Behandlung und Vermeidung heikler Themen in Gesprächen eines Sornmerkurses in Poznàn (zusammen mit Dr. Reinhold Schmitt), 2. Kolloquium und Vereinsgründung des „Görlitzer Kreises”, 28. - 30.10.1994, Görlitz

Prof. Dr. Reinhard Fiehler: 3.6.1994, Der Empiriebegriff der Diskursanalyse, Kolloquium des SFB 245: Sprache und Situation, IDS Mannheim

25.6.1994, Stereotypenforschung: qualitative und quantitative Methoden, Kolloquium 'Cultural Encounters in the 'New' Europe. Conflict, Coexistence or Conciliation?', Universität Wien

22.9.1994, Gibt es einen Kommunikationsstil des Alters? Beobachtungen zur interaktiven Akzentuierung von Alter im Gespräch, Sektion 'Textlinguistik und Stilistik', im Rahmen der Jahrestagung 1994 der GAL, Universität Trier

17.10.1994, Mündlichkeit als Herausforderung der Sprachgeschichte, Universität Greifswald

Dr. Claudia Fraas: 14.9.1994, Bedeutungskonstitution in Texten - das IDENTITÄTS-Konzept im Diskurs zur deutschen Einheit, Lexicology and Lexical Semantics (Internationale Tagung, veranstaltet von der Universität Münster), Münster

Prof. Dr. Gisela Harras: 25.1.1994, Zum Empiriebegriff in der Linguistik, Kolloquium des SFB 245: Sprache und Situation, IDS Mannheim 1.6.1994, A concept of frame for describing speechact-verbs, Princeton University, Princeton N.J., USA

4.9.1994, A Model for describing speechact-verbs, EURALEXTagung, Amsterdam

30.10.1994, Zur Konzeptuellen Basis der kontrastiven Lexikologie, Werkstattgespräch: Kontrastive Lexikologie, Universität Kopenhagen

6.12.1994, Zur Argumentstruktur von Sprechaktverben, Universität Bielefeld

Priv. Doz. Dr. Ulrike Haß-Zumkehr: 6.7.1994, Die „echten” und die "falschen” Deutschen. Zur Identität der deutschen Juden im 19. Jahrhundert, Gesellschaft für deutsche.Sprache, Zweig Heidelberg, in Zusammenarbeit mit dem Germanistischen Seminar, Universität Heidelberg 
Dr. Manfred W. Hellmann: 24.1.1994, Wörterbuch des Wendedeutsch - Zum sprachlichen Wandel in beiden Teilen Deutschlands, "Literarischer Salon” der Universität Hannover, Hannover 22.6.1994, Deutsch im Westen - Deutsch im Osten: Probleme nach der Vereinigung, Gesellschaft für deutsche Sprache und Germanistisches Seminar der Universität Heidelberg, Universität Heidelberg

8.9.1994, Wortschatzdifferenzen und Verständigung - Sprachliche Probleme in Deutschland nach der Vereinigung.

Faszination Wort - Sprache und Rhetorik in der Mediengesellschaft, Konrad-Adenauer-Stiftung, Schwäbisch Gmünd

8.11.1994, Ostdeutsch/Westdeutsch - Sprache als Brücke oder Barriere? Multiplikatorentagung Innere Einheit, Bundeszentrale für politische Bildung - Außenstelle Berlin

22.11.1994, Themen, Diskurs, Wortschatz der Wendezeit - Analysen auf der Grundlage des Mannheimer Wende-Korpus, Linguistisches Kolloquium der Universität GHS Essen, Universität Essen

Prof. Dr. Dieter Herberg: 5.5.1994, Schlüsselwörter der Wendezeit. Ein lexikologisch-lexikographisches Projekt zur Auswertung des IDSWende-Korpus, Seventh International Symposium on Lexicography, May 5. - 6., 1994, Universität Kopenhagen

18.11.1994, Lexikalischer Wandel 1989/90. Zur Analyse von Schlüsselwörtern der Wendezeit. Internationale Fachkonferenz „Sprachnormen und Sprachnormwandel”, 17. - 18.11.1994, Universität Rostock

Prof. Dr. Werner Kallmeyer: 10.5.1994, Zustimmen und Widersprechen Zur Gesprächsanalyse von Problem- und Konfliktgesprächen, Kolloquium „Textlinguistik und Gesprächsanalyse”, 8. - 10.5.1994, Germanistisches Seminar der Universität Budapest

29.7.1994, Das Mannheimer Stadtprojekt, Klausurtagung „Erforschung moderner Stadtsprachen”, Stadtsprachenprojekt München, Kloster Zangberg (bei München)

Dr. Inken Keim-Zingelmann: 29. - 30.8.1994, Formen der Höflichkeit in unterschiedlichen sozialen Gruppen. Workshop zu „Konzepten kommunikativer Tugenden" (Deutsch-Japanisch), Sanda/Osaka, Japan

2.4.1994, Formelhaftes Sprechen als Merkmal sozialen Stils, Sommerseminar für germanistische Linguisten, Osaka, Japan

Dr. Klaus-Peter Konerding: 15.4.1994, Situationstypen und Frames eine kritische Bewertung, Kolloquium zur Typologie und Übersetzung von Kultur, systemen”, Fachbereich 8 der Universität des Saarlandes, Saarbrïcken 
15.9.1994, Framesemantik für Sprechaktverben, International Conference Lexikology and Lexical Semantics, Westfälische Wilhelms-Universität Münster

Dr. Barbara Kraft: 13.4.1994 (zusammen mit Christina Lanzen, Berlin): Zur Entwicklung des Widersprechens bei Vorschulkindern, Symposium Deutschdidaktik, Deutsches Seminar der Universität Zürich, Zürich

3.5.1994, Imperativgebrauch in gesprochener Sprache, Linguistisches Kolloquium, Universität Dortmund, Institut für deutsche Sprache und Literatur, Dortmund

Dr. Wolf-Andreas Liebert: 19.3.1994, Wenn AIDS-Forscher über ihre Metaphern nachdenken. Zum Zusammenspiel von verbaler Interaktion, Hintergrundwissen, Reflexion und Innovation, Fünfter internationaler KongreB der I.A.D.A. vom 18. - 20. 3. 1994, Sorbonne, Paris

24.3.1994, The Cognitive Map. A new Approach for the Acquisition and Analysis of Cognitive Models, 19. internationales L.A.U.D.-Symposium, 22. - 24. 3.1994, Duisburg

27.3.1994, Réprésentations sociales et la métaphore, École des Hautes Études, Paris

19.4.1994, Machina ex Metaphora. How to Use the Creative Potential of the Humanities for the "Hard Sciences", Joint International Conference ALLC-ACH94 "Consensus ex Machina”, 19.-23. 4. 1994, Sorbonne, Paris

3.9.1994, Lascaux - a Hypermedia Lexicon of Metaphor Models for Scientific Imagination, 6. internationaler EURALEX-KongreB, 30.8.-3.9.1994, Amsterdam

3.11.1994, Lascaux - Kognitive Lexikographie am Beispiel, Gemeinsame Sitzung des Kolloquiums für Lexikologie und Lexikographie des Germanistischen Seminars der Universität Heidelberg und des Forschungskolloquiums des Instituts für deutsche Sprache, Mannheim

Dr. Katharina Meng: 14.4.1994, Narrative Sozialisationen, Symposium Deutschdidaktik, Zürich

28.9.1994: Zweisprachigkeit in rußlanddeutschen Familien in Deutschland, IDS-Aussiedlerprojekt, Workshop „Sprachliche Integration von Aussiedlern", IDS Mannheim

30.9.1994, Sprachbiographie einer rußlanddeutschen Familie, Kolloquium „Funktionale Pragmatik: Sprachwege”, Hamburg

Prof. Dr. Wolfgang Motsch: 11.3.1994, Konversationelle Implikaturen und Illokutionstypen, Jahrestagung der DGrS, Münster 
5.7.1994, Semantische Grundlagen der Wortbildung, Linguistisches Kolloquium, Universität Essen

6.7.1994, Adjektivwortbildung, Germanistisches Institut Universität Bochum

Robert Neumann: 3.2.1994, MECOLB Kick-Off Meeting, Kommission der Europäischen Gemeinschaften, Luxemburg

11.2.1994, GLDV - Arbeitskreis „Korpora”, Aktivitäten des Arbeitskreises Korpora der GLDV, Institut für deutsche Sprache, Mannheim

9.6.1994, 1. MECOLB-Usergroup-Treffen, Institut für deutsche Sprache, Mannheim

14.9.1994, Elektronische Korpora: Ein Paradigmenwechsel?, Deutscher Germanistentag, Aachen

20.10.1994, Cosmas-Workshop für die MECOLB-Usergroup, Institut für deutsche Sprache, Mannheim

Pantelis Nikitopoulos, Dipl.rer.pol.: 14.3.1994, Grundnormen und -werte in einer pluralistischen multikulturellen Gesellschaft (Podiumsdiskussion), Mannheimer Abendakademie, Mannheim

31.5.1994, Vom Nationalstaat zur Multikulturellen Gesellschaft. Chance oder Irrweg?, Rückkehr zum Nationalstaat oder Entwicklung einer multikulturellen Gesellschaft?, Mannheimer Abendakademie, Mannheim

23.11.1994, Schlaglichter auf Euro-Schlagwörter: über soziolinguistische, politologisch-historische „Beziehungskisten”, Europawoche, Ministerium für Kultur und Sport, Stuttgart

Dr. Werner Nothdurft, Dipl. Psych.: 11.4.1994, Gemeinsam musizieren. Plädoyer für ein neues Leitbild für die Betrachtung mündlicher Kommunikation, (zusammen mit Prof. Dr. Johannes Schwitalla) Symposium Deutschdidaktik, Zürich

28.4.1994, Der Sprecher spricht. Reflexionen in einem kommunikationswissenschaftlichen Vorurteil, SFB-Kolloquium "Interaktionsereignis", Institut für deutsche Sprache, Mannheim

23.5.1994, Bilder Hören. Über das Zustandekommen von Metaphern in mündlicher Kommunikation, Academie du Midi, Chateau de Nyer

1.6.1994, Verstehen und Verständigung zwischen Experten und Laien, FHS Fulda

21.9.1994, Plädoyer für die Abschaffung des Verstehens, GAL, Trier

Dr. Renate Pasch: 10.3.1994, Implikaturen und lexikalisch induzierte Präsuppositionen, 16. Jahrestagung 1994, AG 11, DGrS, 9. - 11. März 1994, Münster 
Ulrich Reitemeier: 27. - 29.9.1994, Kommunikationsbeziehungen zwischen Aussiedlern und Einheimischen, Sprachfähigkeiten, Sprachentwicklung und sprachliches Handeln bei Aussiedlern in Deutschland - empirische Zugänge, Aussiedlerprojekt am Institut für deutsche Sprache, Mannheim

Prof. Dr. Hartmut Schmidt: 5.5.1994, Die neuere Geschichte des Berlinischen, Universität Kopenhagen

11.10.1994, Traditionen des Formulierens, Einführung und „Freiheitskollokationen", IDS-Kolloquium, Mannheim

Dr. Reinhold Schmitt: 4.5.1994, Schwellensteher. Sprachliche Präsenz und interaktiver Austausch in einem Kiosk, Universität Bielefeld 28.10. - 30.10.1994, Zur Behandlung und Vermeidung heikler Themen in Gesprächen des Sommerkurses in Poznań (zusammen mit Dr. Mechthild Elstermann), 2. Kolloquium und Vereinsgründung des "Görlitzer Kreises”, Görlitz

12.12.1994, Zur narrativen Konstruktion sozialer Identität, Universität Berlin

Dr. Norbert Schrader: 4.11.1994, Praktische Orthographiedarstellungen von Adelung bis zur zweiten orthographischen Konferenz, DFG-Projekt-Kolloquium: Das Rechtschreibwörterbuch, Institut für deutsche Sprache, Mannheim

Helmut Schumacher: 29.3.1994, Valenzwörterbücher für DaF, Internationaler FremdsprachenkongreB, Fachverband Moderne Fremdsprachen (FMF)/Fédération Internationale des Professeurs de Langues Vivantes (FIPLV), Universität Hamburg 14. - 15.12.1994, Valenzlexikographie und DaF-Unterricht, Seminar zur germanistischen Linguistik und Traduktologie, Catédra Humboldt, Universität Havanna, Kuba

15.12.1994, Aktuelle Projekte des Instituts für deutsche Sprache, Mannheim, Seminar zur gemanistischen Linguistik und Traduktologie, Catédra Humboldt, Universität Havanna, Kuba 20.12.1994, Zur Reform der deutschen Orthographie, Universität Havanna, Cátedra Humboldt

Dr. Carmen Spiegel: 22.9.1994, Selbst- und Fremdstilisierungen in umweltpolitischen Auseinandersetzungen, GAL, Trier

Kathrin Steyer: 26.4.1994, Reformulierungen im Diskurs (Kolloquium), Germanistisches Institut, Universität Halle

Prof. Dr. Gerhard Stickel: 19.1.1994, The Institute for the German Language: Its Aims and Organization, Tokio

20.1.1994, Corpora of the Institute for the German Language and their Use, Tokio 
13.9.1994, Das IDS als Kulturinstitution (Beitrag zur 'Kulturbörse'), Germanistentag, Aachen

19.9.1994, Verbreitete Meinungen zum heutigen Deutsch, Internationaler Ferienkurs der Universität Mannheim, Mannheim

26.10.1994, Mißbrauch von Sprache?, 1. Mannheimer Sprachfestival, Artes Liberales, Mannheim

Dr. Wilfried Schütte: 2.7.1994, Boulevardisierung von Information, Kolloquium „Oralität und Schriftlichkeit im Fernsehen”, Kommission für Fragen der Sprachentwicklung, Institut für deutsche Sprache, Mannheim

12.9.1994, Graffiti - Schmiererei oder Alltagskultur? Internationaler Sommerkurs der Universität Mannheim, Universität Mannheim

23.9.1994, Anthropologie und Konversationsanalyse: Ist das Konzept der ,joking relationship" brauchbar, um Funktionen von Scherzen in sozialen Welten zu beschreiben? 25. Jahrestagung der Gesellschaft für Angewandte Linguistik GAL e.V., Arbeitskreis "Humor, Witz und Lachen in der Diskursanalyse”, Trier

Prof. Dr. Johannes Schwitalla: 12.1.1994, Rhetorik im Alltag, Das Beispiel "Small-Talk" vor dem eigentlichen Thema, Gesellschaft für deutsche Sprache, Zweig Heidelberg, in Zusammenarbeit mit dem germanistischen Seminar, Universität Heidelberg

7.2.1994, Pragmatik in der Grammatik, Vorschläge für eine kommunikative Grammatik der gesprochenen Sprache, Institut für deutsche Philologie, Universität Würzburg

17.3.1994, Verbale Machtdemonstrationen, IADA (Internationale Assoziation für Dialoganalyse), Paris

11.4.1994, Gemeinsam musizieren. Eine neue Metapher zur Beschreibung verbaler Kommunikation (zusammen mit Dr. Werner Nothdurft), Internationale Deutschlehrertagung, Zürich

3.9.1994, Grundsätzliche Überlegungen zur Beschreibung kultureller Unterschiede beim Sprechen, 14. Sommerseminar für Linguisten, Osaka

10.11.1994, Textsorten und Textsortenstile in Ehetraktaten des 15. und 16. Jahrhunderts, Tagung Text und Geschlecht, Deutsches Seminar der Universität Basel, Leuenberg bei Basel

Dr. Angelika Storrer: 27.1.1994: Phraseolexeme als Sorgenkinder der maschinellen Sprachverarbeitung, Kolloquium zur Lexikographie und Lexikologie, Universität Heidelberg

11.2.1994, ELWIS: Korpusgestützte Entwicklung lexikalischer Wissensbasen, Treffen des Arbeitskreises „Korpora” der Gesell- 
schaft für linguistische Datenverarbeitung GLDV, Institut für deutsche Sprache, Mannheim

17.2.1994, LexParse: Ein Parser zur maschinellen Analyse von Wörterbuchstrukturen, Arbeitstreffen: Lexikon und Text, Schloß Hohentübingen

27.5.1994, Situationsbezogene Valenzbeschreibung, Kolloquium „Kulturspezifisches Übersetzen”, Universität Saarbrücken

6.6.1994, Mehrwortlexeme in der maschinellen Übersetzung, Kolloquium zur Computerlexikographie, Universität Leipzig

8.12.1994, Metalexikographische Methoden in der Computerlexikographie, Kolloquium zur Lexikographie und Lexikologie, Universität Heidelberg

Dr. Wolfgang Teubert: 11.2.1994, Das Projekt "Network of European Reference Corpora" und seine Ergebnisse, Tagung des KorpusAusschusses, Gesellschaft für linguistische Datenverarbeitung, Mannheim

12.5.1994, The Concept of Work since Antiquity, Harvard Medical School, Department of Psychology, Boston, Mass.

17.5.1994, The Challenge of Parallel Corpora, The Malvern Seminar, School of English, University of Birmingham, Malvern, U.K. 13.9.1994, Neologie und Korpus, Tagung: Lexicology and lexical Semantics, Universität Münster, Münster

24.9.1994, The Concept of Work, Tagung: Conceiving of Europe - Diversity in Unity, ASTON University, Birmingham

28.9.1994, Sprache und Landschaftsbild, Kategorien der Naturwahrnehmung, Ferienkurs Universität Mannheim, Mannheim 11.11.1994, Cooperation Issues: Language Resources, Language and Technology in Europe 2000. The BALTIC's Perspective, Institute of Mathematics and Computer Science, Riga

18.11.1994, Cooperation/Issues: Language Resources, Symposium: Jazyk a Počitačové Technologie, Matematičko-fyzikálui Karlovy university, Prag

Prof. Dr. Rainer Wimmer: 13.9.1994, Sprachkultur, Sprachkritik, Sprachberatung als Aufgaben der Germanistik, Deutscher Germanistentag, Aachen

Dr. Edeltraud Winkler: 3.9.1994, (zusammen mit Prof. Dr. G. Harras) A Model for Describing Speech Act Verbs. The Semantic Base of a Polyfunctional Dictionary, 6. EURALEX Jahrestagung, Amsterdam 
Dr. Ricarda Wolf: 23.9.1994, Intonatorische Kontrastierung bei Äußerungsexpansionen, Sprech- und Gesprächsstile, Gesellschaft für Angewandte Linguistik, Sektion Sprech- und Gesprächsstile, Trier

4. Studienaufenthalte und Besuche in- und ausländischer Wissenschaftler am IDS; Gastwissenschaftler

Dr. O. Abdykaimova, Kyrgyzstan, Kirgisien - Dr. Magdolna Bartha, Budapest, Ungarn - Prof. Dr. Peter Bassola, Budapest, Ungarn - Dr. M. Teresa Bianco, Neapel, Italien - Prof. Dr. Carlo Serra Borneto, Rom, Italien - Prof. Liu Chunde, Tianjin, China - Marina Denissowa, Samara, RuBland - Zaira Duka, Neapel, Italien - Jutta Eschenbach, Halden, Norwegen - Dr. Ewa Geller, Warschau, Polen - Detelina Georgieva, Sofia, Bulgarien - Joanna Golonka, Rzeszow, Polen - Prof. Dr. John Gumperz, Santa Barbara, USA - Piklu Gautam Gupta, Manchester, Großbritannien - Prof. Wanheng Han, Tianjin, China - Prof. Dr. Hernandez Eduardo, Havanna, Kuba - Bertalan Iker, Budapest, Ungarn Prof. Dr. Marja Järventausta, Jyväskylä, Finnland - Prof. Dr. Alan Kirkness, Auckland, Neuseeland - Prof. Dr. Jarmo Korhonen, Oulu, Finnland - Dr. Michail Kotin, Berlin - Prof. Dr. Kunzmann-Müller, Berlin - Prof. Dr. Ewald Lang, Berlin - Prof. Dr. Rachim Murjazov, Ufa, Rußland Prof. Andreas Musolff, Birmingham, Großbritannien - Karen Nordvig, Kopenhagen, Dänemark - Dr. Peter Paul, Clayton, Australien - Galina Pawlowa, Sofia, Bulgarien - Anna Petrova, Saratov, Rußland - Svetlana Poljakova, Berlin - Carmen Pop, Cluj-Napoca, Rumänien - Doz. Dr. Ekaterina Protassova, Helsinki, Finnland - Dr. Mechthild Rickheit, Melle - Dr. Ladislav Sisak, Presov, Slowakei - Dr. Frantisek Sticha, Prag, Tschechische Republik - Dr. Jürgen Streek, St. Barbara, USA - Ailing Sun, Tianjin, China - Dr. Ildiko Szobszli, Szeged, Ungarn - Carmela Viggiano, Neapel, Italien - Dr. Johanna Watzinger-Tharp, Utah, USA Prof. Susumu Zaima, Matsusaka, Japan

\section{Gremien und Mitarbeiter des Instituts füi deutsche Sprache}

(Stand 1.12.1994)

\subsection{Kuratorium}

Vorsitzender: Prof. Dr. Horst Sitta, Zürich

Stellvertreter: Prof. Dr. Friedhelm Debus, Kiel

Prof. Dr. Walther Dieckmann, Berlin - Dr. Elke Donalies, IDS - Prof. Dr. Hans-Werner Eroms, Passau - Prof. Dr. Gerhard Helbig, Leipzig - Dr. Irmtraud Jüttner, IDS - Prof. Dr. Wolfgang Klein, Nimwegen, Nieder- 
lande - Prof. Dr. Heinrich Löfler, Basel - Dr. Renate Pasch, IDS - Prof. Dr. Barbara Sandig, Saarbrücken - Helmut Schumacher, IDS - Prof. Dr. Peter Wiesinger, Wien - Bürgermeister Lothar Mark als Vertreter der Stadt Mannheim - Min.Rat Naumer und Reg. Dir. Dr. Amann als Vertreter des Ministeriums für Wissenschaft und Forschung des Landes Baden-Württemberg - Reg. Dir. Dr. Philipps als Vertreter des Bundesministeriums für Forschung und Technologie - Herr VLR I Piecha als Vertreter des Auswärtigen Amts - Dir. Peter Roschy als Vertreter des Vereins der Freunde des Instituts für deutsche Sprache

\subsection{Vorstand}

Prof. Dr. Gerhard Stickel - Prof. Dr. Rainer Wimmer (bis 30.09.94)

\subsection{Institutsrat}

Direktoren: Prof. Dr. Gerhard Stickel - Prof. Dr. Rainer Wimmer (bis 30.09.94); Abteilungsleiter: Prof. Dr. Reinhard Fiehler (Gesprochene Sprache) - Prof. Dr. Gisela Harras (Lexikologie und Wortbildung) Prof. Dr. Werner Kallmeyer (Verbale Interaktion) - Prof. Dr. Hartmut Schmidt (Historische Lexikologie und Lexikographie) - Dr. Wolfgang Teubert (Sprachentwicklung in der Gegenwart) - Priv.Doz. Dr. Gisela Zifonun (Grammatik); Mitarbeitervertreter: Franz Josef Berens - Dr. Mechthild Elstermann - Dr. Klaus Heller - Gerd Piroth

\subsection{Mitarbeiter und Mitarbeiterinnen des Instituts}

\section{Abteilung Grammatik}

Abteilungsleiterin: Priv.Doz. Dr. Gisela Zifonun; Wissenschaftliche Mitarbeiter: Prof. Dr. Joachim Ballweg - Dr. Ursula Brauße - Dr. Eva Breindl-Hiller (beurlaubt) - Helmut Frosch - Ursula Hoberg - Dr. Renate Pasch - Prof. Dr. Bruno Strecker - Dr. Angelika Storrer - Klaus Vorderwülbecke (beurlaubt); Programmierer: Roman Schneider;

Sekretärin: Ruth Maurer

\section{Abteilung Lexikologie und Wortbildung}

Abteilungsleiterin: Prof. Dr. Gisela Harras; Wissenschaftliche Mitarbeiter: Dr. Klaus Heller - Monika Kolvenbach, M.A. - Dr. Klaus-Peter Konerding - Jacqueline Kubczak - Dr. Wolfgang Mentrup-Wenzel - Prof. Dr. Wolfgang Motsch - Vera de Ruiter - Renate Schmidt - Helmut Schumacher - Dr. Edeltraud Winkler;

Sekretärinnen: Susanne Bergmann (beurlaubt) - Karin Laton - Renate Wegener 
Abteilung Historische Lexikologie und Lexikographie

Abteilungsleiter: Prof. Dr. Hartmut Schmidt; Wissenschaftliche Mitarbeiter: Dr. Elke Donalies - Gabriele Hoppe - Dr. Heidrun KämperJensen - Isolde Nortmeyer - Dr. Elisabeth Link - Dr. Gerhard Strauß - Prof. Dr. Joachim Schildt - Dr. Rosemarie Schnerrer - Oda Vietze Priv.Doz. Dr. Ulrike Haß-Zumkehr;

Sekretärinnen: Sabina Schuster - Sigrid Ziehr

Abteilung Sprachentwicklung in der Gegenwart

Abteilungsleiter: Dr. Wolfgang Teubert; Wissenschaftliche Mitarbeiter: Dr. Claudia Fraas - Dr. Manfred W. Hellmann - Prof. Dr. Dieter Herberg - Dr. Michael Kinne - Dipl.rer.pol. Pantelis Nikitopoulos - Dr. Doris Steffens - Kathrin Steyer - Deniz Tandogan - Dr. Elke Tellenbach;

Sekretärin: Ingrid Karlsson

Abteilung Verbale Interaktion

Abteilungsleiter: Prof. Dr. Werner Kallmeyer; Wissenschaftliche Mitarbeiter: Dr. Inken Keim-Zingelmann - Dr. Wolfgang Klein, M.A. - Dipl. Psych. Dr. Werner Nothdurft, M.A. - Dr. Reinhold Schmitt, M.A. Prof. Dr. Johannes Schwitalla (beurlaubt) - Dr. Wilfried Schütte - Dr. Carmen Spiegel - Dipl. Psych. Dorothea Wilk (beurlaubt) - Dr. Ricarda Wolf;

Sekretärinnen: Hanni Kohlhase - Doris Richter

Abteilung Gesprochene Sprache

Abteilungsleiter: Prof. Dr. Reinhard Fiehler; Wissenschaftliche Mitarbeiter: Dr. Karl-Heinz Bausch - Dr. Nina Berend - Sylvia Dickgießer, M.A. - Dr. Mechthild Elstermann - Dr. Barbara Kraft - Dr. Katharina Meng - Dipl.Soz. Ulrich Reitemeier - Dr. Peter Schröder - Dr. Peter Wagener; Toningenieur: Wolfgang Rathke

Sekretärin: Vladimira Schroeder

Öffentlichkeitsarbeit und Dokumentation/Bibliothek

Leiter: Priv.Doz. Dr. Bernd Ulrich Biere (beurlaubt); - Dr. Annette Trabold, M.A.; Wissenschaftlicher Mitarbeiter: Franz Josef Berens; Dokumentarin: Katrin Freese, M.A.; EDV-Mitarbeiter: Claus Hoffmann; Texterfassung: Ursula Blum - Cornelia Kayser - Ria Schiel;

Bibliothekarinnen: Lucia Berst - Birgit Günther - Dipl.Bibl. Eva Teubert;

Sekretärin: Iris Wohlfarth 


\section{Linguistische Datenverarbeitung}

Leiter: Robert Neumann; Wissenschaftliche Mitarbeiter: Dipl.Ing. Cyril Belica - Franck Bodmer - Sylvie Costantino - Dr. Irmtraud Jüttner - Dipl.Math. Dr. Rudolf Schmidt - Dipl.Inf. Eric Seubert - Doris al-Wadi; Mitarbeiter in der Datenverarbeitung: Siegmund Gruschka Rainer KrauB - Peter Mückenmüller - Ingrid Schellhammer - Uwe Sommer;

Sekretärin: Gerda Beck

Verwaltung und Vorstandssekretariat

Verwaltungsleiter: Harald Forschner; Verwaltungsangestellte: Monika Buchmüller (beurlaubt) - Gerhard Köck - Hildegard Magis - Gerd Piroth - Marianne Wardein - Hannelore Wittmann - Manfred Wondra; Telefonist: Franz-Albert Werner; Hausmeister: Uwe Zipf; Vorstandssekretariat: Cornelia Pfützer-König - Barbara Stolz;

\subsection{Doktoranden}

Andreas Müller - Sylvia Roderburg - Josef Stumpf

\subsection{Wissenschaftlicher Rat}

\section{Ehrenmitglieder}

Prof. Dr. Johannes Erben, Bonn - Prof. Dr. Hans Glinz, Wädenswil Prof. Dr. Siegfried Grosse, Bochum - Prof. Dr. Peter von Polenz, Korlingen;

\section{Ordentliche Mitglieder}

Prof. Dr. Hans Altmann, München - Prof. Dr. Gerhard Augst, Siegen - Prof. Dr. Karl-Richard Bausch, Bochum - Prof. Dr. Anne Betten, Eichstätt - Prof. Dr. Klaus Brinker, Hamburg - Prof. Dr. Karl-Dieter Bünting, Essen - Prof. Dr. Harald Burger, Zürich - Prof. Dr. Dieter Cherubim, Göttingen - Prof. Dr. Günther Drosdowski, Mannheim - Prof. Dr. Konrad Ehlich, München - Prof. Dr. Peter Eisenberg, Potsdam - Prof. Dr. Ulla Fix, Leipzig - Prof. Dr. Jan Goossens, Münster - Prof. Dr. Elisabeth Gülich, Bielefeld - Prof. Dr. Walter Haas, Freiburg/Schweiz - Prof. Dr. Franz Josef Hausmann, Erlangen - Prof. Dr. Helmut Henne, Braunschweig - Prof. Dr. Hans Jürgen Heringer, Augșburg - Prof. Dr. Rudolf Hoberg, Darmstadt - Prof. Dr. Werner Hoffmann, Mannheim - Prof. Dr. Klaus-Jürgen Hutterer, Graz - Prof. Dr. Ludwig Jäger, Aachen - Gerhard Kaufmann, München - Prof. Dr. Rudi Keller, München - Prof. Dr. Dieter Krallmann, Essen - Prof. Dr. Gotthard Lerchner, Leipzig - I'rof. 
Dr. Hans Moser, Innsbruck - Prof. Dr. Horst Haider Munske, Erlangen - Prof. Dr. Gerhard Nickel, Stuttgart - Prof. Dr. Uwe Pörksen, Freiburg - Prof. Dr. Rainer Rath, Saarbrücken - Prof. Dr. Oskar Reichmann, Heidelberg - Prof. Dr. Marga Reis, Tübingen - Prof. Dr. Gert Rickheit, Bielefeld - Prof. Dr. Helmut Schnelle, Bochum - Prof. Dr. Stefan Sonderegger, Uetikon - Prof. Dr. Hugo Steger, Freiburg - Prof. Dr. Dieter Stellmacher, Göttingen - Prof. Dr. Georg Stötzel, Düsseldorf - Prof. Dr. Erich Straßner, Tübingen - Prof. Dr. Heinz Vater, Köln - Prof. Dr. Hans Wellmann, Augsburg - Prof. Dr. Otmar Werner, Freiburg - Prof. Dr. Sigurd Wichter, Münster - Prof. Dr. Herbert Ernst Wiegand, Heidelberg - Prof. Dr. Norbert Richard Wolf, Würzburg - Prof. Dr. Dieter Wunderlich, Düsseldorf

Emeritiert: Prof. Dr. Klaus Baumgärtner, Stuttgart - Prof. Dr. Hermann Bausinger, Tübingen - Prof. Dr. Werner Besch, Bonn - Prof. Dr. Hennig Brinkmann, Münster - Prof. Dr. Dr. h.c. Eugenio Coseriu, Tübingen Prof. Dr. Hellmut Geißner, Landau - Prof. Dr. Helmut Gipper, Wolbeck - Prof. Dr. Gerhard Heilfurth, Marburg - Prof. Dr. Blanka Horacek, Wien - Prof. Dr. Johann Knobloch, Bonn - Prof. Dr. Theodor Lewandowski, Köln - Prof. Dr. Günter Neumann, Würzburg - Dr.h.c. Otto Nüssler, Wiesbaden - Prof. Dr. Els Oksaar, Hamburg - Prof. Dr. Ingo Reiffenstein, Salzburg - Prof. Dr. Lutz Röhrich, Freiburg - Prof. Dr. Albrecht Schöne, Göttingen - Prof. Dr. Rudolf Schützeichel, Münster Prof. Dr. Hansjakob Seiler, Köln - Prof. Dr. Mario Wandruszka, Anif Prof. Dr. Harald Weinrich, München - Prof. Dr. Werner Winter; Kiel Prof. Dr. Paul Zinsli, Bern

Korrespondierende Mitglieder in Europa

Prof. Dr. Werner Abraham, Groningen, Niederlande - Prof. Dr. Pierre Bange, Lyon, Frankreich - Prof. Dr. Daniel Bresson, Aix-en-Provence, Frankreich - Prof. Dr. Andrzej Z. Bzdega, Posen, Polen - Prof. Dr. Jean David, Metz, Frankreich - Prof. Dr. Jovan Djukanović, Belgrad, Jugoslawien - Prof. Dr. Martin Durrell, London, Großbritannien - Doz. Lic. Phil. Mogens Dyhr, Kopenhagen, Dänemark - Prof. Dr. Cathrine Fabricius-Hansen, Oslo, Norwegen - Prof. Dr. Franciszek Grucza, Warschau, Polen - Prof. Dr. Regina Hessky, Budapest. Ungarn - Prof. Dr. Fernand Hoffmann, Luxemburg, Luxemburg - Prof. Dr. William Jones, London, Großbritannien - Prof. Dr. Gottfried Kolde, Genf, Schweiz Prof. Dr. Jarmo Korhonen, Turku, Finnland - Prof. Dr. Hans-Peter Kromann, Kopenhagen, Dänemark - Prof. Dr. Oddleif Leirbukt, Troms $\varnothing$, Norwegen - Prof. Dr. Jacques Lerot, Louvain-la-Neuve, Belgien - Prof. Dr. Zdeněk Massařik, Brünn, Tschechische Republik - Prof. Dr. Norbert Morciniec, Breslau, Polen - Prof. Dr. Kurt Nyholm, Åbo, Finnland 
- Prof. Dr. Pavel Petkov, Sofia, Bulgarien - Prof. Dr. Marthe Philipp, Straßburg, Frankreich - Prof. Dr. Inger Rosengren, Lund, Schweden Prof. Dr. Carlo Serra-Borneto, Rom, Italien - Prof. Dr. Emil Skála, Prag, Tschechische Republik - Prof. Dr. Anthony William Stanforth, Edinburg, Großbritannien - Prof. Dr. Aleksander Szulc, Krakau, Polen - Prof. Dr. Vural Ülkü, Mersin, Türkei - Prof. Dr. Paul Valentin, Paris, Frankreich - Prof. Dr. R.A. Wisbey, London, Großbritannien - Prof. Dr. Jean-Marie Zemb, Paris, Frankreich - Prof. Dr. Stanislav Žepić, Zagreb, Kroatien - Prof. Dr. Zoran Žiletić, Belgrad, Jugoslawien

Emeritiert: Prof. Dr. Eduard Beneš, Prag, Tschechische Republik - Prof. Dr. Jan Czochralski, Warschau, Polen - Prof. Dr. Torsten Dahlberg, Göteborg, Schweden - Prof. Dr. Erik Erämetsä, Turku, Finnland - Prof. Dr. Jean Fourquet, Fresnes, Frankreich - Prof. Dr. K. Hyldgaard-Jensen, Göteborg, Schweden - Prof. Dr. Mihai Isbăsęscu, Bukarest, Rumänien - Prof. Dr. Rudolf E. Keller, Manchester, Großbritannien - Prof. Dr. Gustav Korlén, Nacka, Schweden - Prof. Dr. Odo Leys, Löwen, Belgien - Prof. Dr. Kai B. Lindgren, Espoo, Finnland - Prof. Dr. S. Mironoff, Moskau, Rußland - Prof. Dr. Karl Mollay, Budapest, Ungarn - Prof. Dr. Pavica Mrazović, Novi Sad, Jugoslawien - Prof. Dr. Hanna Popadić, Sarajevo, Bosnien - Prof. Dr. Laurits Saltveit, Haugesund, Norwegen Prof. Dr. Dr.h.c. Gilbert de Smet, Gent, Belgien - Prof. Dr. C. Soeteman, Oegstgeest, Niederlande - Prof. Dr. Birgit Stolt, Stockholm, Schweden

- Prof. Dr. Bjarne Ulvestad, Bergen, Norwegen

Korrespondierende Mitglieder in Übersee

Prof. Dr. Elmer H. Antonsen, Urbana, Ill., USA - Prof. Dr. Emmon Bach, Austin, Texas, USA - Prof. Dr. Michael Clyne, Clayton, Victoria, Australien - Prof. Dr. F. van Coetsem, Ithaca, N.Y., USA - Prof. Dr. Jürgen Eichhoff, Madison, Wisconsin, USA - Prof. Tozo Hayakawa, Tokyo, Japan - Prof. Dr. Robert D. King, Austin, Texas, USA - Prof. Dr. Alan Kirkness, Auckland, Neuseeland - Prof. Dr. Byron J. Koekkoek, Buffalo, N.Y., USA - Prof. Dr. Herbert Kufner, Ithaca, N.Y., USA Prof. Dr. Hans Kuhn, Canberra, Australien - Prof. Dr. Albert L. Lloyd, Philadelphia, Pennsylvania, USA

Emeritiert: Prof. Dr. Marvin Folsom, Provo, Utah, USA - Prof. Dr. Einar Haugen, Cambridge, Mass., USA - Prof. Eijiro Iwasaki, Kamakura, Japan - Prof. Dr. W.P. Lehmann, Austin, Texas, USA - Prof. Dr. Georg Metcalf, Sacramento, California, USA - Prof. Dr. William G. Moulton, Bristol, Rhode Island, USA - Prof. Dr. Herbert Penzl, Berkeley, Calif., USA - Prof. Dr. Erwin Theodor Rosenthal, São Paulo, Brasilien - Prof. Dr. Otto Springer, Philadelphia, Pennsylvania, USA 


\subsection{Kommissionen}

Kommission für Rechtschreibfragen

Prof. Dr. Gerhard Augst, Siegen (Vorsitzender) - Prof. Dr. Dieter Nerius, Rostock (Stellvertr. Vorsitzender) - Prof. Dr. Günther Drosdowski, Mannheim - Prof. Dr. Peter Eisenberg, Berlin - Dr. Klaus Heller, IDS - Prof. Dr. Dieter Herberg, IDS - Prof. Dr. Manfred Kohrt, Bonn Prof. Dr. Horst Haider Munske, Erlangen - Prof. Dr. Burkhard Schaeder, Siegen - Prof. Dr. Eberhard Stock, Halle - Prof. Dr. Hermann Zabel, Dortmund

Kommission für Fragen der Sprachentwicklung

Prof. Dr. Werner Holly, Chemnitz-Zwickau (Vorsitzender) - Priv.Doz. Dr. Bernd Ulrich Biere, IDS (Stellvertr. Vorsitzender) - Prof. Dr. Dieter Cherubim, Göttingen - Prof. Dr. Walther Dieckmann, Berlin - Prof. Dr. Helmut Henne, Braunschweig - Prof. Dr. Rudolf Hoberg, Darmstadt - Prof. Dr. Heinrich Löffler, Basel - Ltd. Reg. Dir, a.D. Dr. Walter Otto, Würzburg - Prof. Dr. Barbara Sandig, Saarbrücken - Dr. Werner Scholze-Stubenrecht, Mannheim - Prof. Dr. Hugo Steger, Freiburg - Priv.Doz. Dr. Gisela Zifonun, IDS

\subsection{Beiräte}

Beirat „Lexikon der Lehnwortbildung”

Prof. Dr. Johannes Erben, Bonn - Prof. Dr. Manfred Höfler, Düsseldorf - Prof. Dr. Horst Haider Munske, Erlangen - Prof. Dr. Peter von Polenz, Korlingen

Beirat „Deutsches Fremdwörterbuch”

Prof. Dr. Oskar Reichmann, Heidelberg - Prof. Dr. Michael Schlaefer, Göttingen - Dr. Heino Speer, Heidelberg

Beirat „Erklärende Synonymik"

Prof. Dr. Herbert Ernst Wiegand, Heidelberg - Prof. Dr. Peter Rolf Lutzeier, London - Prof. Dr. Georg Meggle, Leipzig

Beirat „Rhetorik”

Prof. Dr. Barbara Sandig, Saarbrücken (Vorsitzende) - Prof. Dr. Walter Dieckmann, Berlin - Prof. Dr. Carl Friedrich Graumann, Heidelberg Prof. Dr. Elisabeth Gülich, Bielefeld - Prof. Dr. Werner Holly, ChemitzZwickau 


\section{Besondere Nachrichten}

Prof. Dr. Johannes Schwitalla wechselte zum WS 1994/95 auf eine Professur für deutsche Sprachwissenschaft an der Universität Würzburg.

\section{Personalstärke, Anschriften, finanzielle Angaben}

7.1 Personalstärke (Stand: 1.12.1994)

Mitarbeiter (einschl. Teilzeit- und Projektmitarbeiter):

wissenschaftliche Angestellte 68 (davon beurlaubt: 5 )

Verwaltungs-/technische Angestellte (davon beurlaubt: 2)

Projekt-Mitarbeiter

(davon beurlaubt: 1 )

40

7

$\overline{115}$

Doktoranden

3

\subsection{Anschrift}

Institut für deutsche Sprache

R5, 6-13

D-68161 Mannheim

Postanschrift:

Postfach 101621

D-68016 Mannheim

Telefon (0621) 1581-0

Telefax (0621) 1581-200

e-mail: vorstand@ids-mannheim.de

7.3 Haushalte des Instituts im Berichtsjahr

Einnahmen:

Ministerium für Wissenschaft und Forschung

Baden-Württemberg

DM $\quad 6.776 .350,-$

Bundesministerium für Forschung und Technologie

Stadt Mannheim

DM 6.776.350,-

eigene Einnahmen

DM $8.000,-$

\begin{tabular}{lr} 
DM & $137.000,-$ \\
\hline DM & $13.697 .700,-$
\end{tabular} 
Ausgaben:

Personalausgaben

Sachausgaben

DM 10.965.400, -

Investitionen

DM 2.656.300, -

DM $\frac{76.000,-}{\text { DM }}$

Projektmittel:

Deutsche Forschungsgemeinschaft

(DFG), Bonn

Projekt „Rußlanddeutsch"

Personalmittel

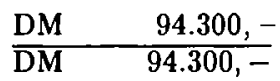

Deutsche Forschungsgemeinschaft

(DFG), Bonn

Projekt "Wissenschaftlicher Austausch mit Rubland"

Personalmittel

Sachmittel

\begin{tabular}{lr} 
DM & $19.800,-$ \\
DM & $1.300,-$ \\
\hline DM & $21.100,-$
\end{tabular}

Projekt „Initiative Reaktionen” (SFB 245)

Personalmittel

\begin{tabular}{lr} 
DM & $143.400,-$ \\
DM & $11.000,-$ \\
\hline DM & $154.400,-$
\end{tabular}

Sachmittel

\begin{tabular}{lr} 
DM & $102.800,-$ \\
DM & $1.700,-$ \\
\hline DM & $104.500,-$ \\
& \\
\hline DM & $65.000,-$
\end{tabular}

Projekt "Orthographie, bis 1901"

Personalmittel

\begin{tabular}{lr} 
DM & $68.920,-$ \\
DM & $3.000,-$ \\
\hline DM & $71.920,-$
\end{tabular}

Sachmittel 
Projekt „Rechtschreibwörter-

bücher-Benutzung"

Personalmittel

DM 28.800,-

Sachmittel

\begin{tabular}{lr} 
DM & $200,-$ \\
\hline DM & $29.000,-$
\end{tabular}

Stiftung Volkswagenwerk

"Deutsch-Zentrum Tianjin/China"

Personalmittel

Sachmittel

\begin{tabular}{lr} 
DM & $20.000,-$ \\
DM & $20.000,-$ \\
\hline DM & $40.000,-$
\end{tabular}

Kommission der EG

Projekt „Multilingual Environment for Corpus-Based Lexicon Building"

Personalmittel

\begin{tabular}{lr} 
DM & $178.390,-$ \\
DM & $34.910,-$ \\
\hline DM & $213.300,-$
\end{tabular}

Projekt „Environmental Innovation" Personalmittel

\begin{tabular}{lr} 
DM & $17.815,-$ \\
DM & $8.885,-$ \\
\hline DM & $26.700,-$
\end{tabular}

Summe der Projektmittel

DM 755.220, -

Ordentlicher Haushalt

DM 13.697.700, -

DM 14.452.920,- 


\section{Veröffentlichungen im Jahre 1994}

\section{SCHRIFTEN DES INSTITUTS FÜR DEUTSCHE SPRACHE}

Verlag Walter de Gruyter, Berlin/New York

Band 4: Friedhelm Debus/Werner Kallmeyer/Gerhard Stickel (Hg.): Kommunikation in der Stadt.

4.1: Werner Kallmeyer ( $\mathrm{Hg}$.$) :$

Exemplarische Analysen des Sprachverhaltens in Mannheim. 1994.

\section{STUDIENBIBLIOGRAPHIEN SPRACHWISSENSCHAFT}

Im Auftrag des Instituts für deutsche Sprache hg. von Ludger Hoffmann (bis Bd. 9); Manfred W. Hellmann (ab Bd. 10)

Julius Groos Verlag, Heidelberg

Band 9: Michael Kinne/Johannes Schwitalla: Sprache im Nationalsozialismus. 1994

Band 10: Ludwig M. Eichinger:

Deutsche Wortbildung. 1994

Band 11: Volker Hinnenkamp:

Interkulturelle Kommunikation. 1994

FORSCHUNGSBERICHTE DES INSTITUTS FÜR DEUTSCHE SPRACHE

Herausgegeben von Rainer Wimmer, Bruno Strecker und Gisela Zifonun Gunter Narr Verlag, Tübingen

Band 61: Nothdurft, Werner/Ulrich Reitemeier/Peter Schröder:

Beratungsgespräche. Analyse asymmetrischer Dialoge. 1994

Band 71: Ursula Brauße: Lexikalische Funktionen der Synsemantika. 1994

Band 72: Renate Pasch: Konzessivität von wenn-Konstruktionen. 1994 
Band 73: Silke Maurer/Reinhold Schmitt: Small-talk, Klatsch und agressive Spiele. Ein Textband. 1994

\section{DEUTSCH IM KONTRAST}

Im Auftrag des Instituts für deutsche Sprache hg. von Ulrich Engel und Klaus Vorderwülbecke

Julius Groos Verlag, Heidelberg

Band 14: Watzlaw Miodek:

Die Begrüßungs- und Abschiedsformeln im Deutschen und im Polnischen. 1994

\section{PHONAI}

Herausgegeben von Walter Haas und Peter Wagener

Max Niemeyer Verlag, Tübingen

Band 41: Angelika Redder/ Konrad Ehlich (Hg.):

Gesprochene Sprache. Transkripte und

Tondokumente. 1994

\section{DEUTSCHE SPRACHE}

Zeitschrift für Theorie, Praxis, Dokumentation

Im Auftrag des Instituts für deutsche Sprache hg. von Siegfried Grosse (Geschäftsführer), Hans Werner Eroms, Gisela Harras, Gerhard Stickel

Erich Schmidt Verlag, Berlin

Redaktion: Franz Josef Berens

Register 1-20: Sonderheft. Berlin 1994

Jahrgang 1994: 4 Hefte

SPRACHREPORT - Informationen und Meinungen zur deutschen Sprache

Hg. vom Institut für deutsche Sprache

Jahrgang 1994: 4 Hefte.

Extraausgabe: Rechtschreibreform 


\section{PUBLIKATIONEN IM EIGENVERLAG}

Doris al-Wadi: COSMAS Benutzerhandbuch Institut für deutsche Sprache Mannheim 1994

9. Satzung des Instituts für deutsche Sprache

Sitz Mannheim

vom 28. Oktober 1994

Von der Stiftungsaufsichtsbehörde, dem Regierungspräsidium Karlsruhe, genehmigt gemäß $§ 6$ Abs. 4 Satz 1 StiftG am 23.11.1994

\section{$\S 1$ Name, Sitz und Rechtsform der Stiftung}

(1) Die Stiftung führt den Namen „Institut für deutsche Sprache” (Abkürzung: IDS). Sitz der Stiftung ist Mannheim.

(2) Sie ist eine Stiftung des bürgerlichen Rechts.

(3) Rechnungsjahr ist das Kalenderjahr.

\section{$\S 2$ Stiftungszweck}

(1) Die Stiftung verfolgt den Zweck, die deutsche Sprache in ihrem gegenwärtigen Gebrauch und in ihrer neueren Geschichte wissenschaftlich zu erforschen und zu dokumentieren. Sie pflegt die Zusammenarbeit mit anderen in- und ausländischen Einrichtungen ähnlicher Zielsetzung.

(2) Die Stiftung verfolgt ausschließlich und unmittelbar gemeinnützige Zwecke im Sinne des Abschnitts „Steuerbegünstigte Zwecke” der Abgabenordnung. Sie ist selbstlos tätig.

\section{$\S 3$ Stiftungsvermögen}

(1) Das Grundstockvermögen der Stiftung besteht aus den Einrichtungsgegenständen, den Archiven und den Bibliotheken des Instituts.

(2) Die Stiftung funanziert ihre Arbeiten

1. aus Zuwendungen der Bundesrepublik Deutschland, des Landes Baden-Württemberg und der Stadt Mannheim,

2. aus Zuschüssen des Vereins „Freunde des Instituts für deutsche Sprache",

3. aus Zuwendungen Dritter zur Erfüllung des Stiftungszwecks,

4. aus Einnahmen aus der Tätigkeit des Instituts,

5. aus Erträgen des Stiftungsvermögens. 
(3) Die Mittel dürfen nur für die satzungsmäßigen Zwecke verwendet werden. Die Stifter und ihre Rechtsnachfolger dürfen in ihrer Eigenschaft als Stifter keine Zuwendungen aus Mitteln der Stiftung erhalten. Niemand darf durch Ausgaben, die dem Zweck der Stiftung fremd sind, oder durch unverhältnismäßig hohe Vergütungen begünstigt werden.

(4) Der Nachweis über die Verwendung der Mittel zu gemeinnützigen Zwecken ist durch ordnungsmäBige Aufzeichnungen über die Einnahmen und Ausgaben zu führen.

\section{$\S 4$ Organe}

Organe der Stiftung sind:

1. das Kuratorium,

2. der Vorstand,

3. der Institutsrat.

\section{$\S 5$ Zusammensetzung des Kuratoriums}

(1) Das Kuratorium besteht aus

1. zwei Vertretern der Bundesrepublik Deutschland,

2. zwei Vertretern des Landes Baden-Württemberg,

3. einem Vertreter der Stadt Mannheim,

4. einem Vertreter des Vereins "Freunde des Instituts für deutsche Sprache e.V.",

5. neun weiteren, nicht im Institut tätigen Personen, die durch wissenschaftliche oder sonstige Leistungen im Aufgabenbereich des Instituts ausgewiesen sind,

6. vier wissenschaftlichen Mitarbeitern des Instituts; wissenschaftliche Mitarbeiter im Sinne dieser Satzung sind alle Mitarbeiter, die mindestens nach der Eingangsstufe des Bundesangestelltentarifvertrages für wissenschaftliche Mitarbeiter mit abgeschlossener Hochschulausbildung vergütet werden.

(2) Die Mitglieder nach Absatz 1 Nr. 1 und 2 können sich gegenseitig vertreten. Die übrigen Mitglieder können sich durch von ihnen bevollmächtigte Mitglieder des Kuratoriums vertreten lassen; jedes dieser Mitglieder darf die Vertretung nur für ein anderes Mitglied übernehmen.

(3) Mitglieder des Institutsrats gemäß $§ 9$ Abs. 1 können nicht Mitglieder des Kuratoriums sein.

(4) Die in Absatz 1 Nr. 5 genannten Mitglieder werden auf die Dauer von sechs Jahren vom Kuratorium berufen; einmalige Wiederwahl ist zulässig. Scheidet ein Mitglied während seiner Berufungszeit aus, 
so wird das hierfür neu zu berufende Mitglied nur für den restlichen Berufungszeitraum berufen. Die Mitgliedschaft im Kuratorium verlängert sich für den Vorsitzenden und seinen Stellvertreter um den Zeitraum, um den ihre Amtszeit als Vorsitzender oder stellvertretender Vorsitzender die Dauer der Mitgliedschaft nach Satz 1 übersteigt. Für die Amtszeit der ihnen nachfolgenden Mitglieder im Kuratorium gilt Satz 2 entsprechend.

(5) Die in Absatz $1 \mathrm{Nr} .6$ genannten Mitglieder werden von den wissenschaftlichen Mitarbeitern des Instituts auf die Dauer von drei Jahren gewählt. Einmalige Wiederwahl ist zulässig. Wählbar ist, wer seit mindestens einem Jahr als wissenschaftlicher Mitarbeiter im Institut tätig ist. Das Nähere regelt eine vom Institutsrat zu erlassende Wahlordnung, die der Zustimmung des Kuratoriums bedarf.

(6) Die Mitglieder des Kuratoriums sind ehrenamtlich tätig. Sie erhalten Ersatz ihrer Aufwendungen nach den Reisekostenbestimmungen des Landes Baden-Württemberg.

\section{§ 6 Aufgaben des Kuratoriums}

(1) Das Kuratorium überwacht die Rechtmäßigkeit, Zweckmäßigkeit und Wirtschaftlichkeit der Stiftungsgeschäfte. Es gibt dem Institut Richtlinien für die wissenschaftliche Arbeit, zu Grundsatzfragen der Organisation und Verwaltung, und es berät den Entwurf des jährlichen Wirtschaftsplans und der mittelfristigen Finanzpläne. Es kann dem Vorstand in wichtigen Angelegenheiten Weisungen erteilen.

(2) Das Kuratorium beschließt insbesondere über

1. die Bestellung des Direktors und des stellvertretenden Direktors,

2. den Abschluß, die Änderung und Kündigung des Anstellungsvertrags des Direktors; dabei wird das Institut durch den Vorsitzenden des Kuratoriums vertreten,

3. die Grundsätze für die Beurteilung des Erfolgs der wissenschaftlichen Arbeiten,

4. die Entlastung des Vorstands aufgrund der Prüfungsberichte,

5. die Einrichtung, Aufösung und Zusammenlegung von Abteilungen und von zentralen Arbeitsstellen,

6. die Einrichtung von Kommissionen für besondere Aufgaben und von Beiräten zu größeren Forschungsvorhaben.

(3) Der Zustimmung des Kuratoriums bedürfen

1. die Arbeitsplanung des Instituts,

2. die Bestellung der Abteilungsleiter und die Übertragung anderer längerfristiger wissenschaftlicher Leitungsaufgaben,

3. der Abschluß und die Änderung von über- und außertariflichen Anstellungsverträgen und von Honorarverträgen mit laufenden 
Bezügen, die einen vom Kuratorium festzulegenden Betrag übersteigen,

4. außergewöhnliche, über den Rahmen des laufenden Geschäftsbetriebs hinausgehende Rechtsgeschäfte,

5. die Annahme von Forschungsaufträgen und Drittmitteln, die einen vom Kuratorium festzulegenden Umfang übersteigen.

(4) In Fällen, die keinen Aufschub bis zur Herbeiführung eines Beschlusses des Kuratoriums dulden, genügt die vorherige schriftliche $\mathrm{Zu}$ stimmung des Vorsitzenden des Kuratoriums. Er rechtfertigt seine Entscheidung auf der nächsten Kuratoriumssitzung.

\section{§ 7 Verfahren des Kuratoriums}

(1) Das Kuratorium tagt mindestens einmal jährlich. Es ist beschlubfähig, wenn zwei Drittel seiner Mitglieder anwesend oder vertreten sind, darunter die Mitglieder nach $\S 5 \mathrm{Abs} .1 \mathrm{Nr} .1$ und 2. Beschlüsse des Kuratoriums werden mit der Mehrheit der abgegebenen Stimmen gefaßt. Jedes Mitglied des Kuratoriums führt eine Stimme. Ergibt sich bei Abstimmungen Stimmengleichheit, so gibt die Stimme des Vorsitzenden den Ausschlag. Beschlüsse können auch schriftlich gefaßt werden, wenn kein Mitglied diesem Verfahren widerspricht.

(2) Beschlüsse mit finanziellen Auswirkungen oder von grundsätzlicher Bedeutung für die Struktur und Organisation des Instituts sowie die Vergütung von wissenschaftlichen Mitarbeitern ohne abgeschlossene Hochschulausbildung in Vergütungsgruppen, die für Mitarbeiter mit abgeschlossener Hochschulausbildung vorgesehen sind, bedürfen der Zustimmung der Mitglieder nach $\S 5 \mathrm{Abs} .1 \mathrm{Nr} .1$ bis 3 .

(3) Das Kuratorium wählt jeweils auf die Dauer von vier Jahren aus den in $\$ 5 \mathrm{Abs} .1 \mathrm{Nr} .5$ genannten Mitgliedern seinen Vorsitzenden und dessen Stellvertreter. Eine zweimalige Wiederwahl ist möglich. Der Vorsitzende führt die Bezeichnung „Präsident des Instituts für deutsche Sprache". Ihm obliegt die Vorbereitung der Sitzungen des Kuratoriums sowie die Herbeiführung von Beschlüssen im schriftlichen Verfahren. Bis zu einer Neuwahl führt der bisherige Vorsitzende die Geschäfte weiter.

(4) Der Vorstand des Instituts und ein Vertreter des Betriebsrats nehmen mit beratender Stimme an den Sitzungen teil.

(5) Das Kuratorium kann sich eine Geschäftsordnung geben. 


\section{$\S 8$ Vorstand}

(1) Vorstand im Sinne von $\S 26$ BGB ist der Direktor des Instituts. er muß Wissenschaftler sein. Er führt die Geschäfte der Stiftung und vertritt sie gerichtlich und außergerichtlich.

(2) Der Vorstand ist für die Durchführung der Beschlüsse des Kuratoriums und des Institutsrats verantwortlich. Der Vorstand beschließt den jährlichen Wirtschaftsplan und die mittelfristigen Finanzpläne. Er vollzieht den Wirtschaftsplan.

(3) Der Vorstand entscheidet im Benehmen mit dem jeweils zuständigen Abteilungsleiter, Forschungsgruppen- oder Arbeitsstellenleiter über die Einstellung der wissenschaftlichen Mitarbeiter. Der Vorstand schließt die Arbeitsverträge mit den Arbeitnehmern der Stiftung ab. Er überträgt längerfristige Leitungsaufgaben nach Maßgabe von $\S 6$ Abs. 3 Nr. 2.

(4) Der stellvertretende Direktor vertritt den Direktor im Falle der Verhinderung in allen Angelegenheiten des Instituts. Dem stellvertretenden Direktor werden vom Direktor bestimmte Geschäftsbereiche zur ständigen Besorgung übertragen.

\section{$\oint 9$ Institutsrat}

(1) Dem Institutsrat gehören an:

1. der Direktor und der stellvertretende Direktor,

2. die Abteilungsleiter,

3. drei gewählte Vertreter der wissenschaftlichen Mitarbeiter,

4. ein gewählter Vertreter der bibliothekarischen und technischen Mitarbeiter.

Den Vorsitz im Institutsrat hat der Direktor, im Falle seiner Verhinderung der stellvertretende Direktor.

(2) Die in Abs. $1 \mathrm{Nr} .3$ genannten Mitglieder werden von den wissenschaftlichen Mitarbeitern auf die Dauer von zwei Jahren gewählt. Das in Absatz $1 \mathrm{Nr} .4$ genannte Mitglied wird von den bibliothekarischen und technischen Mitarbeitern auf die Dauer von zwei Jahren gewählt. Als Mitglieder nach Absatz 1 Nr. 3 und 4 sind Mitarbeiter wählbar, die seit mindestens einem Jahr am Institut tätig sind; zweimalige Wiederwahl ist zulässig. Das Nähere regelt eine vom Institutrat zu erlassende Wahlordnung, die der Zustimmung des Kuratoriums bedarf.

(3) Der Institutsrat wirkt an der Planung, Koordinierung und Abstimmung der wissenschaftlichen Arbeiten des Instituts mit.

(4) Der Institutsrat beschließt über die Arbeitsplanung des Instituts und ihre Fortschreibung. 
(5) Der Institutsrat berät über:

1. den Entwurf des Wirtschaftsplans,

2. Maßnahmen im Vollzug des Wirtschaftsplans mit wesentlichen Auswirkungen auf die wissenschaftliche Arbeit,

3. die Einstellung wissenschaftlicher Mitarbeiter, die Zuordnung wissenschaftlicher Mitarbeiter zu Abteilungen und die Übertragung längerfristiger Leitungsaufgaben.

(6) Der Institutsrat ist beschlußfähig, wenn zwei Drittel seiner Mitglieder anwesend sind. Die Mitglieder können sich im Fall ihrer Verhinderung durch von ihnen bevollmächtigte Mitglieder des Institutsrats vertreten lassen; jedes Mitglied darf die Vertretung nur für ein anderes Mitglied übernehmen. Beschlüsse des Institutsrats werden mit der Mehrheit der abgegebenen Stimmen gefaßt. Bei Stimmengleichheit gibt die Stimme des Vorsitzenden den Ausschlag.

(7) Der Präsident und sein Stellvertreter können an den Sitzungen des Institutsrats mit beratender Stimme teilnehmen.

(8) Der Institutsrat kann sich eine Geschäftsordnung geben, die der $\mathrm{Zu}$ stimmung des Kuratoriums bedarf.

\section{§ 10 Forschungsgruppen, Abteilungen, zentrale Arbeitsstellen}

(1) Die Arbeiten der Stiftung werden in Forschungsgruppen, die in Abteilungen zusammengefaßt sind, und in zentralen Arbeitsstellen durchgeführt.

(2) Der Leiter einer Forschungsgruppe ist für die Projektarbeit im Rahmen der Arbeitsplanung verantwortlich.

(3) Der Leiter einer Abteilung leitet auch eine Forschungsgruppe. Er ist für die Koordinierung und Abstimmung der wissenschaftlichen Arbeiten in seiner Abteilung zuständig und verantwortlich. Er sorgt im Benehmen mit den Forschungsgruppen für die Fortschreibung der Planung in seiner Abteilung.

(4) Die zentralen Arbeitsstellen leisten wissenschaftliche und administrative Dienste für das Institut insgesamt. Die Arbeitsstellenleiter unterstehen unmittelbar dem Vorstand.

\section{§11 Abteilungsversammlung, Arbeitsstellenversammlung}

Die Versammlung besteht aus den Mitarbeitern der Abteilung bzw. Arbeitsstelle und wird von dem zuständigen Leiter einberufen. Eine Versammlung ist auf Antrag eines Drittels der Mitarbeiter einzuberufen. Der Leiter informiert über die Angelegenheiten der Abteilung bzw. Arbeitsstelle. 


\section{$\S 12$ Wissenschaftlicher Rat}

(1) Das Kuratorium kann zur Beratung der Organe der Stiftung bei der Durchführung von wissenschaftlichen Aufgaben und zur Herstellung und zum Ausbau der Kontakte zur linguistischen und germanistischen Forschung sowie zum internationalen Austausch zwischen dem Institut und Hochschulen und sonstigen Forschungseinrichtungen im In- und Ausland einen Wissenschaftlichen Rat berufen.

(2) Der Wissenschaftliche Rat besteht aus:

1. ordentlichen Mitgliedern,

2. korrespondierenden Mitgliedern,

3. Ehrenmitgliedern.

(3) Ordentliche Mitglieder können Personen werden, die im deutschsprachigen Raum tätig und in der Lage sind, die Ziele der Stiftung nachhaltig zu fördern. Sie werden vom Kuratorium auf die Dauer von sechs Jahren berufen. Einmalige Wiederberufung ist möglich.

(4) Korrespondierende Mitglieder können Personen werden, die im nichtdeutschsprachigen Raum tätig und in der Lage sind, die Ziele der Stiftung nachhaltig zu fördern. Sie werden vom Kuratorium berufen.

(5) Die Ehrenmitgliedschaft wird vom Kuratorium verliehen.

(6) Die Mitgliedschaft erlischt

1. bei ordentlichen Mitgliedern nach Ablauf der Dauer der Berufung,

2. bei korrespondierenden Mitgliedern mit dem Ende der beruflichen Tätigkeit (Pensionierung, Emeritierung),

3. durch Austritt,

4. durch AusschluB.

(7) Der AusschluB eines Mitglieds erfolgt durch BeschluB des Kuratoriums, wenn das Mitglied das Ansehen oder die Interessen der Stiftung schädigt. Vor dem Beschluß ist das Mitglied zu hören. Der Ausschluß ist dem Mitglied schriftlich mitzuteilen.

(8) Der Wissenschaftliche Rat kann sich eine Geschäftsordnung geben, die der Zustimmung des Kuratoriums bedarf.

\section{§ 13 Mitarbeiter des Instituts}

Die Mitarbeiter des Instituts werden nach den für die Angehörigen des Öffentlichen Dienstes des Landes Baden-Württemberg geltenden Grundsätzen beschäftigt und vergütet. 


\section{$\S 14$ Rechnungsprüfung}

(1) Der Bundesminister für Forschung und Technologie und das Ministerium für Wissenschaft und Forschung Baden-Württemberg sind berechtigt, die Verwendung der Zuwendungen durch Einsicht in die Bücher, Belege und sonstigen Geschäftsunterlagen sowie durch örtliche Erhebungen zu prüfen oder durch Beauftragte prüfen zu lassen.

(2) Der Bundesrechnungshof und der Rechnungshof des Landes BadenWürttemberg haben ein gesetzliches Prüfungsrecht nach $\$ 91$ BHO/LHO.

\section{$\S 15$ Satzungsänderung}

(1) Die Satzung kann mit Zweidrittelmehrheit der Stimmen des Kuratoriums, darunter den Stimmen der Vertreter des Bundes und des Landes, nach Anhörung des Institutsrats geändert werden. Die Beschlubfassung über eine Satzungsänderung kann nur erfolgen, wenn auf der Sitzung des Kuratoriums drei Viertel der Mitglieder anwesend oder vertreten sind. Ist das nicht der Fall, lädt der Vorsitzende zu einer weiteren Sitzung im Abstand von mindestens einem Monat ein. Auf dieser Sitzung genügt eine Zweidrittelmehrheit der anwesenden oder vertretenen Mitglieder; darauf muß der Vorsitzende in seinem Einladungsschreiben hinweisen.

(2) Zu einer Änderung des $\S 5$ Abs. 1 Nr. 6 bedarf es darüber hinaus der Zustimmung der Mehrheit der gewählten wissenschaftlichen Mitarbeiter im Kuratorium.

\section{$\S 16$ Auflösung der Stiftung}

(1) Bei einer Auflösung der Stiftung oder beim Wegfall ihres bisherigen Zwecks fällt das Vermögen der Stiftung an eine Körperschaft des öffentlichen Rechts oder an eine steuerbegünstigt besonders anerkannte Körperschaft zur Verwendung für die in $\S 2$ dieser Satzung angeführten steuerbegünstigten Zwecke. Diese Vermögensverfügung bedarf der Zustimmung der in $\S 5$ Abs. $1 \mathrm{Nr}$. 1 bis 3 genannten Kuratoriumsmitglieder.

(2) Falls diese Kuratoriumsmitglieder nicht zustimmen, fällt das Vermögen im Verhältnis der geleisteten Zuschüsse an die Bundesrepublik Deutschland, das Land Baden-Württemberg und die Stadt Mannheim. 
(3) Der BeschluB über die Verwendung des Vermögens nach Abs 1 und 2 darf erst nach Einwilligung des Finanzamts ausgeführt werden.

\section{$\S 17$}

Diese Satzung tritt am 01. Dezember 1994 in Kraft. Gleichzeitig tritt die bisherige Satzung vom 16. Juni 1992 außer Kraft. 

Jahrbücher des

Instituts für deutsche Sprache

\section{Das 19. Jahrhundert}

Sprachgeschichtliche Wurzeln des heutigen Deutsch Herausgegeben von Rainer Wimmer

509 Seiten. Mit 7 Abbildungen. 1991. Broschur.

ISBN 3110129604

(Jahrbuch 1990)

\section{Deutsche Syntax}

Ansichten und Aussichten

Herausgegeben von Ludger Hoffmann

VI, 613 Seiten. 1992. Broschur. ISBN 3110137062 (Jahrbuch 1991)

\section{Deutsch als Verkehrssprache in Europa}

Herausgegeben von Joachim Born und Gerhard Stickel

VI, 342 Seiten. 1993. Broschur. ISBN 3110140063

(Jahrbuch 1992)

\section{Die Ordnung der Wörter}

\section{Kognitive und lexikalische Strukturen}

Herausgegeben von Gisela Harras

V, 403 Seiten. Mit 26 Abbildungen und 7 Tabellen. 1995.

Gebunden. ISBN 3110144387

(Jahrbuch 1993)

Walter de Gruyter $\begin{gathered}W \\ \mathrm{DE} \\ \mathrm{D}\end{gathered}$ Berlin $\cdot$ New York 


\section{Kommunikation in der Stadt}

Teil 1: Exemplarische Analysen des

Sprachverhaltens in Mannheim

Herausgegeben von Werner Kallmeyer

IX, 697 Seiten. Mit 1 Abbildung und 2 Karten. 1994.

Gebunden. ISBN 3110143801

(Schriften des Instituts für deutsche Sprache, Band 4.1)

Der Band enthält eine soziolinguistische Untersuchung des sprachlichen Verhaltens von Gruppen aus unterschiedlichen städtischen Milieus. Die Beiträge analysieren die pragmatischen Regeln des Sprechens, phonologische Variationen, formelhaftes Sprechen und Ausdrucksformen der sozialen Kategorisierung anhand von transkribierten Gesprächsaufnahmen.

\section{Teil 2: Ethnographien von Mannheimer Stadtteilen}

Herausgegeben von Werner Kallmeyer

V, 525 Seiten. 1995. Gebunden. ISBN 311 014381-X

(Schriften des Instituts für deutsche Sprache, Band 4.2)

Inhalt: W. Kallmeyer: Ethnographie städtischen Lebens. Zur Einführung in die Stadtteilbeschreibungen. - I. Keim: Die Westliche Unterstadt. - J. Schwitalla: Vogelstang. - K.-H. Bausch: Auskünfte über Mannheim. Textausschnitte aus ethnographischen Interviews.

Walter de Gruyter $\begin{gathered}W \\ D \\ G\end{gathered}$ Berlin · New York 